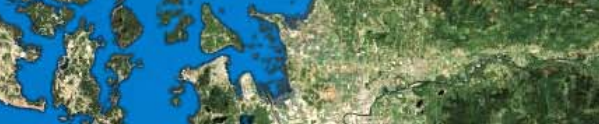

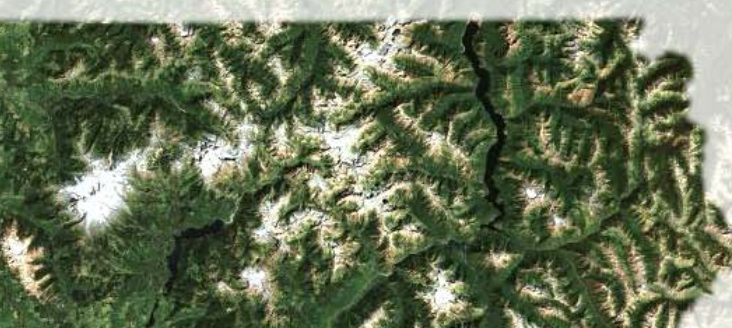

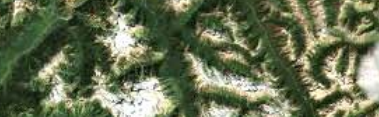

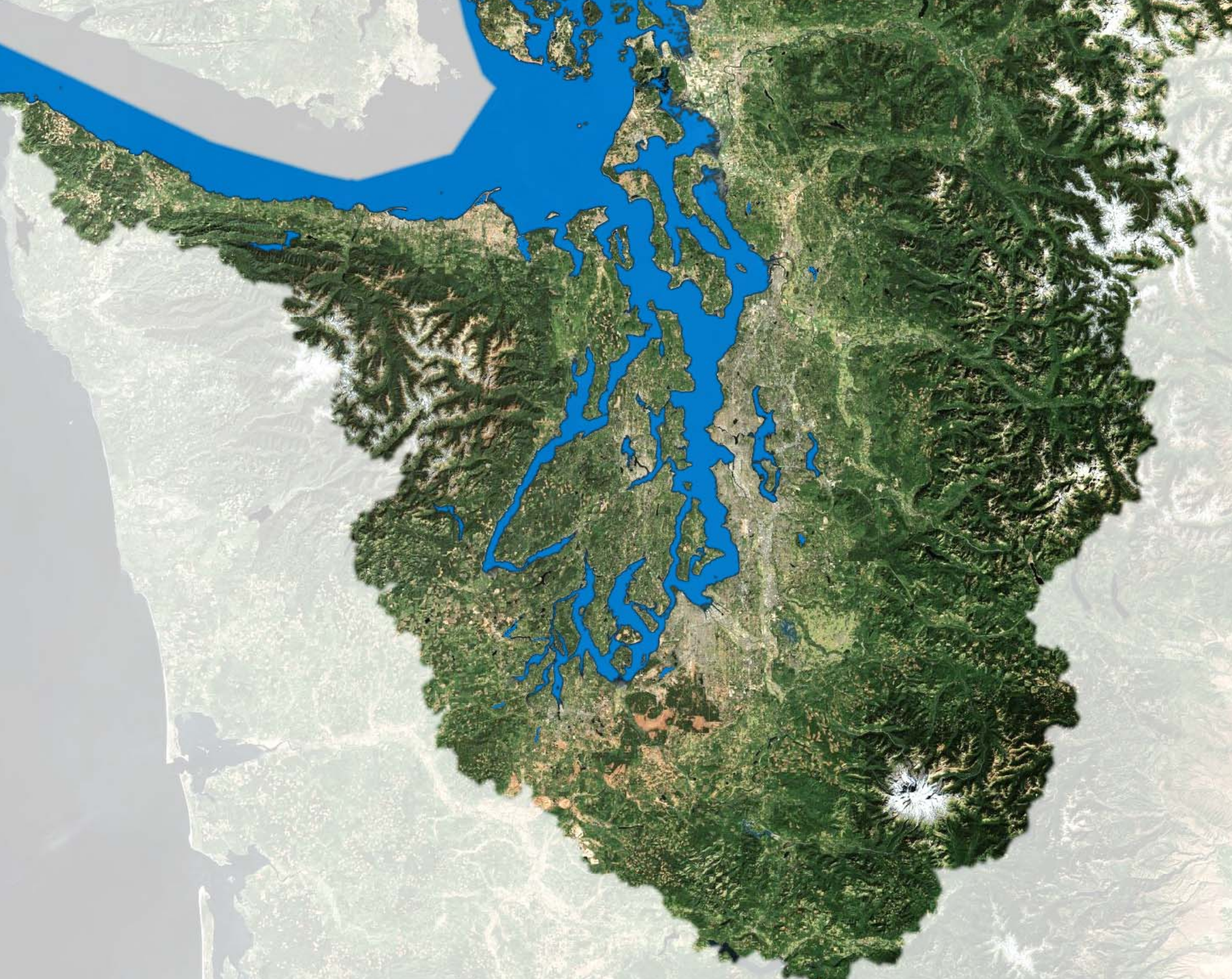

\title{
Control of Toxic Chemicals in Puget Sound, Phase 3: Study of Atmospheric Deposition of Air Toxics to the Surface of Puget Sound
}

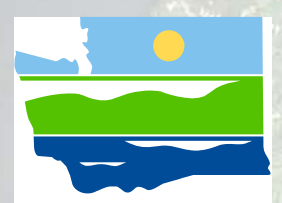

DEPARTMENT OF

ECOLOGY

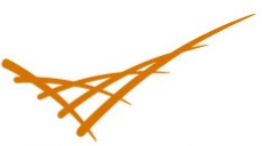

Pacific Northwest NATIONAL LABORATORY

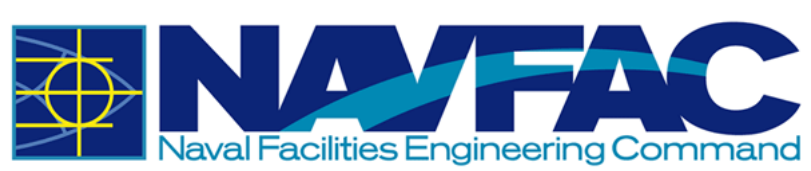




\section{Publication and Contact Information}

This report is available on the Department of Ecology's website at www.ecy.wa.gov/pubs/1002012.pdf

For more information contact:

Air Quality Program

P.O. Box 47600

Olympia, WA 98504-7600

Phone: $360-407-6800$

Washington State Department of Ecology - www.ecy.wa.gov

o Headquarters, Olympia 360-407-6000

o Northwest Regional Office, Bellevue 425-649-7000

o Southwest Regional Office, Olympia 360-407-6300

o Central Regional Office, Yakima 509-575-2490

o Eastern Regional Office, Spokane 509-329-3400

To ask about the availability of this document in a format for the visually impaired, call the Air Quality Program at 360-407-6800. Persons with hearing loss can call 711 for Washington Relay Service. Persons with a speech disability can call 877-833-6341. 


\title{
Control of Toxic Chemicals in Puget Sound, Phase 3: Study of Atmospheric Deposition of Air Toxics to the Surface of Puget Sound
}

\author{
by \\ Brandenberger, J.M., P. Louchouarn, L-J Kuo, E.A. Crecelius, V. Cullinan \\ G.A. Gill, C. Garland, J. Williamson, and R. Dhammapala
}

Air Quality Program

Washington State Department of Ecology

Olympia, Washington 


\title{
DISCLAIMER
}

This report was prepared as an account of work sponsored by an agency of the United States Government. Neither the United States Government nor any agency thereof, nor Battelle Memorial Institute, nor any of their employees, makes any warranty, express or implied, or assumes any legal liability or responsibility for the accuracy, completeness, or usefulness of any information, apparatus, product, or process disclosed, or represents that its use would not infringe privately owned rights. Reference herein to any specific commercial product, process, or service by trade name, trademark, manufacturer, or otherwise does not necessarily constitute or imply its endorsement, recommendation, or favoring by the United States Government or any agency thereof, or Battelle Memorial Institute. The views and opinions of authors expressed herein do not necessarily state or reflect those of the United States Government or any agency thereof.

\author{
PACIFIC NORTHWEST NATIONAL LABORATORY \\ operated by \\ BATTELLE \\ for the \\ UNITED STATES DEPARTMENT OF ENERGY \\ under Contract DE-AC05-76RL01830
}

Printed in the United States of America

Available to DOE and DOE contractors from the

Office of Scientific and Technical Information,

P.O. Box 62, Oak Ridge, TN 37831-0062;

ph: (865) 576-8401

fax: (865) 576-5728

email: reports@adonis.osti.gov

\author{
Available to the public from the National Technical Information Service, \\ U.S. Department of Commerce, 5285 Port Royal Rd., Springfield, VA 22161 \\ ph: (800) 553-6847 \\ fax: (703) 605-6900 \\ email: orders@ntis.fedworld.gov \\ online ordering: http://www.ntis.gov/ordering.htm
} This document was printed on recycled paper. 


\section{Table of Contents}

List of Figures and Tables.................................................................................... iii

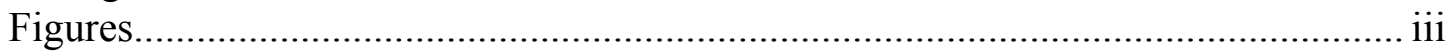

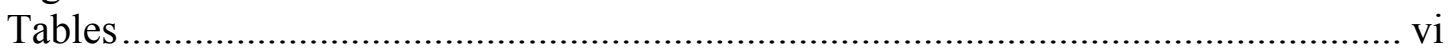

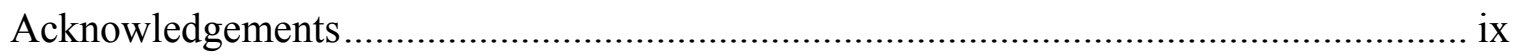

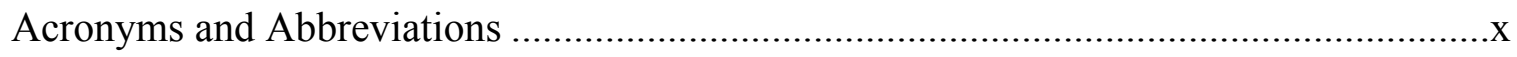

Abstract/Executive Summary ………………...................................................... xiii

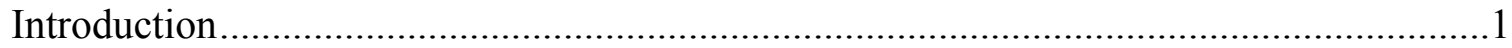

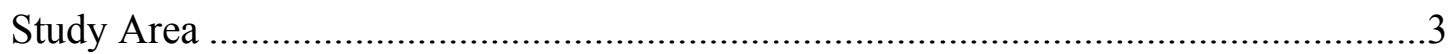

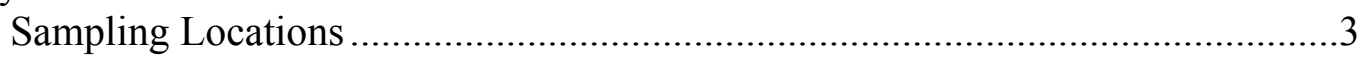

Chemicals of Concern .........................................................................................

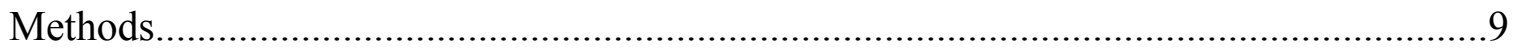

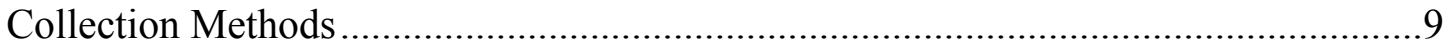

PAHs, Anhydrosugars, and PBDEs...............................................................13

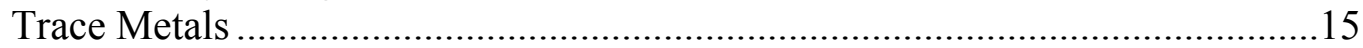

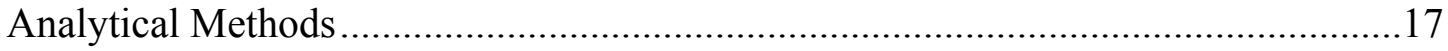

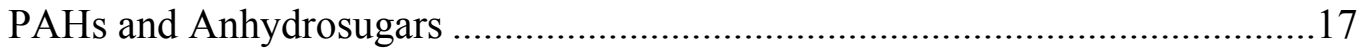

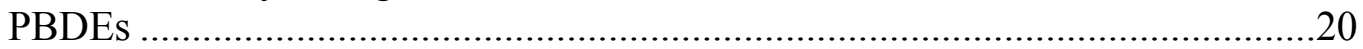

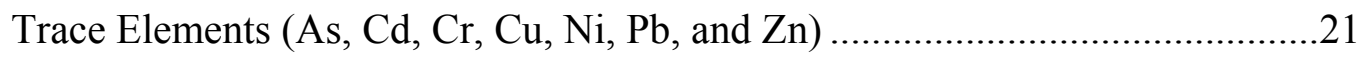

Mercury and Monomethylmercury....................................................................23

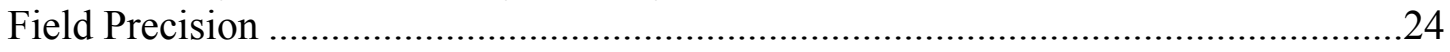

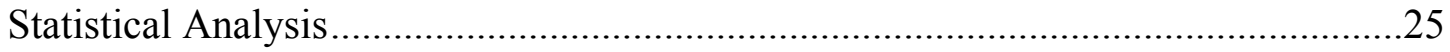

Atmospheric Deposition Flux Results .................................................................27

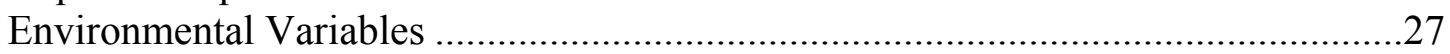

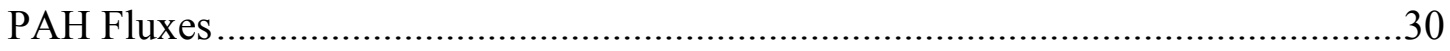

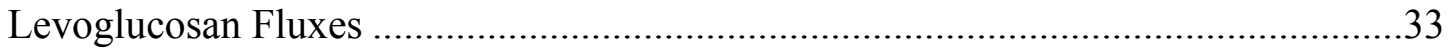

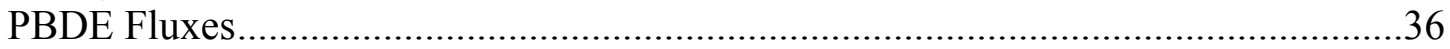

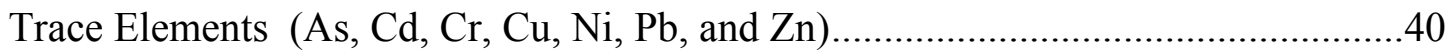

Mercury and Monomethylmercury ……………………........................................5

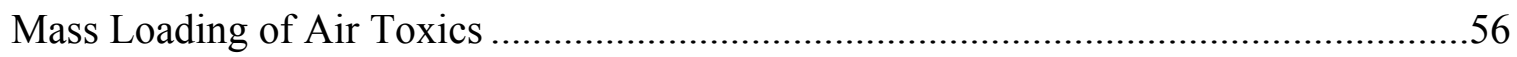

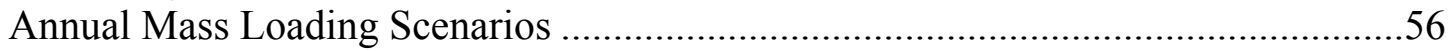

Mass Loading Estimates for PAHs …………………………………………......59

Mass Loading Estimates for PBDEs............................................................................61

Mass Loading Estimates for Trace Elements and Mercury .........................................63

Watershed versus Atmospheric Fluxes .....................................................................66

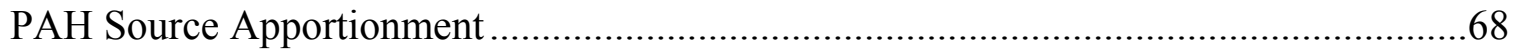

Qualitative Reconstructions of Combustion Source Inputs .........................................68

Principal Component Analysis and Semi-quantitative Reconstructions of

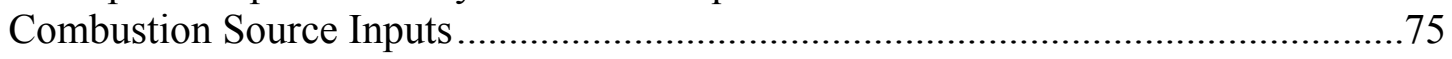

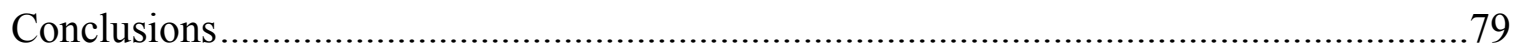




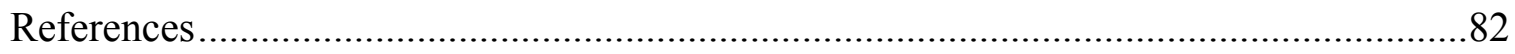

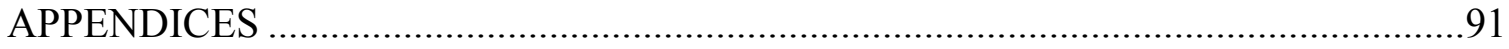

APPENDIX A PAH and Biomarkers ...................................................................... A-1

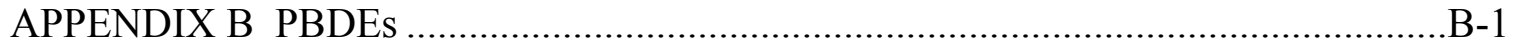

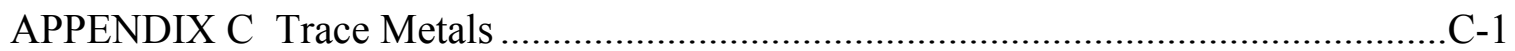

APPENDIX D Total Mercury and Methyl Mercury............................................. D-1

APPENDIX E Atmospheric Deposition Task 1 Literature Review and Site

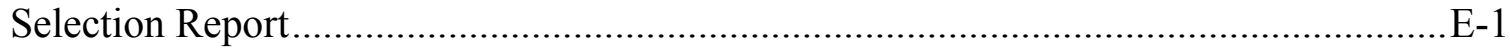

APPENDIX F Atmospheric Deposition Year 1 Data Report ........................................F-1 


\section{List of Figures and Tables}

$\underline{\text { Page }}$

\section{Figures}

Figure 1.--- Seven primary stations (red) and the Tyee Marina (TM) station (yellow). Primary stations were Padilla Bay (PB), Sequim Bay (SB), West Point (WP), Port Orchard (PO), Hood Canal (HC), Tacoma Commencement Bay (TCB), and Nisqually River (NR). The 11 compartments in the Puget Sound box model (Pelletier and Mohamedali 2009) are illustrated.

Figure 2.--- The distribution of the average annual cumulative precipitation (inches) for Puget Sound from 1995-2007 in the box plot for each station. The box boundaries are the $25^{\text {th }}$ and $75^{\text {th }}$ percentile, with the median in the box, dashed blue line is the mean, whiskers are the 10th and 90th percentiles, and the asterisks are outliers. The cumulative precipitation data for each station during 2008 (yellow) and 2009 (red) were plotted within the historical data distribution.

Figure 3.--- Bulk atmospheric deposition collector with stainless steel funnel in the center draining down into the wood box for organic parameters, clear Teflon ${ }^{\circledR} 1 \mathrm{~L}$ bottles for trace elements (left arm), and opaque Teflon ${ }^{\circledR}$ $1 \mathrm{~L}$ bottles for mercury speciation (right arm).

Figure 4.--- Flow diagram for onsite field extraction of bulk deposition and subsequent laboratory sample extractions for PAHs, anhydrosugars, and PBDEs.

Figure 5.--- Relationship between pyrogenic PAHs (Pyr PAH) [fluoranthene, pyrene, benzo[a]anthracene, chrysene, benzo[b]fluoranthene, benzo[k]fluoranthene, benzo[a]pyrene, indeno[1,2,3-c,d]pyrene, dibenz[a,h]anthracene, benzo[g,h,i]perylene] and high molecular weight PAHs (HMW PAH) [benzo[b]fluoranthene, benzo[k]fluoranthene, benzo[a]pyrene, indeno[1,2,3-c,d]pyrene, dibenz[a,h]anthracene, benzo[g,h,i]perylene].

Figure 6.--- Least square means for ranked precipitation by station with the variation from month removed and by month with the variation from stations removed.

Figure 7.--- Box and whisker plot of PM 2.5 by station and season (wet and dry). The solid line within the box marks the median and the red dot marks the mean. The lower and upper boundaries of the box are the 25 th and 75 th percentile, respectively. The whiskers (error bars) below and above the box indicate the 10th and 90th percentiles. The asterisks are outliers. 
Figure 8.--- Box plot of carcinogenic PAHs fluxes ( $\mathrm{ng} / \mathrm{m}^{2} /$ day) for eight stations (CPAH). The box boundaries are the $25^{\text {th }}$ and $75^{\text {th }}$ percentile, with the median in the box, dashed blue line is the mean, whiskers are the 10th and 90th percentiles, and the asterisks are outliers.

Figure 9.--- Box plot of pyrogenic PAHs fluxes ( $\mathrm{ng} / \mathrm{m}^{2} /$ day) for eight stations (pyrPAHs). The box boundaries are the $25^{\text {th }}$ and $75^{\text {th }}$ percentile, with the median in the box, dashed blue line is the mean, whiskers are the 10th and 90th percentiles, and the asterisks are outliers.

Figure 10.---Levoglucosan fluxes at the eight stations during the 19 sampling events.

Figure 11.--- Levoglucosan fluxes $\left(\mu \mathrm{g} / \mathrm{m}^{2} /\right.$ day) for eight stations during dry season (May-Sept) and wet season (Oct.-Apr.). The box boundaries are the 25 th and 75 th percentile, with the median in the box, dashed blue line is the mean, whiskers are the 10th and 90th percentiles, and the asterisks are outliers

Figure 12.--- The levoglucosan vs. mannosan relationship in wet and dry deposition over the Puget Sound. The ratio between these two anhydrosugars discriminates sources of biomass combustion (hardwood vs. softwood combustion). The low slope $(<5)$ indicates softwood combustion is the main source of biomass combustion.

Figure 13.---Total PBDEs fluxes (ng/m²/day) from eight stations from events 1 through 19.

Figure 14.--- Box plot of total PBDE fluxes (ng/m²/day) for eight stations. The box boundaries are the $25^{\text {th }}$ and $75^{\text {th }}$ percentile, with the median in the box, dashed blue line is the mean, whiskers are the 10th and 90th percentiles, and the asterisks are outliers.

Figure 15.--- Effects of (a) station; and (b) season on the total PBDE fluxes. The geometric mean and associated 95\% confidence limits are plotted for each station and then each season.

Figure 16.---Distributions of BDE-47, 99, 209 at the eight sampled stations.

Figure 17.--- Arsenic fluxes for the eight stations. The box boundaries are the $25^{\text {th }}$ and $75^{\text {th }}$ percentile, with the median in the box, dashed blue line is the mean, whiskers are the 10th and 90th percentiles, and the asterisks are outliers.

Figure 18.--- Copper fluxes for the eight stations. The box boundaries are the $25^{\text {th }}$ and $75^{\text {th }}$ percentile, with the median in the box, dashed blue line is the mean, whiskers are the 10th and 90th percentiles, and the asterisks are outliers

Figure 19.--- Lead fluxes for the eight stations. The box boundaries are the $25^{\text {th }}$ and $75^{\text {th }}$ percentile, with the median in the box, dashed blue line is the mean, whiskers are the 10th and 90th percentiles, and the asterisks are outliers.

Figure 20.--- The generalized linear model (GLM) for As (a) and $\mathrm{Cr}$ (b) with main effects by both station and season. 
Figure 21.--- Mercury (a) and methylmercury (b) fluxes for the eight stations, if available. The box boundaries are the $25^{\text {th }}$ and $75^{\text {th }}$ percentile, with the median in the box, dashed blue line is the mean, whiskers are the 10th and 90th percentiles, and the asterisks are outliers.

Figure 22.--- The solid lines are the linear regression models with dashed $95^{\text {th }}$ percentile confidence intervals for total mercury fluxes $\left(\mathrm{ng} / \mathrm{m}^{2} / \mathrm{d}\right)$ and cumulative precipitation during each sampling. The black lines are the linear regressions for TCB and the blue lines are linear repressions for all other stations.

Figure 23.--- The total $\mathrm{Pb}$ atmospheric deposition fluxes $\left(\mu \mathrm{g} / \mathrm{m}^{2} /\right.$ day) relative to the cumulative precipitation measured during each event for each station.

Figure 24.--- The distribution of the cumulative precipitation (inches) measured at or near the stations during each of the 2008/2009 two-week integrated sampling events. The y-axis reference line is the mean of all data. The lines within the diamonds represent the mean and $95 \%$ confidence intervals for the each season.

Figure 25.--- Estimates of atmospheric loadings for carcinogenic PAHs (CPAHs in top plot; $\mathrm{Kg} / \mathrm{yr}$ ) and pyrogenic PAHs (pyro-PAH in bottom plot; $\mathrm{Kg} / \mathrm{yr}$ ) to the surface of Puget Sound using three scenarios described above. The median, 25th, and 75th percentile atmospheric loading estimates are compared to 50th, 75th, and 25th probability of exceedance (POE) ranges for atmospheric (ATMDEP) and surface runoff (RUNOFF) loading estimates (Hart Crowser, Inc. 2007; Herrera Environmental Consulting, Inc. 2010, respectively).

Figure 26.--- Estimates of atmospheric loadings of PBDEs $(\mathrm{Kg} / \mathrm{yr})$ to the surface of Puget Sound using three scenarios described above. The median, 25th, and 75 th percentile atmospheric loading estimates are compared to 50 th, 75th, and 25th probability of exceedance (POE) ranges for atmospheric (ATMDEP) and surface runoff (RUNOFF) loading estimates (Hart Crowser, Inc. 2007; Herrera Environmental Consulting, Inc. 2010, respectively).

Figure 27.--- The annual atmospheric deposition loads for $\mathrm{As}, \mathrm{Cd}, \mathrm{Cu}, \mathrm{Pb}$, and $\mathrm{Zn}$ (MT/yr) and $\mathrm{THg}(\mathrm{Kg} / \mathrm{yr})$ are calculated for this study using the three scenarios discussed above. The median, $25^{\text {th }}$, and $75^{\text {th }}$ percentile loads are compared to the $50^{\text {th }}, 75^{\text {th }}$, and $25^{\text {th }}$ probability of exceedance ranges for atmospheric (ATMDEP) and surface runoff (RUNOFF) loading estimates (Hart Crowser, Inc. 2007; Herrera Environmental Consulting, Inc. 2010, respectively).

Figure 28.--- Methylphenanthrene to phenanthrene ratio (MP/P) vs. fluoranthene over the sum of fluoranthene and pyrene in a) atmospheric deposition samples and b) surface sediments $(0-5 \mathrm{~cm})$ in the Hood Canal and Main Basin.

Figure 29.--- Ratio of indeno[1,2,3-c,d]pyrene to the sum of indeno[1,2,3-c,d]pyrene and benzo[g,h,i]perylene vs. fluoranthene over the sum of fluoranthene and pyrene in a) atmospheric deposition samples and b) surface 
sediments $(0-5 \mathrm{~cm})$ in the Hood Canal and Main Basin, as well as atmospheric deposition samples from 1989-1990 (Crecelius 1991 and EPA 1991)

Figure 30.--- Ratio of retene to the sum retene and chrysene vs. 1,7-DMP over the sum of 1,7- and 2,6-DMP in a) atmospheric deposition samples and b) sediment cores in the Hood Canal (HC3) and Main Basin (PS4).

Figure 31.--- Principal component analysis (PCA) projections of PAH variables (loadings). The variance accounted for each PC is shown in brackets after the axis label.

Figure 32.--- PCA projections of samples (upper section) and typical fingerprint signatures of specific quadrants (bar graphs). The variance accounted for each PC is shown in brackets after the axis label. Fingerprint signatures: a) TCB represents the lower left quadrant of the PCA showing a typical petroleum combustion fingerprint; b) $\mathrm{HC}$ represents the lower right quadrant of the PCA showing a typical biomass combustion fingerprint; c) TM represents the upper left quadrant of the PCA showing fossil fuel combustion mixture fingerprint (possibly diesel); d) PO represents the upper right quadrant of the PCA showing a combustion mixture fingerprint with high influence of biomass.

Figure 33.--- Frequency distributions of atmospheric deposition samples falling in specific source categories determined using a) the PCA model (left panel) and $b$ ) the Ret/(Ret+Chy) ratio (right panel).

\section{Tables}

Table 1.--- Atmospheric deposition station number, identification code, name, and coordinates.

Table 2.--- List of chemical constituents measured in bulk atmospheric deposition in Puget Sound.

Table 3.--- Sampling dates for each of the nineteen events with days deployed, rain collected at the station, field duplicate locations, and average ambient temperature.

Table 4.--- Method detection limits, reporting limits, method and field blank concentrations, standard reference material (SRM) or on-going precision/recovery (OPR), matrix spike recovery, and laboratory duplicate relative percent difference (RPD).

Table 5.--- Descriptive statistics for environmental variables by station expressed as the average over the $\sim 14$ day deployment, except precipitation is cumulative.

Table 6.--- Lower half of the correlation matrix for environmental variables. 
Table 7.--- Regional median wind direction over the course of the study

Table 8.--- Daily fluxes of polycyclic aromatic hydrocarbons (PAHs) and levoglucosan at the eight stations around the Puget Sound.

Table 9.--- Daily atmospheric deposition fluxes of total PBDEs at the eight stations around the Puget Sound.

Table 10.--- The trace element descriptive statistics for bulk atmospheric deposition with concentrations $(\mu \mathrm{g} / \mathrm{L})$, volume weighted concentrations, and daily fluxes $\left(\mu \mathrm{g} / \mathrm{m}^{2} / \mathrm{d}\right)$ using the median concentrations.

Table 11.--- Station clusters for the $\mathrm{Cr}, \mathrm{Ni}, \mathrm{Cu}, \mathrm{As}$, and $\mathrm{Pb}$ fluxes.....................................44

Table 12.--- Correlation matrix for metals, PAHs, and anhydrosugar fluxes.

Table 13.--- Descriptive statistics for total mercury ( $\mathrm{THg}$ ) and monomethylmercury (MMHg) atmospheric deposition concentrations (ng/L), volume weighted concentrations, daily fluxes $\left(\mathrm{ng} / \mathrm{m}^{2} / \mathrm{d}\right)$ using the median concentrations, and percent of the total deposition occurring as $\mathrm{MMHg}$

Table 14.--- Descriptive statistics for the daily fluxes of total mercury (THg) at each station during both the wet and dry season......

Table 15.--- The atmospheric flux stations and surfaces areas of the waters of Puget Sound used to calculate annual mass loads for each chemical of concern using the three scenarios to delineate the data based on spatial and temporal factors.

Table 16.--- Estimates of atmospheric loadings ( $\mathrm{Kg} / \mathrm{yr})$ of carcinogenic and pyrogenic PAHs (CPAH and pyro-PAH, respectively) to the surface of the Puget Sound using three scenarios including no seasonal or spatial differentiation (Scenario 1), a spatial differentiation of sub-basins (Scenario 2), and spatiotemporal differentiation of fluxes in sub-basins (Scenario 3 ). The median, $25^{\text {th }}$, and $75^{\text {th }}$ percentile atmospheric loading estimates are compared to the $50^{\text {th }}, 75^{\text {th }}$, and $25^{\text {th }}$ probability of exceedance ranges for atmospheric (ATMDEP) and surface runoff (RUNOFF) loading estimates (Hart Crowser, Inc. 2007; Herrera Environmental Consulting, Inc. 2010, respectively).

Table 17.--- Estimates of atmospheric loadings (Kg/yr) of total PBDE to the surface of the Puget Sound using three scenarios including no seasonal or spatial differentiation (Scenario 1), a spatial differentiation of subbasins (Scenario 2), and spatiotemporal differentiation of fluxes in subbasins (Scenario 3). The atmospheric loading estimates are compared to $25^{\text {th }}, 50^{\text {th }}$, and $75^{\text {th }}$ probability of exceedance (POE) ranges for atmospheric (ATMDEP) and surface runoff (RUNOFF) loading estimates (Hart Crowser, Inc. 2007; Herrera Environmental Consultants, Inc. 2010, respectively).

Table 18.--- Estimates of atmospheric loadings for trace elements and mercury to the surface of Puget Sound using three scenarios described above. The atmospheric loading estimates are compared to 25th, 50th, and 75th probability of exceedance (POE) ranges for atmospheric (ATMDEP) 
and surface runoff (RUNOFF) loading estimates, if available (Hart Crowser, Inc. 2007; Herrera Environmental Consulting, Inc. 2010).

Table 19.--- Comparison of median annual atmospheric vs. sedimentary fluxes of PAHs and trace metals in two basins of Puget Sound: Main Basin and Hood Canal.

Table 20.--- Comparison of surface runoff loading and sedimentary loadings for carcinogenic PAHs (CPAHs) and lead $(\mathrm{Pb})$ in two basins of Puget Sound: Main Basin and Hood Canal................................................................67

Table 21.--- Diagnostic ratio of distinct PAH source signatures. ......................................69 


\section{Acknowledgements}

The authors would like to acknowledge the following organization for providing access to their facilities: Padilla Bay National Estuarine Research Reserve, Pacific Northwest National Laboratory, Environmental Protection Agency Manchester Environmental Laboratories, University of Washington Big Beef Creek Fish Research, University of Washington Tacoma, Tyee Marina, and Nisqually Reach Nature Center. The authors received valuable field operations support from Jim Devereaux and Bob Krueger from King County. In addition, Cheryl Greengrove and Julie Masura from University of Washington Tacoma provided logistical and meteorological data support. Laboratory analytical support was provided by Brenda Lasorsa, Key-Young Choe, and Jordana Wood. Finally, the authors would like to thank the many reviewers from the Washington Department of Ecology Environmental Assessment and Air Quality Programs and also Dwight Leisle from the Naval Facilities Engineering Command and Dr. Bob Johnston from the Space and Naval Warfare Systems Center. 


\section{Acronyms and Abbreviations}

\begin{tabular}{|c|c|}
\hline 1,7-DMP & 1,7-Dimethylphenanthrene \\
\hline 2,6-DMP & 2,6-Dimethylphenanthrene \\
\hline 3,6-DMP & 3,6-Dimethylphenanthrene \\
\hline An & Anthracene \\
\hline As & Arsenic \\
\hline ASE & Accelerated solvent extractor \\
\hline $\mathrm{BaA}$ & Benzo[a]anthracene \\
\hline $\mathrm{BaP}$ & Benzo[a]pyrene \\
\hline $\mathrm{BbF}$ & Benzo[b]fluoranthene \\
\hline $\mathrm{BC}$ & Black carbon \\
\hline BghiP & Benzo[g,h,i]perylene \\
\hline $\mathrm{BkF}$ & Benzo[k]fluoranthene \\
\hline BSTFA & N,O-bis(trimethylsilyl)trifluoroacetamide \\
\hline C1-Phe/An & Methyl-Phe/An \\
\hline $\mathrm{Cd}$ & Cadmium \\
\hline Chy & Chrysene \\
\hline $\mathrm{COC}$ & Chain of custody \\
\hline CPAHs & Carcinogenic PAHs \\
\hline $\mathrm{Cr}$ & Chromium \\
\hline $\mathrm{Cu}$ & Copper \\
\hline $\mathrm{CV}$ & Coefficient of variation \\
\hline CVAF & Cold vapor atomic fluorescence technique \\
\hline $\mathrm{DbA}$ & Dibenz $[\mathrm{a}, \mathrm{h}]$ anthracene \\
\hline DCM & Dichloromethane \\
\hline DI & Deionized water \\
\hline DUP & Duplicate station \\
\hline Ecology & Washington Department of Ecology \\
\hline EI & Electron impact \\
\hline EPA & Environmental Protection Agency (United States) \\
\hline $\mathrm{F} 1$ & Fluoranthene \\
\hline GC/ECD & Gas chromatography with electron capture detector \\
\hline GC/MS & Gas chromatography-mass spectrometry \\
\hline GFF & Glass fiber filter \\
\hline GIS & Geographic Information System \\
\hline GLM & Generalized linear model \\
\hline
\end{tabular}




\begin{tabular}{|c|c|}
\hline HBB & Hexabromobiphenyl \\
\hline $\mathrm{HCl}$ & Hydrochloric acid \\
\hline $\mathrm{Hg}^{\circ}$ & Elemental mercury \\
\hline HMW & High molecular weight \\
\hline $\mathrm{HNO}_{3}$ & Nitric acid \\
\hline $\mathrm{HC}$ & Hood Canal \\
\hline ICP-MS & Inductively coupled plasma-mass spectrometer \\
\hline $\mathrm{InP}$ & Indeno[1,2,3-c,d]pyrene \\
\hline LMW & Low molecular weight \\
\hline LULC & land-use and land-cover \\
\hline Lvg & Levoglucosan \\
\hline MDN & Mercury Deposition Network \\
\hline MDL & Method detection limit \\
\hline $\mathrm{MMHg}$ & Monomethylmercury \\
\hline $\mathrm{MP} / \mathrm{P}$ & Ratio of methylphenanthrenes to phenanthrene \\
\hline MSL & Marine Science Laboratory \\
\hline $\mathrm{Ni}$ & Nickel \\
\hline NIST & National Institute of Standards and Technology \\
\hline NOAA & National Oceanic and Atmospheric Administration \\
\hline NR & Nisqually River \\
\hline OCN & Octachlroronaphthalene \\
\hline OPR & Ongoing precision recovery \\
\hline PAHs & Polycyclic aromatic hydrocarbons \\
\hline $\mathrm{Pb}$ & Lead \\
\hline $\mathrm{PB}$ & Padilla Bay \\
\hline PBDEs & Polybrominated diphenyl ethers \\
\hline PCA & Principal Component Analysis \\
\hline PCBs & Polychlorinated biphenyls \\
\hline Per & Perylene \\
\hline PFE & Pressurized fluid extraction \\
\hline Phe & Phenanthrene \\
\hline PM & Particulate matter \\
\hline PNW & Pacific Northwest \\
\hline $\mathrm{PO}$ & Port Orchard \\
\hline POE & Probability of exceedance \\
\hline Py & Pyrene \\
\hline Pyr-PAHS & Pyrogenic PAHs \\
\hline QA/QC & Quality assurance and quality control program \\
\hline
\end{tabular}




$\begin{array}{ll}\text { Ret } & \text { Retene } \\ \text { RL } & \text { Reporting limit } \\ \text { RPD } & \text { Relative percent difference } \\ \text { RSD } & \text { Relative standard deviation } \\ \text { SB } & \text { Sequim Bay } \\ \text { SJF/SOG } & \text { Straits of Juan de Fuca and Georgia } \\ \text { SPMD } & \text { Semipermeable Membrane Devices } \\ \text { SnCl } & \text { Stannous chloride } \\ \text { SPE } & \text { Solid phase extraction } \\ \text { SRM } & \text { Standard reference material } \\ \text { TCB } & \text { Tacoma Commencement Bay } \\ \text { TCMX } & \text { Tetrachlorometaxylene } \\ \text { THg } & \text { Total mercury } \\ \text { TM } & \text { Tyee Marina } \\ \text { TRM } & \text { Total recoverable metals } \\ \text { U.S. } & \text { United States } \\ \text { WP } & \text { West Point } \\ \text { Zn } & \text { Zinc } \\ & \end{array}$




\section{Abstract/Executive Summary}

The results of the Phase 1 Toxics Loading study suggested that runoff from the land surface and atmospheric deposition directly to marine waters have resulted in considerable loads of contaminants to Puget Sound (Hart Crowser, Inc. 2007). The limited data available for atmospheric deposition fluxes throughout Puget Sound was recognized as a significant data gap. Therefore, this study provided revisions to prior estimates or first reported atmospheric deposition fluxes of polycyclic aromatic hydrocarbons (PAHs), polybrominated diphenyl ethers (PBDEs), and select trace elements for Puget Sound. Samples representing bulk atmospheric deposition were collected during 2008 and 2009 at seven stations around Puget Sound spanning from Padilla Bay south to Nisqually River including Hood Canal and the Straits of Juan de Fuca. Revised annual loading estimates were calculated for each of the toxics and demonstrated an overall decrease in the atmospheric loading estimates except for PBDEs and total mercury (THg).

The median atmospheric deposition flux of total PBDE $\left(7.0 \mathrm{ng} / \mathrm{m}^{2} / \mathrm{d}\right)$ was higher than that presented in the Phase 1 report $\left(50^{\text {th }}\right.$ probability of exceedance load was $2.0 \mathrm{ng} / \mathrm{m}^{2} / \mathrm{d}$; Hart Crowser, Inc. 2007). The difference may be associated to the significantly higher PBDE fluxes measured in the present study at the urban/industrial site of Tacoma (TCB). This station was the only one that showed statistically higher values than average depositional fluxes measured at all other sites and was the only site that represented industrial regions of Puget Sound. In addition, seasonal differences were observed for PBDE fluxes with dry season fluxes higher than those observed during the wet season. The most abundant congeners comprising the total fluxes were BDEs-47, 99, and 209 with BDE-209 the most abundant. High similarity of the proportional distribution of these three congeners was found across sampling stations in Puget Sound pointing to a regional consistency in the source(s). The estimated mass loading of total PBDE in Puget Sound ranged from 15.6-20.3 Kg/yr and was similar in magnitude to PBDE mass loading $(17.1 \pm 6.5 \mathrm{Kg} / \mathrm{yr})$ reported for the Straits of Georgia.

The revised atmospheric loading estimates for trace elements were all lower than prior estimates except for $\mathrm{THg}$, which was not significantly different from the original estimates. The THg fluxes were significantly correlated with precipitation but suggested regional differences in what would be defined as dry deposition during low- to no-precipitation events. The modeled dry deposition fluxes at TCB were a factor of three higher than modeled dry deposition fluxes for all other stations (which were not significantly different from each other). Therefore, a localized source may provide a relatively constant dry deposition supplemented by a wet depositional flux that varies as a function of total rainfall.

The highest median fluxes for all trace elements were measured at TCB; however, the partial data set for the other Tacoma station (Tyee Marina) suggested that high fluxes at TCB were localized and not representative of fluxes falling on the surface waters of Puget Sound as a whole. Significantly lower fluxes were recorded at the rural sites (Hood Canal, Sequim Bay, 
Port Orchard, and Padilla Bay) compared to the high-density urban and industrial sites near Tacoma and Seattle (TCB, Tyee Marina, and West Point). In all stations and seasons, the strong correlations between lead $(\mathrm{Pb})$, copper $(\mathrm{Cu})$, and high molecular weight PAHs suggest that emissions of these metals to the atmosphere of the Puget Sound are linked to combustion processes and/or co-occurring processes (i.e., break pad wear and tear and vehicular traffic emissions). However, more research is needed to identify the common source/process responsible for the consistent emissions of pyrogenic $\mathrm{PAHs}, \mathrm{Pb}$, and $\mathrm{Cu}$ in the region.

The median atmospheric deposition flux for pyrogenic PAHs $\left(34.2 \mathrm{ng} / \mathrm{m}^{2} / \mathrm{d}\right.$; without TCB) shows a relatively narrow range across all stations (interquartile range: $21.2-61.1 \mathrm{ng} / \mathrm{m}^{2} / \mathrm{d}$ ) and shows no influence of season. Only the Tacoma site (TCB) showed substantially larger median fluxes $\left(583.6 \mathrm{ng} / \mathrm{m}^{2} / \mathrm{d}\right.$; interquartile range: $\left.311.8-657.5 \mathrm{ng} / \mathrm{m}^{2} / \mathrm{d}\right)$. Yet, despite having the highest fluxes with respect to other stations, this area of the Puget Sound has experienced more than an order of magnitude decline in depositional fluxes of pyrogenic PAHs over the last $\sim 20$ years pointing to the influence of environmental regulations on controlling combustion emissions. The more extensive and spatiotemporal sampling of depositional fluxes across the entire Puget Sound led to a revised estimate of atmospheric loadings of carcinogenic and pyrogenic PAHs to the surface of the Sound. The atmospheric deposition fluxes of levoglucosan point to a strong influence of season on the emissions of biomass combustion byproducts to the atmosphere of the Puget Sound. The two to three order of magnitude peaks in fluxes during the winter period point to the role of wood-burning stoves (and potentially, temperature inversions) on air quality during the wet season.

A semi-quantitative apportionment study permitted a first-order characterization of source inputs to the atmosphere of the Puget Sound. Both biomarker ratios and a principal component analysis confirmed regional data from the Puget Sound and Straits of Georgia region and pointed to the predominance of biomass and fossil fuel (mostly liquid petroleum products such as gasoline and/or diesel) combustion as source inputs of combustion by-products to the atmosphere of the region and subsequently to the waters of Puget Sound.

In summary, four major conclusions are derived from this study: 1) the depositional fluxes of a majority of the selected toxic elements (trace metals) and compounds (PAHs) in the urban/industrial area of Tacoma have decreased significantly (close to an order of magnitude for most) in the last $\sim 20$ years, 2) deposition fluxes directly to the waters of Puget Sound are spatially homogenous except in industrial regions and are not necessary representative of watershed deposition rate over a large range of land use and land cover classifications, 3) direct atmospheric deposition of trace elements and PAHs on the Puget Sound surface contributes only $1-5 \%$ of total inputs to sedimentary repositories, and 4) first-order estimates of sedimentary fluxes of $\mathrm{Pb}$ and $\mathrm{PAHs}$ in the Puget Sound system suggest that revised annual surface runoff estimates may be appropriate based on the sedimentary fluxes representing the last decade of inputs. 


\section{Introduction}

Atmospheric deposition of toxic contaminants was identified as a potentially important contributor of lead $(\mathrm{Pb})$, arsenic (As), polycyclic aromatic hydrocarbons (PAHs) and other organic compounds to the mass of toxics entering Puget Sound each year (U.S. Environmental Protection Agency [EPA] 1991). Anthropogenic sources of toxics may provide particulate or gas phase toxics to the atmosphere from activities such as vehicular exhaust, other mobile combustion sources, smoke from wood-burning stoves or slash burning, commercial and industrial emissions and material storage, and dust from soil erosion. The degradation of urban air quality has long been recognized as a significant risk to human health-in the early $18^{\text {th }}$ Century, intensive periods of high-sulfur coal burning in Europe killed over 4000 people (Wilkins 1954). However, it took several centuries to realize that the cross media transfer of these atmospheric toxics to surface waters may also result in significant ecological risk and potentially serve as a secondary route of exposure to humans (e.g., by seafood consumption). During the 1980s, Puget Sound studies measured toxic chemicals in airborne particulates in coastal regions and found the concentrations exceeded the draft sediment criteria (EPA 1991). This emphasized the need to better understand the deposition and potential accumulation of air toxics into marine sediment, and ultimately, food webs. Since that time, many studies have demonstrated the ecological and economic significance of the deposition of air toxics onto sensitive coastal ecosystems (e.g., Offenberg and Baker 1997; Gustafson and Dickhut 1997).

Combustion activities and processes still remain major contributors to air pollution in urban systems even as regulations have improved overall air quality. The pathways for transporting these toxics to Puget Sound waters range from direct deposition on the water surface to deposition on the landscape and subsequent mobilization during runoff events. In 2006, a Washington State statute declared that one of the objectives for ensuring the health and recovery of Puget Sound was to significantly reduce toxics entering Puget Sound marine waters. The Washington Department of Ecology (Ecology) began a phased approach to understanding and quantifying the loads of toxics entering Puget Sound from permitted point sources (e.g., industrial and municipal wastewater), surface runoff, atmospheric deposition, combined sewer overflow, and direct spills. This information will support the Puget Sound Partnership, Ecology, and other agencies in the development of decision trees targeting how and where to target toxics reduction efforts to provide the most benefit for Puget Sound.

The first step in this phased approach was to calculate an inventory of current toxic loadings. Ecology conducted a literature review, compiled available data from the Pacific Northwest (PNW) and national studies, and estimated the mass loads of various toxic chemicals entering Puget Sound from these sources (Hart Crowser, Inc. 2007). The probability of exceedence (POE) loads for surface run-off and atmospheric deposition (directly to marine waters) suggested that, relative to the other sources quantified, these were the two most important routes of entry for toxics reaching Puget Sound (Hart Crowser, Inc. 2007). They also highlighted the 
complexity and large uncertainties in these two dominant loading terms. Therefore, the Phase 2 reports and their addendums further refined the surface runoff estimates with more recent land use data and alternate runoff coefficients (EnviroVision Corporation and Herrera Environmental Consultants, Inc. 2008; Herrera Environmental Consultants, Inc. 2010). Due to the limited recent atmospheric data and the associated large data uncertainties for the atmospheric deposition loading estimates, Hart Crowser, Inc. (2007) recommended collecting and analyzing atmospheric deposition samples to better understand the atmospheric deposition rates to the waters of Puget Sound.

The estimated atmospheric deposition directly to Puget Sound was an important source of PAHs, polybrominated diphenyl ethers (PBDEs), and heavy metals. In most cases, atmospheric loading directly to the marine waters and tidelands was greater than or comparable to the loading estimates from surface runoff (Hart Crowser, Inc. 2007; Herrera Environmental Consultants, Inc. 2010). The best available literature data were compiled for these reports; however, significant limitations were the lack of spatially extensive data representing the various coastal land-use and land-cover (LULC) activities and temporally robust data sets within the Puget Sound (except for the National Atmospheric Deposition Network with the Mercury Deposition Network [MDN]) monitoring for total mercury (THg) in wet deposition (see http://nadp.sws.uiuc.edu/)]. The most recent atmospheric deposition program that coupled field monitoring with modeling approaches was conducted in 1989-1990 in Commencement Bay (EPA 1991; deposition data referenced previously as Crecelius et al. 1991). The study provided six months of two-week integrated deposition sampling and provided daily atmospheric deposition rates for PAHs and select heavy metals. The study identified three topics requiring additional research in order to apply the data to other regions of Puget Sound. These areas were the deposition sampling technique (poor PAH preservation in the field), the length of the sampled period (only six months), and the spatial coverage of the sampling (only Commencement Bay region). In addition, the study was conducted over ten years ago and may not represent the current atmospheric deposition because environmental regulations have targeted emission reductions from point sources. The success of the local economy in the 1990s attracted people and industries to the Puget Sound resulting in a $30 \%$ population increase from the 1990 s to the 2000 s and a $>24 \%$ increase in average annual daily traffic (S837; Washington State Department of Transportation 2001). Rapid increases in non-point sources, such as vehicular exhaust, are more difficult to estimate and require a current understanding of daily atmospheric deposition fluxes and their spatiotemporal distribution in coastal areas of varying LULC classifications to better extrapolate the deposition rates and calculate a mass loading of these toxics to the surface waters of Puget Sound.

In response to this identified data gap, EPA, Ecology and the U. S. Navy collaborated to fund a two-year study on atmospheric deposition fluxes for select metals, PAHs, PBDE, and biomarkers used to assess potential inputs of combustion-derived constituents to the Puget Sound. This report summarizes the atmospheric deposition fluxes collected from August 2008 through October 2009. The overarching question this project was designed to answer is, "What is the loading of toxics from atmospheric deposition directly to the waters of the Puget Sound?" Addressing this question requires answering additional questions such as: 1) What are the toxics 
associated with combustion emissions?, 2) Do the average annual loads of these toxics vary seasonally and /or spatially in Puget Sound?, and 3) Do certain types of combustion processes (i.e., wood-burning stoves vs. gasoline combustion) contribute a larger relative proportion of the total load of atmospherically derived PAHs to the waters of Puget Sound?

With these objectives in mind, the project was divided into three tasks. The first task included summarizing the current literature on atmospheric deposition in Puget Sound and relevant national studies, selecting a list of toxics and biomarkers required to meet the project objectives, selecting representative field locations in Puget Sound, defining the field collection methodology, and defining the analytical chemistry methods for all selected toxics (Appendix E and F). The second task was to conduct field measurements of bulk atmospheric deposition during the winter wet season and summer dry season. The third task was to calculate current annual atmospheric deposition rates, compare the updated atmospheric deposition fluxes to the previously reported fluxes, compare the annual atmospheric deposition loads to prior atmospheric and surface runoff loading estimates, compare those loads to independent watershed loads derived from sediment accumulation rates in core samples, and conduct a qualitative assessment of the predominant source inputs of combustion-derived constituents to Puget Sound via atmospheric deposition. This report summarizes the project finding from all three tasks.

\section{Study Area}

\section{Sampling Locations}

Seven sampling locations were selected around Puget Sound to represent a range of geographic regions, precipitation patterns, and potential air pollution sources. Atmospheric deposition collectors were deployed to represent deposition directly on the waters of Puget Sound within specific regions of Ecology's box model (Figure 1 - Red markers; Pelletier and Mohamedali 2009). Table 1 lists the station numbers, identification codes, and coordinates. Figure 1 illustrates the 11 regions in the box model including: South Sound, Main basin, North Hood Canal, South Hood Canal, Whidbey, The Tacoma Narrows, Elliott Bay, Sinclair/Dyes Inlet, Commencement Bay, Admiralty Inlet, and the Straits of Juan de Fuca and Georgia (SJF/SOG). Generally, there is a flux station located in each of the boxes with the exception of Admiralty Inlet, Whidbey Basin, South Hood Canal, Elliott Bay, and The Tacoma Narrows. The distribution of the stations and box model compartments is discussed further in the mass loading analyses. An eighth location was added on the shores of Commencement Bay (Tyee Marina [TM]-see Figure 1, yellow marker-which is directly across the waters of Commencement Bay from the Tacoma Commencement Bay station [TCB]). The TM station was added to better understand the area of influence for the TCB station, which exhibited significantly different depositional fluxes for nearly all of the parameters (see discussion below).

The stations were grouped into rural/sub-urban, rural/industrial, and industrial/urban based on the dominant LULC in the coastal region around the station. See Appendix F for detailed 
descriptions of the sampling locations and site photos. Rural and sub-urban stations were located on Sequim Bay, Rich Passage in Port Orchard, Hood Canal, and the Nisqually River delta. The Sequim Bay (SB) site was located at the Pacific Northwest National Laboratory, Marine Sciences Laboratory (MSL). This station represented the Straits of Juan de Fuca with potential emission sources from farmlands and wood-burning stoves. The Port Orchard (PO) station was located at the EPA, Ecology, and National Oceanic and Atmospheric Administration (NOAA) Manchester Environmental Laboratories. This station represented the urban bays of Sinclair and Dyes Inlet and western central Puget Sound basin. The station potentially received emissions from shipping, select industry, and low to moderate density urban development emissions from the surrounding cities and communities (Silverdale, Bremerton, and Bainbridge Island). The third rural/sub-urban station was on Hood Canal (HC) at the University of Washington Big Beef Creek Fisheries Research Station. This station was selected to represent air quality for Hood Canal and other nearshore areas characterized as rural forested lands. The rural/sub-urban station representing south Puget Sound was the Nisqually River (NR) station located at the Nisqually Reach Nature Center. The station was surrounded by moderate density development and forested areas.

The only rural/industrial station was located on Padilla Bay (PB) at the Padilla Bay National Estuarine Research Reserve. This station represented northern Puget Sound, including the San Juan Islands, southern Strait of Georgia, and Whidbey Island. Some of the sources of air emissions included the farm lands of the Skagit Valley, several oil refineries, and the urban region of the city of Vancouver, British Columbia, Canada.

Two industrial/urban stations were deployed during the entire study: 1) West Point (WP) and 2) TCB. The WP station was located on the beach property of the METRO King County wastewater treatment plant and represented the central basin of Puget Sound and Elliott Bay. The wind patterns at the station were generally north/south providing primarily marine air masses over the station. Possible air emission sources included ships, trains, and other urban air emissions. The TCB station was located on the University of Washington, Tacoma campus near 21 st Street and Jefferson Avenue on the roof of the West-Side Grocery Building. The station is surrounded by high density urban development and industrial activities within the Port of Tacoma on Commencement Bay tide flats. This is the most industrialized sampling location with a range of pulp and paper mills, metal refining, and other industrial activities that combust both wood and hydrocarbon fuels. The deposition chemistry for TCB was significantly different from the other stations; therefore, an additional station was added in the Commencement Bay region. The station was located at the Tyee Marina off Marine Drive and directly across Commencement Bay from the TCB station (See Figure 1 insert). The TM station was sampled during events 14-19 in May/June and then from July through October 2009 (see Methods Section). The TM station was at sea level surrounded by the marina, a forested bluff, and the other industrial activities operating within Commencement Bay tide flats. 


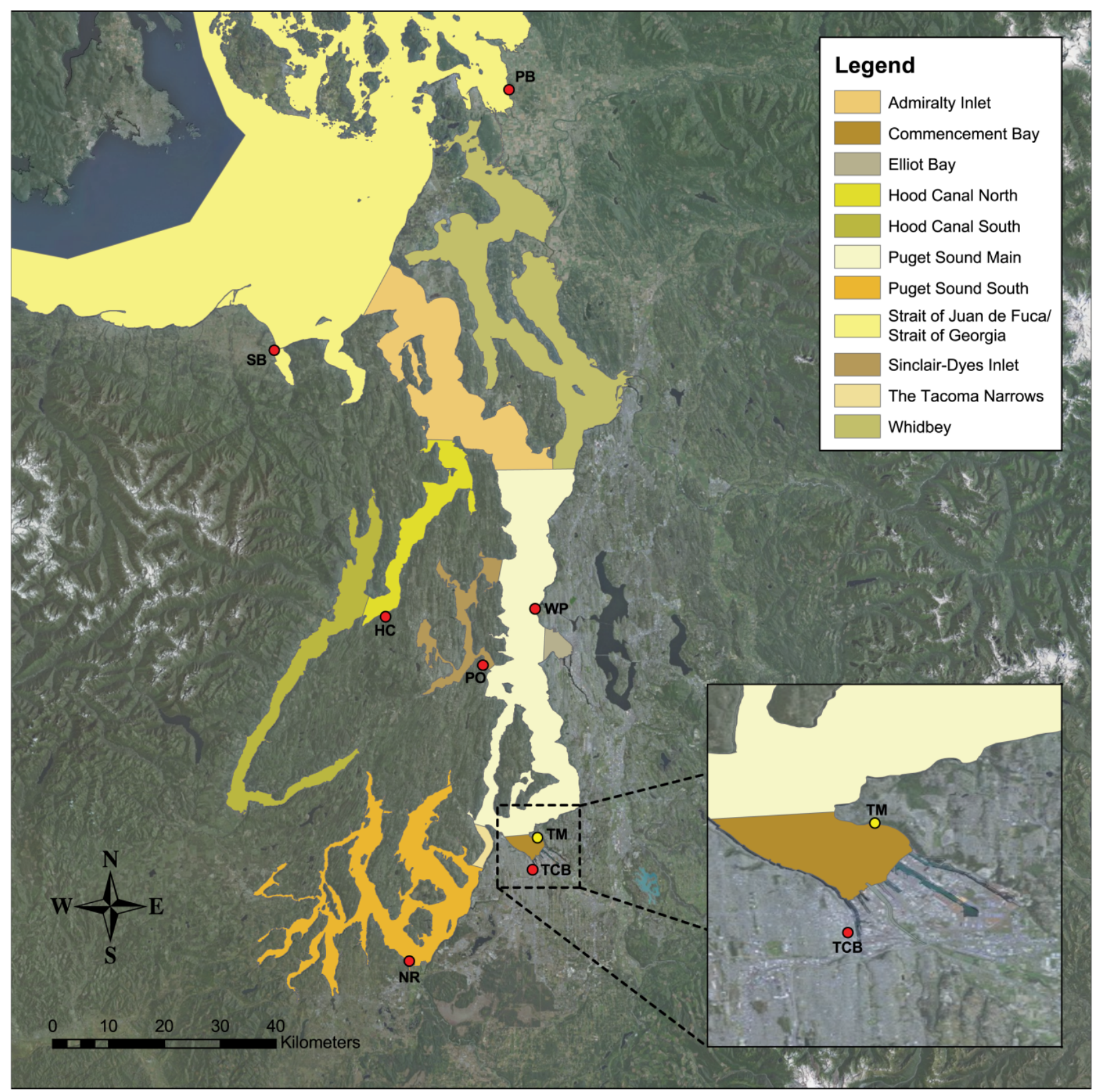

Figure 1. Seven primary stations (red) and the Tyee Marina (TM) station (yellow). Primary stations were Padilla Bay (PB), Sequim Bay (SB), West Point (WP), Port Orchard (PO), Hood Canal (HC), Tacoma Commencement Bay (TCB), and Nisqually River (NR). The 11 compartments in the Puget Sound box model (Pelletier and Mohamedali 2009) are illustrated. 
Table 1. Atmospheric deposition station number, identification code, name, and coordinates.

\begin{tabular}{|lllll|}
\hline $\begin{array}{l}\text { Station } \\
\text { Num. }\end{array}$ & $\begin{array}{l}\text { Station } \\
\text { ID }\end{array}$ & Name & $\begin{array}{l}\text { Coordinates } \\
\text { (degrees, minutes, seconds) }\end{array}$ \\
\hline \hline 1 & PB & Padilla Bay & $48^{\circ} 29^{\prime} 39.40^{\prime \prime} \mathrm{N}$ & $122^{\circ} 28^{\prime} 44.87^{\prime \prime} \mathrm{W}$ \\
2 & $\mathrm{SB}$ & Sequim Bay & $48^{\circ} 04^{\prime} 42.29^{\prime \prime} \mathrm{N}$ & $123^{\circ} 02^{\prime} 41.17^{\prime \prime} \mathrm{W}$ \\
3 & $\mathrm{WP}$ & West Point, Seattle & $47^{\circ} 39^{\prime} 50.34^{\prime \prime} \mathrm{N}$ & $122^{\circ} 25^{\prime} 34.20^{\prime \prime} \mathrm{W}$ \\
4 & $\mathrm{PO}$ & Port Orchard, Manchester & $47^{\circ} 34^{\prime} 26.03^{\prime \prime} \mathrm{N}$ & $122^{\circ} 33^{\prime} 04.27^{\prime \prime} \mathrm{W}$ \\
5 & HC & Hood Canal, Seabeck & $47^{\circ} 39^{\prime} 07.13^{\prime \prime} \mathrm{N}$ & $122^{\circ} 46^{\prime} 51.16^{\prime \prime} \mathrm{W}$ \\
6 & TCB & Tacoma Commencement Bay & $47^{\circ} 14^{\prime} 45.59^{\prime \prime} \mathrm{N}$ & $122^{\circ} 26^{\prime} 13.95^{\prime \prime} \mathrm{W}$ \\
7 & NR & Nisqually River Delta & $47^{\circ} 06^{\prime} 02.39^{\prime \prime} \mathrm{N}$ & $122^{\circ} 43^{\prime} 37.16^{\prime \prime} \mathrm{W}$ \\
8 & TM & Tyee Marina & $47^{\circ} 17^{\prime} 51.52^{\prime \prime} \mathrm{N}$ & $122^{\circ} 25^{\prime} 27.70^{\prime \prime} \mathrm{W}$ \\
\hline
\end{tabular}

Generally, the PNW is characterized by few days of no measurable precipitation and relatively short average antecedent dry periods. Halkola (2004) showed that the distribution of storm sizes was dominated by small storm events with total precipitation in 24 hours measuring from 0.11 to 0.5 inches. The average annual cumulative precipitation near the sampling locations ranged from less than 20 inches in Sequim to over 50 inches near PO and HC stations. The variability in the average annual cumulative precipitation amounts from 1995-2007 is shown in Figure 2 as the box plots. The 1995-2007 data were provided by PRISM Climate Group, Oregon State University (http://www.prismclimate.org). Overlaid on the box plot are the average annual cumulative precipitation amounts for 2008 and 2009 during the study period. The 2008 and 2009 data were provided by the Community Collaborative Rain, Hail, and Snow Network, NOAA (http://www.cocorahs.org) created February 2010. The average precipitation data during the study suggest that the sampling period would be considered representative based on the inter-annual variability over the previous decade. The 2009 data for Sequim Bay are the only exception as the data falls outside the 90th percentile for the historical data. The typical precipitation patterns in the PNW are characterized by a very distinct wet season from November through April and a dry season from May through October; therefore, the sampling periods were collected to represent both seasonal patterns. 


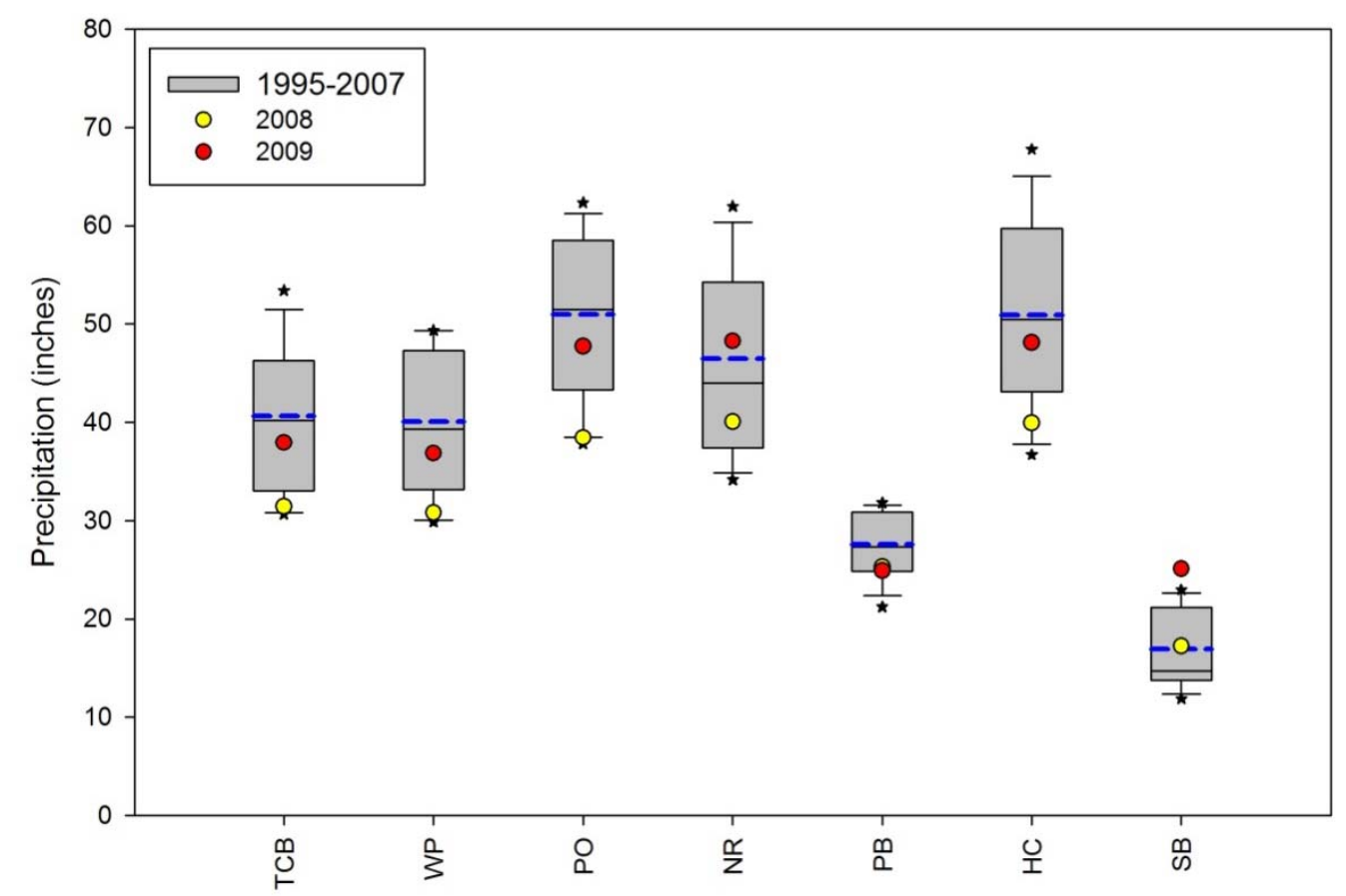

Figure 2. The distribution of the average annual cumulative precipitation (inches) for Puget Sound from 1995-2007 in the box plot for each station. The box boundaries are the $25^{\text {th }}$ and $75^{\text {th }}$ percentile, with the median in the box, dashed blue line is the mean, whiskers are the 10th and 90th percentiles, and the asterisks are outliers. The cumulative precipitation data for each station during 2008 (yellow) and 2009 (red) were plotted within the historical data distribution.

\section{Chemicals of Concern}

Recent data for atmospheric deposition of various toxics were extremely limited for many areas of Puget Sound. Therefore, a literature review was used to guide the selection of toxics to characterize atmospheric deposition (Appendix E). The list of chemical constituents selected was derived considering many factors including availability of regional data, chemical stability, and known regional and/or global atmospheric transport pathways. Emerging toxics not represented in regional studies (e.g., PBDE), national literature values, toxicity, and available budget were also considered. Table 2 lists both the selected toxics and required biomarkers to support source identification of the PAH data. The creation of this list was largely supported by the Phase 1 report (Hart Crowser, Inc. 2007).

Specialized analytical chemistry techniques were necessary for many of the selected toxics and the biomarkers required for source identification. Therefore, a collaborative project was developed with the U.S. Navy to support the addition of THg and monomethylmercury (MMHg) determinations. In addition, the U. S. Navy is currently funding the polychlorinated biphenyls (PCBs) analyses of the archived splits from this study. The samples will be analyzed for the NOAA Status and Trends program list of 18 PCB congeners including PCB-8, 18,28, 44, 52, 66, $101,105,118,128,138,153,170,180,187,195,206$, and 209 (O'Connor 2002). The 
atmospheric deposition fluxes and annual loads of THg are reported herein and will be used, along with the PCB fluxes, to update the mass balances for THg and PCBs calculated for Sinclair and Dyes Inlet (draft final report Brandenberger et al. to be published in 2010).

Table 2. List of chemical constituents measured in bulk atmospheric deposition in Puget Sound.

\begin{tabular}{l}
\hline Trace Metals \\
Arsenic \\
Cadmium \\
Copper \\
Lead \\
Zinc \\
Total Mercury and Monomethyl Mercury \\
PBDEs \\
BDE-17, 28, 47, 66, 71 85, 99, 100, 138, 153, 154, 183, 190, 209 \\
Carcinogenic PAHs \\
Benzo[a]anthracene \\
Chrysene \\
Benzo[b]fluoranthene \\
Benzo[k]fluoranthene \\
Benzo[a]pyrene \\
Indeno[1,2,3-c,d]pyrene \\
Dibenzo[a,h]anthracene \\
Pyrogenic PAHs \\
Fluoranthene \\
Pyrene \\
Benzo[a]anthracene \\
Chrysene \\
Benzo[b]fluoranthene \\
Benzo[k]fluoranthene \\
Benzo[a]pyrene \\
Indeno[1,2,3-c,d]pyrene \\
Dibenzo[a,h]anthracene \\
Benzo[g,h,i]perylene \\
Anhydrosugars \\
Levoglucosan, Mannosan, Galactosan \\
Additional PAH Markers \\
Phenanthrene; anthracene; perylene; retene; 3,6-dimethylphenanthrene; 2,6- \\
dimethylphenanthrene; $1,7-$ dimethylphenanthrene; C1 Methyl-Phe/An \\
\hline
\end{tabular}




\section{Methods}

\section{Collection Methods}

Bulk atmospheric deposition samples were sequentially collected from August 28 to December 11, 2008; February 25 to June 9, 2009; and July 29 to October 8, 2009 at seven stations on or close to the Puget Sound shore. A duplicate station was placed at different stations for the first 12 sampling events to assess field variability, and an eighth station was added in May 2009 (Events \# 14-19) at TM to evaluate the spatial influence of the fluxes measured at TCB. The duplicate was deployed for at least two events at the SB, PO, HC, TCB, and NR stations. The event numbers, collection dates, days deployed, and average temperature and precipitation for each sampling event are summarized in Table 3 .

The field equipment was designed to passively collect bulk atmospheric deposition without requiring electrical power. Deposition collectors were placed approximately 6 feet off the ground on a framework constructed from untreated wood in a tripod design. The framework held separate sample collectors for organics, trace metals, and mercury speciation (Figure 3).

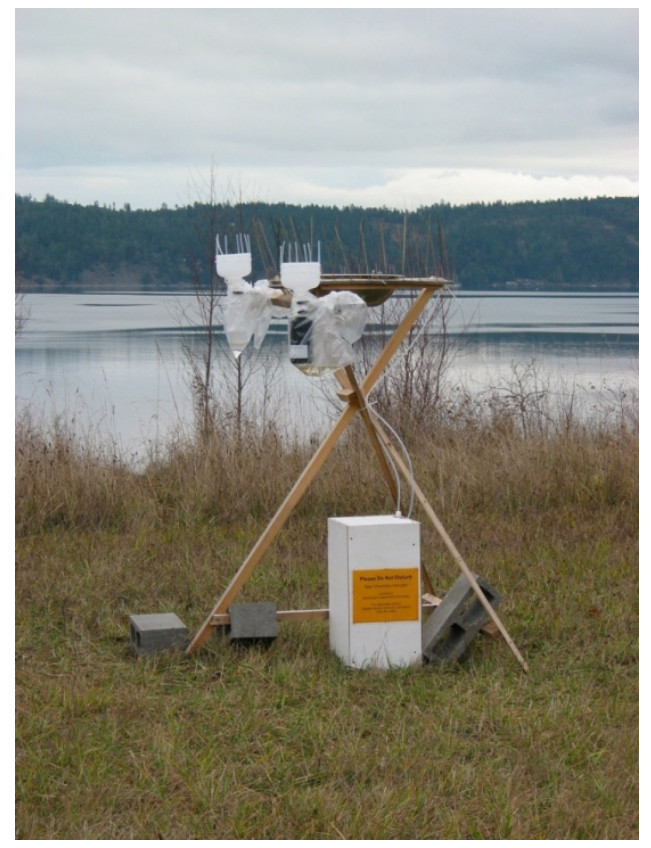

Figure 3. Bulk atmospheric deposition collector with stainless steel funnel in the center draining down into the wood box for organic parameters, clear Teflon ${ }^{\circledR} 1 \mathrm{~L}$ bottles for trace elements (left arm), and opaque Teflon $\circledast 1 \mathrm{~L}$ bottles for mercury speciation (right arm).

A chain of custody (COC) was filled out and held on file at MSL for each event and field team. The COC contained, at a minimum, the station ID, unique sample ID for each container (i.e., capsule for organics, metals, MMHg, etc.), parameters requested, date of deployment and recovery, volume of rinse water for the metals, volume of water extracted by the organics 
extraction capsule, field anomalies, or unusual weather conditions over the sampling period. The field work was divided into two teams: 1) King County Environmental Laboratory maintained PB, WP, TCB, and NR stations, and 2) MSL maintained stations PO, SB, and HC. The samples were recovered from the field, double bagged, and stored in a cooler until arrival at MSL. Most were delivered the day of collection, but occasionally samples were stored at King County at $4^{\circ} \mathrm{C}$ until shipped overnight to MSL. Since the samples were deployed for approximately 14 days, the metals sampling equipment contained preservative, and the organic aliquot contained solid phase extraction disks to preserve the samples. Each laboratory maintains a quality assurance and quality control program (QA/QC). All QA/QC procedures, such as equipment blanks and field duplicates, are discussed in Section 2.2.

Table 3. Sampling dates for each of the nineteen events with days deployed, rain collected at the station, field duplicate locations, and average ambient temperature.

\begin{tabular}{|c|c|c|c|c|c|c|c|}
\hline $\begin{array}{l}\text { Station } \\
\text { ID }\end{array}$ & $\begin{array}{l}\text { Event } \\
\text { No. }\end{array}$ & $\begin{array}{l}\text { Field } \\
\text { Dup } \\
\end{array}$ & $\begin{array}{l}\text { Date } \\
\text { Deployed } \\
\end{array}$ & $\begin{array}{l}\text { Date } \\
\text { Recovered }\end{array}$ & $\begin{array}{l}\text { Days } \\
\text { Deployed } \\
\end{array}$ & $\begin{array}{l}\text { Average } \\
\text { Temperature } \\
\left({ }^{\circ} \mathrm{F}\right) \\
\end{array}$ & $\begin{array}{l}\text { Cumulative } \\
\text { Precipitation } \\
\text { (inches) } \\
\end{array}$ \\
\hline $\mathrm{HC}$ & 1 & & $9 / 3 / 08$ & $9 / 17 / 08$ & 14 & 59.9 & 0.00 \\
\hline $\mathrm{HC}$ & 2 & & 9/17/08 & $10 / 6 / 08$ & 19 & 55.8 & 1.97 \\
\hline $\mathrm{HC}$ & 3 & & $10 / 6 / 08$ & $10 / 16 / 08$ & 10 & 47.9 & 0.80 \\
\hline $\mathrm{HC}$ & 4 & & $10 / 16 / 08$ & $10 / 29 / 08$ & 13 & 47.3 & 0.16 \\
\hline $\mathrm{HC}$ & 5 & $x$ & $10 / 29 / 08$ & $11 / 8 / 08$ & 10 & 49.6 & $5.07^{*}$ \\
\hline $\mathrm{HC}$ & 6 & $x$ & $11 / 8 / 08$ & $11 / 20 / 08$ & 12 & 48.2 & 1.69 \\
\hline $\mathrm{HC}$ & 7 & $x$ & $11 / 20 / 08$ & $12 / 11 / 08$ & 21 & 43.7 & 0.98 \\
\hline $\mathrm{HC}$ & 8 & & $2 / 26 / 09$ & $3 / 12 / 09$ & 14 & 38.5 & 1.38 \\
\hline $\mathrm{HC}$ & 9 & & $3 / 12 / 09$ & $3 / 25 / 09$ & 13 & 40.9 & 2.53 \\
\hline $\mathrm{HC}$ & 10 & & $3 / 25 / 09$ & $4 / 8 / 09$ & 14 & 43.6 & 0.91 \\
\hline $\mathrm{HC}$ & 11 & & $4 / 8 / 09$ & $4 / 22 / 09$ & 14 & 47.7 & 1.77 \\
\hline $\mathrm{HC}$ & 12 & & $4 / 22 / 09$ & $5 / 5 / 09$ & 13 & 49.0 & 2.70 \\
\hline $\mathrm{HC}$ & 13 & & $5 / 5 / 09$ & $5 / 20 / 09$ & 15 & 50.9 & 2.39 \\
\hline $\mathrm{HC}$ & 14 & & $5 / 20 / 09$ & $6 / 5 / 09$ & 16 & 60.7 & 0.00 \\
\hline $\mathrm{HC}$ & 15 & & $7 / 30 / 09$ & $8 / 14 / 09$ & 15 & 64.1 & 0.55 \\
\hline $\mathrm{HC}$ & 16 & & $8 / 14 / 09$ & $8 / 26 / 09$ & 12 & 62.6 & 0.03 \\
\hline $\mathrm{HC}$ & 17 & & $8 / 26 / 09$ & $9 / 11 / 09$ & 16 & 60.9 & 1.71 \\
\hline $\mathrm{HC}$ & 18 & & 9/11/09 & $9 / 25 / 09$ & 14 & 61.0 & 0.40 \\
\hline $\mathrm{HC}$ & 19 & & 9/25/09 & $10 / 14 / 09$ & 19 & 49.8 & 1.39 \\
\hline NR & 1 & & $8 / 29 / 08$ & 9/12/08 & 14 & 59.6 & 0.00 \\
\hline NR & 2 & & $9 / 12 / 08$ & 9/24/08 & 12 & 57.9 & 0.30 \\
\hline NR & 3 & & $9 / 24 / 08$ & $10 / 15 / 08$ & 21 & 52.5 & 2.29 \\
\hline NR & 4 & & $10 / 15 / 08$ & $10 / 30 / 08$ & 15 & 47.8 & 0.54 \\
\hline $\mathrm{NR}$ & 5 & & $10 / 30 / 08$ & $11 / 12 / 08$ & 13 & 50.8 & $9.50 *$ \\
\hline NR & 6 & & $11 / 12 / 08$ & $11 / 24 / 08$ & 12 & 44.7 & 0.79 \\
\hline NR & 7 & & $11 / 24 / 08$ & $12 / 11 / 08$ & 17 & 43.7 & 0.32 \\
\hline NR & 8 & & $2 / 25 / 09$ & $3 / 12 / 09$ & 15 & 38.8 & 1.33 \\
\hline NR & 9 & & $3 / 12 / 09$ & $3 / 25 / 09$ & 13 & 41.0 & 2.98 \\
\hline NR & 10 & $x$ & $3 / 25 / 09$ & $4 / 8 / 09$ & 14 & 44.3 & 1.44 \\
\hline
\end{tabular}




\begin{tabular}{|c|c|c|c|c|c|c|c|}
\hline $\begin{array}{l}\text { Station } \\
\text { ID }\end{array}$ & $\begin{array}{l}\text { Event } \\
\text { No. }\end{array}$ & $\begin{array}{l}\text { Field } \\
\text { Dup }\end{array}$ & $\begin{array}{l}\text { Date } \\
\text { Deployed }\end{array}$ & $\begin{array}{l}\text { Date } \\
\text { Recovered }\end{array}$ & $\begin{array}{l}\text { Days } \\
\text { Deployed }\end{array}$ & $\begin{array}{l}\text { Average } \\
\text { Temperature } \\
\left({ }^{\circ} \mathrm{F}\right) \\
\end{array}$ & $\begin{array}{l}\text { Cumulative } \\
\text { Precipitation } \\
\text { (inches) }\end{array}$ \\
\hline NR & 11 & $x$ & $4 / 8 / 09$ & $4 / 22 / 09$ & 14 & 48.6 & 1.77 \\
\hline NR & 12 & $x$ & $4 / 22 / 09$ & $5 / 7 / 09$ & 15 & 49.0 & 3.60 \\
\hline NR & 13 & & $5 / 7 / 09$ & $5 / 21 / 09$ & 14 & 51.9 & 1.42 \\
\hline NR & 14 & & $5 / 21 / 09$ & $6 / 4 / 09$ & 14 & 61.8 & 0.00 \\
\hline NR & 15 & & $7 / 30 / 09$ & $8 / 12 / 09$ & 13 & 65.2 & 0.92 \\
\hline NR & 16 & & $8 / 12 / 09$ & $8 / 27 / 09$ & 15 & 63.1 & 0.24 \\
\hline NR & 17 & & $8 / 27 / 09$ & $9 / 8 / 09$ & 12 & 60.7 & 2.16 \\
\hline NR & 18 & & 9/8/09 & 9/24/09 & 16 & 61.5 & 0.33 \\
\hline NR & 19 & & 9/24/09 & $10 / 7 / 09$ & 13 & 51.8 & 0.20 \\
\hline PB & 1 & & $8 / 28 / 08$ & 9/12/08 & 15 & & 0.23 \\
\hline PB & 2 & & $9 / 12 / 08$ & $9 / 25 / 08$ & 13 & & 0.70 \\
\hline $\mathrm{PB}$ & 3 & & 9/25/08 & $10 / 15 / 08$ & 20 & & 0.89 \\
\hline PB & 4 & & $10 / 15 / 08$ & $10 / 29 / 08$ & 14 & & 0.28 \\
\hline $\mathrm{PB}$ & 5 & & $10 / 29 / 08$ & $11 / 13 / 08$ & 15 & & 4.99* \\
\hline PB & 6 & & $11 / 13 / 08$ & $11 / 25 / 08$ & 12 & & 0.28 \\
\hline PB & 7 & & $11 / 25 / 08$ & $12 / 11 / 08$ & 16 & & 1.55 \\
\hline $\mathrm{PB}$ & 8 & & $2 / 26 / 09$ & $3 / 11 / 09$ & 13 & & 0.47 \\
\hline PB & 9 & & $3 / 11 / 09$ & $3 / 25 / 09$ & 14 & & 1.17 \\
\hline $\mathrm{PB}$ & 10 & & $3 / 25 / 09$ & $4 / 8 / 09$ & 14 & & 1.49 \\
\hline PB & 11 & & $4 / 8 / 09$ & $4 / 23 / 09$ & 15 & & 0.99 \\
\hline PB & 12 & & $4 / 23 / 09$ & $5 / 6 / 09$ & 13 & & 0.62 \\
\hline PB & 13 & & $5 / 6 / 09$ & $5 / 21 / 09$ & 15 & & 2.31 \\
\hline PB & 14 & & $5 / 21 / 09$ & $6 / 3 / 09$ & 13 & & 0.11 \\
\hline $\mathrm{PB}$ & 15 & & \begin{tabular}{|l|l|}
$7 / 09$ \\
\end{tabular} & $8 / 12 / 09$ & 14 & & 0.67 \\
\hline PB & 16 & & $8 / 12 / 09$ & $8 / 26 / 09$ & 14 & & 0.01 \\
\hline PB & 17 & & $8 / 26 / 09$ & 9/9/09 & 14 & & 0.34 \\
\hline $\mathrm{PB}$ & 18 & & 9/9/09 & $9 / 24 / 09$ & 15 & & 0.60 \\
\hline $\mathrm{PB}$ & 19 & & 9/24/09 & $10 / 7 / 09$ & 13 & & 0.33 \\
\hline $\mathrm{PO}$ & 1 & & 9/3/08 & 9/17/08 & 14 & 59.9 & 0.00 \\
\hline $\mathrm{PO}$ & 2 & & 9/17/08 & $10 / 6 / 08$ & 19 & 55.8 & 1.51 \\
\hline $\mathrm{PO}$ & 3 & $x$ & 10/6/08 & 10/16/08 & 10 & 47.9 & 0.35 \\
\hline $\mathrm{PO}$ & 4 & $x$ & 10/16/08 & $10 / 29 / 08$ & 13 & 47.3 & 0.15 \\
\hline $\mathrm{PO}$ & 5 & & $10 / 29 / 08$ & $11 / 7 / 08$ & 9 & 49.6 & 5.90* \\
\hline $\mathrm{PO}$ & 6 & & $11 / 7 / 08$ & $11 / 20 / 08$ & 12 & 48.2 & 1.19 \\
\hline $\mathrm{PO}$ & 7 & & $11 / 20 / 08$ & $12 / 11 / 08$ & 21 & 43.7 & 0.49 \\
\hline $\mathrm{PO}$ & 8 & & $2 / 26 / 09$ & $3 / 12 / 09$ & 14 & 38.5 & 1.02 \\
\hline $\mathrm{PO}$ & 9 & & $3 / 12 / 09$ & $3 / 25 / 09$ & 13 & 40.9 & 1.92 \\
\hline $\mathrm{PO}$ & 10 & & $3 / 25 / 09$ & $4 / 8 / 09$ & 14 & 43.6 & 1.52 \\
\hline $\mathrm{PO}$ & 11 & & $4 / 8 / 09$ & $4 / 22 / 09$ & 14 & 47.7 & 1.27 \\
\hline $\mathrm{PO}$ & 12 & & $4 / 22 / 09$ & $5 / 5 / 09$ & 13 & 49.0 & 2.85 \\
\hline $\mathrm{PO}$ & 13 & & $5 / 5 / 09$ & $5 / 20 / 09$ & 15 & 50.9 & 2.22 \\
\hline $\mathrm{PO}$ & 14 & & $5 / 20 / 09$ & $6 / 5 / 09$ & 16 & 60.7 & 0.00 \\
\hline $\mathrm{PO}$ & 15 & & $7 / 30 / 09$ & $8 / 14 / 09$ & 15 & 64.1 & 0.49 \\
\hline
\end{tabular}




\begin{tabular}{|c|c|c|c|c|c|c|c|}
\hline $\begin{array}{l}\text { Station } \\
\text { ID } \\
\end{array}$ & $\begin{array}{l}\text { Event } \\
\text { No. } \\
\end{array}$ & $\begin{array}{l}\text { Field } \\
\text { Dup } \\
\end{array}$ & $\begin{array}{l}\text { Date } \\
\text { Deployed }\end{array}$ & $\begin{array}{l}\text { Date } \\
\text { Recovered } \\
\end{array}$ & $\begin{array}{l}\text { Days } \\
\text { Deployed } \\
\end{array}$ & $\begin{array}{l}\text { Average } \\
\text { Temperature } \\
\left({ }^{\circ} \mathrm{F}\right) \\
\end{array}$ & $\begin{array}{l}\text { Cumulative } \\
\text { Precipitation } \\
\text { (inches) } \\
\end{array}$ \\
\hline $\mathrm{PO}$ & 16 & & $8 / 14 / 09$ & $8 / 26 / 09$ & 12 & 62.6 & 0.00 \\
\hline $\mathrm{PO}$ & 17 & & $8 / 26 / 09$ & $9 / 11 / 09$ & 16 & 60.9 & 1.31 \\
\hline $\mathrm{PO}$ & 18 & & 9/11/09 & 9/25/09 & 14 & 61.0 & 0.28 \\
\hline $\mathrm{PO}$ & 19 & & $9 / 25 / 09$ & $10 / 14 / 09$ & 19 & 49.8 & 0.80 \\
\hline SB & 1 & $x$ & $9 / 2 / 08$ & 9/18/08 & 16 & & 0.01 \\
\hline SB & 2 & $x$ & 9/18/08 & $10 / 2 / 08$ & 14 & & 0.32 \\
\hline SB & 3 & & $10 / 2 / 08$ & $10 / 15 / 08$ & 13 & & 0.27 \\
\hline SB & 4 & & $10 / 15 / 08$ & $10 / 30 / 08$ & 15 & & 0.35 \\
\hline SB & 5 & & $10 / 30 / 08$ & $11 / 10 / 08$ & 11 & & 2.29 \\
\hline SB & 6 & & $11 / 10 / 08$ & $11 / 25 / 08$ & 12 & & 0.70 \\
\hline SB & 7 & & $11 / 25 / 08$ & $12 / 11 / 08$ & 16 & & 0.37 \\
\hline SB & 8 & & $2 / 25 / 09$ & $3 / 12 / 09$ & 15 & & 1.06 \\
\hline SB & 9 & & $3 / 12 / 09$ & $3 / 29 / 09$ & 17 & & 1.40 \\
\hline SB & 10 & & $3 / 29 / 09$ & $4 / 13 / 09$ & 15 & & 0.83 \\
\hline SB & 11 & & $4 / 13 / 09$ & $4 / 28 / 09$ & 15 & & 0.20 \\
\hline SB & 12 & & $4 / 28 / 09$ & $5 / 11 / 09$ & 13 & & 0.51 \\
\hline SB & 13 & & $5 / 11 / 09$ & $5 / 27 / 09$ & 16 & & 1.66 \\
\hline SB & 14 & & $5 / 27 / 09$ & $6 / 8 / 09$ & 12 & & 0.00 \\
\hline SB & 15 & & $8 / 3 / 09$ & $8 / 18 / 09$ & 15 & & 0.34 \\
\hline SB & 16 & & $8 / 15 / 09$ & 8/29/09 & 11 & & 0.00 \\
\hline SB & 17 & & $8 / 29 / 09$ & 9/11/09 & 13 & & 0.30 \\
\hline SB & 18 & & 9/11/09 & $9 / 25 / 09$ & 14 & & 0.22 \\
\hline SB & 19 & & 9/25/09 & $10 / 13 / 09$ & 18 & & 0.25 \\
\hline TCB & 1 & & $8 / 29 / 08$ & 9/12/08 & 14 & 59.0 & 0.00 \\
\hline TCB & 2 & & $9 / 12 / 08$ & $9 / 24 / 08$ & 12 & 58.0 & 0.29 \\
\hline TCB & 3 & & 9/24/08 & 10/15/08 & 21 & 53.0 & 1.37 \\
\hline TCB & 4 & & 10/15/08 & $10 / 30 / 08$ & 15 & 49.0 & 0.69 \\
\hline TCB & 5 & & $10 / 30 / 08$ & $11 / 12 / 08$ & 13 & 51.0 & 7.81* \\
\hline TCB & 6 & & $11 / 12 / 08$ & $11 / 24 / 08$ & 12 & 46.0 & 0.58 \\
\hline TCB & 7 & & $11 / 12 / 08$ & $11 / 24 / 08$ & 17 & 45.0 & 0.37 \\
\hline TCB & 8 & $x$ & $11 / 24 / 08$ & $12 / 11 / 08$ & 15 & 39.0 & 1.35 \\
\hline TCB & 9 & $x$ & $2 / 25 / 09$ & $3 / 12 / 09$ & 13 & 42.0 & 2.73 \\
\hline TCB & 10 & & $3 / 12 / 09$ & $3 / 25 / 09$ & 14 & 45.0 & 1.65 \\
\hline TCB & 11 & & $4 / 8 / 09$ & $4 / 22 / 09$ & 14 & 48.0 & 1.81 \\
\hline TCB & 12 & & $4 / 22 / 09$ & $5 / 7 / 09$ & 15 & 49.0 & 3.21 \\
\hline TCB & 13 & & $5 / 7 / 09$ & $5 / 21 / 09$ & 14 & 51.0 & 1.21 \\
\hline TCB & 14 & & $5 / 21 / 09$ & $6 / 4 / 09$ & 14 & 61.0 & 0.00 \\
\hline TCB & 15 & & $7 / 30 / 09$ & $8 / 12 / 09$ & 13 & & 0.43 \\
\hline TCB & 16 & & $8 / 12 / 09$ & $8 / 27 / 09$ & 15 & & 0.07 \\
\hline TCB & 17 & & $8 / 27 / 09$ & $9 / 8 / 09$ & 12 & & 2.07 \\
\hline TCB & 18 & & 9/8/09 & 9/24/09 & 16 & & 0.24 \\
\hline TCB & 19 & & 9/24/09 & $10 / 7 / 09$ & 13 & & 0.44 \\
\hline WP & 1 & & $8 / 28 / 08$ & 9/12/08 & 15 & \begin{tabular}{|l|}
63.8 \\
\end{tabular} & 0.00 \\
\hline
\end{tabular}




\begin{tabular}{|c|c|c|c|c|c|c|c|}
\hline $\begin{array}{l}\text { Station } \\
\text { ID }\end{array}$ & $\begin{array}{l}\text { Event } \\
\text { No. }\end{array}$ & $\begin{array}{l}\text { Field } \\
\text { Dup }\end{array}$ & $\begin{array}{l}\text { Date } \\
\text { Deployed }\end{array}$ & $\begin{array}{l}\text { Date } \\
\text { Recovered }\end{array}$ & $\begin{array}{l}\text { Days } \\
\text { Deployed }\end{array}$ & $\begin{array}{l}\text { Average } \\
\text { Temperature } \\
\left({ }^{\circ} \mathrm{F}\right) \\
\end{array}$ & $\begin{array}{l}\text { Cumulative } \\
\text { Precipitation } \\
\text { (inches) }\end{array}$ \\
\hline WP & 2 & & 9/12/08 & $9 / 25 / 08$ & 13 & 61.4 & 0.59 \\
\hline WP & 3 & & $9 / 25 / 08$ & $10 / 14 / 08$ & 19 & 57.2 & 1.28 \\
\hline WP & 4 & & $10 / 14 / 08$ & $10 / 29 / 08$ & 15 & 52.2 & 0.31 \\
\hline WP & 5 & & $10 / 29 / 08$ & $11 / 13 / 08$ & 15 & 53.5 & $4.16^{\star}$ \\
\hline WP & 6 & & $11 / 13 / 08$ & $11 / 25 / 08$ & 12 & 49.5 & 0.30 \\
\hline WP & 7 & & $11 / 25 / 08$ & $12 / 11 / 08$ & 16 & 48.0 & 0.56 \\
\hline WP & 8 & & $2 / 26 / 09$ & $3 / 11 / 09$ & 13 & 42.1 & 1.12 \\
\hline WP & 9 & & $3 / 11 / 09$ & $3 / 25 / 09$ & 14 & 44.2 & 1.92 \\
\hline WP & 10 & & $3 / 25 / 09$ & $4 / 8 / 09$ & 14 & 47.3 & 1.53 \\
\hline WP & 11 & & $4 / 8 / 09$ & $4 / 23 / 09$ & 15 & 51.1 & 0.98 \\
\hline WP & 12 & & $4 / 23 / 09$ & $5 / 6 / 09$ & 13 & 53.3 & 2.79 \\
\hline WP & 13 & & $5 / 6 / 09$ & $5 / 21 / 09$ & 15 & 54.7 & 2.03 \\
\hline WP & 14 & & $5 / 21 / 09$ & $6 / 3 / 09$ & 13 & 65.0 & 0.00 \\
\hline WP & 15 & & $7 / 29 / 09$ & $8 / 12 / 09$ & 14 & 69.2 & 0.34 \\
\hline WP & 16 & & $8 / 12 / 09$ & $8 / 26 / 09$ & 14 & 66.1 & 0.34 \\
\hline WP & 17 & & $8 / 26 / 09$ & 9/9/09 & 14 & 64.6 & 1.16 \\
\hline WP & 18 & & 9/9/09 & 9/24/09 & 15 & 66.2 & 0.44 \\
\hline WP & 19 & & 9/24/09 & $10 / 7 / 09$ & 13 & 56.8 & 0.80 \\
\hline TM & 14 & & $5 / 20 / 09$ & $6 / 4 / 09$ & 15 & & 0.00 \\
\hline TM & 15 & & $7 / 30 / 09$ & $8 / 12 / 09$ & 13 & & 0.39 \\
\hline TM & 16 & & $8 / 12 / 09$ & $8 / 27 / 09$ & 15 & & 0.06 \\
\hline TM & 17 & & $8 / 27 / 09$ & 9/8/09 & 12 & & 1.83 \\
\hline TM & 18 & & 9/8/09 & $9 / 24 / 09$ & 16 & & 0.21 \\
\hline TM & 19 & & 9/24/09 & 10/7/09 & 13 & & 0.21 \\
\hline
\end{tabular}

\section{PAHs, Anhydrosugars, and PBDEs}

Atmospheric deposition samples for PAHs, anhydrosugars, and PBDEs were collected using a stainless steel funnel with a diameter of $45 \mathrm{~cm}$ and surface area of $0.159 \mathrm{~m}^{2}$. Wet deposition and dry deposition (rinsed from the funnel by deionized water) gravity feeds down a length of Teflon $^{\circledR}$ tubing into a Teflon ${ }^{\circledR}$ filter cartridge capsule housed inside a wooden box. The samples were shielded from light exposure to prevent photo-oxidation. The transfer tubing was equipped with a vent line made of Teflon ${ }^{\circledR}$ and fitted with a Teflon ${ }^{\circledR}$ screen at the height of the funnel top (Figure 3). The deposition water was extracted onsite at a rate of $\sim 3 \mathrm{~mL}$ per minute through a series of three glass fiber filters (GFF) separating two different types of Empore ${ }^{\circledR}$ extraction disks with different sorbent materials. The first disk was an Empore ${ }^{\circledR}$ SDB-RPS disk, which is a poly(styrenedivinylbenzene) copolymer that has been modified with sulfonic acid groups to make it hydrophilic. The second disk was an Empore ${ }^{\circledR} \mathrm{C} 18$, which has an octadecyl functional group bonded to a silica surface to make it hydrophobic and provide nonpolar interaction sites. The extraction scheme is illustrated in Figure 4 along with the PAHs, anhydrosugars, and PBDEs 
flow diagram for the collection and sample extraction process. This sampling method was adapted from that used by the Chesapeake Bay program (Baker et al. 1992), and simultaneous extraction of hydrophobic/hydrophilic organic compounds in snow (Usenko et al. 2005).

Large wooden skewers jutted up from the sampling frame to deter birds from landing on the sampling apparatus. One side of this crown of thorns was designed to be removed during sample recovery allowing access to the funnel for washing of dry deposition into the capsule before recovery. A natural hair paint brush pre-cleaned with methanol before each recovery was use to scrub particles from the inside of the funnel. The funnel surface was washed with deionized water (DI) using a pre-cleaned Teflon ${ }^{\circledR}$ squirt bottle and the brush. The outlet of the extraction capsule was fitted with another piece of Teflon ${ }^{\circledR}$ tubing that drained into a calibrated reservoir to provide a volume of water extracted. When recovering the capsule, the Teflon ${ }^{\circledR}$ tubing was used to create a closed system to prevent further extraction of air during transit back to the laboratory. A Teflon ${ }^{\circledR}$ plug was used to seal the vent tubing connector, and the entire capsule was bagged and stored in a cooler at $4 \pm 2{ }^{\circ} \mathrm{C}$. Samples were transported to MSL where the capsules were opened, all GFF and extract disks were removed using stainless steel tweezers, and samples were stored in a pre-cleaned, $2 \mathrm{oz}$. glass jar at $-80 \pm 1{ }^{\circ} \mathrm{C}$. Samples were shipped to Texas A\&M University for extraction of all organic compounds and for analyses of PAHs and biomarkers. 


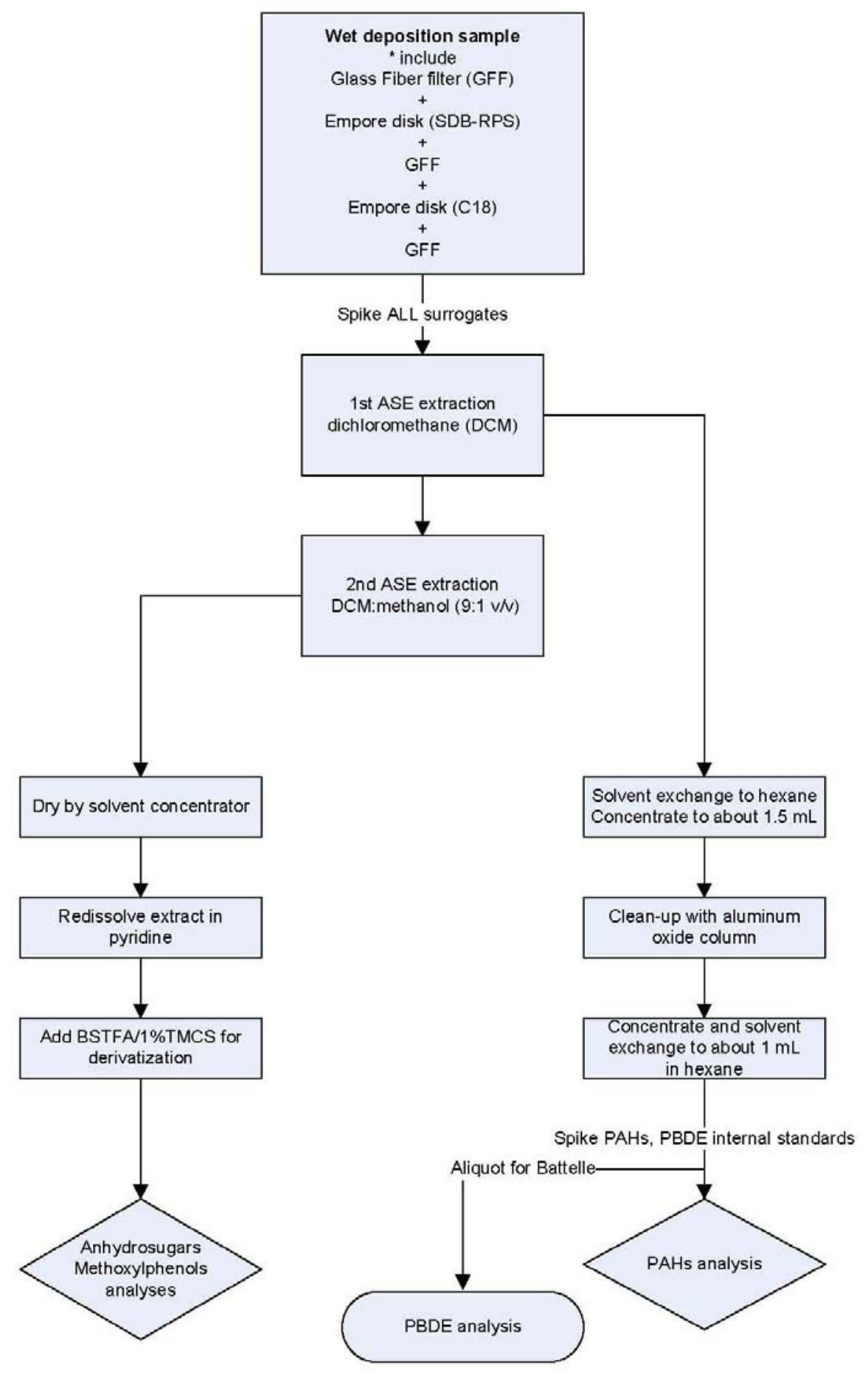

Figure 4. Flow diagram for onsite field extraction of bulk deposition and subsequent laboratory sample extractions for PAHs, anhydrosugars, and PBDEs.

\section{Trace Metals}

Atmospheric deposition samples for trace element measurements were collected using a bulk deposition sampler following procedures similar to those described in Landing et al. (1998) and 
Guentzel et al. (1998, 2001). The sampler consists of three components: an upward facing funnel made of fluorocarbon high density polyethylene (F-HDPE), a Teflon ${ }^{\circledR}$ collar, and a 1L Teflon ${ }^{\circledR}$ sample bottle. Opaque (black) Teflon ${ }^{\circledR}$ bottles were used for MMHg samples to prevent photodegradation of MMHg. Clear Teflon ${ }^{\circledR}$ bottles were used for all other trace element collections. A crown of thorns made from Teflon ${ }^{\circledR}$ tubing was attached to the outside rim of the funnel to deter birds. The Teflon ${ }^{\circledR}$ collar mates the funnel to the Teflon ${ }^{\circledR}$ sample bottle and was manufactured from a solid block. Threads were cut into two sides of the Teflon ${ }^{\circledR}$ block to allow the funnel and sample bottle to be secured into it. An air port was necessary on the side of the collar to allow air inside the sample bottle to escape as rainfall enters. The bulk deposition sampler was held in place with a new stainless steel three-finger clamp and attached to the wooden tripod. The clamp and bottle were covered with a plastic bag to prevent back splash contamination from the stainless steel clamps. The size of the funnel for all trace elements depended on the annual precipitation patterns at the specific site. Three sizes of funnels were deployed during the sampling. They were identified as $4 \mathrm{~L}, 2 \mathrm{~L}$, and $1 \mathrm{~L}$ funnels (noted on COC) with a surface area of $0.0172 \mathrm{~m}^{2}, 0.0104 \mathrm{~m}^{2}$, and $0.00636 \mathrm{~m}^{2}$, respectively. The surface areas of the funnel used for each sample are provided in Appendix C and D.

All equipment (funnels, thorns, bottles, etc.) was rigorously cleaned with laboratory detergent (Micro) and soaked in nitric acid for at least three days. Teflon ${ }^{\circledR}$ equipment was soaked in hot concentrated nitric acid $\left(\mathrm{HNO}_{3}\right)$ followed by a hydrochloric acid $(\mathrm{HCl})$ soak at $65^{\circ} \mathrm{C}$. Each cleaning step was followed by a thorough rinsing with 18 megaohm high-purity DI water and dried in a class-100 clean-air bench. All equipment was double bagged in polyethylene bags and handled using gloved hands and the clean hands - dirty hands sampling approach detailed by the EPA 1600 series methods. The clear Teflon ${ }^{\circledR}$ bottles were used to collect samples for arsenic (As), cadmium $(\mathrm{Cd})$, chromium $(\mathrm{Cr})$, copper $(\mathrm{Cu})$, nickel $(\mathrm{Ni})$, lead $(\mathrm{Pb})$, zinc $(\mathrm{Zn})$, and $\mathrm{THg}$ analysis and were pre-acidified with $2 \mathrm{~mL}$ of $50 \%$ double-distilled $\mathrm{HNO}_{3}$ to prevent adsorption of trace elements onto the bottle walls. The opaque bottles were to collect MMHg samples and serve as a duplicate for THg. The opaque bottles were pre-acidified with $2 \mathrm{~mL}$ of $10 \% \mathrm{HCl}$ for preserving the $\mathrm{THg}$ and $\mathrm{MMHg}$ collections.

After approximately a two-week integrated sampling period, the samplers were recovered using the EPA Method 1669 protocol for trace element sampling. Non-powder latex or nitrile gloves were used throughout the recovery process. The funnel surface was rinsed with DI water to remove any particles deposited on the funnel surface. A calibrated $10-\mathrm{mL}$ pipette was used to deliver each volume of DI water, and the total rinse volume was recorded on the COC. The deployed 1L Teflon ${ }^{\circledR}$ bottle was unscrewed from the funnel and collar, re-capped, and stored double bagged in a cooler. The $\mathrm{pH}$ of each sample was checked and adjusted with additional acid (if necessary) to be $<2.0$ or approximately $0.2 \% \mathrm{HNO}_{3}$ for the trace elements and $0.5 \% \mathrm{HCl}$ for the THg and MMHg samples. Anomalies, such as bird droppings in the funnel or missing equipment, were recorded on the COC. 


\section{Analytical Methods}

The extraction and analyses for PAHs and biomarkers were conducted at Texas A\&M University, Galveston, TX and College Station, TX. Appendix A summarizes the data for events 1 through 19. Splits of each extract were shipped to MSL for PBDE analyses. Appendix B summarizes the PBDE data for events 1 through 19. Finally, this report and Appendices C and D summarize the trace elements and mercury speciation analyses, respectively, conducted by MSL.

\section{PAHs and Anhydrosugars}

The GFF and extraction disks recovered from the field capsules were lyophilized before extraction. This process was conducted at both Texas A\&M University and MSL and is discussed in detail below. The dried samples were then spiked with multiple perdeuterated surrogate standards or artificial internal standards according to established methods (Usenko et al. 2005; Kuo et al. 2008; Louchouarn et al. 2009). The samples were spiked with d7levoglucosan (National Institute of Standards and Technology [NIST] Standard Reference Material [SRM] 2267) for anhydrosugar analyses, five perdeuterated standards (d8-naphthalene, d10-acenaphthene, d10-phenanthrene, d12-chrysene, and d12-perylene) for the PAH analyses, and a mixture of chlorinated and brominated surrogates (PCB 103, PCB 198, hexabromobiphenyl) for the PBDE analyses. The two solid phase extraction (SPE) disks and three GFF's in each sample were extracted via pressurized fluid extraction (PFE) with an accelerated solvent extractor (ASE) (Dionex ASE-200) at $10.3 \mathrm{MPa}$ and $100^{\circ} \mathrm{C}$. The samples were then processed sequentially, first with dichloromethane (DCM) to extract hydrophobic constituents (PAHs and PBDE) and then using a more polar solvent mixture (DCM:MeOH: 9:1, $\mathrm{v} / \mathrm{v}$ ) to extract anhydrosugars (Figure 4).

The dichloromethane extracts (for PAH analyses) were reduced in volume to $1-2 \mathrm{~mL}$ and solvent exchanged to hexane using a water bath. The concentrated extracts were cleaned up by using aluminum oxide columns. The eluent was then concentrated to $1 \mathrm{~mL}$ and stored until gas chromatography mass spectrometry (GC/MS) analysis. Before injection, $100 \mu \mathrm{L}$ of a PAH internal standard solution (d10-Fluorene and d12-Benzo[a]pyrene) was spiked into the extracts to assess the analytical recoveries of surrogates. The dichloromethane: methanol extracts (anhydrosugars) were evaporated to dryness using a LabConco ${ }^{\mathrm{TM}}$ solvent concentrator. Samples were then redissolved in $500 \mu \mathrm{L}$ pyridine. An aliquot $(75 \mu \mathrm{L})$ was transferred to a glass vial and combined with $75 \mu \mathrm{L}$ of N,O-bis(trimethylsilyl)trifluoroacetamide (BSTFA) containing $1 \%$ trimethylchlorosilane (TMCS; Supelco, PA, USA). The sample was derivatized by heating at $75^{\circ} \mathrm{C}$ for 1 hour in a heating block. After derivatization, $50 \mu \mathrm{L}$ of tri-isopropylbenzene (Aldrich, MO, USA) was added to serve as a GC-internal standard for calculation of d7-levoglucosan recovery (Simpson et al. 2004; Louchouarn et al. 2009).

The samples were analyzed using GC/MS with a Varian Ion Trap 3800/4000 system fitted with a fused silica column (VF 5MS, $30 \mathrm{~m}$ x $0.25 \mathrm{~mm}$ inside diameter; Varian Inc.). Each sample was injected, under splitless mode, into a straight glass liner inserted into the GC 
injection port; helium was used as the carrier gas $(1.0 \mathrm{~mL} / \mathrm{min}$.). For anhydrosugar analysis, the $\mathrm{GC}$ oven was programmed from $65^{\circ} \mathrm{C}\left(2 \mathrm{~min}\right.$ isothermal) to $300^{\circ} \mathrm{C}$ ( $5 \mathrm{~min}$ isothermal) at $6^{\circ} \mathrm{C} / \mathrm{min}$, whereas for PAHs analysis, the $\mathrm{GC}$ oven was programmed from $60^{\circ} \mathrm{C}$ to $150^{\circ} \mathrm{C}$ at a temperature ramp rate $15^{\circ} \mathrm{C} / \mathrm{min}$, from $150^{\circ} \mathrm{C}$ to $220^{\circ} \mathrm{C}$ at $5^{\circ} \mathrm{C} / \mathrm{min}$, and from $220^{\circ} \mathrm{C}$ to $300^{\circ} \mathrm{C}$ (20 min isothermal) at $10^{\circ} \mathrm{C} / \mathrm{min}$. The $\mathrm{GC}$ injector and $\mathrm{GC} / \mathrm{MS}$ interface were maintained at $280^{\circ} \mathrm{C}$ and $270^{\circ} \mathrm{C}$, respectively. The MS was operated in the electron impact ionization (EI, 70 $\mathrm{eV}$ ) and full scan modes for anhydrosugar monitoring and selective ion storage mode for $\mathrm{PAH}$ monitoring. Data were acquired and processed with the Varian MS Workstation software (version 6.6). Compound identification was performed using GC retention times and by comparing mass spectra with those of commercially available standards. Quantification was performed using relative response factors obtained from the analysis of calibration solutions made with certified standards.

Initial tests demonstrated that the use of methanol reduces the recovery of the more hydrophobic hydrocarbons, such as PAHs, from Empore ${ }^{\mathrm{TM}}$ disks. Repeated extractions using two different ASE filling agents (diatomaceous earth and combusted sand) also showed lower recoveries of PAHs with combusted sand. We thus tested a sequential extraction procedure using diatomaceous earth to fill the extraction cells and in which we extracted first the hydrophobic hydrocarbons using only dichloromethane followed by a second extraction using the dichloromethane:methanol mixture $(9: 1, \mathrm{v} / \mathrm{v})$ to extract the anhydrosugars (levoglucosan and its isomers). To test the potential impact of this sequential extraction on anhydrosugar recovery, a series of SPE disks was spiked with known amounts of levoglucosan as well as d7levoglucosan and extracted sequentially using the protocol mentioned above. The first DCM extraction yielded undetectable levoglucosan levels, whereas levoglucosan recovery in the DCM:MeOH extract averaged 105 $\pm 13 \%(n=3)$. In addition, replicates of the NIST SRM 1649 Organics in Urban Particulate Matter were extracted using the same sequential protocol to assess the variability of the levoglucosan quantification from environmental samples over the course of the study. Replicate extractions of the SRM 1649 yielded an average levoglucosan concentration of $139.2 \pm 8.3 \mu \mathrm{g} / \mathrm{g}(\mathrm{n}=13)$. This value represents $\sim 85 \%$ of the previously reported levoglucosan concentration for this NIST SRM but shows a similar precision of 4-5\% (Kuo et al. 2008; Louchouarn et al. 2009). The levoglucosan to mannosan ratio, however, was not significantly different between the two methods. Further tests demonstrated that this $15 \%$ loss in recovery could be explained by a change in filling matrix used in the ASE cells. The diatomaceous earth sorbent used here may shield fine particles from the solvent generating lower anhydrosugar yields than when combusted sand was used in prior studies (Kuo et al. 2008; Louchouarn et al. 2009). Since we sought to optimize the PAH extraction and demonstrated that the levoglucosan extraction was consistent (precision $<5 \%$ ) and quantitative (recovery of $\sim 100 \%$ in spiked SPE disks), we used diatomaceous earth as the filling matrix of choice in our extraction protocol. The average recovery of the d7-levoglucosan surrogate was consistent throughout the entire study at $75 \pm 11 \%$.

Blank SPE-GFF assemblies were extracted and treated similarly as sample SPE. In all cases, levoglucosan was undetectable in the SPE blanks. The Method Detection Limit (MDL) of $20 \mathrm{ng}$, 
recently reported by Kuo et al. (2008) and Louchouarn et al. (2009), was converted to flux units using a surface area of $0.159 \mathrm{~m}^{2}$ and time of 14 days to yield $9.0 \mathrm{ng} / \mathrm{m}^{2} / \mathrm{d}$. This value was three orders of magnitude lower than the lowest levoglucosan flux measured in the present study $\left(11 \mu \mathrm{g} / \mathrm{m}^{2} / \mathrm{d}\right)$.

The average recoveries of the PAH surrogates were $41 \pm 13 \%, 53 \pm 14 \%, 71 \pm 14 \%, 77 \pm 11 \%$, and $79 \pm 13 \%$ for $\mathrm{d} 8$-naphthalene, d10-acenaphthene, d10-phenanthrene, d12-chrysene, and d12perylene, respectively. Analytical precision determined from repeat analyses of selected samples (1 or 2 for each GC/MS analysis series) ranged from 1.3 to $7.9 \%$. In addition, accuracy was assessed using the NIST SRM 1649 included in each extraction series $(n=18)$. The concentration of each individual PAH was generally within $\pm 20 \%$ of the certificate value. The MDL was estimated as three times the average mass of each PAH in the blank SPE-GFF assemblies (eluted with DI water and lyophilized at Texas A\&M). The MDL, converted into units similar to those of bi-weekly fluxes, ranged from 0.01 to $27.88 \mathrm{ng} / \mathrm{m}^{2} / \mathrm{d}$ with low to medium molecular weight PAHs (2-4 rings) showing the higher range $\left(3.2 \pm 7 \mathrm{ng} / \mathrm{m}^{2} / \mathrm{d}\right)$ and high molecular weight (HMW) PAHs (5-6 rings) showing the lower range $\left(0.2 \pm 0.3 \mathrm{ng} / \mathrm{m}^{2} / \mathrm{d}\right)$. The values from procedure blanks associated with each extraction series were mostly below the MDL.

The blank SPE-GFF assemblies associated with four events (7-10) showed substantial contamination of low to medium molecular weight PAHs with values ranging from 50 to $7500 \mathrm{ng}$. The source was traced back to the lypophilization unit at MSL, which was later discovered to have been used for sediments highly contaminated with volatile hydrocarbons. Only samples from events 7-10 were contaminated during lyophilized. Additional tests were performed on this unit to confirm there was no sample contamination for the other events. A complete lack of HMW contamination in events 7-10 and a strong correlation between HMW PAHs and the sum of pyrogenic PAHs in all non-contaminated series (events 1-6 and 11-19; Figure 5) provides a means to estimate the sum of pyrogenic PAHs in events 7-10 using the measured fluxes of HMW PAHs. 


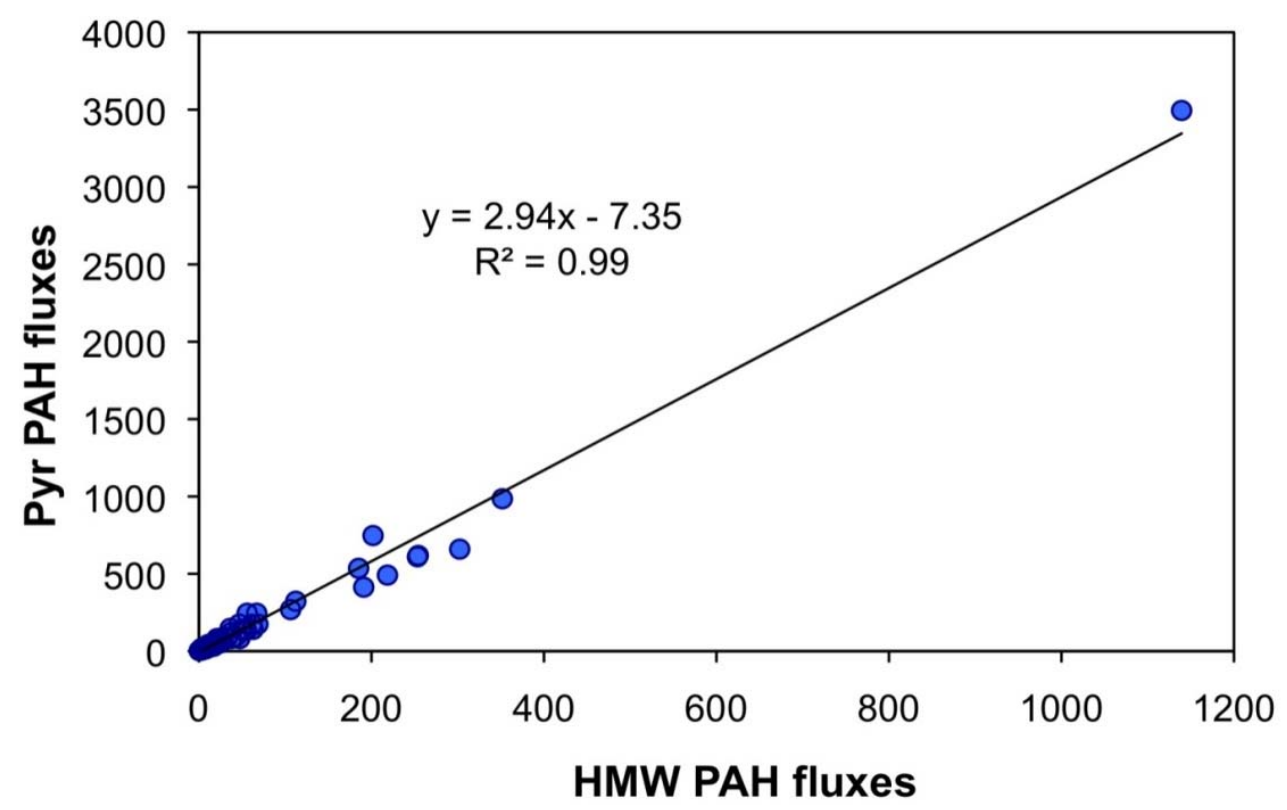

Figure 5. Relationship between pyrogenic PAHs (Pyr PAH) \{fluoranthene, pyrene, benzo[a]anthracene, chrysene, benzo[b]fluoranthene, benzo[k]fluoranthene, benzo[a]pyrene, indeno[1,2,3-c,d]pyrene, dibenz[a,h]anthracene, benzo[g,h,i]perylene $\}$ and high molecular weight PAHs (HMW PAH) \{benzo[b]fluoranthene, benzo[k]fluoranthene, benzo[a]pyrene, indeno[1,2,3-c,d]pyrene, dibenz[a,h]anthracene, benzo[g,h,i]perylene $\}$.

\section{PBDEs}

The samples for PBDE analyses were extracted simultaneously with the PAHs. A combination of chlorinated and brominated surrogates (PCB 103, PCB 198, hexabromobiphenyl [HBB]) was used to assess the efficiencies for both the extraction and analysis methods. A split $(\sim 500 \mu \mathrm{l})$ of the extract prepared at Texas A\&M was shipped to MSL for PBDE analyses. The aluminum oxide cleanup did not sufficiently remove interfering, co-extracted compounds and an additional sulfuric acid cleanup step (Covaci et al. 2003) was conducted on the sample extract splits. Equal amounts of the hexane sample extract and concentrated sulfuric acid were added to a screw cap GC vial, agitated for about 30 seconds, and then allowed to separate. The hexane sample extract was removed and placed into another GC autosampler vial for analysis. The internal standard solution containing octachlroronaphthalene $(\mathrm{OCN})$ and tetrachlorometaxylene (TCMX) was added to assess analytical recoveries.

The PBDE analyses were performed using a GC-Electron Capture Detector (GC/ECD) with an Agilent $6890 \mathrm{GC}$, micro ECD system fitted with two fused silica columns (J\&W DB-5HT and J\&W DB17HT) for dual column confirmation. Each sample was injected under splitless mode. Helium was used as the carrier gas $(\sim 1.0 \mathrm{~mL} / \mathrm{min})$. The $\mathrm{GC}$ oven was programmed from $100^{\circ} \mathrm{C}$ (3 min isothermal) to $300^{\circ} \mathrm{C}\left(30 \mathrm{~min}\right.$ isothermal) at $5^{\circ} \mathrm{C} / \mathrm{min}$. The $\mathrm{GC}$ injector was maintained at $290^{\circ} \mathrm{C}$ and the detectors at $310^{\circ} \mathrm{C}$. Compound identification was performed using $\mathrm{GC}$ retention times and compared to calibration standards. Quantification was performed using a linear or quadratic equations calculated from the analysis of calibration solutions made with certified 
standards. Dual column confirmation for each PBDE congener was conducted on all samples. If the concentrations from both columns were within $25 \%$, the value was accepted while outside this window the value was rejected and re-analyzed. In all cases, data were reported from column J\&W DB-5HT.

The average recoveries of surrogates HBB, PCB-103, PCB-198 were $118 \pm 28 \%, 86 \pm 8 \%$, and $101 \pm 8 \%$, respectively. The reporting limit (RL) was determined as the lowest calibration standard of $0.5 \mathrm{ng} / \mathrm{L}$, except for BDE-209, which was $2.0 \mathrm{ng} / \mathrm{L}$. Procedural blanks and SRM 1649 were included with each extraction series to serve as extraction and analysis quality control samples. Sixteen procedural blanks were nearly all less than the RL. Only one blank showed detectable BDE-99, whereas another showed detectable BDE-209. There is no certified BDE value reported for SRM 1649. In sixteen samples of SRM 1649, BDE-28, -47, -154, and -209 were consistently detected with relative standard deviations (RSD) of 14-32\%. Seven field blanks were also analyzed and consisted of capsules packed using the cleaning and transport protocol discussed above, taken to the field, returned to the laboratory and treated as samples taken through the storage and lyophilization process. The PBDEs were generally less than the RL. However, detectable BDE-28, -47, -99, and -100 were found in some of these blanks. We further compared the blanks potentially compromised during the freeze-drying process (see PAH discussion above and samples WA232, 235, 239, 297, 298 in Appendix B) to the other blank prepared in the alternate unit (WA295, 296). For BDE-28, -47, -99, and -100 there was no significant difference observed between these two groups of blanks showing that PBDE analysis, unlike for PAHs, was not affected by the lyophilization issue. Finally, we conducted a field extraction efficiency test where rainwater was collected, passed through a GFF filter, spiked with a known mass of a PBDE mixture (12.5 ng), and poured into a field deployed collector. The spiked rainwater was allowed to passively drip through the capsule simulating a field collection event. The results for the efficiency test averaged 52\% recovery and ranged from $32 \%$ for BDE209 to $70 \%$ for BDE-47 and BDE-183. Later tests suggested that around $12 \%$ of the PBDE loss may be associated to the absorption of PBDEs onto the walls of the glass container used to prepare the spiked rainwater. Even though the spiked sample was placed in the field collection funnel within minutes of preparation, the glass jar was not extracted to account for this potential loss. Therefore, the field extraction efficiency may be from 44-82\%. In either case, the PBDE fluxes may slightly underestimate the true flux, particularly for BDE-209. All results are provided in Appendix B and indicate the collection equipment sufficiently captures the PBDEs from the rainwater but may underestimate the fluxes of BDE-209.

\section{Trace Elements (As, Cd, Cr, Cu, $\mathrm{Ni}, \mathrm{Pb}$, and $\mathrm{Zn}$ )}

The water samples representing two-week integrated bulk atmospheric deposition were analyzed for $\mathrm{As}, \mathrm{Cd}, \mathrm{Cr}, \mathrm{Cu}, \mathrm{Ni}, \mathrm{Pb}$, and $\mathrm{Zn}$. The samples were acid solubilized to destroy colloidal complexes following EPA Method 1640 Section 12.2.7 - Total Recoverable Metals analytes (TRM). The digested samples were analyzed on a Perkin Elmer 6100 inductively coupled plasma-mass spectrometer (ICP-MS) following a modification of EPA Method 1638 
utilizing in-line addition of the internal standards indium and bismuth. The ICP-MS was run in peak hopping mode with a dwell time of $100 \mathrm{~ms}$ and integration time of $1000 \mathrm{~ms}$ with values reported as the average of three injections. Calibration was performed daily as a linear regression of a five-point curve using certified standards and yielding a correlation coefficient of $r^{2}>0.9999$. All data are provided in Appendix C. Instrumental drift was $<8 \%$ for all analyses, and the calibration was verified using the riverine SRM $1640(n=14)$. Table 4 summarizes the quality control data for the analytical batches including: MDLs, average analytical blank concentrations with one standard deviation (sd), field blank concentrations, SRM recoveries, matrix spike recoveries, and average laboratory duplicate RPDs. Low-level verification samples were analyzed at three to five times the RL (defined as $3.18^{*} \mathrm{MDL}$ ) to ensure acceptable accuracy near the RL on a daily basis.

Table 4. Method detection limits, reporting limits, method and field blank concentrations, standard reference material (SRM) or on-going precision/recovery (OPR), matrix spike recovery, and laboratory duplicate relative percent difference (RPD).

\begin{tabular}{|c|c|c|c|c|c|c|c|c|c|}
\hline & $\mathrm{Cr}$ & $\mathrm{Ni}$ & $\mathrm{Cu}$ & $\mathrm{Zn}$ & As & Cd & $\mathrm{Pb}$ & $\mathrm{THg}$ & MMHg \\
\hline Units & & & & $\mu g / L$ & & & & \multicolumn{2}{|c|}{$\mathrm{ng} / \mathrm{L}$} \\
\hline MDL & 0.051 & 0.011 & $\begin{array}{c}0.005 \\
3\end{array}$ & 0.014 & $\begin{array}{c}0.007 \\
1\end{array}$ & $\begin{array}{c}0.003 \\
3\end{array}$ & $\begin{array}{c}0.002 \\
2\end{array}$ & 0.100 & 0.010 \\
\hline $\mathrm{RL}$ & 0.16 & 0.034 & 0.017 & 0.043 & 0.023 & 0.011 & $\begin{array}{c}0.007 \\
0\end{array}$ & 0.32 & 0.032 \\
\hline $\begin{array}{c}\text { Method } \\
\text { Blanks } \pm 1 \text { sd }\end{array}$ & $\begin{array}{c}0.225 \pm 0.07 \\
9\end{array}$ & $<\mathrm{MDL}$ & $<\mathrm{MDL}$ & $<\mathrm{RL}$ & $<\mathrm{MDL}$ & $<\mathrm{MDL}$ & $<M D L$ & $<M D L$ & $<M D L$ \\
\hline $\mathrm{N}$ & 14 & 14 & 14 & 14 & 14 & 14 & 14 & 51 & 39 \\
\hline $\begin{array}{l}\text { Field Blanks } \\
\qquad \mathrm{N}\end{array}$ & $\begin{array}{c}<\mathrm{RL} \\
4\end{array}$ & $\begin{array}{c}0.124 \\
\pm 0.14 \\
3 \\
4\end{array}$ & $\begin{array}{c}<\mathrm{RL} \\
4\end{array}$ & $\begin{array}{c}0.228 \\
\pm 0.297 \\
4\end{array}$ & $\begin{array}{c}<\mathrm{RL} \\
4\end{array}$ & $\begin{array}{c}<\mathrm{MDL} \\
4\end{array}$ & $\begin{array}{c}<\mathrm{RL} \\
4\end{array}$ & $\begin{array}{c}<\mathrm{RL} \\
4\end{array}$ & $\begin{array}{c}<\mathrm{MDL} \\
4\end{array}$ \\
\hline $\begin{array}{c}\text { SRM/OPR } \\
\text { Accuracy } \pm 1 \text { sd } \\
(\%)\end{array}$ & $103 \pm 4 \%$ & $\begin{array}{c}100 \pm \\
3 \%\end{array}$ & $\begin{array}{c}102 \pm \\
3 \%\end{array}$ & $104 \pm 4 \%$ & $\begin{array}{l}98 \pm \\
4 \%\end{array}$ & $\begin{array}{c}100 \pm \\
3 \%\end{array}$ & $\begin{array}{c}102 \pm \\
3 \%\end{array}$ & $\begin{array}{c}101 \pm \\
4 \%\end{array}$ & $\begin{array}{c}101 \pm \\
5 \%\end{array}$ \\
\hline $\mathrm{N}$ & 14 & 14 & 14 & 14 & 14 & 14 & 14 & 50 & 12 \\
\hline $\begin{array}{c}\text { Matrix Spike } \\
\text { Accuracy }\end{array}$ & $99 \pm 3 \%$ & $\begin{array}{l}98 \pm \\
3 \%\end{array}$ & $\begin{array}{c}100 \pm \\
3 \%\end{array}$ & $100 \pm 4 \%$ & $\begin{array}{l}98 \pm \\
3 \%\end{array}$ & $\begin{array}{l}98 \pm \\
2 \%\end{array}$ & $\begin{array}{c}100 \pm \\
3 \%\end{array}$ & $\begin{array}{c}101 \pm \\
4 \%\end{array}$ & $\begin{array}{l}82 \pm \\
16 \%\end{array}$ \\
\hline $\mathrm{N}$ & 17 & 17 & 17 & 17 & 17 & 17 & 17 & 53 & 28 \\
\hline $\begin{array}{l}\text { Laboratory } \\
\text { Precision } \\
\text { (RPD) }\end{array}$ & $6 \pm 5 \%$ & $\begin{array}{l}4 \pm \\
3 \%\end{array}$ & $\begin{array}{l}2 \pm \\
2 \%\end{array}$ & $2 \pm 4 \%$ & $\begin{array}{l}5 \pm \\
6 \%\end{array}$ & $\begin{array}{c}9 \pm \\
11 \%\end{array}$ & $\begin{array}{l}1 \pm \\
1 \%\end{array}$ & $\begin{array}{l}7 \pm \\
5 \%\end{array}$ & $\begin{array}{l}16 \pm \\
13 \%\end{array}$ \\
\hline $\mathrm{N}$ & 17 & 17 & 17 & 17 & 17 & 17 & 17 & 17 & 10 \\
\hline
\end{tabular}

The SRM 1648 Trace Elements in Urban Particulate Matter was used to verify the digestion efficiency on a similar matrix. A solution was prepared containing $50 \mathrm{mg}$ of the SRM mixed with $200 \mathrm{~mL}$ of DI water then treated as a deposition sample. Thirteen replicates of SRM 1648 
were leached and results are presented in Appendix C. Since the TRM digestion method is only a leach, the $\mathrm{Al}$ recoveries averaged $30 \pm 1 \%$. The partial leaching of the urban dust was also demonstrated by the $\mathrm{Cr}(15 \pm 1 \%)$ recoveries. Both low recoveries resulted from the incomplete dissolution of the mineral phases present in the urban particulate matter. The SRM is certified based on a total dissolution and not directly comparable to the deposition samples. However, multiple replicates were used to ensure good precision throughout the sampling. The average recoveries and RSDs for the other metals were Ni $63 \pm 3 \%$, Cu $78 \pm 2 \%$, Zn $81 \pm 3 \%$, As $93 \pm$ $4 \%, \mathrm{Cd} 80 \pm 2 \%$, and $\mathrm{Pb} 89 \pm 3 \%$. The leach method was selected to represent environmentally relevant conditions of release into natural waters.

Fourteen method blanks were prepared and analyzed with the samples. The concentrations were less than the RL for all metals except $\mathrm{Cr}$, which averaged $(0.225 \pm 0.079 \mu \mathrm{g} / \mathrm{L})$ and was slightly higher than the RL $(0.152 \mu \mathrm{g} / \mathrm{L})$. The contribution of Cr resulted from the leaching of an interfering compound during the TRM process and was therefore subtracted from the sample concentrations. Matrix spike recoveries were used to further assess potential interferences.

Field quality control samples included field duplicates (discussed below) and field equipment blanks $(\mathrm{n}=4)$. The average concentrations and standard deviations of the field blank samples are provided in Table 4. The equipment blank concentrations were generally less than the RL, except for $\mathrm{Ni}$ and $\mathrm{Zn}$. The detected equipment blanks were used to correct the data for contributions from the equipment or DI water used to rinse the funnel. The average concentrations of the equipment blanks were multiplied by $60 \mathrm{~mL}$ to provide the mass of each element contributed to the deposition sample from the equipment. This mass was then subtracted before calculating the mass fluxes.

\section{Mercury and Monomethylmercury}

The water samples representing two-week integrated bulk atmospheric deposition were analyzed for THg and a subset were analyzed for MMHg. The THg concentrations in solution were determined following EPA Method 1631, Revision E. The method is a cold vapor atomic fluorescence technique (CVAF), based upon the emission of $254 \mathrm{~nm}$ radiation by excited elemental mercury $\left(\mathrm{Hg}^{0}\right)$ atoms in an inert gas stream. Mercuric ions in the oxidized sample were reduced to elemental $\mathrm{Hg}^{0}$ with stannous chloride $\left(\mathrm{SnCl}_{2}\right)$ reductant and then purged onto gold-coated sand traps as a means of pre-concentration and interference removal. Mercury vapor was thermally desorbed to a second analytical gold trap and then a gas phase fluorescence cell at room temperature. The fluorescence signal (peak area) was proportional to the quantity of mercury collected, which was quantified using a minimum of five certified standards.

The MMHg concentrations were determined using modifications of the Bloom (1989), which was submitted as a draft EPA Method 1630 (never promulgated). The method also uses CVAF detection, but first the sample was distilled into a clean water matrix. Then, an ethylating agent was added to the distilled sample to form a volatile methyl-ethylmercury derivative and then purged onto graphite carbon traps as a means of preconcentration and interference removal. The 
sample was then isothermally chromatographed, pyrolitically broken down to $\mathrm{Hg}^{0}$, and detected using CVAF. Both the THg and MMHg methods use a calibration factor for each standard, which was the peak units divided by the picograms of THg. The calibration curve was acceptable if the RSD for the calibration factor was $\leq 15 \%$. Laboratory quality control samples prepared with each analytical batch included method blanks, OPR, laboratory duplicates, SRM, and matrix spikes. A summary of the quality control results is presented in Table 4 and all data are provided in Appendix D.

The five-point daily calibration curves for THg and MMHg yielded an average RSD of 3.9\% $(\mathrm{n}=17)$ and $5.8 \%(\mathrm{n}=12)$, respectively. Instrumental drift was $<8 \%$ for $\mathrm{THg}$ and $<15 \%$ for MMHg. Accuracy was independently verified using SRM $1641(\mathrm{n}=17)$ for $\mathrm{THg}$ with average recoveries of $97 \pm 2 \%$ and SRM DORM-2 (Dogfish Muscle; $n=12$ ) for MMHg $101 \pm 5 \%$. Lowlevel verification samples were also analyzed at three to five times the RL to ensure acceptable accuracy near the RL on a daily basis. The RL for THg was $0.318 \mathrm{ng} / \mathrm{L}$ and for $\mathrm{MMHg}$ was $0.032 \mathrm{ng} / \mathrm{L}$. Three method blanks and two OPRs were prepared and analyzed with each batch of samples.

Field quality control samples included field duplicates and field equipment blanks. Four equipment blanks were collected, and concentrations were less than the RL. Traces of THg and $\mathrm{MMHg}$ were detected and subsequently subtracted from the calculated fluxes as discussed above for the trace elements.

\section{Field Precision}

A duplicate tripod collector was deployed at different stations during 12 of the 19 sampling events. Duplicate field collectors were deployed at SB, HC, TCB, and NR stations. Overall, the variability for the suite of parameters was relatively low (averaged 19-35\% RPD) except when the fluxes approached the detection limits or due to documented field anomalies such as bird droppings or insects. The relatively low intra-station variability suggested that each sampling event was indicative of flux conditions at the site during the sampling period.

The average RPD for levoglucosan was 19\% (range: 6-30\%) with the highest values during periods of low levoglucosan fluxes. The same range of variability was also measured for the PAHs with an average of 21\% RPD (range: 5-36\%) and again, the highest variability was measured on the lowest PAH fluxes. A majority of the BDE congeners were not detected in the duplicate samples. The average RPD for all detected BDE congeners was 34\% (range: 0 $103 \%$ ). The BDE-47 was detected in $71 \%$ of the duplicates and averaged $25 \%$ RPD (range: $10-$ $37 \%$ ). The BDE-99 and BDE-209 were the only other congeners detected in $43 \%$ and $57 \%$, respectively, of the duplicates. The average RPDs for these congeners were $23 \%$ RPD (range: 6-40\%) and 38\% RPD (range: 10-72\%), respectively.

The field variability for the trace elements averaged 35\% RPD (range: $22-55 \%$ ). The higher RPDs were generally associated to duplicate pairs with visible differences between the two 
samples, such as small insects or bird droppings. Measures were taken to deter birds and insects as they can contribute significant concentrations of select trace elements, THg, and MMHg. This potential source of variability was considered significant for the mercury species and required additional field duplicates. Forty-four samples included field duplicates as THg was measured from both the black or opaque Teflon ${ }^{\circledR}$ and the clear Teflon ${ }^{\circledR}$. The average RPD/RSD was $29 \%$ (range: $2-98 \%$ ). The higher relative errors were generally associated with sample concentrations near or below the RL or samples with visible differences such as insects or bird droppings. Seven field duplicates were collected for MMHg as only five of the seven stations were sampled for MMHg. The average RPD was 70\% (range: $8-142 \%$ ) with the highest RPDs attributed to the presence of small $(<4 \mathrm{~mm})$ winged insects, but overall, the concentrations were within an order of magnitude of the MDL.

Overall the field reproducibility for all the parameters averaged 20\% RPD. This demonstrates that field reproducibility was not a significant source of error in the flux measurements. In addition, the collection equipment demonstrated bulk fluxes could be consistently reproduced at a wide varied of sampling locations ranging from rural areas to industrial regions.

\section{Statistical Analysis}

Descriptive statistics including the pair wise correlation coefficients were calculated for environmental variables (temperature, precipitation, particulate matter $[\mathrm{PM}] 2.5$, black carbon $[\mathrm{BC}]$, and wind direction). The data distribution for precipitation was evaluated with a nonparametric Kruskal-Wallis test $(\alpha=0.05)$ to determine if a seasonal pattern was observed. Descriptive statistics for the fluxes (PAHs, PBDEs, and metals), including the pair-wise correlation, were calculated by station and season. Differences between fluxes were evaluated by stations within levels of development (industrial/urban, sub-urban, and rural) and by season (wet and dry) using the Kruskal-Wallis test $(\alpha=0.05)$. Analysis was conducted using Minitab (Minitab Release 13.32, Minitab Inc., 2000).

For the fluxes (PAHs, PBDEs, and metals), a generalized linear model (GLM) was used to test the effects of station, season, and the station by season interaction for those stations sampled during both seasons. The TM station only had observations during the dry season and was not included in the full model analysis. If the interaction effect in the full model was not significant, a reduced model was used to test the main effects of station and season. The TM events were included in the reduced model analysis. For both models, fluxes were transformed to the log base 10 to reduce the heterogeneity of the within class variances. Statistical outliers (determined using the Q-test) were removed from the analysis to maintain normally distributed residuals. Analysis was conducted using Minitab (Minitab Release 13.32, Minitab Inc., 2000).

Source apportionment of PAHs was conducted using two separate analyses. The first method was based on the percentage of observations within specific ranges of target PAHs. For example, the discrimination between the by-products of incomplete combustion from liquid fuel and biomass (and coal) can be supported by an analysis of the ratios of retene (Ret) to the sum of 
Ret and chrysene (Chy; for more details on PAH ratio signatures, see section 5.1). This ratio is a diagnostic indicator used specifically for the identification of softwood burning and petroleum combustion. The second method was based on principal component analysis (PCA) of the standardized flux from levoglucosan and 16 PAHs, which had greater than $60 \%$ of their observations above the detection limit. Standardization was achieved by removing the mean flux from each observation and dividing by the standard deviation calculated from all observations. PCA analysis was conducted on the correlation matrix. Variables and observations were then projected onto the vector space provided by the first two principal components (eigenvalues $>$ 2.0; containing 51.8\% of the total variance). Quadrants produced by the two axes were defined by the magnitude of each flux's coefficients in the eigenvectors and defined as a type of combustion (petroleum, biomass, or mixed). The percentage of observations within each quadrant was used to estimate the percentage of each source. Analysis was conducted using Statistica (Statistica 6.1, StatSoft Inc., 2003). 


\section{Atmospheric Deposition Flux Results}

The daily fluxes for the organic compounds (anhydrosugars, PAHs, and PBDEs), trace elements, and $\mathrm{Hg}$ species were calculated for each sample. The organic compounds were quantified based on the mass of each compound extracted by the GFF and SPE disks. Therefore, only flux measurements were reported for each sample. The fluxes for the organics were calculated as the mass of each compound divided by the surface area of the stainless steel funnel $\left(0.159 \mathrm{~m}^{2}\right)$ and the number of days deployed. This provided mass fluxes in units of $\mathrm{ng}$ or $\mu \mathrm{g} /$ $\mathrm{m}^{2} /$ day.

For the trace elements and $\mathrm{Hg}$ species, the mass of each element deposited during the deployment was determined from the sample solution (total volume $=$ volume of rainfall collected + volume of rinse water + acid preservative). The solution concentration (ng/L or $\mu \mathrm{g} / \mathrm{L}$ ) was multiplied by the total volume, corrected for the mass of an element contributed by the rinse water or preservative, divided by the surface area of the funnel, and then divided by the number of days deployed. Additional information for the flux calculations were provided in the sections below. All data for these calculations are provided in the appendices for each of the parameters.

\section{Environmental Variables}

Cumulative precipitation (inches), ambient temperature $\left({ }^{\circ} \mathrm{F}\right), \mathrm{PM} 2.5\left(\mu \mathrm{g} / \mathrm{m}^{3}\right), \mathrm{BC}\left(\mu \mathrm{g} / \mathrm{m}^{3}\right)$, and wind direction (degrees) were measured at each station and sampling event or collected from nearby weather stations when available (Table 5). The correlation between environmental variables was low; the least correlated variable $(\mathrm{r}=0.002)$ was between temperature and PM 2.5 and precipitation and $\mathrm{BC}$. The greatest correlation was between $\mathrm{BC}$ and PM $2.5(\mathrm{r}=0.54$;

Table 6) and was not significant.

Table 5. Descriptive statistics for environmental variables by station expressed as the average over the $\sim 14$ day deployment, except precipitation is cumulative.

\begin{tabular}{|c|c|c|c|c|c|c|c|c|c|c|}
\hline Variable & Station & $\mathrm{N}$ & Mean & Median & StDev & Minimum & Maximum & 25th & 75th & CV \\
\hline \multirow{4}{*}{$\begin{array}{c}\text { Ambient } \\
\text { Temperature } \\
\left({ }^{\circ} \mathrm{F}\right)\end{array}$} & $\mathrm{HC}$ & 19 & 51.7 & 49.6 & 7.8 & 38.5 & 64.1 & 47.3 & 60.7 & $15 \%$ \\
\cline { 2 - 11 } & $\mathrm{NR}$ & 19 & 52.4 & 51.8 & 8.1 & 38.8 & 65.2 & 44.7 & 60.7 & $15 \%$ \\
\cline { 2 - 11 } & $\mathrm{PO}$ & 19 & 51.7 & 49.6 & 7.8 & 38.5 & 64.1 & 47.3 & 60.7 & $15 \%$ \\
\cline { 2 - 11 } & $\mathrm{TCB}$ & 13 & 50.0 & 49.0 & 6.6 & 39.0 & 61.0 & 45.0 & 55.5 & $13 \%$ \\
\cline { 2 - 11 } & $\mathrm{TM}$ & 1 & 61.0 & 61.0 & -- & 61.0 & 61.0 & -- & -- & -- \\
\cline { 2 - 11 } & $\mathrm{WP}$ & 18 & 56.1 & 54.1 & 8.4 & 42.1 & 69.2 & 49.1 & 64.7 & $15 \%$ \\
\hline \multirow{4}{*}{$\begin{array}{c}\text { Precipitation } \\
\text { (inches) }\end{array}$} & $\mathrm{HC}$ & 19 & 1.39 & 1.38 & 1.25 & 0.00 & 5.07 & 0.40 & 1.97 & $90 \%$ \\
\cline { 2 - 11 } & $\mathrm{NR}$ & 19 & 1.59 & 0.92 & 2.18 & 0.00 & 9.50 & 0.30 & 2.16 & $137 \%$ \\
\cline { 2 - 10 } & $\mathrm{PB}$ & 19 & 0.95 & 0.62 & 1.14 & 0.01 & 4.99 & 0.28 & 1.17 & $120 \%$ \\
\cline { 2 - 10 } & $\mathrm{PO}$ & 19 & 1.23 & 1.02 & 1.39 & 0.00 & 5.90 & 0.28 & 1.52 & $113 \%$ \\
\hline
\end{tabular}




\begin{tabular}{|c|c|c|c|c|c|c|c|c|c|c|}
\hline Variable & Station & $\mathrm{N}$ & Mean & Median & StDev & Minimum & Maximum & 25th & 75th & $\mathrm{CV}$ \\
\hline & SB & 19 & 0.58 & 0.34 & 0.62 & 0.00 & 2.29 & 0.22 & 0.83 & $106 \%$ \\
\hline & TCB & 17 & 1.49 & 1.21 & 1.90 & 0.00 & 7.81 & 0.27 & 1.94 & $127 \%$ \\
\hline & TM & 6 & 0.45 & 0.21 & 0.69 & 0.00 & 1.83 & 0.05 & 0.75 & $153 \%$ \\
\hline & WP & 18 & 1.08 & 0.70 & 1.08 & 0.00 & 4.16 & 0.33 & 1.63 & $100 \%$ \\
\hline \multirow{8}{*}{$\begin{array}{l}\text { PM 2.5* } \\
\left(\mu g / m^{3}\right)\end{array}$} & $\mathrm{HC}$ & 19 & 6.8 & 6.2 & 2.5 & 3.3 & 11.8 & 4.7 & 7.7 & $36 \%$ \\
\hline & NR & 19 & 5.3 & 4.8 & 2.0 & 1.8 & 10.0 & 4.1 & 5.6 & $37 \%$ \\
\hline & PB & 12 & 3.9 & 3.9 & 0.9 & 2.9 & 5.8 & 3.1 & 4.4 & $22 \%$ \\
\hline & $\mathrm{PO}$ & 19 & 6.8 & 6.2 & 2.5 & 3.3 & 11.8 & 4.7 & 7.7 & $36 \%$ \\
\hline & SB & 19 & 6.9 & 6.1 & 1.7 & 5.0 & 10.4 & 5.8 & 8.8 & $24 \%$ \\
\hline & TCB & 17 & 6.1 & 5.8 & 2.2 & 3.6 & 10.9 & 4.4 & 7.6 & $35 \%$ \\
\hline & TM & 6 & 6.3 & 5.6 & 1.6 & 4.7 & 9.0 & 5.1 & 7.8 & $26 \%$ \\
\hline & WP & 18 & 5.5 & 5.2 & 2.3 & 3.1 & 12.2 & 3.8 & 6.4 & $41 \%$ \\
\hline \multirow{2}{*}{$\begin{array}{c}\mathrm{BC}^{*} \\
\left(\mu \mathrm{g} / \mathrm{m}^{3}\right)\end{array}$} & TCB & 17 & 1.34 & 1.10 & 0.67 & 0.70 & 2.90 & 0.75 & 1.80 & $50 \%$ \\
\hline & TM & 6 & 1.10 & 1.00 & 0.34 & 0.70 & 1.60 & 0.85 & 1.45 & $31 \%$ \\
\hline \multirow{6}{*}{$\begin{array}{l}\text { Wind } \\
\text { Direction* } \\
\text { (degrees) }\end{array}$} & $\mathrm{HC}$ & 19 & 102 & 91 & 89 & 0 & 349 & 64 & 104 & $87 \%$ \\
\hline & NR & 13 & 216 & 196 & 49 & 158 & 340 & 187 & 245 & $23 \%$ \\
\hline & $\mathrm{PO}$ & 19 & 102 & 91 & 89 & 0 & 349 & 64 & 104 & $87 \%$ \\
\hline & TCB & 17 & 241 & 243 & 82 & 19 & 356 & 204 & 298 & $34 \%$ \\
\hline & TM & 6 & 239 & 266 & 119 & 12 & 347 & 179 & 317 & $50 \%$ \\
\hline & WP & 18 & 195 & 187 & 96 & 24 & 359 & 137 & 258 & $49 \%$ \\
\hline \multicolumn{11}{|c|}{$\begin{array}{l}\text { * Data was from the air monitoring database in Washington's air monitoring network } \\
\text { (https://fortress.wa.gov/ecy/enviwa/Default.htm). Weather stations selected for our sampling stations } \\
\text { were: Meadowdale-Blackbird Dr (for HC \& PO); Nisqually Valley \& Lacey station (for NR); Anacortes- } \\
\text { Bartholomew Rd (for PB); Port Townsend-San Juan Ave (for SB); Tacoma-Alexander Ave \& Tacoma- } \\
\text { Tower Dr (for TCB \& TM); Seattle-Queen Anne Hill \& Seattle-Olive St (for WP). }\end{array}$} \\
\hline
\end{tabular}

Table 6. Lower half of the correlation matrix for environmental variables.

\begin{tabular}{|l|c|c|c|c|}
\hline Environmental Variable & $\begin{array}{c}\text { Ambient } \\
\text { Temperature } \\
(n=89)\end{array}$ & $\begin{array}{c}\text { Precipitation } \\
(n=136)\end{array}$ & $\begin{array}{c}\text { PM 2.5 } \\
(n=129)\end{array}$ & $\begin{array}{c}B C \\
(n=23)\end{array}$ \\
\hline Precipitation $(n=136)$ & -0.299 & -- & -- & -- \\
\hline PM 2.5 $(n=19)$ & 0.002 & -0.205 & -- & -- \\
\hline BC $(n=23)$ & -0.229 & -0.002 & 0.54 & -- \\
\hline Wind Direction $(n=92)$ & 0.311 & -0.136 & -0.225 & -0.421 \\
\hline
\end{tabular}

Precipitation was the most variable over the course of the study (coefficient of variation [CV] ranging from $90 \%$ to $153 \%$ ) and the most consistently collected environmental variable. A generalized linear model on rank transformed precipitation with the main effects of station and month was used to determine whether a season associated with precipitation (dry and wet) would be useful (Figure 6). The mean precipitation at stations was not significantly different $(p=0.289)$, but the mean precipitation for each month was significantly different $(p<0.001)$. Tukey's pair-wise comparison between months showed that the mean precipitation for August 
and September was significantly less than for March and April $(p<0.01)$. The mean precipitation for May was nearly significantly less than for April $(p<0.057)$ and significantly less than for March $(p=0.016)$. Based on the Kruskal-Wallis nonparametric test, the median precipitation during the Dry Season (May, July, August, and September) was significantly less $(p<0.001)$ than the Wet Season (October, November, February, March, and April). On average, the rainfall during the Dry Season was 0.65 inches per two-week time period (95\% CI: 0.48 to 0.82 in.) while the Wet Season average rainfall was 1.69 inches (95\% CI: 1.77 to 2.13 in.). Thus, all further statistical analyses were conducted by grouping the data by both station and season.

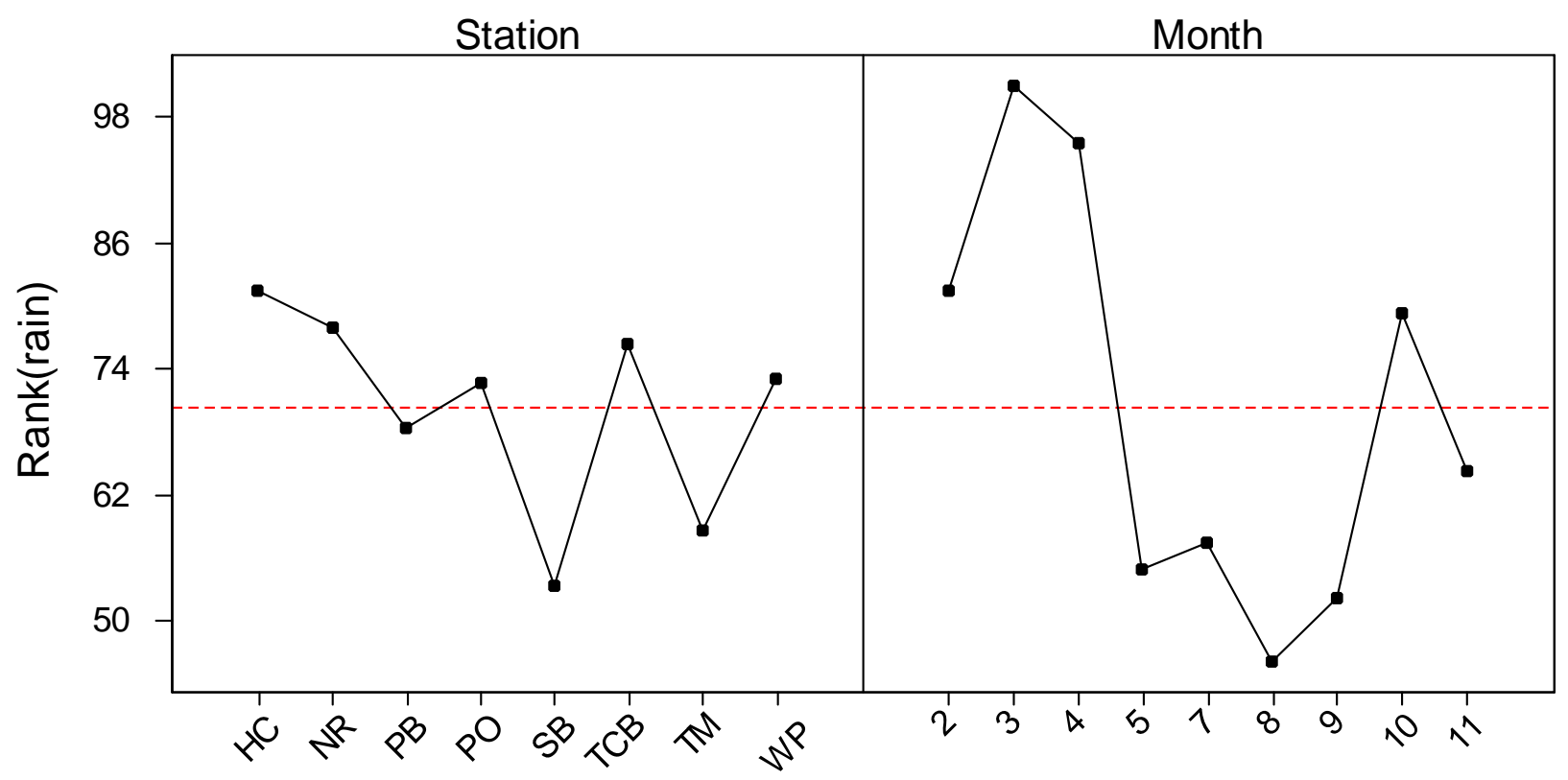

Figure 6. Least square means for ranked precipitation by station with the variation from month removed and by month with the variation from stations removed.

The median temperature during the dry season was significantly greater than the median temperature during the wet season (Kruskal-Wallis, $p<0.001$ ). The dry season temperature was on average $59.3^{\circ} \mathrm{F}\left(95 \% \mathrm{CI}: 57.9\right.$ to $\left.60.6^{\circ} \mathrm{F}\right)$. The wet season temperature was on average $46.3{ }^{\circ} \mathrm{F}\left(95 \% \mathrm{CI}: 45.0\right.$ to $\left.47.6^{\circ} \mathrm{F}\right)$. Median PM 2.5 values were not significantly different between seasons $(p=0.305)$; however, they were significantly different between station-season combinations $(p=0.001)$. Median PM 2.5 was largest at HC, PO, and SB stations during the wet season and smallest at PB during both the wet and dry seasons (Figure 7).

BC was only collected near TCB and TM stations. Median BC values were not significantly different between seasons (Kruskal-Wallis, $p=0.535$ ) or between station-season combinations $(p=0.800)$. Median wind direction was significantly different between station-season combinations $(p<0.001)$. Median wind directions are characterized in Table 7. 


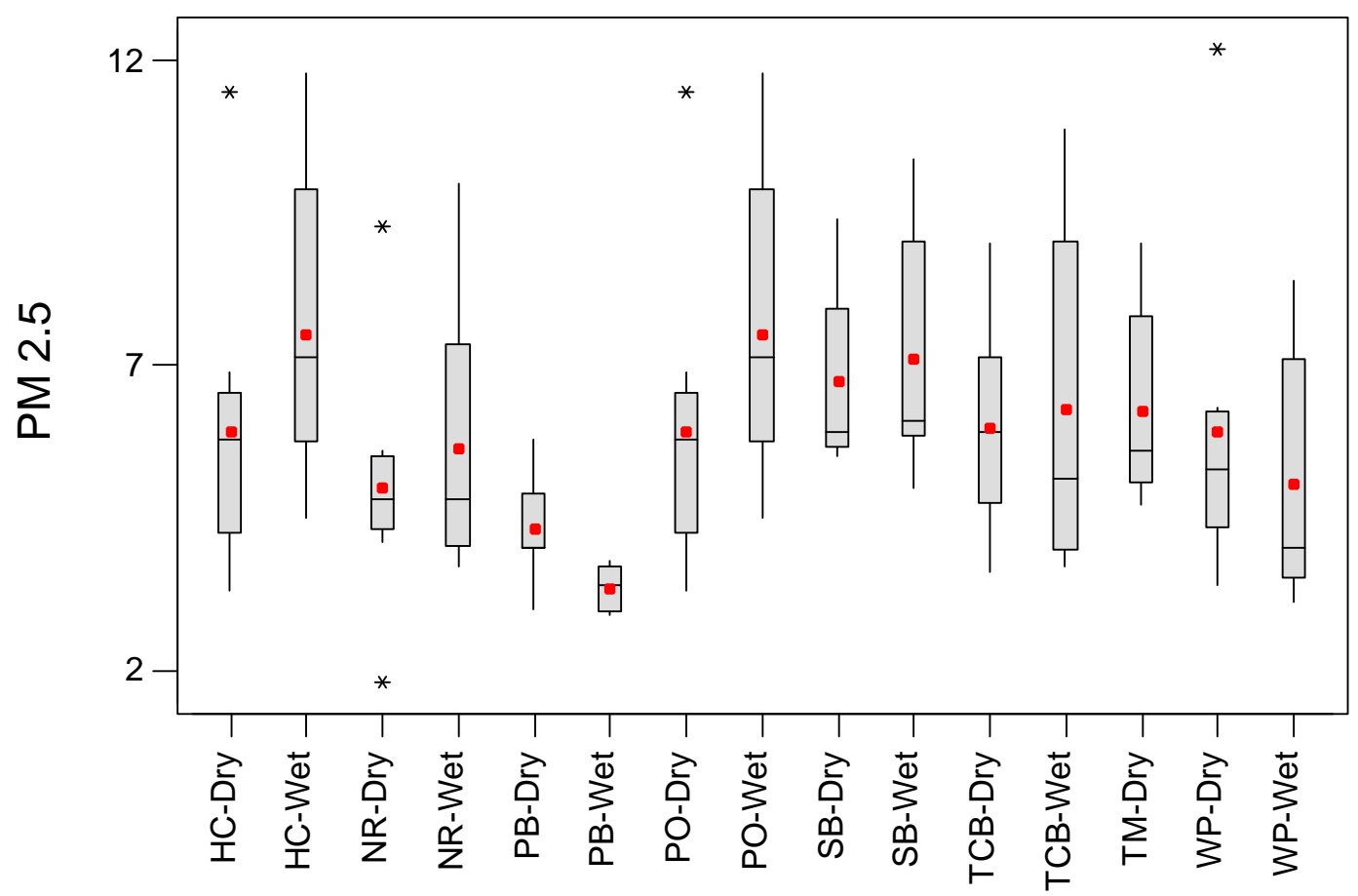

Figure 7. Box and whisker plot of PM 2.5 by station and season (wet and dry). The solid line within the box marks the median and the red dot marks the mean. The lower and upper boundaries of the box are the 25th and 75th percentile, respectively. The whiskers (error bars) below and above the box indicate the 10th and 90th percentiles. The asterisks are outliers.

Table 7. Regional median wind direction over the course of the study.

\begin{tabular}{|c|c|c|}
\hline \multirow{2}{*}{ Station } & \multicolumn{2}{|c|}{ Median Wind Direction } \\
\cline { 2 - 3 } & Dry Season & Wet Season \\
\hline HC & East & East \\
\hline NR & West & South \\
\hline PB & -- & -- \\
\hline PO & East & East \\
\hline SB & -- & -- \\
\hline TCB & West & South-West \\
\hline TM & West & -- \\
\hline WP & South-West & South-East \\
\hline
\end{tabular}

\section{PAH Fluxes}

For consistency with prior studies (EPA 1991; Hart Crowser, Inc. 2007; Herrera Environmental Consultants, Inc. 2010), we present the PAH fluxes under two general categories (see Table 2: carcinogenic PAHs [CPAHs; $\mathrm{n}=7$ ] and pyrogenic PAHs [pyr-PAHs: $\mathrm{n}=10$ ]). The list of Pyr-PAHs corresponds to the sum of CPAHs and additional high molecular PAHs presented in the Phase 1 and 2 reports and their addendums (Hart Crowser, Inc. 2007; Herrera 
Environmental Consultants, Inc. 2010), and was similar to the 10 PAHs identified by Crecelius (1991) as part of the EPA (1991) sum of combustion PAHs. In addition, since polyurethane foam plugs were not used in the present study, the deposition of low molecular PAHs $(<200)$ through gas absorption ( $>90 \%$ of total atmospheric deposition to water surfaces; Gigliotti et al., 2005) was not determined. Instead, the present sampling protocol was optimized for PAHs with a molecular weight $\geq 228$. Since atmospheric deposition of these PAHs to water bodies occurs primarily (>95\%) though dry particle and wet deposition processes (Gigliotti et al. 2005), the lack of gas phase sampling in this study has little bearing on the estimated loading calculations for the presented carcinogenic and pyrogenic PAHs.

Carcinogenic PAHs contributed under half (42 $\pm 8 \%$ ) of the total fluxes of pyr-PAHs. There was no statistical effect of seasonality on flux variations but rather a station-specific influence (Figures 8 and 9). The TCB station showed consistently higher fluxes relative to other stations, and in some cases, by as much as one order of magnitude (Table 8). At this station, the fluxes of CPAHs and pyr-PAHs ranged from 50 to $1500 \mathrm{ng} / \mathrm{m}^{2} / \mathrm{d}$ and from 140 to $3500 \mathrm{ng} / \mathrm{m}^{2} / \mathrm{d}$, respectively, with the highest values during the fall and spring sampling periods (October-April). The second highest fluxes were recorded at TM, the other station in the Tacoma area, with fluxes ranging from 9 to 90 and from 22 to $246 \mathrm{ng} / \mathrm{m}^{2} / \mathrm{d}$ for CPAHs and pyr-PAHs, respectively (only sampled during the dry period; Figures 8 and 9). All other stations showed lower and statistically undistinguishable fluxes during all 19 events sampled.

There exists only one set of historical data of PAH fluxes that is comparable to the present study. Deposited aerosols were sampled biweekly at five sites in Tacoma from July 1989 to January 1990. Results of that study are presented in EPA (1991) and include compiled PAH and metal fluxes at sites comparable to the TCB and TM stations. During that period, fluxes of CPAHs and Pyr-PAHs ranged from 2150 to 9200 and from 3600 to $15100 \mathrm{ng} / \mathrm{m}^{2} / \mathrm{d}$, respectively (median: 5540 and 9140, respectively). These fluxes are one order of magnitude higher than those reported today in the industrial/urban station of Tacoma (TCB and TM) suggesting that fluxes of combustion hydrocarbons have declined markedly in the last $\sim 20$ years in the region. In addition, the proportion of CPAHs to Pyr-PAHs decreased from $60 \pm 1 \%$ to $42 \pm 8 \%$. The EPA (1991) report recognized the deposition sampling methods required additional research and may underestimate the true flux due to poor field preservation of the PAHs. Therefore, this study adapted new sampling methods to improve the extraction and retention of hydrocarbons in the field, but without the wetted surface used in the EPA (1991) study, the current flux rates may underestimate the low molecular weight PAH contributions to the total load of PAHs from atmospheric deposition. 


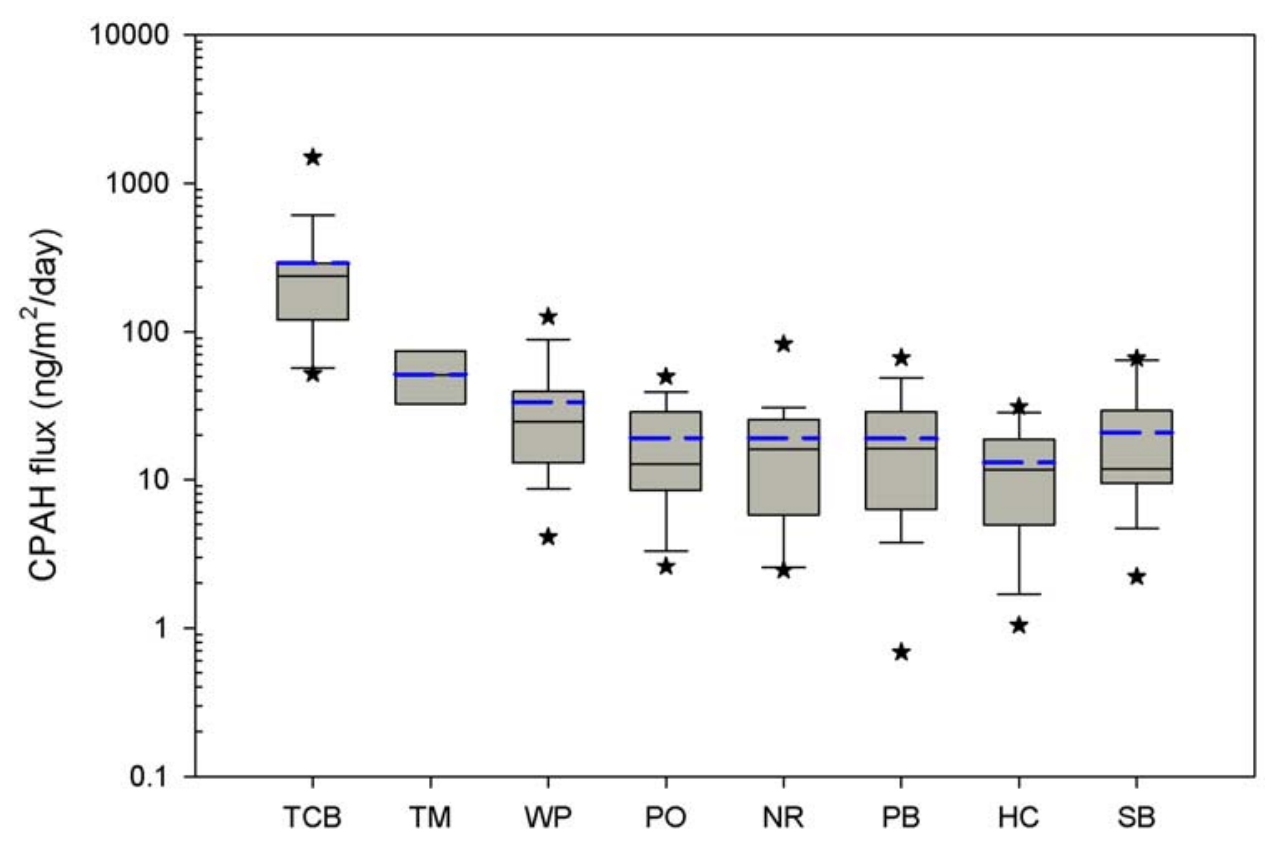

Figure 8. Box plot of carcinogenic PAHs fluxes ( $\mathrm{ng} / \mathrm{m}^{2} /$ day) for eight stations (CPAH). The box boundaries are the $25^{\text {th }}$ and $75^{\text {th }}$ percentile, with the median in the box, dashed blue line is the mean, whiskers are the 10th and 90th percentiles, and the asterisks are outliers.

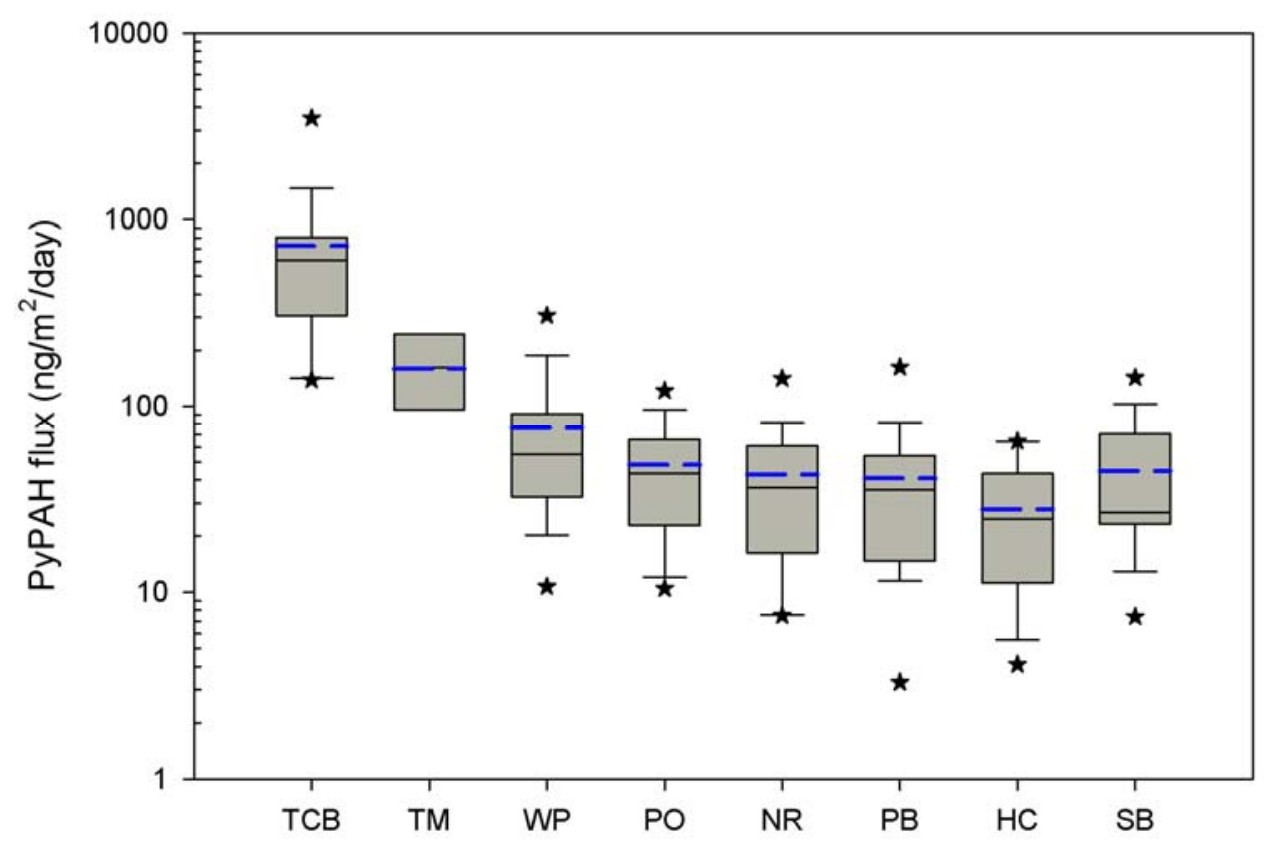

Figure 9. Box plot of pyrogenic PAHs fluxes ( $\left.\mathrm{ng} / \mathrm{m}^{2} / \mathrm{day}\right)$ for eight stations (pyr-PAHs). The box boundaries are the $25^{\text {th }}$ and $75^{\text {th }}$ percentile, with the median in the box, dashed blue line is the mean, whiskers are the 10th and 90th percentiles, and the asterisks are outliers. 
Table 8. Daily fluxes of polycyclic aromatic hydrocarbons (PAHs) and levoglucosan at the eight stations around the Puget Sound.

\begin{tabular}{|c|c|c|c|c|c|c|}
\hline Site & Mean & Median & 75th & 25 th & Min & $\operatorname{Max}$ \\
\hline \multicolumn{7}{|c|}{ CPAHs (ng/m²/d) } \\
\hline $\mathrm{HC}$ & 13.0 & 11.6 & 18.4 & 5.3 & 1.0 & 31.3 \\
\hline NR & 19.0 & 16.0 & 25.7 & 7.0 & 2.4 & 82.6 \\
\hline PB & 18.8 & 16.1 & 23.9 & 6.7 & 0.7 & 66.7 \\
\hline PO & 19.0 & 12.6 & 28.7 & 9.0 & 2.6 & 49.9 \\
\hline SB & 20.7 & 11.8 & 27.2 & 9.5 & 2.2 & 66.2 \\
\hline TCB & 289 & 238 & 277 & 125 & 52.0 & 1490 \\
\hline TM & 51.6 & 51.3 & 67.7 & 41.4 & 8.7 & 87.0 \\
\hline WP & 33.6 & 24.7 & 38.9 & 14.4 & 4.1 & 126 \\
\hline \multicolumn{7}{|c|}{ Pyr-PAHs $\left(n g / m^{2} / d\right)$} \\
\hline $\mathrm{HC}$ & 27.8 & 24.8 & 38.6 & 12.5 & 4.1 & 64.6 \\
\hline NR & 42.6 & 36.3 & 59.6 & 17.8 & 7.5 & 141 \\
\hline PB & 40.4 & 35.3 & 49.2 & 15.4 & 3.3 & 157 \\
\hline $\mathrm{PO}$ & 47.7 & 43.4 & 65.6 & 23.9 & 10.5 & 117 \\
\hline SB & 44.3 & 26.6 & 58.8 & 23.5 & 7.4 & 142 \\
\hline TCB & 710 & 584 & 658 & 312 & 139 & 3495 \\
\hline TM & 75.4 & 54.8 & 228 & 127 & 21.6 & 246 \\
\hline WP & 159 & 161 & 87.6 & 34.9 & 10.7 & 296 \\
\hline \multicolumn{7}{|c|}{ Levoglucosan $\left(\mu \mathrm{g} / \mathrm{m}^{2} / \mathrm{d}\right)$} \\
\hline $\mathrm{HC}$ & 275 & 90.6 & 315 & 38.5 & 11.0 & 1654 \\
\hline NR & 107 & 69.9 & 118 & 43.8 & 14.8 & 504 \\
\hline PB & 199 & 76.3 & 189 & 32.9 & 14.2 & 1176 \\
\hline $\mathrm{PO}$ & 239 & 78.3 & 209 & 47.9 & 11.9 & 1751 \\
\hline SB & 229 & 61.1 & 240 & 35.3 & 0.0 & 1330 \\
\hline TCB & 114 & 57.3 & 174 & 36.1 & 26.3 & 420 \\
\hline TM & 248 & 78.1 & 183 & 30.4 & 18.8 & 1482 \\
\hline WP & 34.6 & 24.7 & 39.3 & 19.5 & 13.5 & 82.7 \\
\hline
\end{tabular}

\section{Levoglucosan Fluxes}

Levoglucosan and its anhydrosugar isomers (mannosan and galactosan) were prevalent at all sampling locations. Levoglucosan is an unambiguous molecular biomarker for biomass combustion (Simoneit et al. 1999; Simoneit 2002; Kuo et al. 2008; Schmidl et al. 2008). In contrast to PAH fluxes, total levoglucosan fluxes showed a marked seasonal distribution (December-April; Figure 10). Although the levoglucosan fluxes were shown to be independent of precipitation patterns, they showed significant differences between the spring-summer period (May-September) and the fall-winter period (October-April; Figure 11), two seasons that are characterized by drier and wetter conditions, respectively. The median spring-summer flux for 
the entire study area was $43 \mu \mathrm{g} / \mathrm{m}^{2} / \mathrm{d}$ (interquartile range: $27-76 \mu \mathrm{g} / \mathrm{m}^{2} / \mathrm{d}$ ) vs. $152 \mu \mathrm{g} / \mathrm{m}^{2} / \mathrm{d}$ (interquartile range: $62-330 \mu \mathrm{g} / \mathrm{m}^{2} / \mathrm{d}$ ) for the fall-winter median flux.

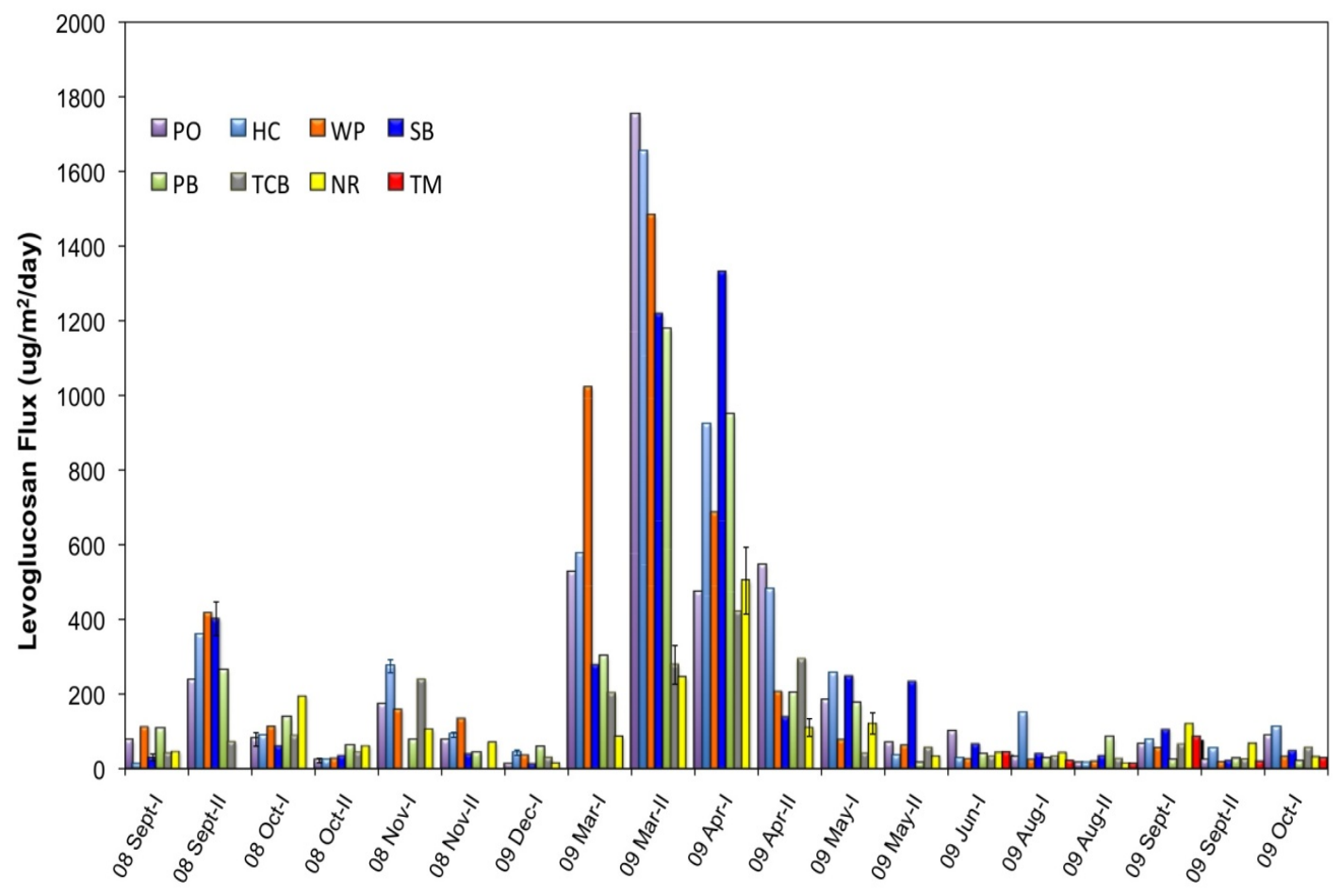

Figure 10. Levoglucosan fluxes at the eight stations during the 19 sampling events.

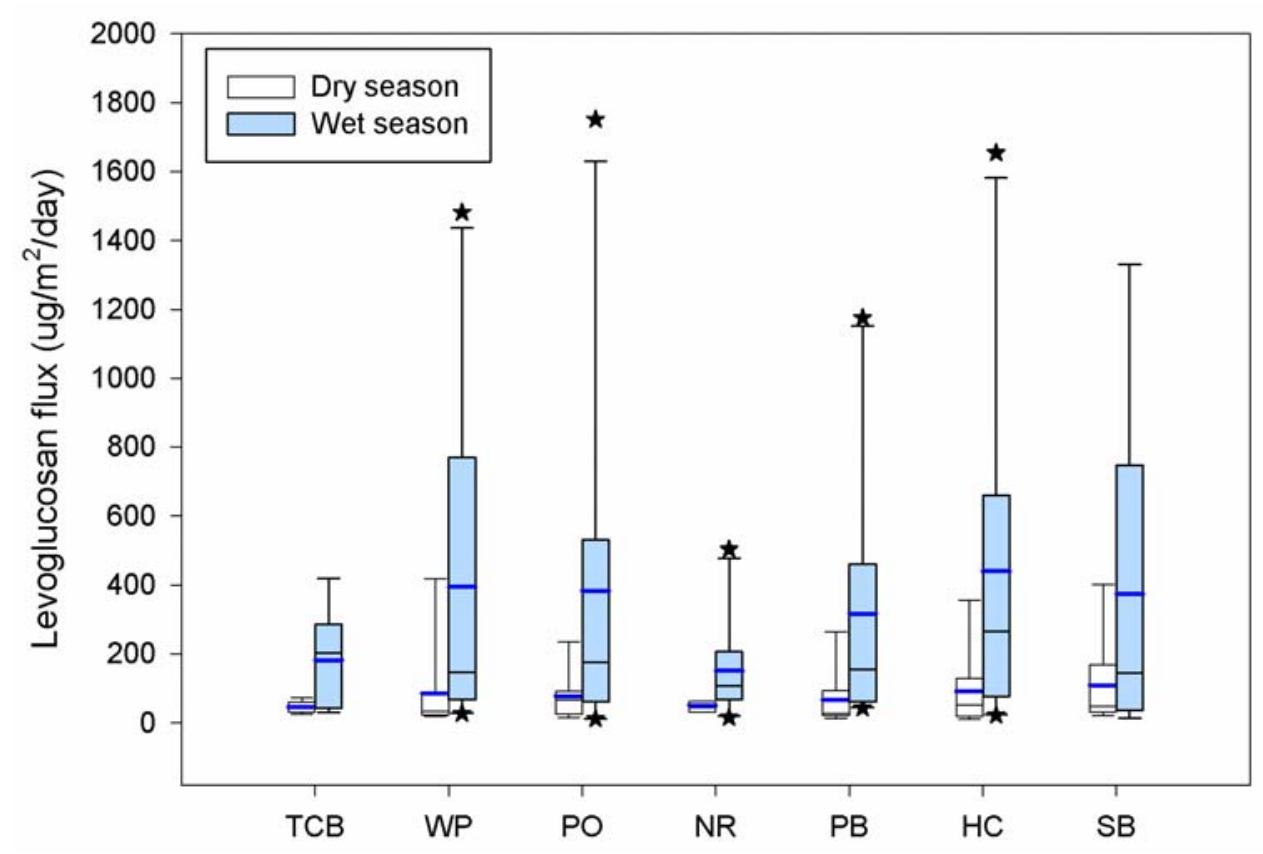

Figure 11. Levoglucosan fluxes ( $\mu \mathrm{g} / \mathrm{m}^{2} /$ day) for eight stations during dry season (May-Sept) and wet season (Oct.-Apr.). The box boundaries are the 25th and 75th percentile, with the median in the box, dashed blue line is the mean, whiskers are the 10th and 90th percentiles, and the asterisks are outliers. 
Additional seasonal fluctuations were observed with a smaller peak in fluxes from early September-early November $\left(200-400 \mu \mathrm{g} / \mathrm{m}^{2} / \mathrm{d}\right)$. From early October to December, levoglucosan fluxes remained relatively low, ranging from 10 to $270 \mu \mathrm{g} / \mathrm{m}^{2} / \mathrm{d}$. No samples were collected from late December to early February; samples we not taken due to freezing conditions and exceptionally high snow accumulations at sea level. However, part of the cold season was still represented in the late February to early April sampling. During this period, levoglucosan levels increased by an order of magnitude ranging from 100 to $1750 \mu \mathrm{g} / \mathrm{m}^{2} / \mathrm{d}$ from late February to late April. This peak in late March-early April was then followed by decreasing fluxes back to ranges observed in early fall $\left(40-200 \mu \mathrm{g} / \mathrm{m}^{2} / \mathrm{d}\right)$. In 2009 , no late summer-early fall increase in levoglucosan fluxes was observed as was the case for 2008. These inter-annual differences in levoglucosan fluxes in later summer-early fall point to temporal differences in the inputs of combustion-derived particulates during the wildfire seasons. In contrast, the two to three order of magnitude increases in peak fluxes during the late winter period points to the role of woodburning stoves (and potentially temperature inversions) on air quality during the wet season.

Detailed characterization of the yield of levoglucosan to one of its isomers (mannosan) in fuel source emissions can further discriminate between specific inputs of biomass combustion (i.e., softwood vs. hardwood, recent biomass vs. brown coal) in atmospheric PM (Fabbri et al. 2008; Schmidl et al. 2008; Caseiro et al. 2009; Fabbri et al. 2009). The positive relationship between levoglucosan and mannosan (Figure 12) confirms that both anhydrosugars are indeed derived from the same source. The slope of the relationship ( 4.0) further points to softwood as the primary source of biomass being combusted in the region (Ward et al. 2006; Schmidl et al. 2008; Caseiro et al. 2009; Fabbri et al. 2009). However, this relationship is only valid for the late summer to early winter period (August-December) as mannosan and galactosan became undetectable in the winter to spring period (February-May). This suggests a shift in combustion source (i.e., biomass vs. brown coals) and/or a change in combustion temperature conditions. Indeed, mannosan production is more sensitive to combustion conditions than that of levoglucosan and tends to be degraded at lower combustion temperatures and duration (Kuo et al. 2010a). 


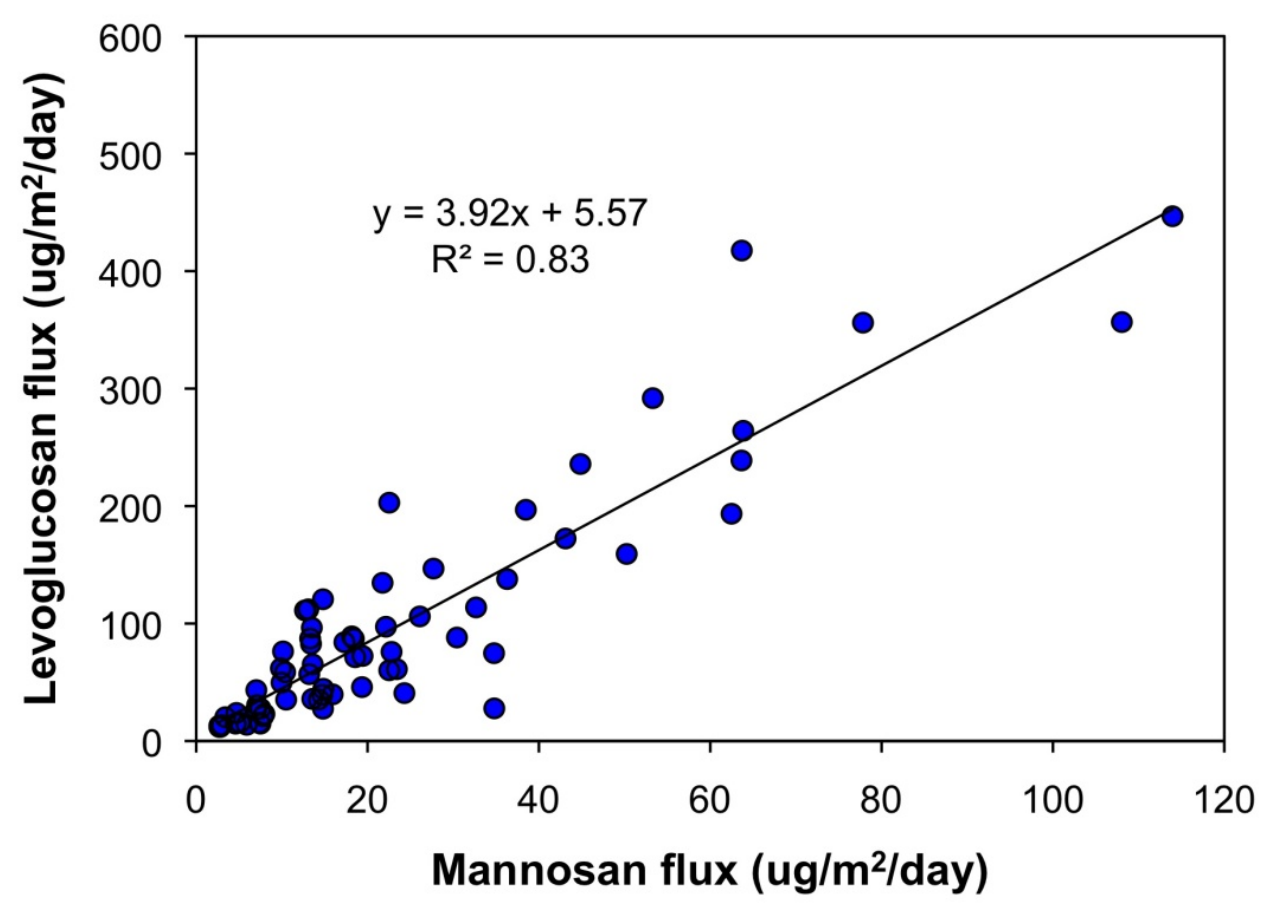

Figure 12. The levoglucosan vs. mannosan relationship in wet and dry deposition over the Puget Sound. The ratio between these two anhydrosugars discriminates sources of biomass combustion (hardwood vs. softwood combustion). The low slope $(<5)$ indicates softwood combustion is the main source of biomass combustion.

\section{PBDE Fluxes}

Total PBDE flux is the sum of 14 PBDE congeners (BDE 17, 28, 47, 66, 71, 85, 99, 100, $138,153,154,183,190$, and 209). The fluxes for BDEs below the MDL were calculated based on the instrument MDL and collection information for that sample. The median PBDE flux across all stations and events was $7.0 \mathrm{ng} / \mathrm{m}^{2} / \mathrm{d}$ (range: $3.0-171 \mathrm{ng} / \mathrm{m}^{2} / \mathrm{d}$ ). This summing notation includes the full MDL for congeners that were not detected and would serve as the most conservative estimate for the daily flux. An alternate summing convention is to assume values below the MDL are zero, and this would serve as the least conservative estimate. Replacing BDE congeners below the MDL with a zero before summing provides a median flux of 4.4 $\mathrm{ng} / \mathrm{m}^{2} / \mathrm{d}$ (range: $0.42-170 \mathrm{ng} / \mathrm{m}^{2} / \mathrm{d}$ ). In this case, both summing conventions are higher than the estimated median flux of $2 \mathrm{ng} / \mathrm{m}^{2} / \mathrm{d}\left(0.5-6.0 \mathrm{ng} / \mathrm{m}^{2} / \mathrm{d}\right)$ reported in the Phase 1 report (Hart Crowser, Inc. 2007).

The median atmospheric flux from the present study is comparable to background atmospheric deposition $\left(7.64 \mathrm{ng} / \mathrm{m}^{2} / \mathrm{d}\right.$; Usenko et al. 2007) measured at a remote site in the Rocky Mountain National Park (Mills Lake). In comparison to other water bodies in the world, the median flux over Puget Sound was smaller than the reported values in a sub-alpine lake in northern Italy (17.6 ng/m $/ 2$; Mariani et al. 2008) and coastal areas in Korea (28-240 ng/ $/ \mathrm{m}^{2} / \mathrm{d}$; Moon et al. 2007). However, it should be noted that different BDE congeners and summing 
conventions for non-detected congeners were used for the total PBDEs calculation in the literature, and comparisons should be made with caution.

Table 9. Daily atmospheric deposition fluxes of total PBDEs at the eight stations around the Puget Sound.

\begin{tabular}{|ccccccc|}
\hline Station & Mean & Median & $\mathbf{7 5}^{\text {th }}$ & $\mathbf{2 5}^{\text {th }}$ & Min & Max \\
\hline \hline \multicolumn{7}{c}{ Total PBDE $\left(\mathbf{n g} / \mathbf{m}^{2} / \mathbf{d}\right)$} \\
\hline HC & 7.0 & 5.5 & 7.1 & 4.5 & 4.1 & 23.1 \\
NR & 6.7 & 6.7 & 8.3 & 4.9 & 3.8 & 9.6 \\
PB & 6.1 & 5.5 & 8.1 & 4.8 & 3.3 & 9.0 \\
PO & 7.0 & 6.7 & 8.8 & 4.9 & 3.8 & 11.1 \\
SB & 6.2 & 6.0 & 8.0 & 4.9 & 3.0 & 9.6 \\
TCB & 30.4 & 23.8 & 27.3 & 14.1 & 7.1 & 170.5 \\
TM & 13.4 & 14.4 & 15.5 & 11.1 & 4.2 & 21.9 \\
WP & 8.2 & 7.8 & 10.6 & 5.4 & 3.7 & 14.6 \\
\hline
\end{tabular}

As shown in Figure 13, similar total PBDE fluxes were observed in most sampling stations throughout the entire sampling period, except for the Tacoma stations (TCB and TM). Excluding the Tacoma stations, the median fluxes have a very narrow range (from 5.5 to $7.8 \mathrm{ng} / \mathrm{m}^{2} / \mathrm{d}$ ). The median PBDE flux at TCB was $22.5 \mathrm{ng} / \mathrm{m}^{2} / \mathrm{d}$, which was about three to four times higher than that at other stations (Figure 14; Table 9). We further used a generalized linear model to assess the role of different factors (station and season) on depositional fluxes. The results show that total PBDE flux in TCB was significantly higher than that of other stations $(p<0.0001)$ (Figure 15a). The high PBDE fluxes indicate that urban/industrial areas may be a hot spot for PBDE emissions. This observation was in line with the findings in many other studies (Hoh and Hites 2005; Harner et al. 2006; Venier and Hites 2008). On the other hand, as shown in Figure 15b, GLM also shows that there is a significant difference in the total PBDE fluxes between the wet and relatively drier seasons (October-April and May-September, respectively; $p=0.0002$ ). Our data show that the wet season was characterized by a statistically lower total PBDE flux than the drier season. The seasonal variation for the total PBDE flux was driven by the BDE-209 fluxes, as BDEs-47 and 99 did not vary seasonally and comprise a smaller fraction of the total PBDE. The BDE-209 fluxes were higher in the warm, dry season sampled in this study. A plausible explanation for this phenomenon is that ambient temperatures during the dry season were significantly higher than during the wet season. Wilford et al. (2004) indicated that compared to outdoor air, indoor air has a much higher PBDE level. During the cool season (here, the wet season), house windows are often closed, thus limiting emissions of the high PBDE from indoor air (Harner et al. 2006). However, more seasonal PBDE data are needed to further evaluate this hypothesis. 


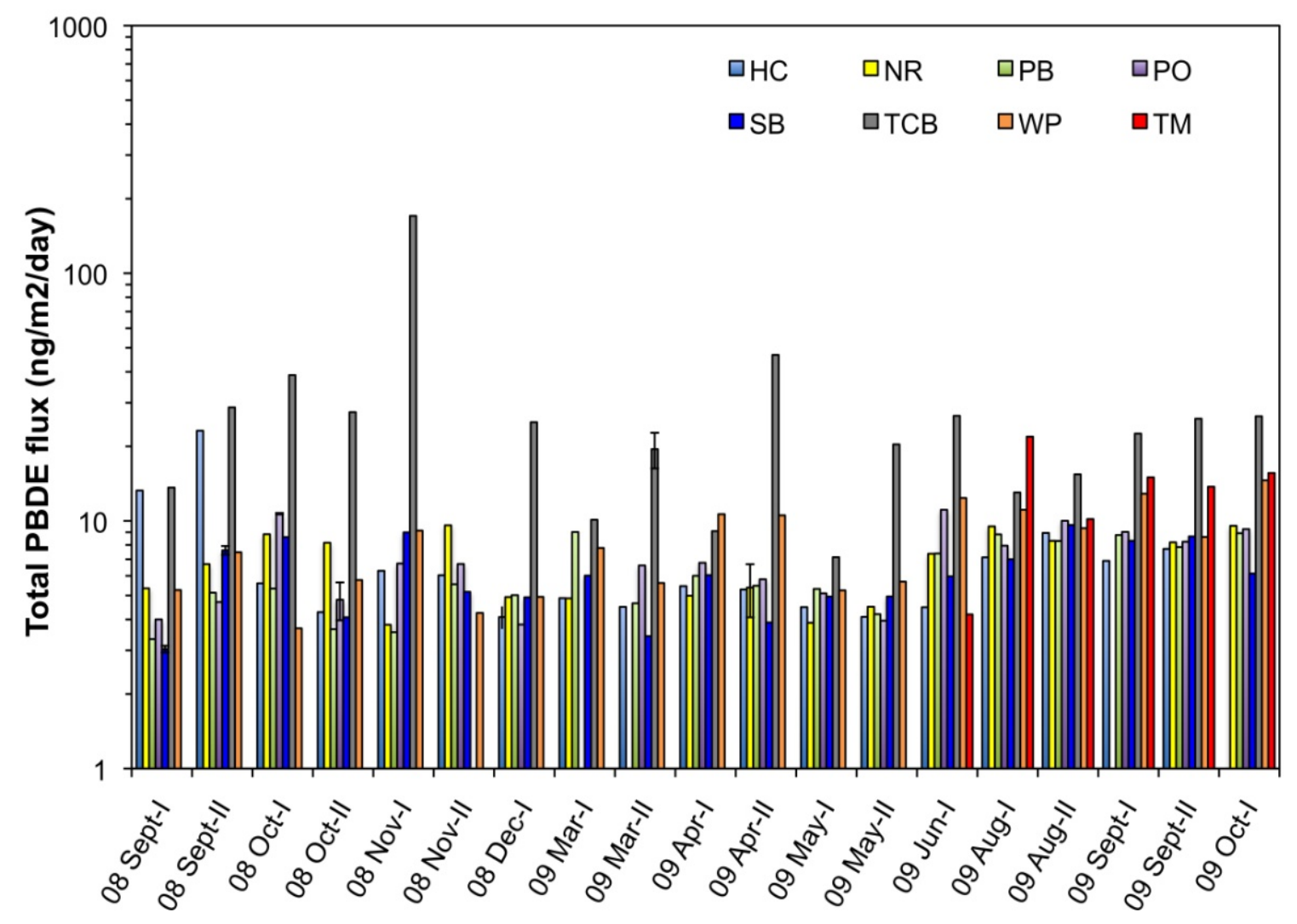

Figure 13. Total PBDEs fluxes ( $\mathrm{ng} / \mathrm{m}^{2} /$ day) from eight stations from events 1 through 19.

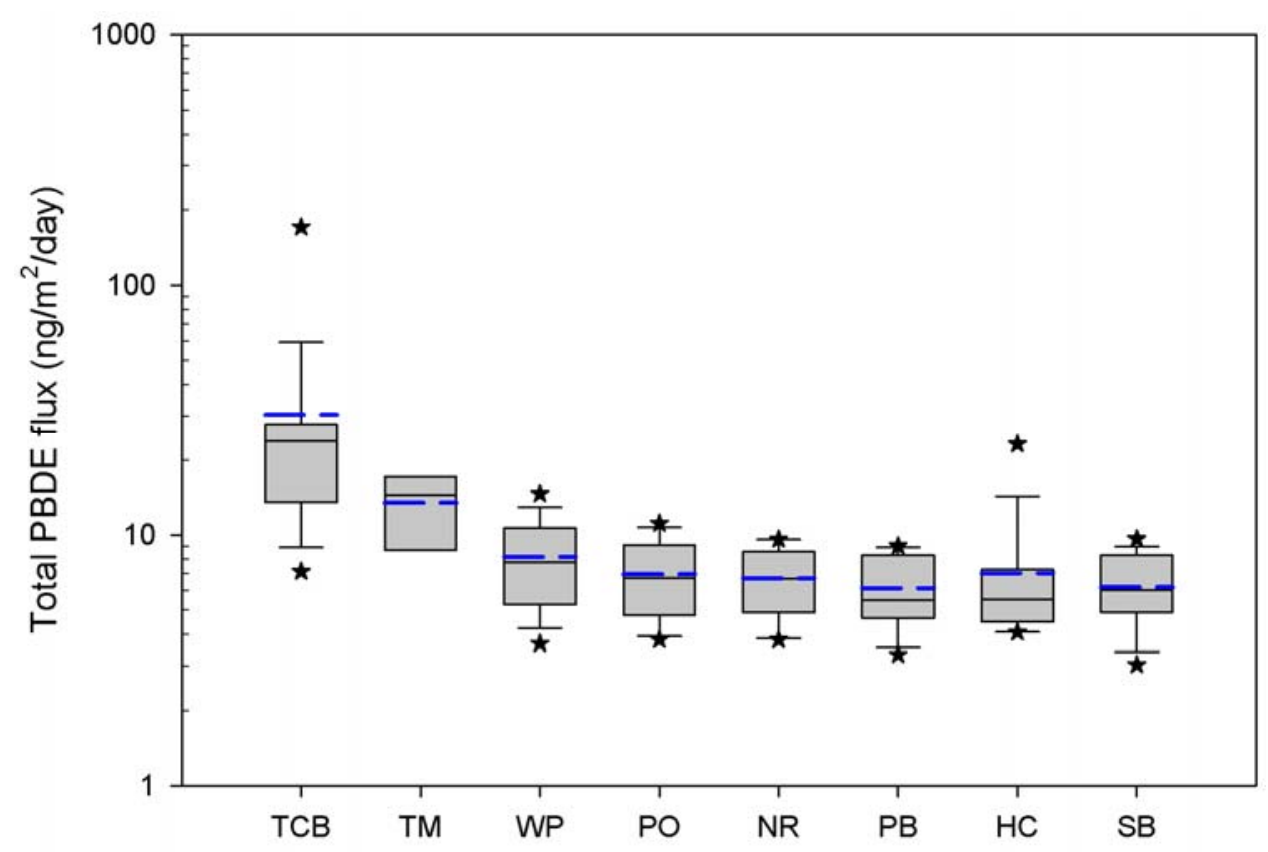

Figure 14. Box plot of total PBDE fluxes ( $\mathrm{ng} / \mathrm{m}^{2} /$ day) for eight stations. The box boundaries are the $25^{\text {th }}$ and $75^{\text {th }}$ percentile, with the median in the box, dashed blue line is the mean, whiskers are the 10th and 90th percentiles, and the asterisks are outliers. 


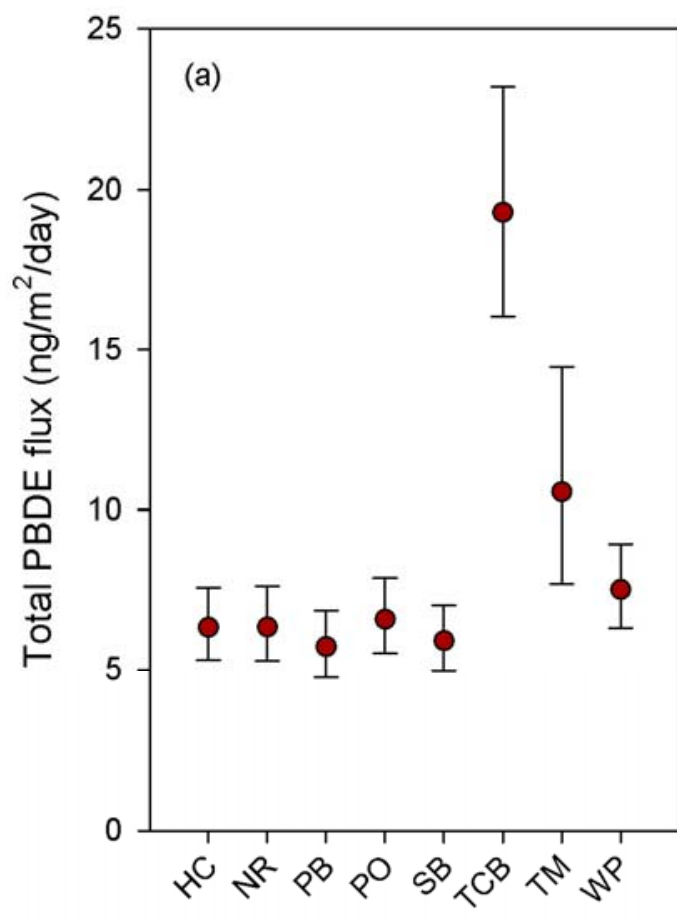

Station (b)

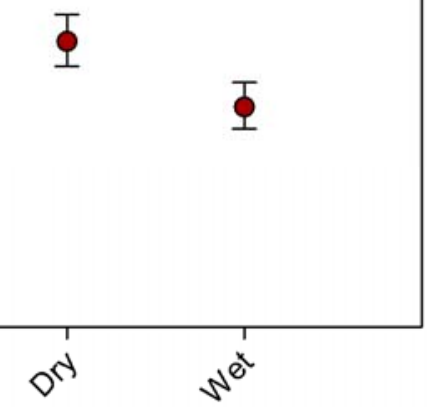

Season

Figure 15. Effects of (a) station; and (b) season on the total PBDE fluxes. The geometric mean and associated 95\% confidence limits are plotted for each station and then each season.

BDE-209 was prevalent at all eight stations and constituted the largest portion of the sum of the PBDEs (average 45\%; range 4.5-89.4\%). This observation is in line with the findings for other regions around the world (Hale et al. 2003; Hayakawa et al. 2004; Ter Schure et al. 2004; Gouin et al. 2005; Shen et al. 2006; Moon et al. 2007; Vives et al. 2007; Mariani et al. 2008). Relatively high BDEs-47 and 99 were also found in many samples but their contribution to total PBDEs was much lower than that of BDE-209 (average 8.6\% and 6.8\% for BDEs 47 and 99, respectively). However, it should be noted that the proportion of BDE-209 in the total PBDE may potentially be underestimated due to the relatively lower recovery of this compound in the field recovery tests. Except for BDEs-47, 99, 209, other BDEs are often below their MDL. To understand the potential difference in sources among stations, distributions of BDE-47, 99, and 209 for eight stations are plotted in Figure 16. The similar distribution patterns of these three BDEs across all stations suggest a common source(s) for the region. Station TM shows a slightly different distribution, but this results from the lack of a wet season representation because only dry season events 14-19 were sampled at this station. The average values of the BDE-47/BDE-99 ratio for eight stations span from 0.87 to 1.91 , which is higher than that of the U.S. commercial penta-BDE product DE-71 (0.79; La Guardia et al. 2006), indicating that multisources and degradation products from higher brominated BDEs may contribute to the overall composition of atmospheric PBDE fluxes. The dominance of BDE-209 in the Puget Sound samples is consistent with the fact that BDE-209 is the predominant constituent $(>90 \%)$ of the deca-BDE formulation, which is the currently available commercial PBDE mixture (La Guardia 
et al. 2006). The higher proportion of BDE-209 in the bulk atmospheric deposition in this study, although potentially underestimated, may be a concern for public health since studies have indicated that BDE-209 could degrade to less brominated PBDEs, which are more toxic and bioaccumulative (Stapleton and Dodder 2008).

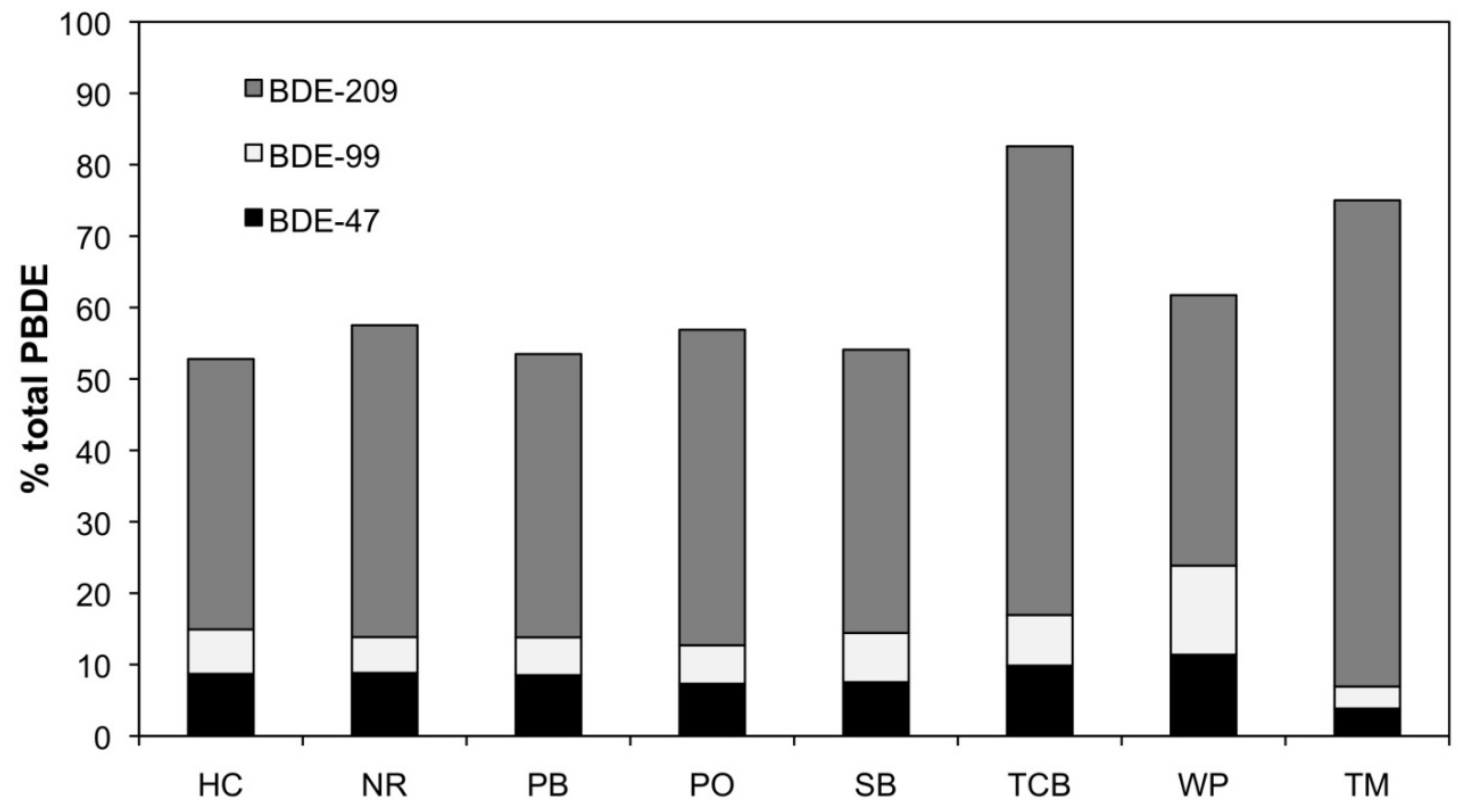

Figure 16. Distributions of BDE-47, 99, 209 at the eight sampled stations.

\section{Trace Elements (As, $\mathrm{Cd}, \mathrm{Cr}, \mathrm{Cu}, \mathrm{Ni}, \mathrm{Pb}$, and $\mathrm{Zn}$ )}

The solution concentrations from the field collectors, surface areas of the funnel, mass of the element contributed by the rinse water, and the calculated daily fluxes are provided in Appendix C. The fluxes for trace metals with concentrations below the MDL were calculated based on the instrument MDL and the collection information for that sample.

The concentrations from atmospheric deposition samples are often reported as volumeweighted in order to normalize the data to better represent a precipitation normalized concentration. This sample weighting procedure gives less emphasis to small sample volumes, which contribute little total mass input to the flux calculation. This approach to normalizing the data requires highly accurate measurements of the volume sampled. Although the volume extracted was calculated for the PAH and PBDE samplers, the accuracy was insufficient to use the volume as a normalizing tool, and concentrations (only fluxes) were not reported for these parameters. A quick comparison of the metals was conducted on the data to evaluate whether a volume-weighted concentration would be a more representative method for expressing the concentrations and then fluxes of the various toxics. Volume-weighted concentrations were determined using the following equation: 


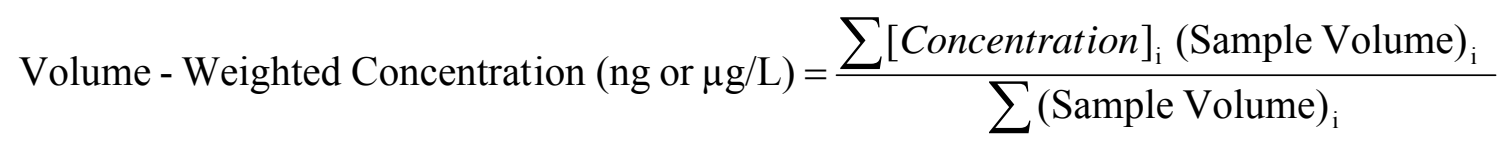

Table 10 summarizes the descriptive statistics for the concentrations, shows the volumeweighted concentration, and presents the median and quartiles for the daily fluxes. The distribution of the cumulative precipitation during the study represents both a statistically different wet and dry season. Since the data represent both seasonal precipitation conditions, using the median and quartile concentrations to then calculate and represent the daily flux of a parameter provides a means for normalizing, with respect to extreme precipitation events, (either higher or lower than normal precipitation) within the sampled data. Although samples were collected during the PNW dry season (defined as May through September), there are very few two-week periods with no measurable precipitation. Therefore, the two-week integrated sampling also normalizes the data set by integrating larger periods of time than other studies. The RPDs between station median concentrations and volume-weighted concentrations are relatively low (15-19\% RPD) and volume-weighted concentrations are generally higher. The exceptions were the fluxes from TM, where the volume-weighted concentrations were lower as the TM data set does not contain a full seasonal record and was influenced significantly by small volumes collected that are not representative of a full seasonal precipitation pattern. The TM station was used to evaluate the sphere of influence for the TCB station and was excluded from analyses where the data were not divided into seasonal categories. Using either the median concentration or the volume weighted concentration yields similar daily fluxes based on this data set. In addition, volume-weighted concentrations eliminate the ability to express the data in a range of concentrations for each site. Therefore, all further data analyses were conducted on the median and quartiles.

Table 10. The trace element descriptive statistics for bulk atmospheric deposition with concentrations $(\mu \mathrm{g} / \mathrm{L})$, volume weighted concentrations, and daily fluxes $\left(\mu \mathrm{g} / \mathrm{m}^{2} / \mathrm{d}\right)$ using the median concentrations.

\begin{tabular}{|c|c|c|c|c|c|c|c|c|c|}
\hline \multirow[t]{2}{*}{ Station } & \multirow[t]{2}{*}{$\mathbf{N}$} & \multicolumn{5}{|c|}{ Concentration ( $\mu \mathrm{g} / \mathrm{L})$} & \multicolumn{3}{|c|}{ Daily Fluxes $\left(\mu \mathrm{g} / \mathrm{m}^{2} / \mathrm{d}\right)$} \\
\hline & & Mean & $\begin{array}{l}\text { Vol.- } \\
\text { Weighted }\end{array}$ & Median & 25th & 75th & Median & 25th & 75th \\
\hline \multicolumn{10}{|c|}{ Arsenic } \\
\hline $\mathrm{HC}$ & 19 & 0.0576 & 0.0518 & 0.0644 & 0.0450 & 0.0718 & 0.11 & 0.076 & 0.15 \\
\hline NR & 19 & 0.142 & 0.111 & 0.123 & 0.0691 & 0.177 & 0.22 & 0.13 & 0.34 \\
\hline PB & 17 & 0.113 & 0.104 & 0.112 & 0.0949 & 0.131 & 0.14 & 0.10 & 0.18 \\
\hline $\mathrm{PO}$ & 19 & 0.118 & 0.0993 & 0.108 & 0.079 & 0.149 & 0.15 & 0.093 & 0.20 \\
\hline SB & 19 & 0.185 & 0.155 & 0.155 & 0.109 & 0.187 & 0.13 & 0.061 & 0.29 \\
\hline TCB & 19 & 0.409 & 0.259 & 0.203 & 0.140 & 0.407 & 0.45 & 0.35 & 0.65 \\
\hline TM & 6 & 0.239 & 0.168 & 0.254 & 0.187 & 0.298 & 0.20 & 0.12 & 0.25 \\
\hline WP & 18 & 0.0938 & 0.0841 & 0.0864 & 0.0709 & 0.119 & 0.15 & 0.086 & 0.21 \\
\hline \multicolumn{10}{|c|}{ Cadmium } \\
\hline
\end{tabular}




\begin{tabular}{|c|c|c|c|c|c|c|c|c|c|}
\hline \multirow[t]{2}{*}{ Station } & \multirow[t]{2}{*}{$\mathbf{N}$} & \multicolumn{5}{|c|}{ Concentration ( $\mu \mathrm{g} / \mathrm{L})$} & \multicolumn{3}{|c|}{ Daily Fluxes $\left(\mu \mathrm{g} / \mathrm{m}^{2} / \mathrm{d}\right)$} \\
\hline & & Mean & $\begin{array}{l}\text { Vol.- } \\
\text { Weighted }\end{array}$ & Median & 25th & 75th & Median & 25 th & 75th \\
\hline $\mathrm{HC}$ & 19 & 0.0112 & 0.00938 & 0.00644 & 0.00534 & 0.0146 & 0.017 & 0.0096 & 0.026 \\
\hline NR & 19 & 0.0161 & 0.0127 & 0.0137 & 0.00764 & 0.0204 & 0.023 & 0.012 & 0.035 \\
\hline PB & 17 & 0.0542 & 0.0287 & 0.0140 & 0.0120 & 0.0213 & 0.017 & 0.014 & 0.034 \\
\hline $\mathrm{PO}$ & 19 & 0.0116 & 0.00981 & 0.0102 & 0.00736 & 0.0118 & 0.015 & 0.0069 & 0.024 \\
\hline SB & 19 & 0.0225 & 0.0179 & 0.0202 & 0.0117 & 0.0238 & 0.018 & 0.0090 & 0.031 \\
\hline TCB & 19 & 0.0580 & 0.0391 & 0.0321 & 0.0171 & 0.105 & 0.068 & 0.042 & 0.11 \\
\hline TM & 6 & 0.0326 & 0.0170 & 0.0268 & 0.0188 & 0.0387 & 0.021 & 0.013 & 0.026 \\
\hline WP & 18 & 0.0118 & 0.00991 & 0.0100 & 0.00848 & 0.0128 & 0.017 & 0.012 & 0.025 \\
\hline \multicolumn{10}{|c|}{ Chromium } \\
\hline $\mathrm{HC}$ & 19 & 0.164 & 0.121 & 0.147 & 0.0643 & 0.217 & 0.19 & 0.10 & 0.42 \\
\hline NR & 19 & 0.317 & 0.229 & 0.263 & 0.151 & 0.440 & 0.33 & 0.25 & 0.66 \\
\hline PB & 17 & 0.439 & 0.365 & 0.321 & 0.205 & 0.454 & 0.41 & 0.27 & 0.54 \\
\hline $\mathrm{PO}$ & 19 & 0.251 & 0.183 & 0.193 & 0.139 & 0.200 & 0.23 & 0.15 & 0.45 \\
\hline SB & 19 & 1.78 & 1.49 & 1.04 & 0.635 & 1.71 & 0.63 & 0.41 & 3.0 \\
\hline TCB & 19 & 1.14 & 0.745 & 0.713 & 0.411 & 1.48 & 1.4 & 0.99 & 2.1 \\
\hline TM & 6 & 0.493 & 0.24 & 0.378 & 0.315 & 0.416 & 0.24 & 0.14 & 0.29 \\
\hline WP & 18 & 0.307 & 0.237 & 0.255 & 0.172 & 0.307 & 0.35 & 0.27 & 0.58 \\
\hline \multicolumn{10}{|c|}{ Copper } \\
\hline $\mathrm{HC}$ & 19 & 0.661 & 0.350 & 0.288 & 0.206 & 0.511 & 0.61 & 0.46 & 0.90 \\
\hline NR & 19 & 1.32 & 0.789 & 0.852 & 0.406 & 1.90 & 1.8 & 1.2 & 2.5 \\
\hline PB & 17 & 1.89 & 1.14 & 0.915 & 0.707 & 1.24 & 1.3 & 0.77 & 1.4 \\
\hline $\mathrm{PO}$ & 19 & 0.984 & 0.728 & 0.705 & 0.416 & 1.18 & 1.1 & 0.64 & 1.6 \\
\hline SB & 19 & 2.73 & 2.12 & 2.05 & 1.08 & 3.80 & 1.6 & 0.93 & 3.8 \\
\hline TCB & 19 & 10.7 & 6.60 & 5.52 & 2.35 & 15.5 & 12 & 8.1 & 19 \\
\hline TM & 6 & 4.31 & 2.64 & 4.39 & 3.14 & 5.91 & 2.7 & 2.2 & 3.3 \\
\hline WP & 18 & 0.968 & 0.883 & 0.892 & 0.641 & 1.11 & 1.4 & 0.96 & 2.0 \\
\hline \multicolumn{10}{|c|}{ Nickel } \\
\hline $\mathrm{HC}$ & 19 & 0.314 & 0.199 & 0.151 & 0.114 & 0.381 & 0.29 & 0.23 & 0.51 \\
\hline NR & 19 & 0.567 & 0.380 & 0.438 & 0.167 & 0.612 & 0.5 & 0.35 & 0.86 \\
\hline PB & 17 & 0.777 & 0.647 & 0.578 & 0.373 & 1.20 & 0.74 & 0.32 & 1.1 \\
\hline $\mathrm{PO}$ & 19 & 0.621 & 0.473 & 0.408 & 0.239 & 0.745 & 0.48 & 0.33 & 1.1 \\
\hline SB & 19 & 2.82 & 2.28 & 1.94 & 1.14 & 3.48 & 1.6 & 0.66 & 0.41 \\
\hline TCB & 19 & 1.65 & 1.05 & 1.31 & 0.474 & 2.44 & 1.9 & 1.6 & 2.8 \\
\hline TM & 6 & 0.950 & 0.652 & 1.13 & 0.824 & 1.20 & 0.7 & 0.42 & 0.96 \\
\hline WP & 18 & 0.704 & 0.535 & 0.538 & 0.267 & 0.805 & 0.81 & 0.5 & 1.1 \\
\hline \multicolumn{10}{|c|}{ Lead } \\
\hline $\mathrm{HC}$ & 19 & 0.182 & 0.128 & 0.124 & 0.0974 & 0.187 & 0.30 & 0.15 & 0.37 \\
\hline NR & 19 & 0.501 & 0.369 & 0.357 & 0.233 & 0.66 & 0.75 & 0.52 & 1.1 \\
\hline PB & 17 & 0.337 & 0.299 & 0.328 & 0.171 & 0.443 & 0.43 & 0.21 & 0.52 \\
\hline
\end{tabular}




\begin{tabular}{|c|c|c|c|c|c|c|c|c|c|}
\hline \multirow[t]{2}{*}{ Station } & \multirow[t]{2}{*}{$\mathbf{N}$} & \multicolumn{5}{|c|}{ Concentration ( $\mu \mathrm{g} / \mathrm{L})$} & \multicolumn{3}{|c|}{ Daily Fluxes $\left(\mu \mathrm{g} / \mathrm{m}^{2} / \mathrm{d}\right)$} \\
\hline & & Mean & $\begin{array}{l}\text { Vol.- } \\
\text { Weighted }\end{array}$ & Median & 25th & 75th & Median & 25th & 75th \\
\hline PO & 19 & 0.281 & 0.208 & 0.201 & 0.154 & 0.332 & 0.38 & 0.18 & 0.45 \\
\hline SB & 19 & 0.732 & 0.608 & 0.648 & 0.404 & 0.781 & 0.53 & 0.27 & 1.1 \\
\hline TCB & 19 & 7.34 & 4.41 & 3.00 & 1.67 & 7.69 & 5.9 & 4.5 & 8.6 \\
\hline TM & 6 & 1.59 & 1.14 & 1.55 & 0.719 & 2.29 & 1.1 & 0.83 & 1.8 \\
\hline WP & 18 & 0.413 & 0.318 & 0.322 & 0.231 & 0.422 & 0.57 & 0.35 & 0.80 \\
\hline \multicolumn{10}{|c|}{ Zinc } \\
\hline $\mathrm{HC}$ & 19 & 4.40 & 2.86 & 3.11 & 1.8 & 4.43 & 4.8 & 2.9 & 8.4 \\
\hline NR & 19 & 7.86 & 2.59 & 5.68 & 2.46 & 10.4 & 8.8 & 6.1 & 14 \\
\hline PB & 17 & 13.7 & 10.4 & 5.00 & 3.25 & 7.4 & 6.9 & 3.9 & 10 \\
\hline PO & 19 & 3.89 & 3.07 & 2.52 & 1.81 & 4.24 & 4.7 & 2.2 & 6.8 \\
\hline SB & 19 & 9.37 & 7.40 & 8.10 & 4.91 & 10.7 & 5.5 & 4.2 & 10 \\
\hline TCB & 19 & 35.1 & 21.7 & 22.2 & 11.6 & 61.5 & 49 & 31 & 52 \\
\hline TM & 6 & 14.7 & 8.89 & 16.7 & 12.9 & 19.4 & 11 & 7.2 & 13 \\
\hline WP & 18 & 6.09 & 4.77 & 4.83 & 3.33 & 5.68 & 6.8 & 5.6 & 11 \\
\hline
\end{tabular}

The fluxes for all trace elements were significantly higher at TCB compared to all other stations $(p \leq 0.008)$. If TCB was removed from the analysis, there was no significant difference between stations for $\mathrm{Zn}(p=0.097)$ and $\mathrm{Cd}(p=0.373)$. For the other elements, the stations statistically cluster into four groups, shown in Table 11. Overall, the stations are very comparable with HC and PO clustering with overall lower fluxes, and TCB, TM, and WP clustering with overall higher fluxes. Figures 17 through 19 show the distribution of the data for $\mathrm{As}, \mathrm{Cu}$, and $\mathrm{Pb}$, respectively, with the asterisks identifying extremes from the data set distribution. Statistically, these are classified as outliers for this data set, but the data set only includes one year of sampling, which limits the ability to extrapolate the data. However, the total precipitation during the study period was not considered anomalous compared to the last decade of data (see Figure 2); therefore, the fluxes are considered reasonable estimates for extrapolating daily flux rates into calculations for the annual bulk atmospheric deposition load when all other uncertainties are considered (sampling methodology, site representation, surface area calculation error, etc.). 
Table 11. Station clusters for the $\mathrm{Cr}, \mathrm{Ni}, \mathrm{Cu}, \mathrm{As}$, and $\mathrm{Pb}$ fluxes.

\begin{tabular}{|c|c|c|c|c|c|}
\hline & Clusters: & A & B & C & D \\
\hline \multirow{5}{*}{\multicolumn{2}{|c|}{$\mathrm{Cr}$}} & $\mathrm{HC}$ & NR & NR & $\mathrm{TCB}$ \\
\hline & & NR & $\mathrm{PO}$ & PB & \\
\hline & & $\mathrm{PO}$ & $\mathrm{TM}$ & SB & \\
\hline & & TM & WP & WP & \\
\hline & & WP & & & \\
\hline \multirow{5}{*}{\multicolumn{2}{|c|}{$\mathrm{Ni}$}} & $\mathrm{HC}$ & NR & PB & SB \\
\hline & & NR & PB & SB & $\mathrm{TCB}$ \\
\hline & & PB & $\mathrm{PO}$ & TM & \\
\hline & & $\mathrm{PO}$ & $\mathrm{TM}$ & WP & \\
\hline & & TM & & & \\
\hline \multirow{5}{*}{\multicolumn{2}{|c|}{$\mathrm{Cu}$}} & $\mathrm{HC}$ & NR & NR & $\mathrm{TCB}$ \\
\hline & & PB & PB & PB & \\
\hline & & $\mathrm{PO}$ & $\mathrm{PO}$ & SB & \\
\hline & & & SB & WP & \\
\hline & & & WP & & \\
\hline \multirow{6}{*}{\multicolumn{2}{|c|}{ As }} & $\mathrm{HC}$ & NR & TCB & \\
\hline & & PB & PB & TM & \\
\hline & & $\mathrm{PO}$ & $\mathrm{PO}$ & & \\
\hline & & SB & $\mathrm{SB}$ & & \\
\hline & & TM & $\mathrm{TM}$ & & \\
\hline & & WP & WP & & \\
\hline \multirow{5}{*}{$\mathrm{Pb}$} & & $\mathrm{HC}$ & NR & NR & TCB \\
\hline & & PB & PB & PB & \\
\hline & & $\mathrm{PO}$ & $\mathrm{PO}$ & SB & \\
\hline & & $\mathrm{SB}$ & $\mathrm{SB}$ & TM & \\
\hline & & WP & WP & WP & \\
\hline
\end{tabular}




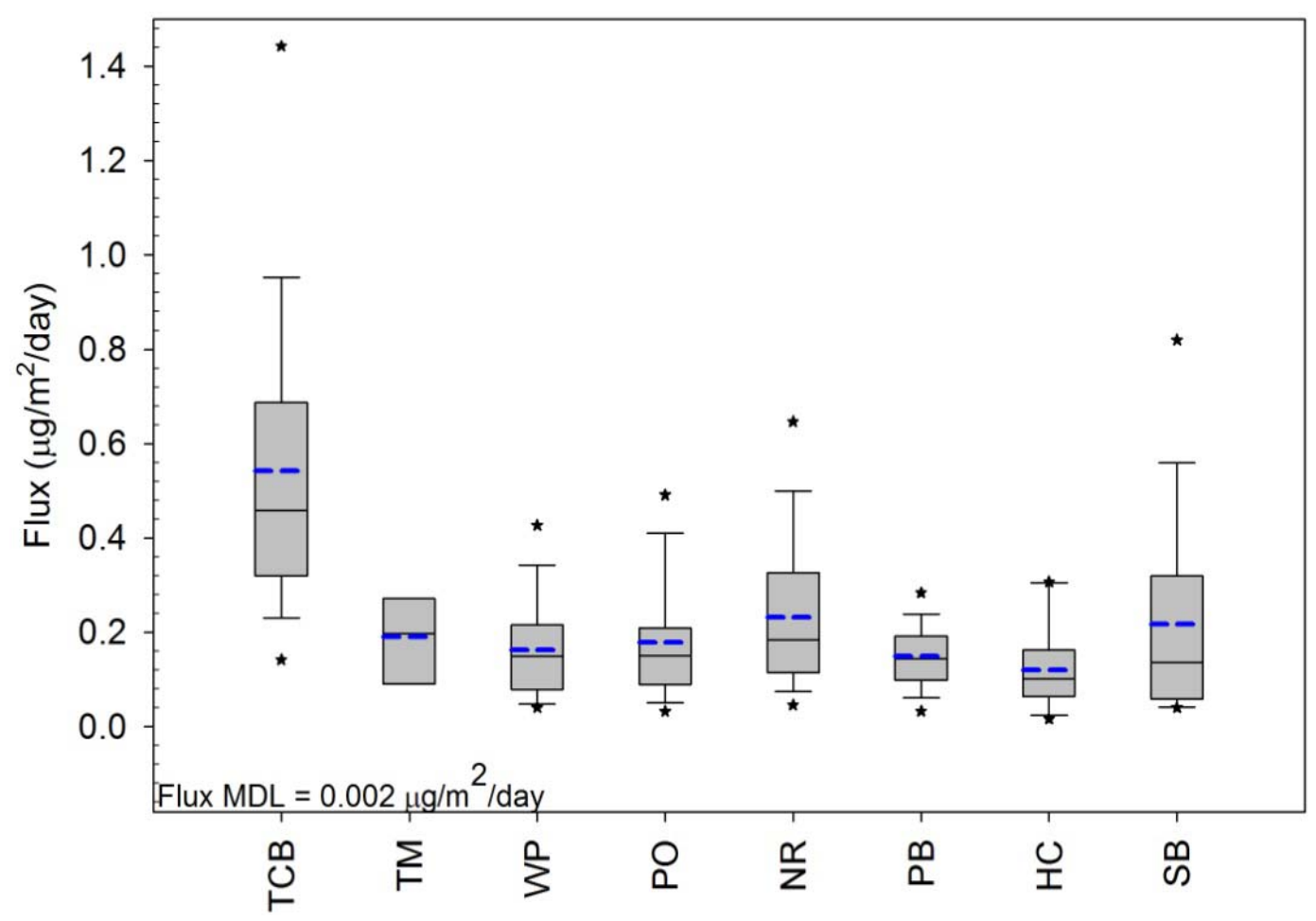

Figure 17. Arsenic fluxes for the eight stations. The box boundaries are the $25^{\text {th }}$ and $75^{\text {th }}$ percentile, with the median in the box, dashed blue line is the mean, whiskers are the 10th and 90th percentiles, and the asterisks are outliers.

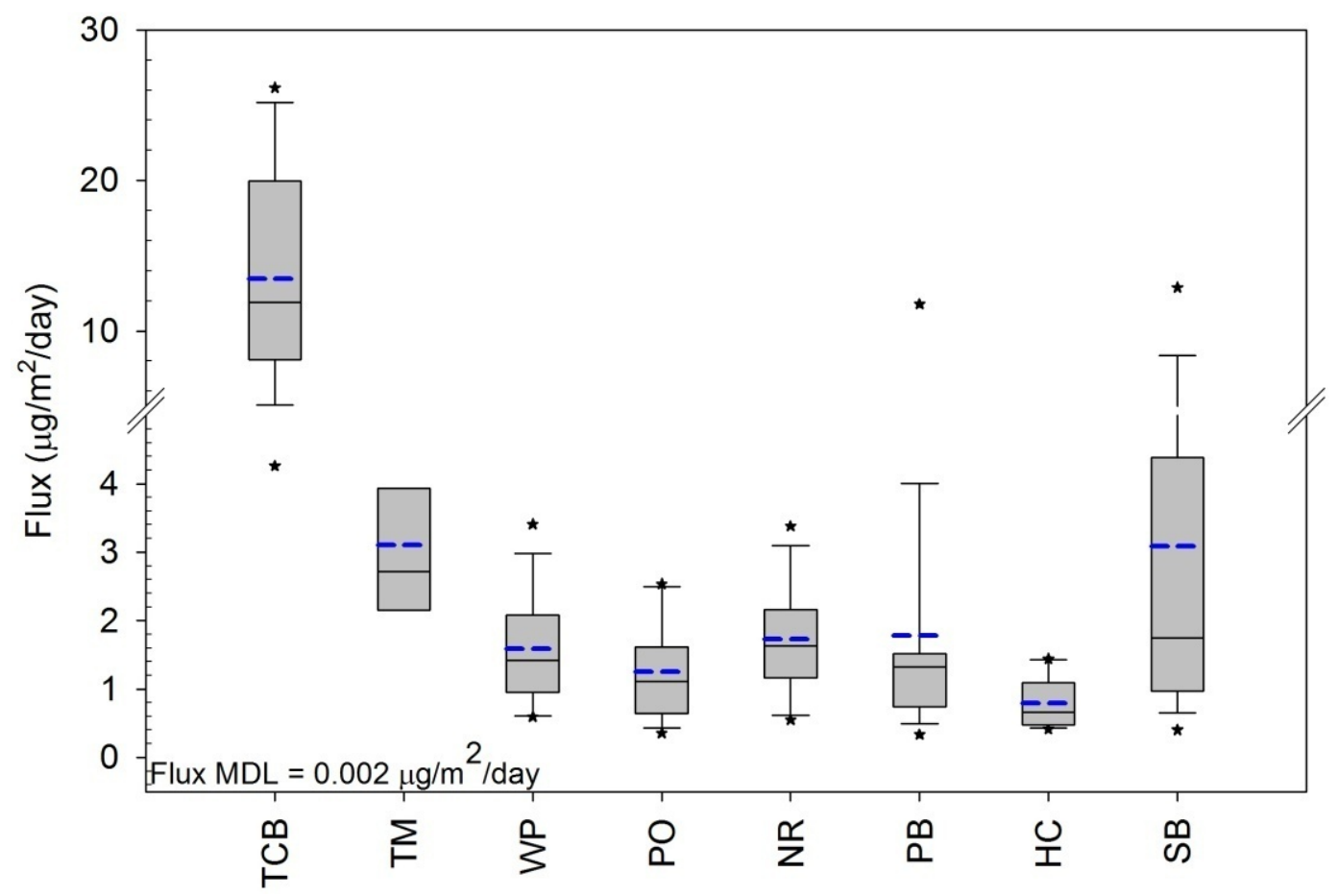

Figure 18. Copper fluxes for the eight stations. The box boundaries are the $25^{\text {th }}$ and $75^{\text {th }}$ percentile, with the median in the box, dashed blue line is the mean, whiskers are the 10th and 90th percentiles, and the asterisks are outliers. 


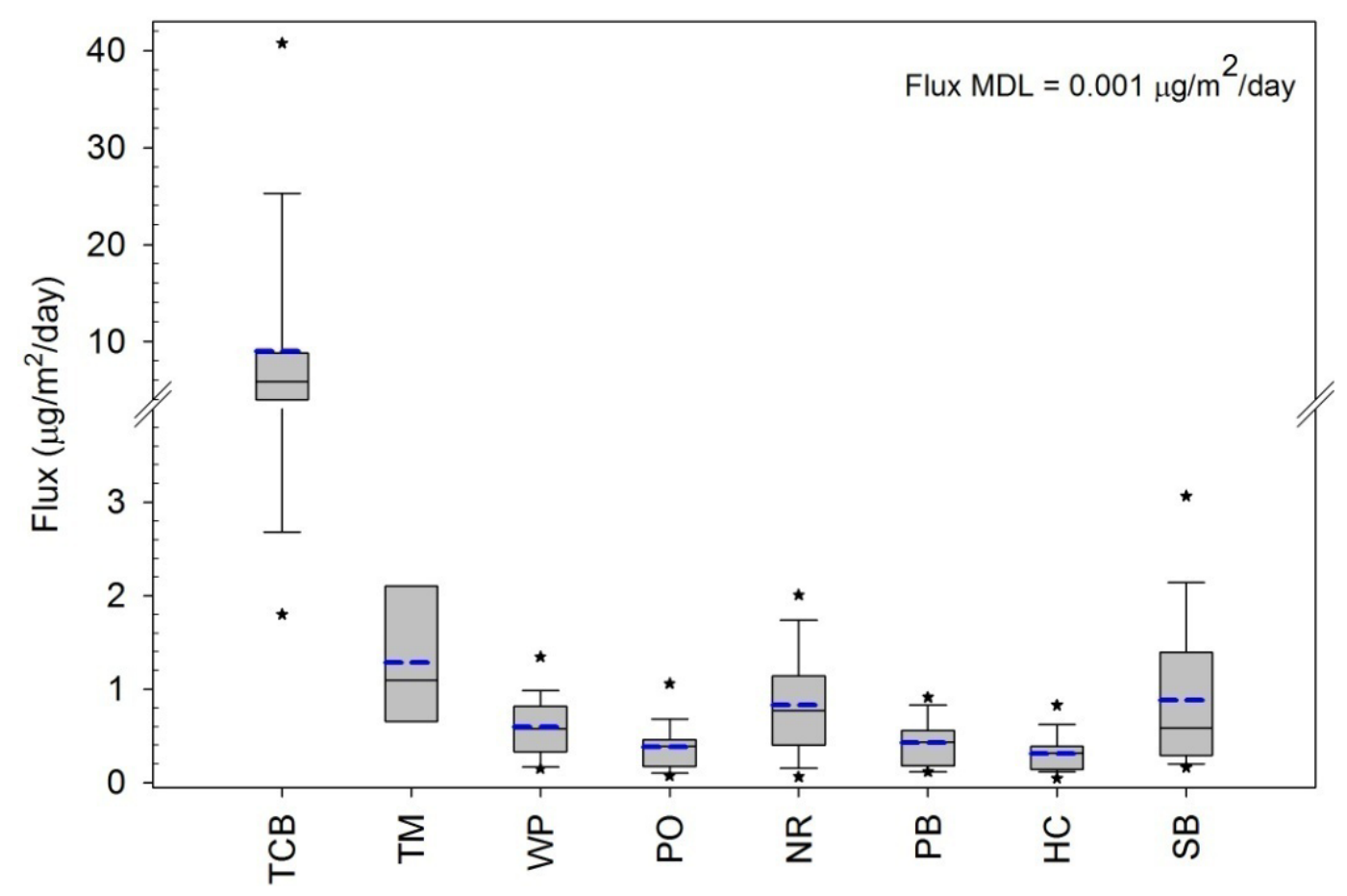

Figure 19. Lead fluxes for the eight stations. The box boundaries are the $25^{\text {th }}$ and $75^{\text {th }}$ percentile, with the median in the box, dashed blue line is the mean, whiskers are the 10th and 90th percentiles, and the asterisks are outliers.

The significantly higher fluxes measured at TCB could not be reproduced at the TM station located $6 \mathrm{~km}$ to the northeast of TCB (see Figure 1). Most of the trace element fluxes at TM were 1-6 times lower than those at TCB; however, $\mathrm{Cu}$ and $\mathrm{Pb}$ fluxes were 2-21 times lower. The spatial heterogeneity of atmospheric deposition within the industrial region of Commencement Bay was also document by Crecelius (1991; within EPA 1991). They reported average daily atmospheric deposition fluxes for a transect of stations extending from the highly industrial sites within the Port of Tacoma to less industrial sites on the shoreline, and a sub-urban site within the watershed (Riverside School). The reported flux ranges for $\mathrm{Cu}, \mathrm{Pb}$, and As were 30$149 \mu \mathrm{g} / \mathrm{m}^{2} / \mathrm{d}, 35-653 \mu \mathrm{g} / \mathrm{m}^{2} / \mathrm{d}$, and $1.8-18 \mu \mathrm{g} / \mathrm{m}^{2} / \mathrm{d}$, respectively (EPA 1991). Our data show significantly lower ranges for the TCB and TM stations with $2.2-26 \mu \mathrm{g} / \mathrm{m}^{2} / \mathrm{d}, 0.24-41 \mu \mathrm{g} / \mathrm{m}^{2} / \mathrm{d}$, and $0.06-1.4 \mu \mathrm{g} / \mathrm{m}^{2} / \mathrm{d}$, respectively. The new deposition fluxes are significantly lower if the three highly industrial sites previously monitored by EPA (1991; identified as Morse Supply, Sea-Land, and Alexander Avenue) are included. To extrapolate the atmospheric deposition data from this study to calculate an annual atmospheric deposition load to the waters of Puget Sound as a whole, it would be more appropriate to compare the TCB and TM ranges with those from the Tyee Marina and the Riverside School sampling locations reported in the EPA (1991) study. The mean atmospheric deposition fluxes reported by EPA (1991) for those two stations were $\mathrm{Cu}$ : $20-50 \mu \mathrm{g} / \mathrm{m}^{2} / \mathrm{d}, \mathrm{Pb}: 22-42 \mu \mathrm{g} / \mathrm{m}^{2} / \mathrm{d}$, and As: $1.8 \mu \mathrm{g} / \mathrm{m}^{2} / \mathrm{d}$. Our data fall within the lower end of these ranges. This suggests there has been a significant decrease in atmospheric deposition fluxes around Commencement Bay since 1989-1990 (Crecelius 1991 and EPA 1991). However, 
it should be noted that trace element quantification methods have improved markedly since the quantifications methods used in EPA (1991).

The median annual atmospheric deposition fluxes for all stations, except TCB and TM, fall more in line with the rural/sub-urban data reported from the Chesapeake Bay Program (1999). For example, the averages for $\mathrm{Cu}$ and $\mathrm{Pb}$ reported by the Chesapeake Bay Program in the 1990s were 2 and $3 \mu \mathrm{g} / \mathrm{m}^{2} / \mathrm{d}$, respectively. In our study, the median of all stations for $\mathrm{Cu}$ and $\mathrm{Pb}$ were 9.2 and $5.1 \mu \mathrm{g} / \mathrm{m}^{2} / \mathrm{d}$, but if the TCB and TM stations are removed from the data set, the medians were 1.2 and $0.42 \mu \mathrm{g} / \mathrm{m}^{2} / \mathrm{d}$, respectively. In the case of As, the Chesapeake Bay Program (1991) reported a mean deposition flux of $0.4 \mu \mathrm{g} / \mathrm{m}^{2} / \mathrm{d}$, while our median of all stations was $0.17 \mu \mathrm{g} / \mathrm{m}^{2} / \mathrm{d}$ (interquartile range: $0.11-0.31 \mu \mathrm{g} / \mathrm{m}^{2} / \mathrm{d}$ ) and both are an order of magnitude lower than the average reported in EPA (1991) for the Commencement Bay region. This suggests that over the last 18 years, regulations and public education have resulted in an overall decrease in the fluxes of $\mathrm{Cu}, \mathrm{Pb}$, and $\mathrm{As}$ in the Tacoma region and they are approaching values reported in rural regions of Chesapeake Bay. However, the $\mathrm{Cu}$ and $\mathrm{Pb}$ fluxes remain higher in the urban/industrial area of Commencement Bay compared to rural/sub-urban areas around Puget Sound.

The GLM model was further used to evaluate the effect of either station or season on the data set. As discussed above, TCB had the greatest influence on all fluxes, while other stations were not significantly different. Removing the influence of the station on the data set and distributing the data into the wet and relatively drier seasons (October-April and May-September, respectively; $p=0.0002$ ), shows that only As and $\mathrm{Cr}$ have significantly higher fluxes in the wet season than the dry season $(p=0.001 ; p=0.008$; Figure 20).

If the influence of TCB is removed from the data set, the Kruskal-Wallis test show SB-wet and SB-dry for $\mathrm{Cr}$ and $\mathrm{Ni}$ are significantly higher fluxes than the other stations, and TM-dry was significantly higher for $\mathrm{Cu}(p=0.001)$ and $\mathrm{Pb}(p=0.002)$. Therefore, the data set is heavily influenced by the higher fluxes at SB-wet, TCB-wet, and TCB-dry and the lower fluxes at POdry, HC-wet, and HC-dry. Many studies have reported higher fluxes in the dry season versus the wet season (e.g., EPA 1991; Baker 1997). In this study, the season was statistically defined using the mean precipitation for each event during the study year as discussed above. The lack of statistically significant seasonal differences for most of the trace element fluxes may result from larger rain events during the summer dry season (see Table 3) or an under representation of the dry deposition in the bulk deposition sampler. Additional research focusing on separate wet and dry deposition collectors would be needed to further understand the true differences in the seasonal fluxes.

The SB station was located in a rural coastal area and was anticipated to fall in line with fluxes from other rural stations such as HC. Therefore, the data set was evaluated to determine if the high fluxes measured at SB during certain events were representative of a larger spatial area and should be included in the loading calculations for Puget Sound. The Kruskal-Wallis test shows that $\mathrm{Cr}(p<0.0001)$ and $\mathrm{Ni}(p<0.0001)$ fluxes from SB-wet were significantly higher 
than all other stations and seasons except at TCB. The high fluxes for $\mathrm{Cr}$ and Ni may be attributed to the wind driven deposition of sand during wind storms from the north/northeast that generally occur during the wet season. This was hypothesized as the field log notes indicated sand grains were deposited inside the funnels for trace elements following such storm events. If the high fluxes are attributed to the deposition of sand because the station is too close to the edge of the bluff, then the fluxes would not be considered representative of the annual conditions for atmospheric deposition. Since $\mathrm{Cr}$ and $\mathrm{Ni}$ are correlated $(\mathrm{r}=0.91)$ and are generally associated with sand/dust particle deposition in rural areas, this appears to be a reasonable hypothesis for the SB station. However, the data could not be corrected for potential station issues; therefore, the SB data were removed from the loading analysis as not representative of the regional deposition.
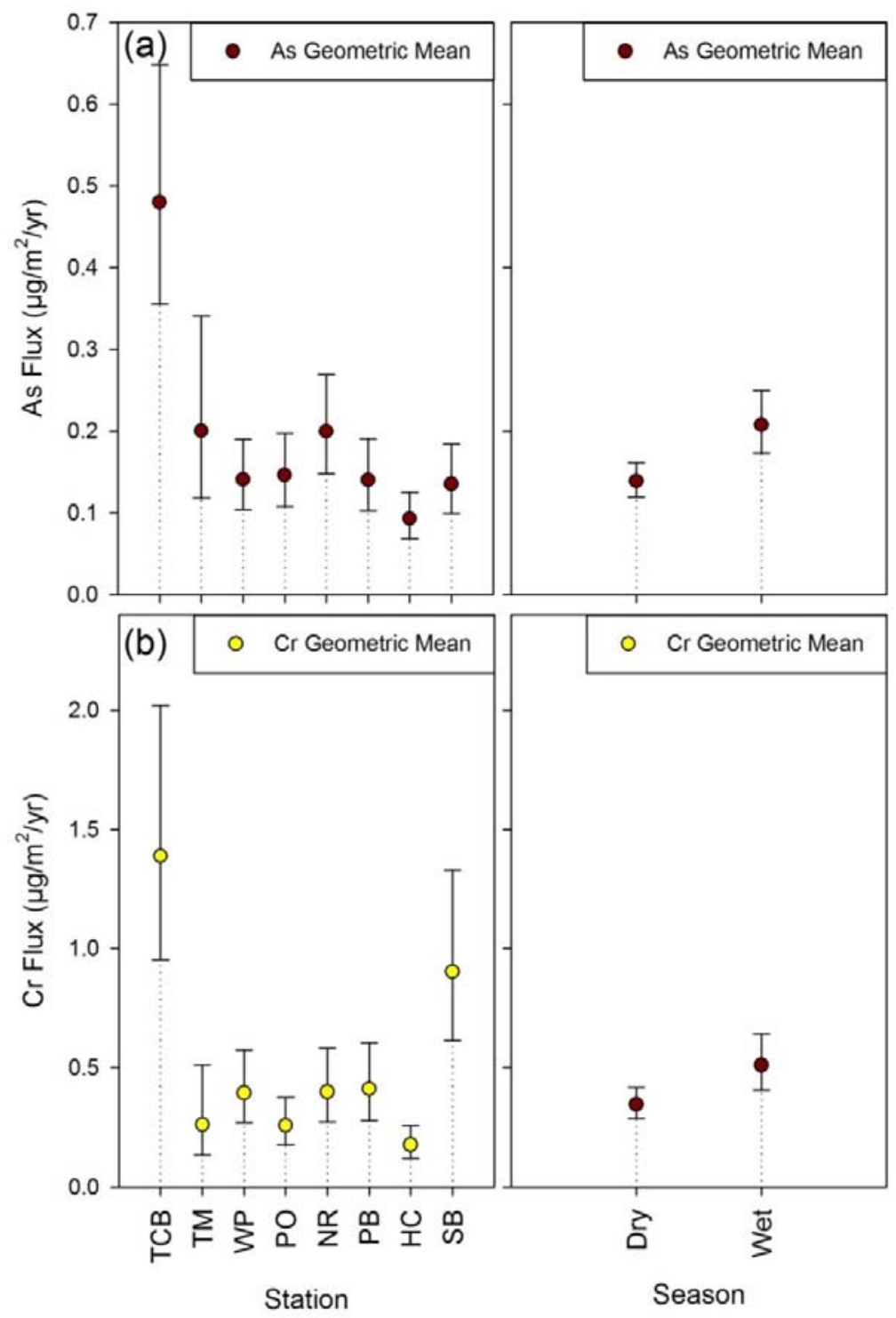

Figure 20. The generalized linear model (GLM) for $\mathrm{As}(\mathrm{a})$ and $\mathrm{Cr}(\mathrm{b})$ with main effects by both station and season. The circles are the median with $25^{\text {th }}$ and $75^{\text {th }}$ percentile error bars. 
The fluxes for $\mathrm{Cu}$ and $\mathrm{Pb}$ were highly correlated for all stations $(\mathrm{r}=0.82)$, and they were both correlated to the sums of CPAHs and pyro-PAHs (see Statistical Analysis Methods and Table 12). The statistically significant relationship between these two metals and individual pyrogenic PAHs that trace high-temperature combustion (i.e., benzo[b]fluoranthene, indeno[1,2,3c,d]pyrene, benzo[g,h,i]perylene) point to a potential common source (i.e., fossil fuel combustion) and/or a process (e.g., vehicular traffic) responsible for the simultaneous release of these contaminants to the atmosphere of the Puget Sound region. The lack of a relationship between $\mathrm{Cu}$ and $\mathrm{Pb}$ and biomass combustion markers (i.e., levoglucosan, retene, 1,7dimethylphenanthrene) further suggests that biomass combustion was not a significant source of these two metals to the atmosphere of the Puget Sound. Because these correlations were observed throughout the entire Puget Sound, this suggests a basin-wide consistency in the sources and/or processes responsible for the emissions of these two metals and high-temperature combustion markers. Whether these emissions are related to industrial processes or vehicular traffic is uncertain and a more detailed study (i.e., a roadside emission study) would be required to truly address the sources of these correlations. A detailed discussion on the use of PAH and molecular markers of combustion as tracers for various combustion sources was provided below.

Table 12. Correlation matrix for metals, PAHs, and anhydrosugar fluxes.

\begin{tabular}{|c|c|c|c|c|c|c|c|c|}
\hline & $\mathrm{Cr}$ & $\mathrm{Ni}$ & $\mathrm{Cu}$ & $\mathrm{Zn}$ & As & Cd & $\mathbf{P b}$ & THg Flux \\
\hline CPAHs & 0.14 & 0.14 & 0.79 & 0.63 & 0.50 & 0.39 & 0.77 & 0.41 \\
\hline Pyr-PAHs & 0.14 & 0.15 & 0.81 & 0.63 & 0.51 & 0.38 & 0.79 & 0.40 \\
\hline $\begin{array}{l}\text { 3,6- } \\
\text { Dimethylphenanthrene }\end{array}$ & 0.17 & 0.17 & 0.34 & 0.25 & 0.32 & 0.14 & 0.18 & 0.32 \\
\hline $\begin{array}{l}2,6- \\
\text { Dimethylphenanthrene }\end{array}$ & 0.07 & 0.10 & 0.75 & 0.54 & 0.50 & 0.33 & 0.67 & 0.38 \\
\hline Anthracene & 0.10 & 0.11 & 0.81 & 0.60 & 0.45 & 0.40 & 0.88 & 0.36 \\
\hline Fluoranthene & 0.12 & 0.14 & 0.79 & 0.59 & 0.51 & 0.36 & 0.75 & 0.37 \\
\hline Pyrene & 0.14 & 0.15 & 0.83 & 0.63 & 0.53 & 0.39 & 0.80 & 0.38 \\
\hline Chrysene & 0.14 & 0.14 & 0.81 & 0.62 & 0.51 & 0.40 & 0.79 & 0.42 \\
\hline Benzo[b]fluoranthene & 0.15 & 0.15 & 0.79 & 0.64 & 0.51 & 0.38 & 0.74 & 0.41 \\
\hline Indeno[1,2,3-c,d]pyrene & 0.14 & 0.14 & 0.79 & 0.62 & 0.47 & 0.38 & 0.78 & 0.40 \\
\hline Benzo[g,h,i]perylene & 0.16 & 0.16 & 0.81 & 0.64 & 0.49 & 0.38 & 0.80 & 0.37 \\
\hline \multicolumn{9}{|c|}{ Biomass Combustion Markers } \\
\hline Levoglucosan & 0.08 & 0.08 & -0.09 & 0.00 & 0.10 & 0.02 & -0.09 & 0.29 \\
\hline Retene & 0.01 & 0.03 & 0.12 & 0.10 & 0.14 & 0.07 & 0.06 & 0.30 \\
\hline $\begin{array}{l}\text { 1,7- } \\
\text { Dimethylphenanthrene }\end{array}$ & 0.09 & 0.12 & 0.50 & 0.39 & 0.40 & 0.26 & 0.42 & 0.47 \\
\hline
\end{tabular}




\section{Mercury and Monomethylmercury}

The fluxes for THg and MMHg were calculated, as discussed above. The concentrations and fluxes were reported in units of $\mathrm{ng} / \mathrm{L}$ and $\mathrm{ng} / \mathrm{m}^{2} / \mathrm{d}$, respectively, and all data are provided in Appendix D. Table 13 summarizes the descriptive statistics for the concentrations, shows the volume-weighted concentration, and presents the median and quartiles for the daily fluxes. The daily fluxes were calculated using the median, $25^{\text {th }}$, and 75 th percentile concentrations. The lack of a pronounced extended dry season within the two-week sampling period for each event yielded relatively similar daily fluxes between the median and volume weighted concentrations. The RPDs between the concentrations were generally 5-20\% with volume-weighted concentrations generally higher. The data analyses were conducted on the median and quartiles of the data set, as discussed above.

Table 13. Descriptive statistics for total mercury $(\mathrm{THg})$ and monomethylmercury $(\mathrm{MMHg})$ atmospheric deposition concentrations (ng/L), volume weighted concentrations, daily fluxes (ng/ $\left./ \mathrm{m}^{2} / \mathrm{d}\right)$ using the median concentrations, and percent of the total deposition occurring as $\mathrm{MMHg}$.

\begin{tabular}{|c|c|c|c|c|c|c|c|c|c|}
\hline \multirow[t]{2}{*}{ Site } & \multirow[t]{2}{*}{$\mathbf{N}$} & \multicolumn{5}{|c|}{ Concentration (ng/L) } & \multicolumn{3}{|c|}{ Daily Fluxes (ng/m $\left.{ }^{2} / \mathrm{d}\right)$} \\
\hline & & Mean & $\begin{array}{l}\text { Vol.- } \\
\text { Weighted }\end{array}$ & Median & $25^{\text {th }}$ & $75^{\text {th }}$ & Median & 25th & 75th \\
\hline \multicolumn{10}{|c|}{ THg } \\
\hline $\mathrm{HC}$ & 19 & 4.11 & 4.23 & 3.81 & 2.35 & 5.51 & 8.3 & 3.2 & 14 \\
\hline NR & 19 & 5.26 & 4.34 & 4.67 & 2.84 & 6.67 & 7.1 & 4.5 & 14 \\
\hline PB & 18 & 6.01 & 5.21 & 4.25 & 3.58 & 5.22 & 6.1 & 3.50 & 10 \\
\hline $\mathrm{PO}$ & 19 & 4.74 & 4.62 & 4.99 & 2.99 & 5.58 & 6.9 & 3.0 & 13 \\
\hline SB & 19 & 6.01 & 4.59 & 4.17 & 3.21 & 7.50 & 4.4 & 2.6 & 6.8 \\
\hline TCB & 19 & 9.40 & 7.42 & 7.06 & 4.37 & 13.3 & 14 & 8.0 & 20 \\
\hline TM & 6 & 6.08 & 4.94 & 5.85 & 4.52 & 6.92 & 4.0 & 2.9 & 5.1 \\
\hline WP & 19 & 6.12 & 6.21 & 5.42 & 3.64 & 7.9 & 8.8 & 4.8 & 18 \\
\hline \multicolumn{10}{|c|}{ MMHg } \\
\hline $\mathrm{HC}$ & 18 & 0.180 & 0.121 & 0.0891 & 0.0581 & 0.169 & 0.18 & 0.13 & 0.28 \\
\hline NR & 10 & 0.301 & 0.204 & 0.189 & 0.140 & 0.230 & 0.42 & 0.21 & 0.57 \\
\hline $\mathrm{PO}$ & 18 & 0.102 & 0.0839 & 0.0659 & 0.0378 & 0.0851 & 0.092 & 0.053 & 0.21 \\
\hline SB & 18 & 0.316 & 0.193 & 0.165 & 0.0708 & 0.294 & 0.15 & 0.087 & 0.35 \\
\hline TCB & 12 & 0.123 & 0.117 & 0.0969 & 0.0686 & 0.155 & 0.30 & 0.059 & 0.51 \\
\hline \multicolumn{10}{|c|}{$\% \mathrm{THg}$ as $\mathrm{MMHg}$} \\
\hline $\mathrm{HC}$ & 18 & $5.6 \%$ & & $3.4 \%$ & $1.0 \%$ & $7.1 \%$ & $3.4 \%$ & $1.0 \%$ & $7.1 \%$ \\
\hline NR & 10 & $5.2 \%$ & & $4.2 \%$ & $3.2 \%$ & $6.3 \%$ & $4.2 \%$ & $3.2 \%$ & $6.3 \%$ \\
\hline $\mathrm{PO}$ & 18 & $2.1 \%$ & & $1.4 \%$ & $0.7 \%$ & $2.4 \%$ & $1.4 \%$ & $0.7 \%$ & $2.4 \%$ \\
\hline SB & 18 & $4.6 \%$ & & $2.8 \%$ & $1.9 \%$ & $5.5 \%$ & $2.8 \%$ & $1.9 \%$ & $5.5 \%$ \\
\hline TCB & 12 & $2.2 \%$ & & $1.8 \%$ & $0.8 \%$ & $2.9 \%$ & $1.8 \%$ & $0.8 \%$ & $2.9 \%$ \\
\hline
\end{tabular}


The distribution of the data for each station shows THg was the only trace element with no statistical differences between all stations ( $p=0.056$; Figure 21), although there are regional patterns with higher fluxes measured at TCB. The cluster analyses for THg grouped the data into two categories with all stations overlapping TCB. It should also be noted that the lower fluxes for TM are not directly comparable to the other stations because it was only sampled during the dry season and does not represent the data range for an annual record. The lack of significant spatial variability suggests these fluxes may be extrapolated, with some confidence, to the larger area of Puget Sound. However, localized industrial areas may need to be considered separately.

The portion of the THg concentrations occurring as $\mathrm{MMHg}$ averaged 3.9\% and ranged from $0.14-32 \%$ (Table 13). The highest percentages were noted at NR and maybe due to the noted high levels of pollen and other organic material incorporated into the deposition collectors. Another possibility is the incorporation of small insects trapped inside the collection bottle with the pollen (see Hammerschmidt and Fitzgerald 2005). The opening at the bottom of the Teflon ${ }^{\circledR}$ collar was $5 \mathrm{~mm}$ and allowed small winged insects to enter the sample collection bottle. In addition, the higher MMHg may not be from the pollen itself but rather a process where the pollen provided a reactive surface. Other anomalies were several samples containing bird droppings in the funnel that were removed from the data set (see Appendix F) because the $\mathrm{THg}$ and MMHg concentrations were significantly higher, 21-44 $\mathrm{ng} / \mathrm{L}$ and 8.2-17 $\mathrm{ng} / \mathrm{L}$, respectively. These samples had $\sim 39-40 \%$ of the THg occurring as MMHg.

While the mechanism for the presence of MMHg in rainfall is debated in the literature, numerous observations have been made that suggest it is typically present at levels of less than $1.5 \%$ of the THg in rainfall (Bloom and Watras 1989; Ebinghaus et al. 1999; Mason et al. 1997; Mason et al. 2000; Lawson and Mason 2001; Nguyen et al. 2005). A current hypothesis for the source of MMHg in precipitation is the abiotic methylation of $\mathrm{Hg}$ by carboxylic acids, particularly acetate (Gardfeldt et al. 2003; Hammerschmidt et al. 2007; Conaway et al. 2010). This may contribute to the higher values reported for the Great Lakes area (up to 18\%) and Sweden (3\% Hall et al. 2005; Munthe et al. 1995). Conaway et al. (2010) recently reported the THg concentrations collected in Monterey Bay, California from storms off the Pacific Ocean were $0.3-22 \%$ MMHg and averaged 3.7\% (Conaway et al. 2010). The SB station is likely to be the most comparable and demonstrated similar results with an average of $4.6 \%$, median of $2.8 \%$, and range $0.4-16 \%$. Therefore, atmospheric deposition of THg may represent an important MMHg source and substrate of MMHg production in some areas. 

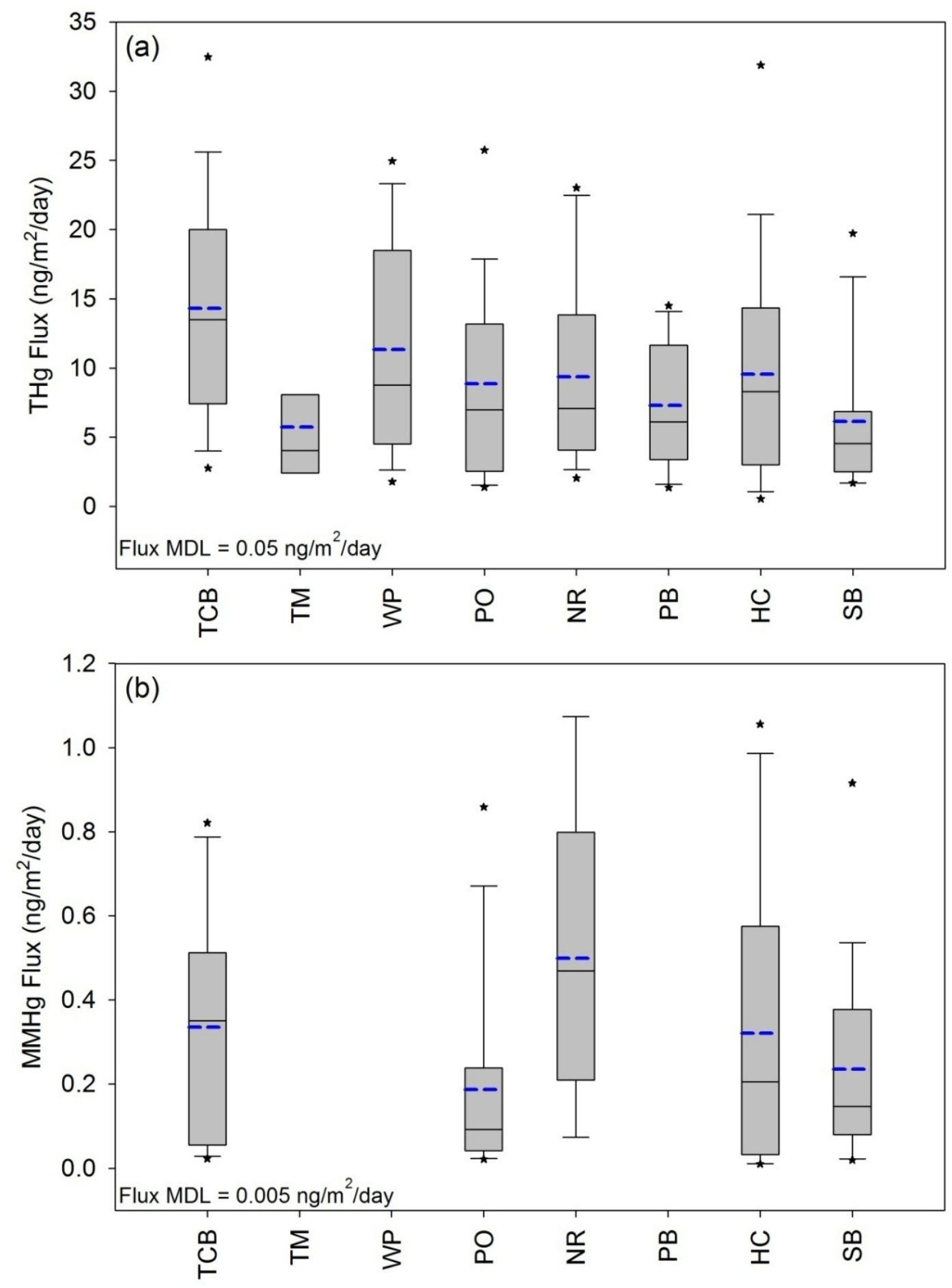

Figure 21. Mercury (a) and methylmercury (b) fluxes for the eight stations, if available. The box boundaries are the $25^{\text {th }}$ and $75^{\text {th }}$ percentile, with the median in the box, dashed blue line is the mean, whiskers are the 10th and 90th percentiles, and the asterisks are outliers.

Along with spatial variability, temporal variability was evaluated. The THg fluxes, and to a lesser degree $\mathrm{MMHg}$, were a significant function of cumulative precipitation for all stations $(p<$ 
$0.03)$ except PB $(p=0.502)$. Since the season for this study was defined by precipitation patterns, the daily fluxes were divided into wet season events (May-September) and dry season events (October-April), and the descriptive statistics were recalculated to allow the determination of seasonal fluxes (Table 14).

Table 14. Descriptive statistics for the daily fluxes of total mercury ( $\mathrm{THg})$ at each station during both the wet and dry season.

\begin{tabular}{|l|c|c|c|c|}
\hline \multicolumn{1}{|c|}{ Station } & $\mathbf{N}$ & \multicolumn{3}{c|}{ Daily Fluxes $\left(\mathbf{n g} / \mathbf{m}^{2} / \mathbf{d}\right)$} \\
\hline \multicolumn{5}{|c|}{ THg Wet } \\
\hline HC & 19 & 10 & 3.4 & 15 \\
\hline NR & 19 & 11 & 5.0 & 14 \\
\hline PB & 18 & 5.7 & 3.4 & 8.1 \\
\hline PO & 19 & 11 & 6.6 & 14 \\
\hline SB & 19 & 6.0 & 4.6 & 6.8 \\
\hline TCB & 19 & 13 & 10 & 21 \\
\hline WP & 19 & 10 & 3.6 & 18 \\
\hline \multicolumn{5}{|c|}{ THg Dry } \\
\hline HC & 19 & 7.2 & 2.4 & 13 \\
\hline NR & 19 & 5.7 & 4.3 & 12 \\
\hline PB & 18 & 10 & 3.5 & 13 \\
\hline PO & 19 & 5.4 & 2.1 & 13 \\
\hline SB & 19 & 3.8 & 2.4 & 4.3 \\
\hline TCB+TM & 19 & 5.8 & 4.0 & 18 \\
\hline WP & 19 & 7.9 & 4.8 & 18 \\
\hline
\end{tabular}

The THg concentrations and then the fluxes illustrate a typical washout effect during the wet season, as is well documented in many other studies (e.g., Hall et al. 2005). A similar washout effect for MMHg has not been observed by this study or other studies (Conaway et al. 2010). The linear regression of THg fluxes and total precipitation collected during each sampling event yielded no significant difference between the slopes for all stations $(p=0.44$; Figure 22$)$.

However, TCB had a significantly different intercept $(p=0.01)$ from all other stations, which were indistinguishable from each other $(p=0.98)$. The linear model for TCB THg flux (black line) was defined as:

TCB Model: Flux $\left(\mathrm{ng} / \mathrm{m}^{2} / \mathrm{d}\right)=8.79+5.564 *$ Cumulative Precipitation (inches) and the model for all other stations (blue line) was defined as:

All Others: Flux $\left(\mathrm{ng} / \mathrm{m}^{2} / \mathrm{d}\right)=3.29+5.564 *$ Cumulative Precipitation (inches) 
Using these two models, most stations show a good fit with $\mathrm{r}^{2}$ values ranging from 0.43 to 0.90 , with the exception of the PB station, which had a lack of fit. The lack of fit for PB may be driven by the deposition of small black particles noted in one of the events. A Q-test determined the event was an outlier, and it was removed from the data set. The concentration of $\mathrm{THg}$ measured in that event was $149 \mathrm{ng} / \mathrm{L}$ and suggests there may be variable, localized sources of $\mathrm{Hg}$ in this area that are not representative of the other sampling locations. The fact that all other stations fit into the two models suggests there are regional influences on the bulk deposition fluxes that were not found to be significant in the ANOVA test discussed above. Therefore, the models present a method for estimating fluxes to a wide range of LULC classification, but additional data are required to fully understand the PB sources.

The bulk deposition collection methods used in this study may underestimate the dry deposition flux as discussed above. Using these two models, the dry deposition would thus be defined as the y-intercept. The TCB model would thus produce a dry deposition flux that is three times higher than all other stations. This suggests a localized source may provide a relatively constant dry deposition to the Tacoma region, and there is an additive scavenging flux occurring as wet deposition during precipitation events.

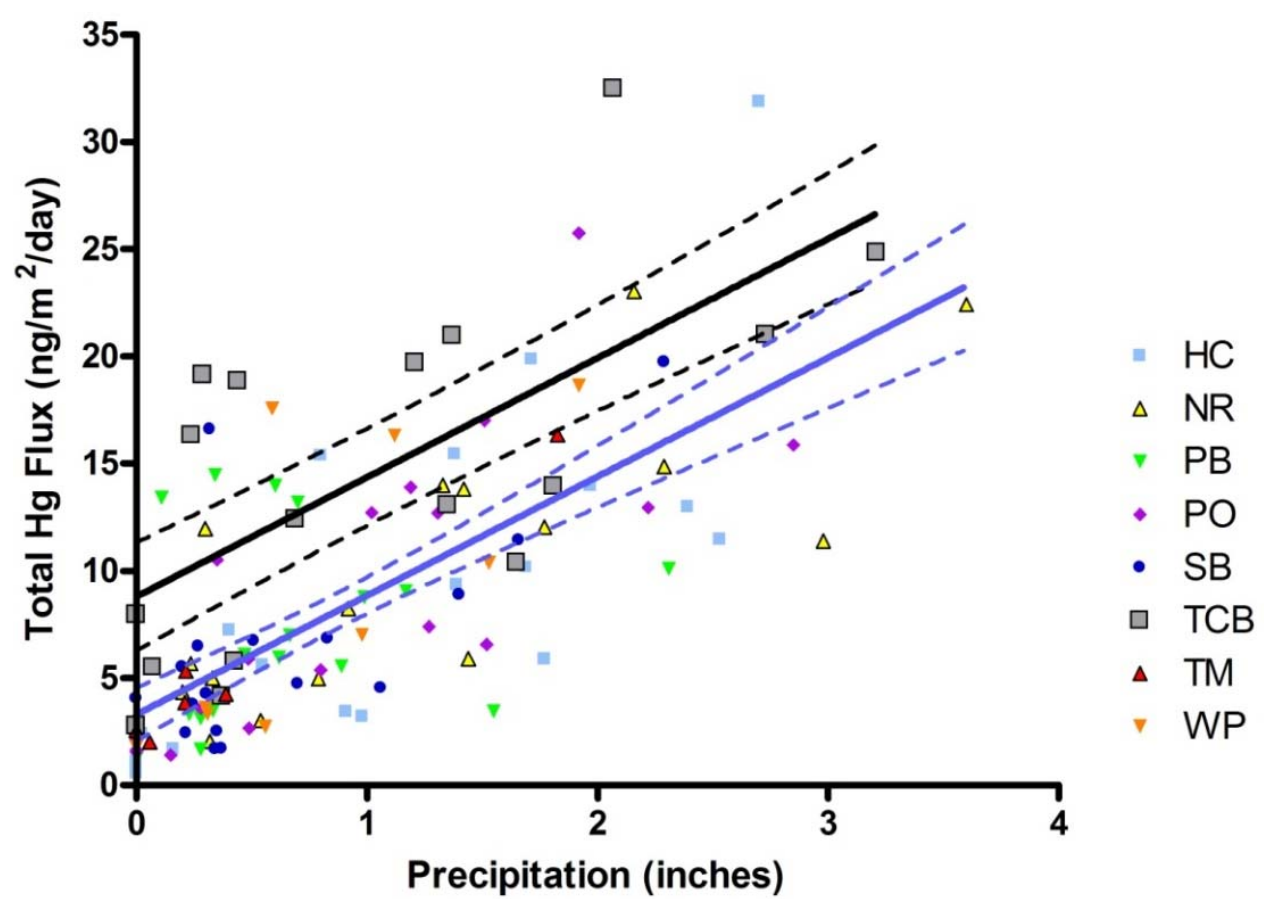

Figure 22. The solid lines are the linear regression models with dashed $95^{\text {th }}$ percentile confidence intervals for total mercury fluxes $\left(\mathrm{ng} / \mathrm{m}^{2} / \mathrm{d}\right.$ ) and cumulative precipitation during each sampling. The black lines are the linear regressions for TCB and the blue lines are linear repressions for all other stations.

The wet depositional flux is a function of both the concentration of chemicals in the raindrops and the precipitation amount. Toxics emitted from a source as small (sub-micron) particles or gases are easily removed from the atmosphere during rain events. As the particle 
sizes become larger, the deposition tends to be more continuous and less dependent on rain events, which allows the dry deposition to become a more significant portion of the total atmospheric deposition (Baker 1997). The relationship between cumulative precipitation and $\mathrm{THg}$ fluxes (Figure 22) contrast nicely with $\mathrm{Pb}$, which shows no dependence to precipitation but rather and more likely, a proximity to sources (Figure 23). This illustrates the difference between toxics that are heavily dependent on wet deposition in Puget Sound compared to those such as $\mathrm{Pb}$ (and $\mathrm{Cu}$, see correlations above), which are likely emitted from sources as larger particles that do not travel long distances from their sources (as seen in the TCB and TM comparison above). The atmospheric chemistry for $\mathrm{Hg}$ is complex and generally well studied (see review by Sprovieri et al. 2010). The anthropogenic sources of THg are often emitted to the atmosphere in these three forms: elemental $\mathrm{Hg}$, reactive gaseous $\mathrm{Hg}$, and particulate $\mathrm{Hg}$. Seigneur et al. (2004) showed that an increase in atmospheric THg fluxes in urban regions is primarily the result of local/regional source deposition and not long-range transport. The THg fluxes in the PNW appear to be a combination of both longer range regional sources and more localized sources in the industrial region of Tacoma.

The MDN maintains an atmospheric deposition monitoring station in the urban areas of Seattle, which reported an average annual wet deposition flux of $19 \mathrm{ng} / \mathrm{m}^{2} / \mathrm{d}$ in 2008 (see a review by Lamb and Van Bowersox 2000; see http://nadp.sws.uiuc.edu/MDN/mdndata.aspx for annual data access). This was similar to the median reported for TCB of $14 \mathrm{ng} / \mathrm{m}^{2} / \mathrm{d}$ (interquartile range: $8.0-20 \mathrm{ng} / \mathrm{m}^{2} / \mathrm{d}$ ), but higher than the median fluxes reported at WP $8.8 \mathrm{ng} / \mathrm{m}^{2} / \mathrm{d}$ (interquartile range: $4.8-18 \mathrm{ng} / \mathrm{m}^{2} / \mathrm{d}$ ). Since the MDN station is located within the urban watersheds of Seattle, this again supports the need to understand the regional variability of atmospheric deposition of $\mathrm{Hg}$ to the watersheds. The deposition of $\mathrm{Hg}$ to the surface of Puget Sound appears relatively uniform, except where industrial areas extend to the shoreline.

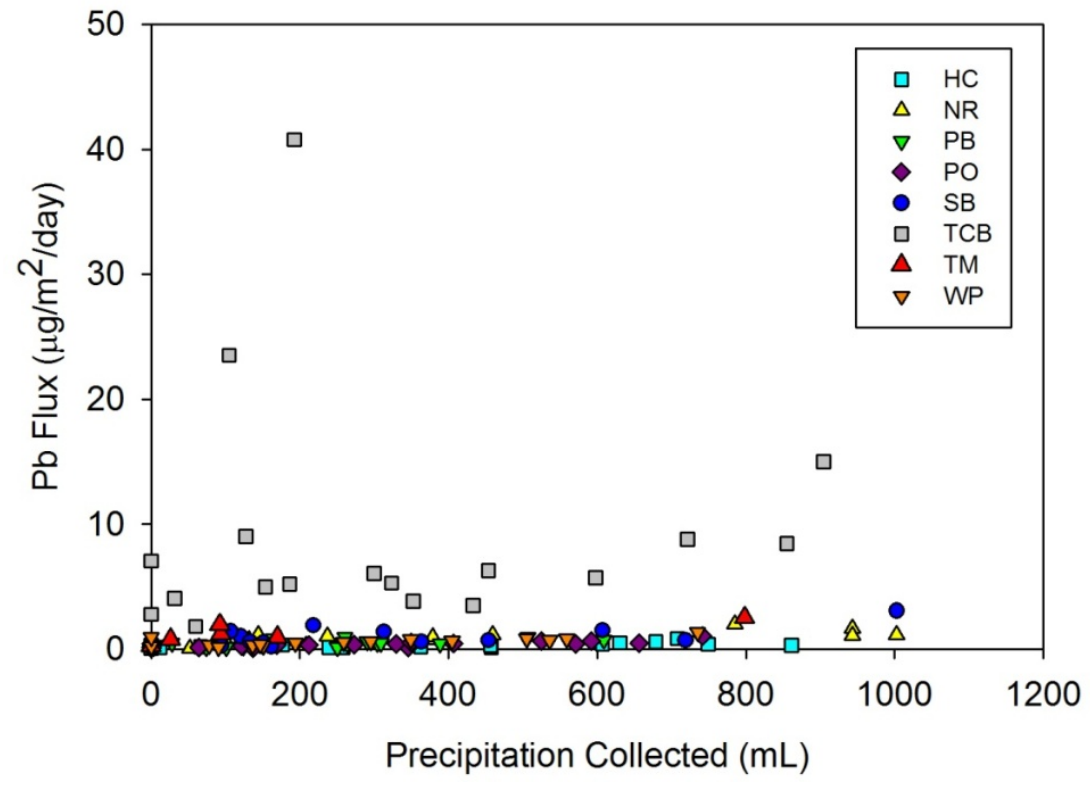

Figure 23. The total $\mathrm{Pb}$ atmospheric deposition fluxes $\left(\mu \mathrm{g} / \mathrm{m}^{2} /\right.$ day $)$ relative to the cumulative precipitation measured during each event for each station. 


\section{Mass Loading of Air Toxics}

\section{Annual Mass Loading Scenarios}

The daily fluxes measured in this study were used to estimate the annual mass loading of CPAH and pyro-PAHs, total PBDEs, trace elements, and mercury. Daily fluxes were calculated from sample-derived data. The daily fluxes were then extrapolated to represent an annual load using three different scenarios that test the sensitivity of the data set to surface area of Puget Sound, season, and spatial data collected. The data set collected has a statistically defined dry season identified as sampling conducted in May, July, August, and September and wet season October, November, February, March, and April. The statistical difference between the wet and dry season was representative of the precipitation patterns in the PNW (as discussed above). To calculate an annual load to Puget Sound based on only one year of data, the assumption that the months not sampled are represented in the sampled data sets is valid. The annual mass loading to the waters of Puget Sound via atmospheric deposition were thus calculated using three separate scenarios to test the sensitivity of the mass loads to the spatial and temporal variability within the data sets for each chemical of concern. Annual atmospheric loads were calculated using the following equation:

Mass $\operatorname{Load}_{\mathrm{i}}\left(\frac{\mathrm{Kg}}{\mathrm{yr}}\right)=\sum_{\mathrm{x}}$ Daily Flux $\left(\frac{\mu \mathrm{g}}{\mathrm{m}^{2} * \mathrm{~d}}\right) \times \frac{\mathrm{d}}{\mathrm{yr}} \times S A\left(K m^{2}\right) \times 0.001$

Where the annual mass load for parameter $i$ is defined as the sum of the individual products for scenario $x$, which is the product of the daily flux, the number of days per year, the surface area of the water, and a constant unit conversion factor. The three scenarios discussed below will vary the spatial and temporal resolution of the daily fluxes and the spatial resolution of the surface area.

\section{Scenario 1}

The first scenario used the median, $25^{\text {th }}$, and $75^{\text {th }}$ percentile daily fluxes of all stations and seasons and the total surface area of the waters of Puget Sound as defined by Pelletier and Mohamedali (2009) for Ecology's Phase 2: Development of Simple Numerical Models. The surface area calculations are derived from the 1992 Puget Sound Atlas Geographic Information System (GIS) Database as referenced by Pelletier and Mohamedali (2009). The surface area used to represent the waters of Puget Sound included the portions of the Straits of Juan de Fuca and Straits of Georgia located within the United States border (see highlighted regions in Figure 1). The total surface area was $7285 \mathrm{Km}^{2}$ (provided by G. Pelletier personal communication, 2009) and was $15 \%$ smaller than the $8530 \mathrm{Km}^{2}$ used by Hart Crowser, Inc. 
(2007). To remain consistent with Ecology's loading studies, the total surface area of $7285 \mathrm{Km}^{2}$ was used and GIS files were provided by Pelletier (personal communication 2009).

\section{Scenario 2}

The second scenario spatially delineates the Puget Sound surface area and daily fluxes determined in this study into the Puget Sound boxes created for circulation models by Babson et al. (2006) and further refined into 11 boxes to delineate the urban bays (Pelletier and Mohamedali 2009). These studies segregated the surface area into the following boxes: South Sound, Main basin, North Hood Canal, South Hood Canal, Whidbey, The Tacoma Narrows, Elliott Bay, Sinclair/Dyes Inlet, Commencement Bay, Admiralty Inlet, and the Straits of Juan de Fuca and Georgia. Figure 1 illustrates the delineated boxes and the locations of the atmospheric deposition flux stations. Generally there is a flux station located in each of the boxes with the exception of Admiralty Inlet, Whidbey Basin, South Hood Canal, Elliott Bay, and The Tacoma Narrows. The SB station was not used for the loading calculations due to the potential for anomalous fluxes resulting from localized sand deposition (discussed above). Based on the cluster analyses for the stations, the PB and $\mathrm{HC}$ stations were pooled to represent the Straits of Juan de Fuca and Georgia and Admiralty Inlet boxes as PB compared to SB and HC provided an additional rural/low residential landscape station. The PB station was used to represent the Whidbey Basin, and the urban/industrial TCB station was used to represent the Elliott Bay box. Finally, TCB and TM (only for Scenario 3 Dry Season) were used to present The Tacoma Narrows Box. Table 15 provides the surface areas and flux stations used for each of the loading scenarios. 
Table 15. The atmospheric flux stations and surfaces areas of the waters of Puget Sound used to calculate annual mass loads for each chemical of concern using the three scenarios to delineate the data based on spatial and temporal factors.

\begin{tabular}{|c|c|c|c|c|c|c|c|c|}
\hline \multirow[b]{2}{*}{ Region } & \multicolumn{2}{|c|}{ Scenario 1} & \multicolumn{2}{|c|}{ Scenario 2} & \multicolumn{2}{|c|}{ Scenario 3 Wet } & \multicolumn{2}{|c|}{ Scenario 3 Dry } \\
\hline & $\begin{array}{c}\text { Flux } \\
\text { Station }\end{array}$ & $\begin{array}{c}\text { Surface } \\
\text { Area }^{1} \\
\left(\mathrm{Km}^{2}\right)\end{array}$ & $\begin{array}{c}\text { Flux } \\
\text { Station }\end{array}$ & $\begin{array}{c}\text { Surface } \\
\text { Area }^{1} \\
\left(\mathrm{Km}^{2}\right)\end{array}$ & $\begin{array}{l}\text { Flux } \\
\text { Station }\end{array}$ & $\begin{array}{c}\text { Surface } \\
\text { Area }^{1} \\
\left(\mathrm{Km}^{2}\right)\end{array}$ & $\begin{array}{l}\text { Flux } \\
\text { Station }\end{array}$ & $\begin{array}{c}\text { Surface } \\
\text { Area }^{1} \\
\left(\mathrm{Km}^{2}\right)\end{array}$ \\
\hline South Sound & \multirow{11}{*}{$\begin{array}{c}\text { Median } \\
\text { HC, } \\
\text { NR, } \\
\text { WP, } \\
\text { PO, } \\
\text { TCB }\end{array}$} & \multirow{11}{*}{7285} & NR & 424.7 & NR & 424.7 & NR & 424.7 \\
\hline Main Basin & & & $\begin{array}{l}\text { WP, } \\
\text { PO }\end{array}$ & 585.0 & WP, PO & 585.0 & WP, PO & 585.0 \\
\hline $\begin{array}{l}\text { North Hood } \\
\text { Canal }\end{array}$ & & & $\mathrm{HC}$ & 138.6 & $\mathrm{HC}$ & 138.6 & $\mathrm{HC}$ & 138.6 \\
\hline $\begin{array}{l}\text { South Hood } \\
\text { Canal }\end{array}$ & & & $\mathrm{HC}$ & 243.3 & $\mathrm{HC}$ & 243.3 & $\mathrm{HC}$ & 243.3 \\
\hline Whidbey Basin & & & $\mathrm{PB}$ & 615.5 & $\mathrm{~PB}$ & 615.5 & $\mathrm{~PB}$ & 615.5 \\
\hline The Narrows & & & TCB & 12.9 & TCB & 12.9 & $\begin{array}{c}\text { TCB, } \\
\text { TM }\end{array}$ & 12.9 \\
\hline Elliott Bay & & & ТСВ & 20.9 & TCB & 20.9 & $\begin{array}{l}\text { TCB, } \\
\text { TM }\end{array}$ & 20.9 \\
\hline $\begin{array}{l}\text { Sinclair/Dyes } \\
\text { Inlet }\end{array}$ & & & $\mathrm{PO}$ & 91.3 & $\mathrm{PO}$ & 91.3 & PO & 91.3 \\
\hline $\begin{array}{l}\text { Commencement } \\
\text { Bay }\end{array}$ & & & TCB & 20.7 & TCB & 20.7 & $\begin{array}{c}\text { TCB, } \\
\text { TM }\end{array}$ & 20.7 \\
\hline Admiralty Inlet & & & $\mathrm{HC}, \mathrm{PB}$ & 411.2 & $\mathrm{HC}, \mathrm{PB}$ & 411.2 & $\mathrm{HC}, \mathrm{PB}$ & 411.2 \\
\hline SJF/SOG & & & $\mathrm{HC}, \mathrm{PB}$ & 4720.8 & $\mathrm{HC}, \mathrm{PB}$ & 4720.8 & $\mathrm{HC}, \mathrm{PB}$ & 4720.8 \\
\hline
\end{tabular}

\section{Scenario 3}

The third scenario takes the spatial delineation in Scenario 2 and further divides the data into seasonal fluxes, as discussed above. As some of the chemicals of concern illustrated statistically significant differences between the seasonal fluxes and/or a relationship with the precipitation patterns, this provided a more detailed annual loading scenario. However, it should be noted that not all parameters had statistically different fluxes in the two seasons, and results would be similar to Scenario 2. The flux data were divided into October through April for the wet season (212 days) and May through September for the dry season (153 days). The precipitation patterns in the PNW do not generally provide for an extended period with no measurable precipitation compared to other studies in more arid regions. Therefore, the perception of a dry season should be approached with caution. Although statistically the precipitation collected during this study was significantly different between seasons $(\mathrm{p}<0.0001)$ and did not appear anomalous relative to the historical data of annual precipitation (Figure 2), there were significant rain events during the dry season. Figure 24 shows the overall distribution of cumulative precipitation during the two seasons with the mean of both seasons expressed as the y-axis reference line. The diamonds then illustrated the mean and confidence intervals when the data were divided into the two seasons. This shows there were statistically different distribution medians for the two seasons, but there was overlap of some events between the two seasons. 


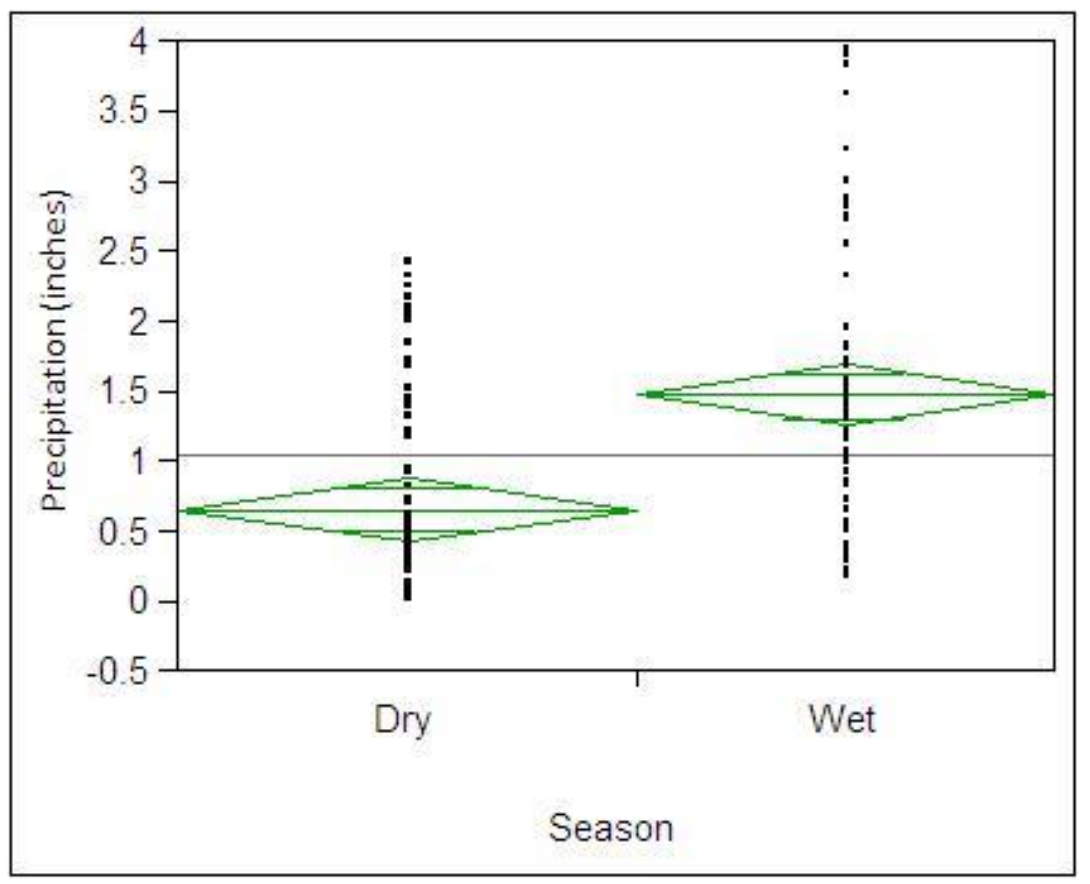

Figure 24. The seasonal distribution of the cumulative precipitation (inches) measured at or near the stations during each of the 2008/2009 two-week integrated sampling events. The $y$-axis reference line is the mean of all data. The lines within the diamonds represent the mean and $95 \%$ confidence intervals for the each season.

\section{Mass Loading Estimates for PAHs}

Estimates of atmospheric loadings were calculated for both carcinogenic and pyrogenic PAHs. These loadings are comparable to those presented in the Phase 1 report (Hart Crowser, Inc. 2007) since they include the same sum of PAHs. However, the surface area used for Puget Sound in the Phase 1 report was $8530 \mathrm{Km}^{2}$ and a little larger than the $7286 \mathrm{Km}^{2}$ used here, as discussed above. Therefore, at least $\sim 15 \%$ of any decrease in the total atmospheric loads calculated can be ascribed to this change in surface area. To evaluate the influence of direct airsea deposition on the total PAH loadings to the Puget Sound, we also present the PAH loading estimates derived from surface runoff as revised and presented in the Phase 2 Report Amendment (Herrera Environmental Consultants, Inc. 2010). The results from all three scenarios are presented in graphical and tabular form in Figure 25 and Table 16, respectively. Despite the high level of spatial and temporal detail included in Scenarios 2 and 3, all three models give strikingly similar results and suggest that the atmospheric loadings of PAHs to the Puget Sound are relatively uniform throughout the basin. Indeed, except for the highly industrial station in Tacoma, we observed no significant spatial or temporal difference in median fluxes across all other stations (see Figures 8 and 9).

The present loading estimates, derived from over a year's worth of biweekly sampling, are close to two orders of magnitude lower than prior estimates (Figure 25). These latter estimates (Hart Crowser, Inc. 2007) were determined from a series of deposition data, which included 
several stations in Tacoma sampled in 1989 and 1990 (Crecelius 1991; EPA 1991). Present data from the industrial station of Tacoma (TCB) have already shown that depositional fluxes of PAHs have decreased at least one order of magnitude in the last $\sim 20$ years, so the substantial drop in atmospheric loadings can be explained initially by the availability of newer flux estimates than those used in the Phase 1 report (i.e., CPAH: $1000 \mathrm{ng} / \mathrm{m}^{2} / \mathrm{d}$; interquartile range: 5000-100 ng/ $\mathrm{m}^{2} / \mathrm{d}$; Hart Crowser, Inc. 2007). In addition, although the annual median depositional flux at TCB (CPAH: $240 \mathrm{ng} / \mathrm{m}^{2} / \mathrm{d}$; interquartile range: $278-125 \mathrm{ng} / \mathrm{m}^{2} / \mathrm{d}$ ) is within the lower range of the median flux used in the Phase 1 report, this area seems to have only a local influence on the overall depositional flux of the entire Puget Sound Basin (CPAH: $18 \mathrm{ng} / \mathrm{m}^{2} / \mathrm{d}$; interquartile range: $34-9 \mathrm{ng} / \mathrm{m}^{2} / \mathrm{d}$ ). Hence, the present study provides revised estimates of the atmospheric loadings of PAHs that are probably more consistent with conditions today and applicable to all the waters of Puget Sound.

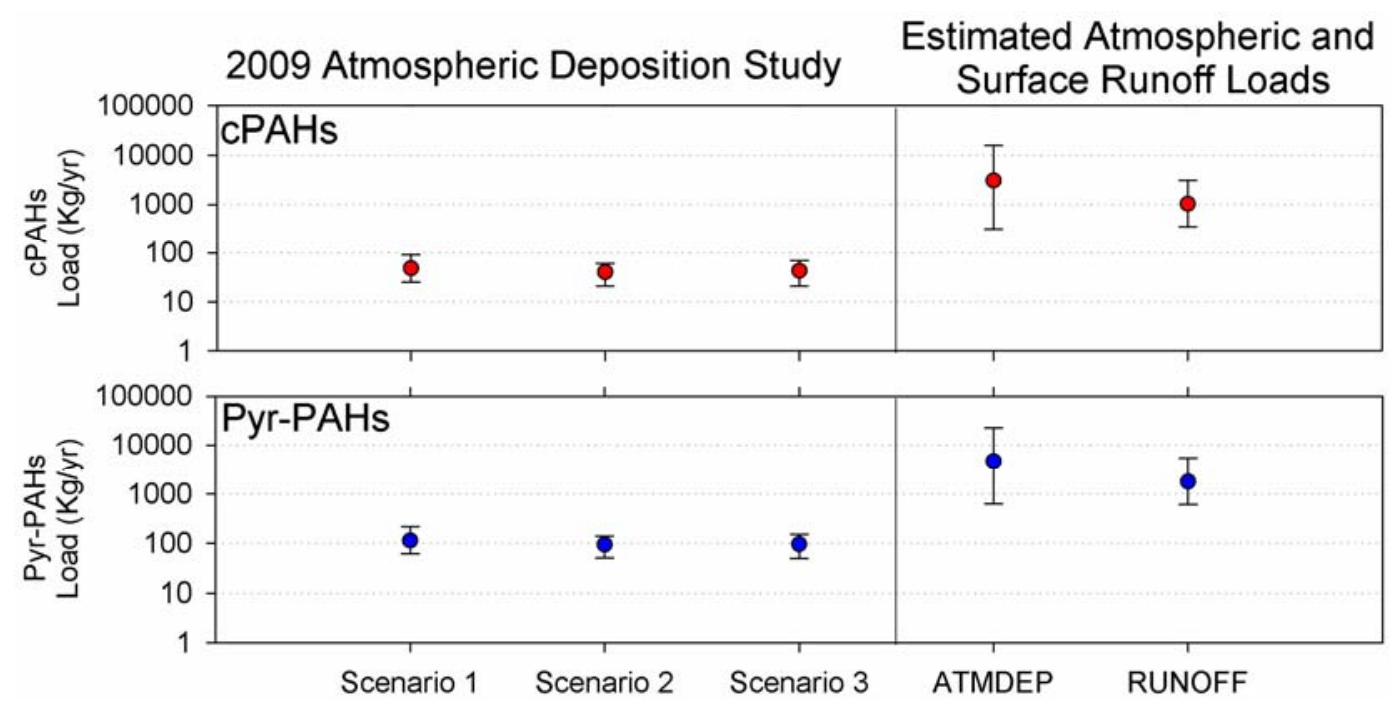

Figure 25. Estimates of atmospheric loadings for carcinogenic PAHs (CPAHs in top plot; $\mathrm{Kg} / \mathrm{yr}$ ) and pyrogenic PAHs (pyro-PAH in bottom plot; $\mathrm{Kg} / \mathrm{yr}$ ) to the surface of Puget Sound using three scenarios described above. The median, 25th, and 75th percentile atmospheric loading estimates are compared to 50th, 75th, and 25th probability of exceedance (POE) ranges for atmospheric (ATMDEP) and surface runoff (RUNOFF) loading estimates (Hart Crowser, Inc. 2007; Herrera Environmental Consulting, Inc. 2010, respectively). 
Table 16. Estimates of atmospheric loadings (Kg/yr) of carcinogenic and pyrogenic PAHs (CPAH and pyro-PAH, respectively) to the surface of the Puget Sound using three scenarios including no seasonal or spatial differentiation (Scenario 1), a spatial differentiation of sub-basins (Scenario 2), and spatiotemporal differentiation of fluxes in sub-basins (Scenario 3). The median, $25^{\text {th }}$, and $75^{\text {th }}$ percentile atmospheric loading estimates are compared to the $50^{\text {th }}$, $75^{\text {th }}$, and $25^{\text {th }}$ probability of exceedance ranges for atmospheric (ATMDEP) and surface runoff (RUNOFF) loading estimates (Hart Crowser, Inc. 2007; Herrera Environmental Consulting, Inc. 2010, respectively).

\begin{tabular}{|c|c|c|c|c|c|c|}
\hline & Scenario 1 & $\begin{array}{c}\text { Scenario } \\
2 \\
\end{array}$ & $\begin{array}{c}\text { Scenario } \\
3 \\
\end{array}$ & POE & ATMDEP & RUNOFF \\
\hline \multicolumn{7}{|c|}{ СРАН (Kg/yr) } \\
\hline Median & 48.1 & 40.2 & 43.2 & 50 & 3100 & 1030 \\
\hline 25th & 25.1 & 20.5 & 20.8 & 75 & 310 & 3100 \\
\hline 75th & 90.7 & 60.6 & 69.8 & 25 & 16000 & 352 \\
\hline \multicolumn{7}{|c|}{ Pyro-PAH (Kg/yr) } \\
\hline Median & 113 & 94 & 95.8 & 50 & 4700 & 1775 \\
\hline 25th & 60.9 & 49.6 & 48.8 & 75 & 620 & 5390 \\
\hline 75th & 217 & 140 & 153 & 25 & 22200 & 601 \\
\hline
\end{tabular}

\section{Mass Loading Estimates for PBDEs}

Atmospheric PBDE loadings to the Puget Sound Basin were estimated via three scenarios and compared to the probability of exceedence estimates for atmospheric and surface runoff loadings reported by Hart Crowser, Inc. (2007) and Herrera Environmental Consultants, Inc. (2010), respectively. The results are shown in Figure 26 and Table 17. Similar to the atmospheric PAH loadings, the atmospheric PBDE loadings from the three scenarios are statistically undistinguishable (median values $=15.6-20.3 \mathrm{Kg} / \mathrm{yr}$ ). This is not surprising since the total PBDE fluxes are relatively uniform across most of the stations, except for TCB (Figure 14).

In contrast to the PAH loadings, however, the estimated median atmospheric PBDE loadings in the present study are from two to three times higher than the $50^{\text {th }}$ probability of exceedence (POE) estimate reported by Hart Crowser, Inc. (2007) in the Phase 1 report and more than an order of magnitude higher than the revised estimated surface runoff loadings (Herrera Environmental Consultants, Inc. 2010). Approximately 14\% of the difference would be accounted for in the different surface areas used by the two studies. However, it should be noted that the PBDE fluxes reported herein may be considered underestimated by around 18-56\%, particularly for BDE-209, which comprises a majority of the total PBDE flux. A higher atmospheric deposition flux would thus suggest that deposition of PBDEs onto the waters of Puget Sound may be a more significant portion of the total load of PBDEs than the watershed runoff portion. 
The data used to derive the PBDE surface runoff loads were primarily based on research focused on PBDEs in Washington rivers and lakes (Ecology 2006). In that report, the PBDEs in the water column were sampled by using semipermeable membrane devices (SPMDs). However, since BDE-209 cannot effectively equilibrate with SPMDs, it was undetectable in the water samples reported (Ecology 2006). Because BDE-209 is often found to be the dominant BDE congener in air, rain, waste streams, and sediment samples (Hayakawa et al. 2004; Ter Schure et al. 2004; Moon et al. 2007; Qiu et al. 2007; Vives et al. 2007; Mariani et al. 2008; Petreas and Oros 2009), failure to sample this BDE congener would result in the underestimation of the total PBDE flux in the surface runoff. Therefore, additional data are warranted for a better estimation of the surface runoff loadings and atmospheric deposition loads. Nevertheless, it is worth noting that the estimated atmospheric PBDE loadings in the Puget Sound Basin derived from this study are very similar to the recently reported value for the Strait of Georgia (17.1 $\pm 6.5 \mathrm{Kg} / \mathrm{yr}$; Noël et al. 2009). Considering the similar surface area of Puget Sound and the Strait of Georgia (7285 and $8900 \mathrm{~km}^{2}$, respectively), the overall fluxes of atmospheric deposition on these two vicinal water bodies are also similar. Since both basins have similar proportions of urban and rural areas, information from the Strait of Georgia suggests a regional consistency in PBDE atmospheric deposition fluxes in the PNW.

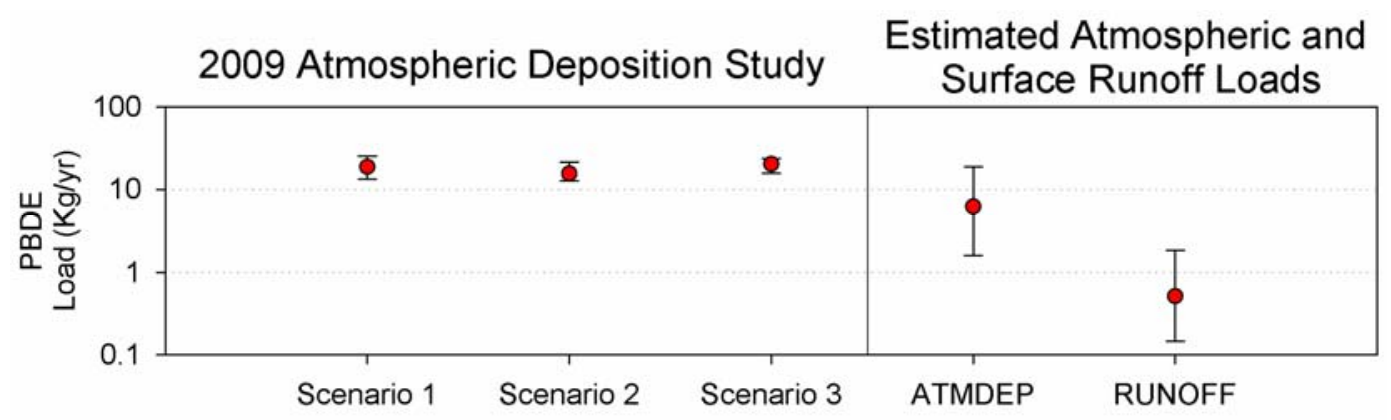

Figure 26. Estimates of atmospheric loadings of PBDEs $(\mathrm{Kg} / \mathrm{yr})$ to the surface of Puget Sound using three scenarios described above. The median, 25th, and 75th percentile atmospheric loading estimates are compared to 50th, 75th, and 25th probability of exceedance (POE) ranges for atmospheric (ATMDEP) and surface runoff (RUNOFF) loading estimates (Hart Crowser, Inc. 2007; Herrera Environmental Consulting, Inc. 2010, respectively). 
Table 17. Estimates of atmospheric loadings (Kg/yr) of total PBDE to the surface of the Puget Sound using three scenarios including no seasonal or spatial differentiation (Scenario 1), a spatial differentiation of sub-basins (Scenario 2), and spatiotemporal differentiation of fluxes in subbasins (Scenario 3). The atmospheric loading estimates are compared to $25^{\text {th }}, 50^{\text {th }}$, and $75^{\text {th }}$ probability of exceedance (POE) ranges for atmospheric (ATMDEP) and surface runoff (RUNOFF) loading estimates (Hart Crowser, Inc. 2007; Herrera Environmental Consultants, Inc. 2010, respectively).

\begin{tabular}{|c|ccc|c|ccc|}
\cline { 2 - 4 } \multicolumn{1}{c|}{} & $\begin{array}{c}\text { Scenario } \\
1\end{array}$ & $\begin{array}{c}\text { Scenario } \\
2\end{array}$ & $\begin{array}{c}\text { Scenario } \\
3\end{array}$ & POE & ATMDEP & RUNOFF \\
\hline \multicolumn{7}{c}{ Total PBDE (Kg/yr) } \\
\hline Median & 18.8 & 15.6 & 20.3 & $\mathbf{5 0}$ & $\mathbf{6 . 2}$ & $\mathbf{0 . 5 1 6}$ \\
25th & 13.3 & 12.7 & 15.7 & $\mathbf{7 5}$ & $\mathbf{1 . 6}$ & $\mathbf{0 . 1 4 6}$ \\
75th & 25.5 & 21.4 & 23.8 & $\mathbf{2 5}$ & $\mathbf{1 9}$ & $\mathbf{1 . 8 6}$ \\
\hline
\end{tabular}

\section{Mass Loading Estimates for Trace Elements and Mercury}

The annual mass loads for trace elements and $\mathrm{THg}$ were determined for the three scenarios discussed above. These annual mass loading estimates for atmospheric deposition were then compared to those calculated in 2007 using best available literature values (Hart Crowser, Inc. 2007). In most cases, the regional data available were over ten years old and would not reflect recent reductions in source emission around Puget Sound. The results from all three scenarios along with the POE atmospheric deposition loads (Hart Crowser, Inc. 2007) and surface runoff loads (Herrera Environmental Consultants, Inc. 2010) are presented in graphical and tabular form in Figure 27 and Table 18, respectively. When using the median of the data sets, the three scenarios provide similar results suggesting the influence of the high fluxes measured at TCB are localized when comparing the loads to the entire surface of Puget Sound. In fact, the most sensitive variable was the surface area calculations and fluxes applied to the Straits as they are the largest surface areas in the spatially delineated model.

The revised atmospheric loading estimates for the trace elements were all lower than prior estimates by a factor of $8,32,10,25$, and 3 for $\mathrm{As}, \mathrm{Cd}, \mathrm{Cu}, \mathrm{Pb}$, and $\mathrm{Zn}$, respectively. $\mathrm{The} \mathrm{THg}$ loads were not significantly different from the original estimates. For all metals except THg, the original estimates (Hart Crowser, Inc. 2007) were heavily dependent on data from EPA (1991), which represented the industrial/urban area of Commencement Bay sampled from 1989-1990. As was seen in our comparison of the TCB and TM stations, the high fluxes of TCB were localized and not representative of the surface waters of Puget Sound as a whole. To evaluate reductions through time in atmospheric deposition loads, only the TCB region was directly comparable to previously sampled fluxes (except $\mathrm{THg}$ ). The fluxes in this region have declined significantly since the 1990s (except THg). Therefore, the present study provides revised estimates of the atmospheric loadings of trace elements that are probably more consistent with conditions today and more representative of atmospheric fluxes providing a load of these toxics to the waters of Puget Sound. 


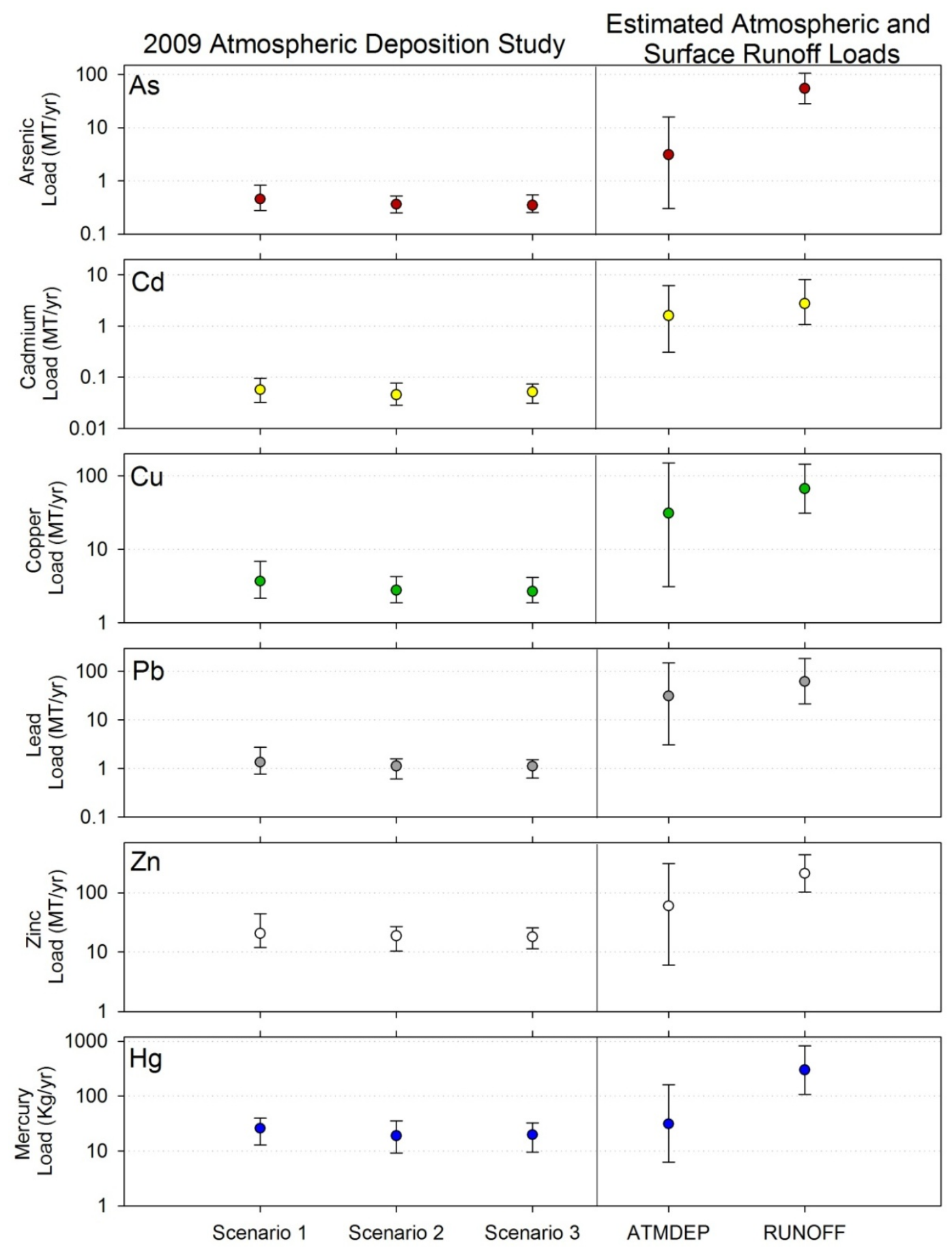

Figure 27. The annual atmospheric deposition loads for $\mathrm{As}, \mathrm{Cd}, \mathrm{Cu}, \mathrm{Pb}$, and $\mathrm{Zn}(\mathrm{MT} / \mathrm{yr})$ and THg $(\mathrm{Kg} / \mathrm{yr})$ are calculated for this study using the three scenarios discussed above. The median, $25^{\text {th }}$, and $75^{\text {th }}$ percentile loads are compared to the $50^{\text {th }}, 75^{\text {th }}$, and $25^{\text {th }}$ probability of exceedance ranges for atmospheric (ATMDEP) and surface runoff (RUNOFF) loading estimates (Hart Crowser, Inc. 2007; Herrera Environmental Consulting, Inc. 2010, respectively). 
Table 18. Estimates of atmospheric loadings for trace elements and mercury to the surface of Puget Sound using three scenarios described above. The atmospheric loading estimates are compared to 25th, 50th, and 75th probability of exceedance (POE) ranges for atmospheric (ATMDEP) and surface runoff (RUNOFF) loading estimates, if available (Hart Crowser, Inc. 2007; Herrera Environmental Consulting, Inc. 2010).

\begin{tabular}{|c|c|c|c|c|c|c|}
\hline & Scenario 1 & Scenario 2 & Scenario 3 & POE & ATMDEP & RUNOFF \\
\hline \multicolumn{7}{|c|}{ Arsenic (MT/yr) } \\
\hline Median & 0.45 & 0.36 & 0.35 & 50 & 3.1 & 54.2 \\
\hline 25th & 0.28 & 0.25 & 0.25 & 75 & 0.3 & 28.1 \\
\hline 75th & 0.82 & 0.51 & 0.54 & 25 & 16 & 105 \\
\hline \multicolumn{7}{|c|}{ Cadmium (Kg/yr) } \\
\hline Median & 57 & 45 & 52 & 50 & 1600 & 2740 \\
\hline 25th & 32 & 28 & 31 & 75 & 310 & 1080 \\
\hline 75th & 96 & 76 & 74 & 25 & 6200 & 8160 \\
\hline \multicolumn{7}{|c|}{ Chromium (MT/yr) } \\
\hline Median & 1.1 & 0.97 & 0.92 & & & \\
\hline 25th & 0.54 & 0.47 & 0.5 & & & \\
\hline 75th & 2 & 1.4 & 1.4 & & & \\
\hline \multicolumn{7}{|c|}{ Copper (MT/yr) } \\
\hline Median & 3.7 & 2.8 & 2.7 & 50 & 31 & 66.8 \\
\hline 25th & 2.2 & 1.9 & 1.9 & 75 & 3.1 & 31.1 \\
\hline 75th & 6.8 & 4.2 & 4.1 & 25 & 150 & 144 \\
\hline \multicolumn{7}{|c|}{ Lead (MT/yr) } \\
\hline Median & 1.3 & 1.3 & 1.1 & 50 & 31 & 61.6 \\
\hline 25th & 0.77 & 0.77 & 0.63 & 75 & 3.1 & 21.3 \\
\hline 75th & 2.8 & 2.8 & 1.5 & 25 & 150 & 184 \\
\hline \multicolumn{7}{|c|}{ Nickel (MT/yr) } \\
\hline Median & 1.8 & 1.3 & 1.2 & & & \\
\hline 25th & 0.96 & 0.8 & 0.84 & & & \\
\hline 75th & 4 & 2.2 & 2.4 & & & \\
\hline \multicolumn{7}{|c|}{ Zinc (MT/yr) } \\
\hline Median & 21 & 19 & 18 & 50 & 60 & 211 \\
\hline 25th & 12 & 10 & 11 & 75 & 6 & 102 \\
\hline 75th & 44 & 27 & 26 & 25 & 310 & 439 \\
\hline \multicolumn{7}{|c|}{ Mercury (Kg/yr) } \\
\hline Median & 26 & 19 & 20 & 50 & 31 & 299 \\
\hline 25th & 13 & 9.2 & 9.4 & 75 & 6.2 & 108 \\
\hline 75th & 39 & 36 & 33 & 25 & 160 & 829 \\
\hline
\end{tabular}




\section{Watershed versus Atmospheric Fluxes}

We tested the potential validity of presented atmospheric mass loadings using two approaches. First, we compared the atmospheric fluxes measured in the Hood Canal and Main Basin to sedimentary fluxes measured in previously dated sediment cores from these same basins (Kuo et al. 2010b; Brandenberger et al. 2008a; b). The premise is that the atmospheric loading estimates would be validated if the relationship between atmospheric and sedimentary fluxes is consistent with that reported between the atmospheric and surface runoff loadings. Secondly, we compared surface runoff loadings in the Main Basin and Hood Canal with those derived from sedimentary fluxes in those two basins.

The compilation of sedimentary fluxes of PAHs and selected particle reactive trace metals for the two cores in each of Hood Canal and Main Basin are presented in Table 19 along with median atmospheric fluxes for deposition stations in those basins (Hood Canal = HC; Puget Sound Main Basin = PO, WP, and TCB). At all stations, the atmospheric deposition corresponds to $1-5 \%$ of the sedimentary fluxes, which is similar to the ratio (0-5\%) determined using the revised atmospheric loadings from the Phase 1 report and revised surface runoff loadings from Herrera Environmental Consultants, Inc. (2010) (Scenario 1-3 vs. Surface Runoff, respectively; Tables 19 and 20). This suggests that the route of entry of contaminant to the Puget Sound is predominantly through surface runoffs rather than direct air-sea deposition inputs (except potentially PBDEs not analyzed in the sediment cores). In the second approach, we assumed that each sediment core was representative of sedimentary fluxes in the north and south sections of their respective basin. Another major assumption was that most long-term accumulation of contaminants occurred only in sediments in contact with the deep-water layers and not in shallow sedimentary systems. These assumptions are probably oversimplifications of the entire Puget Sound system, but the loadings comparison is meant only as a first-order comparison to test for major discrepancies (or lack thereof) between sedimentary vs. surface runoff loadings estimates. The premise is that differences of less than an order of magnitude between the two independent estimates would provide some level of consistency supporting the surface runoff estimates.

The results, presented in Table 19, show that loadings derived from sedimentary fluxes are 617 fold higher than surface runoff loading estimates for both carcinogenic PAHs and lead (two particle-reactive and relatively stable contaminants). The top $5 \mathrm{~cm}$ of sediments used for these calculations encompass from 10 to 15 years of past inputs to the systems. Hence, the current loading estimates from runoffs may naturally be lower because of substantial decreases in overall inputs during the same period. The one-order of magnitude decreases in atmospheric deposition observed in the Port of Tacoma for both CPAHs and metals (see discussion above) over the last $\sim 20$ years supports this explanation. However, more work would be required (e.g., sediment traps in different basins, transect of cores to compare water column fluxes to sediment-water accumulation fluxes, continuous sampling of surface runoffs) to confirm that such a difference is due to measurable declines in surface inputs rather than any other potential explanation (large- 
scale lateral transport of shallow water sediments to the deep sedimentation basins). In addition, this approach further confirms the predominant role of surface runoffs in the transfer of contaminants to the Puget Sound.

Table 19. Comparison of median annual atmospheric vs. sedimentary fluxes of PAHs and trace metals in two basins of Puget Sound: Main Basin and Hood Canal.

\begin{tabular}{|c|c|c|c|c|c|c|c|}
\hline & \multicolumn{4}{|c|}{ Main Basin } & \multicolumn{3}{|c|}{ Hood Canal } \\
\hline & \multirow{2}{*}{$\begin{array}{c}\text { Atmos. } \\
\text { TCB }\end{array}$} & \multirow{2}{*}{$\begin{array}{c}\text { Sedt } \\
\text { PS1 }\end{array}$} & \multirow{2}{*}{$\begin{array}{l}\text { Atmos. } \\
\text { WP-PO }\end{array}$} & \multirow{2}{*}{$\begin{array}{c}\text { Sedt. } \\
\text { PS4 }\end{array}$} & \multirow{2}{*}{$\begin{array}{c}\text { Atmos. } \\
\text { HC }\end{array}$} & \multicolumn{2}{|c|}{ Sedt. } \\
\hline & & & & & & $\mathrm{HC} 3$ & HC5 \\
\hline $\mathrm{CPAHs}^{\mathrm{a}}$ & 86.9 & 2169 & 9.5 & 10788 & 4.7 & 221 & 494 \\
\hline Pyr-PAHs ${ }^{a}$ & 213 & 4266 & 22.3 & 22944 & 10.1 & 536 & 1726 \\
\hline $\mathrm{Pb}^{\mathrm{b}}$ & 2.15 & 146 & 0.16 & 161 & 0.11 & 18.1 & 38.7 \\
\hline $\mathrm{Zn}^{\mathrm{b}}$ & 17.9 & 419 & 2.1 & 701 & 1.7 & 23.5 & 239 \\
\hline $\mathrm{Cu}^{\mathrm{b}}$ & 4.38 & 198 & 0.43 & 273 & 0.22 & 11.3 & 113 \\
\hline $\mathrm{Ni}^{\mathrm{b}}$ & 0.69 & 155 & 0.23 & 291 & 0.11 & 93.9 & 112 \\
\hline $\mathrm{Cr}^{\mathrm{b}}$ & 0.51 & 274 & 0.11 & 578 & 0.068 & 154 & 204 \\
\hline $\mathrm{Hg}^{\mathrm{a}}$ & 5.1 & 852 & 2.8 & 893 & 3.0 & 113 & 49.0 \\
\hline \multicolumn{8}{|c|}{${ }^{a}$ Fluxes in $\mu \mathrm{g} / \mathrm{m}^{2} / \mathrm{yr}$} \\
\hline & $\mathrm{m}^{2} / \mathrm{yr}$ & & & & & & \\
\hline
\end{tabular}

Table 20. Comparison of surface runoff loading and sedimentary loadings for carcinogenic PAHs (CPAHs) and lead $(\mathrm{Pb})$ in two basins of Puget Sound: Main Basin and Hood Canal.

\begin{tabular}{|c|c|c|c|c|}
\hline & N. Main Basin & S. Main Basin & $\begin{array}{l}\text { N. Hood } \\
\text { Canal }\end{array}$ & $\begin{array}{l}\text { S. Hood } \\
\text { Canal }\end{array}$ \\
\hline $\begin{array}{l}\text { Surface area of deep sediments } \\
\left(\mathrm{m}^{2}\right)^{1} \\
\text { Sediment Core } \mathrm{ID}^{2}\end{array}$ & $\begin{array}{c}1.9 \mathrm{E}+08 \\
\text { PS4 }\end{array}$ & $\begin{array}{c}1.7 \mathrm{E}+08 \\
\text { PS1 }\end{array}$ & $\begin{array}{c}\text { 1.1E+08 } \\
\text { HC5 }\end{array}$ & $\begin{array}{c}2.7 \mathrm{E}+08 \\
\mathrm{HC} 3\end{array}$ \\
\hline $\begin{array}{l}\text { CPAH Watershed Runoff Load } \\
(\mu \mathrm{g} / \mathrm{yr})^{3} \\
\text { CPAH Flux Sedts }\left(\mu \mathrm{g} / \mathrm{m}^{2} / \mathrm{yr}\right)^{2} \\
\text { CPAH Sedt Load }(\mu \mathrm{g} / \mathrm{yr})\end{array}$ & $\begin{array}{c}7.2 \mathrm{E}+10 \\
10788 \\
2.0 \mathrm{E}+12 \\
\end{array}$ & $\begin{array}{c}7.2 \mathrm{E}+10 \\
2169 \\
4.0 \mathrm{E}+11 \\
\end{array}$ & $\begin{array}{c}5.0 \mathrm{E}+9 \\
494 \\
5.5 \mathrm{E}+10 \\
\end{array}$ & $\begin{array}{c}4.3 \mathrm{E}+10 \\
221 \\
6.0 \mathrm{E}+10 \\
\end{array}$ \\
\hline Loading Ratio (Sedt/Runoff) & \multicolumn{2}{|c|}{$16.8 \pm 11.2$} & \multicolumn{2}{|c|}{$6.2 \pm 4.9$} \\
\hline $\begin{array}{l}\text { Pb Watershed Runoff Load } \\
(\mathrm{mg} / \mathrm{yr})^{3} \\
\mathrm{~Pb} \text { Flux Sedts }\left(\mathrm{mg} / \mathrm{m}^{2} / \mathrm{yr}\right) \\
\mathrm{Pb} \text { Sedt Load }(\mathrm{mg} / \mathrm{yr})\end{array}$ & $\begin{array}{c}3.8 \mathrm{E}+09 \\
161 \\
3.0 \mathrm{E}+10 \\
\end{array}$ & $\begin{array}{l}3.8 \mathrm{E}+09 \\
146 \\
2.7 \mathrm{E}+10\end{array}$ & $\begin{array}{c}3.3 \mathrm{E}+09 \\
38.7 \\
4.3 \mathrm{E}+09\end{array}$ & $\begin{array}{c}3.2 \mathrm{E}+09 \\
18.1 \\
4.9 \mathrm{E}+09\end{array}$ \\
\hline Loading Ratio (Sedt/Runoff) & \multicolumn{2}{|c|}{$7.5 \pm 0.4$} & \multicolumn{2}{|c|}{$7.3 \pm 5.8$} \\
\hline
\end{tabular}




\section{PAH Source Apportionment}

\section{Qualitative Reconstructions of Combustion Source Inputs}

PAHs in the environment can originate from diverse inputs including higher plants' microdebris, diagenetic alterations of organic matter, oil spills and coal fragments, industrial processes (i.e., smelters), and incomplete combustion by-products from the burning of diverse fuels (coal, fossil fuel, wood, and grass). In general, a high proportion of parent and high molecular weight PAHs is found in combustion residues such as soots and chars, whereas low molecular weight and alkylated homologues tend to predominate in unburned fossil fuels (coal and petroleum) and creosote (Boehm 2006). Because the composition pattern of PAHs is both source- and process-specific (Youngblood and Blumer 1975; Yunker et al. 2002; Boehm 2006), PAH diagnostic ratios have often been used in source identification in both atmospheric (Schauer et al. 1996; Simcik et al. 1999; Dickhut et al. 2000; Larsen and Baker 2003; Ding et al. 2007) and sediment studies (Yunker et al. 1996; 2002, 2003; Lima et al. 2003; Yan et al. 2005; Elmquist et al. 2007; Kuo et al. 2010b). For example, the ratio of methylphenanthrenes to phenanthrene (MP/P) has been shown to differentiate PAHs originating from combustion processes (pyrogenic: $\mathrm{MP} / \mathrm{P}<1$ ) from those resulting from thermal maturation of fossil fuels (petrogenic: $\mathrm{MP} / \mathrm{P}>5$; Table 21 ). Another diagnostic ratio commonly used to identify pyrogenic vs. petrogenic sources of PAHs in environmental samples is the ratio of fluoranthene to the sum of fluoranthene and pyrene, with a threshold of 0.40 discriminating between petrogenic and pyrogenic inputs and ratios of $0.4-0.5$ and $>0.5$ characteristic, respectively, of inputs from petroleum and biomass combustion (Table 21). The ratio of Indeno[1,2,3-c,d]pyrene (InP) to the sum of InP and Benzo[g,h,i]perylene (BghiP) permits discrimination between petrogenic inputs $(<0.20)$ and combustion sources $(0.20-0.50$ : petroleum vs. $>0.50$ : biomass $)$. The discrimination between the incomplete liquid fuel combustion by-products and biomass (and coal) combustion can be further supported by two additional ratios. The ratios of 1,7-dimethylphenanthrene (1,7DMP) to the sum of 1,7- and 2,6-dimethylphenanthrene (2,6-DMP) and retene (Ret) to the sum of Ret and chrysene (Chy) are used to distinguish PAHs from combustion of fossil fuels $(<0.45$ and $0.15-0.50$, respectively), a mixture of coal and biomass (0.45-0.70 and 0.50-0.83, respectively) and softwoods ( $>0.70$ and $>0.83$, respectively) (Table 21$)$. 
Table 21. Diagnostic ratio of distinct PAH source signatures.

\begin{tabular}{|c|c|c|c|c|}
\hline \multirow[b]{2}{*}{ PAH Ratios } & \multirow[b]{2}{*}{ Petrogenic } & \multicolumn{3}{|c|}{ Pyrogenic } \\
\hline & & $\begin{array}{l}\text { Petroleum } \\
\text { combustion }\end{array}$ & $\begin{array}{l}\text { Petrol. comb./Wood } \\
\text { comb. mixture }\end{array}$ & $\begin{array}{c}\text { Wood } \\
\text { combustion }\end{array}$ \\
\hline $\mathrm{MP} / \mathrm{P}^{\mathrm{a}, \mathrm{b}}$ & $>>5$ & & $0.40-0.70$ & \\
\hline $\mathrm{Fl} /(\mathrm{Fl}+\mathrm{Py})^{\mathrm{b}, \mathrm{c}}$ & $<0.40$ & $0.40-0.50$ & & $>0.50$ \\
\hline $\ln P /(\operatorname{InP}+B g h i P)^{c}$ & $<0.20$ & $0.20-0.50$ & - & $>0.50$ \\
\hline 1,7-DMP/(1,7- + 2,6-DMP $)^{d}$ & - & 0.45 & $0.45-0.70$ & $0.70-1.0$ \\
\hline Ret/(Ret + Chy $)^{\text {e }}$ & - & $0.15-0.50$ & $0.50-0.83$ & $0.83-1.0$ \\
\hline
\end{tabular}

These diagnostic ratios are plotted for the eight stations in Figures 28-30. Because a consistency between PAH signatures of atmospheric aerosols and sediments has been used in the past in the Chicago region to demonstrate that atmospheric deposition of particles is the major source of PAHs to the surface of Lake Michigan (Simcik et al. 1999), we performed a similar comparison of PAH signatures in depositional samples to those of sediments cores from the Puget Sound/Hood Canal system (Kuo et al. 2010b) and from the Strait of Georgia to the north (Yunker et al. 2002, 2003). The MP/P ratio vs. Fl/(Fl+Py) property-property plot shows that all PAHs in the atmospheric deposition study are derived from combustion and that these PAHs are composed of a mixture from petroleum and biomass combustion (Figure 28a). Although the differentiation between coal and biomass combustion cannot be readily made with these PAH ratios, the low utilization of coal in the state of Washington suggests that combustion of coal may not be as important a source input of pyrogenic by-products to the atmosphere of the Puget Sound as biomass and petroleum combustion. This is in contrast to the Midwest and Northeast of the U.S., where coal has historically been a major source of combustion by-products to the atmosphere and coastal waters (Simcik et al. 1999; Dickhut et al. 2000). A similar graphical representation of PAH source signatures for surface sediments in southern Hood Canal (core HC3) and the Main Basin (cores PS1 and PS4) show that most sediments of Puget Sound receive a slightly higher proportion of inputs from petrogenic and petroleum combustion sources than that observed in atmospheric particles (Figure 28b). The northern section of Hood Canal (core HC5), however, falls within the signature composition of atmospheric particles, which points to a higher proportion of inputs from biomass combustion. 

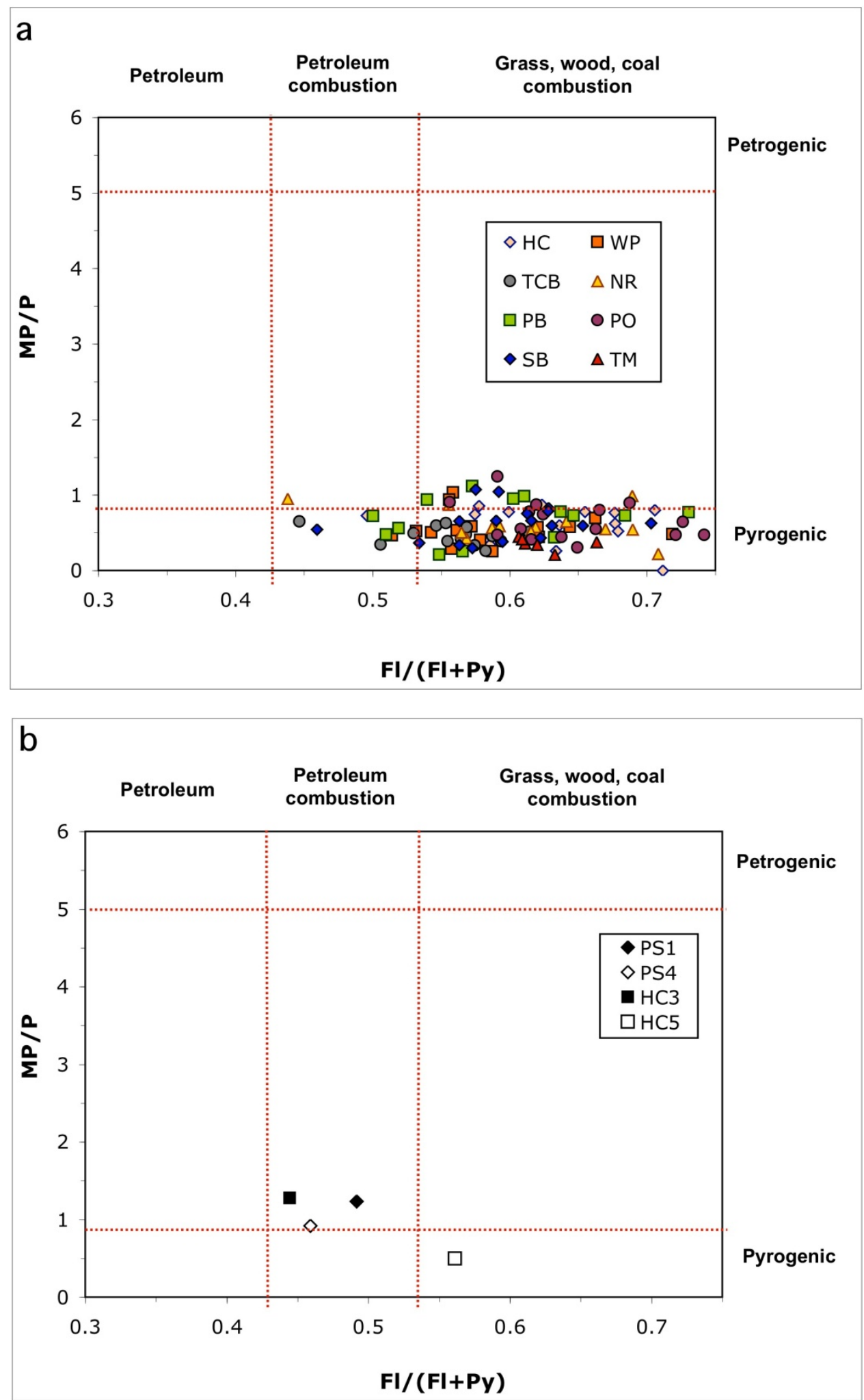

Figure 28. Methylphenanthrene to phenanthrene ratio (MP/P) vs. fluoranthene over the sum of fluoranthene and pyrene in a) atmospheric deposition samples and b) surface sediments (0$5 \mathrm{~cm}$ ) in the Hood Canal and Main Basin. 
The $\mathrm{InP} /(\mathrm{InP}+\mathrm{BghiP})$ ratio vs. $\mathrm{Fl} /(\mathrm{Fl}+\mathrm{Py})$ property-property plot further confirms that the PAHs in the atmospheric deposition study are derived from a mixture of petroleum and biomass combustion (Figure 29a). In this sample series, most $\mathrm{InP} /(\mathrm{InP}+\mathrm{BghiP})$ ratios are $<0.5$ indicating petroleum combustion, whereas the large proportion of $\mathrm{Fl} /(\mathrm{Fl}+\mathrm{Py})$ ratios are $>0.5$ indicating wood combustion. Similar results have been observed in sediment samples of the Strait of Georgia (Yunker et al. 2002, 2003) and may suggest that the wood combustion threshold of 0.5 for $\mathrm{InP} /(\mathrm{InP}+\mathrm{BghiP})$ may be slightly too high (Yunker et al. 2002). However, the distribution of these $\mathrm{PAH}$ signatures falls within the range of light urban to remote lake sediments in the British Columbia study (Yunker et al. 2002) suggesting that, in the Strait of Georgia region, atmospheric particles are much less impacted from inputs of petroleum combustion than urban coastal sediments. This conclusion is further supported by PAH signatures from surface sediments of the Puget Sound (Figure 29b), which show that, except for the northern section of Hood Canal, most sedimentary systems of the Puget Sound receive a higher proportion of inputs from petroleum combustion than atmospheric particles. In fact, $\mathrm{PAH}$ signatures of aerosols collected in Tacoma in 1989-1990 (Crecelius 1991 and EPA 1991) confirm the mixed nature of atmospheric particles and the significant contribution of biomass combustion to the total atmospheric flux of PAHs in the region (Figure 29b). The consistency of atmospheric signatures over the last $\sim 20$ years suggests that despite an order of magnitude reduction in depositional fluxes of carcinogenic and pyrogenic PAHs during that period (see discussion above), there have been no relative changes in the source inputs of these combustionderived contaminants. In addition, the dichotomy between the atmospheric and sedimentary signatures itself suggests that sediments receive a slightly higher proportion of petroleumderived constituents (the MP/P ratios point to the addition of petrogenic inputs in addition to the pyrogenic sources of PAHs; Figure 28b). Deposition of oil residues on impervious surface areas and wash out, as well as wastewater inputs, may be some of the processes responsible for the bypassing of atmospheric transport of a portion of petrogenic and petroleum combustion byproducts and their direct transfer into streams. These results further support the need for focused efforts to understand the watershed contribution to the Puget Sound and the importance of the petroleum combustion deposition on the watershed and subsequent remobilization to Puget Sound via surface runoff. 

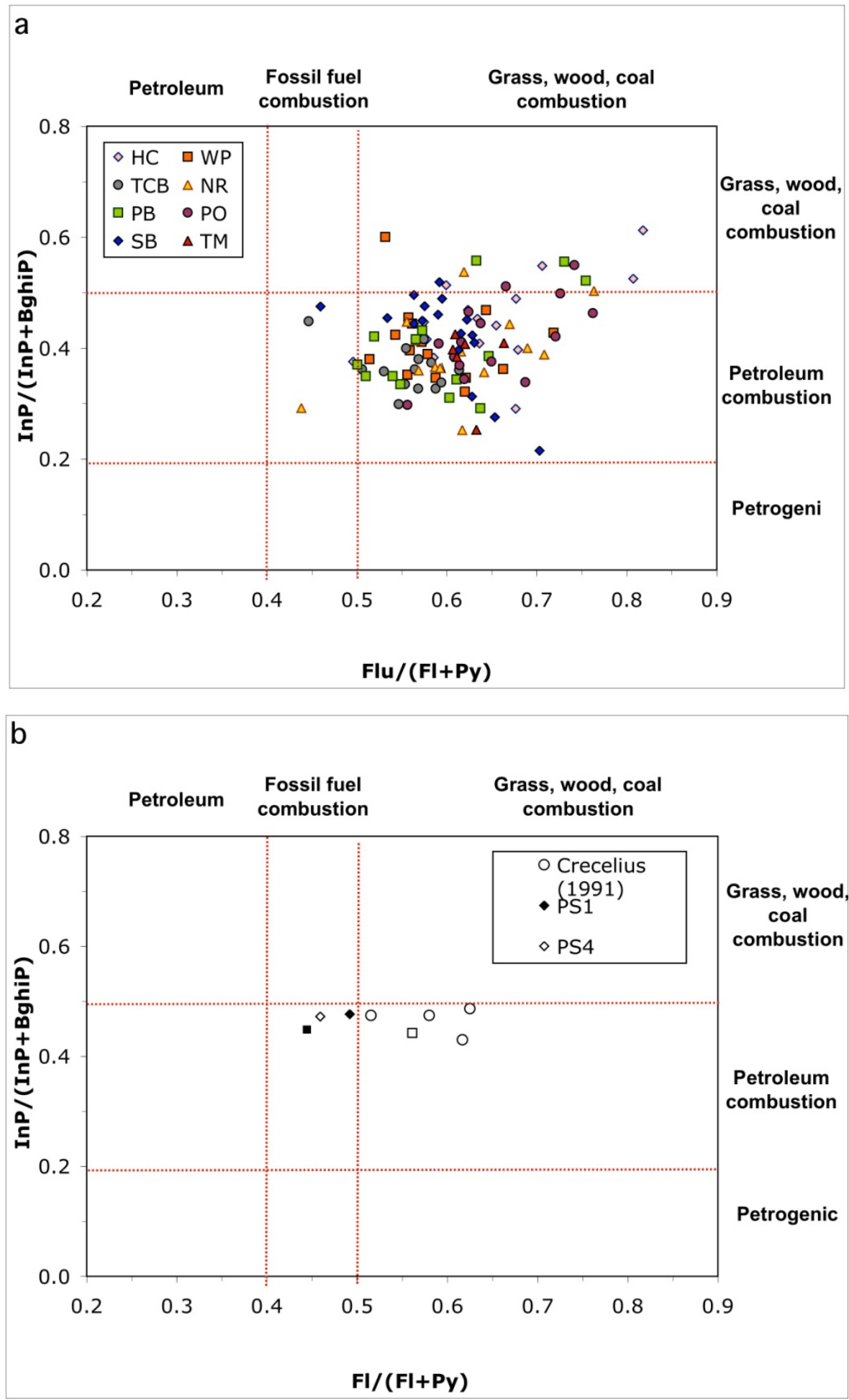

Figure 29. Ratio of indeno[1,2,3-c,d]pyrene to the sum of Indeno[1,2,3-c,d]pyrene and benzo[g,h,i]perylene vs. fluoranthene over the sum of fluoranthene and pyrene in a) atmospheric deposition samples and b) surface sediments $(0-5 \mathrm{~cm})$ in the Hood Canal and Main Basin, as well as atmospheric deposition samples from 1989-1990 (Crecelius 1991 and EPA 1991). 
A more detailed evaluation of the role of biomass vs. petroleum combustion can be determined from the Ret/(Ret+Chy) vs. 1,7-DMP/(1,7-+2,6-DMP) property-property plot (Figure 30). Both retene and 1,7-DMP are released in proportionally greater amounts (sometimes exclusively) from biomass combustion (Benner et al. 1995; Kuo et al. 2010b; Yan et al. 2005; Yunker et al. 2002). High Ret/(Ret+Chy) ratios are particularly useful for tracing inputs from softwood combustion (Yan et al. 2005). The distribution of the depositional samples (Figure 30a) confirm again the mixed nature of combustion sources with biomass (softwood) combustion being the predominant source of PAHs in a number of samples and stations. As expected, the samples showing the highest proportion of inputs from vehicular emissions are the three urban stations (WP, TCB, and TM) supporting the use of these ratios to provide a qualitative estimate of combustion sources to the atmosphere of the region. The historical reconstructions of these same ratio signatures in sediment cores from southern Hood Canal (HC3) and the Main Basin off Seattle (PS4) show that biomass combustion have always predominated in the Hood Canal, whereas the mid- $20^{\text {th }}$ century peak in industrialization and urban development in the Seattle region has led to PAH signatures more typical of fossil fuel combustion of the kind observed today in these urban systems (Figure 30b). 

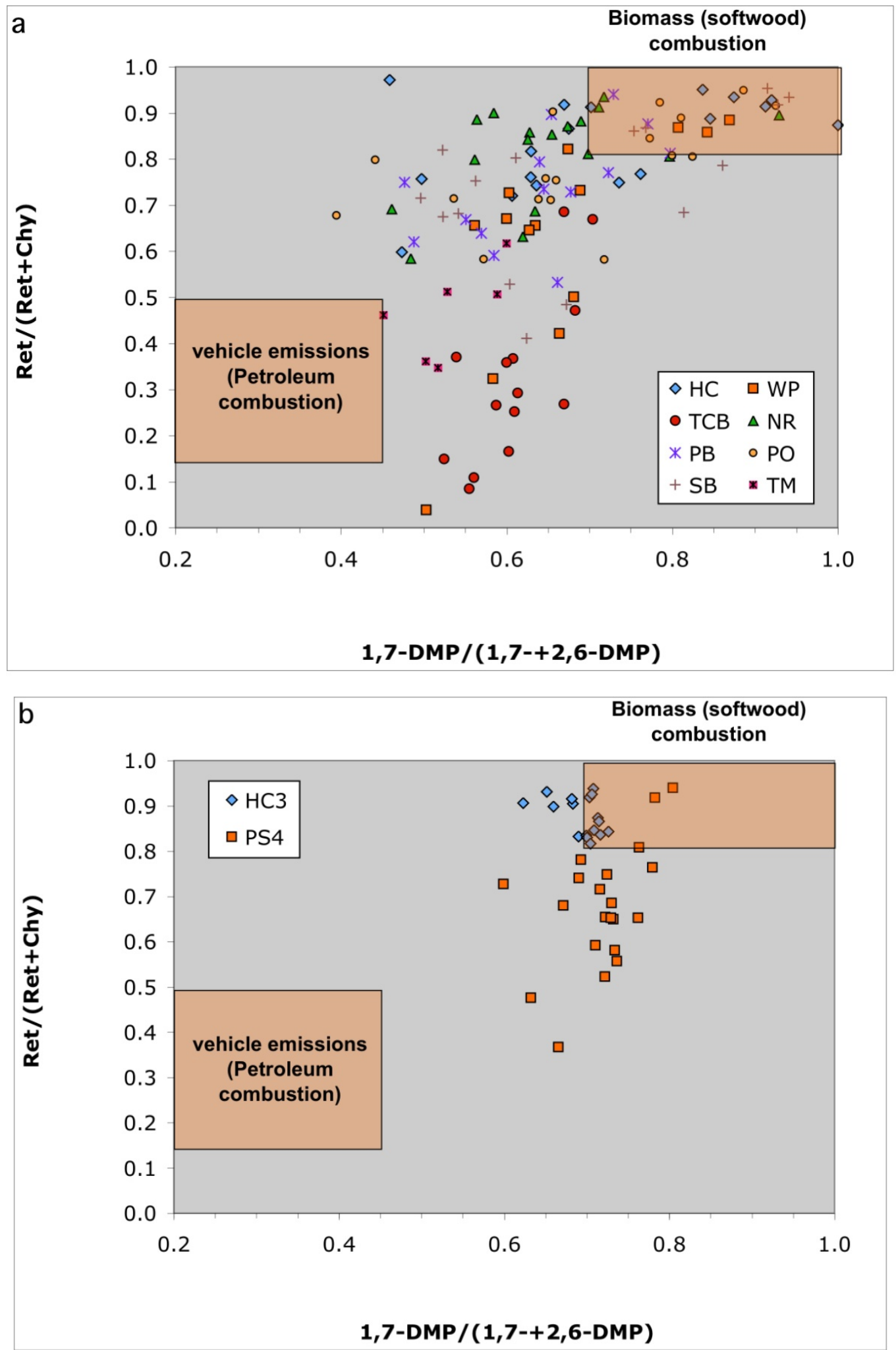

Figure 30. Ratio of retene to the sum retene and chrysene vs. 1,7-DMP over the sum of 1,7- and 2,6DMP in a) atmospheric deposition samples and b) sediment cores in the Hood Canal (HC3) and Main Basin (PS4). 


\section{Principal Component Analysis and Semi-quantitative Reconstructions of Combustion Source Inputs}

To provide a more robust interpretation of the PAH data, a PCA model was developed based on the atmospheric depositional data and using a series of parent and alkylated PAHs as well as levoglucosan, an exclusive biomarker of biomass combustion (Kuo et al. 2008). The PCA model classifies the PAHs into two major categories and two additional sub-categories (Figure 31). The first PC (PC1, horizontal) explains roughly 38\% of the variance in the data set, whereas the second PC (PC2, vertical) explains a further $13 \%$ of the variance. Some major discrimation occurs across the first PC with alkylated PAHs and levoglucosan (right) plotting opposite from parent PAHs (left). On the lower right hand corner (Quadrant 2), retene, 1,7-DMP, and levoglucosan recognized for their biomass combustion origin form a cluster away from 4- to 6ring parent PAHs (left; Quadrant 1), 3-4-ring PAHs (top left; Quadrant 3), and other alkylated PAHs (top right; Quadrant 4). Retene and 1,7-DMP being plotted in the same region as levoglucosan provides strong evidence for their common biomass combustion origin (Benner et al. 1995; Yan et al. 2005; Kuo et al. 2010b). In addition, since levoglucosan is produced exclusively in a narrow range of temperatures $\left(150-350^{\circ} \mathrm{C}\right.$; Kuo et al. 2008), the cluster in Quadrant 2 probably points to emissions of low-temperature chars. In contrast, the hightemperature conditions characteristic of fossil fuel combustion leads to soot particles enriched in high molecular weight PAHs and depleted in alkylated homologues (Wang et al. 1999; Boehm 2006). Hence, the clustering of the high molecular PAHs in the Quadrant 1 of the PCA plot suggests that these hydrocarbons are derived from high-temperature combustion of fossil fuels. The discrimination of the second $\mathrm{PC}$ is a not as clear as that of $\mathrm{PC} 1$. The occurrence of lower molecular weight (three-ring) and alkylated homologues in the upper sections of the PCA plot suggests these constituents are characteristic of petrogenic residues and/or lower temperature combustion conditions. Indeed, 2,6-DMP has been reported in gasoline combustion residues whereas 3,6-DMP, pyrene, fluoranthene, and anthracene are usually strongly associated with diesel combustion source inputs (Benner et al. 1995; Maciejczyk et al. 2004; Lima et al. 2003, 2005). The second PC may thus discriminate between mixed inputs composed of unburned petrogenic residues and diesel combustion by-products (upper quadrants) from the fossil and biomass combustion inputs described earlier (lower quadrants). The present PCA analysis segregates the loading factors in a very similar way as a PCA performed on sediments and suspended particles of the Strait of Georgia and the inner Vancouver Harbor (Yunker et al. 1996). In that latter analysis, high molecular parent PAHs cluster on the left-hand side just below the x-axis as in the present PCA. Similarly, retene and alkylated low molecular PAHs segregate on the right hand side of the PCA with alkyl-PAHs plotting in the upper quadrant and retene plotting close to the $\mathrm{X}$-axis. In a subsequent PCA of lake sediments from British Columbia (Yunker et al. 2003), 2,6-DMP plots with alkylated low molecular PAHs, whereas 1,7DMP is shifted away from the petroleum PAHs towards retene. These results, and the striking similarity between the three sets of analyses, provide a consistent set of PAH signatures at the regional scale, which support the source reconstructions provided by these PCA and the molecular ratios. 


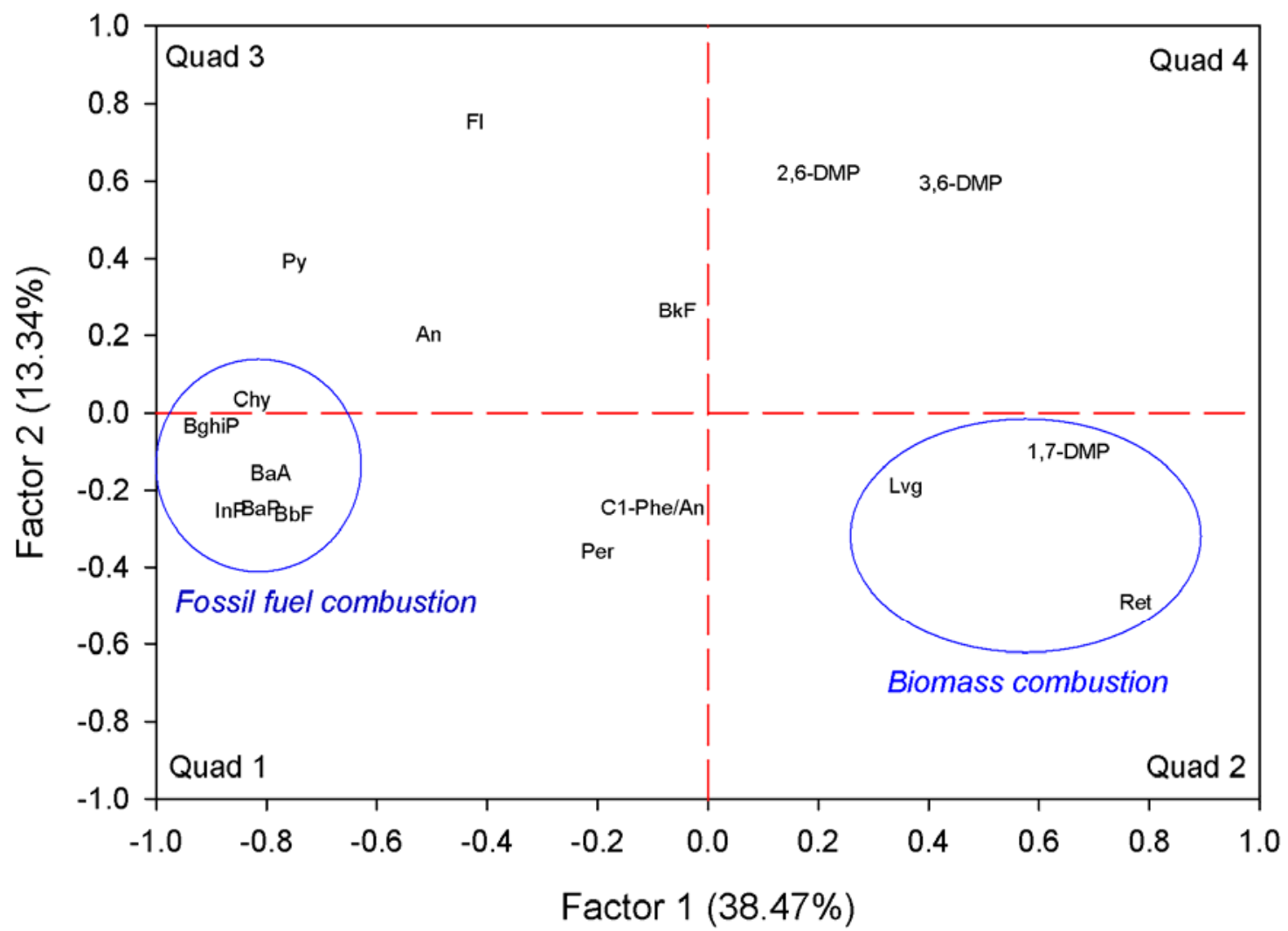

Figure 31. Principal component analysis (PCA) projections of PAH variables (loadings). The variance accounted for each PC is shown in brackets after the axis label.

In the corresponding score plot (Figure 32), the atmospheric samples project across the entire spectrum with a large number of urban samples (TCB, WP, TM) plotting in the petroleum and diesel combustion regions (Quadrants 1 and 3, respectively), whereas non-urban samples (HC) tend to plot in the lower right region of biomass combustion (Quadrant 2). A number of suburban stations (PO, NR) plot in the alkyl-PAH region of the PCA (Quadrant 4) suggesting the predominant input of a mixture of biomass combustion and potentially petrogenic and/or diesel combustion residues. The relative amount of these PAHs classes is better visualized in the bar graphs that represent the typical fingerprint for each quadrant (Figure 32a-d). The fingerprint of Quadrant 1 (TCB) is composed of a negligible fraction of alkylated PAHs with a relatively high proportion of 4- to 6-ring PAHs confirming the predominant inputs from vehicular emissions. Quadrant 2 (HC) shows a high proportion of alkylated PAHs that are derived from biomass combustion (retene and 1,7-DMP) while four- to six-ring PAHs are virtually absent, suggesting low-temperature biomass combustion residues. Quadrant 3 (TM) shows a fingerprint that is very typical of diesel combustion by-products (Wang et al. 1999; Lima et al. 2003, 2005) dominated by four-ring PAHs (Py, Flu, BaA, and Chy) but still showing a small fraction of alkyl-substituted PAHs and five- to six-ring PAHs. Finally, Quadrant 4 (PO) shows a predominance for Fl and Py with the addition of alkylated PAHs (3,6-, 2,6-, and 1,7-DMP, as well as retene) suggesting a mixture between petrogenic inputs and biomass low-temperature combustion. 

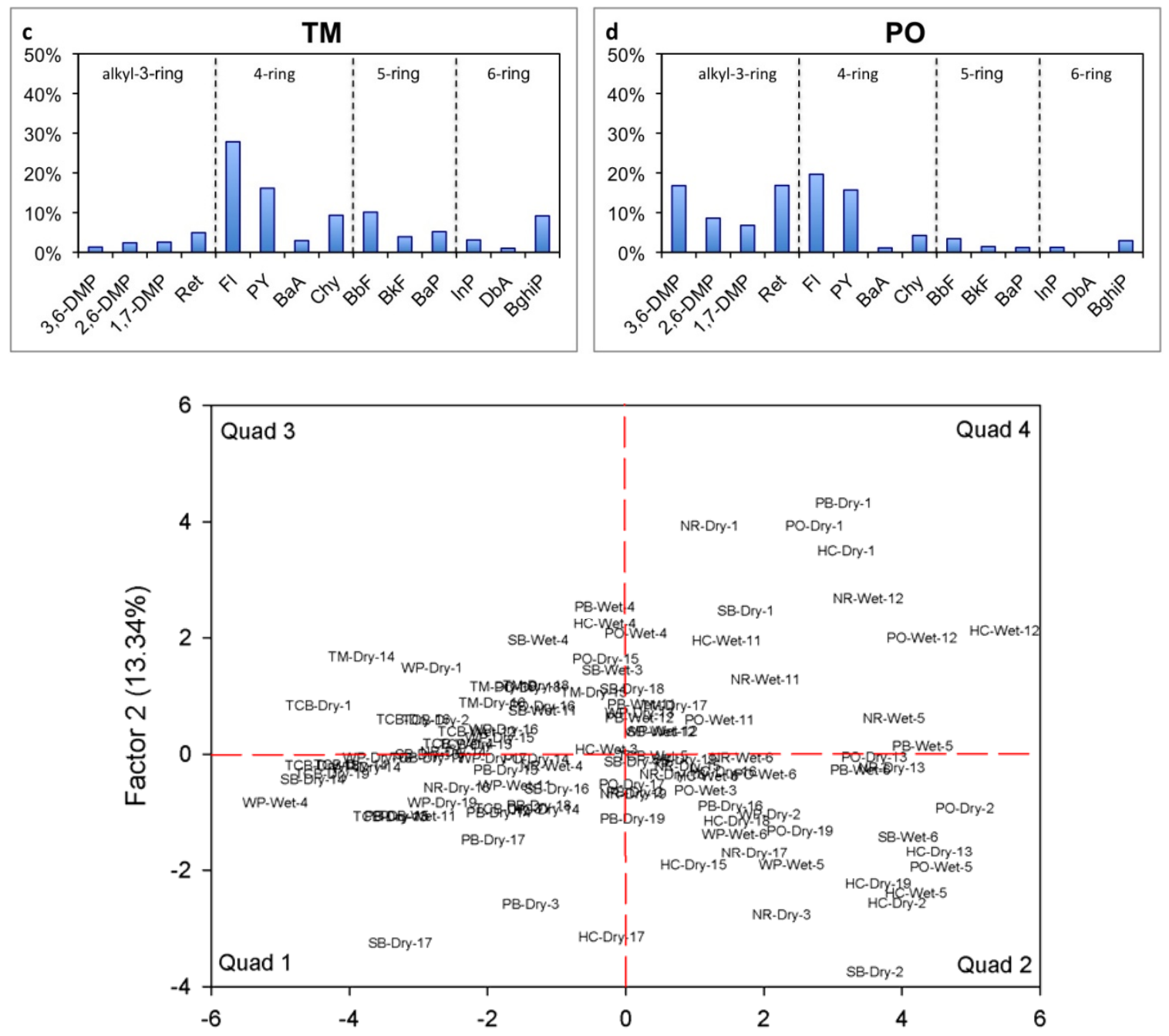

Factor $1(38.47 \%)$
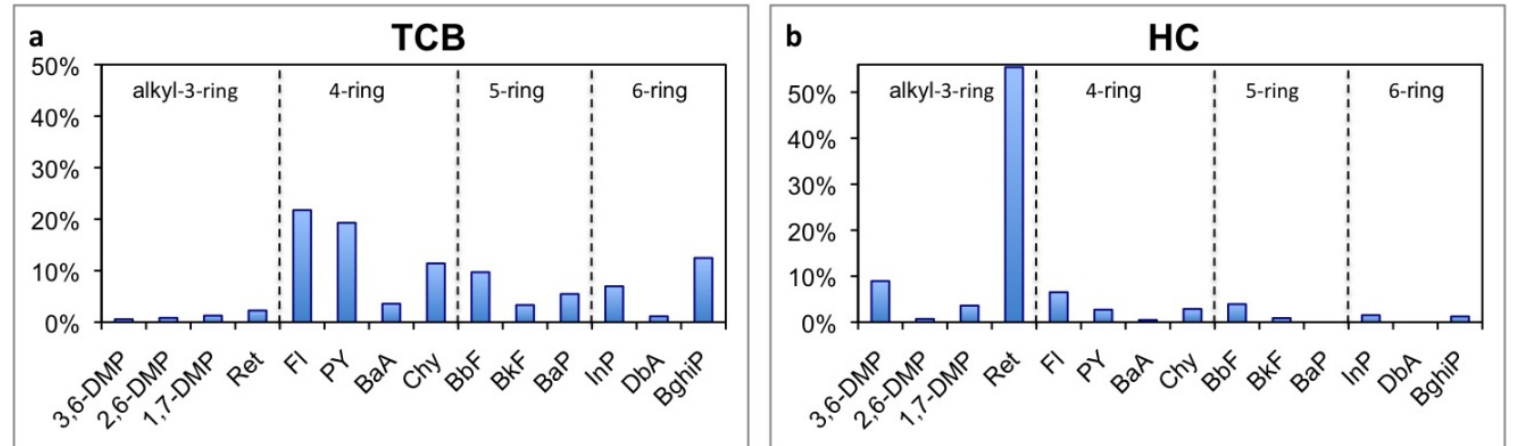

Figure 32. PCA projections of samples (upper section) and typical fingerprint signatures of specific quadrants (bar graphs). The variance accounted for each PC is shown in brackets after the axis label. Fingerprint signatures: a) TCB represents the lower left quadrant of the PCA showing a typical petroleum combustion fingerprint; b) $\mathrm{HC}$ represents the lower right quadrant of the PCA showing a typical biomass combustion fingerprint; c) TM represents the upper left quadrant of the PCA showing fossil fuel combustion mixture fingerprint (possibly diesel); d) PO represents the upper right quadrant of the PCA showing a combustion mixture fingerprint with high influence of biomass. 
Using this analysis and the Ret/(Ret+Chy) ratio, we built a semi-quantitative apportionment reconstruction of source inputs at each station of study. In both the PCA and the Ret/(Ret+Chy) approach, the frequency of observations within each signature endmember was used to estimate the percentage of inputs from each source. In the case of the PCA, occurrence of a sample in a particular quadrant was assigned a specific source predominance of petroleum combustion (Quadrant 1), biomass combustion (Quadrant 2), mixture of petroleum and diesel combustion/petrogenic inputs (Quadrant 3), and mixture of biomass combustion and diesel combustion/petrogenic inputs (Quadrant 4). In the Ret/(Ret+Chy) approach, petroleum combustion was assigned to ratios ranging $0.15-0.50$; biomass combustion was assigned to ratios ranging $0.83-1.0$; and a mixture of both sources to ratios ranging $0.50-0.83$. The results of this first-order apportionment are presented in Figure 33. Although the two models show apparent differences in the estimates of petroleum combustion-derived inputs, estimates for biomass combustion match remarkably well $\left(\mathrm{r}^{2}=0.87\right)$. Both models suggest that the three urban/industrial stations (TCB, WP, TM) are dominated by petroleum combustion and/or petroleum/diesel combustion mixture (40-80\%), whereas rural to sub-urban stations (HC, NR, $\mathrm{PB}, \mathrm{PO})$ show a higher frequency of inputs $(\sim 50 \%)$ falling in the biomass combustion endmember with an additional substantial proportion (20-30\%) in the petroleum/biomass combustion mixture. These frequency distributions, and in particular the agreements in biomass combustion estimates, point to a) the influence of wood burning (both from wildfire and domestic heating stoves) on the quality of aerosols in the Puget Sound, and b) the importance of fossil fuel combustion and vehicular traffic on emissions of atmospheric particulates in the urbanized south eastern region of the Sound.
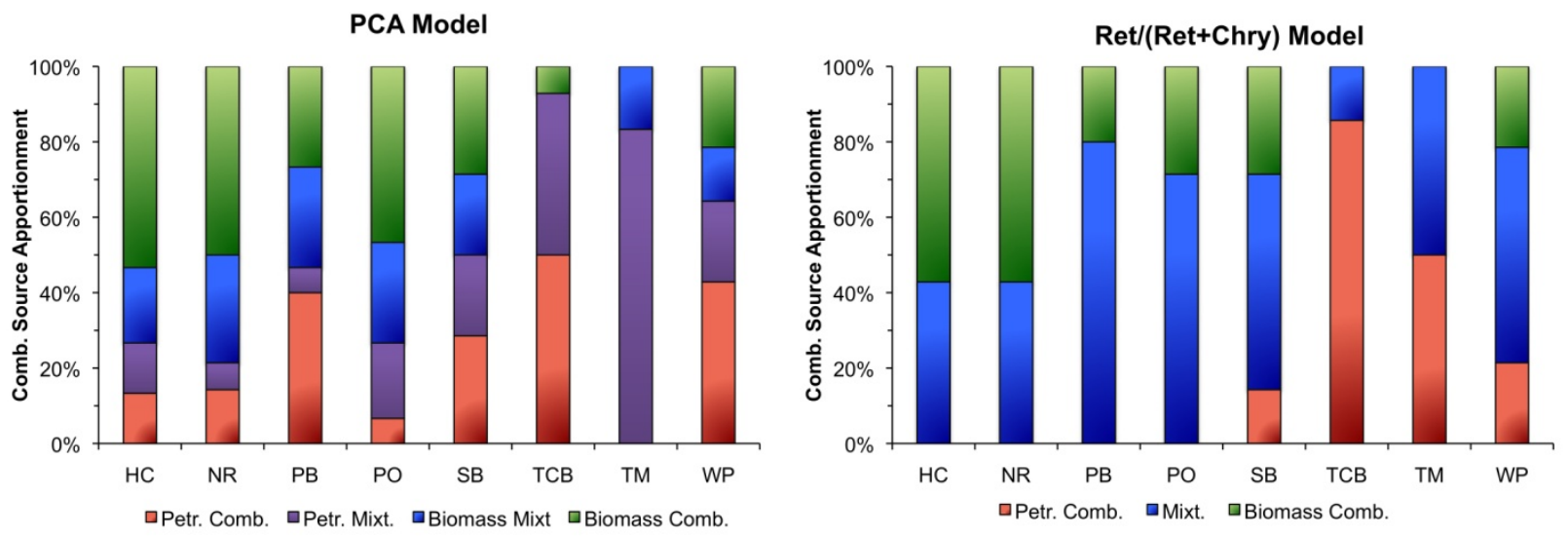

Figure 33. Frequency distributions of atmospheric deposition samples falling in specific source categories determined using a) the PCA model (left panel) and b) the Ret/(Ret+Chy) ratio (right panel). 


\section{Conclusions}

The results of the Phase 1 Toxics Loading study suggest that runoff from the land surface and atmospheric deposition directly to marine waters have resulted in considerable loads of contaminants to Puget Sound (Hart Crowser, Inc. 2007). The limited data available for atmospheric deposition fluxes in Puget Sound, except THg, was recognized as a significant data gap. Therefore, this study provided more recent or first reported atmospheric deposition fluxes of PAHs, PBDEs, and select trace elements for Puget Sound. Samples representing bulk atmospheric deposition were collected during 2008 and 2009 at seven stations around Puget Sound spanning from Padilla Bay south to Nisqually River including Hood Canal and the Straits of Juan de Fuca. Wet deposition was a significant process for atmospheric deposition in the PNW, and the total precipitation during the study period at each station was generally within the precipitation ranges for the last several decades. Revised annual loading estimates were calculated for each of the toxics and demonstrated an overall decrease in the atmospheric loading estimates except for PBDEs and THg.

The median atmospheric deposition flux of total PBDE $\left(7.0 \mathrm{ng} / \mathrm{m}^{2} / \mathrm{d}\right)$ was higher than that of the Hart Crowser, Inc. (2007) Phase 1 estimate $\left(2.0 \mathrm{ng} / \mathrm{m}^{2} / \mathrm{d}\right)$. The urban/industrial sites of Tacoma have significantly higher total PBDE fluxes than other study stations, which were not statistically different. In addition, seasonal differences were observed for PBDE and THg fluxes. The dry season has higher fluxes than the wet season for PBDE. Among all target PBDEs measured, BDEs-47, 99, and 209 are the major congeners in the samples and BDE-209 is the most abundant congener. High similarity of the proportional distribution of these three congeners is found across sampling stations in Puget Sound, suggesting there is a regional consistency in the source(s). In addition, the estimated mass loading of total PBDE in Puget Sound ranges from 15.6-20.3 Kg/yr (median) by using three estimation scenarios, and the results from these scenarios are not statistically different. Notably, a similar magnitude of PBDE mass loading $(17.1 \pm 6.5 \mathrm{Kg} / \mathrm{yr})$ was reported for the Strait of Georgia. Given the similar surface areas between Puget Sound and the Strait of Georgia, the consistency in their mass loadings may indicate that there is a general atmospheric PBDE flux in the PNW region.

The revised atmospheric loading estimates for trace elements were all lower than prior estimates by a factor of 3 to 32, except for $\mathrm{THg}$, which was not significantly different from the original estimates. The THg fluxes were significantly correlated with precipitation but suggested regional differences in what would be defined as dry deposition during low- to no-precipitation events. The modeled dry deposition fluxes at station TCB were a factor of three higher than modeled dry deposition flux for all other stations (which were not significant from each other). Therefore, a localized source may provide a relatively constant dry deposition with an additive flux of a magnitude that is a function of total rainfall. In addition, atmospherically deposited mercury may be more available to methylation than mercury already within a system, which can be rendered less available by complexation or sorption (Harris et al. 2007; Mason et al. 2000; 
Rolfhus et al. 2003). Thus, atmospheric deposition of mercury may represent an important $\mathrm{MMHg}$ source and substrate of $\mathrm{MMHg}$ production in aquatic environments.

For all other trace elements, the original annual atmospheric deposition loading estimates (Hart Crowser, Inc. 2007) were heavily dependent on data from Crecelius (1991), which represented the industrial/urban area of Commencement Bay sampled from 1989 to 1990. The highest median fluxes for all trace elements were measured at TCB; however, the partial data set for the Tyee Marina station suggested that high fluxes at TCB were localized and not representative of fluxes falling on the surface waters of Puget Sound as a whole. Significantly lower fluxes were recorded at the rural sites (HC, SB, PO, PB) compared to the high-density urban and industrial sites near Tacoma and Seattle (TCB, TM, WP). In all stations and seasons, the strong correlations between $\mathrm{Pb}, \mathrm{Cu}$, and high molecular weight $\mathrm{PAHs}$ suggest that emissions of these metals to the atmosphere of the Puget Sound may be linked to combustion processes and/or co-occurring processes (i.e., break pad wear and tear and vehicular traffic emissions). However, more research is needed to identify the common sources/processes responsible for the consistent emissions of pyrogenic $\mathrm{PAHs}$ and $\mathrm{Pb}$ and $\mathrm{Cu}$ in the region.

The median atmospheric deposition flux for pyrogenic PAHs $\left(34.2 \mathrm{ng} / \mathrm{m}^{2} / \mathrm{d}\right.$; without TCB) shows a relatively narrow range across all stations (interquartile range: $21.2-61.1 \mathrm{ng} / \mathrm{m}^{2} / \mathrm{d}$ ) and shows no influence of season. Only TCB showed substantially larger median fluxes $\left(583.6 \mathrm{ng} / \mathrm{m}^{2} / \mathrm{d}\right.$; interquartile range: $\left.311.8-657.5 \mathrm{ng} / \mathrm{m}^{2} / \mathrm{d}\right)$. Yet, despite having the highest fluxes with respect to other stations, this area of the Puget Sound has experienced more than an order of magnitude decline in depositional fluxes of pyrogenic PAHs over the last $\sim 20$ years (Crecelius 1991) pointing to the influence of environmental regulations on combustion emissions. The more extensive and spatiotemporal sampling of depositional fluxes across the entire Puget Sound from the present study led to a revised estimate of atmospheric loadings of carcinogenic and pyrogenic PAHs to the surface of the Sound. Irrespective of the scenario used, all loadings estimates were virtually identical and suggest a two-order of magnitude decrease with respect to previous estimates. The atmospheric deposition fluxes of levoglucosan point to a strong influence of season on the emissions of biomass combustion byproducts to the atmosphere of the Puget Sound. The two to three order of magnitude peaks in fluxes during the winter period point to the role of wood-burning stoves (and potentially temperature inversions) on air quality during the wet season. Inter-annual differences in levoglucosan fluxes in late summerearly fall also point to temporal differences in the inputs of combustion-derived particulates during wildfire seasons. A semi-quantitative apportionment study permitted a first-order characterization of source inputs to the atmosphere of the Puget Sound. Both biomarker ratios and a PCA confirmed regional data from the Puget Sound and Strait of Georgia region and pointed to the predominance of biomass and fossil fuel (mostly liquid) combustion as source inputs of combustion by-products to the atmosphere of the region. This contrasts findings from the Midwest and Northeast, where coal still contributes the majority of inputs of combustion byproducts to the atmosphere. 
In summary, four major conclusions are derived from this study: 1) the depositional fluxes of a majority of the selected toxic elements (trace metals) and compounds (PAHs) in the urban/industrial area of Tacoma have decreased significantly (close to an order of magnitude for most) in the last $\sim 20$ years, 2) deposition fluxes directly to the waters of Puget Sound are spatially homogenous except in industrial regions and are not necessary representative of watershed deposition rate over a large range of land use and land cover classifications, 3) direct atmospheric deposition of trace elements and PAHs on the Puget Sound surface contributes only $1-5 \%$ of total inputs to sedimentary repositories, and 4) first-order estimates of sedimentary fluxes of $\mathrm{Pb}$ and $\mathrm{PAHs}$ in the Puget Sound system suggest that revised annual surface runoff estimates may be appropriate based on the sedimentary fluxes representing the last decade of inputs. 


\section{References}

Babson, A.L., M. Kawase, and P. MacCready. 2006. Seasonal and interannual variability in the circulation of Puget Sound, WA: A box model study. Atmosphere-Ocean, 44 (1) 2006, 29-45.

Baker, J.E. ed. (1997). Atmospheric Deposition of Contaminants to the Great Lakes and Coastal Waters. SETAC Press, Pensacola, FL, pp. 451.

Baker, J.E., Dickhut, R.M., Cutter, G.A., Church, T.M., Ondov J.M. (1992). The Chesapeake Bay Atmospheric Deposition Study. CBADS Quality Assurance Plan.

Benner, J., B. A.; Wise, S. A.; Currie, L. A.; Klouda, G. A.; Klinedinst, D. B.; Zweidinger, R. B.; Stevens, R. K.; Lewis, C. W. (1995). Distinguishing the contributions of residential wood combustion and mobile source emissions using relative concentrations of dimethylphenanthrene isomers. Environmental Science and Technology 29: 2382-2389.

Bloom, N.S. (1989). Determination of Picogram Levels of Methylmercury by Aqueous Phase Ethylation, Followed by Cryogenic Gas Chromatography with Cold Vapor Atomic Fluorescence Detection. Can. J. Fish Aq. Sci. 7: 1131.

Bloom, N. S. and C. J. Watras (1989). Observations of methylmercury in precipitation, The Science of the Total Environment, 87/88: 199-207.

Boehm, P.D. (2006). Polycyclic aromatic hydrocarbons, in R.D., M., and Murphy, B.L., eds., Environmental Forensics: A Contaminant Specific Approach, Academic Press.

Brandenberger, J.M., E.A. Crecelius, and P. Louchouarn (2008a). Historical inputs an natural recovery rates of heavy metals and organic biomarkers in Puget Sound during the $20^{\text {th }}$ Century. Environmental Science and Technology 42: 6786-6790.

Brandenberger, J.M., E.A. Crecelius, P. Louchouarn, S.R. Cooper, K. McDougall, E. Leopold, and G. Liu. (2008b). Reconstructing trends in hypoxia using multiple paleoecological indicators recorded in sediment cores from Puget Sound, WA. National Oceanic and Atmospheric Administration, Pacific Northwest National Laboratory Report No. PNWD-4013, 158pp.

Brandenberger, J.M. E.A. Crecelius, G.A. Gill, and R.K. Johnston. (2010- in final draft). Contaminant mass balance for Sinclair and Dyes Inlets, Puget Sound, Washington. Prepared for the Puget Sound Naval Shipyard and Intermediate Maintenance Facility Project ENVVEST. 
Caseiro, A., Bauer, H., Schmidl, C., Pio, C.A. Puxbaum, H. (2009). Wood burning impact on PM10 in three Austrian regions. Atmos. Env. 43: 2186-2195.

Conaway, C., F.J. Black, P. Weiss-Penzias, M. Gault-Ringold, and A. R. Flegal. (2010). Mercury speciation in Pacific coastal rainwater, Monterey Bay, California. Atmos. Env. 44: 1788-1797.

Covaci, A., Voorspoels, S., de Boer, J. 2003. Determination of brominated flame retardants, with emphasis on polybrominated diphenyl ethers (PBDEs) in environmental and human samples—a review. Environment International 29:735-756.

Crecelius, E. A. (1991). Estimate of the Atmospheric Deposition of Contaminants on Commencement Bay. Washington, 84th Annual Meeting and Exhibition, Vancouver, British Columbia. 91-60.4

Dickhut, R.M., Canuel, E.A., Gustafson, K.E., Liu, K., Arzayus, K.M., Walker, S.E., Edgecombe, G., Gaylor, M.O., Macdonald, E.H. (2000). Automotive sources of carcinogenic polycyclic aromatic hydrocarbons associated with particulate matter in the Chesapeake Bay region. Environmental Science \& Technology 34: 4635-4640.

Ding, X., Wang, X.-M., Xie, Z.-Q., Xiang, C.-H., Mai, B.-X., Sun, L.-G., Zheng, M., Sheng, G.Y., Fu, J.-M., Poschl, U. (2007). Atmospheric polycyclic aromatic hydrocarbons observed over the North pacific Ocean and the Arctic area: Spatial distribution and source identification. Atmospheric Environment 41: 2061-2072.

Ebinghaus, R., S. G. Jennings, W. H. Schroeder, T. Berg, T. Donaghy, J. Guentzel, C. Kenny, H.H. Kock, K. Kvietkus, W. Landing, T. Muhleck, J. Munthe, E.M. Prestbo, D. Schneeberger, F. Slemr, J. Sommar, A. Urba, D. Wallschlager, and Z. Xiao (1999). International field intercomparison measurements of atmospheric mercury species at Mace Head, Ireland. Atmospheric Environment 33: 3063-3073.

Elmquist, M., Zencak, Z., Gustafsson, Ö. (2007). A 700 year sediment record of black carbon and polycyclic aromatic hydrocarbons near the EMEP air monitoring station in Aspvreten, Sweden. Environ. Sci. Technol. 41: 6926-6932.

EnviroVision Corporation; Herrera Environmental Consultants, Inc.; Washington Department of Ecology. (2008). Phase 2: Improved Estimates of Toxic Chemical Loadings to Puget Sound from Surface Runoff and Roadways. Ecology Publication Number 08-10-084. August 2008. Olympia, Washington http://www.ecy.wa.gov/biblio/0810084.html

Environmental Protection Agency (EPA) (1991). Evaluation of the Atmospheric Deposition of Toxic Contaminants to Puget Sound. Report No. Puget Sound Water Quality Authority and EPA Region 10 Puget Sound Estuary Program. EPA 910/9-91-027, pp173. 
Fabbri, D., Marynowski, L., Fabianska, M.J., Zaton, M. Simoneit, B.R.T. (2008). Levoglucosan and other cellulose markers in pyrolysates of Miocene lignites geochemical and environmental implications. Environmental Science and Technology 42: 2957-2963.

Fabbri, D., Torri, C., Simoneit, B.R.T., Leszek, M., Rushdi, A.I. Fabianska, M.J. (2009). Levoglucosan and other cellulose and lignin markers in emissions from burning of Miocene lignites. Atmospheric Environment 43: 2286-2295.

Fine, P.M., Cass, G.R., Simoneit, B.R. (2001). Chemical characterization of fine particle emissions from fireplace combustion of woods grown in the northeastern United States. Environmental Science and Technology 35: 2665-2675.

Gardfeldt, K., Munthe, J., Stromberg, D., Lindqvist, O. (2003). A kinetic study on the abiotic methylation of divalent mercury in the aqueous phase. Science of the Total Environment 304: $127-136$.

Gigliotti C.L., Totten L.A., Offenberg J.H., Dachs J., Reinfelder J.R., Nelson E.D., Glenn T.R., Eisenreich S.J. (2005). Atmospheric concentrations and deposition of polycyclic aromatic hydrocarbons to the Mid-Atlantic East Coast region. Environmental Science and Technology 39: 5550-5559.

Gouin, T., Harner, T., Daly, G.L., Wania, F., Mackay, D., Jones, K.C. (2005). Variability of concentrations of polybrominated diphenyl ethers and polychlorinated biphenyls in air: Implications for monitoring, modeling and control. Atmospheric Environment 39: 151166.

Guentzel, J. L., W. M. Landing, G. A. Gill and C. D. Pollman (2001). Processes influencing rainfall deposition of mercury in Florida: The FAMS Project (1992-1996).

Environmental Science and Technology 35: 863-873.

Guentzel, J. L., W. M. Landing, G. A. Gill, and C. D. Pollman (1998). Mercury and major ions in rainfall, throughfall and foliage from the Florida Everglades. The Science of the Total Environment 213: 43-51.

Gustafson, K.E., Dickhut, R.M. (1997). Distribution of polycyclic aromatic hydrocarbons in southern Chesapeake Bay surface water: Evaluation of three methods for determining freely dissolved water concentrations. Environmental Toxicology and Chemistry 16: $452-461$.

Hale, R.C., Alaee, M., Manchester-Neesvig, J.B., Stapleton, H.M., Ikonomou, M.G. (2003). Polybrominated diphenyl ether flame retardants in the North American environment. Environmental International 29: 771-779. 
Halkola H. (2004). Analaysis of Precipitation Data from the ENVVEST Study Area for Water Year 2003, Appendix C. Space and Naval Warfare Systems Center (SPAWAR) Report No. pp. 18.

Hall, B. D., H. Manolopoulos, J.P. Hurley, J.J. Schauer, V.L.St. Louis, D. Kenski, J. Graydon, C.L. Babiarz, L.B. Cleckner, and G.J. Keeler (2005). Methyl and total mercury in precipitation in the Great lakes region. Atmospheric Environment 39: 75577569.

Harner, T.; Shoeib, M.; Diamond, M.; Ikonomou, M. G.; Stern, G. (2006). Passive sampler derived air concentrations of PBDEs along an urban-rural transect: Spatial and temporal trends. Chemosphere 64: 262-267.

Hammerschmidt, C. R. and W. F. Fitzgerald (2005). Methylmercury in Mosquitoes Related to Atmospheric Mercury Deposition and Contamination. Environ. Sci. Technol. 39: 3034-3039.

Hammerschmidt, C.R., Lamborg, C.H., Fitzgerald, W.F. (2007). Aqueous phase methylation as a potential source of methylmercury in wet deposition. Atmospheric Environment 41: $1663-1668$.

Hart Crowser, Inc.; Washington Department of Ecology; U.S. Environmental Protection Agency; and Puget Sound Partnership (2007). Phase 1: Initial Estimate of Toxic Chemical Loadings to Puget Sound. Ecology Publication Number 07-10-079. October 2007. Olympia, Washington. http://www.ecy.wa.gov/programs/wq/pstoxics/index.html.

Herrera Environmental Consultants, Inc. (2010). Addendum 2, Phase 1 and Phase 2 Toxics Loading Reports, Technical Memorandum, January 8, 2010. Ecology Publication Number 08-10-084 Addendum 2. January 2010. Olympia, Washington.

Harris, R.C., and others. (2007). Whole-ecosystem study shows rapid fish-mercury response to changes in mercury deposition. Proceedings of the National Academy of Sciences of the United States of America. 104: 16586-16591.

Hayakawa, K.; Takatsuki, H.; Watanabe, I.; Sakai, S. (2004). Polybrominated diphenyl ethers (PBDEs), polybrominated dibenzo-p-dioxins/dibenzofurans (PBDD/Fs) and monobromopolychlorinated dibenzo-p-dioxins/dibenzofurans (MoBPXDD/Fs) in the atmosphere and bulk deposition in Kyoto, Japan. Chemosphere 57: 343-356.

Hoh, E.; Hites, R. A. (2005). Brominated flame retardants in the atmosphere of the EastCentral United State. Environ. Sci. Technol. 39: 7794-7802. 
Kuo, L.-J., Herbert, B.E. Louchouarn, P. (2008). Can levoglucosan be used to characterize and quantify char/charcoal black carbon in environmental media? Organic Geochemistry 39: 1466-1478.

Kuo, L-J., Herbert B.E., and Louchouarn P. (2010a - In preparation). Solvent extractable lignin-derived monomers in plant charcoals: tracers of biomass combustion inputs to soils, aquatic systems, and aerosols. Organic Geochemistry.

Kuo, L.-J., P. Louchouarn, B.E. Herbert, J.M. Brandenberger, T.L. Wade, and E.A. Crecelius (2010b In Review). Combustion-derived substances in deep basins of Puget Sound: Historical inputs from fossil fuel and biomass combustion. Environmental Science and Technology, in review.

Landers, D.H., S.L. Simonich, D.A. Jaffe, L.H. Geiser, D.H. Campbell, A.R. Schwindt, C.B. Schreck, M.L. Kent, W.D. Hafner, H.E. Taylor, K.J. Hageman, S. Usenko, L.K. Ackerman, J.E. Schrlau, N.L. Rose, T.F. Blett, and M.M. Erway (2008). The Fate, Transport, and Ecological Impacts of Airborne Contaminants in Western National Parks (USA). EPA/600/R-07/138. U.S. Environmental Protection Agency, Office of Research and Development, NHEERL, Western Ecology Division, Corvallis, Oregon.

La Guardia, M. J.; Hale, R. C.; Harvey, E. (2006). Detailed polybrominated diphenyl ether (PBDE) congener composition of the widely used Penta-, Octa-, and Deca-PBDE technical flame-retardant mixtures. Environ. Sci. Technol. 40: 6247-6254.

Lamb, D. and V. Bowersox (2000). The national atmospheric deposition program: an overview. Atmospheric Environment 34: 1661-1663

Landing, W. M., J. L. Guentzel, J.J. Perry, jr., G. A. Gill, and C. D. Pollman (1998). Methods for measuring mercury and other trace species in rainfall and aerosols in Florida. Atmospheric Environment 32: 909-918.

Larsen, R.K., Baker, J.E. (2003). Source apportionment of polycyclic aromatic hydrocarbons in the urban atmosphere: A comparison of three methods. Environmental Science \& Technology 37: 1873-1881.

Lawson, N. M. and R. P. Mason (2001). Concentration of Mercury, Methylmercury, Cadmium, Lead, Arsenic, and Selenium in the Rain and Stream Water of two Contrasting Watersheds in Western Maryland, Water Research 35: 4039-4052.

Lima, A.L., Eglinton, T.I., Reddy, C.M. (2003). High-resolution record if pyrogenic polycyclic aromatic hydrocarbon deposition during the 20th century. Environ. Sci. Technol. 37: 53-61. 
Lima, A.L.C., Farrington, J.W., Reddy, C.M. (2005). Combustion-derived polycyclic aromatic hydrocarbons in the environment - A review. Environmental Forensics 6(2): 109-131.

Louchouarn, P., Kuo, L.-J., Wade, T. L., Schantz, M. (2009). Determination of Levoglucosan and its Isomers in Size Fractions of Aerosol Standard Reference Materials. Atmospheric Environment 43: 5630-5636.

Maciejczyk, P.B., Offenberg, J.H., Clemente, J., Blaustein, M., Thurston, G.D., and Chen, L.C. (2004). Ambient pollutant concentrations measured by a mobile laboratory in South Bronx, NY. Atmospheric Environment 38: 5283-5294.

Mariani, G.; Canuti, E.; Castro-Jimenez, J.; Christoph, E. H.; Eisenreich, S. J.; Hanke, G.; Skejo, H.; Umlauf, G. (2008). Atmospheric input of POPs into Lake Maggiore (Northern Italy): PBDE concentrations and profile in air, precipitation, setting material and sediments. Chemosphere 73: S114-S121.

Mason, R. P., N. M. Lawson, and G. R. Sheu (2000). Annual and seasonal trends in mercury deposition in Maryland. Atmospheric Environment 34: 1691-1701.

Mason, R. P., N. M. Lawson, and K. A. Sullivan (1997). The concentration, speciation and sources of mercury in Chesapeake Bay Precipitation. Atmospheric Environment 31: 3541-3350.

Moon, H.-B.; Kannan, K.; Lee, S.-J.; Choi, M. (2007). Atmospheric deposition of polybrominated diphenyl ethers (PBDEs) in coastal areas in Korea. Chemosphere 66: 585-593.

Munthe, J.; Hultberg, H.; Lee, Y.-H.; Parkman, H.; Iverfeldt, Å., and Renberg, I. (1995). Trends of mercury and methyl-mercury in deposition, run-off water and sediments in relation to experimental manipulations and acidification. Water Air Soil Pollut. 85: 43-748

Nguyen, H. L., M. Leermakers, S. Kurunczi, L. Bozo, and W. Baeyens (2005). Mercury distribution and speciation in Lake Balaton, Hungary. Science of the Total Environment 340: $231-246$.

Noël, M.; Dangerfield, N.; Hourston, R. A. S.; Belzer, W.; Shaw, P.; Yunker, M. B.; Ross, P. S. (2009). Do trans-Pacific air masses deliver PBDEs to coastal British Columbia, Canada? Environ. Pollut. 157: 3404-3412.

O'Connor, T.P. (2002), National distribution of chemical concentrations in mussels and oysters in the USA. Marine Environmental Research 53: 117-143.

Offenberg, J.H., Baker, J.E. (1997). Polychlorinated biphenyls in Chicago precipitation: Enhanced wet deposition to near-shore Lake Michigan. Environmental Science \& Technology 31: 1534-1538 
Petreas, M.; Oros, D. (2009). Polybrominated diphenyl ethers in California wastestreams. Chemosphere 74: 996-1001.

Pelletier, G. and T. Mohamedali (2009). Control of toxic chemicals in Puget Sound Phase 2: Development of simple numerical models. The long-term fate and bioaccumulation of polychlorinated biphenyls in Puget Sound. Environmental Assessment Program Washington State Department of Ecology, Olympia, WA. Publication Number: 09-03015. http://www.ecy.wa.gov/biblio/0903015.html.

Pelletier, G. (2009). Personal Communication and GIS shape files from Ecology. February, 20, 2009.

Qiu, X.; Marvin, C. H.; Hites, R. A. (2007). Dechlorane plus and other flame retardants in a sediment core from Lake Ontario. Environ. Sci. Technol. 41: 6014-6019.

Rolfhus, K.R. and others. (2003). Distribution and fluxes of total and methylmercury in Lake Superior. Environmental Science \& Technology 37: 865-872.

Schmidl, C., Marr, L.L., Caseiro, A., Kotianova, P., Berner, A., Bauer, H., Kasper-Giebl, A. Puxbaum, H. (2008). Chemical characterization of fine particle emissions from wood stove combustion of common woods growing in mid-European Alpine regions. Atmospheric Environment 42: 126-141.

Schauer, J.J., Rogge, W.F., Hildemann, L.M., Mazurek, M.A., and Cass, G.R. (1996). Source apportionment of airborne particulate matter using organic compounds as tracers: Atmospheric Environment 30: 3837-3855.

Seigneur, C., K. Vijayaraghaven, K. Lohman, P. Karamchandani, and C. Scott. (2004). Global Source Attribution for Mercury Deposition in the United States. Environ. Sci. Technol. 38: 555-569.

Shen, L., Wania, F., Lei, Y.D., Teixeira, C., Muir, D.C.G., Xiao, H. (2006). Polychlorinated biphenyls and polybrominated diphenyl ehters in the North American atmosphere. Environmental Pollution 144: 434-444.

Simcik, M.F., Eisenreich, S.J., Lioy, P.J. (1999). Source apportionment and source/sink relationships of PAHs in the coastal atmosphere of Chicago and Lake Michigan. Atmospheric Environment 33: 5071-5079.

Simoneit, B.R.T. (2002). Biomass burning - a review of organic tracers for smoke from incomplete combustion. Applied Geochemistry 17: 129-162.

Simoneit, B.R.T., Schauer, J.J., Nolte, C.G., Oros, D.R., Elias, V.O., Fraser, M.P., Rogge, W.F. Cass, G.R. (1999). Levoglucosan, a tracer for cellulose in biomass burning and atmospheric particles. Atmospheric Environment 33: 173-182. 
Simpson, C.D., Dills, R.L., Katz, B.S. Kalman, D.A. (2004). Determination of levoglucosan in atmospheric fine particulate matter. Journal of Air and Waste Management Association 54: $689-694$.

Sprovieri, F, N. Pirrone, R. Ebinghaus, H. Kock, and A. Dommergue. (2010). Worldwide atmospheric mercury measurements: a review and synthesis of spatial and temporal trends. Atmospheric Chemistry and Physics Discussions. 10: 1261-1307.

Stapleton, H.M., Dodder, N.G. (2008). Photodegradation of decabromodiphenyl ether in house dust by natural sunlight. Environmental Toxicology and Chemistry 27: 306-312.

Ter Schure, A. H.; Larsson, P.; Agrell, C.; Boon, J. P. (2004). Atmospheric transport of polybrominated diphenyl ethers and polychlorinated biphenyls to the Baltic Sea. Environ. Sci. Technol. 38: 1282-1287.

Usenko, S., K.J. Hageman, D.W. Schmedding, G.R. Wilson, and S.L. Simonich (2005). Trace analysis of semivolatile organic compounds in large volume samples of snow, lake water, and groundwater. Environmental Science and Technology 39: 6006-6015.

Usenko, S.; Landers, D. H.; Appleby, P. G.; Simonich, S. L. (2007). Current and historical deposition of PBDEs, pesticides, PCBs, and PAHs to Rocky Mountain National Park. Environ. Sci. Technol. 41: 7235-7241.

Venier, M.; Hites, R. A. (2008). Flame retardants in the atmosphere near the Great Lakes. Environ. Sci. Technol. 42: 4745-4751.

Vives, I., Canuti, E., Castro-Jimenez, J., Christoph, E. H., Eisenreich, S. J., Hanke, G., Huber, T., Mariani, G., Mueller, A., Skejo, H., Umlauf, G., Wollgast, J. (2007). Occurence of polychlorinated dibenzo-p-dioxins and dibenzofurans (PCDD/Fs), polychlorinated biphenyls (PCBs) and polybrominated diphenyl ethers (PBDEs) in Lake Maggiore (Italy and Switzerland). Journal of Environmental Monitoring 9: 589-598.

Wang, Z.D., Fingas, M., Shu, Y.Y., Sigouin, L., Landriault, M., Lambert, P., Turpin, R., Campagna, P., Mullin, J. (1999). Quantitative characterization of PAHs in burn residue and soot samples and differentiation of pyrogenic PAHs from petrogenic PAHs - The 1994 Mobile Burn Study. Environmental Science \& Technology 33: 3100-3109.

Ward, T.J., Hamilton, R.F., Dixon, R.W., Paulsen, M. Simpson, C.D. (2006). Characterization and evaluation of smoke tracers in PM: Results from the 2003 Montana wildfire season. Atmospheric Environment 40: 7005-7017.

Washington State Department of Transportation (2001). 2000 Annual Traffic Report. http://www.wsdot.wa.gov/mapsdata/tdo/annualtrafficreport.htm 
Wilford, B. H., Harner, T., Zhu, J., Shoeib, M., Jones, K. C. (2004). Passive sampling survey of polybrominated diphenyl ether flame retardants in indoor and outdoor air in Ottawa, Canada: Implications for sources and exposure. Environ. Sci. Technol. 38: 53125318.

Wilkins, E.T. 1954. Air pollution and the London fog of December 1952. J.R. Sanitary Inst., $74: 1$.

Yan, B.Z., Abrajano, T.A., Bopp, R.F., Chaky, D.A., Benedict, L.A., Chillrud, S.N., (2005). Molecular tracers of saturated and polycyclic aromatic hydrocarbon inputs into Central Park Lake, New York City. Environmental Science \& Technology 39: 7012-7019.

Youngblood, W., Blumer, M. (1975). Polycyclic aromatic hydrocarbons in the environment: homologous series in soils and recent marine sediments. Geochim. Cosmochim. Acta 39: $1303-1314$.

Yunker, M.B., Snowdon, L.R., Macdonald, R.W., Smith, J.N., Fowler, M.G., Skibo, D.N., McLaughlin, F.A., Danyushevskaya, A.I., Petrova, V.I., Ivanov, G.I. (1996). Polycyclic aromatic hydrocarbon composition and potential sources for sediment samples from the Beaufort and Barents Seas. Environ. Sci. Technol. 30: 1310-1320.

Yunker, M.B., Macdonald, R.W., Vingarzan, R., Mitchell, R.H., Goyette, D., Sylvestre, S. (2002). PAHs in the Fraser River basin: a critical appraisal of PAH ratios as indicators of PAH source and composition. Organic Geochemistry 33: 489-515.

Yunker, M.B. and R.W. Macdonald (2003). Alkane and PAH depositional history, sources and fluxes in sediments from the Fraser River Basin and Strait of Georgia, Canada. Organic Geochemistry 34: 1429-1454.

Washington State Department of Ecology. (Ecology) (2006). PBDE flame retardants in Washington rivers and lakes:Concentrations in fish and water, 2005-06.; Publication No. 06-03-027; Washington State Department of Ecology: Olympia, WA, 2006. 


\section{Appendix A: PAH, Biomarker Data}


Field Sample Results - Biomarker, PAHs

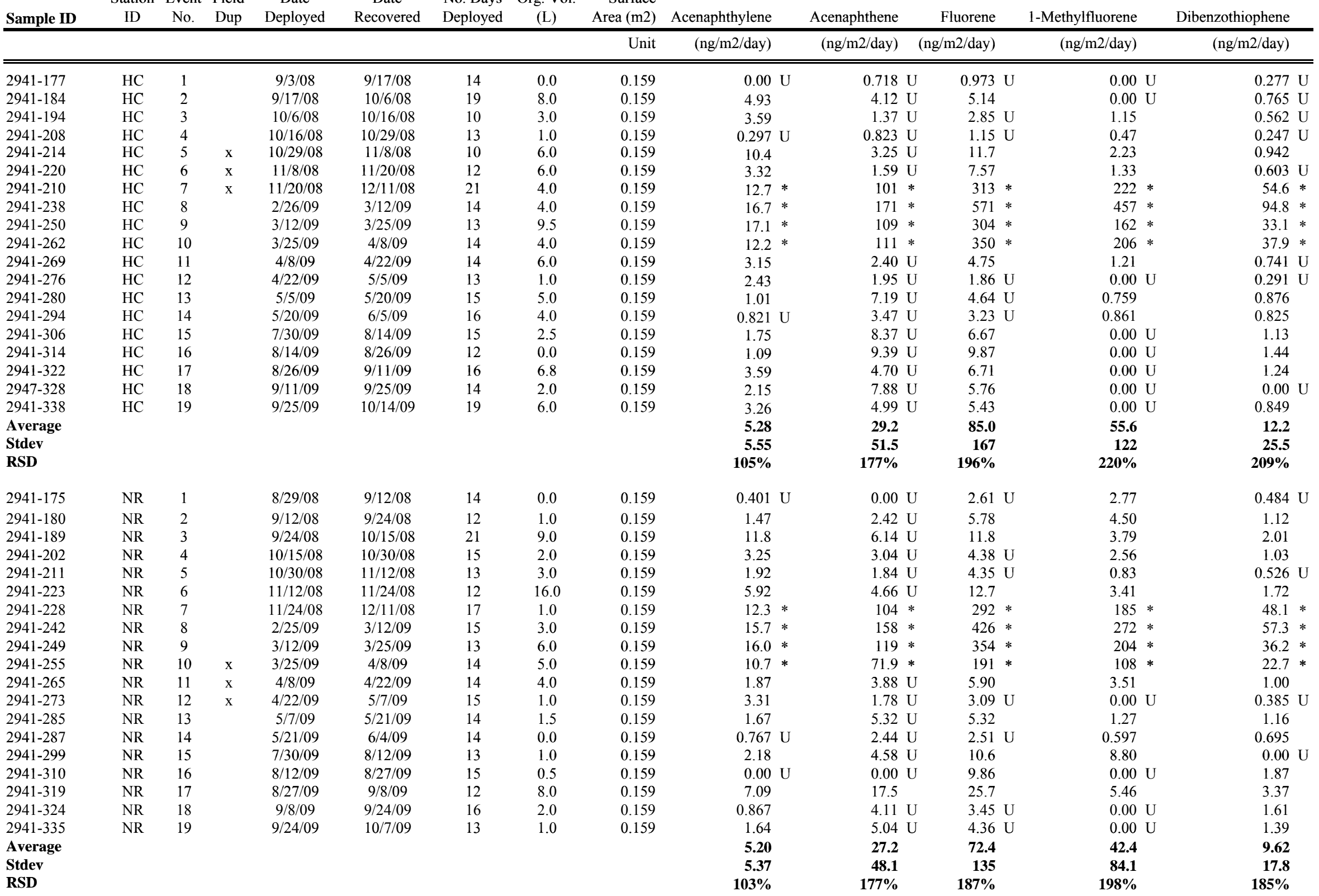


Field Sample Results - Biomarker, PAHs

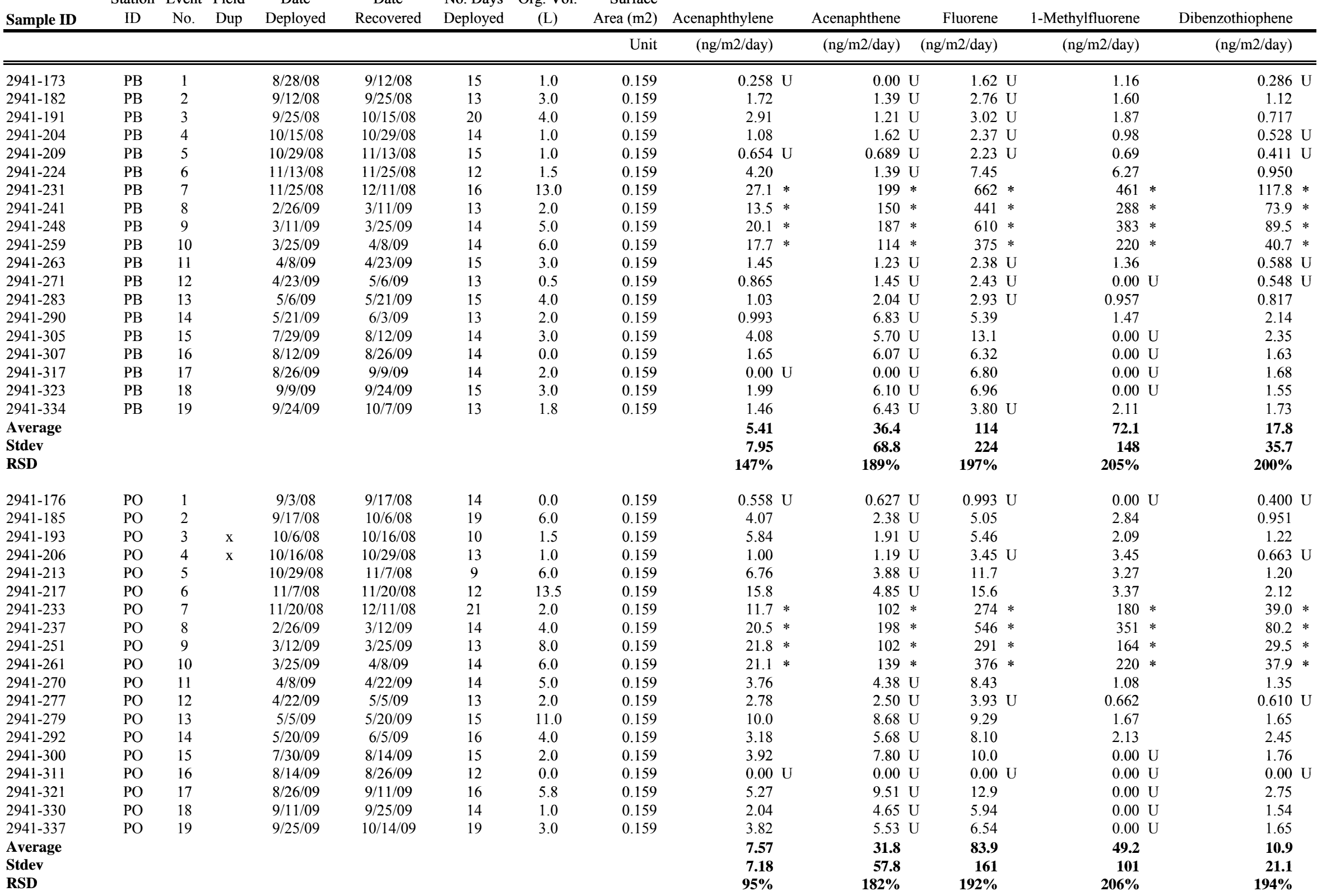


Field Sample Results - Biomarker, PAHs

\begin{tabular}{|c|c|c|c|c|c|c|c|c|c|c|c|c|c|c|c|}
\hline Sample ID & ID & No. & Dup & Deployed & Recovered & Deployed & (L) & Area (m2) & Acenaphthylene & Acenaphthene & & Fluorene & 1-Methylfluorene & Dibenzothiophene & \\
\hline & & & & & & & & Unit & (ng/m2/day) & (ng/m2/day) & & (ng/m2/day) & (ng/m2/day) & (ng/m2/day) & \\
\hline $2941-178$ & SB & 1 & $\mathrm{x}$ & 9/2/08 & $9 / 18 / 08$ & 16 & $<20 \mathrm{~mL}$ & 0.159 & $0.443 \mathrm{U}$ & 0.485 & U & $1.19 \mathrm{U}$ & $0.00 \mathrm{~L}$ & $0.294 \mathrm{I}$ & $\mathrm{U}$ \\
\hline 2941-186 & SB & 2 & $\mathrm{x}$ & 9/18/08 & $10 / 2 / 08$ & 14 & 1.5 & 0.159 & 2.67 & 1.61 & $\mathrm{U}$ & $3.27 \mathrm{U}$ & 0.962 & $0.769 \mathrm{I}$ & $\mathrm{U}$ \\
\hline $2941-195$ & SB & 3 & & $10 / 2 / 08$ & $10 / 15 / 08$ & 13 & 1.5 & 0.159 & 1.84 & 1.45 & $\mathrm{U}$ & $2.87 \mathrm{U}$ & 1.40 & 0.519 & $\mathrm{U}$ \\
\hline $2941-205$ & SB & 4 & & $10 / 15 / 08$ & $10 / 30 / 08$ & 15 & 2.0 & 0.159 & 2.76 & 1.20 & U & $3.82 \mathrm{U}$ & 1.14 & $0.540 \mathrm{~L}$ & $\mathrm{U}$ \\
\hline $2941-216$ & SB & 5 & & $10 / 30 / 08$ & $11 / 10 / 08$ & 11 & 14.0 & 0.159 & 17.2 & 8.86 & $\mathrm{U}$ & 34.6 & 5.39 & 1.49 & \\
\hline $2941-218$ & SB & 6 & & $11 / 10 / 08$ & $11 / 25 / 08$ & 12 & 3.0 & 0.159 & 1.64 & 0.945 & U & $2.92 \mathrm{U}$ & 0.697 & $0.480 \mathrm{I}$ & $\mathrm{U}$ \\
\hline $2941-219$ & SB & 7 & & $11 / 25 / 08$ & $12 / 11 / 08$ & 16 & 2.0 & 0.159 & $11.3 *$ & 107 & * & $260 *$ & 162 & 43.3 & * \\
\hline $2941-245$ & SB & 8 & & $2 / 25 / 09$ & $3 / 12 / 09$ & 15 & 4.5 & 0.159 & $18.1 *$ & 154 & * & $427 *$ & 282 & $66.7=$ & $*$ \\
\hline $2941-252$ & SB & 9 & & $3 / 12 / 09$ & $3 / 29 / 09$ & 17 & 5.0 & 0.159 & $14.8 *$ & 116 & * & $364 *$ & 218 & 40.1 & $*$ \\
\hline $2941-260$ & SB & 10 & & $3 / 29 / 09$ & $4 / 13 / 09$ & 15 & 5.0 & 0.159 & $18.2 *$ & 143 & * & $444 *$ & 272 & 48.7 & $*$ \\
\hline $2941-268$ & SB & 11 & & 4/13/09 & $4 / 28 / 09$ & 15 & $<1$ & 0.159 & 1.02 & 1.56 & U & $2.10 \mathrm{U}$ & 0.732 & $0.449 \mathrm{~L}$ & $\mathrm{U}$ \\
\hline $2941-278$ & SB & 12 & & $4 / 28 / 09$ & $5 / 11 / 09$ & 13 & 2.0 & 0.159 & 0.921 & 1.21 & $\mathrm{U}$ & $2.38 \mathrm{U}$ & 0.546 & $0.526 \mathrm{I}$ & $\mathrm{U}$ \\
\hline 2941-281 & SB & 13 & & $5 / 11 / 09$ & $5 / 27 / 09$ & 16 & 5.5 & 0.159 & 1.88 & 3.49 & U & $3.06 \mathrm{U}$ & 2.65 & 1.26 & \\
\hline $2941-286$ & SB & 14 & & $5 / 27 / 09$ & $6 / 8 / 09$ & 12 & 0.0 & 0.159 & 1.19 & 3.89 & $\mathrm{U}$ & $2.63 \mathrm{U}$ & $0.00 \mathrm{~L}$ & 0.913 & \\
\hline 2941-303 & SB & 15 & & $8 / 3 / 09$ & $8 / 18 / 09$ & 15 & 1.8 & 0.159 & 3.29 & 5.83 & U & 4.80 & $0.00 \mathrm{~L}$ & 1.26 & \\
\hline $2941-313$ & SB & 16 & & $8 / 15 / 09$ & $8 / 29 / 09$ & 11 & 0.0 & 0.159 & 2.63 & 14.5 & & 22.8 & $0.00 \mathrm{I}$ & 2.43 & \\
\hline $2941-320$ & SB & 17 & & $8 / 29 / 09$ & $9 / 11 / 09$ & 13 & 1.3 & 0.159 & $0.00 \mathrm{U}$ & 4.40 & U & 7.95 & 4.37 & $0.00 \mathrm{I}$ & U \\
\hline $2941-329$ & SB & 18 & & 9/11/09 & $9 / 25 / 09$ & 14 & 1.0 & 0.159 & $0.00 \mathrm{U}$ & 3.70 & U & $3.56 \mathrm{U}$ & $0.00 \mathrm{~L}$ & 0.852 & \\
\hline $2941-336$ & SB & 19 & & 9/25/09 & $10 / 13 / 09$ & 18 & 1.9 & 0.159 & 1.99 & 8.52 & U & 5.23 & $0.00 \mathrm{~L}$ & 1.63 & \\
\hline Average & & & & & & & & & 5.36 & 30.6 & & 84.1 & 50.1 & 11.2 & \\
\hline Stdev & & & & & & & & & 6.69 & 53.6 & & 158 & 99.9 & 21.0 & \\
\hline RSD & & & & & & & & & $125 \%$ & $175 \%$ & & $187 \%$ & $199 \%$ & $188 \%$ & \\
\hline 2941-174 & TCB & 1 & & $8 / 29 / 08$ & $9 / 12 / 08$ & 14 & 0.0 & 0.159 & 1.78 & 1.50 & $\mathrm{U}$ & $2.64 \mathrm{U}$ & 1.18 & 1.56 & \\
\hline 2941-181 & TCB & 2 & & 9/12/08 & $9 / 24 / 08$ & 12 & 1.5 & 0.159 & 4.03 & 3.59 & U & 7.47 & 2.08 & 2.70 & \\
\hline $2941-188$ & $\mathrm{TCB}$ & 3 & & $9 / 24 / 08$ & $10 / 15 / 08$ & 21 & 6.0 & 0.159 & 13.9 & 17.3 & & 29.4 & 8.09 & 8.84 & \\
\hline 2941-203 & TCB & 4 & & $10 / 15 / 08$ & $10 / 30 / 08$ & 15 & 2.0 & 0.159 & 7.40 & 7.49 & U & 14.1 & 8.09 & 3.60 & \\
\hline $2941-212$ & $\mathrm{TCB}$ & 5 & & $10 / 30 / 08$ & $11 / 12 / 08$ & 13 & 20.0 & 0.159 & 46.7 & 43.2 & & 81.0 & 17.4 & 17.2 & \\
\hline $2941-229$ & TCB & 7 & & $11 / 12 / 08$ & $11 / 24 / 08$ & 17 & 1.5 & 0.159 & $15.0 *$ & 103 & * & $271 *$ & 183 & $43.6=$ & $*$ \\
\hline $2941-240$ & $\mathrm{TCB}$ & 8 & & $11 / 24 / 08$ & $12 / 11 / 08$ & 15 & 5.5 & 0.159 & $30.7 *$ & 275 & * & $987 *$ & $836 *$ & 184.1 & $*$ \\
\hline $2941-243$ & TCB & 8 & & $2 / 25 / 09$ & $3 / 12 / 09$ & 15 & 5.5 & 0.159 & $28.8 *$ & 173 & $*$ & $446 *$ & 282 & 71.8 & $*$ \\
\hline $2941-245 b$ & TCB & 9 & $\mathrm{x}$ & 2/25/09 & 3/12/09 & 13 & 8.0 & 0.159 & $35.1 *$ & 105 & * & $307 *$ & 162 & 37.7 & $*$ \\
\hline $2941-256$ & $\mathrm{TCB}$ & 10 & & $3 / 12 / 09$ & $3 / 25 / 09$ & 14 & 6.5 & 0.159 & $27.7 *$ & 178 & * & $537 *$ & $316=$ & 63.8 & $*$ \\
\hline 2941-267 & TCB & 11 & & $4 / 8 / 09$ & $4 / 22 / 09$ & 14 & 5.0 & 0.159 & 13.6 & 13.6 & & 27.2 & 8.48 & 7.64 & \\
\hline $2941-274$ & $\mathrm{TCB}$ & 12 & & $4 / 22 / 09$ & $5 / 7 / 09$ & 15 & 3.0 & 0.159 & 11.6 & 7.03 & U & 13.9 & 2.13 & 5.48 & \\
\hline $2941-282$ & TCB & 13 & & $5 / 7 / 09$ & $5 / 21 / 09$ & 14 & 10.0 & 0.159 & 22.3 & 21.7 & & 29.6 & 6.42 & 10.8 & \\
\hline $2941-288$ & $\mathrm{TCB}$ & 14 & & $5 / 21 / 09$ & $6 / 4 / 09$ & 14 & 0.0 & 0.159 & 12.6 & 7.63 & $\mathrm{U}$ & 9.77 & 1.97 & 5.45 & \\
\hline 2941-301 & TCB & 15 & & 7/30/09 & $8 / 12 / 09$ & 13 & 1.5 & 0.159 & 14.7 & 37.2 & & 50.0 & $0.00 \mathrm{~L}$ & 11.4 & \\
\hline 2941-309 & TCB & 16 & & $8 / 12 / 09$ & $8 / 27 / 09$ & 15 & 1.0 & 0.159 & 7.20 & 8.58 & $\mathrm{U}$ & 14.6 & $0.00 \mathrm{~L}$ & 4.98 & \\
\hline $2941-316$ & TCB & 17 & & $8 / 27 / 09$ & 9/8/09 & 12 & 9.5 & 0.159 & 34.0 & 38.9 & & 66.4 & 10.4 & 16.7 & \\
\hline $2941-326$ & TCB & 18 & & 9/8/09 & 9/24/09 & 16 & 1.0 & 0.159 & 14.6 & 12.7 & & 16.2 & $0.00 \mathrm{~L}$ & 8.20 & \\
\hline 2941-333 & $\mathrm{TCB}$ & 19 & & $9 / 24 / 09$ & 10/7/09 & 13 & 1.8 & 0.159 & 23.2 & 40.9 & & 30.1 & 8.58 & 24.46 & \\
\hline Average & & & & & & & & & 19.2 & 57.7 & & 154.8 & 97.6 & 27.9 & \\
\hline Stdev & & & & & & & & & 12.0 & 75.9 & & 257.4 & 205.1 & 43.1 & \\
\hline RSD & & & & & & & & & $62 \%$ & $132 \%$ & & $166 \%$ & $210 \%$ & $154 \%$ & \\
\hline
\end{tabular}


Field Sample Results - Biomarker, PAHs

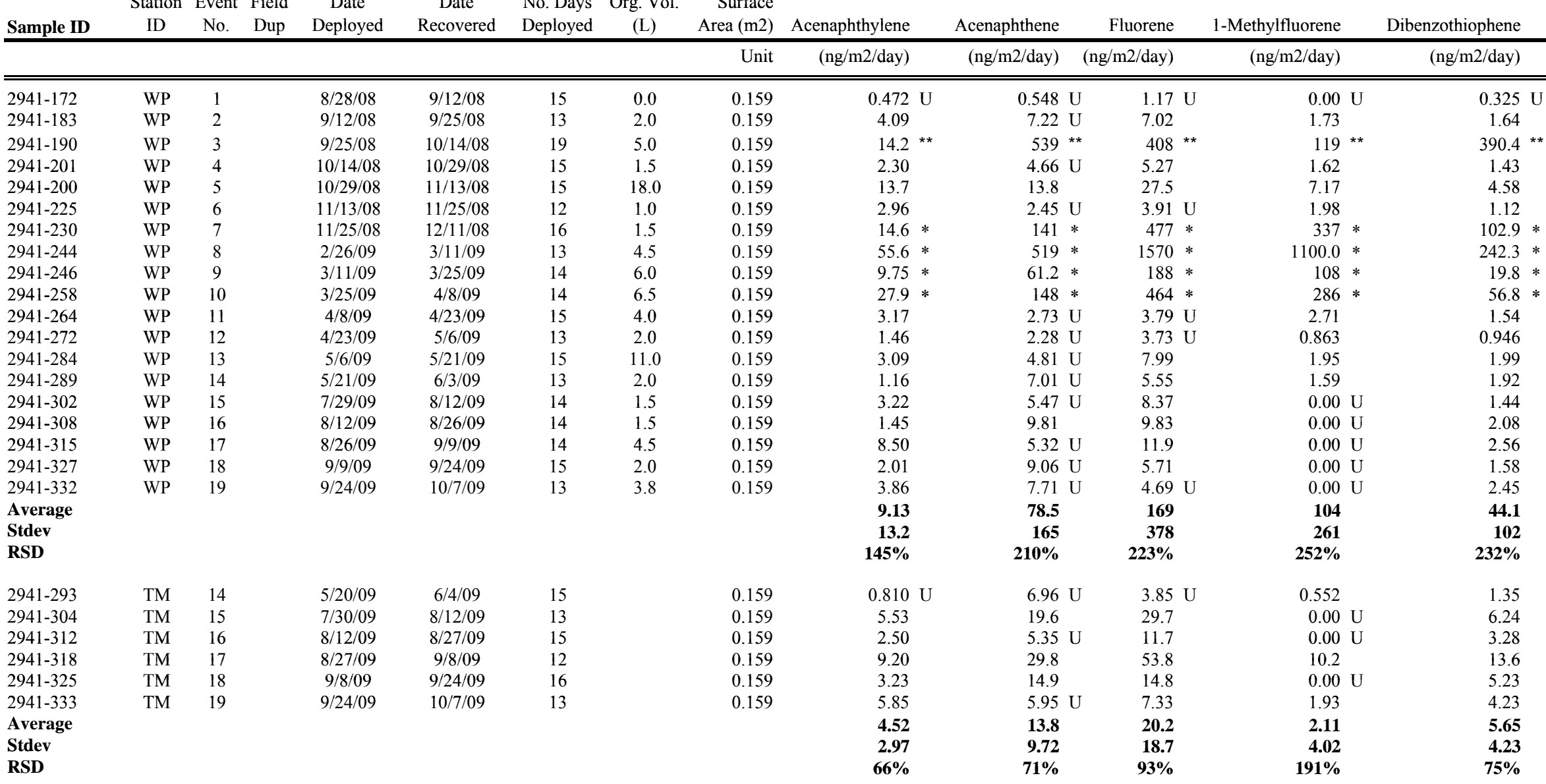

NA $\quad$ Not available

** Outlier; see narration

Carcinogenic PAHs: benzo(a)anthracene, chrysene, benzo(b)fluoranthene,

benzo(k)fluoranthene, benzo(a)pyrene, indeno(1,2,3-c,d)pyrene, dibenz(a,h)anthracene

Pyrogenic PAHs: fluoranthene, pyrene, benzo(a)anthracene, chrysene,

b benzo(b)fluoranthene, benzo(k)fluoranthene, benzo(a)pyrene, indeno(1,2,3-c,d)pyrene, dibenz(a,h)anthracene, benzo(g,h,i)perylene

c High molecular weight PAHs: benzo(b)fluoranthene, benzo(k)fluoranthene,

benzo(a)pyrene, indeno(1,2,3-c,d)pyrene, dibenz(a,h)anthracene, benzo(g,h,i)perylene 
Field Sample Results - Biomarker, PAHs

Station Event Field Date Date No Days Org Vol

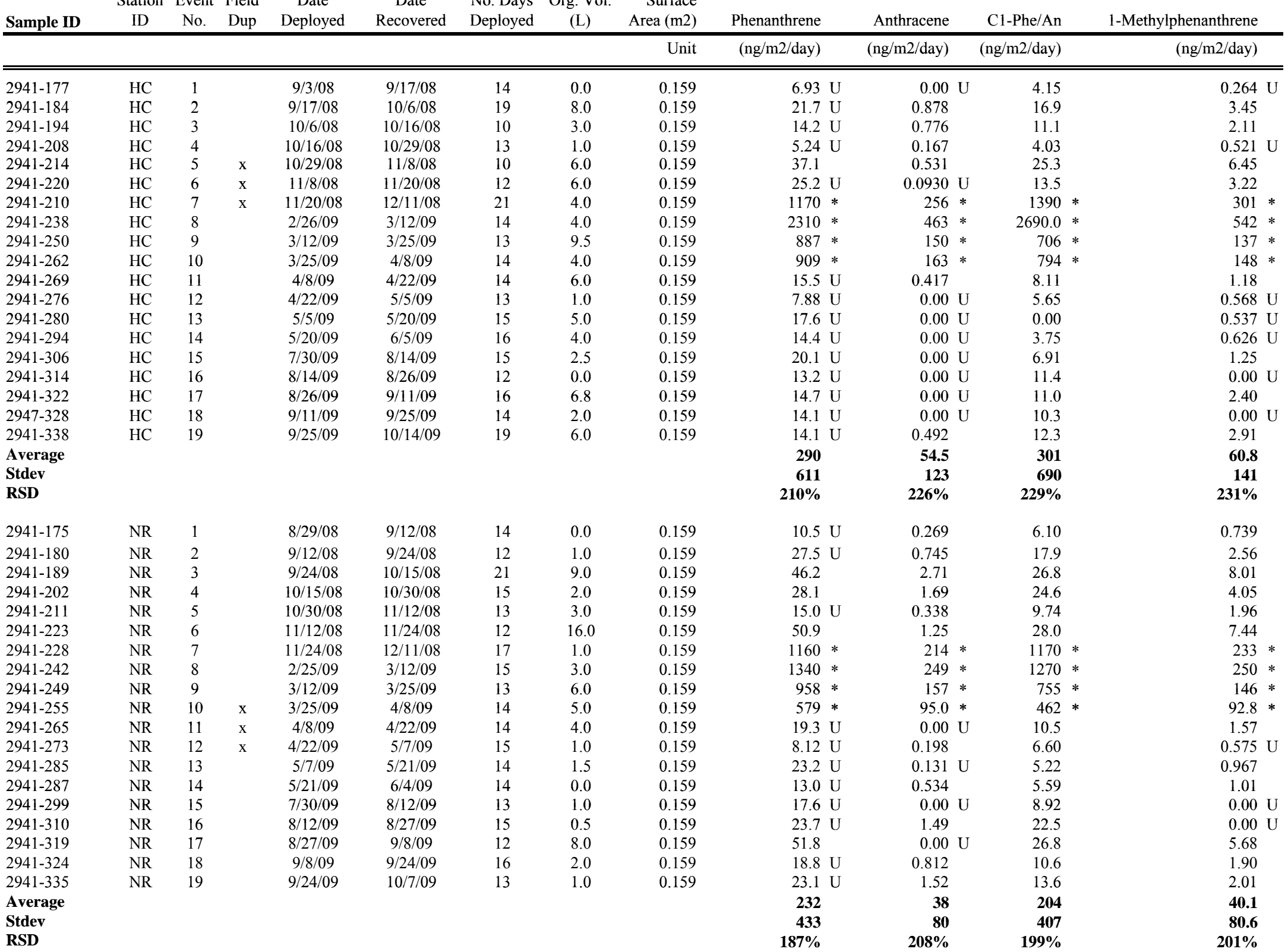


Field Sample Results - Biomarker, PAHs

Station Event Field Date Date Funnel

\begin{tabular}{|c|c|c|c|c|c|c|c|c|c|c|c|c|c|}
\hline Sample ID & ID & $\begin{array}{l}\text { Event } \\
\text { No. }\end{array}$ & Dup & Deployed & Recovered & $\begin{array}{l}\text { No. Days } \\
\text { Deployed }\end{array}$ & $\begin{array}{l}\text { (L) } \\
\text { (L). vis. }\end{array}$ & Area (m2) & Phenanthrene & Anthracene & C1-Phe/An & 1-Methylphenanthrene & \\
\hline & & & & & & & & Unit & (ng/m2/day) & $(\mathrm{ng} / \mathrm{m} 2 /$ day $)$ & (ng/m2/day) & (ng/m2/day) & \\
\hline $2941-173$ & PB & 1 & & $8 / 28 / 08$ & $9 / 12 / 08$ & 15 & 1.0 & 0.159 & $6.61 \mathrm{U}$ & 0.00 & 4.82 & 0.524 & $4 \mathrm{U}$ \\
\hline $2941-182$ & PB & 2 & & $9 / 12 / 08$ & $9 / 25 / 08$ & 13 & 3.0 & 0.159 & $13.6 \mathrm{U}$ & 0.780 & 13.4 & 2.72 & \\
\hline 2941-191 & PB & 3 & & $9 / 25 / 08$ & $10 / 15 / 08$ & 20 & 4.0 & 0.159 & $15.8 \mathrm{U}$ & 1.24 & 17.7 & 3.61 & \\
\hline $2941-204$ & $\mathrm{~PB}$ & 4 & & $10 / 15 / 08$ & $10 / 29 / 08$ & 14 & 1.0 & 0.159 & $9.70 \mathrm{U}$ & 0.338 & 7.55 & 0.842 & \\
\hline 2941-209 & PB & 5 & & $10 / 29 / 08$ & $11 / 13 / 08$ & 15 & 1.0 & 0.159 & $8.73 \mathrm{U}$ & 0.183 & 9.51 & 1.33 & \\
\hline $2941-224$ & PB & 6 & & $11 / 13 / 08$ & $11 / 25 / 08$ & 12 & 1.5 & 0.159 & $23.0 \mathrm{U}$ & 0.00 & 17.7 & 3.60 & \\
\hline $2941-231$ & PB & 7 & & $11 / 25 / 08$ & $12 / 11 / 08$ & 16 & 13.0 & 0.159 & $2660 *$ & 507 & 2670 & 580 & $0 *$ \\
\hline $2941-248$ & PB & 9 & & $3 / 11 / 09$ & $3 / 25 / 09$ & 14 & 5.0 & 0.159 & $2130 *$ & 391 & $1800 *$ & 351 & $1 *$ \\
\hline $2941-259$ & PB & 10 & & $3 / 25 / 09$ & $4 / 8 / 09$ & 14 & 6.0 & 0.159 & $970 *$ & 181 & 868 & 179 & $9 *$ \\
\hline $2941-263$ & $\mathrm{~PB}$ & 11 & & $4 / 8 / 09$ & $4 / 23 / 09$ & 15 & 3.0 & 0.159 & $10.5 \mathrm{U}$ & 0.297 & 7.65 & 1.18 & \\
\hline $2941-271$ & PB & 12 & & $4 / 23 / 09$ & $5 / 6 / 09$ & 13 & 0.5 & 0.159 & $8.71 \mathrm{U}$ & 0.380 & 8.28 & 0.988 & \\
\hline $2941-283$ & PB & 13 & & $5 / 6 / 09$ & $5 / 21 / 09$ & 15 & 4.0 & 0.159 & $12.5 \mathrm{U}$ & 0.258 & 5.46 & 0.805 & \\
\hline $2941-290$ & PB & 14 & & $5 / 21 / 09$ & $6 / 3 / 09$ & 13 & 2.0 & 0.159 & 36.5 & 0.521 & 7.82 & 1.70 & \\
\hline $2941-305$ & PB & 15 & & 7/29/09 & $8 / 12 / 09$ & 14 & 3.0 & 0.159 & 31.1 & 1.76 & 17.6 & 2.60 & \\
\hline $2941-307$ & PB & 16 & & $8 / 12 / 09$ & $8 / 26 / 09$ & 14 & 0.0 & 0.159 & 34.7 & 0.549 & 8.83 & 2.31 & \\
\hline $2941-317$ & PB & 17 & & $8 / 26 / 09$ & 9/9/09 & 14 & 2.0 & 0.159 & $18.3 \mathrm{U}$ & 0.00 & 17.2 & 2.54 & \\
\hline $2941-323$ & PB & 18 & & 9/9/09 & $9 / 24 / 09$ & 15 & 3.0 & 0.159 & 29.9 & 0.00 & 14.2 & 2.54 & \\
\hline Stdev & & & & & & & & & 832 & 158 & 794 & 168 & \\
\hline RSD & & & & & & & & & $203 \%$ & $211 \%$ & $208 \%$ & $212 \%$ & \\
\hline $2941-176$ & $\mathrm{PO}$ & 1 & & $9 / 3 / 08$ & $9 / 17 / 08$ & 14 & 0.0 & 0.159 & $7.98 \mathrm{U}$ & 0.00 & 7.24 & 0.960 & \\
\hline $2941-185$ & $\mathrm{PO}$ & 2 & & $9 / 17 / 08$ & $10 / 6 / 08$ & 19 & 6.0 & 0.159 & $20.0 \mathrm{U}$ & 0.685 & 12.9 & 2.83 & \\
\hline $2941-193$ & $\mathrm{PO}$ & 3 & $\mathrm{x}$ & $10 / 6 / 08$ & $10 / 16 / 08$ & 10 & 1.5 & 0.159 & $27.6 \mathrm{U}$ & 1.53 & 20.9 & 5.13 & \\
\hline 2941-206 & $\mathrm{PO}$ & 4 & $\mathrm{x}$ & $10 / 16 / 08$ & $10 / 29 / 08$ & 13 & 1.0 & 0.159 & $12.0 \mathrm{U}$ & 0.513 & 10.6 & 1.36 & \\
\hline $2941-213$ & $\mathrm{PO}$ & 5 & & $10 / 29 / 08$ & $11 / 7 / 08$ & 9 & 6.0 & 0.159 & 39.6 & 0.887 & 31.7 & 6.95 & \\
\hline $2941-217$ & $\mathrm{PO}$ & 6 & & $11 / 7 / 08$ & $11 / 20 / 08$ & 12 & 13.5 & 0.159 & 64.3 & 1.20 & 30.6 & 7.70 & \\
\hline $2941-233$ & PO & 7 & & $11 / 20 / 08$ & $12 / 11 / 08$ & 21 & 2.0 & 0.159 & $955 *$ & 185 & 1020 & 199 & $9 *$ \\
\hline $2941-237$ & $\mathrm{PO}$ & 8 & & $2 / 26 / 09$ & $3 / 12 / 09$ & 14 & 4.0 & 0.159 & $1830 *$ & 347 & 1840 & 364 & $4 *$ \\
\hline $2941-251$ & PO & 9 & & $3 / 12 / 09$ & $3 / 25 / 09$ & 13 & 8.0 & 0.159 & $781 *$ & 115 & 602 & 127 & $7 *$ \\
\hline $2941-261$ & $\mathrm{PO}$ & 10 & & $3 / 25 / 09$ & $4 / 8 / 09$ & 14 & 6.0 & 0.159 & $942 *$ & 163 & 819 & 155 & $5 *$ \\
\hline $2941-270$ & $\mathrm{PO}$ & 11 & & $4 / 8 / 09$ & $4 / 22 / 09$ & 14 & 5.0 & 0.159 & 29.8 & 0.526 & 14.1 & 2.45 & \\
\hline $2941-277$ & $\mathrm{PO}$ & 12 & & $4 / 22 / 09$ & $5 / 5 / 09$ & 13 & 2.0 & 0.159 & $16.4 \mathrm{U}$ & 0.211 & 9.03 & 1.23 & \\
\hline $2941-279$ & $\mathrm{PO}$ & 13 & & $5 / 5 / 09$ & $5 / 20 / 09$ & 15 & 11.0 & 0.159 & 45.5 & 0.678 & 13.2 & 3.65 & \\
\hline 2941-292 & PO & 14 & & $5 / 20 / 09$ & $6 / 5 / 09$ & 16 & 4.0 & 0.159 & 44.9 & 0.974 & 13.6 & 2.84 & \\
\hline $2941-300$ & $\mathrm{PO}$ & 15 & & 7/30/09 & $8 / 14 / 09$ & 15 & 2.0 & 0.159 & 29.3 & 0.00 & 12.1 & 0.00 & $0 \mathrm{U}$ \\
\hline 2941-311 & PO & 16 & & $8 / 14 / 09$ & $8 / 26 / 09$ & 12 & 0.0 & 0.159 & $10.1 \mathrm{U}$ & 0.00 & 12.5 & 1.57 & \\
\hline $2941-321$ & $\mathrm{PO}$ & 17 & & $8 / 26 / 09$ & $9 / 11 / 09$ & 16 & 5.8 & 0.159 & 38.2 & 0.00 & 17.0 & 3.12 & \\
\hline Stdev & & & & & & & & & 499 & 94.0 & 494 & 97.3 & \\
\hline RSD & & & & & & & & & $192 \%$ & $218 \%$ & $208 \%$ & $208 \%$ & \\
\hline
\end{tabular}


Field Sample Results - Biomarker, PAHs

Station Event Field Date Date Funnel

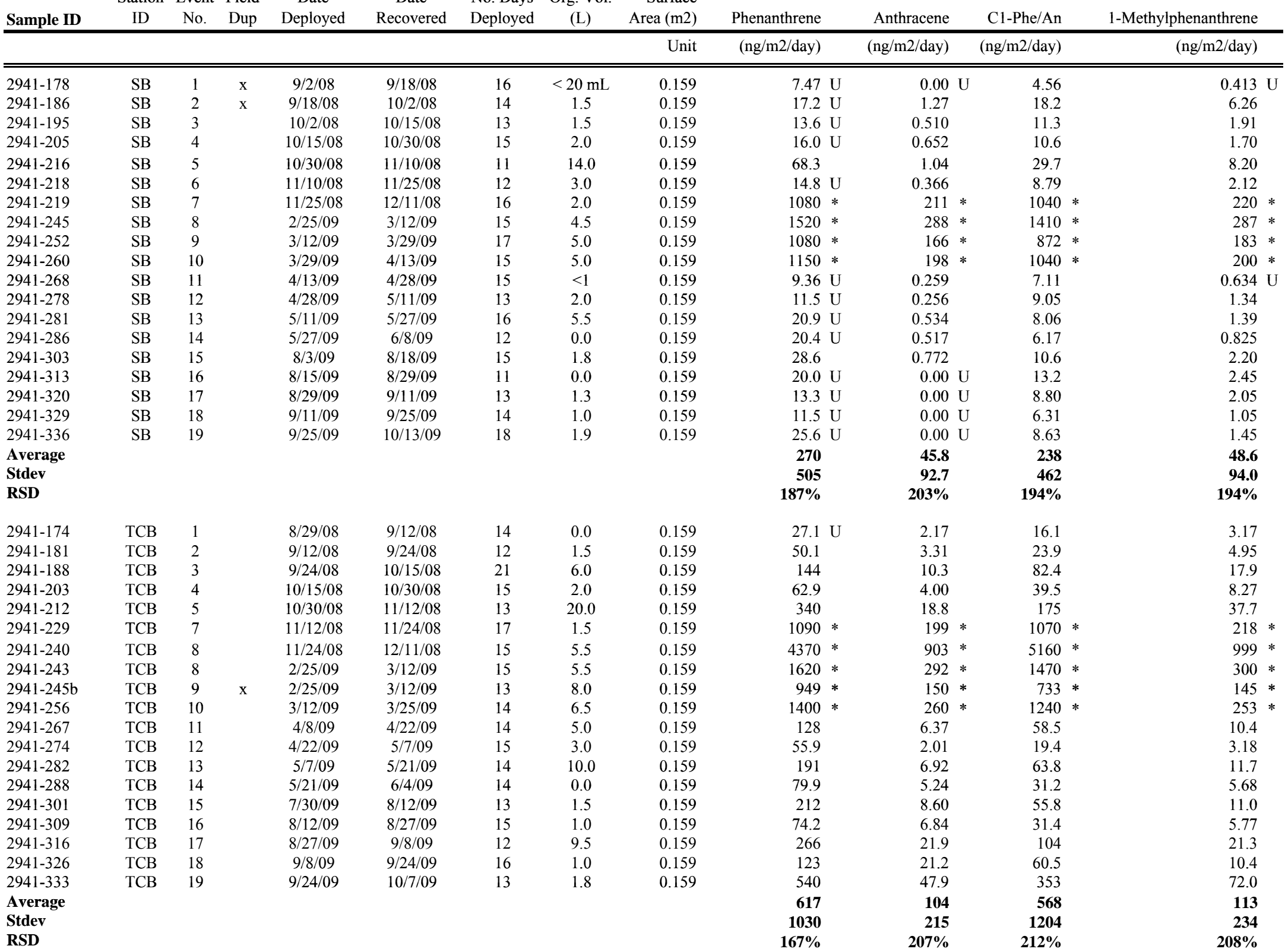


Field Sample Results - Biomarker, PAHs

\begin{tabular}{|c|c|c|c|c|c|c|c|c|c|c|c|c|}
\hline Sample ID & $\begin{array}{l}\text { Station } \\
\text { ID }\end{array}$ & $\begin{array}{l}\text { Event } \\
\text { No. }\end{array}$ & $\begin{array}{l}\text { Fleld } \\
\text { Dup }\end{array}$ & $\begin{array}{c}\text { Date } \\
\text { Deployed }\end{array}$ & $\begin{array}{l}\text { Date } \\
\text { Recovered }\end{array}$ & $\begin{array}{l}\text { No. Days } \\
\text { Deployed }\end{array}$ & $\begin{array}{l}\text { (L) } \\
\text { (L) vol. }\end{array}$ & $\begin{array}{r}\text { Surrace } \\
\text { Area (m2) }\end{array}$ & Phenanthrene & Anthracene & C1-Phe/An & 1-Methylphenanthrene \\
\hline & & & & & & & & Unit & (ng/m2/day) & (ng/m2/day) & (ng/m2/day) & (ng/m2/day) \\
\hline 2941-172 & WP & 1 & & $8 / 28 / 08$ & $9 / 12 / 08$ & 15 & 0.0 & 0.159 & $7.63 \mathrm{U}$ & 0.276 & 4.39 & $0.487 \mathrm{U}$ \\
\hline 2941-183 & WP & 2 & & $9 / 12 / 08$ & $9 / 25 / 08$ & 13 & 2.0 & 0.159 & 29.6 & 0.843 & 13.2 & 2.82 \\
\hline 2941-190 & WP & 3 & & $9 / 25 / 08$ & $10 / 14 / 08$ & 19 & 5.0 & 0.159 & $6130^{* *}$ & $662 * x$ & $3200 * *$ & 632 ** \\
\hline 2941-201 & WP & 4 & & $10 / 14 / 08$ & $10 / 29 / 08$ & 15 & 1.5 & 0.159 & $22.3 \mathrm{U}$ & 1.55 & 11.3 & 2.10 \\
\hline 2941-200 & WP & 5 & & $10 / 29 / 08$ & $11 / 13 / 08$ & 15 & 18.0 & 0.159 & 81.9 & 2.21 & 47.5 & 13.6 \\
\hline $2941-225$ & WP & 6 & & $11 / 13 / 08$ & $11 / 25 / 08$ & 12 & 1.0 & 0.159 & $23.1 \mathrm{U}$ & 0.692 & 23.9 & 3.91 \\
\hline $2941-230$ & WP & 7 & & $11 / 25 / 08$ & $12 / 11 / 08$ & 16 & 1.5 & 0.159 & $2550 *$ & $499 *$ & $2712 *$ & $538 *$ \\
\hline $2941-246$ & WP & 9 & & $3 / 11 / 09$ & $3 / 25 / 09$ & 14 & 6.0 & 0.159 & $558 *$ & $86.5 *$ & $440 *$ & $83.0 *$ \\
\hline $2941-258$ & WP & 10 & & $3 / 25 / 09$ & $4 / 8 / 09$ & 14 & 6.5 & 0.159 & $1260 *$ & $235 *$ & $1140 *$ & $216 *$ \\
\hline $2941-264$ & WP & 11 & & $4 / 8 / 09$ & $4 / 23 / 09$ & 15 & 4.0 & 0.159 & $25.7 \mathrm{U}$ & 0.943 & 24.2 & 3.48 \\
\hline $2941-272$ & WP & 12 & & $4 / 23 / 09$ & $5 / 6 / 09$ & 13 & 2.0 & 0.159 & $13.0 \mathrm{U}$ & 0.404 & 9.04 & 1.18 \\
\hline 2941-284 & WP & 13 & & $5 / 6 / 09$ & $5 / 21 / 09$ & 15 & 11.0 & 0.159 & $25.2 \mathrm{U}$ & 0.788 & 12.1 & 2.40 \\
\hline 2941-289 & WP & 14 & & $5 / 21 / 09$ & $6 / 3 / 09$ & 13 & 2.0 & 0.159 & 36.0 & 1.05 & 9.29 & 1.84 \\
\hline $2941-302$ & WP & 15 & & 7/29/09 & $8 / 12 / 09$ & 14 & 1.5 & 0.159 & $22.8 \mathrm{U}$ & 0.783 & 10.6 & 2.19 \\
\hline $2941-308$ & WP & 16 & & $8 / 12 / 09$ & $8 / 26 / 09$ & 14 & 1.5 & 0.159 & 38.0 & 1.00 & 10.9 & 1.89 \\
\hline $2941-315$ & WP & 17 & & $8 / 26 / 09$ & 9/9/09 & 14 & 4.5 & 0.159 & 32.4 & 1.87 & 19.0 & 2.98 \\
\hline $2941-327$ & WP & 18 & & 9/9/09 & $9 / 24 / 09$ & 15 & 2.0 & 0.159 & 28.1 & 2.14 & 11.5 & 2.00 \\
\hline Average & & & & & & & & & 872 & 139 & 727 & 141 \\
\hline Stdev & & & & & & & & & 1880 & 306 & 1601 & 308 \\
\hline RSD & & & & & & & & & $216 \%$ & $220 \%$ & $220 \%$ & $219 \%$ \\
\hline 2941-293 & TM & 14 & & $5 / 20 / 09$ & $6 / 4 / 09$ & 15 & & 0.159 & $25.9 \mathrm{U}$ & 0.561 & 5.45 & 0.815 \\
\hline 2941-304 & TM & 15 & & 7/30/09 & $8 / 12 / 09$ & 13 & & 0.159 & 91.1 & 6.91 & 31.2 & 5.88 \\
\hline $2941-312$ & $\mathrm{TM}$ & 16 & & $8 / 12 / 09$ & $8 / 27 / 09$ & 15 & & 0.159 & 46.0 & 1.68 & 20.6 & 3.43 \\
\hline 2941-318 & $\mathrm{TM}$ & 17 & & $8 / 27 / 09$ & $9 / 8 / 09$ & 12 & & 0.159 & 187 & 5.45 & 70.3 & 11.8 \\
\hline $2941-325$ & $\mathrm{TM}$ & 18 & & $9 / 8 / 09$ & $9 / 24 / 09$ & 16 & & 0.159 & 79.5 & 3.20 & 28.9 & 4.98 \\
\hline $2941-333$ & $\mathrm{TM}$ & 19 & & $9 / 24 / 09$ & $10 / 7 / 09$ & 13 & & 0.159 & 69.9 & 5.20 & 29.1 & 5.32 \\
\hline Average & & & & & & & & & 83.2 & 3.83 & 30.9 & 5.37 \\
\hline Stdev & & & & & & & & & 55.9 & 2.44 & 21.5 & 3.63 \\
\hline RSD & & & & & & & & & $67 \%$ & $64 \%$ & $70 \%$ & $68 \%$ \\
\hline
\end{tabular}

NA $\quad$ Not available

** Outlier; see narration

Carcinogenic PAHs: benzo(a)anthracene, chrysene, benzo(b)fluoranthene,

benzo(k)fluoranthene, benzo(a)pyrene, indeno(1,2,3-c,d)pyrene, dibenz(a,h)anthracene Pyrogenic PAHs: fluoranthene, pyrene, benzo(a)anthracene, chrysene,

b benzo(b)fluoranthene, benzo(k)fluoranthene, benzo(a)pyrene, indeno(1,2,3-c,d)pyrene, dibenz(a,h)anthracene, benzo(g,h,i)perylene

c High molecular weight PAHs: benzo(b)fluoranthene, benzo(k)fluoranthene,

benzo(a)pyrene, indeno(1,2,3-c,d)pyrene, dibenz(a,h)anthracene, benzo(g,h,i)perylene 
Field Sample Results - Biomarker, PAHs

\begin{tabular}{|c|c|c|c|c|c|c|c|c|c|c|c|c|}
\hline Sample ID & ID & No. & Dup & Deployed & Recovered & Deployed & (L) & Area (m2) & 3,6-Dimethylphenanthrene & & 2,6-Dimethylphenanthrene & 1,7-Dimethylphenanthrene \\
\hline & & & & & & & & Unit & (ng/m2/day) & & (ng/m2/day) & (ng/m2/day) \\
\hline $2941-177$ & $\mathrm{HC}$ & 1 & & $9 / 3 / 08$ & 9/17/08 & 14 & 0.0 & 0.159 & 4.04 & & $0.445 \mathrm{U}$ & 0.439 \\
\hline $2941-184$ & $\mathrm{HC}$ & 2 & & $9 / 17 / 08$ & $10 / 6 / 08$ & 19 & 8.0 & 0.159 & 19.2 & & $0.887 \mathrm{U}$ & 9.25 \\
\hline 2941-194 & $\mathrm{HC}$ & 3 & & $10 / 6 / 08$ & $10 / 16 / 08$ & 10 & 3.0 & 0.159 & 4.78 & & $0.807 \mathrm{U}$ & 2.25 \\
\hline 2941-208 & $\mathrm{HC}$ & 4 & & $10 / 16 / 08$ & $10 / 29 / 08$ & 13 & 1.0 & 0.159 & 2.55 & & $0.334 \mathrm{U}$ & 0.300 \\
\hline $2941-214$ & $\mathrm{HC}$ & 5 & $\mathrm{x}$ & $10 / 29 / 08$ & $11 / 8 / 08$ & 10 & 6.0 & 0.159 & 15.5 & & 1.41 & 11.6 \\
\hline $2941-220$ & $\mathrm{HC}$ & 6 & $\mathrm{x}$ & $11 / 8 / 08$ & $11 / 20 / 08$ & 12 & 6.0 & 0.159 & 9.54 & & 0.987 & 2.26 \\
\hline $2941-210$ & $\mathrm{HC}$ & 7 & $\mathrm{x}$ & $11 / 20 / 08$ & $12 / 11 / 08$ & 21 & 4.0 & 0.159 & 67.8 & * & $63.1 *$ & $120 *$ \\
\hline $2941-238$ & $\mathrm{HC}$ & 8 & & 2/26/09 & $3 / 12 / 09$ & 14 & 4.0 & 0.159 & 140 & * & $142 *$ & $247 *$ \\
\hline $2941-250$ & $\mathrm{HC}$ & 9 & & $3 / 12 / 09$ & $3 / 25 / 09$ & 13 & 9.5 & 0.159 & 28.5 & $*$ & $27.6 *$ & $46.8 *$ \\
\hline $2941-262$ & $\mathrm{HC}$ & 10 & & $3 / 25 / 09$ & 4/8/09 & 14 & 4.0 & 0.159 & 30.4 & * & $34.3 *$ & $58.1 *$ \\
\hline $2941-269$ & $\mathrm{HC}$ & 11 & & $4 / 8 / 09$ & $4 / 22 / 09$ & 14 & 6.0 & 0.159 & 3.47 & & $0.784 \mathrm{U}$ & 1.21 \\
\hline $2941-276$ & $\mathrm{HC}$ & 12 & & $4 / 22 / 09$ & $5 / 5 / 09$ & 13 & 1.0 & 0.159 & 3.96 & & $0.579 \mathrm{U}$ & 1.17 \\
\hline $2941-280$ & $\mathrm{HC}$ & 13 & & $5 / 5 / 09$ & $5 / 20 / 09$ & 15 & 5.0 & 0.159 & 3.78 & & $0.825 \mathrm{U}$ & 0.698 \\
\hline 2941-294 & $\mathrm{HC}$ & 14 & & $5 / 20 / 09$ & $6 / 5 / 09$ & 16 & 4.0 & 0.159 & 0.224 & $\mathrm{U}$ & $0.547 \mathrm{U}$ & 0.955 \\
\hline 2941-306 & $\mathrm{HC}$ & 15 & & 7/30/09 & $8 / 14 / 09$ & 15 & 2.5 & 0.159 & 0.00 & $\mathrm{U}$ & $0.458 \mathrm{U}$ & 2.50 \\
\hline $2941-314$ & $\mathrm{HC}$ & 16 & & $8 / 14 / 09$ & $8 / 26 / 09$ & 12 & 0.0 & 0.159 & 0.00 & $\mathrm{U}$ & $0.818 \mathrm{U}$ & 1.70 \\
\hline $2941-322$ & $\mathrm{HC}$ & 17 & & $8 / 26 / 09$ & $9 / 11 / 09$ & 16 & 6.8 & 0.159 & 0.00 & $\mathrm{U}$ & $0.00 \mathrm{U}$ & 1.83 \\
\hline $2947-328$ & $\mathrm{HC}$ & 18 & & 9/11/09 & $9 / 25 / 09$ & 14 & 2.0 & 0.159 & 0.00 & U & 1.01 & 2.38 \\
\hline $2941-338$ & $\mathrm{HC}$ & 19 & & $9 / 25 / 09$ & $10 / 14 / 09$ & 19 & 6.0 & 0.159 & 0.483 & $\mathrm{U}$ & $0.787 \mathrm{U}$ & 5.46 \\
\hline Average & & & & & & & & & 17.6 & & 14.6 & 27.1 \\
\hline Stdev & & & & & & & & & 34.1 & & 35.0 & 61.1 \\
\hline RSD & & & & & & & & & $194 \%$ & & $239 \%$ & $225 \%$ \\
\hline $2941-175$ & NR & 1 & & $8 / 29 / 08$ & $9 / 12 / 08$ & 14 & 0.0 & 0.159 & 3.93 & & $0.762 \mathrm{U}$ & 0.652 \\
\hline 2941-180 & NR & 2 & & 9/12/08 & $9 / 24 / 08$ & 12 & 1.0 & 0.159 & 7.33 & & 1.69 & 2.85 \\
\hline 2941-189 & NR & 3 & & 9/24/08 & 10/15/08 & 21 & 9.0 & 0.159 & 3.16 & & 1.62 & 21.2 \\
\hline 2941-202 & NR & 4 & & $10 / 15 / 08$ & $10 / 30 / 08$ & 15 & 2.0 & 0.159 & 4.21 & & 1.40 & 2.43 \\
\hline 2941-211 & NR & 5 & & $10 / 30 / 08$ & $11 / 12 / 08$ & 13 & 3.0 & 0.159 & 7.13 & & $0.783 \mathrm{U}$ & 1.93 \\
\hline $2941-223$ & NR & 6 & & $11 / 12 / 08$ & $11 / 24 / 08$ & 12 & 16.0 & 0.159 & 5.85 & & 1.61 & 6.30 \\
\hline $2941-228$ & NR & 7 & & $11 / 24 / 08$ & $12 / 11 / 08$ & 17 & 1.0 & 0.159 & 57.2 & * & $49.1 *$ & $82.8 *$ \\
\hline $2941-242$ & NR & 8 & & $2 / 25 / 09$ & $3 / 12 / 09$ & 15 & 3.0 & 0.159 & 55.7 & * & $51.3 *$ & $90.4 *$ \\
\hline 2941-249 & NR & 9 & & $3 / 12 / 09$ & $3 / 25 / 09$ & 13 & 6.0 & 0.159 & 31.1 & * & $30.1 *$ & $56.6 *$ \\
\hline $2941-255$ & NR & 10 & $\mathrm{x}$ & $3 / 25 / 09$ & 4/8/09 & 14 & 5.0 & 0.159 & 19.8 & * & $19.4 *$ & $34.1 *$ \\
\hline $2941-265$ & NR & 11 & $\mathrm{x}$ & 4/8/09 & $4 / 22 / 09$ & 14 & 4.0 & 0.159 & 2.38 & & $0.669 \mathrm{U}$ & 1.55 \\
\hline $2941-273$ & NR & 12 & $\mathrm{x}$ & $4 / 22 / 09$ & $5 / 7 / 09$ & 15 & 1.0 & 0.159 & 3.45 & & $0.440 \mathrm{U}$ & 0.591 \\
\hline $2941-285$ & NR & 13 & & $5 / 7 / 09$ & $5 / 21 / 09$ & 14 & 1.5 & 0.159 & 0.137 & $\mathrm{U}$ & $0.618 \mathrm{U}$ & 1.57 \\
\hline $2941-287$ & NR & 14 & & $5 / 21 / 09$ & $6 / 4 / 09$ & 14 & 0.0 & 0.159 & 0.332 & $\mathrm{U}$ & $0.739 \mathrm{U}$ & 1.20 \\
\hline 2941-299 & NR & 15 & & $7 / 30 / 09$ & $8 / 12 / 09$ & 13 & 1.0 & 0.159 & 0.00 & $\mathrm{U}$ & 1.28 & 1.65 \\
\hline $2941-310$ & NR & 16 & & $8 / 12 / 09$ & $8 / 27 / 09$ & 15 & 0.5 & 0.159 & 0.00 & U & 3.53 & 3.31 \\
\hline 2941-319 & NR & 17 & & $8 / 27 / 09$ & 9/8/09 & 12 & 8.0 & 0.159 & 1.46 & & 2.47 & 5.49 \\
\hline 2941-324 & NR & 18 & & 9/8/09 & $9 / 24 / 09$ & 16 & 2.0 & 0.159 & 0.00 & $\mathrm{U}$ & 1.11 & 2.10 \\
\hline $2941-335$ & NR & 19 & & 9/24/09 & 10/7/09 & 13 & 1.0 & 0.159 & 1.03 & & 1.50 & 3.09 \\
\hline Average & & & & & & & & & 10.7 & & 8.95 & 16.8 \\
\hline Stdev & & & & & & & & & 17.9 & & 16.4 & 28.5 \\
\hline RSD & & & & & & & & & $166 \%$ & & $183 \%$ & $169 \%$ \\
\hline
\end{tabular}


Field Sample Results - Biomarker, PAHs

Station Event Field Date Funnel

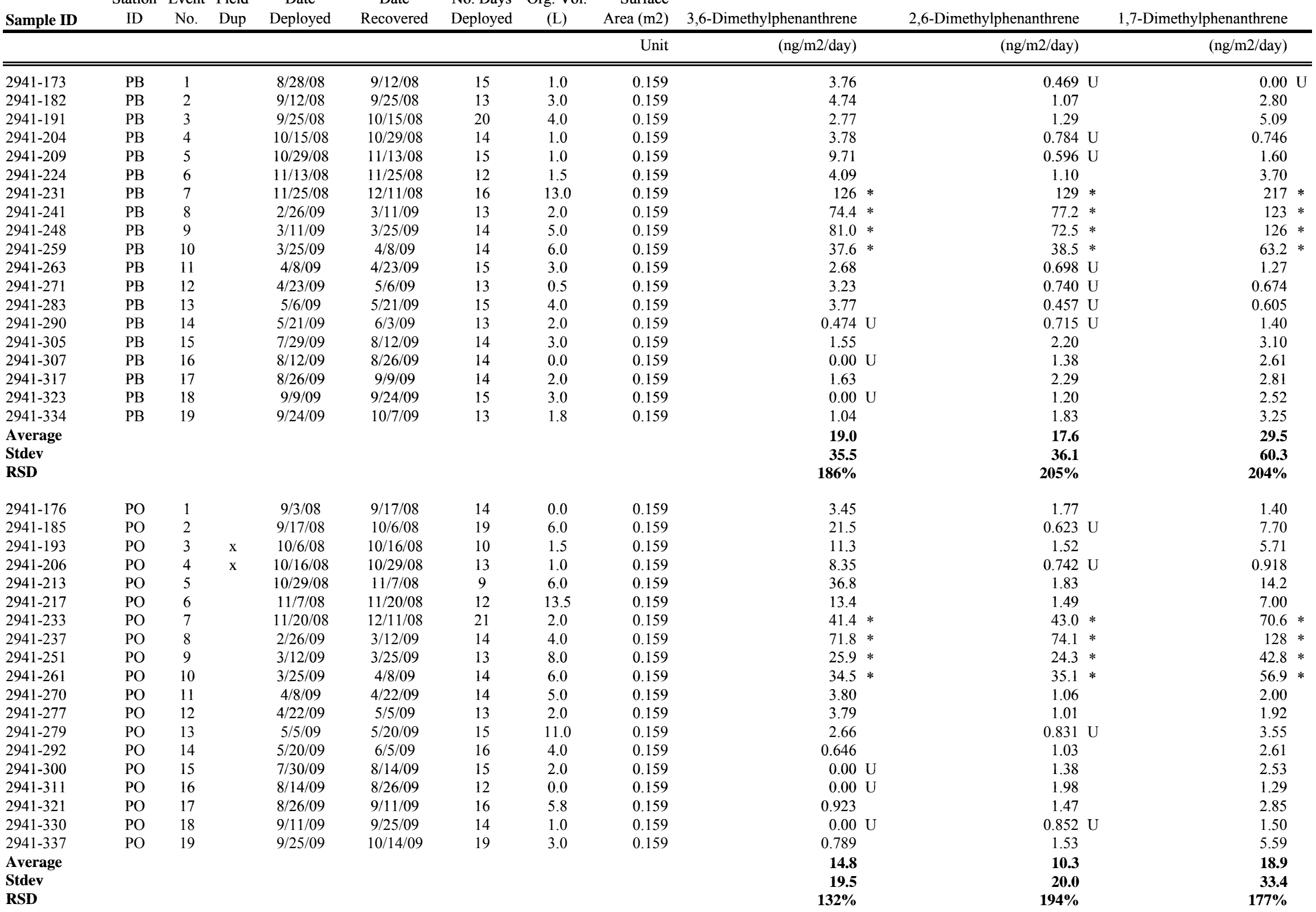


Field Sample Results - Biomarker, PAHs

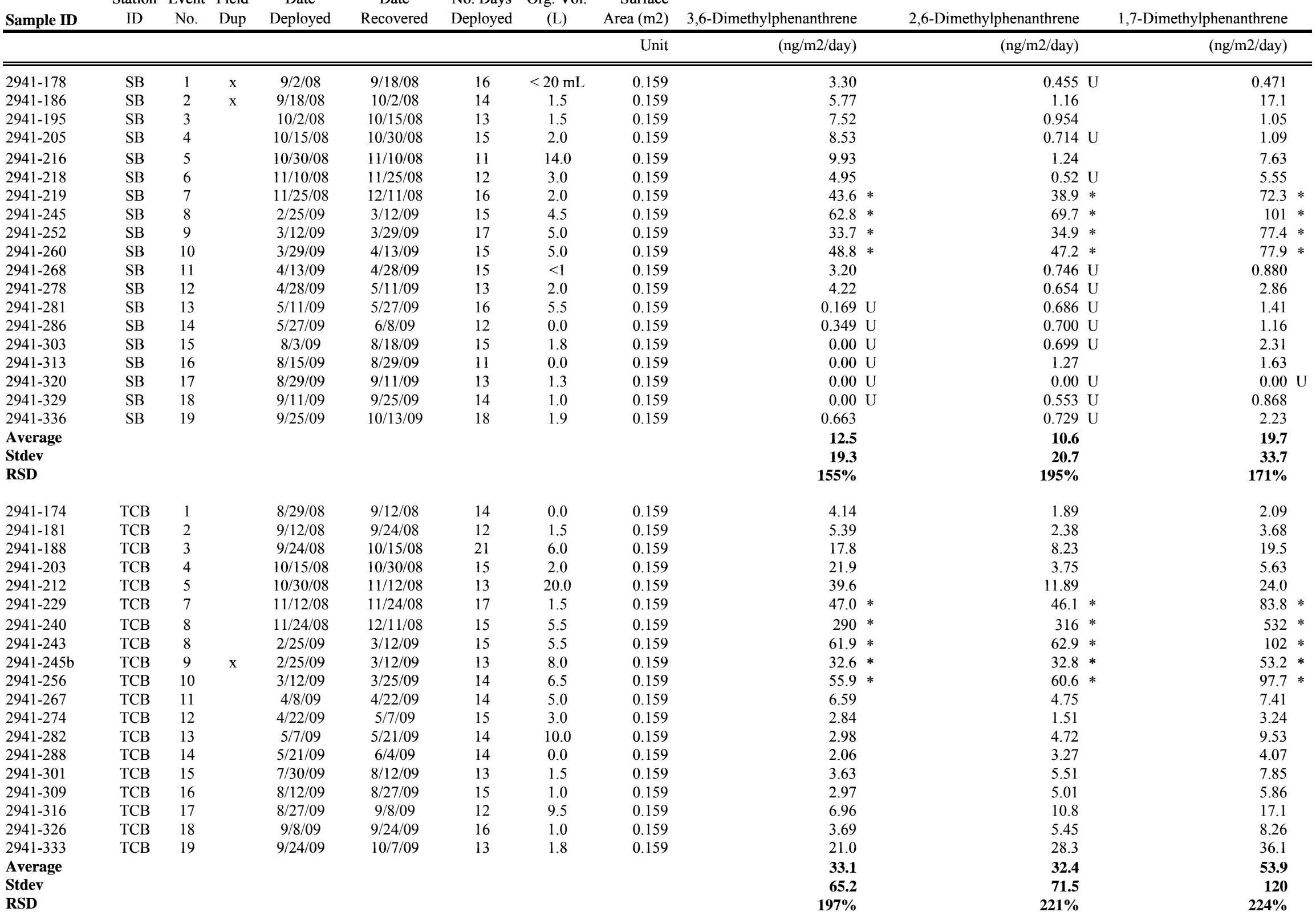


Field Sample Results - Biomarker, PAHs

\begin{tabular}{|c|c|c|c|c|c|c|c|c|c|c|c|}
\hline Sample ID & ID & No. & Dup & Deployed & Recovered & $\begin{array}{l}\text { No. Days } \\
\text { Deployed }\end{array}$ & $\begin{array}{l}\text { (L) } \\
\text { (n) vol. }\end{array}$ & Area (m2) & 3,6-Dimethylphenanthrene & 2,6-Dimethylphenanthrene & 1,7-Dimethylphenanthrene \\
\hline & & & & & & & & Unit & (ng/m2/day) & (ng/m2/day) & (ng/m2/day) \\
\hline $2941-172$ & WP & 1 & & $8 / 28 / 08$ & $9 / 12 / 08$ & 15 & 0.0 & 0.159 & 2.22 & $0.00 \mathrm{U}$ & $0.00 \mathrm{~L}$ \\
\hline $2941-183$ & WP & 2 & & $9 / 12 / 08$ & $9 / 25 / 08$ & 13 & 2.0 & 0.159 & 3.74 & 1.04 & 4.36 \\
\hline 2941-190 & WP & 3 & & $9 / 25 / 08$ & $10 / 14 / 08$ & 19 & 5.0 & 0.159 & 169 ** & 175 ** & 177 * \\
\hline 2941-201 & WP & 4 & & $10 / 14 / 08$ & $10 / 29 / 08$ & 15 & 1.5 & 0.159 & 2.46 & 0.839 & 1.65 \\
\hline 2941-200 & WP & 5 & & $10 / 29 / 08$ & $11 / 13 / 08$ & 15 & 18.0 & 0.159 & 5.13 & 3.06 & 20.3 \\
\hline $2941-225$ & WP & 6 & & $11 / 13 / 08$ & $11 / 25 / 08$ & 12 & 1.0 & 0.159 & 5.06 & 1.24 & 6.61 \\
\hline $2941-230$ & WP & 7 & & $11 / 25 / 08$ & $12 / 11 / 08$ & 16 & 1.5 & 0.159 & $122 *$ & $136 *$ & $212 *$ \\
\hline $2941-244$ & WP & 8 & & 2/26/09 & $3 / 11 / 09$ & 13 & 4.5 & 0.159 & $252 *$ & $284 *$ & $468 *$ \\
\hline $2941-246$ & WP & 9 & & $3 / 11 / 09$ & $3 / 25 / 09$ & 14 & 6.0 & 0.159 & $16.8 *$ & $16.8 *$ & $28.8 *$ \\
\hline $2941-258$ & WP & 10 & & $3 / 25 / 09$ & $4 / 8 / 09$ & 14 & 6.5 & 0.159 & $51.3 *$ & $49.2 *$ & $80.2 *$ \\
\hline $2941-264$ & WP & 11 & & $4 / 8 / 09$ & $4 / 23 / 09$ & 15 & 4.0 & 0.159 & 3.30 & 1.54 & 3.29 \\
\hline $2941-272$ & WP & 12 & & $4 / 23 / 09$ & $5 / 6 / 09$ & 13 & 2.0 & 0.159 & 4.29 & $0.916 \mathrm{U}$ & 1.89 \\
\hline $2941-284$ & WP & 13 & & $5 / 6 / 09$ & $5 / 21 / 09$ & 15 & 11.0 & 0.159 & 2.91 & 1.43 & 3.17 \\
\hline $2941-289$ & WP & 14 & & $5 / 21 / 09$ & $6 / 3 / 09$ & 13 & 2.0 & 0.159 & $0.608 \mathrm{U}$ & 1.00 & 1.40 \\
\hline $2941-302$ & WP & 15 & & 7/29/09 & $8 / 12 / 09$ & 14 & 1.5 & 0.159 & 1.03 & 1.49 & 2.27 \\
\hline $2941-308$ & WP & 16 & & $8 / 12 / 09$ & $8 / 26 / 09$ & 14 & 1.5 & 0.159 & $0.00 \mathrm{U}$ & 1.61 & 2.41 \\
\hline $2941-315$ & WP & 17 & & $8 / 26 / 09$ & 9/9/09 & 14 & 4.5 & 0.159 & 1.47 & 2.36 & 4.10 \\
\hline $2941-327$ & WP & 18 & & 9/9/09 & $9 / 24 / 09$ & 15 & 2.0 & 0.159 & $0.00 \mathrm{U}$ & 1.03 & 1.32 \\
\hline $2941-332$ & WP & 19 & & 9/24/09 & $10 / 7 / 09$ & 13 & 3.8 & 0.159 & 1.48 & 2.75 & 4.62 \\
\hline Average & & & & & & & & & 33.9 & 35.8 & 53.9 \\
\hline Stdev & & & & & & & & & 69.9 & 77.5 & 117 \\
\hline RSD & & & & & & & & & $206 \%$ & $216 \%$ & $218 \%$ \\
\hline $2941-293$ & $\mathrm{TM}$ & 14 & & $5 / 20 / 09$ & $6 / 4 / 09$ & 15 & & 0.159 & $0.319 \mathrm{U}$ & $0.583 \mathrm{U}$ & 0.624 \\
\hline $2941-304$ & TM & 15 & & 7/30/09 & $8 / 12 / 09$ & 13 & & 0.159 & 1.82 & 2.78 & 4.16 \\
\hline $2941-312$ & TM & 16 & & $8 / 12 / 09$ & $8 / 27 / 09$ & 15 & & 0.159 & 1.81 & 2.36 & 2.65 \\
\hline $2941-318$ & $\mathrm{TM}$ & 17 & & $8 / 27 / 09$ & $9 / 8 / 09$ & 12 & & 0.159 & 4.16 & 7.70 & 6.32 \\
\hline $2941-325$ & TM & 18 & & $9 / 8 / 09$ & $9 / 24 / 09$ & 16 & & 0.159 & 1.62 & 2.62 & 2.64 \\
\hline $2941-333$ & $\mathrm{TM}$ & 19 & & $9 / 24 / 09$ & $10 / 7 / 09$ & 13 & & 0.159 & 1.96 & 3.48 & 4.97 \\
\hline Average & & & & & & & & & 1.95 & 3.25 & 3.56 \\
\hline Stdev & & & & & & & & & 1.24 & 2.38 & 2.02 \\
\hline RSD & & & & & & & & & $64 \%$ & $73 \%$ & $57 \%$ \\
\hline
\end{tabular}

NA $\quad$ Not available

** Outlier; see narration

Carcinogenic PAHs: benzo(a)anthracene, chrysene, benzo(b)fluoranthene,

benzo(k)fluoranthene, benzo(a)pyrene, indeno(1,2,3-c,d)pyrene, dibenz(a,h)anthracene Pyrogenic PAHs: fluoranthene, pyrene, benzo(a)anthracene, chrysene,

b benzo(b)fluoranthene, benzo(k)fluoranthene, benzo(a)pyrene, indeno(1,2,3-c,d)pyrene, dibenz(a,h)anthracene, benzo(g,h,i)perylene

c High molecular weight PAHs: benzo(b)fluoranthene, benzo(k)fluoranthene,

benzo(a)pyrene, indeno(1,2,3-c,d)pyrene, dibenz(a,h)anthracene, benzo(g,h,i)perylene 
Field Sample Results - Biomarker, PAHs

Station Event Field Date Date Funnel

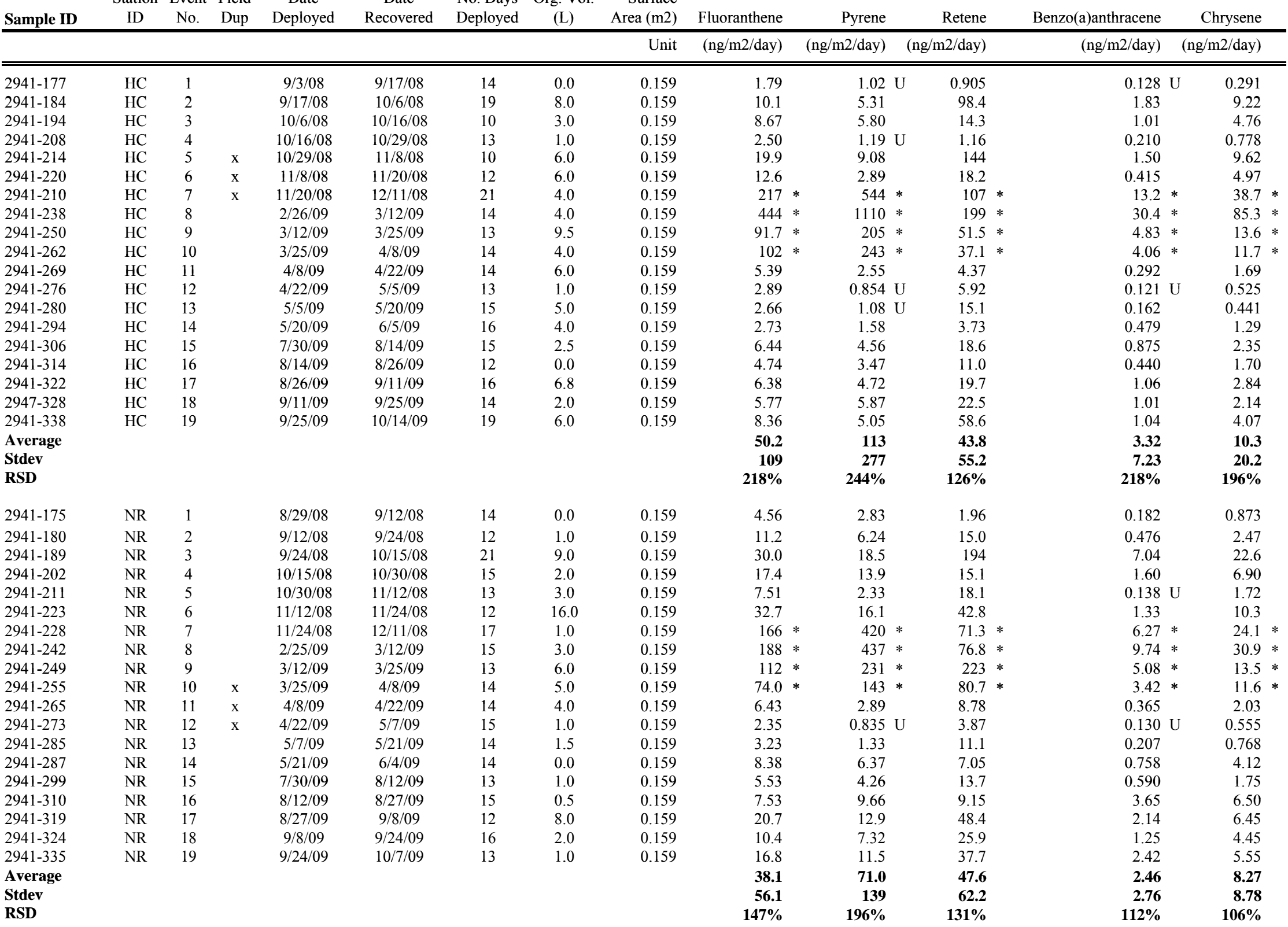


Field Sample Results - Biomarker, PAHs

Station Event Field Date Date Funnel

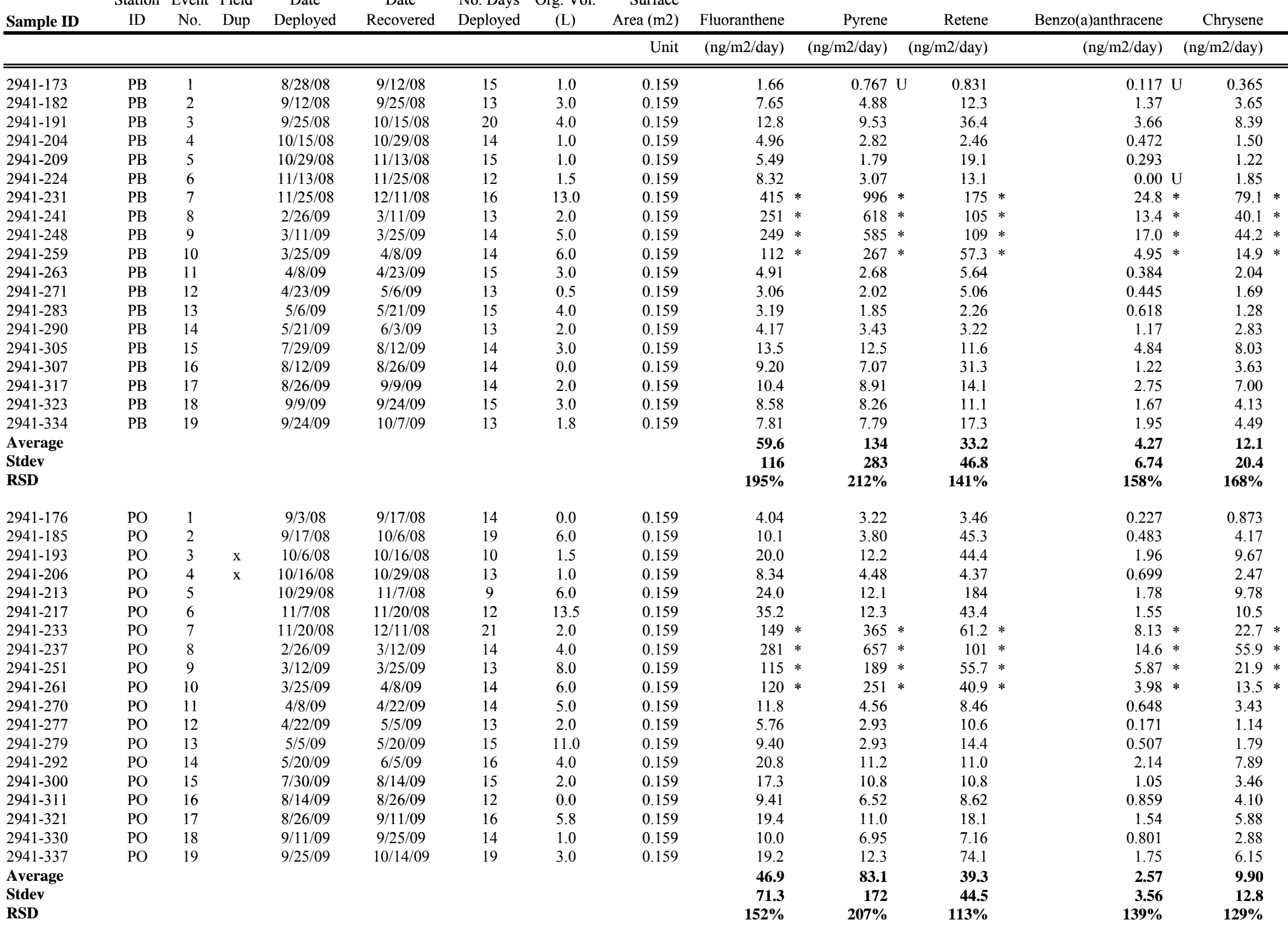


Field Sample Results - Biomarker, PAHs

Station Event Field Date Date Funnel

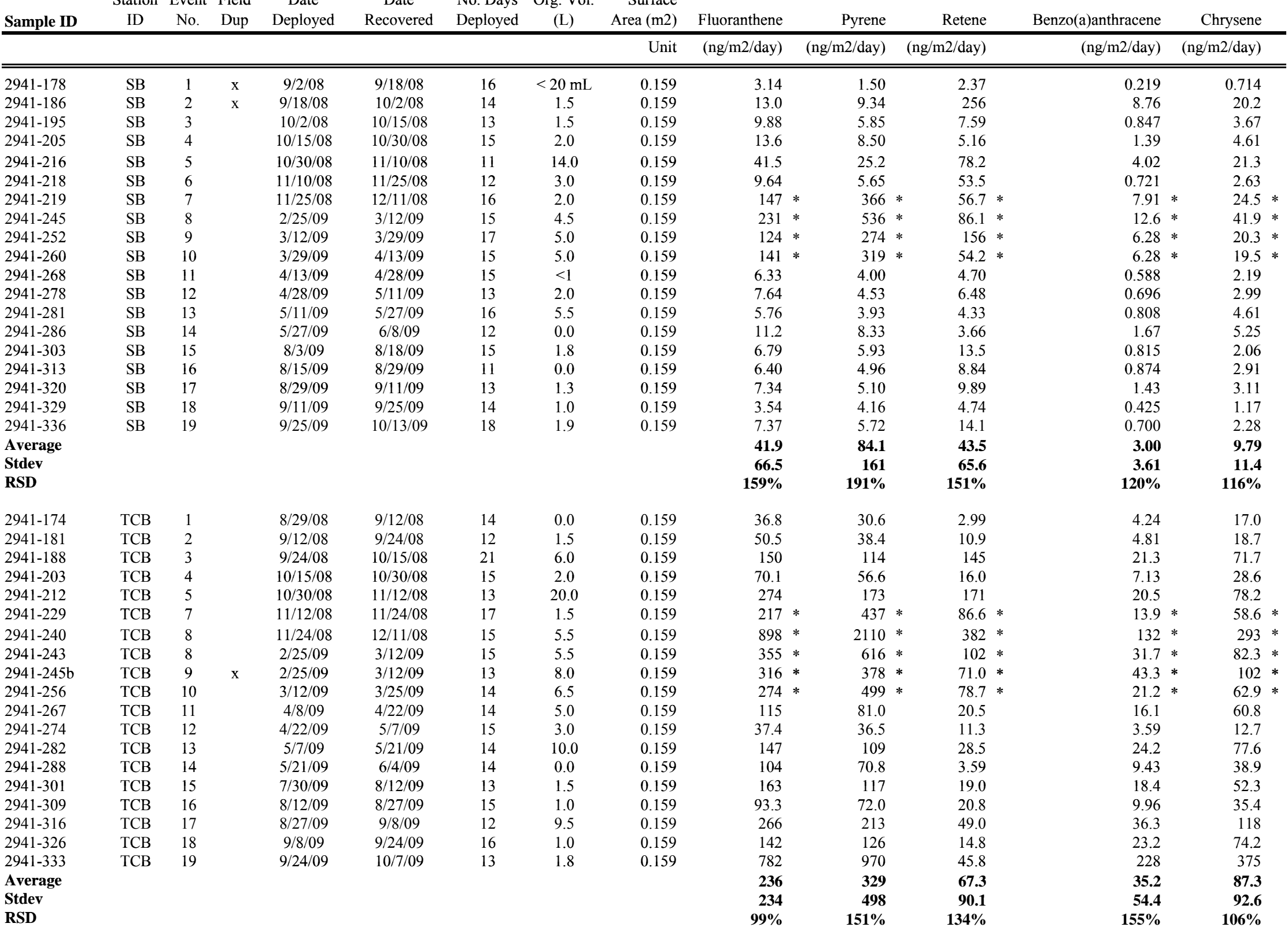


Field Sample Results - Biomarker, PAHs

\begin{tabular}{|c|c|c|c|c|c|c|c|c|c|c|c|c|c|}
\hline Sample ID & $\begin{array}{l}\text { Station } \\
\text { ID }\end{array}$ & $\begin{array}{l}\text { Event } \\
\text { No. }\end{array}$ & $\begin{array}{l}\text { Field } \\
\text { Dup }\end{array}$ & $\begin{array}{c}\text { Date } \\
\text { Deployed }\end{array}$ & $\begin{array}{c}\text { Date } \\
\text { Recovered }\end{array}$ & $\begin{array}{l}\text { No. Days } \\
\text { Deployed }\end{array}$ & $\begin{array}{l}\text { Urg. Vol. } \\
\text { (L) }\end{array}$ & $\begin{array}{r}\text { Surface } \\
\text { Area }(\mathrm{m} 2)\end{array}$ & Fluoranthene & Pyrene & Retene & Benzo(a)anthracene & Chrysene \\
\hline & & & & & & & & Unit & (ng/m2/day) & (ng/m2/day) & (ng/m2/day) & (ng/m2/day) & (ng/m2/day) \\
\hline 2941-172 & WP & 1 & & $8 / 28 / 08$ & $9 / 12 / 08$ & 15 & 0.0 & 0.159 & 3.39 & 2.08 & 0.967 & 0.396 & 1.07 \\
\hline 2941-183 & WP & 2 & & $9 / 12 / 08$ & $9 / 25 / 08$ & 13 & 2.0 & 0.159 & 11.1 & 6.74 & 26.5 & 1.03 & 4.01 \\
\hline 2941-190 & WP & 3 & & $9 / 25 / 08$ & $10 / 14 / 08$ & 19 & 5.0 & 0.159 & 6130 & 5400 & $105 * *$ & 2300 & 2610 \\
\hline 2941-201 & WP & 4 & & $10 / 14 / 08$ & $10 / 29 / 08$ & 15 & 1.5 & 0.159 & 17.7 & 14.9 & 5.91 & 3.24 & 8.12 \\
\hline 2941-200 & WP & 5 & & $10 / 29 / 08$ & $11 / 13 / 08$ & 15 & 18.0 & 0.159 & 49.5 & 27.4 & 191 & 4.52 & 24.8 \\
\hline $2941-225$ & WP & 6 & & $11 / 13 / 08$ & $11 / 25 / 08$ & 12 & 1.0 & 0.159 & 14.8 & 11.7 & 38.2 & 1.39 & 6.32 \\
\hline $2941-230$ & WP & 7 & & $11 / 25 / 08$ & $12 / 11 / 08$ & 16 & 1.5 & 0.159 & 389 & 1010 & $152 *$ & 22.7 & 61.7 \\
\hline $2941-244$ & WP & 8 & & $2 / 26 / 09$ & $3 / 11 / 09$ & 13 & 4.5 & 0.159 & 959 & 2240 & $418 *$ & 57.7 & 183 \\
\hline $2941-246$ & WP & 9 & & $3 / 11 / 09$ & $3 / 25 / 09$ & 14 & 6.0 & 0.159 & 69.7 & 133 & $29.6 *$ & 3.14 & 11.0 \\
\hline $2941-258$ & WP & 10 & & $3 / 25 / 09$ & $4 / 8 / 09$ & 14 & 6.5 & 0.159 & 158 & 362 & $60.7 *$ & 6.61 & 21.1 \\
\hline $2941-264$ & WP & 11 & & $4 / 8 / 09$ & $4 / 23 / 09$ & 15 & 4.0 & 0.159 & 14.6 & 11.6 & 7.22 & 1.94 & 7.18 \\
\hline $2941-272$ & WP & 12 & & $4 / 23 / 09$ & $5 / 6 / 09$ & 13 & 2.0 & 0.159 & 6.86 & 3.50 & 9.82 & 0.566 & 2.13 \\
\hline 2941-284 & WP & 13 & & $5 / 6 / 09$ & $5 / 21 / 09$ & 15 & 11.0 & 0.159 & 9.30 & 3.64 & 7.24 & 0.702 & 2.65 \\
\hline $2941-289$ & WP & 14 & & $5 / 21 / 09$ & $6 / 3 / 09$ & 13 & 2.0 & 0.159 & 12.2 & 8.57 & 2.97 & 1.77 & 6.20 \\
\hline $2941-302$ & WP & 15 & & $7 / 29 / 09$ & $8 / 12 / 09$ & 14 & 1.5 & 0.159 & 11.8 & 11.2 & 11.6 & 1.41 & 4.35 \\
\hline 2941-308 & WP & 16 & & $8 / 12 / 09$ & $8 / 26 / 09$ & 14 & 1.5 & 0.159 & 15.9 & 12.6 & 10.5 & 1.91 & 5.18 \\
\hline $2941-315$ & WP & 17 & & $8 / 26 / 09$ & 9/9/09 & 14 & 4.5 & 0.159 & 24.8 & 18.6 & 18.9 & 3.38 & 9.90 \\
\hline $2941-327$ & WP & 18 & & 9/9/09 & $9 / 24 / 09$ & 15 & 2.0 & 0.159 & 9.00 & 6.56 & 7.47 & 1.80 & 3.92 \\
\hline $2941-332$ & WP & 19 & & $9 / 24 / 09$ & $10 / 7 / 09$ & 13 & 3.8 & 0.159 & 32.6 & 25.5 & 26.2 & 6.31 & 14.4 \\
\hline Average & & & & & & & & & 418 & 490 & 59.5 & 127 & 157 \\
\hline Stdev & & & & & & & & & 1400 & 1310 & 102 & 526 & 595 \\
\hline RSD & & & & & & & & & $335 \%$ & $267 \%$ & $171 \%$ & $413 \%$ & $379 \%$ \\
\hline $2941-293$ & TM & 14 & & $5 / 20 / 09$ & $6 / 4 / 09$ & 15 & & 0.159 & 6.78 & 3.94 & 1.21 & 0.717 & 2.27 \\
\hline 2941-304 & $\mathrm{TM}$ & 15 & & 7/30/09 & $8 / 12 / 09$ & 13 & & 0.159 & 59.2 & 36.3 & 19.3 & 3.71 & 12.0 \\
\hline $2941-312$ & TM & 16 & & $8 / 12 / 09$ & $8 / 27 / 09$ & 15 & & 0.159 & 41.8 & 27.1 & 11.8 & 2.93 & 11.2 \\
\hline $2941-318$ & $\mathrm{TM}$ & 17 & & $8 / 27 / 09$ & $9 / 8 / 09$ & 12 & & 0.159 & 107 & 54.5 & 19.5 & 4.58 & 22.8 \\
\hline $2941-325$ & $\mathrm{TM}$ & 18 & & 9/8/09 & $9 / 24 / 09$ & 16 & & 0.159 & 63.9 & 40.7 & 11.7 & 3.17 & 20.7 \\
\hline $2941-333$ & $\mathrm{TM}$ & 19 & & $9 / 24 / 09$ & $10 / 7 / 09$ & 13 & & 0.159 & 87.9 & 56.4 & 29.1 & 5.96 & 28.3 \\
\hline Average & & & & & & & & & 61.2 & 36.5 & 15.4 & 3.51 & 16.2 \\
\hline Stdev & & & & & & & & & 35.2 & 19.4 & 9.46 & 1.76 & 9.45 \\
\hline RSD & & & & & & & & & $58 \%$ & $53 \%$ & $61 \%$ & $50 \%$ & $58 \%$ \\
\hline
\end{tabular}

NA $\quad$ Not available

** $\quad$ Outlier; see narration

Carcinogenic PAHs: benzo(a)anthracene, chrysene, benzo(b)fluoranthene,

benzo(k)fluoranthene, benzo(a)pyrene, indeno(1,2,3-c,d)pyrene, dibenz(a,h)anthracene

Pyrogenic PAHs: fluoranthene, pyrene, benzo(a)anthracene, chrysene,

b benzo(b)fluoranthene, benzo(k)fluoranthene, benzo(a)pyrene, indeno(1,2,3-c,d)pyrene, dibenz(a,h)anthracene, benzo(g,h,i)perylene

High molecular weight PAHs: benzo(b)fluoranthene, benzo(k)fluoranthene,

benzo(a)pyrene, indeno(1,2,3-c,d)pyrene, dibenz(a,h)anthracene, benzo(g,h,i)perylene 
Field Sample Results - Biomarker, PAHs

Station Event Field Date Date No Days Org Vol Sunnel

\begin{tabular}{|c|c|c|c|c|c|c|c|c|c|c|c|c|c|}
\hline Sample ID & ID & No. & Dup & Deployed & Recovered & Deployed & (L) & Area (m2) & Benzo(b)fluoranthene & Benzo(k)fluoranthene & Benzo(a)pyrene & Perylene & \\
\hline & & & & & & & & Unit & (ng/m2/day) & (ng/m2/day) & (ng/m2/day) & (ng/m2/day) & \\
\hline 2941-177 & $\mathrm{HC}$ & 1 & & $9 / 3 / 08$ & $9 / 17 / 08$ & 14 & 0.0 & 0.159 & $0.285 \mathrm{U}$ & $0.160 \mathrm{U}$ & $0.00 \mathrm{U}$ & 0.00 & $0 \mathrm{U}$ \\
\hline 2941-184 & $\mathrm{HC}$ & 2 & & $9 / 17 / 08$ & $10 / 6 / 08$ & 19 & 8.0 & 0.159 & 9.62 & 2.68 & 2.38 & 0.368 & \\
\hline 2941-194 & $\mathrm{HC}$ & 3 & & $10 / 6 / 08$ & $10 / 16 / 08$ & 10 & 3.0 & 0.159 & 3.52 & 3.32 & 0.910 & 0.00 & $0 \mathrm{U}$ \\
\hline 2941-208 & $\mathrm{HC}$ & 4 & & $10 / 16 / 08$ & $10 / 29 / 08$ & 13 & 1.0 & 0.159 & 1.20 & 0.383 & $0.00 \mathrm{U}$ & 0.00 & $0 \mathrm{U}$ \\
\hline $2941-214$ & $\mathrm{HC}$ & 5 & $\mathrm{x}$ & $10 / 29 / 08$ & $11 / 8 / 08$ & 10 & 6.0 & 0.159 & 12.0 & 2.75 & 0.850 & 0.00 & $0 \mathrm{U}$ \\
\hline $2941-220$ & $\mathrm{HC}$ & 6 & $\mathrm{x}$ & $11 / 8 / 08$ & $11 / 20 / 08$ & 12 & 6.0 & 0.159 & 8.22 & 1.26 & $0.00 \mathrm{U}$ & 0.167 & \\
\hline 2941-210 & $\mathrm{HC}$ & 7 & $\mathrm{x}$ & $11 / 20 / 08$ & $12 / 11 / 08$ & 21 & 4.0 & 0.159 & 10.1 & 3.32 & 3.24 & 1.12 & \\
\hline $2941-238$ & $\mathrm{HC}$ & 8 & & 2/26/09 & $3 / 12 / 09$ & 14 & 4.0 & 0.159 & 5.21 & 4.04 & 3.45 & 1.45 & \\
\hline $2941-250$ & $\mathrm{HC}$ & 9 & & $3 / 12 / 09$ & $3 / 25 / 09$ & 13 & 9.5 & 0.159 & 7.10 & 1.65 & 1.88 & 0.451 & \\
\hline $2941-262$ & $\mathrm{HC}$ & 10 & & $3 / 25 / 09$ & $4 / 8 / 09$ & 14 & 4.0 & 0.159 & 4.14 & 1.14 & 1.43 & 0.283 & \\
\hline $2941-269$ & $\mathrm{HC}$ & 11 & & $4 / 8 / 09$ & $4 / 22 / 09$ & 14 & 6.0 & 0.159 & 1.36 & 0.976 & $0.00 \mathrm{U}$ & 0.00 & $0 \mathrm{U}$ \\
\hline $2941-276$ & $\mathrm{HC}$ & 12 & & $4 / 22 / 09$ & $5 / 5 / 09$ & 13 & 1.0 & 0.159 & $0.00 \mathrm{U}$ & 1.97 & $0.00 \mathrm{U}$ & 0.00 & $0 \mathrm{U}$ \\
\hline $2941-280$ & $\mathrm{HC}$ & 13 & & $5 / 5 / 09$ & $5 / 20 / 09$ & 15 & 5.0 & 0.159 & 0.942 & $0.14 \mathrm{U}$ & $0.00 \mathrm{U}$ & 2.32 & \\
\hline 2941-294 & $\mathrm{HC}$ & 14 & & $5 / 20 / 09$ & $6 / 5 / 09$ & 16 & 4.0 & 0.159 & 1.44 & 0.558 & 0.987 & 0.439 & \\
\hline 2941-306 & $\mathrm{HC}$ & 15 & & 7/30/09 & $8 / 14 / 09$ & 15 & 2.5 & 0.159 & 3.73 & 1.19 & 1.25 & 1.20 & \\
\hline $2941-314$ & $\mathrm{HC}$ & 16 & & $8 / 14 / 09$ & $8 / 26 / 09$ & 12 & 0.0 & 0.159 & 1.64 & 0.826 & $0.00 \mathrm{U}$ & 0.00 & $0 \mathrm{U}$ \\
\hline $2941-322$ & $\mathrm{HC}$ & 17 & & $8 / 26 / 09$ & $9 / 11 / 09$ & 16 & 6.8 & 0.159 & 7.15 & 2.46 & 1.64 & 3.00 & \\
\hline $2947-328$ & $\mathrm{HC}$ & 18 & & $9 / 11 / 09$ & $9 / 25 / 09$ & 14 & 2.0 & 0.159 & 2.60 & 1.02 & 1.58 & 0.00 & $0 \mathrm{U}$ \\
\hline $2941-338$ & $\mathrm{HC}$ & 19 & & $9 / 25 / 09$ & $10 / 14 / 09$ & 19 & 6.0 & 0.159 & 3.16 & 1.24 & 1.42 & 0.406 & \\
\hline Average & & & & & & & & & 4.39 & 1.64 & 1.11 & 0.590 & \\
\hline Stdev & & & & & & & & & 3.64 & 1.15 & 1.10 & 0.863 & \\
\hline RSD & & & & & & & & & $83 \%$ & $70 \%$ & $99 \%$ & $146 \%$ & \\
\hline $2941-175$ & NR & 1 & & $8 / 29 / 08$ & $9 / 12 / 08$ & 14 & 0.0 & 0.159 & $0.782 \mathrm{U}$ & 0.367 & $0.00 \mathrm{U}$ & 0.00 & $0 \mathrm{U}$ \\
\hline 2941-180 & NR & 2 & & $9 / 12 / 08$ & $9 / 24 / 08$ & 12 & 1.0 & 0.159 & 2.68 & 1.08 & 0.602 & 0.00 & $0 \mathrm{U}$ \\
\hline 2941-189 & NR & 3 & & $9 / 24 / 08$ & $10 / 15 / 08$ & 21 & 9.0 & 0.159 & 26.5 & 5.79 & 5.75 & 1.08 & \\
\hline 2941-202 & NR & 4 & & $10 / 15 / 08$ & $10 / 30 / 08$ & 15 & 2.0 & 0.159 & 10.2 & 2.11 & 1.50 & 0.356 & \\
\hline 2941-211 & NR & 5 & & $10 / 30 / 08$ & $11 / 12 / 08$ & 13 & 3.0 & 0.159 & 1.49 & 0.413 & $0.00 \mathrm{U}$ & 0.00 & $0 \mathrm{U}$ \\
\hline $2941-223$ & NR & 6 & & $11 / 12 / 08$ & $11 / 24 / 08$ & 12 & 16.0 & 0.159 & 8.85 & 3.54 & 1.26 & 0.00 & $0 \mathrm{U}$ \\
\hline $2941-228$ & NR & 7 & & $11 / 24 / 08$ & $12 / 11 / 08$ & 17 & 1.0 & 0.159 & 3.47 & 1.57 & 1.14 & 0.00 & $0 \mathrm{U}$ \\
\hline $2941-242$ & NR & 8 & & $2 / 25 / 09$ & $3 / 12 / 09$ & 15 & 3.0 & 0.159 & 6.79 & 1.43 & 2.51 & 0.885 & \\
\hline $2941-249$ & NR & 9 & & $3 / 12 / 09$ & $3 / 25 / 09$ & 13 & 6.0 & 0.159 & 6.95 & 1.38 & 2.38 & 0.572 & \\
\hline $2941-255$ & NR & 10 & $\mathrm{x}$ & $3 / 25 / 09$ & $4 / 8 / 09$ & 14 & 5.0 & 0.159 & 8.23 & 2.78 & 3.10 & 0.683 & \\
\hline $2941-265$ & NR & 11 & $\mathrm{x}$ & $4 / 8 / 09$ & $4 / 22 / 09$ & 14 & 4.0 & 0.159 & $0.00 \mathrm{U}$ & 2.19 & 0.427 & 0.00 & $0 \mathrm{U}$ \\
\hline $2941-273$ & NR & 12 & $\mathrm{x}$ & $4 / 22 / 09$ & $5 / 7 / 09$ & 15 & 1.0 & 0.159 & $0.633 \mathrm{U}$ & 2.83 & 0.130 & 0.00 & $0 \mathrm{U}$ \\
\hline $2941-285$ & NR & 13 & & $5 / 7 / 09$ & $5 / 21 / 09$ & 14 & 1.5 & 0.159 & 0.913 & 0.324 & $0.00 \mathrm{U}$ & 0.00 & $0 \mathrm{U}$ \\
\hline $2941-287$ & NR & 14 & & $5 / 21 / 09$ & $6 / 4 / 09$ & 14 & 0.0 & 0.159 & 3.62 & 1.55 & 2.12 & 1.04 & \\
\hline 2941-299 & NR & 15 & & $7 / 30 / 09$ & $8 / 12 / 09$ & 13 & 1.0 & 0.159 & 3.38 & 1.05 & 0.673 & 0.00 & $0 \mathrm{U}$ \\
\hline 2941-310 & NR & 16 & & $8 / 12 / 09$ & $8 / 27 / 09$ & 15 & 0.5 & 0.159 & 4.07 & 1.44 & 4.38 & 0.00 & $0 \mathrm{U}$ \\
\hline 2941-319 & NR & 17 & & $8 / 27 / 09$ & 9/8/09 & 12 & 8.0 & 0.159 & 9.79 & 3.37 & 3.14 & 4.36 & \\
\hline 2941-324 & NR & 18 & & $9 / 8 / 09$ & $9 / 24 / 09$ & 16 & 2.0 & 0.159 & 3.39 & 1.18 & 1.20 & 0.00 & $0 \mathrm{U}$ \\
\hline 2941-335 & NR & 19 & & 9/24/09 & $10 / 7 / 09$ & 13 & 1.0 & 0.159 & 6.29 & 2.65 & 3.83 & 1.13 & \\
\hline Average & & & & & & & & & 5.69 & 1.95 & 1.80 & 0.532 & \\
\hline Stdev & & & & & & & & & 5.98 & 1.34 & 1.65 & 1.02 & \\
\hline RSD & & & & & & & & & $105 \%$ & $69 \%$ & $92 \%$ & $192 \%$ & \\
\hline
\end{tabular}


Field Sample Results - Biomarker, PAHs

Station Event Field Date Date Nunnel

\begin{tabular}{|c|c|c|c|c|c|c|c|c|c|c|c|c|c|}
\hline Sample ID & ID & $\begin{array}{l}\text { No. } \\
\text { Nont }\end{array}$ & Dup & Deployed & Recovered & $\begin{array}{l}\text { No. Days } \\
\text { Deployed }\end{array}$ & $\begin{array}{l}\text { (L) } \\
\text { (L) vi. }\end{array}$ & Area (m2) & Benzo(b)fluoranthene & Benzo(k)fluoranthene & Benzo(a)pyrene & Perylene & \\
\hline & & & & & & & & Unit & (ng/m2/day) & (ng/m2/day) & (ng/m2/day) & (ng/m2/day) & \\
\hline $2941-173$ & PB & 1 & & $8 / 28 / 08$ & $9 / 12 / 08$ & 15 & 1.0 & 0.159 & $0.204 \mathrm{U}$ & $0.00 \mathrm{U}$ & $0.00 \mathrm{~L}$ & 0.00 & $0 \mathrm{U}$ \\
\hline $2941-182$ & PB & 2 & & $9 / 12 / 08$ & $9 / 25 / 08$ & 13 & 3.0 & 0.159 & 3.23 & 0.826 & 1.01 & 0.260 & \\
\hline 2941-191 & PB & 3 & & $9 / 25 / 08$ & $10 / 15 / 08$ & 20 & 4.0 & 0.159 & 12.1 & 2.44 & 6.69 & 0.682 & \\
\hline 2941-204 & PB & 4 & & $10 / 15 / 08$ & $10 / 29 / 08$ & 14 & 1.0 & 0.159 & 1.56 & 0.614 & 0.515 & 0.00 & $0 \mathrm{U}$ \\
\hline $2941-209$ & PB & 5 & & $10 / 29 / 08$ & $11 / 13 / 08$ & 15 & 1.0 & 0.159 & 1.27 & 0.410 & $0.00 \mathrm{~L}$ & 0.00 & $0 \mathrm{U}$ \\
\hline $2941-224$ & PB & 6 & & $11 / 13 / 08$ & $11 / 25 / 08$ & 12 & 1.5 & 0.159 & 2.58 & 0.753 & $0.00 \mathrm{~L}$ & 0.00 & $0 \mathrm{U}$ \\
\hline $2941-231$ & PB & 7 & & $11 / 25 / 08$ & $12 / 11 / 08$ & 16 & 13.0 & 0.159 & 10.6 & 2.94 & 3.31 & 1.18 & \\
\hline $2941-241$ & PB & 8 & & $2 / 26 / 09$ & $3 / 11 / 09$ & 13 & 2.0 & 0.159 & 7.08 & 1.63 & 3.22 & 1.02 & \\
\hline $2941-248$ & PB & 9 & & $3 / 11 / 09$ & $3 / 25 / 09$ & 14 & 5.0 & 0.159 & 20.5 & 2.89 & 8.11 & 1.45 & \\
\hline $2941-259$ & PB & 10 & & $3 / 25 / 09$ & 4/8/09 & 14 & 6.0 & 0.159 & 3.47 & 3.19 & 2.56 & 0.396 & \\
\hline $2941-263$ & PB & 11 & & $4 / 8 / 09$ & $4 / 23 / 09$ & 15 & 3.0 & 0.159 & 1.35 & 1.43 & 1.02 & 0.153 & \\
\hline $2941-271$ & PB & 12 & & $4 / 23 / 09$ & $5 / 6 / 09$ & 13 & 0.5 & 0.159 & 1.27 & 1.88 & $0.00 \mathrm{~L}$ & 0.831 & \\
\hline $2941-283$ & PB & 13 & & $5 / 6 / 09$ & $5 / 21 / 09$ & 15 & 4.0 & 0.159 & 1.48 & 0.606 & 1.25 & 0.332 & \\
\hline $2941-290$ & PB & 14 & & $5 / 21 / 09$ & $6 / 3 / 09$ & 13 & 2.0 & 0.159 & 2.63 & 1.17 & 2.42 & 0.536 & \\
\hline $2941-305$ & PB & 15 & & 7/29/09 & $8 / 12 / 09$ & 14 & 3.0 & 0.159 & 7.45 & 1.60 & 5.21 & 1.31 & \\
\hline 2941-307 & PB & 16 & & 8/12/09 & $8 / 26 / 09$ & 14 & 0.0 & 0.159 & 3.77 & 1.23 & 1.37 & 0.00 & $0 \mathrm{U}$ \\
\hline $2941-317$ & PB & 17 & & $8 / 26 / 09$ & 9/9/09 & 14 & 2.0 & 0.159 & 8.00 & 1.06 & 4.07 & 1.34 & \\
\hline $2941-323$ & PB & 18 & & 9/9/09 & $9 / 24 / 09$ & 15 & 3.0 & 0.159 & 4.52 & 1.04 & 2.80 & 0.00 & $0 \mathrm{U}$ \\
\hline $2941-334$ & $\mathrm{~PB}$ & 19 & & $9 / 24 / 09$ & $10 / 7 / 09$ & 13 & 1.8 & 0.159 & 3.73 & 1.38 & 2.23 & 0.647 & \\
\hline Average & & & & & & & & & 5.10 & 1.43 & 2.41 & 0.534 & \\
\hline Stdev & & & & & & & & & 5.00 & 0.896 & 2.31 & 0.519 & \\
\hline RSD & & & & & & & & & $98 \%$ & $63 \%$ & $96 \%$ & $97 \%$ & \\
\hline $2941-176$ & $\mathrm{PO}$ & 1 & & $9 / 3 / 08$ & $9 / 17 / 08$ & 14 & 0.0 & 0.159 & $0.705 \mathrm{U}$ & $0.296 \mathrm{U}$ & 0.246 & 0.00 & $0 \mathrm{U}$ \\
\hline 2941-185 & PO & 2 & & 9/17/08 & $10 / 6 / 08$ & 19 & 6.0 & 0.159 & 3.27 & 0.864 & 0.470 & 0.00 & $0 \mathrm{U}$ \\
\hline $2941-193$ & $\mathrm{PO}$ & 3 & $\mathrm{x}$ & $10 / 6 / 08$ & $10 / 16 / 08$ & 10 & 1.5 & 0.159 & 9.47 & 2.49 & 1.76 & 0.376 & \\
\hline $2941-206$ & $\mathrm{PO}$ & 4 & $\mathrm{x}$ & $10 / 16 / 08$ & $10 / 29 / 08$ & 13 & 1.0 & 0.159 & 2.75 & 1.26 & 0.545 & 0.00 & $0 \mathrm{U}$ \\
\hline $2941-213$ & PO & 5 & & $10 / 29 / 08$ & $11 / 7 / 08$ & 9 & 6.0 & 0.159 & 11.8 & 3.08 & 1.16 & 0.00 & $0 \mathrm{U}$ \\
\hline $2941-217$ & PO & 6 & & $11 / 7 / 08$ & $11 / 20 / 08$ & 12 & 13.5 & 0.159 & 11.6 & 2.75 & 1.01 & 0.00 & $0 \mathrm{U}$ \\
\hline $2941-233$ & PO & 7 & & $11 / 20 / 08$ & 12/11/08 & 21 & 2.0 & 0.159 & 3.15 & 1.32 & 1.51 & 0.684 & \\
\hline $2941-237$ & $\mathrm{PO}$ & 8 & & $2 / 26 / 09$ & $3 / 12 / 09$ & 14 & 4.0 & 0.159 & 11.8 & 4.95 & 5.86 & 1.43 & \\
\hline $2941-251$ & PO & 9 & & $3 / 12 / 09$ & $3 / 25 / 09$ & 13 & 8.0 & 0.159 & 17.9 & 3.86 & 4.97 & 0.977 & \\
\hline $2941-261$ & $\mathrm{PO}$ & 10 & & $3 / 25 / 09$ & $4 / 8 / 09$ & 14 & 6.0 & 0.159 & 8.22 & 2.34 & 2.89 & 0.539 & \\
\hline $2941-270$ & PO & 11 & & 4/8/09 & $4 / 22 / 09$ & 14 & 5.0 & 0.159 & 2.96 & 1.14 & $0.00 \mathrm{~L}$ & 0.00 & $0 \mathrm{U}$ \\
\hline $2941-277$ & PO & 12 & & $4 / 22 / 09$ & $5 / 5 / 09$ & 13 & 2.0 & 0.159 & $0.626 \mathrm{U}$ & 1.37 & $0.00 \mathrm{~L}$ & 0.00 & $0 \mathrm{U}$ \\
\hline $2941-279$ & $\mathrm{PO}$ & 13 & & $5 / 5 / 09$ & $5 / 20 / 09$ & 15 & 11.0 & 0.159 & 1.53 & 0.623 & $0.00 \mathrm{~L}$ & 0.00 & $0 \mathrm{U}$ \\
\hline $2941-292$ & PO & 14 & & $5 / 20 / 09$ & $6 / 5 / 09$ & 16 & 4.0 & 0.159 & 7.62 & 2.92 & 3.57 & 0.655 & \\
\hline $2941-300$ & $\mathrm{PO}$ & 15 & & 7/30/09 & $8 / 14 / 09$ & 15 & 2.0 & 0.159 & 3.31 & 1.66 & 1.30 & 0.00 & $0 \mathrm{U}$ \\
\hline 2941-311 & PO & 16 & & $8 / 14 / 09$ & $8 / 26 / 09$ & 12 & 0.0 & 0.159 & 3.45 & $0.00 \mathrm{U}$ & 1.63 & 0.00 & $0 \mathrm{U}$ \\
\hline $2941-321$ & $\mathrm{PO}$ & 17 & & $8 / 26 / 09$ & $9 / 11 / 09$ & 16 & 5.8 & 0.159 & 7.05 & 1.55 & 2.00 & 2.22 & \\
\hline 2941-330 & $\mathrm{PO}$ & 18 & & 9/11/09 & $9 / 25 / 09$ & 14 & 1.0 & 0.159 & 3.58 & 1.23 & 0.762 & 0.00 & $0 \mathrm{U}$ \\
\hline $2941-337$ & $\mathrm{PO}$ & 19 & & $9 / 25 / 09$ & $10 / 14 / 09$ & 19 & 3.0 & 0.159 & 5.09 & 1.68 & 2.22 & 0.706 & \\
\hline Average & & & & & & & & & 6.09 & 1.86 & 1.68 & 0.400 & \\
\hline Stdev & & & & & & & & & 4.67 & 1.25 & 1.65 & 0.612 & \\
\hline RSD & & & & & & & & & $77 \%$ & $67 \%$ & $98 \%$ & $153 \%$ & \\
\hline
\end{tabular}


Field Sample Results - Biomarker, PAHs

Station Event Field Date Date Funnel

\begin{tabular}{|c|c|c|c|c|c|c|c|c|c|c|c|c|}
\hline Sample ID & ID & No. & Dup & Deployed & Recovered & Deployed & (L) & Area $(\mathrm{m} 2)$ & Benzo(b)fluoranthene & Benzo(k)fluoranthene & Benzo(a)pyrene & Perylene \\
\hline & & & & & & & & Unit & (ng/m2/day) & (ng/m2/day) & (ng/m2/day) & (ng/m2/day) \\
\hline $2941-178$ & SB & 1 & $\mathrm{x}$ & $9 / 2 / 08$ & $9 / 18 / 08$ & 16 & $<20 \mathrm{~mL}$ & 0.159 & $0.600 \mathrm{U}$ & 0.376 & 0.116 & 0.118 \\
\hline 2941-186 & SB & 2 & $\mathrm{x}$ & $9 / 18 / 08$ & $10 / 2 / 08$ & 14 & 1.5 & 0.159 & 18.4 & 4.53 & 5.18 & 0.806 \\
\hline 2941-195 & SB & 3 & & $10 / 2 / 08$ & $10 / 15 / 08$ & 13 & 1.5 & 0.159 & 3.21 & 1.13 & 0.644 & $0.00 \mathrm{U}$ \\
\hline $2941-205$ & SB & 4 & & $10 / 15 / 08$ & $10 / 30 / 08$ & 15 & 2.0 & 0.159 & 4.20 & 2.06 & 0.844 & $0.00 \mathrm{U}$ \\
\hline $2941-216$ & SB & 5 & & $10 / 30 / 08$ & $11 / 10 / 08$ & 11 & 14.0 & 0.159 & 23.3 & 5.80 & 3.06 & 0.532 \\
\hline $2941-218$ & SB & 6 & & $11 / 10 / 08$ & $11 / 25 / 08$ & 12 & 3.0 & 0.159 & 3.35 & 1.10 & 0.277 & $0.00 \mathrm{U}$ \\
\hline 2941-219 & SB & 7 & & $11 / 25 / 08$ & $12 / 11 / 08$ & 16 & 2.0 & 0.159 & 2.76 & 1.33 & 1.50 & $0.00 \mathrm{U}$ \\
\hline $2941-245$ & SB & 8 & & 2/25/09 & $3 / 12 / 09$ & 15 & 4.5 & 0.159 & 13.4 & 3.64 & 5.36 & 1.29 \\
\hline $2941-252$ & SB & 9 & & $3 / 12 / 09$ & $3 / 29 / 09$ & 17 & 5.0 & 0.159 & 12.3 & 2.86 & 3.56 & 0.851 \\
\hline $2941-260$ & SB & 10 & & $3 / 29 / 09$ & $4 / 13 / 09$ & 15 & 5.0 & 0.159 & 9.46 & 2.66 & 3.83 & 0.689 \\
\hline $2941-268$ & SB & 11 & & 4/13/09 & $4 / 28 / 09$ & 15 & $<1$ & 0.159 & 2.62 & 1.18 & 1.58 & 0.272 \\
\hline $2941-278$ & SB & 12 & & $4 / 28 / 09$ & $5 / 11 / 09$ & 13 & 2.0 & 0.159 & 3.71 & 1.86 & 1.04 & 0.470 \\
\hline 2941-281 & SB & 13 & & $5 / 11 / 09$ & $5 / 27 / 09$ & 16 & 5.5 & 0.159 & 2.76 & 1.26 & 1.32 & 0.425 \\
\hline $2941-286$ & SB & 14 & & $5 / 27 / 09$ & $6 / 8 / 09$ & 12 & 0.0 & 0.159 & 7.35 & 2.95 & 3.76 & 0.758 \\
\hline $2941-303$ & SB & 15 & & $8 / 3 / 09$ & $8 / 18 / 09$ & 15 & 1.8 & 0.159 & 2.91 & 2.12 & 1.39 & $0.00 \mathrm{U}$ \\
\hline 2941-313 & SB & 16 & & $8 / 15 / 09$ & $8 / 29 / 09$ & 11 & 0.0 & 0.159 & 3.29 & 1.11 & 1.57 & $0.00 \mathrm{U}$ \\
\hline $2941-320$ & SB & 17 & & $8 / 29 / 09$ & $9 / 11 / 09$ & 13 & 1.3 & 0.159 & 7.68 & 2.09 & 1.94 & 3.91 \\
\hline 2941-329 & SB & 18 & & 9/11/09 & $9 / 25 / 09$ & 14 & 1.0 & 0.159 & 1.49 & 0.386 & $0.00 \mathrm{U}$ & $0.00 \mathrm{U}$ \\
\hline $2941-336$ & SB & 19 & & 9/25/09 & 10/13/09 & 18 & 1.9 & 0.159 & 2.36 & 0.759 & 1.13 & $0.00 \mathrm{U}$ \\
\hline Average & & & & & & & & & 6.59 & 2.06 & 2.01 & 0.532 \\
\hline Stdev & & & & & & & & & 6.20 & 1.42 & 1.64 & 0.905 \\
\hline RSD & & & & & & & & & $94 \%$ & $69 \%$ & $82 \%$ & $170 \%$ \\
\hline $2941-174$ & TCB & 1 & & $8 / 29 / 08$ & $9 / 12 / 08$ & 14 & 0.0 & 0.159 & 15.5 & 5.53 & 6.00 & 1.38 \\
\hline 2941-181 & TCB & 2 & & 9/12/08 & $9 / 24 / 08$ & 12 & 1.5 & 0.159 & 18.5 & 6.86 & 8.01 & 1.51 \\
\hline 2941-188 & TCB & 3 & & 9/24/08 & $10 / 15 / 08$ & 21 & 6.0 & 0.159 & 82.1 & 17.7 & 26.6 & 5.47 \\
\hline 2941-203 & TCB & 4 & & $10 / 15 / 08$ & $10 / 30 / 08$ & 15 & 2.0 & 0.159 & 33.9 & 9.72 & 11.5 & 1.87 \\
\hline $2941-212$ & TCB & 5 & & $10 / 30 / 08$ & $11 / 12 / 08$ & 13 & 20.0 & 0.159 & 75.1 & 19.4 & 20.7 & 4.34 \\
\hline $2941-229$ & TCB & 7 & & $11 / 12 / 08$ & $11 / 24 / 08$ & 17 & 1.5 & 0.159 & 29.2 & 13.2 & 17.8 & 3.64 \\
\hline $2941-240$ & TCB & 8 & & $11 / 24 / 08$ & 12/11/08 & 15 & 5.5 & 0.159 & 69.8 & 18.2 & 38.6 & 13.5 \\
\hline $2941-243$ & TCB & 8 & & $2 / 25 / 09$ & $3 / 12 / 09$ & 15 & 5.5 & 0.159 & 73.9 & 23.5 & 37.0 & 8.24 \\
\hline $2941-245 b$ & TCB & 9 & $\mathrm{x}$ & 2/25/09 & $3 / 12 / 09$ & 13 & 8.0 & 0.159 & 132 & 39.6 & 63.9 & 12.0 \\
\hline $2941-256$ & TCB & 10 & & $3 / 12 / 09$ & $3 / 25 / 09$ & 14 & 6.5 & 0.159 & 62.4 & 18.7 & 28.0 & 5.70 \\
\hline $2941-267$ & TCB & 11 & & $4 / 8 / 09$ & $4 / 22 / 09$ & 14 & 5.0 & 0.159 & 67.9 & 21.7 & 29.5 & 6.54 \\
\hline $2941-274$ & TCB & 12 & & $4 / 22 / 09$ & $5 / 7 / 09$ & 15 & 3.0 & 0.159 & 15.4 & 5.34 & 6.98 & 1.05 \\
\hline $2941-282$ & TCB & 13 & & $5 / 7 / 09$ & $5 / 21 / 09$ & 14 & 10.0 & 0.159 & 80.9 & 34.0 & 47.5 & 8.72 \\
\hline $2941-288$ & TCB & 14 & & $5 / 21 / 09$ & $6 / 4 / 09$ & 14 & 0.0 & 0.159 & 48.5 & 12.1 & 22.5 & 3.34 \\
\hline 2941-301 & TCB & 15 & & $7 / 30 / 09$ & $8 / 12 / 09$ & 13 & 1.5 & 0.159 & 52.0 & 16.1 & 24.4 & 7.92 \\
\hline 2941-309 & TCB & 16 & & $8 / 12 / 09$ & $8 / 27 / 09$ & 15 & 1.0 & 0.159 & 32.2 & 9.98 & 12.8 & 4.15 \\
\hline $2941-316$ & TCB & 17 & & $8 / 27 / 09$ & 9/8/09 & 12 & 9.5 & 0.159 & 104 & 30.1 & 46.6 & 11.9 \\
\hline $2941-326$ & TCB & 18 & & 9/8/09 & $9 / 24 / 09$ & 16 & 1.0 & 0.159 & 63.2 & 21.6 & 35.6 & 8.30 \\
\hline $2941-333$ & TCB & 19 & & $9 / 24 / 09$ & $10 / 7 / 09$ & 13 & 1.8 & 0.159 & 308 & 95.0 & 245 & 42.2 \\
\hline Average & & & & & & & & & 71.8 & 22.0 & 38.4 & 7.99 \\
\hline Stdev & & & & & & & & & 64.8 & 20.0 & 52.4 & 9.10 \\
\hline RSD & & & & & & & & & $90 \%$ & $91 \%$ & $137 \%$ & $114 \%$ \\
\hline
\end{tabular}


Field Sample Results - Biomarker, PAHs

\begin{tabular}{|c|c|c|c|c|c|c|c|c|c|c|c|c|}
\hline Sample ID & ID & $\begin{array}{l}\text { Event } \\
\text { No. }\end{array}$ & Dup & Deployed & Recovered & $\begin{array}{l}\text { No. Days } \\
\text { Deployed }\end{array}$ & (L) & Area (m2) & Benzo(b)fluoranthene & Benzo(k)fluoranthene & Benzo(a)pyrene & Perylene \\
\hline & & & & & & & & Unit & (ng/m2/day) & (ng/m2/day) & (ng/m2/day) & (ng/m2/day) \\
\hline 2941-172 & WP & 1 & & $8 / 28 / 08$ & $9 / 12 / 08$ & 15 & 0.0 & 0.159 & 1.06 & 0.578 & 0.434 & $0.00 \mathrm{U}$ \\
\hline $2941-183$ & WP & 2 & & $9 / 12 / 08$ & $9 / 25 / 08$ & 13 & 2.0 & 0.159 & 3.92 & 1.42 & 1.31 & 0.318 \\
\hline 2941-190 & WP & 3 & & $9 / 25 / 08$ & $10 / 14 / 08$ & 19 & 5.0 & 0.159 & 4280 ** & 855 ** & 2370 ** & 297 ** \\
\hline $2941-201$ & WP & 4 & & $10 / 14 / 08$ & $10 / 29 / 08$ & 15 & 1.5 & 0.159 & 13.2 & 3.33 & 6.82 & 1.24 \\
\hline 2941-200 & WP & 5 & & $10 / 29 / 08$ & $11 / 13 / 08$ & 15 & 18.0 & 0.159 & 28.4 & 9.12 & 3.51 & 0.783 \\
\hline $2941-225$ & WP & 6 & & $11 / 13 / 08$ & $11 / 25 / 08$ & 12 & 1.0 & 0.159 & 7.84 & 2.24 & 1.65 & 0.489 \\
\hline $2941-230$ & WP & 7 & & $11 / 25 / 08$ & $12 / 11 / 08$ & 16 & 1.5 & 0.159 & 4.22 & 3.06 & 2.56 & $0.00 \mathrm{U}$ \\
\hline $2941-244$ & WP & 8 & & $2 / 26 / 09$ & $3 / 11 / 09$ & 13 & 4.5 & 0.159 & 35.8 & 15.6 & 13.8 & 5.08 \\
\hline $2941-246$ & WP & 9 & & $3 / 11 / 09$ & $3 / 25 / 09$ & 14 & 6.0 & 0.159 & 9.66 & 2.54 & 2.69 & 0.517 \\
\hline $2941-258$ & WP & 10 & & $3 / 25 / 09$ & $4 / 8 / 09$ & 14 & 6.5 & 0.159 & 12.2 & 2.32 & 5.08 & 0.756 \\
\hline $2941-264$ & WP & 11 & & $4 / 8 / 09$ & $4 / 23 / 09$ & 15 & 4.0 & 0.159 & 6.63 & 4.14 & 3.41 & 0.450 \\
\hline $2941-272$ & WP & 12 & & $4 / 23 / 09$ & $5 / 6 / 09$ & 13 & 2.0 & 0.159 & 2.70 & 1.07 & 1.64 & 0.225 \\
\hline $2941-284$ & WP & 13 & & $5 / 6 / 09$ & $5 / 21 / 09$ & 15 & 11.0 & 0.159 & 2.91 & 1.46 & 1.45 & 0.363 \\
\hline $2941-289$ & WP & 14 & & $5 / 21 / 09$ & $6 / 3 / 09$ & 13 & 2.0 & 0.159 & 7.53 & 2.49 & 3.76 & 0.620 \\
\hline 2941-302 & WP & 15 & & 7/29/09 & $8 / 12 / 09$ & 14 & 1.5 & 0.159 & 5.13 & 1.63 & 2.01 & 1.15 \\
\hline $2941-308$ & WP & 16 & & $8 / 12 / 09$ & $8 / 26 / 09$ & 14 & 1.5 & 0.159 & 5.88 & 1.86 & 3.17 & $0.00 \mathrm{U}$ \\
\hline $2941-315$ & WP & 17 & & $8 / 26 / 09$ & 9/9/09 & 14 & 4.5 & 0.159 & 8.55 & 2.60 & 5.58 & 1.00 \\
\hline $2941-327$ & WP & 18 & & 9/9/09 & $9 / 24 / 09$ & 15 & 2.0 & 0.159 & 4.92 & 1.50 & 2.38 & 0.860 \\
\hline $2941-332$ & WP & 19 & & 9/24/09 & $10 / 7 / 09$ & 13 & 3.8 & 0.159 & 16.0 & 5.09 & 11.2 & 2.13 \\
\hline Average & & & & & & & & & 235 & 48.3 & 129 & 16.5 \\
\hline Stdev & & & & & & & & & 980 & 195 & 543 & 68.0 \\
\hline RSD & & & & & & & & & $418 \%$ & $405 \%$ & $422 \%$ & $412 \%$ \\
\hline 2941-293 & $\mathrm{TM}$ & 14 & & $5 / 20 / 09$ & $6 / 4 / 09$ & 15 & & 0.159 & 2.47 & 0.957 & 1.27 & 0.215 \\
\hline 2941-304 & $\mathrm{TM}$ & 15 & & 7/30/09 & $8 / 12 / 09$ & 13 & & 0.159 & 12.6 & 3.87 & 4.08 & 2.32 \\
\hline $2941-312$ & TM & 16 & & $8 / 12 / 09$ & $8 / 27 / 09$ & 15 & & 0.159 & 10.6 & 3.36 & 4.41 & 2.19 \\
\hline $2941-318$ & TM & 17 & & $8 / 27 / 09$ & $9 / 8 / 09$ & 12 & & 0.159 & 20.2 & 5.99 & 5.84 & 1.35 \\
\hline $2941-325$ & $\mathrm{TM}$ & 18 & & $9 / 8 / 09$ & $9 / 24 / 09$ & 16 & & 0.159 & 17.0 & 4.94 & 4.77 & 1.19 \\
\hline $2941-333$ & $\mathrm{TM}$ & 19 & & $9 / 24 / 09$ & $10 / 7 / 09$ & 13 & & 0.159 & 24.5 & 7.84 & 8.22 & 2.30 \\
\hline Average & & & & & & & & & 14.5 & 4.49 & 4.76 & 1.60 \\
\hline Stdev & & & & & & & & & 7.76 & 2.36 & 2.28 & 0.838 \\
\hline RSD & & & & & & & & & $53 \%$ & $53 \%$ & $48 \%$ & $53 \%$ \\
\hline
\end{tabular}

NA $\quad$ Not available

** $\quad$ Outlier; see narration

Carcinogenic PAHs: benzo(a)anthracene, chrysene, benzo(b)fluoranthene,

benzo(k)fluoranthene, benzo(a)pyrene, indeno(1,2,3-c,d)pyrene, dibenz(a,h)anthracene Pyrogenic PAHs: fluoranthene, pyrene, benzo(a)anthracene, chrysene,

b benzo(b)fluoranthene, benzo(k)fluoranthene, benzo(a)pyrene, indeno(1,2,3-c,d)pyrene, dibenz(a,h)anthracene, benzo(g,h,i)perylene

c High molecular weight PAHs: benzo(b)fluoranthene, benzo(k)fluoranthene,

benzo(a)pyrene, indeno(1,2,3-c,d)pyrene, dibenz(a,h)anthracene, benzo(g,h,i)perylene 
Field Sample Results - Biomarker, PAHs

\begin{tabular}{|c|c|c|c|c|c|c|c|c|c|c|c|}
\hline Sample ID & ID & No. & Dup & Deployed & Recovered & Deployed & (L) & Area (m2) & Indeno(1,2,3-c,d)pyrene & Dibenz(a,h)anthracene & Benzo(g,h,i)perylene \\
\hline & & & & & & & & Unit & (ng/m2/day) & (ng/m2/day) & (ng/m2/day) \\
\hline $2941-177$ & $\mathrm{HC}$ & 1 & & $9 / 3 / 08$ & $9 / 17 / 08$ & 14 & 0.0 & 0.159 & 0.177 & $0.00 \mathrm{U}$ & 0.256 \\
\hline $2941-184$ & $\mathrm{HC}$ & 2 & & $9 / 17 / 08$ & $10 / 6 / 08$ & 19 & 8.0 & 0.159 & 2.81 & $0.00 \mathrm{U}$ & 3.55 \\
\hline 2941-194 & $\mathrm{HC}$ & 3 & & $10 / 6 / 08$ & $10 / 16 / 08$ & 10 & 3.0 & 0.159 & 2.75 & $0.00 \mathrm{U}$ & 2.60 \\
\hline $2941-208$ & $\mathrm{HC}$ & 4 & & $10 / 16 / 08$ & $10 / 29 / 08$ & 13 & 1.0 & 0.159 & 0.301 & $0.00 \mathrm{U}$ & 0.733 \\
\hline $2941-214$ & $\mathrm{HC}$ & 5 & $\mathrm{x}$ & $10 / 29 / 08$ & $11 / 8 / 08$ & 10 & 6.0 & 0.159 & 4.52 & $0.00 \mathrm{U}$ & 4.37 \\
\hline $2941-220$ & $\mathrm{HC}$ & 6 & $\mathrm{x}$ & $11 / 8 / 08$ & $11 / 20 / 08$ & 12 & 6.0 & 0.159 & 2.48 & $0.00 \mathrm{U}$ & 1.76 \\
\hline $2941-210$ & $\mathrm{HC}$ & 7 & $\mathrm{x}$ & $11 / 20 / 08$ & $12 / 11 / 08$ & 21 & 4.0 & 0.159 & 3.01 & 0.550 & 3.71 \\
\hline $2941-238$ & $\mathrm{HC}$ & 8 & & $2 / 26 / 09$ & $3 / 12 / 09$ & 14 & 4.0 & 0.159 & 1.92 & $0.00 \mathrm{U}$ & 2.35 \\
\hline $2941-250$ & $\mathrm{HC}$ & 9 & & $3 / 12 / 09$ & $3 / 25 / 09$ & 13 & 9.5 & 0.159 & 3.88 & 0.509 & 2.63 \\
\hline $2941-262$ & $\mathrm{HC}$ & 10 & & $3 / 25 / 09$ & $4 / 8 / 09$ & 14 & 4.0 & 0.159 & 1.22 & $0.00 \mathrm{U}$ & 2.18 \\
\hline $2941-269$ & $\mathrm{HC}$ & 11 & & $4 / 8 / 09$ & $4 / 22 / 09$ & 14 & 6.0 & 0.159 & 0.613 & $0.00 \mathrm{U}$ & 0.929 \\
\hline $2941-276$ & $\mathrm{HC}$ & 12 & & $4 / 22 / 09$ & $5 / 5 / 09$ & 13 & 1.0 & 0.159 & $0.00 \mathrm{U}$ & $0.00 \mathrm{U}$ & $0.00 \mathrm{U}$ \\
\hline $2941-280$ & $\mathrm{HC}$ & 13 & & $5 / 5 / 09$ & $5 / 20 / 09$ & 15 & 5.0 & 0.159 & $0.00 \mathrm{U}$ & $0.00 \mathrm{U}$ & 0.125 \\
\hline 2941-294 & $\mathrm{HC}$ & 14 & & $5 / 20 / 09$ & $6 / 5 / 09$ & 16 & 4.0 & 0.159 & 0.755 & 0.492 & 0.911 \\
\hline 2941-306 & $\mathrm{HC}$ & 15 & & 7/30/09 & 8/14/09 & 15 & 2.5 & 0.159 & 1.35 & 0.833 & 2.18 \\
\hline $2941-314$ & $\mathrm{HC}$ & 16 & & $8 / 14 / 09$ & $8 / 26 / 09$ & 12 & 0.0 & 0.159 & 1.06 & $0.00 \mathrm{U}$ & 1.48 \\
\hline $2941-322$ & $\mathrm{HC}$ & 17 & & $8 / 26 / 09$ & $9 / 11 / 09$ & 16 & 6.8 & 0.159 & 2.06 & 1.44 & 2.54 \\
\hline $2947-328$ & $\mathrm{HC}$ & 18 & & 9/11/09 & $9 / 25 / 09$ & 14 & 2.0 & 0.159 & 1.14 & 1.47 & 1.89 \\
\hline $2941-338$ & $\mathrm{HC}$ & 19 & & $9 / 25 / 09$ & 10/14/09 & 19 & 6.0 & 0.159 & 1.55 & 1.77 & 1.76 \\
\hline Average & & & & & & & & & 1.66 & 0.372 & 1.89 \\
\hline Stdev & & & & & & & & & 1.31 & 0.589 & 1.22 \\
\hline RSD & & & & & & & & & $79 \%$ & $158 \%$ & $65 \%$ \\
\hline $2941-175$ & NR & 1 & & $8 / 29 / 08$ & $9 / 12 / 08$ & 14 & 0.0 & 0.159 & 0.247 & $0.00 \mathrm{U}$ & 0.730 \\
\hline 2941-180 & NR & 2 & & 9/12/08 & $9 / 24 / 08$ & 12 & 1.0 & 0.159 & 0.968 & $0.00 \mathrm{U}$ & 1.74 \\
\hline 2941-189 & NR & 3 & & 9/24/08 & 10/15/08 & 21 & 9.0 & 0.159 & 11.4 & 3.60 & 9.77 \\
\hline 2941-202 & NR & 4 & & $10 / 15 / 08$ & $10 / 30 / 08$ & 15 & 2.0 & 0.159 & 3.35 & $0.00 \mathrm{U}$ & 4.13 \\
\hline $2941-211$ & NR & 5 & & $10 / 30 / 08$ & 11/12/08 & 13 & 3.0 & 0.159 & 0.492 & $0.00 \mathrm{U}$ & 0.485 \\
\hline $2941-223$ & NR & 6 & & $11 / 12 / 08$ & $11 / 24 / 08$ & 12 & 16.0 & 0.159 & 3.00 & 0.469 & 3.77 \\
\hline $2941-228$ & NR & 7 & & $11 / 24 / 08$ & 12/11/08 & 17 & 1.0 & 0.159 & 0.698 & 0.165 & 2.06 \\
\hline $2941-242$ & NR & 8 & & 2/25/09 & 3/12/09 & 15 & 3.0 & 0.159 & 2.61 & $0.00 \mathrm{U}$ & 3.64 \\
\hline $2941-249$ & NR & 9 & & $3 / 12 / 09$ & $3 / 25 / 09$ & 13 & 6.0 & 0.159 & 2.58 & 2.85 & 2.85 \\
\hline $2941-255$ & NR & 10 & $\mathrm{x}$ & $3 / 25 / 09$ & $4 / 8 / 09$ & 14 & 5.0 & 0.159 & 4.28 & 0.638 & 5.97 \\
\hline $2941-265$ & NR & 11 & $\mathrm{x}$ & $4 / 8 / 09$ & $4 / 22 / 09$ & 14 & 4.0 & 0.159 & 0.762 & $0.00 \mathrm{U}$ & 1.14 \\
\hline $2941-273$ & NR & 12 & $\mathrm{x}$ & $4 / 22 / 09$ & $5 / 7 / 09$ & 15 & 1.0 & 0.159 & $0.00 \mathrm{U}$ & $0.00 \mathrm{U}$ & 0.098 \\
\hline $2941-285$ & NR & 13 & & $5 / 7 / 09$ & $5 / 21 / 09$ & 14 & 1.5 & 0.159 & 0.234 & 0.108 & 0.368 \\
\hline $2941-287$ & NR & 14 & & $5 / 21 / 09$ & $6 / 4 / 09$ & 14 & 0.0 & 0.159 & 1.63 & 0.873 & 2.90 \\
\hline 2941-299 & NR & 15 & & $7 / 30 / 09$ & $8 / 12 / 09$ & 13 & 1.0 & 0.159 & 1.20 & 1.04 & 1.69 \\
\hline $2941-310$ & NR & 16 & & $8 / 12 / 09$ & $8 / 27 / 09$ & 15 & 0.5 & 0.159 & 2.47 & 2.17 & 5.99 \\
\hline 2941-319 & NR & 17 & & $8 / 27 / 09$ & 9/8/09 & 12 & 8.0 & 0.159 & 3.13 & 2.84 & 4.81 \\
\hline $2941-324$ & NR & 18 & & 9/8/09 & $9 / 24 / 09$ & 16 & 2.0 & 0.159 & 1.53 & 2.99 & 2.64 \\
\hline $2941-335$ & NR & 19 & & $9 / 24 / 09$ & $10 / 7 / 09$ & 13 & 1.0 & 0.159 & 2.41 & 2.49 & 4.20 \\
\hline Average & & & & & & & & & 2.26 & 1.07 & 3.10 \\
\hline Stdev & & & & & & & & & 2.52 & 1.29 & 2.42 \\
\hline RSD & & & & & & & & & $112 \%$ & $121 \%$ & $78 \%$ \\
\hline
\end{tabular}


Field Sample Results - Biomarker, PAHs

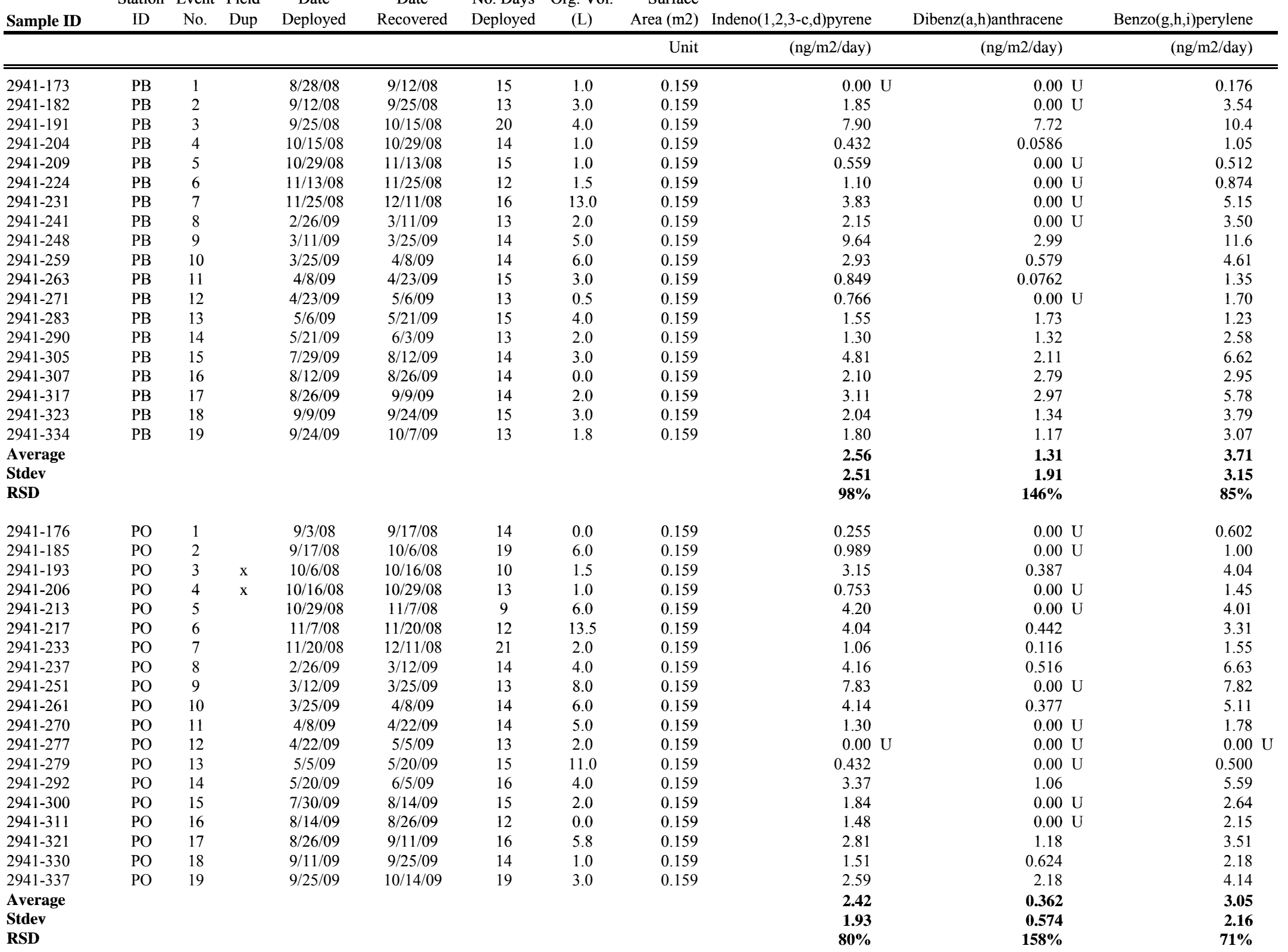


Field Sample Results - Biomarker, PAHs

\begin{tabular}{|c|c|c|c|c|c|c|c|c|c|c|c|}
\hline Sample ID & ID & No. & Dup & Deployed & Recovered & Deployed & (L) & Area (m2) & Indeno(1,2,3-c,d)pyrene & Dibenz $(\mathrm{a}, \mathrm{h})$ anthracene & Benzo $(\mathrm{g}, \mathrm{h}, \mathrm{i})$ perylene \\
\hline & & & & & & & & Unit & (ng/m2/day) & (ng/m2/day) & (ng/m2/day) \\
\hline $2941-178$ & SB & 1 & $\mathrm{x}$ & $9 / 2 / 08$ & $9 / 18 / 08$ & 16 & $<20 \mathrm{~mL}$ & 0.159 & 0.184 & $0.00 \mathrm{U}$ & 0.544 \\
\hline $2941-186$ & SB & 2 & $\mathrm{x}$ & 9/18/08 & $10 / 2 / 08$ & 14 & 1.5 & 0.159 & 7.26 & $0.00 \mathrm{U}$ & 7.32 \\
\hline $2941-195$ & SB & 3 & & $10 / 2 / 08$ & $10 / 15 / 08$ & 13 & 1.5 & 0.159 & 1.38 & $0.00 \mathrm{U}$ & 1.88 \\
\hline $2941-205$ & SB & 4 & & $10 / 15 / 08$ & $10 / 30 / 08$ & 15 & 2.0 & 0.159 & 1.68 & $0.00 \mathrm{U}$ & 2.25 \\
\hline $2941-216$ & SB & 5 & & $10 / 30 / 08$ & $11 / 10 / 08$ & 11 & 14.0 & 0.159 & 7.75 & 0.929 & 9.41 \\
\hline $2941-218$ & SB & 6 & & $11 / 10 / 08$ & $11 / 25 / 08$ & 12 & 3.0 & 0.159 & 1.27 & 0.154 & 1.82 \\
\hline $2941-219$ & SB & 7 & & $11 / 25 / 08$ & $12 / 11 / 08$ & 16 & 2.0 & 0.159 & 0.696 & $0.00 \mathrm{U}$ & 1.39 \\
\hline $2941-245$ & SB & 8 & & $2 / 25 / 09$ & $3 / 12 / 09$ & 15 & 4.5 & 0.159 & 5.87 & 0.984 & 7.02 \\
\hline $2941-252$ & SB & 9 & & $3 / 12 / 09$ & $3 / 29 / 09$ & 17 & 5.0 & 0.159 & 5.02 & 1.09 & 4.97 \\
\hline $2941-260$ & SB & 10 & & $3 / 29 / 09$ & $4 / 13 / 09$ & 15 & 5.0 & 0.159 & 3.74 & 1.08 & 5.18 \\
\hline $2941-268$ & SB & 11 & & $4 / 13 / 09$ & $4 / 28 / 09$ & 15 & $<1$ & 0.159 & 1.12 & 0.125 & 1.70 \\
\hline $2941-278$ & SB & 12 & & $4 / 28 / 09$ & $5 / 11 / 09$ & 13 & 2.0 & 0.159 & 0.760 & $0.00 \mathrm{U}$ & 1.67 \\
\hline $2941-281$ & SB & 13 & & $5 / 11 / 09$ & $5 / 27 / 09$ & 16 & 5.5 & 0.159 & 1.35 & $0.00 \mathrm{U}$ & 1.41 \\
\hline $2941-286$ & SB & 14 & & $5 / 27 / 09$ & $6 / 8 / 09$ & 12 & 0.0 & 0.159 & 3.28 & 0.793 & 4.02 \\
\hline 2941-303 & SB & 15 & & $8 / 3 / 09$ & $8 / 18 / 09$ & 15 & 1.8 & 0.159 & 1.39 & $0.00 \mathrm{U}$ & 1.67 \\
\hline $2941-313$ & SB & 16 & & $8 / 15 / 09$ & $8 / 29 / 09$ & 11 & 0.0 & 0.159 & 2.06 & $0.00 \mathrm{U}$ & 2.09 \\
\hline $2941-320$ & SB & 17 & & $8 / 29 / 09$ & $9 / 11 / 09$ & 13 & 1.3 & 0.159 & 2.38 & $0.00 \mathrm{U}$ & 2.79 \\
\hline $2941-329$ & SB & 18 & & 9/11/09 & $9 / 25 / 09$ & 14 & 1.0 & 0.159 & 0.511 & 0.710 & 0.565 \\
\hline $2941-336$ & SB & 19 & & $9 / 25 / 09$ & $10 / 13 / 09$ & 18 & 1.9 & 0.159 & 1.23 & 0.713 & 1.53 \\
\hline Average & & & & & & & & & 2.58 & 0.35 & 3.12 \\
\hline Stdev & & & & & & & & & 2.30 & 0.45 & 2.52 \\
\hline RSD & & & & & & & & & $89 \%$ & $129 \%$ & $81 \%$ \\
\hline 2941-174 & TCB & 1 & & $8 / 29 / 08$ & $9 / 12 / 08$ & 14 & 0.0 & 0.159 & 7.37 & 1.85 & 17.3 \\
\hline 2941-181 & TCB & 2 & & 9/12/08 & $9 / 24 / 08$ & 12 & 1.5 & 0.159 & 9.19 & $0.00 \mathrm{U}$ & 18.9 \\
\hline $2941-188$ & $\mathrm{TCB}$ & 3 & & $9 / 24 / 08$ & $10 / 15 / 08$ & 21 & 6.0 & 0.159 & 44.7 & 9.18 & 73.0 \\
\hline $2941-203$ & TCB & 4 & & $10 / 15 / 08$ & $10 / 30 / 08$ & 15 & 2.0 & 0.159 & 15.9 & 3.58 & 31.6 \\
\hline $2941-212$ & $\mathrm{TCB}$ & 5 & & $10 / 30 / 08$ & $11 / 12 / 08$ & 13 & 20.0 & 0.159 & 31.3 & $0.00 \mathrm{U}$ & 55.4 \\
\hline $2941-229$ & TCB & 7 & & $11 / 12 / 08$ & $11 / 24 / 08$ & 17 & 1.5 & 0.159 & 13.5 & $0.00 \mathrm{U}$ & 33.5 \\
\hline $2941-240$ & $\mathrm{TCB}$ & 8 & & $11 / 24 / 08$ & $12 / 11 / 08$ & 15 & 5.5 & 0.159 & 31.0 & 4.98 & 47.7 \\
\hline $2941-243$ & TCB & 8 & & $2 / 25 / 09$ & $3 / 12 / 09$ & 15 & 5.5 & 0.159 & 43.3 & 4.66 & 55.4 \\
\hline $2941-245 b$ & TCB & 9 & $\mathrm{x}$ & 2/25/09 & $3 / 12 / 09$ & 13 & 8.0 & 0.159 & 74.9 & 8.88 & 90.8 \\
\hline $2941-256$ & TCB & 10 & & $3 / 12 / 09$ & $3 / 25 / 09$ & 14 & 6.5 & 0.159 & 32.9 & 6.53 & 51.2 \\
\hline $2941-267$ & TCB & 11 & & $4 / 8 / 09$ & $4 / 22 / 09$ & 14 & 5.0 & 0.159 & 31.6 & 2.90 & 64.9 \\
\hline $2941-274$ & $\mathrm{TCB}$ & 12 & & $4 / 22 / 09$ & $5 / 7 / 09$ & 15 & 3.0 & 0.159 & 7.16 & 0.928 & 12.6 \\
\hline $2941-282$ & TCB & 13 & & $5 / 7 / 09$ & $5 / 21 / 09$ & 14 & 10.0 & 0.159 & 54.7 & 8.51 & 76.7 \\
\hline $2941-288$ & TCB & 14 & & $5 / 21 / 09$ & $6 / 4 / 09$ & 14 & 0.0 & 0.159 & 29.6 & 20.3 & 58.0 \\
\hline 2941-301 & TCB & 15 & & 7/30/09 & $8 / 12 / 09$ & 13 & 1.5 & 0.159 & 32.5 & 5.75 & 54.3 \\
\hline 2941-309 & TCB & 16 & & $8 / 12 / 09$ & $8 / 27 / 09$ & 15 & 1.0 & 0.159 & 19.5 & 3.54 & 34.3 \\
\hline $2941-316$ & TCB & 17 & & $8 / 27 / 09$ & 9/8/09 & 12 & 9.5 & 0.159 & 64.3 & 9.84 & 96.6 \\
\hline $2941-326$ & TCB & 18 & & 9/8/09 & $9 / 24 / 09$ & 16 & 1.0 & 0.159 & 45.3 & 7.37 & 81.2 \\
\hline $2941-333$ & $\mathrm{TCB}$ & 19 & & $9 / 24 / 09$ & $10 / 7 / 09$ & 13 & 1.8 & 0.159 & 205 & 33.7 & 253 \\
\hline Average & & & & & & & & & 41.8 & 6.97 & 63.5 \\
\hline Stdev & & & & & & & & & 43.8 & 8.06 & 51.8 \\
\hline RSD & & & & & & & & & $105 \%$ & $116 \%$ & $82 \%$ \\
\hline
\end{tabular}


Field Sample Results - Biomarker, PAHs

\begin{tabular}{|c|c|c|c|c|c|c|c|c|c|c|c|}
\hline Sample ID & ID & No. & Dup & Deployed & Recovered & Deployed & (L) & Area (m2) & Indeno $(1,2,3-\mathrm{c}, \mathrm{d})$ pyrene & Dibenz(a,h)anthracene & Benzo(g,h,i)perylene \\
\hline & & & & & & & & Unit & (ng/m2/day) & (ng/m2/day) & (ng/m2/day) \\
\hline 2941-172 & WP & 1 & & $8 / 28 / 08$ & $9 / 12 / 08$ & 15 & 0.0 & 0.159 & 0.556 & $0.00 \mathrm{U}$ & 1.17 \\
\hline 2941-183 & WP & 2 & & $9 / 12 / 08$ & $9 / 25 / 08$ & 13 & 2.0 & 0.159 & 1.64 & $0.00 \mathrm{U}$ & 3.10 \\
\hline 2941-190 & WP & 3 & & $9 / 25 / 08$ & $10 / 14 / 08$ & 19 & 5.0 & 0.159 & 1573 ** & 753 ** & 1050 * \\
\hline $2941-201$ & WP & 4 & & $10 / 14 / 08$ & $10 / 29 / 08$ & 15 & 1.5 & 0.159 & 6.17 & $0.00 \mathrm{U}$ & 8.37 \\
\hline $2941-200$ & WP & 5 & & $10 / 29 / 08$ & $11 / 13 / 08$ & 15 & 18.0 & 0.159 & 11.6 & 2.50 & 13.2 \\
\hline $2941-225$ & WP & 6 & & $11 / 13 / 08$ & $11 / 25 / 08$ & 12 & 1.0 & 0.159 & 3.05 & 0.312 & 4.65 \\
\hline $2941-230$ & WP & 7 & & $11 / 25 / 08$ & $12 / 11 / 08$ & 16 & 1.5 & 0.159 & 0.944 & $0.00 \mathrm{U}$ & 1.00 \\
\hline $2941-244$ & WP & 8 & & $2 / 26 / 09$ & 3/11/09 & 13 & 4.5 & 0.159 & 17.3 & $0.00 \mathrm{U}$ & 20.7 \\
\hline $2941-246$ & WP & 9 & & $3 / 11 / 09$ & $3 / 25 / 09$ & 14 & 6.0 & 0.159 & 4.64 & 0.659 & 4.20 \\
\hline $2941-258$ & WP & 10 & & $3 / 25 / 09$ & $4 / 8 / 09$ & 14 & 6.5 & 0.159 & 5.60 & 1.00 & 7.46 \\
\hline $2941-264$ & WP & 11 & & $4 / 8 / 09$ & $4 / 23 / 09$ & 15 & 4.0 & 0.159 & 3.56 & 0.501 & 6.56 \\
\hline $2941-272$ & WP & 12 & & $4 / 23 / 09$ & $5 / 6 / 09$ & 13 & 2.0 & 0.159 & 1.03 & $0.00 \mathrm{U}$ & 1.82 \\
\hline $2941-284$ & WP & 13 & & $5 / 6 / 09$ & $5 / 21 / 09$ & 15 & 11.0 & 0.159 & 1.57 & 0.362 & 2.11 \\
\hline $2941-289$ & WP & 14 & & $5 / 21 / 09$ & $6 / 3 / 09$ & 13 & 2.0 & 0.159 & 3.36 & 1.50 & 6.34 \\
\hline $2941-302$ & WP & 15 & & $7 / 29 / 09$ & 8/12/09 & 14 & 1.5 & 0.159 & 2.65 & 0.654 & 4.32 \\
\hline $2941-308$ & WP & 16 & & $8 / 12 / 09$ & $8 / 26 / 09$ & 14 & 1.5 & 0.159 & 3.75 & 1.07 & 4.49 \\
\hline $2941-315$ & WP & 17 & & $8 / 26 / 09$ & 9/9/09 & 14 & 4.5 & 0.159 & 5.47 & 2.89 & 7.83 \\
\hline $2941-327$ & WP & 18 & & $9 / 9 / 09$ & $9 / 24 / 09$ & 15 & 2.0 & 0.159 & 2.23 & 1.03 & 3.50 \\
\hline $2941-332$ & WP & 19 & & $9 / 24 / 09$ & $10 / 7 / 09$ & 13 & 3.8 & 0.159 & 8.94 & 2.65 & 11.2 \\
\hline Average & & & & & & & & & 87.2 & 40.4 & 61.2 \\
\hline Stdev & & & & & & & & & 360 & 172 & 240 \\
\hline RSD & & & & & & & & & $413 \%$ & $427 \%$ & $392 \%$ \\
\hline 2941-293 & TM & 14 & & $5 / 20 / 09$ & $6 / 4 / 09$ & 15 & & 0.159 & 0.757 & 0.247 & 2.24 \\
\hline $2941-304$ & $\mathrm{TM}$ & 15 & & $7 / 30 / 09$ & $8 / 12 / 09$ & 13 & & 0.159 & 5.92 & 1.08 & 8.61 \\
\hline $2941-312$ & $\mathrm{TM}$ & 16 & & $8 / 12 / 09$ & $8 / 27 / 09$ & 15 & & 0.159 & 7.05 & 1.17 & 10.7 \\
\hline $2941-318$ & $\mathrm{TM}$ & 17 & & $8 / 27 / 09$ & $9 / 8 / 09$ & 12 & & 0.159 & 8.82 & 2.34 & 12.7 \\
\hline $2941-325$ & $\mathrm{TM}$ & 18 & & $9 / 8 / 09$ & $9 / 24 / 09$ & 16 & & 0.159 & 7.04 & 1.74 & 11.3 \\
\hline $2941-333$ & TM & 19 & & $9 / 24 / 09$ & $10 / 7 / 09$ & 13 & & 0.159 & 10.6 & 1.57 & 14.3 \\
\hline Average & & & & & & & & & 6.69 & 1.36 & 9.96 \\
\hline Stdev & & & & & & & & & 3.33 & 0.707 & 4.24 \\
\hline RSD & & & & & & & & & $50 \%$ & $52 \%$ & $43 \%$ \\
\hline
\end{tabular}

NA $\quad$ Not available

** $\quad$ Outlier; see narration

Carcinogenic PAHs: benzo(a)anthracene, chrysene, benzo(b)fluoranthene,

benzo(k)fluoranthene, benzo(a)pyrene, indeno(1,2,3-c,d)pyrene, dibenz(a,h)anthracene Pyrogenic PAHs: fluoranthene, pyrene, benzo(a)anthracene, chrysene,

b benzo(b)fluoranthene, benzo(k)fluoranthene, benzo(a)pyrene, indeno(1,2,3-c,d)pyrene, dibenz(a,h)anthracene, benzo(g,h,i)perylene

c High molecular weight PAHs: benzo(b)fluoranthene, benzo(k)fluoranthene,

benzo(a)pyrene, indeno(1,2,3-c,d)pyrene, dibenz(a,h)anthracene, benzo(g,h,i)perylene 
Field Sample Results - Biomarker, PAHs

\begin{tabular}{llllr} 
Station Event Field Date Date No. Days & Org. Vol. & Surface \\
\hline
\end{tabular}

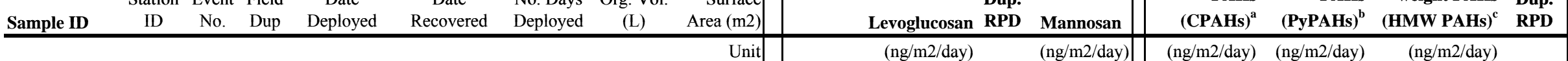

PAHs

Pyrogenic High molecular Field PAHs weight PAHs Dup.

\begin{tabular}{|c|c|c|c|c|c|c|c|c|c|c|c|c|c|c|c|c|}
\hline & & & & & & & & Unit & & (ng/m2/day) & & (ng/m2/day) & (ng/m2/day) & (ng/m2/day) & (ng/m2/day) & \\
\hline $2941-177$ & $\mathrm{HC}$ & 1 & & $9 / 3 / 08$ & $9 / 17 / 08$ & 14 & 0.0 & 0.159 & & 11000 & & & 1.04 & 4.10 & 0.879 & \\
\hline 2941-184 & $\mathrm{HC}$ & 2 & & 9/17/08 & $10 / 6 / 08$ & 19 & 8.0 & 0.159 & & 356000 & & 77800 & 28.5 & 47.5 & 21.0 & \\
\hline 2941-194 & $\mathrm{HC}$ & 3 & & $10 / 6 / 08$ & $10 / 16 / 08$ & 10 & 3.0 & 0.159 & & 88100 & & 30400 & 16.3 & 33.3 & 13.1 & \\
\hline 2941-208 & $\mathrm{HC}$ & 4 & & $10 / 16 / 08$ & $10 / 29 / 08$ & 13 & 1.0 & 0.159 & & 23000 & & 7960 & 2.87 & 7.29 & 2.62 & \\
\hline $2941-214$ & $\mathrm{HC}$ & 5 & $\mathrm{x}$ & $10 / 29 / 08$ & $11 / 8 / 08$ & 10 & 6.0 & 0.159 & & 274000 & $6 \%$ & 53300 & 31.3 & 64.6 & 24.5 & $73 \%$ \\
\hline $2941-220$ & $\mathrm{HC}$ & 6 & $\mathrm{x}$ & $11 / 8 / 08$ & $11 / 20 / 08$ & 12 & 6.0 & 0.159 & & 90600 & $7 \%$ & 22100 & 17.3 & 34.6 & 13.7 & $87 \%$ \\
\hline $2941-210$ & $\mathrm{HC}$ & 7 & $\mathrm{x}$ & $11 / 20 / 08$ & $12 / 11 / 08$ & 21 & 4.0 & 0.159 & & 42800 & $16 \%$ & 11800 & & & 23.9 & $23 \%$ \\
\hline $2941-238$ & $\mathrm{HC}$ & 8 & & $2 / 26 / 09$ & 3/12/09 & 14 & 4.0 & 0.159 & & 573000 & & & & & 17.0 & \\
\hline $2941-250$ & $\mathrm{HC}$ & 9 & & $3 / 12 / 09$ & $3 / 25 / 09$ & 13 & 9.5 & 0.159 & & 1650000 & & & & & 17.7 & \\
\hline $2941-262$ & $\mathrm{HC}$ & 10 & & $3 / 25 / 09$ & 4/8/09 & 14 & 4.0 & 0.159 & & 922000 & & & & & 10.1 & \\
\hline $2941-269$ & $\mathrm{HC}$ & 11 & & 4/8/09 & 4/22/09 & 14 & 6.0 & 0.159 & & 478000 & & & 4.94 & 13.8 & 3.88 & \\
\hline $2941-276$ & $\mathrm{HC}$ & 12 & & $4 / 22 / 09$ & $5 / 5 / 09$ & 13 & 1.0 & 0.159 & & 255000 & & & 2.62 & 6.36 & 1.97 & \\
\hline $2941-280$ & $\mathrm{HC}$ & 13 & & $5 / 5 / 09$ & $5 / 20 / 09$ & 15 & 5.0 & 0.159 & & 34300 & & & 1.69 & 5.55 & 1.21 & \\
\hline 2941-294 & $\mathrm{HC}$ & 14 & & $5 / 20 / 09$ & $6 / 5 / 09$ & 16 & 4.0 & 0.159 & & 27200 & & & 6.00 & 11.2 & 5.15 & \\
\hline $2941-306$ & $\mathrm{HC}$ & 15 & & 7/30/09 & $8 / 14 / 09$ & 15 & 2.5 & 0.159 & & 146800 & & 27700 & 11.6 & 24.8 & 10.5 & \\
\hline $2941-314$ & $\mathrm{HC}$ & 16 & & $8 / 14 / 09$ & $8 / 26 / 09$ & 12 & 0.0 & 0.159 & & 13800 & & 5900 & 5.66 & 15.3 & 5.01 & \\
\hline $2941-322$ & $\mathrm{HC}$ & 17 & & $8 / 26 / 09$ & 9/11/09 & 16 & 6.8 & 0.159 & & 75900 & & 22800 & 18.7 & 32.3 & 17.3 & \\
\hline $2947-328$ & $\mathrm{HC}$ & 18 & & 9/11/09 & $9 / 25 / 09$ & 14 & 2.0 & 0.159 & & 53000 & & & 11.0 & 24.5 & 9.70 & \\
\hline $2941-338$ & $\mathrm{HC}$ & 19 & & $9 / 25 / 09$ & $10 / 14 / 09$ & 19 & 6.0 & 0.159 & & 111000 & & 12700 & 14.2 & 29.4 & 10.9 & \\
\hline Average & & & & & & & & & Average & 275000 & & 27200 & 11.6 & 23.6 & 11.1 & \\
\hline Stdev & & & & & & & & & Stdev & 410000 & & 22500 & 9.50 & 17.2 & 7.66 & \\
\hline RSD & & & & & & & & & RSD & $149 \%$ & & $83 \%$ & $82 \%$ & $73 \%$ & $69 \%$ & \\
\hline $2941-175$ & NR & 1 & & $8 / 29 / 08$ & $9 / 12 / 08$ & 14 & 0.0 & 0.159 & & 45900 & & 19400 & 2.45 & 10.6 & 2.12 & \\
\hline $2941-180$ & NR & 2 & & $9 / 12 / 08$ & $9 / 24 / 08$ & 12 & 1.0 & 0.159 & & NA & 1 & NA & 8.28 & 27.4 & 7.07 & \\
\hline 2941-189 & NR & 3 & & 9/24/08 & $10 / 15 / 08$ & 21 & 9.0 & 0.159 & & 193000 & & 62500 & 82.6 & 141 & 62.8 & \\
\hline 2941-202 & NR & 4 & & $10 / 15 / 08$ & $10 / 30 / 08$ & 15 & 2.0 & 0.159 & & 61200 & & 23400 & 25.7 & 61.1 & 21.3 & \\
\hline $2941-211$ & NR & 5 & & $10 / 30 / 08$ & $11 / 12 / 08$ & 13 & 3.0 & 0.159 & & 106000 & & 26100 & 4.25 & 14.6 & 2.88 & \\
\hline $2941-223$ & NR & 6 & & $11 / 12 / 08$ & $11 / 24 / 08$ & 12 & 16.0 & 0.159 & & 71300 & & 18600 & 28.7 & 81.2 & 20.9 & \\
\hline $2941-228$ & NR & 7 & & $11 / 24 / 08$ & $12 / 11 / 08$ & 17 & 1.0 & 0.159 & & 15600 & & 5100 & & & 9.11 & \\
\hline $2941-242$ & NR & 8 & & $2 / 25 / 09$ & 3/12/09 & 15 & 3.0 & 0.159 & & 87200 & & 13300 & & & 17.0 & \\
\hline $2941-249$ & NR & 9 & & $3 / 12 / 09$ & $3 / 25 / 09$ & 13 & 6.0 & 0.159 & & 246000 & & & & & 19.0 & \\
\hline $2941-255$ & NR & 10 & $\mathrm{x}$ & $3 / 25 / 09$ & $4 / 8 / 09$ & 14 & 5.0 & 0.159 & & 504000 & $18 \%$ & & & & 25.0 & $29 \%$ \\
\hline $2941-265$ & NR & 11 & $\mathrm{x}$ & $4 / 8 / 09$ & $4 / 22 / 09$ & 14 & 4.0 & 0.159 & & 110000 & $22 \%$ & & 5.78 & 16.2 & 4.52 & \\
\hline $2941-273$ & NR & 12 & $\mathrm{x}$ & $4 / 22 / 09$ & $5 / 7 / 09$ & 15 & 1.0 & 0.159 & & 121000 & $24 \%$ & & 4.28 & 7.56 & 3.70 & $63 \%$ \\
\hline $2941-285$ & NR & 13 & & $5 / 7 / 09$ & $5 / 21 / 09$ & 14 & 1.5 & 0.159 & & 33900 & & & 2.55 & 7.49 & 1.95 & \\
\hline $2941-287$ & NR & 14 & & $5 / 21 / 09$ & $6 / 4 / 09$ & 14 & 0.0 & 0.159 & & 44200 & & & 14.7 & 32.3 & 12.7 & \\
\hline 2941-299 & NR & 15 & & $7 / 30 / 09$ & $8 / 12 / 09$ & 13 & 1.0 & 0.159 & & 43700 & & & 9.69 & 21.2 & 9.04 & \\
\hline $2941-310$ & NR & 16 & & $8 / 12 / 09$ & $8 / 27 / 09$ & 15 & 0.5 & 0.159 & & 14800 & & 7500 & 24.7 & 47.9 & 20.5 & \\
\hline 2941-319 & NR & 17 & & $8 / 27 / 09$ & 9/8/09 & 12 & 8.0 & 0.159 & & 121000 & & 14800 & 30.9 & 69.3 & 27.1 & \\
\hline $2941-324$ & NR & 18 & & $9 / 8 / 09$ & 9/24/09 & 16 & 2.0 & 0.159 & & 68400 & & & 16.0 & 36.3 & 12.9 & \\
\hline $2941-335$ & NR & 19 & & $9 / 24 / 09$ & $10 / 7 / 09$ & 13 & 1.0 & 0.159 & & 32500 & & & 25.6 & 58.2 & 21.9 & \\
\hline Average & & & & & & & & & Average & 107000 & & 21200 & 19.1 & 42.1 & 15.9 & \\
\hline Stdev & & & & & & & & & Stdev & 116000 & & 16900 & 20.3 & 36.1 & 14.0 & \\
\hline RSD & & & & & & & & & RSD & $108 \%$ & & $80 \%$ & $107 \%$ & $86 \%$ & $89 \%$ & \\
\hline
\end{tabular}


Field Sample Results - Biomarker, PAHs

\begin{tabular}{|c|c|c|c|c|c|c|c|c|c|c|c|c|c|c|c|c|}
\hline Sample ID & $\begin{array}{l}\text { Station } \\
\text { ID }\end{array}$ & $\begin{array}{l}\text { Event } \\
\text { No. }\end{array}$ & $\begin{array}{l}\text { Field } \\
\text { Dup }\end{array}$ & $\begin{array}{c}\text { Date } \\
\text { Deployed }\end{array}$ & $\begin{array}{c}\text { Date } \\
\text { Recovered }\end{array}$ & $\begin{array}{l}\text { No. Days } \\
\text { Deployed }\end{array}$ & $\begin{array}{l}\text { Org. Vol. } \\
\text { (L) }\end{array}$ & $\begin{array}{r}\text { Funnel } \\
\text { Surface } \\
\text { Area }(\mathrm{m} 2)\end{array}$ & & Levoglucosan & $\begin{array}{l}\text { Field } \\
\text { Dup. } \\
\text { RPD }\end{array}$ & Mannosan & $\begin{array}{r}\text { Carcinogenic } \\
\text { PAHs } \\
\text { (CPAHs) }^{\mathrm{a}}\end{array}$ & $\begin{array}{r}\text { Pyrogenic } \\
\text { PAHs } \\
\text { (PyPAHs) }^{\text {b }}\end{array}$ & $\begin{array}{r}\text { High molecular } \\
\text { weight PAHs } \\
\text { (HMW PAHs) }^{c}\end{array}$ & $\begin{array}{l}\text { Field } \\
\text { Dup. } \\
\text { RPD }\end{array}$ \\
\hline & & & & & & & & Unit & & (ng/m2/day) & & (ng/m2/day) & (ng/m2/day) & (ng/m2/day) & (ng/m2/day) & \\
\hline $2941-173$ & PB & 1 & & $8 / 28 / 08$ & $9 / 12 / 08$ & 15 & 1.0 & 0.159 & & 105000 & & & 0.686 & 3.29 & 0.380 & \\
\hline 2941-182 & PB & 2 & & $9 / 12 / 08$ & $9 / 25 / 08$ & 13 & 3.0 & 0.159 & & 264000 & & 63800 & 11.9 & 28.0 & 10.5 & \\
\hline 2941-191 & PB & 3 & & $9 / 25 / 08$ & $10 / 15 / 08$ & 20 & 4.0 & 0.159 & & 138000 & & 36300 & 48.9 & 81.6 & 47.3 & \\
\hline 2941-204 & PB & 4 & & $10 / 15 / 08$ & $10 / 29 / 08$ & 14 & 1.0 & 0.159 & & 61900 & & 9880 & 5.15 & 14.0 & 4.23 & \\
\hline 2941-209 & PB & 5 & & $10 / 29 / 08$ & $11 / 13 / 08$ & 15 & 1.0 & 0.159 & & 76300 & & 10100 & 3.76 & 11.6 & 2.75 & \\
\hline $2941-224$ & PB & 6 & & $11 / 13 / 08$ & $11 / 25 / 08$ & 12 & 1.5 & 0.159 & & 43300 & & 7020 & 6.28 & 18.5 & 5.31 & \\
\hline 2941-231 & PB & 7 & & $11 / 25 / 08$ & $12 / 11 / 08$ & 16 & 13.0 & 0.159 & & 58700 & & 10400 & & & 25.8 & \\
\hline 2941-241 & PB & 8 & & 2/26/09 & $3 / 11 / 09$ & 13 & 2.0 & 0.159 & & 299000 & & 245000 & & & 17.6 & \\
\hline 2941-248 & PB & 9 & & $3 / 11 / 09$ & $3 / 25 / 09$ & 14 & 5.0 & 0.159 & & 1180000 & & & & & 55.7 & \\
\hline $2941-259$ & PB & 10 & & $3 / 25 / 09$ & $4 / 8 / 09$ & 14 & 6.0 & 0.159 & & 946000 & & & & & 17.3 & \\
\hline $2941-263$ & PB & 11 & & $4 / 8 / 09$ & $4 / 23 / 09$ & 15 & 3.0 & 0.159 & & 203000 & & & 7.15 & 16.1 & 6.08 & \\
\hline $2941-271$ & PB & 12 & & $4 / 23 / 09$ & $5 / 6 / 09$ & 13 & 0.5 & 0.159 & & 174000 & & & 6.05 & 12.8 & 5.61 & \\
\hline $2941-283$ & PB & 13 & & $5 / 6 / 09$ & $5 / 21 / 09$ & 15 & 4.0 & 0.159 & & 14200 & & & 8.51 & 14.8 & 7.85 & \\
\hline $2941-290$ & PB & 14 & & $5 / 21 / 09$ & $6 / 3 / 09$ & 13 & 2.0 & 0.159 & & 38900 & & & 12.9 & 23.0 & 11.4 & \\
\hline 2941-305 & PB & 15 & & 7/29/09 & $8 / 12 / 09$ & 14 & 3.0 & 0.159 & & 26900 & & 7000 & 34.1 & 66.6 & 27.8 & \\
\hline 2941-307 & PB & 16 & & 8/12/09 & $8 / 26 / 09$ & 14 & 0.0 & 0.159 & & 84100 & & 17300 & 16.1 & 35.3 & 14.2 & \\
\hline $2941-317$ & PB & 17 & & $8 / 26 / 09$ & 9/9/09 & 14 & 2.0 & 0.159 & & 23900 & & 4700 & 29.0 & 54.1 & 25.0 & \\
\hline $2941-323$ & PB & 18 & & 9/9/09 & $9 / 24 / 09$ & 15 & 3.0 & 0.159 & & 24600 & & & 17.5 & 38.2 & 15.5 & \\
\hline $2941-334$ & PB & 19 & & $9 / 24 / 09$ & $10 / 7 / 09$ & 13 & 1.8 & 0.159 & & 19800 & & & 16.8 & 35.4 & 13.4 & \\
\hline Average & & & & & & & & & Average & 199000 & & 41200 & 15.0 & 30.2 & 16.5 & \\
\hline Stdev & & & & & & & & & Stdev & 318000 & & 73900 & 13.2 & 22.2 & 14.7 & \\
\hline RSD & & & & & & & & & RSD & $160 \%$ & & $179 \%$ & $88 \%$ & $74 \%$ & $89 \%$ & \\
\hline $2941-176$ & PO & 1 & & $9 / 3 / 08$ & $9 / 17 / 08$ & 14 & 0.0 & 0.159 & & 75800 & & & 2.60 & 10.5 & 2.10 & \\
\hline 2941-185 & $\mathrm{PO}$ & 2 & & 9/17/08 & $10 / 6 / 08$ & 19 & 6.0 & 0.159 & & 236000 & & 44800 & 10.2 & 25.1 & 6.59 & \\
\hline 2941-193 & PO & 3 & $\mathrm{x}$ & $10 / 6 / 08$ & 10/16/08 & 10 & 1.5 & 0.159 & & 78300 & $23 \%$ & 18000 & 28.9 & 65.1 & 21.3 & $81 \%$ \\
\hline $2941-206$ & $\mathrm{PO}$ & 4 & $\mathrm{x}$ & $10 / 16 / 08$ & $10 / 29 / 08$ & 13 & 1.0 & 0.159 & & 21600 & $28 \%$ & 7440 & 8.47 & 22.7 & 6.75 & $82 \%$ \\
\hline $2941-213$ & PO & 5 & & $10 / 29 / 08$ & $11 / 7 / 08$ & 9 & 6.0 & 0.159 & & 172000 & & 43100 & 31.8 & 71.9 & 24.3 & \\
\hline $2941-217$ & PO & 6 & & $11 / 7 / 08$ & $11 / 20 / 08$ & 12 & 13.5 & 0.159 & & 74800 & & 34800 & 31.8 & 82.6 & 23.1 & \\
\hline $2941-233$ & PO & 7 & & $11 / 20 / 08$ & $12 / 11 / 08$ & 21 & 2.0 & 0.159 & & 11900 & & 2800 & & & 8.70 & \\
\hline $2941-237$ & PO & 8 & & $2 / 26 / 09$ & $3 / 12 / 09$ & 14 & 4.0 & 0.159 & & 527000 & & & & & 33.9 & \\
\hline $2941-251$ & $\mathrm{PO}$ & 9 & & $3 / 12 / 09$ & $3 / 25 / 09$ & 13 & 8.0 & 0.159 & & 1750000 & & & & & 42.4 & \\
\hline $2941-261$ & PO & 10 & & $3 / 25 / 09$ & $4 / 8 / 09$ & 14 & 6.0 & 0.159 & & 473000 & & & & & 23.1 & \\
\hline $2941-270$ & PO & 11 & & $4 / 8 / 09$ & $4 / 22 / 09$ & 14 & 5.0 & 0.159 & & 545000 & & & 9.47 & 27.6 & 7.17 & \\
\hline $2941-277$ & PO & 12 & & $4 / 22 / 09$ & $5 / 5 / 09$ & 13 & 2.0 & 0.159 & & 181000 & & & 3.31 & 12.0 & 2.00 & \\
\hline $2941-279$ & $\mathrm{PO}$ & 13 & & $5 / 5 / 09$ & $5 / 20 / 09$ & 15 & 11.0 & 0.159 & & 67100 & & & 4.88 & 17.7 & 3.08 & \\
\hline $2941-292$ & PO & 14 & & $5 / 20 / 09$ & $6 / 5 / 09$ & 16 & 4.0 & 0.159 & & 99700 & & & 28.6 & 66.2 & 24.1 & \\
\hline $2941-300$ & PO & 15 & & 7/30/09 & $8 / 14 / 09$ & 15 & 2.0 & 0.159 & & 30500 & & & 12.6 & 43.4 & 10.8 & \\
\hline $2941-311$ & PO & 16 & & $8 / 14 / 09$ & $8 / 26 / 09$ & 12 & 0.0 & 0.159 & & 14800 & & 4600 & 11.5 & 29.6 & 8.71 & \\
\hline $2941-321$ & PO & 17 & & $8 / 26 / 09$ & 9/11/09 & 16 & 5.8 & 0.159 & & 65300 & & 13600 & 22.0 & 55.9 & 18.1 & \\
\hline $2941-330$ & $\mathrm{PO}$ & 18 & & 9/11/09 & $9 / 25 / 09$ & 14 & 1.0 & 0.159 & & 22500 & & & 11.4 & 30.6 & 9.88 & \\
\hline $2941-337$ & $\mathrm{PO}$ & 19 & & $9 / 25 / 09$ & $10 / 14 / 09$ & 19 & 3.0 & 0.159 & & 87000 & & 18400 & 21.7 & 57.3 & 17.9 & \\
\hline Average & & & & & & & & & Average & 239000 & & 20800 & 16.0 & 41.2 & 15.5 & \\
\hline Stdev & & & & & & & & & Stdev & 404000 & & 16200 & 10.5 & 23.5 & 11.2 & \\
\hline RSD & & & & & & & & & RSD & $169 \%$ & & $78 \%$ & $66 \%$ & $57 \%$ & $72 \%$ & \\
\hline
\end{tabular}


Field Sample Results - Biomarker, PAHs

\begin{tabular}{|c|c|c|c|c|c|c|c|c|c|c|c|c|c|c|c|c|}
\hline Sample ID & $\begin{array}{c}\text { Station } \\
\text { ID }\end{array}$ & $\begin{array}{c}\text { Event } \\
\text { No. }\end{array}$ & $\begin{array}{l}\text { Field } \\
\text { Dup }\end{array}$ & $\begin{array}{c}\text { Date } \\
\text { Deployed }\end{array}$ & $\begin{array}{c}\text { Date } \\
\text { Recovered }\end{array}$ & $\begin{array}{l}\text { No. Days } \\
\text { Deployed }\end{array}$ & $\begin{array}{l}\text { Org. Vol. } \\
\text { (L) }\end{array}$ & $\begin{array}{r}\text { Funnel } \\
\text { Surface } \\
\text { Area }(\mathrm{m} 2) \\
\end{array}$ & & Levoglucosan & $\begin{array}{l}\text { Field } \\
\text { Dup. } \\
\text { RPD }\end{array}$ & Mannosan & $\begin{array}{r}\text { Carcinogenic } \\
\text { PAHs } \\
(\mathrm{CPAHs})^{\mathrm{a}} \\
\end{array}$ & $\begin{array}{r}\text { Pyrogenic } \\
\text { PAHs } \\
\text { (PyPAHs) }^{\text {b }}\end{array}$ & $\begin{array}{r}\text { High molecular } \\
\text { weight PAHs } \\
\text { (HMW PAHs) }^{c}\end{array}$ & $\begin{array}{l}\text { Field } \\
\text { Dup. } \\
\text { RPD }\end{array}$ \\
\hline & & & & & & & & Unit & & (ng/m2/day) & & (ng/m2/day) & (ng/m2/day) & (ng/m2/day) & (ng/m2/day) & \\
\hline $2941-178$ & SB & 1 & $\mathrm{x}$ & $9 / 2 / 08$ & $9 / 18 / 08$ & 16 & $<20 \mathrm{~mL}$ & 0.159 & & 30200 & $30 \%$ & 11300 & 2.21 & 7.40 & 1.82 & $77 \%$ \\
\hline $2941-186$ & SB & 2 & $\mathrm{x}$ & $9 / 18 / 08$ & $10 / 2 / 08$ & 14 & 1.5 & 0.159 & & 402000 & $11 \%$ & 111000 & 64.3 & 94.0 & 42.6 & $1 \%$ \\
\hline 2941-195 & SB & 3 & & $10 / 2 / 08$ & $10 / 15 / 08$ & 13 & 1.5 & 0.159 & & 61100 & & & 10.9 & 28.5 & 8.24 & \\
\hline $2941-205$ & SB & 4 & & $10 / 15 / 08$ & 10/30/08 & 15 & 2.0 & 0.159 & & 35300 & & 14300 & 14.8 & 39.1 & 11.0 & \\
\hline $2941-216$ & SB & 5 & & $10 / 30 / 08$ & 11/10/08 & 11 & 14.0 & 0.159 & & NA & 1 & NA & 66.2 & 142 & 50.3 & \\
\hline $2941-218$ & SB & 6 & & $11 / 10 / 08$ & $11 / 25 / 08$ & 12 & 3.0 & 0.159 & & 39700 & & 15900 & 9.51 & 26.6 & 7.97 & \\
\hline $2941-219$ & SB & 7 & & $11 / 25 / 08$ & $12 / 11 / 08$ & 16 & 2.0 & 0.159 & & 13100 & & 2700 & & & 7.68 & \\
\hline $2941-245$ & SB & 8 & & $2 / 25 / 09$ & $3 / 12 / 09$ & 15 & 4.5 & 0.159 & & 279000 & & & & & 36.3 & \\
\hline $2941-252$ & SB & 9 & & 3/12/09 & $3 / 29 / 09$ & 17 & 5.0 & 0.159 & & 1220000 & & & & & 29.8 & \\
\hline $2941-260$ & SB & 10 & & $3 / 29 / 09$ & $4 / 13 / 09$ & 15 & 5.0 & 0.159 & & 1330000 & & & & & 25.9 & \\
\hline 2941-268 & SB & 11 & & $4 / 13 / 09$ & $4 / 28 / 09$ & 15 & $<1$ & 0.159 & & 145000 & & & 9.40 & 21.4 & 8.33 & \\
\hline $2941-278$ & SB & 12 & & $4 / 28 / 09$ & $5 / 11 / 09$ & 13 & 2.0 & 0.159 & & 247000 & & & 11.1 & 24.9 & 9.03 & \\
\hline $2941-281$ & SB & 13 & & $5 / 11 / 09$ & $5 / 27 / 09$ & 16 & 5.5 & 0.159 & & 234000 & & & 12.1 & 23.2 & 8.09 & \\
\hline $2941-286$ & SB & 14 & & $5 / 27 / 09$ & $6 / 8 / 09$ & 12 & 0.0 & 0.159 & & 66300 & & & 25.1 & 48.6 & 22.2 & \\
\hline $2941-303$ & SB & 15 & & $8 / 3 / 09$ & $8 / 18 / 09$ & 15 & 1.8 & 0.159 & & 40800 & & 24300 & 10.7 & 25.1 & 9.48 & \\
\hline $2941-313$ & SB & 16 & & $8 / 15 / 09$ & $8 / 29 / 09$ & 11 & 0.0 & 0.159 & & 35200 & & 10500 & 11.8 & 25.3 & 10.1 & \\
\hline $2941-320$ & SB & 17 & & $8 / 29 / 09$ & $9 / 11 / 09$ & 13 & 1.3 & 0.159 & & 1050000 & & & 18.6 & 33.9 & 16.9 & \\
\hline $2941-329$ & SB & 18 & & 9/11/09 & $9 / 25 / 09$ & 14 & 1.0 & 0.159 & & 22300 & & & 4.68 & 12.9 & 3.66 & \\
\hline $2941-336$ & SB & 19 & & $9 / 25 / 09$ & $10 / 13 / 09$ & 18 & 1.9 & 0.159 & & 48600 & & & 9.18 & 23.8 & 7.73 & \\
\hline Average & & & & & & & & & Average & 294000 & & 27100 & 18.7 & 38.5 & 16.7 & \\
\hline Stdev & & & & & & & & & Stdev & 433000 & & 37500 & 19.6 & 35.0 & 14.0 & \\
\hline RSD & & & & & & & & & RSD & $147 \%$ & & $138 \%$ & $105 \%$ & $91 \%$ & $84 \%$ & \\
\hline $2941-174$ & TCB & 1 & & $8 / 29 / 08$ & $9 / 12 / 08$ & 14 & 0.0 & 0.159 & & 42400 & & & 57.5 & 142 & 53.6 & \\
\hline 2941-181 & TCB & 2 & & $9 / 12 / 08$ & $9 / 24 / 08$ & 12 & 1.5 & 0.159 & & 72400 & & 19400 & 66.1 & 174 & 61.5 & \\
\hline 2941-188 & TCB & 3 & & $9 / 24 / 08$ & $10 / 15 / 08$ & 21 & 6.0 & 0.159 & & 89100 & & 18200 & 273 & 610 & 253 & \\
\hline $2941-203$ & TCB & 4 & & $10 / 15 / 08$ & $10 / 30 / 08$ & 15 & 2.0 & 0.159 & & 44500 & & 14800 & 110 & 269 & 106 & \\
\hline $2941-212$ & TCB & 5 & & $10 / 30 / 08$ & $11 / 12 / 08$ & 13 & 20.0 & 0.159 & & 239000 & & 63600 & 245 & 747 & 202 & \\
\hline $2941-229$ & TCB & 7 & & $11 / 12 / 08$ & $11 / 24 / 08$ & 17 & 1.5 & 0.159 & & 30500 & & 7110 & & & 107 & \\
\hline $2941-240$ & TCB & 8 & & $11 / 24 / 08$ & $12 / 11 / 08$ & 15 & 5.5 & 0.159 & & NA & 1 & NA & & & 210 & \\
\hline $2941-243$ & TCB & 8 & & $2 / 25 / 09$ & $3 / 12 / 09$ & 15 & 5.5 & 0.159 & & 203000 & & 22500 & & & 238 & \\
\hline $2941-245 b$ & TCB & 9 & $\mathrm{x}$ & $2 / 25 / 09$ & $3 / 12 / 09$ & 13 & 8.0 & 0.159 & & 278000 & $19 \%$ & & & & 410 & $12 \%$ \\
\hline $2941-256$ & TCB & 10 & & 3/12/09 & $3 / 25 / 09$ & 14 & 6.5 & 0.159 & & 420000 & & & & & 200 & \\
\hline $2941-267$ & TCB & 11 & & $4 / 8 / 09$ & $4 / 22 / 09$ & 14 & 5.0 & 0.159 & & 294000 & & & 230 & 492 & 219 & \\
\hline $2941-274$ & TCB & 12 & & $4 / 22 / 09$ & $5 / 7 / 09$ & 15 & 3.0 & 0.159 & & 42200 & & & 52.0 & 139 & 48.4 & \\
\hline $2941-282$ & TCB & 13 & & $5 / 7 / 09$ & $5 / 21 / 09$ & 14 & 10.0 & 0.159 & & 57100 & & & 327 & 659 & 302 & \\
\hline $2941-288$ & TCB & 14 & & $5 / 21 / 09$ & $6 / 4 / 09$ & 14 & 0.0 & 0.159 & & 33700 & & & 181 & 414 & 191 & \\
\hline 2941-301 & TCB & 15 & & $7 / 30 / 09$ & $8 / 12 / 09$ & 13 & 1.5 & 0.159 & & 34100 & & & 202 & 536 & 185 & \\
\hline 2941-309 & TCB & 16 & & $8 / 12 / 09$ & $8 / 27 / 09$ & 15 & 1.0 & 0.159 & & 27500 & & 14800 & 123 & 323 & 112 & \\
\hline $2941-316$ & TCB & 17 & & $8 / 27 / 09$ & $9 / 8 / 09$ & 12 & 9.5 & 0.159 & & 65900 & & & 410 & 985 & 352 & \\
\hline $2941-326$ & TCB & 18 & & 9/8/09 & $9 / 24 / 09$ & 16 & 1.0 & 0.159 & & 26300 & & & 270 & 619 & 254 & \\
\hline $2941-333$ & TCB & 19 & & $9 / 24 / 09$ & $10 / 7 / 09$ & 13 & 1.8 & 0.159 & & 57400 & & & 1490 & 3490 & 1140 & \\
\hline Average & & & & & & & & & Average & 114000 & & 22900 & 288 & 686 & 244 & \\
\hline Stdev & & & & & & & & & Stdev & 118000 & & 18600 & 362 & 844 & 238 & \\
\hline RSD & & & & & & & & & RSD & $104 \%$ & & $81 \%$ & $125 \%$ & $123 \%$ & $\mathbf{9 7 \%}$ & \\
\hline
\end{tabular}


Field Sample Results - Biomarker, PAHs

\begin{tabular}{|c|c|c|c|c|c|c|c|c|c|c|c|c|c|c|c|}
\hline Sample ID & $\begin{array}{l}\text { Station } \\
\text { ID }\end{array}$ & $\begin{array}{cc}\text { Event } & \text { Field } \\
\text { No. } & \text { Dup } \\
\end{array}$ & $\begin{array}{c}\text { Date } \\
\text { Deployed }\end{array}$ & $\begin{array}{c}\text { Date } \\
\text { Recovered }\end{array}$ & $\begin{array}{l}\text { No. Days } \\
\text { Deployed }\end{array}$ & $\begin{array}{c}\text { Org. Vol. } \\
\text { (L) }\end{array}$ & $\begin{array}{r}\text { Funnel } \\
\text { Surface } \\
\text { Area }(\mathrm{m} 2)\end{array}$ & & Levoglucosan & $\begin{array}{l}\text { Field } \\
\text { Dup. } \\
\text { RPD }\end{array}$ & Mannosan & $\begin{array}{r}\text { Carcinogenic } \\
\text { PAHs } \\
(\mathrm{CPAHs})^{\mathrm{a}} \\
\end{array}$ & $\begin{array}{r}\text { Pyrogenic } \\
\text { PAHs } \\
\text { (PyPAHs) }^{\text {by }} \\
\end{array}$ & $\begin{array}{r}\text { High molecular } \\
\text { weight PAHs } \\
\text { (HMW PAHs) }^{\mathrm{C}}\end{array}$ & $\begin{array}{l}\text { Field } \\
\text { Dup. } \\
\text { RPD } \\
\end{array}$ \\
\hline & & & & & & & Unit & & (ng/m2/day) & & (ng/m2/day) & (ng/m2/day) & (ng/m2/day) & (ng/m2/day) & \\
\hline 2941-172 & WP & 1 & $8 / 28 / 08$ & $9 / 12 / 08$ & 15 & 0.0 & 0.159 & & 112000 & & 13100 & 4.10 & 10.7 & 3.80 & \\
\hline 2941-183 & WP & 2 & $9 / 12 / 08$ & $9 / 25 / 08$ & 13 & 2.0 & 0.159 & & 418000 & & 63700 & 13.3 & 34.2 & 11.4 & \\
\hline 2941-190 & WP & 3 & $9 / 25 / 08$ & $10 / 14 / 08$ & 19 & 5.0 & 0.159 & & 114000 & & 32700 & & & & 1 \\
\hline $2941-201$ & WP & 4 & $10 / 14 / 08$ & $10 / 29 / 08$ & 15 & 1.5 & 0.159 & & 27800 & & 34800 & 40.9 & 81.9 & 37.9 & \\
\hline $2941-200$ & WP & 5 & $10 / 29 / 08$ & $11 / 13 / 08$ & 15 & 18.0 & 0.159 & & 159000 & & 50200 & 84.5 & 175 & 68.4 & \\
\hline $2941-225$ & WP & 6 & $11 / 13 / 08$ & $11 / 25 / 08$ & 12 & 1.0 & 0.159 & & 135000 & & 21800 & 22.8 & 53.9 & 19.7 & \\
\hline $2941-230$ & WP & 7 & $11 / 25 / 08$ & $12 / 11 / 08$ & 16 & 1.5 & 0.159 & & 36700 & & & & & 11.8 & \\
\hline $2941-244$ & WP & 8 & $2 / 26 / 09$ & $3 / 11 / 09$ & 13 & 4.5 & 0.159 & & 1020000 & & 795000 & & & 103 & \\
\hline $2941-246$ & WP & 9 & $3 / 11 / 09$ & $3 / 25 / 09$ & 14 & 6.0 & 0.159 & & 1480000 & & & & & 24.4 & \\
\hline $2941-258$ & WP & 10 & $3 / 25 / 09$ & $4 / 8 / 09$ & 14 & 6.5 & 0.159 & & 686000 & & & & & 33.7 & \\
\hline $2941-264$ & WP & 11 & $4 / 8 / 09$ & $4 / 23 / 09$ & 15 & 4.0 & 0.159 & & 207000 & & & 27.4 & 60.1 & 24.8 & \\
\hline $2941-272$ & WP & 12 & $4 / 23 / 09$ & $5 / 6 / 09$ & 13 & 2.0 & 0.159 & & 78100 & & & 9.15 & 21.3 & 8.27 & \\
\hline $2941-284$ & WP & 13 & $5 / 6 / 09$ & $5 / 21 / 09$ & 15 & 11.0 & 0.159 & & 63600 & & & 11.1 & 26.1 & 9.85 & \\
\hline $2941-289$ & WP & 14 & $5 / 21 / 09$ & $6 / 3 / 09$ & 13 & 2.0 & 0.159 & & 27200 & & & 26.6 & 53.7 & 25.0 & \\
\hline $2941-302$ & WP & 15 & $7 / 29 / 09$ & $8 / 12 / 09$ & 14 & 1.5 & 0.159 & & 25000 & & & 17.8 & 45.2 & 16.4 & \\
\hline $2941-308$ & WP & 16 & $8 / 12 / 09$ & $8 / 26 / 09$ & 14 & 1.5 & 0.159 & & 20300 & & 3400 & 22.8 & 55.8 & 20.2 & \\
\hline $2941-315$ & WP & 17 & $8 / 26 / 09$ & 9/9/09 & 14 & 4.5 & 0.159 & & 56900 & & 13200 & 38.4 & 89.6 & 32.9 & \\
\hline $2941-327$ & WP & 18 & 9/9/09 & $9 / 24 / 09$ & 15 & 2.0 & 0.159 & & 18800 & & & 17.8 & 36.8 & 15.6 & \\
\hline $2941-332$ & WP & 19 & $9 / 24 / 09$ & $10 / 7 / 09$ & 13 & 3.8 & 0.159 & & 33100 & & & 64.5 & 134 & 55.0 & \\
\hline Average & & & & & & & & Average & 248000 & & 114000 & 28.7 & 62.7 & 29.0 & \\
\hline Stdev & & & & & & & & Stdev & 397000 & & 256000 & 22.3 & 45.1 & 24.8 & \\
\hline RSD & & & & & & & & RSD & $160 \%$ & & $225 \%$ & $78 \%$ & $72 \%$ & $85 \%$ & \\
\hline $2941-293$ & $\mathrm{TM}$ & 14 & $5 / 20 / 09$ & $6 / 4 / 09$ & 15 & & 0.159 & & 43000 & & & 8.68 & 21.6 & 7.93 & \\
\hline 2941-304 & TM & 15 & $7 / 30 / 09$ & $8 / 12 / 09$ & 13 & & 0.159 & & 21100 & & & 43.3 & 147 & 36.2 & \\
\hline $2941-312$ & $\mathrm{TM}$ & 16 & $8 / 12 / 09$ & $8 / 27 / 09$ & 15 & & 0.159 & & 13500 & & 3000 & 40.8 & 120 & 37.3 & \\
\hline $2941-318$ & TM & 17 & $8 / 27 / 09$ & $9 / 8 / 09$ & 12 & & 0.159 & & 82700 & & 13400 & 70.5 & 245 & 55.9 & \\
\hline $2941-325$ & TM & 18 & $9 / 8 / 09$ & $9 / 24 / 09$ & 16 & & 0.159 & & 18900 & & & 59.3 & 175 & 46.7 & \\
\hline $2941-333$ & $\mathrm{TM}$ & 19 & $9 / 24 / 09$ & $10 / 7 / 09$ & 13 & & 0.159 & & 28300 & & & 87.0 & 246 & 67.0 & \\
\hline Average & & & & & & & & Average & 34600 & & 8200 & 51.6 & 159 & 41.8 & \\
\hline Stdev & & & & & & & & Stdev & 25700 & & 7350 & 27.2 & 84.5 & 20.3 & \\
\hline RSD & & & & & & & & RSD & $74 \%$ & & $90 \%$ & $53 \%$ & $53 \%$ & $48 \%$ & \\
\hline $\mathrm{NA}$ & \multirow{2}{*}{\multicolumn{7}{|c|}{$\begin{array}{l}\text { Not available } \\
\text { Contamination }\end{array}$}} & & & & & & & & \\
\hline$*$ & & & & & & & & & & & & & & & \\
\hline$* *$ & \multirow{3}{*}{\multicolumn{7}{|c|}{$\begin{array}{l}\text { Outlier; see narration } \\
\text { Carcinogenic PAHs: benzo(a)anthracene, chrysene, benzo(b)fluoranthene, } \\
\text { benzo(k)fluoranthene, benzo(a)pyrene, indeno(1,2,3-c,d)pyrene, dibenz(a,h)anthracene } \\
\text { Pyrogenic PAHs: fluoranthene, pyrene, benzo(a)anthracene, chrysene, } \\
\text { benzo(b)fluoranthene, benzo(k)fluoranthene, benzo(a)pyrene, indeno(1,2,3-c,d)pyrene, } \\
\text { dibenz(a,h)anthracene, benzo(g,h,i)perylene }\end{array}$}} & & & & & & & & \\
\hline $\mathrm{a}$ & & & & & & & & & & & & & & & \\
\hline $\mathrm{b}$ & & & & & & & & & & & & & & & \\
\hline $\mathrm{c}$ & \multicolumn{7}{|c|}{$\begin{array}{l}\text { High molecular weight PAHs: benzo(b)fluoranthene, benzo(k)fluoranthene, } \\
\text { benzo(a)pyrene, indeno(1,2,3-c,d)pyrene, dibenz(a,h)anthracene, benzo(g,h,i)perylene }\end{array}$} & & & & & & & & \\
\hline
\end{tabular}


Field Sample Results - Biomarker, PAHs

Station Event Field Funnel 1,7-DMP

Org. Vol. Surface Flu/(Flu+ InP/(InP+ Ret/(Ret+ (1,7-+2,6-

Phen

\begin{tabular}{|c|c|c|c|c|c|c|c|c|c|c|c|c|c|c|c|c|c|c|}
\hline Sample ID & ID & No. & Dup & Deployed & Recovered & Deployed & (L) & Area (m2) & Py) & BghiP) & Chy) & DMP) & An/178 & $\mathrm{BaA} / 228$ & $\mathbf{M P} / \mathbf{P}$ & Anth $\mathrm{I}$ & Fla/Pyr & $\mathbf{L} / \mathbf{M}$ \\
\hline & & & & & & & & Unit & & & & & & & & & & \\
\hline $2941-177$ & $\mathrm{HC}$ & 1 & & $9 / 3 / 08$ & $9 / 17 / 08$ & 14 & 0.0 & 0.159 & 0.636 & 0.409 & 0.757 & 0.497 & & 0.306 & & & 1.75 & \\
\hline 2941-184 & $\mathrm{HC}$ & 2 & & 9/17/08 & $10 / 6 / 08$ & 19 & 8.0 & 0.159 & 0.655 & 0.441 & 0.914 & 0.913 & & 0.165 & & & 1.90 & 4.58 \\
\hline 2941-194 & $\mathrm{HC}$ & 3 & & $10 / 6 / 08$ & $10 / 16 / 08$ & 10 & 3.0 & 0.159 & 0.599 & 0.514 & 0.750 & 0.736 & & 0.175 & & & 1.49 & 2.90 \\
\hline $2941-208$ & $\mathrm{HC}$ & 4 & & $10 / 16 / 08$ & $10 / 29 / 08$ & 13 & 1.0 & 0.159 & 0.676 & 0.291 & 0.598 & 0.473 & & 0.212 & & & 2.09 & 2.89 \\
\hline $2941-214$ & $\mathrm{HC}$ & 5 & $\mathrm{x}$ & $10 / 29 / 08$ & $11 / 8 / 08$ & 10 & 6.0 & 0.159 & 0.686 & 0.508 & 0.937 & 0.891 & 0.0141 & 0.135 & 0.683 & 70.0 & 2.19 & 5.14 \\
\hline $2941-220$ & $\mathrm{HC}$ & 6 & $\mathrm{x}$ & $11 / 8 / 08$ & $11 / 20 / 08$ & 12 & 6.0 & 0.159 & 0.813 & 0.585 & 0.785 & 0.696 & & 0.077 & & & 4.36 & 4.10 \\
\hline $2941-210$ & $\mathrm{HC}$ & 7 & $\mathrm{x}$ & $11 / 20 / 08$ & $12 / 11 / 08$ & 21 & 4.0 & 0.159 & & 0.448 & & & & & & & & 3.63 \\
\hline $2941-238$ & $\mathrm{HC}$ & 8 & & $2 / 26 / 09$ & $3 / 12 / 09$ & 14 & 4.0 & 0.159 & & 0.450 & & & & & & & & \\
\hline $2941-250$ & $\mathrm{HC}$ & 9 & & 3/12/09 & $3 / 25 / 09$ & 13 & 9.5 & 0.159 & & 0.596 & & & & & & & & \\
\hline $2941-262$ & $\mathrm{HC}$ & 10 & & $3 / 25 / 09$ & $4 / 8 / 09$ & 14 & 4.0 & 0.159 & & 0.359 & & & & & & & & \\
\hline $2941-269$ & $\mathrm{HC}$ & 11 & & $4 / 8 / 09$ & $4 / 22 / 09$ & 14 & 6.0 & 0.159 & 0.679 & 0.397 & 0.721 & 0.606 & & 0.147 & & & 2.11 & \\
\hline $2941-276$ & $\mathrm{HC}$ & 12 & & $4 / 22 / 09$ & $5 / 5 / 09$ & 13 & 1.0 & 0.159 & 0.772 & & 0.919 & 0.669 & & 0.188 & & & 3.38 & \\
\hline $2941-280$ & $\mathrm{HC}$ & 13 & & $5 / 5 / 09$ & $5 / 20 / 09$ & 15 & 5.0 & 0.159 & 0.712 & & 0.972 & 0.458 & & 0.268 & & & 2.47 & \\
\hline 2941-294 & $\mathrm{HC}$ & 14 & & $5 / 20 / 09$ & $6 / 5 / 09$ & 16 & 4.0 & 0.159 & 0.634 & 0.453 & 0.743 & 0.636 & & 0.271 & & & 1.73 & \\
\hline $2941-306$ & $\mathrm{HC}$ & 15 & & $7 / 30 / 09$ & $8 / 14 / 09$ & 15 & 2.5 & 0.159 & 0.585 & 0.383 & 0.888 & 0.845 & & 0.271 & & & 1.41 & 5.30 \\
\hline $2941-314$ & $\mathrm{HC}$ & 16 & & $8 / 14 / 09$ & $8 / 26 / 09$ & 12 & 0.0 & 0.159 & 0.578 & 0.416 & 0.866 & 0.675 & & 0.206 & & & 1.37 & 2.34 \\
\hline $2941-322$ & $\mathrm{HC}$ & 17 & & $8 / 26 / 09$ & $9 / 11 / 09$ & 16 & 6.8 & 0.159 & 0.575 & 0.448 & 0.874 & 1.00 & & 0.272 & & & 1.35 & 3.33 \\
\hline $2947-328$ & $\mathrm{HC}$ & 18 & & $9 / 11 / 09$ & $9 / 25 / 09$ & 14 & 2.0 & 0.159 & 0.496 & 0.376 & 0.913 & 0.702 & & 0.321 & & & 0.983 & \\
\hline $2941-338$ & $\mathrm{HC}$ & 19 & & $9 / 25 / 09$ & $10 / 14 / 09$ & 19 & 6.0 & 0.159 & 0.623 & 0.469 & 0.935 & 0.874 & & 0.203 & & & 1.66 & 8.74 \\
\hline Average & & & & & & & & & & & & & & & & & & \\
\hline Stdev & & & & & & & & & & & & & & & & & & \\
\hline RSD & & & & & & & & & & & & & & & & & & \\
\hline $2941-175$ & NR & 1 & & $8 / 29 / 08$ & $9 / 12 / 08$ & 14 & 0.0 & 0.159 & 0.617 & 0.253 & 0.692 & 0.461 & & 0.173 & & & 1.61 & 2.37 \\
\hline $2941-180$ & NR & 2 & & $9 / 12 / 08$ & $9 / 24 / 08$ & 12 & 1.0 & 0.159 & 0.641 & 0.357 & 0.858 & 0.628 & & 0.161 & & & 1.79 & \\
\hline 2941-189 & NR & 3 & & $9 / 24 / 08$ & $10 / 15 / 08$ & 21 & 9.0 & 0.159 & 0.619 & 0.538 & 0.896 & 0.929 & 0.0554 & 0.238 & 0.580 & 17.0 & 1.62 & 3.09 \\
\hline $2941-202$ & NR & 4 & & $10 / 15 / 08$ & $10 / 30 / 08$ & 15 & 2.0 & 0.159 & 0.555 & 0.448 & 0.687 & 0.634 & 0.0567 & 0.189 & 0.875 & 16.6 & 1.25 & 2.62 \\
\hline $2941-211$ & NR & 5 & & $10 / 30 / 08$ & $11 / 12 / 08$ & 13 & 3.0 & 0.159 & 0.763 & 0.504 & 0.913 & 0.711 & & 0.074 & & & 3.23 & 4.06 \\
\hline $2941-223$ & NR & 6 & & $11 / 12 / 08$ & $11 / 24 / 08$ & 12 & 16.0 & 0.159 & 0.670 & 0.444 & 0.806 & 0.796 & 0.0239 & 0.114 & 0.550 & 40.8 & 2.03 & 3.83 \\
\hline $2941-228$ & NR & 7 & & $11 / 24 / 08$ & $12 / 11 / 08$ & 17 & 1.0 & 0.159 & & 0.253 & & & & & & & & 3.06 \\
\hline $2941-242$ & NR & 8 & & $2 / 25 / 09$ & $3 / 12 / 09$ & 15 & 3.0 & 0.159 & & 0.417 & & & & & & & & 6.56 \\
\hline $2941-249$ & NR & 9 & & $3 / 12 / 09$ & $3 / 25 / 09$ & 13 & 6.0 & 0.159 & & 0.475 & & & & & & & & \\
\hline $2941-255$ & NR & 10 & $\mathrm{x}$ & $3 / 25 / 09$ & $4 / 8 / 09$ & 14 & 5.0 & 0.159 & & 0.418 & & & & & & & & \\
\hline $2941-265$ & NR & 11 & $\mathrm{x}$ & $4 / 8 / 09$ & 4/22/09 & 14 & 4.0 & 0.159 & 0.689 & 0.400 & 0.812 & 0.698 & & 0.152 & & & 2.22 & \\
\hline $2941-273$ & NR & 12 & $\mathrm{x}$ & $4 / 22 / 09$ & $5 / 7 / 09$ & 15 & 1.0 & 0.159 & 0.737 & & 0.874 & 0.573 & & 0.189 & & & 2.81 & \\
\hline $2941-285$ & NR & 13 & & $5 / 7 / 09$ & $5 / 21 / 09$ & 14 & 1.5 & 0.159 & 0.708 & 0.389 & 0.935 & 0.717 & & 0.213 & & & 2.43 & \\
\hline $2941-287$ & NR & 14 & & $5 / 21 / 09$ & $6 / 4 / 09$ & 14 & 0.0 & 0.159 & 0.568 & 0.360 & 0.632 & 0.619 & & 0.156 & & & 1.32 & \\
\hline 2941-299 & NR & 15 & & $7 / 30 / 09$ & $8 / 12 / 09$ & 13 & 1.0 & 0.159 & 0.565 & 0.414 & 0.886 & 0.564 & & 0.252 & & & 1.30 & \\
\hline $2941-310$ & NR & 16 & & $8 / 12 / 09$ & $8 / 27 / 09$ & 15 & 0.5 & 0.159 & 0.438 & 0.292 & 0.585 & 0.484 & & 0.360 & & & 0.78 & 1.97 \\
\hline 2941-319 & NR & 17 & & $8 / 27 / 09$ & $9 / 8 / 09$ & 12 & 8.0 & 0.159 & 0.615 & 0.394 & 0.882 & 0.690 & & 0.249 & 0.518 & & 1.60 & 8.18 \\
\hline $2941-324$ & NR & 18 & & $9 / 8 / 09$ & $9 / 24 / 09$ & 16 & 2.0 & 0.159 & 0.587 & 0.366 & 0.854 & 0.655 & & 0.219 & & & 1.42 & \\
\hline $2941-335$ & NR & 19 & & 9/24/09 & $10 / 7 / 09$ & 13 & 1.0 & 0.159 & 0.593 & 0.364 & 0.872 & 0.674 & & 0.304 & & & 1.45 & \\
\hline
\end{tabular}

Stdev

RSD 
Field Sample Results - Biomarker, PAHs

1,7-DMP /

Station Event Field Date Date No. Days Org. Vol. Surface Flu/(Flu+ InP/(InP+ Ret/(Ret+ (1,7-+2,6-

DMP) An/178 BaA/228 MP/P Anth Fla/Pyr L/M

\begin{tabular}{|c|c|c|c|c|c|c|c|c|c|c|c|c|c|c|c|c|c|c|}
\hline Sample ID & ID & No. & Dup & Deployed & Recovered & Deployed & (L) & Area (m2) & Py) & BghiP) & Chy) & DMP) & An/178 & $\mathrm{BaA} / 228$ & MP/P & Anth & a/Pyr & $\mathbf{L} / \mathbf{M}$ \\
\hline & & & & & & & & Unit & & & & & & & & & & \\
\hline $2941-173$ & PB & 1 & & $8 / 28 / 08$ & $9 / 12 / 08$ & 15 & 1.0 & 0.159 & 0.684 & & 0.695 & & & 0.242 & & & 2.17 & \\
\hline $2941-182$ & PB & 2 & & $9 / 12 / 08$ & $9 / 25 / 08$ & 13 & 3.0 & 0.159 & 0.611 & 0.343 & 0.770 & 0.723 & & 0.273 & & & 1.57 & 4.14 \\
\hline 2941-191 & PB & 3 & & $9 / 25 / 08$ & $10 / 15 / 08$ & 20 & 4.0 & 0.159 & 0.573 & 0.432 & 0.813 & 0.797 & & 0.304 & & & 1.34 & 3.80 \\
\hline 2941-204 & $\mathrm{PB}$ & 4 & & $10 / 15 / 08$ & $10 / 29 / 08$ & 14 & 1.0 & 0.159 & 0.637 & 0.292 & 0.621 & 0.488 & & 0.239 & & & 1.76 & 6.27 \\
\hline $2941-209$ & PB & 5 & & $10 / 29 / 08$ & $11 / 13 / 08$ & 15 & 1.0 & 0.159 & 0.754 & 0.522 & 0.940 & 0.729 & & 0.193 & & & 3.07 & 7.55 \\
\hline $2941-224$ & PB & 6 & & $11 / 13 / 08$ & $11 / 25 / 08$ & 12 & 1.5 & 0.159 & 0.731 & 0.556 & 0.876 & 0.771 & & 0.000 & & & 2.71 & 6.17 \\
\hline $2941-231$ & PB & 7 & & $11 / 25 / 08$ & $12 / 11 / 08$ & 16 & 13.0 & 0.159 & & 0.426 & & & & & & & & 5.64 \\
\hline $2941-241$ & PB & 8 & & $2 / 26 / 09$ & $3 / 11 / 09$ & 13 & 2.0 & 0.159 & & 0.381 & & & & & & & & 1.22 \\
\hline $2941-248$ & $\mathrm{~PB}$ & 9 & & $3 / 11 / 09$ & $3 / 25 / 09$ & 14 & 5.0 & 0.159 & & 0.454 & & & & & & & & \\
\hline $2941-259$ & $\mathrm{~PB}$ & 10 & & $3 / 25 / 09$ & $4 / 8 / 09$ & 14 & 6.0 & 0.159 & & 0.389 & & & & & & & & \\
\hline 2941-263 & PB & 11 & & $4 / 8 / 09$ & $4 / 23 / 09$ & 15 & 3.0 & 0.159 & 0.646 & 0.386 & 0.735 & 0.645 & & 0.159 & & & 1.83 & \\
\hline $2941-271$ & $\mathrm{~PB}$ & 12 & & $4 / 23 / 09$ & $5 / 6 / 09$ & 13 & 0.5 & 0.159 & 0.603 & 0.311 & 0.750 & 0.477 & & 0.208 & & & 1.52 & \\
\hline $2941-283$ & $\mathrm{~PB}$ & 13 & & $5 / 6 / 09$ & $5 / 21 / 09$ & 15 & 4.0 & 0.159 & 0.633 & 0.558 & 0.639 & 0.569 & & 0.326 & & & 1.72 & \\
\hline $2941-290$ & $\mathrm{~PB}$ & 14 & & $5 / 21 / 09$ & $6 / 3 / 09$ & 13 & 2.0 & 0.159 & 0.548 & 0.335 & 0.532 & 0.661 & 0.0141 & 0.293 & 0.214 & 70.0 & 1.21 & \\
\hline $2941-305$ & $\mathrm{~PB}$ & 15 & & $7 / 29 / 09$ & $8 / 12 / 09$ & 14 & 3.0 & 0.159 & 0.519 & 0.421 & 0.591 & 0.585 & 0.0536 & 0.376 & 0.564 & 17.7 & 1.08 & 3.84 \\
\hline $2941-307$ & $\mathrm{~PB}$ & 16 & & $8 / 12 / 09$ & $8 / 26 / 09$ & 14 & 0.0 & 0.159 & 0.566 & 0.416 & 0.896 & 0.654 & 0.0156 & 0.251 & 0.255 & 63.1 & 1.30 & 4.86 \\
\hline $2941-317$ & $\mathrm{~PB}$ & 17 & & $8 / 26 / 09$ & 9/9/09 & 14 & 2.0 & 0.159 & 0.540 & 0.350 & 0.669 & 0.551 & & 0.282 & & & 1.17 & 5.09 \\
\hline $2941-323$ & $\mathrm{~PB}$ & 18 & & 9/9/09 & $9 / 24 / 09$ & 15 & 3.0 & 0.159 & 0.510 & 0.350 & 0.728 & 0.678 & & 0.287 & 0.477 & & 1.04 & \\
\hline 2941-334 & $\mathrm{PB}$ & 19 & & $9 / 24 / 09$ & $10 / 7 / 09$ & 13 & 1.8 & 0.159 & 0.500 & 0.370 & 0.794 & 0.640 & & 0.303 & & & 1.00 & \\
\hline Average & & & & & & & & & & & & & & & & & & \\
\hline Stdev & & & & & & & & & & & & & & & & & & \\
\hline RSD & & & & & & & & & & & & & & & & & & \\
\hline 2941-176 & $\mathrm{PO}$ & 1 & & $9 / 3 / 08$ & $9 / 17 / 08$ & 14 & 0.0 & 0.159 & 0.556 & 0.298 & 0.799 & 0.441 & & 0.207 & & & 1.25 & \\
\hline 2941-185 & $\mathrm{PO}$ & 2 & & $9 / 17 / 08$ & $10 / 6 / 08$ & 19 & 6.0 & 0.159 & 0.726 & 0.498 & 0.916 & 0.925 & & 0.104 & & & 2.65 & 5.27 \\
\hline $2941-193$ & $\mathrm{PO}$ & 3 & $\mathrm{x}$ & $10 / 6 / 08$ & $10 / 16 / 08$ & 10 & 1.5 & 0.159 & 0.620 & 0.438 & 0.821 & 0.790 & & 0.168 & & & 1.63 & 4.35 \\
\hline 2941-206 & $\mathrm{PO}$ & 4 & $\mathrm{x}$ & $10 / 16 / 08$ & $10 / 29 / 08$ & 13 & 1.0 & 0.159 & 0.651 & 0.342 & 0.639 & 0.553 & & 0.221 & & & 1.86 & 2.90 \\
\hline $2941-213$ & $\mathrm{PO}$ & 5 & & $10 / 29 / 08$ & $11 / 7 / 08$ & 9 & 6.0 & 0.159 & 0.665 & 0.511 & 0.949 & 0.886 & 0.0219 & 0.154 & 0.800 & 44.7 & 1.99 & 3.99 \\
\hline $2941-217$ & $\mathrm{PO}$ & 6 & & $11 / 7 / 08$ & $11 / 20 / 08$ & 12 & 13.5 & 0.159 & 0.742 & 0.550 & 0.805 & 0.824 & 0.0183 & 0.129 & 0.475 & 53.7 & 2.87 & 2.15 \\
\hline $2941-233$ & $\mathrm{PO}$ & 7 & & $11 / 20 / 08$ & $12 / 11 / 08$ & 21 & 2.0 & 0.159 & & 0.406 & & & & & & & & 4.25 \\
\hline $2941-237$ & $\mathrm{PO}$ & 8 & & $2 / 26 / 09$ & $3 / 12 / 09$ & 14 & 4.0 & 0.159 & & 0.386 & & & & & & & & \\
\hline $2941-251$ & PO & 9 & & $3 / 12 / 09$ & $3 / 25 / 09$ & 13 & 8.0 & 0.159 & & 0.500 & & & & & & & & \\
\hline $2941-261$ & PO & 10 & & $3 / 25 / 09$ & $4 / 8 / 09$ & 14 & 6.0 & 0.159 & & 0.447 & & & & & & & & \\
\hline $2941-270$ & PO & 11 & & $4 / 8 / 09$ & $4 / 22 / 09$ & 14 & 5.0 & 0.159 & 0.721 & 0.421 & 0.711 & 0.653 & 0.0173 & 0.159 & 0.472 & 56.7 & 2.58 & \\
\hline $2941-277$ & PO & 12 & & $4 / 22 / 09$ & $5 / 5 / 09$ & 13 & 2.0 & 0.159 & 0.663 & & 0.903 & 0.656 & & 0.131 & & & 1.96 & \\
\hline $2941-279$ & PO & 13 & & $5 / 5 / 09$ & $5 / 20 / 09$ & 15 & 11.0 & 0.159 & 0.762 & 0.463 & 0.889 & 0.811 & 0.0147 & 0.221 & 0.291 & 67.1 & 3.21 & \\
\hline 2941-292 & $\mathrm{PO}$ & 14 & & $5 / 20 / 09$ & $6 / 5 / 09$ & 16 & 4.0 & 0.159 & 0.649 & 0.376 & 0.582 & 0.718 & 0.0212 & 0.214 & 0.304 & 46.1 & 1.85 & \\
\hline $2941-300$ & PO & 15 & & $7 / 30 / 09$ & $8 / 14 / 09$ & 15 & 2.0 & 0.159 & 0.616 & 0.411 & 0.758 & 0.647 & & 0.233 & 0.412 & & 1.60 & \\
\hline 2941-311 & PO & 16 & & $8 / 14 / 09$ & $8 / 26 / 09$ & 12 & 0.0 & 0.159 & 0.591 & 0.408 & 0.678 & 0.394 & & 0.173 & & & 1.44 & 3.22 \\
\hline $2941-321$ & PO & 17 & & $8 / 26 / 09$ & $9 / 11 / 09$ & 16 & 5.8 & 0.159 & 0.638 & 0.445 & 0.754 & 0.660 & & 0.208 & 0.445 & & 1.76 & 4.80 \\
\hline $2941-330$ & $\mathrm{PO}$ & 18 & & $9 / 11 / 09$ & $9 / 25 / 09$ & 14 & 1.0 & 0.159 & 0.591 & 0.408 & 0.713 & 0.638 & & 0.218 & & & 1.44 & \\
\hline $2941-337$ & PO & 19 & & $9 / 25 / 09$ & $10 / 14 / 09$ & 19 & 3.0 & 0.159 & 0.608 & 0.385 & 0.923 & 0.785 & 0.0225 & 0.221 & 0.550 & 43.5 & 1.55 & 4.73 \\
\hline
\end{tabular}

Average

Stdev

RSD 
Field Sample Results - Biomarker, PAHs

Funnel $1,7-\mathrm{DMP} /$

DMP) An/178 BaA/228 MP/P Anth

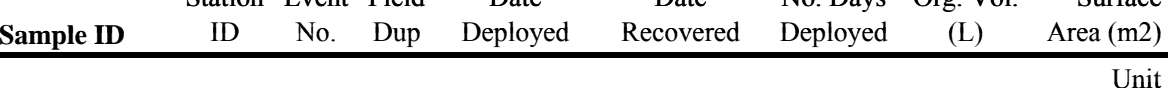

\begin{tabular}{|c|c|c|c|c|c|c|c|c|c|c|c|c|c|c|c|c|c|c|}
\hline $2941-178$ & SB & 1 & $\mathrm{x}$ & $9 / 2 / 08$ & 9/18/08 & 16 & $<20 \mathrm{~mL}$ & 0.159 & 0.677 & 0.253 & 0.769 & 0.509 & & 0.235 & & & 2.10 & 2.67 \\
\hline $2941-186$ & SB & 2 & $\mathrm{x}$ & 9/18/08 & $10 / 2 / 08$ & 14 & 1.5 & 0.159 & 0.582 & 0.498 & 0.927 & 0.936 & & 0.302 & & & 1.39 & 3.62 \\
\hline $2941-195$ & SB & 3 & & $10 / 2 / 08$ & $10 / 15 / 08$ & 13 & 1.5 & 0.159 & 0.628 & 0.423 & 0.674 & 0.523 & & 0.188 & & & 1.69 & \\
\hline $2941-205$ & SB & 4 & & $10 / 15 / 08$ & $10 / 30 / 08$ & 15 & 2.0 & 0.159 & 0.616 & 0.427 & 0.528 & 0.604 & & 0.232 & & & 1.60 & 2.47 \\
\hline $2941-216$ & SB & 5 & & $10 / 30 / 08$ & $11 / 10 / 08$ & 11 & 14.0 & 0.159 & 0.622 & 0.452 & 0.786 & 0.861 & 0.0150 & 0.159 & 0.435 & 65.5 & 1.65 & \\
\hline $2941-218$ & SB & 6 & & $11 / 10 / 08$ & $11 / 25 / 08$ & 12 & 3.0 & 0.159 & 0.631 & 0.410 & 0.953 & 0.915 & & 0.215 & & & 1.71 & 2.50 \\
\hline $2941-219$ & SB & 7 & & $11 / 25 / 08$ & $12 / 11 / 08$ & 16 & 2.0 & 0.159 & & 0.334 & & & & & & & & 4.85 \\
\hline $2941-245$ & SB & 8 & & 2/25/09 & $3 / 12 / 09$ & 15 & 4.5 & 0.159 & & 0.455 & & & & & & & & \\
\hline $2941-252$ & SB & 9 & & 3/12/09 & $3 / 29 / 09$ & 17 & 5.0 & 0.159 & & 0.503 & & & & & & & & \\
\hline $2941-260$ & SB & 10 & & $3 / 29 / 09$ & 4/13/09 & 15 & 5.0 & 0.159 & & 0.419 & & & & & & & & \\
\hline $2941-268$ & SB & 11 & & 4/13/09 & $4 / 28 / 09$ & 15 & $<1$ & 0.159 & 0.613 & 0.397 & 0.682 & 0.541 & & 0.212 & & & 1.58 & \\
\hline $2941-278$ & SB & 12 & & $4 / 28 / 09$ & $5 / 11 / 09$ & 13 & 2.0 & 0.159 & 0.628 & 0.313 & 0.684 & 0.814 & & 0.189 & & & 1.69 & \\
\hline $2941-281$ & SB & 13 & & $5 / 11 / 09$ & $5 / 27 / 09$ & 16 & 5.5 & 0.159 & 0.595 & 0.489 & 0.484 & 0.672 & & 0.149 & & & 1.47 & \\
\hline $2941-286$ & SB & 14 & & $5 / 27 / 09$ & 6/8/09 & 12 & 0.0 & 0.159 & 0.573 & 0.450 & 0.411 & 0.624 & & 0.242 & & & 1.34 & \\
\hline $2941-303$ & SB & 15 & & $8 / 3 / 09$ & 8/18/09 & 15 & 1.8 & 0.159 & 0.534 & 0.455 & 0.868 & 0.768 & 0.0263 & 0.283 & 0.370 & 37.0 & 1.14 & 1.68 \\
\hline $2941-313$ & SB & 16 & & 8/15/09 & $8 / 29 / 09$ & 11 & 0.0 & 0.159 & 0.563 & 0.496 & 0.752 & 0.562 & & 0.231 & & & 1.29 & 3.35 \\
\hline $2941-320$ & SB & 17 & & $8 / 29 / 09$ & $9 / 11 / 09$ & 13 & 1.3 & 0.159 & 0.590 & 0.461 & 0.761 & & & 0.315 & & & 1.44 & \\
\hline $2941-329$ & SB & 18 & & 9/11/09 & 9/25/09 & 14 & 1.0 & 0.159 & 0.459 & 0.475 & 0.803 & 0.611 & & 0.267 & & & 0.850 & \\
\hline $2941-336$ & SB & 19 & & 9/25/09 & $10 / 13 / 09$ & 18 & 1.9 & 0.159 & 0.563 & 0.445 & 0.860 & 0.754 & & 0.235 & & & 1.29 & \\
\hline \multicolumn{19}{|l|}{ Average } \\
\hline \multirow{2}{*}{\multicolumn{19}{|c|}{$\begin{array}{l}\text { Stdev } \\
\text { RSD }\end{array}$}} \\
\hline & & & & & & & & & & & & & & & & & & \\
\hline 2941-174 & TCB & 1 & & 8/29/08 & $9 / 12 / 08$ & 14 & 0.0 & 0.159 & 0.546 & 0.299 & 0.150 & 0.524 & & 0.200 & & & 1.20 & \\
\hline 2941-181 & TCB & 2 & & $9 / 12 / 08$ & 9/24/08 & 12 & 1.5 & 0.159 & 0.568 & 0.327 & 0.368 & 0.608 & 0.0620 & 0.204 & 0.477 & 15.1 & 1.32 & 3.73 \\
\hline 2941-188 & $\mathrm{TCB}$ & 3 & & 9/24/08 & $10 / 15 / 08$ & 21 & 6.0 & 0.159 & 0.569 & 0.380 & 0.669 & 0.704 & 0.0669 & 0.229 & 0.572 & 13.9 & 1.32 & 4.90 \\
\hline 2941-203 & TCB & 4 & & $10 / 15 / 08$ & $10 / 30 / 08$ & 15 & 2.0 & 0.159 & 0.553 & 0.335 & 0.359 & 0.600 & 0.0597 & 0.200 & 0.628 & 15.7 & 1.24 & 3.01 \\
\hline $2941-212$ & $\mathrm{TCB}$ & 5 & & $10 / 30 / 08$ & $11 / 12 / 08$ & 13 & 20.0 & 0.159 & 0.614 & 0.361 & 0.686 & 0.669 & 0.0523 & 0.207 & 0.513 & 18.1 & 1.59 & 3.76 \\
\hline $2941-229$ & $\mathrm{TCB}$ & 7 & & $11 / 12 / 08$ & $11 / 24 / 08$ & 17 & 1.5 & 0.159 & & 0.286 & & & & & & & & 4.29 \\
\hline $2941-240$ & TCB & 8 & & $11 / 24 / 08$ & $12 / 11 / 08$ & 15 & 5.5 & 0.159 & & 0.394 & & & & & & & & \\
\hline $2941-243$ & $\mathrm{TCB}$ & 8 & & 2/25/09 & $3 / 12 / 09$ & 15 & 5.5 & 0.159 & & 0.439 & & & & & & & & 9.02 \\
\hline $2941-245 b$ & TCB & 9 & $\mathrm{x}$ & $2 / 25 / 09$ & $3 / 12 / 09$ & 13 & 8.0 & 0.159 & & 0.452 & & & & & & & & \\
\hline $2941-256$ & $\mathrm{TCB}$ & 10 & & $3 / 12 / 09$ & $3 / 25 / 09$ & 14 & 6.5 & 0.159 & & 0.391 & & & & & & & & \\
\hline $2941-267$ & TCB & 11 & & $4 / 8 / 09$ & 4/22/09 & 14 & 5.0 & 0.159 & 0.587 & 0.327 & 0.252 & 0.609 & 0.0473 & 0.209 & 0.456 & 20.1 & 1.42 & \\
\hline $2941-274$ & $\mathrm{TCB}$ & 12 & & $4 / 22 / 09$ & $5 / 7 / 09$ & 15 & 3.0 & 0.159 & 0.506 & 0.362 & 0.471 & 0.682 & 0.0347 & 0.221 & 0.347 & 27.8 & 1.02 & \\
\hline $2941-282$ & TCB & 13 & & $5 / 7 / 09$ & $5 / 21 / 09$ & 14 & 10.0 & 0.159 & 0.574 & 0.416 & 0.269 & 0.669 & 0.0350 & 0.238 & 0.334 & 27.6 & 1.35 & \\
\hline $2941-288$ & TCB & 14 & & $5 / 21 / 09$ & $6 / 4 / 09$ & 14 & 0.0 & 0.159 & 0.594 & 0.338 & 0.084 & 0.555 & 0.0616 & 0.195 & 0.391 & 15.2 & 1.46 & \\
\hline 2941-301 & TCB & 15 & & $7 / 30 / 09$ & $8 / 12 / 09$ & 13 & 1.5 & 0.159 & 0.583 & 0.374 & 0.266 & 0.587 & 0.0390 & 0.260 & 0.263 & 24.6 & 1.40 & \\
\hline 2941-309 & $\mathrm{TCB}$ & 16 & & 8/12/09 & $8 / 27 / 09$ & 15 & 1.0 & 0.159 & 0.564 & 0.362 & 0.371 & 0.539 & 0.0845 & 0.220 & 0.424 & 10.8 & 1.30 & 1.86 \\
\hline $2941-316$ & $\mathrm{TCB}$ & 17 & & 8/27/09 & 9/8/09 & 12 & 9.5 & 0.159 & 0.555 & 0.400 & 0.293 & 0.613 & 0.0759 & 0.235 & 0.391 & 12.2 & 1.25 & \\
\hline $2941-326$ & TCB & 18 & & 9/8/09 & 9/24/09 & 16 & 1.0 & 0.159 & 0.530 & 0.358 & 0.166 & 0.602 & 0.147 & 0.238 & 0.493 & 5.79 & 1.13 & \\
\hline $2941-333$ & $\mathrm{TCB}$ & 19 & & 9/24/09 & 10/7/09 & 13 & 1.8 & 0.159 & 0.446 & 0.448 & 0.109 & 0.561 & 0.0816 & 0.377 & 0.654 & 11.3 & 0.806 & \\
\hline
\end{tabular}

Stdev

RSD 
Field Sample Results - Biomarker, PAHs

\begin{tabular}{|c|c|c|c|c|c|c|c|c|c|c|c|c|c|c|c|c|c|c|}
\hline Sample ID & $\begin{array}{c}\text { Station } \\
\text { ID }\end{array}$ & $\begin{array}{c}\text { Event } \\
\text { No. }\end{array}$ & $\begin{array}{l}\text { Field } \\
\text { Dup }\end{array}$ & $\begin{array}{c}\text { Date } \\
\text { Deployed }\end{array}$ & $\begin{array}{c}\text { Date } \\
\text { Recovered }\end{array}$ & $\begin{array}{l}\text { No. Days } \\
\text { Deployed }\end{array}$ & $\begin{array}{c}\text { Org. Vol. } \\
\text { (L) }\end{array}$ & $\begin{array}{r}\text { Surface } \\
\text { Area }(\mathrm{m} 2) \\
\end{array}$ & $\begin{array}{r}\text { Flu/(Flu+ } \\
\text { Py) } \\
\end{array}$ & $\begin{array}{r}\text { InP/(InP+ } \\
\text { BghiP) }\end{array}$ & $\begin{array}{r}\text { Ret/(Ret }{ }^{+} \\
\text {Chy) }\end{array}$ & $\begin{array}{r}(1,7-+2,6- \\
\text { DMP) }\end{array}$ & An/178 & $\mathrm{BaA} / 228$ & $\mathbf{M P} / \mathbf{P}$ & $\begin{array}{c}\text { Phen/ } \\
\text { Anth }\end{array}$ & Fla/Pyr & $\mathbf{L} / \mathbf{M}$ \\
\hline & & & & & & & & Unit & & & & & & & & & & \\
\hline $2941-172$ & WP & 1 & & $8 / 28 / 08$ & $9 / 12 / 08$ & 15 & 0.0 & 0.159 & 0.620 & 0.322 & 0.474 & & & 0.270 & & & 1.63 & 8.55 \\
\hline $2941-183$ & WP & 2 & & $9 / 12 / 08$ & $9 / 25 / 08$ & 13 & 2.0 & 0.159 & 0.621 & 0.347 & 0.869 & 0.807 & 0.0277 & 0.204 & 0.446 & 35.1 & 1.64 & 6.56 \\
\hline 2941-190 & WP & 3 & & $9 / 25 / 08$ & $10 / 14 / 08$ & 19 & 5.0 & 0.159 & 0.532 & 0.600 & 0.039 & 0.503 & 0.0974 & 0.468 & 0.522 & 9.26 & 1.14 & 3.49 \\
\hline 2941-201 & WP & 4 & & $10 / 14 / 08$ & $10 / 29 / 08$ & 15 & 1.5 & 0.159 & 0.543 & 0.424 & 0.421 & 0.664 & & 0.285 & & & 1.19 & 0.799 \\
\hline 2941-200 & WP & 5 & & $10 / 29 / 08$ & $11 / 13 / 08$ & 15 & 18.0 & 0.159 & 0.644 & 0.469 & 0.885 & 0.869 & 0.0263 & 0.154 & 0.580 & 37.0 & 1.81 & 3.17 \\
\hline $2941-225$ & WP & 6 & & $11 / 13 / 08$ & $11 / 25 / 08$ & 12 & 1.0 & 0.159 & 0.559 & 0.396 & 0.858 & 0.842 & & 0.180 & & & 1.27 & 6.19 \\
\hline $2941-230$ & WP & 7 & & $11 / 25 / 08$ & $12 / 11 / 08$ & 16 & 1.5 & 0.159 & & 0.486 & & & & & & & & \\
\hline 2941-244 & WP & 8 & & $2 / 26 / 09$ & $3 / 11 / 09$ & 13 & 4.5 & 0.159 & & 0.456 & & & & & & & & 1.28 \\
\hline $2941-246$ & WP & 9 & & $3 / 11 / 09$ & $3 / 25 / 09$ & 14 & 6.0 & 0.159 & & 0.525 & & & & & & & & \\
\hline $2941-258$ & WP & 10 & & $3 / 25 / 09$ & $4 / 8 / 09$ & 14 & 6.5 & 0.159 & & 0.429 & & & & & & & & \\
\hline $2941-264$ & WP & 11 & & $4 / 8 / 09$ & $4 / 23 / 09$ & 15 & 4.0 & 0.159 & 0.556 & 0.352 & 0.501 & 0.681 & & 0.213 & & & 1.25 & \\
\hline $2941-272$ & WP & 12 & & $4 / 23 / 09$ & $5 / 6 / 09$ & 13 & 2.0 & 0.159 & 0.662 & 0.363 & 0.822 & 0.674 & & 0.210 & & & 1.96 & \\
\hline $2941-284$ & WP & 13 & & $5 / 6 / 09$ & $5 / 21 / 09$ & 15 & 11.0 & 0.159 & 0.719 & 0.428 & 0.732 & 0.689 & & 0.209 & & & 2.55 & \\
\hline 2941-289 & WP & 14 & & $5 / 21 / 09$ & $6 / 3 / 09$ & 13 & 2.0 & 0.159 & 0.587 & 0.347 & 0.324 & 0.583 & 0.0282 & 0.222 & 0.258 & 34.4 & 1.42 & \\
\hline 2941-302 & WP & 15 & & $7 / 29 / 09$ & $8 / 12 / 09$ & 14 & 1.5 & 0.159 & 0.514 & 0.380 & 0.727 & 0.603 & & 0.245 & & & 1.06 & \\
\hline $2941-308$ & WP & 16 & & $8 / 12 / 09$ & $8 / 26 / 09$ & 14 & 1.5 & 0.159 & 0.557 & 0.455 & 0.671 & 0.600 & 0.0256 & 0.269 & 0.288 & 38.0 & 1.26 & 5.97 \\
\hline $2941-315$ & WP & 17 & & $8 / 26 / 09$ & 9/9/09 & 14 & 4.5 & 0.159 & 0.572 & 0.411 & 0.656 & 0.635 & 0.0545 & 0.255 & 0.585 & 17.4 & 1.34 & 4.31 \\
\hline $2941-327$ & WP & 18 & & 9/9/09 & $9 / 24 / 09$ & 15 & 2.0 & 0.159 & 0.579 & 0.389 & 0.656 & 0.561 & 0.0709 & 0.315 & 0.408 & 13.1 & 1.37 & \\
\hline $2941-332$ & WP & 19 & & $9 / 24 / 09$ & $10 / 7 / 09$ & 13 & 3.8 & 0.159 & 0.561 & 0.444 & 0.646 & 0.627 & 0.0405 & 0.305 & 0.534 & 23.7 & 1.28 & \\
\hline \multicolumn{19}{|l|}{ Average } \\
\hline \multirow{2}{*}{\multicolumn{19}{|c|}{$\begin{array}{l}\text { Stdev } \\
\text { RSD }\end{array}$}} \\
\hline & & & & & & & & & & & & & & & & & & \\
\hline 2941-293 & TM & 14 & & $5 / 20 / 09$ & $6 / 4 / 09$ & 15 & & 0.159 & 0.633 & 0.253 & 0.347 & 0.517 & & 0.240 & & & 1.72 & \\
\hline 2941-304 & TM & 15 & & $7 / 30 / 09$ & $8 / 12 / 09$ & 13 & & 0.159 & 0.620 & 0.407 & 0.617 & 0.600 & 0.0705 & 0.236 & 0.343 & 13.2 & 1.63 & \\
\hline $2941-312$ & TM & 16 & & $8 / 12 / 09$ & $8 / 27 / 09$ & 15 & & 0.159 & 0.607 & 0.398 & 0.512 & 0.528 & 0.0352 & 0.207 & 0.448 & 27.4 & 1.54 & 4.50 \\
\hline 2941-318 & TM & 17 & & $8 / 27 / 09$ & $9 / 8 / 09$ & 12 & & 0.159 & 0.663 & 0.410 & 0.462 & 0.451 & 0.0284 & 0.167 & 0.377 & 34.2 & 1.97 & 6.17 \\
\hline $2941-325$ & TM & 18 & & $9 / 8 / 09$ & $9 / 24 / 09$ & 16 & & 0.159 & 0.611 & 0.385 & 0.361 & 0.502 & 0.0387 & 0.133 & 0.364 & 24.8 & 1.57 & \\
\hline $2941-333$ & TM & 19 & & $9 / 24 / 09$ & $10 / 7 / 09$ & 13 & & 0.159 & 0.609 & 0.425 & 0.506 & 0.589 & 0.0692 & 0.174 & 0.416 & 13.4 & 1.56 & \\
\hline
\end{tabular}

Average

Stdev

RSD

\footnotetext{
NA $\quad$ Not available

* Contamination

** Outlier; see narration

Carcinogenic PAHs: benzo(a)anthracene, chrysene, benzo(b)fluoranthene,

a benzo(k)fluoranthene, benzo(a)pyrene, indeno(1,2,3-c,d)pyrene, dibenz(a,h)anthracene Pyrogenic PAHs: fluoranthene, pyrene, benzo(a)anthracene, chrysene,

b benzo(b)fluoranthene, benzo(k)fluoranthene, benzo(a)pyrene, indeno(1,2,3-c,d)pyrene, dibenz(a,h)anthracene, benzo(g,h,i)perylene

c High molecular weight PAHs: benzo(b)fluoranthene, benzo(k)fluoranthene,

benzo(a)pyrene, indeno(1,2,3-c,d)pyrene, dibenz(a,h)anthracene, benzo(g,h,i)perylene
} 
Appendix B:
PBDE Data 
Field Sample Results - PBDEs

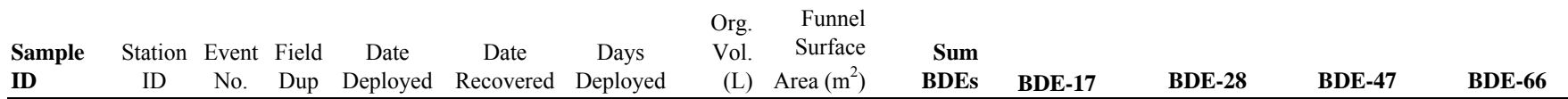

Unit $\quad \mathrm{ng} / \mathrm{m}^{2} / \mathrm{day} \quad \mathrm{ng} / \mathrm{m}^{2} / \mathrm{day} \quad \mathrm{ng} / \mathrm{m}^{2} / \mathrm{day} \quad \mathrm{ng} / \mathrm{m}^{2} / \mathrm{day}$

\begin{tabular}{|c|c|c|c|c|c|c|c|c|c|c|c|c|c|}
\hline $2941-177$ & $\mathrm{HC}$ & 1 & & $9 / 3 / 08$ & 9/17/08 & 14 & 0.0 & 0.159 & 13.3 & $0.225 \mathrm{U}$ & $0.225 \mathrm{U}$ & 0.511 & $0.225 \mathrm{U}$ \\
\hline $2941-184$ & $\mathrm{HC}$ & 2 & & 9/17/08 & $10 / 6 / 08$ & 19 & 8.0 & 0.159 & 23.1 & $0.165 \mathrm{U}$ & $0.165 \mathrm{U}$ & 0.442 & $0.165 \mathrm{U}$ \\
\hline 2941-194 & $\mathrm{HC}$ & 3 & & $10 / 6 / 08$ & $10 / 16 / 08$ & 10 & 3.0 & 0.159 & 5.60 & $0.314 \mathrm{U}$ & $0.314 \mathrm{U}$ & 0.576 & $0.314 \mathrm{U}$ \\
\hline 2941-208 & $\mathrm{HC}$ & 4 & & $10 / 16 / 08$ & $10 / 29 / 08$ & 13 & 1.0 & 0.159 & 4.28 & $0.242 \mathrm{U}$ & $0.242 \mathrm{U}$ & 0.480 & $0.242 \mathrm{U}$ \\
\hline $2941-215$ & $\mathrm{HC}$ & 5 & & $10 / 29 / 08$ & $11 / 8 / 08$ & 10 & 15.0 & 0.159 & 6.29 & $0.314 \mathrm{U}$ & $0.314 \mathrm{U}$ & 0.525 & $0.314 \mathrm{U}$ \\
\hline $2941-220$ & $\mathrm{HC}$ & 6 & & $11 / 8 / 08$ & $11 / 20 / 08$ & 12 & 6.0 & 0.159 & 6.03 & $0.262 \mathrm{U}$ & $0.262 \mathrm{U}$ & 1.06 & $0.262 \mathrm{U}$ \\
\hline $2941-210$ & $\mathrm{HC}$ & 7 & & $11 / 20 / 08$ & $12 / 11 / 08$ & 21 & 4.0 & 0.159 & 3.79 & $0.150 \mathrm{U}$ & 0.297 & 0.551 & $0.150 \mathrm{U}$ \\
\hline 2941-234 & $\mathrm{HC}$ & 7 & $\mathrm{x}$ & $11 / 20 / 08$ & $12 / 11 / 08$ & 21 & 8.0 & 0.159 & 4.39 & 0.522 & 0.929 & 0.471 & $0.150 \mathrm{U}$ \\
\hline $2941-238$ & $\mathrm{HC}$ & 8 & & 2/26/09 & $3 / 12 / 09$ & 14 & 4.0 & 0.159 & 4.88 & 0.383 & 0.519 & 0.463 & $0.225 \mathrm{U}$ \\
\hline $2941-250$ & $\mathrm{HC}$ & 9 & & $3 / 12 / 09$ & $3 / 25 / 09$ & 13 & 9.5 & 0.159 & 4.50 & $0.242 \mathrm{U}$ & 0.280 & 0.415 & $0.242 \mathrm{U}$ \\
\hline $2941-262$ & $\mathrm{HC}$ & 10 & & $3 / 25 / 09$ & $4 / 8 / 09$ & 14 & 4.0 & 0.159 & 5.45 & $0.225 \mathrm{U}$ & $0.225 \mathrm{U}$ & 0.419 & $0.225 \mathrm{U}$ \\
\hline 2941-269 & $\mathrm{HC}$ & 11 & & $4 / 8 / 09$ & $4 / 22 / 09$ & 14 & 6.0 & 0.159 & 5.29 & $0.225 \mathrm{U}$ & $0.225 \mathrm{U}$ & 0.669 & $0.225 \mathrm{U}$ \\
\hline $2941-276$ & $\mathrm{HC}$ & 12 & & $4 / 22 / 09$ & $5 / 5 / 09$ & 13 & 1.0 & 0.159 & 4.49 & $0.242 \mathrm{U}$ & $0.242 \mathrm{U}$ & 0.496 & $0.242 \mathrm{U}$ \\
\hline 2941-280 & $\mathrm{HC}$ & 13 & & $5 / 5 / 09$ & $5 / 20 / 09$ & 15 & 5.0 & 0.159 & 4.10 & $0.210 \mathrm{U}$ & $0.210 \mathrm{U}$ & 0.639 & $0.210 \mathrm{U}$ \\
\hline 2941-294 & $\mathrm{HC}$ & 14 & & $5 / 20 / 09$ & $6 / 5 / 09$ & 16 & 4.0 & 0.159 & 4.48 & $0.196 \mathrm{U}$ & $0.196 \mathrm{U}$ & 0.425 & $0.196 \mathrm{U}$ \\
\hline $2941-306$ & $\mathrm{HC}$ & 15 & & $7 / 30 / 09$ & $8 / 14 / 09$ & 15 & 2.5 & 0.159 & 7.13 & $0.210 \mathrm{U}$ & $0.210 \mathrm{U}$ & $0.210 \mathrm{U}$ & $0.210 \mathrm{U}$ \\
\hline $2941-314$ & $\mathrm{HC}$ & 16 & & $8 / 14 / 09$ & 8/26/09 & 12 & 0.0 & 0.159 & 8.94 & $0.262 \mathrm{U}$ & $0.262 \mathrm{U}$ & $0.262 \mathrm{U}$ & $0.262 \mathrm{U}$ \\
\hline $2941-322$ & $\mathrm{HC}$ & 17 & & $8 / 26 / 09$ & 9/11/09 & 16 & 6.8 & 0.159 & 6.90 & $0.196 \mathrm{U}$ & 0.366 & $0.196 \mathrm{U}$ & $0.196 \mathrm{U}$ \\
\hline $2947-328$ & $\mathrm{HC}$ & 18 & & 9/11/09 & 9/25/09 & 14 & 2.0 & 0.159 & 7.71 & $0.225 \mathrm{U}$ & 0.259 & $0.225 \mathrm{U}$ & $0.225 \mathrm{U}$ \\
\hline $2941-338$ & $\mathrm{HC}$ & 19 & & 9/25/09 & $10 / 14 / 09$ & 19 & 6.0 & 0.159 & & & & & \\
\hline Mean & & & & & & & & & 7.03 & $0.270 \mathrm{U}$ & 0.326 & 0.544 & $0.229 \mathrm{U}$ \\
\hline Stdev & & & & & & & & & 5.40 & -- & 0.200 & 0.169 & -- \\
\hline RSD & & & & & & & & & $77 \%$ & -- & $61 \%$ & $31 \%$ & -- \\
\hline $2941-175$ & NR & 1 & & 8/29/08 & 9/12/08 & 14 & 0.0 & 0.159 & 5.34 & $0.225 \mathrm{U}$ & 0.541 & 1.24 & $0.225 \mathrm{U}$ \\
\hline 2941-180 & NR & 2 & & $9 / 12 / 08$ & 9/24/08 & 12 & 1.0 & 0.159 & 6.69 & $0.262 \mathrm{U}$ & $0.262 \mathrm{U}$ & 0.625 & $0.262 \mathrm{U}$ \\
\hline 2941-189 & NR & 3 & & 9/24/08 & $10 / 15 / 08$ & 21 & 9.0 & 0.159 & 8.83 & $0.150 \mathrm{U}$ & $0.150 \mathrm{U}$ & 0.452 & $0.150 \mathrm{U}$ \\
\hline 2941-202 & NR & 4 & & $10 / 15 / 08$ & $10 / 30 / 08$ & 15 & 2.0 & 0.159 & 8.16 & $0.210 \mathrm{U}$ & $0.210 \mathrm{U}$ & 0.503 & $0.210 \mathrm{U}$ \\
\hline 2941-211 & NR & 5 & & $10 / 30 / 08$ & $11 / 12 / 08$ & 13 & 3.0 & 0.159 & 3.81 & $0.242 \mathrm{U}$ & $0.242 \mathrm{U}$ & $0.242 \mathrm{U}$ & $0.242 \mathrm{U}$ \\
\hline $2941-223$ & NR & 6 & & $11 / 12 / 08$ & $11 / 24 / 08$ & 12 & 16.0 & 0.159 & 9.60 & $0.262 \mathrm{U}$ & $0.262 \mathrm{U}$ & 1.07 & $0.262 \mathrm{U}$ \\
\hline $2941-228$ & NR & 7 & & $11 / 24 / 08$ & $12 / 11 / 08$ & 17 & 1.0 & 0.159 & 4.92 & $0.185 \mathrm{U}$ & 0.280 & 0.340 & $0.185 \mathrm{U}$ \\
\hline $2941-242$ & NR & 8 & & $2 / 25 / 09$ & $3 / 12 / 09$ & 15 & 3.0 & 0.159 & 4.87 & $0.210 \mathrm{U}$ & 0.424 & 0.489 & $0.210 \mathrm{U}$ \\
\hline $2941-255$ & NR & 10 & & $3 / 25 / 09$ & $4 / 8 / 09$ & 14 & 5.0 & 0.159 & 4.99 & $0.225 \mathrm{U}$ & 0.289 & 0.420 & $0.225 \mathrm{U}$ \\
\hline $2941-265$ & NR & 11 & $\mathrm{x}$ & $4 / 8 / 09$ & 4/22/09 & 14 & 4.0 & 0.159 & 6.30 & $0.225 \mathrm{U}$ & $0.225 \mathrm{U}$ & 0.461 & $0.225 \mathrm{U}$ \\
\hline $2941-266$ & NR & 11 & & $4 / 8 / 09$ & $4 / 22 / 09$ & 14 & 4.0 & 0.159 & 4.46 & $0.225 \mathrm{U}$ & $0.225 \mathrm{U}$ & 0.674 & $0.225 \mathrm{U}$ \\
\hline $2941-273$ & NR & 12 & & $4 / 22 / 09$ & $5 / 7 / 09$ & 15 & 1.0 & 0.159 & 3.88 & $0.210 \mathrm{U}$ & $0.210 \mathrm{U}$ & 0.422 & $0.210 \mathrm{U}$ \\
\hline $2941-285$ & NR & 13 & & $5 / 7 / 09$ & $5 / 21 / 09$ & 14 & 1.5 & 0.159 & 4.50 & $0.225 \mathrm{U}$ & $0.225 \mathrm{U}$ & 0.691 & $0.225 \mathrm{U}$ \\
\hline $2941-287$ & NR & 14 & & $5 / 21 / 09$ & $6 / 4 / 09$ & 14 & 0.0 & 0.159 & 7.37 & $0.225 \mathrm{U}$ & $0.225 \mathrm{U}$ & 0.519 & $0.225 \mathrm{U}$ \\
\hline 2941-299 & NR & 15 & & $7 / 30 / 09$ & 8/12/09 & 13 & 1.0 & 0.159 & 9.50 & $0.242 \mathrm{U}$ & $0.242 \mathrm{U}$ & 0.639 & $0.242 \mathrm{U}$ \\
\hline $2941-310$ & NR & 16 & & 8/12/09 & 8/27/09 & 15 & 0.5 & 0.159 & 8.31 & $0.210 \mathrm{U}$ & $0.210 \mathrm{U}$ & $0.210 \mathrm{U}$ & $0.210 \mathrm{U}$ \\
\hline 2941-319 & NR & 17 & & $8 / 27 / 09$ & $9 / 8 / 09$ & 12 & 8.0 & 0.159 & & & & & \\
\hline 2941-324 & NR & 18 & & 9/8/09 & 9/24/09 & 16 & 2.0 & 0.159 & 8.19 & $0.196 \mathrm{U}$ & $0.196 \mathrm{U}$ & 0.396 & $0.196 \mathrm{U}$ \\
\hline $2941-335$ & NR & 19 & & $9 / 24 / 09$ & $10 / 7 / 09$ & 13 & 1.0 & 0.159 & 9.56 & $0.242 \mathrm{U}$ & 0.459 & $0.242 \mathrm{U}$ & $0.242 \mathrm{U}$ \\
\hline Mean & & & & & & & & & 5.99 & $0.219 \mathrm{U}$ & 0.276 & 0.578 & $0.219 \mathrm{U}$ \\
\hline Stdev & & & & & & & & & 1.95 & -- & 0.106 & 0.293 & -- \\
\hline RSD & & & & & & & & & $33 \%$ & -- & $38 \%$ & $51 \%$ & -- \\
\hline $2941-173$ & $\mathrm{~PB}$ & 1 & & $8 / 28 / 08$ & 9/12/08 & 15 & 1.0 & 0.159 & 3.33 & $0.210 \mathrm{U}$ & $0.210 \mathrm{U}$ & 0.606 & $0.210 \mathrm{U}$ \\
\hline $2941-182$ & $\mathrm{~PB}$ & 2 & & 9/12/08 & $9 / 25 / 08$ & 13 & 3.0 & 0.159 & 5.13 & $0.242 \mathrm{U}$ & $0.242 \mathrm{U}$ & 0.421 & $0.242 \mathrm{U}$ \\
\hline 2941-191 & PB & 3 & & $9 / 25 / 08$ & $10 / 15 / 08$ & 20 & 4.0 & 0.159 & 5.33 & $0.157 \mathrm{U}$ & $0.157 \mathrm{U}$ & 0.311 & $0.157 \mathrm{U}$ \\
\hline 2941-204 & PB & 4 & & $10 / 15 / 08$ & $10 / 29 / 08$ & 14 & 1.0 & 0.159 & 3.65 & $0.225 \mathrm{U}$ & $0.225 \mathrm{U}$ & $0.225 \mathrm{U}$ & $0.225 \mathrm{U}$ \\
\hline 2941-209 & PB & 5 & & $10 / 29 / 08$ & $11 / 13 / 08$ & 15 & 1.0 & 0.159 & 3.55 & $0.210 \mathrm{U}$ & $0.210 \mathrm{U}$ & $0.210 \mathrm{U}$ & $0.210 \mathrm{U}$ \\
\hline $2941-224$ & PB & 6 & & $11 / 13 / 08$ & $11 / 25 / 08$ & 12 & 1.5 & 0.159 & 5.55 & $0.262 \mathrm{U}$ & $0.262 \mathrm{U}$ & 1.56 & $0.262 \mathrm{U}$ \\
\hline $2941-231$ & PB & 7 & & $11 / 25 / 08$ & $12 / 11 / 08$ & 16 & 13.0 & 0.159 & 5.02 & 0.667 & 0.196 & 0.776 & $0.196 \mathrm{U}$ \\
\hline 2941-241 & $\mathrm{PB}$ & 8 & & 2/26/09 & 3/11/09 & 13 & 2.0 & 0.159 & 9.02 & $0.242 \mathrm{U}$ & 0.794 & 0.583 & $0.242 \mathrm{U}$ \\
\hline $2941-248$ & $\mathrm{~PB}$ & 9 & & $3 / 11 / 09$ & $3 / 25 / 09$ & 14 & 5.0 & 0.159 & 4.65 & 0.230 & 0.612 & 0.436 & $0.225 \mathrm{U}$ \\
\hline $2941-259$ & $\mathrm{~PB}$ & 10 & & $3 / 25 / 09$ & $4 / 8 / 09$ & 14 & 6.0 & 0.159 & 6.00 & $0.225 \mathrm{U}$ & 0.455 & $0.225 \mathrm{U}$ & $0.225 \mathrm{U}$ \\
\hline $2941-263$ & $\mathrm{~PB}$ & 11 & & $4 / 8 / 09$ & 4/23/09 & 15 & 3.0 & 0.159 & 5.47 & $0.210 \mathrm{U}$ & $0.210 \mathrm{U}$ & 0.466 & $0.210 \mathrm{U}$ \\
\hline $2941-271$ & $\mathrm{~PB}$ & 12 & & 4/23/09 & $5 / 6 / 09$ & 13 & 0.5 & 0.159 & 5.31 & $0.242 \mathrm{U}$ & $0.242 \mathrm{U}$ & 0.401 & $0.242 \mathrm{U}$ \\
\hline $2941-283$ & $\mathrm{~PB}$ & 13 & & $5 / 6 / 09$ & $5 / 21 / 09$ & 15 & 4.0 & 0.159 & 4.20 & $0.210 \mathrm{U}$ & $0.210 \mathrm{U}$ & 0.544 & $0.210 \mathrm{U}$ \\
\hline $2941-290$ & PB & 14 & & $5 / 21 / 09$ & $6 / 3 / 09$ & 13 & 2.0 & 0.159 & 7.38 & $0.242 \mathrm{U}$ & $0.242 \mathrm{U}$ & $0.242 \mathrm{U}$ & $0.242 \mathrm{U}$ \\
\hline 2941-305 & $\mathrm{PB}$ & 15 & & 7/29/09 & 8/12/09 & 14 & 3.0 & 0.159 & 8.82 & $0.225 \mathrm{U}$ & $0.225 \mathrm{U}$ & 0.480 & $0.225 \mathrm{U}$ \\
\hline $2941-307$ & $\mathrm{~PB}$ & 16 & & $8 / 12 / 09$ & $8 / 26 / 09$ & 14 & 0.0 & 0.159 & 8.30 & $0.225 \mathrm{U}$ & $0.225 \mathrm{U}$ & 0.545 & $0.225 \mathrm{U}$ \\
\hline $2941-317$ & $\mathrm{~PB}$ & 17 & & $8 / 26 / 09$ & 9/9/09 & 14 & 2.0 & 0.159 & 8.77 & $0.225 \mathrm{U}$ & $0.225 \mathrm{U}$ & $0.225 \mathrm{U}$ & $0.225 \mathrm{U}$ \\
\hline $2941-323$ & $\mathrm{~PB}$ & 18 & & 9/9/09 & 9/24/09 & 15 & 3.0 & 0.159 & 7.84 & $0.210 \mathrm{U}$ & 0.247 & $0.210 \mathrm{U}$ & $0.210 \mathrm{U}$ \\
\hline $2941-334$ & $\mathrm{~PB}$ & 19 & & 9/24/09 & 10/7/09 & 13 & 1.8 & 0.159 & 8.92 & $0.242 \mathrm{U}$ & $0.242 \mathrm{U}$ & 0.434 & $0.242 \mathrm{U}$ \\
\hline Mean & & & & & & & & & 5.17 & 0.260 & 0.318 & 0.518 & $0.220 \mathrm{U}$ \\
\hline Stdev & & & & & & & & & 1.49 & 0.131 & 0.198 & 0.369 & -- \\
\hline RSD & & & & & & & & & $29 \%$ & $50 \%$ & 0.623 & $71 \%$ & -- \\
\hline
\end{tabular}


Field Sample Results - PBDEs

Sample Station Event Field Date Date Days $\begin{aligned} & \text { Org. } \\ & \text { Vol. Sunnel }\end{aligned}$

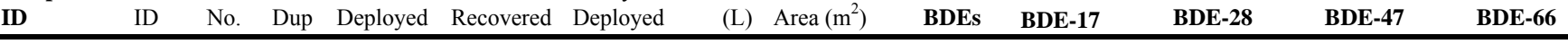

\begin{tabular}{|c|c|c|c|c|c|c|c|c|c|c|c|c|c|}
\hline & & & & & & & & Unit & & $\mathrm{ng} / \mathrm{m}^{2} /$ day & $\mathrm{ng} / \mathrm{m}^{2} /$ day & $\mathrm{ng} / \mathrm{m}^{2} /$ day & $\mathrm{ng} / \mathrm{m}^{2} /$ day \\
\hline $2941-176$ & $\mathrm{PO}$ & 1 & & $9 / 3 / 08$ & $9 / 17 / 08$ & 14 & 0.0 & 0.159 & 4.00 & $0.225 \mathrm{U}$ & $0.225 \mathrm{U}$ & $0.225 \mathrm{U}$ & $0.225 \mathrm{U}$ \\
\hline $2941-185$ & $\mathrm{PO}$ & 2 & & $9 / 17 / 08$ & $10 / 6 / 08$ & 19 & 6.0 & 0.159 & 4.70 & $0.165 \mathrm{U}$ & $0.165 \mathrm{U}$ & 0.775 & $0.165 \mathrm{U}$ \\
\hline 2941-193 & $\mathrm{PO}$ & 3 & & $10 / 6 / 08$ & $10 / 16 / 08$ & 10 & 1.5 & 0.159 & 10.7 & $0.314 \mathrm{U}$ & $0.314 \mathrm{U}$ & $0.314 \mathrm{U}$ & $0.314 \mathrm{U}$ \\
\hline 2941-199 & $\mathrm{PO}$ & 3 & $\mathrm{x}$ & $10 / 6 / 08$ & $10 / 16 / 08$ & 10 & 1.5 & 0.159 & 10.6 & $0.314 \mathrm{U}$ & $0.314 \mathrm{U}$ & 0.649 & $0.314 \mathrm{U}$ \\
\hline $2941-206$ & PO & 4 & & $10 / 16 / 08$ & $10 / 29 / 08$ & 13 & 1.0 & 0.159 & 5.40 & $0.242 \mathrm{U}$ & $0.242 \mathrm{U}$ & 0.413 & $0.242 \mathrm{U}$ \\
\hline 2941-207 & PO & 4 & $\mathrm{x}$ & $10 / 16 / 08$ & $10 / 29 / 08$ & 13 & 1.0 & 0.159 & 4.21 & $0.242 \mathrm{U}$ & $0.242 \mathrm{U}$ & $0.242 \mathrm{U}$ & $0.242 \mathrm{U}$ \\
\hline $2941-213$ & $\mathrm{PO}$ & 5 & & $10 / 29 / 08$ & 11/7/08 & 9 & 6.0 & 0.159 & 6.73 & $0.349 \mathrm{U}$ & $0.349 \mathrm{U}$ & $0.349 \mathrm{U}$ & $0.349 \mathrm{U}$ \\
\hline $2941-217$ & $\mathrm{PO}$ & 6 & & 11/7/08 & $11 / 20 / 08$ & 12 & 13.5 & 0.159 & 6.70 & $0.262 \mathrm{U}$ & $0.262 \mathrm{U}$ & $0.262 \mathrm{U}$ & $0.262 \mathrm{U}$ \\
\hline $2941-233$ & PO & 7 & & $11 / 20 / 08$ & $12 / 11 / 08$ & 21 & 2.0 & 0.159 & 3.82 & $0.150 \mathrm{U}$ & 0.328 & 0.305 & $0.150 \mathrm{U}$ \\
\hline $2941-237$ & $\mathrm{PO}$ & 8 & & 2/26/09 & $3 / 12 / 09$ & 14 & 4.0 & 0.159 & & & & & \\
\hline $2941-251$ & $\mathrm{PO}$ & 9 & & $3 / 12 / 09$ & $3 / 25 / 09$ & 13 & 8.0 & 0.159 & 6.61 & $0.242 \mathrm{U}$ & 0.324 & 0.726 & $0.242 \mathrm{U}$ \\
\hline $2941-261$ & $\mathrm{PO}$ & 10 & & $3 / 25 / 09$ & 4/8/09 & 14 & 6.0 & 0.159 & 6.77 & $0.225 \mathrm{U}$ & 0.596 & 0.865 & $0.225 \mathrm{U}$ \\
\hline $2941-270$ & PO & 11 & & $4 / 8 / 09$ & $4 / 22 / 09$ & 14 & 5.0 & 0.159 & 5.81 & $0.225 \mathrm{U}$ & $0.225 \mathrm{U}$ & 0.835 & $0.225 \mathrm{U}$ \\
\hline $2941-277$ & $\mathrm{PO}$ & 12 & & $4 / 22 / 09$ & $5 / 5 / 09$ & 13 & 2.0 & 0.159 & 5.10 & $0.242 \mathrm{U}$ & $0.242 \mathrm{U}$ & 0.656 & $0.242 \mathrm{U}$ \\
\hline $2941-279$ & $\mathrm{PO}$ & 13 & & $5 / 5 / 09$ & $5 / 20 / 09$ & 15 & 11.0 & 0.159 & 3.96 & $0.210 \mathrm{U}$ & $0.210 \mathrm{U}$ & 0.498 & $0.210 \mathrm{U}$ \\
\hline $2941-292$ & $\mathrm{PO}$ & 14 & & $5 / 20 / 09$ & $6 / 5 / 09$ & 16 & 4.0 & 0.159 & 11.1 & $0.196 \mathrm{U}$ & $0.196 \mathrm{U}$ & $0.196 \mathrm{U}$ & $0.196 \mathrm{U}$ \\
\hline $2941-300$ & $\mathrm{PO}$ & 15 & & $7 / 30 / 09$ & $8 / 14 / 09$ & 15 & 2.0 & 0.159 & 7.94 & $0.210 \mathrm{U}$ & $0.210 \mathrm{U}$ & 0.564 & $0.210 \mathrm{U}$ \\
\hline $2941-311$ & $\mathrm{PO}$ & 16 & & $8 / 14 / 09$ & $8 / 26 / 09$ & 12 & 0.0 & 0.159 & 10.0 & $0.262 \mathrm{U}$ & $0.262 \mathrm{U}$ & $0.262 \mathrm{U}$ & $0.262 \mathrm{U}$ \\
\hline $2941-321$ & $\mathrm{PO}$ & 17 & & $8 / 26 / 09$ & $9 / 11 / 09$ & 16 & 5.8 & 0.159 & 9.03 & $0.196 \mathrm{U}$ & 0.371 & 0.464 & $0.196 \mathrm{U}$ \\
\hline $2941-330$ & $\mathrm{PO}$ & 18 & & $9 / 11 / 09$ & $9 / 25 / 09$ & 14 & 1.0 & 0.159 & 8.24 & $0.225 \mathrm{U}$ & 0.261 & $0.225 \mathrm{U}$ & $0.225 \mathrm{U}$ \\
\hline $2941-337$ & PO & 19 & & $9 / 25 / 09$ & $10 / 14 / 09$ & 19 & 3.0 & 0.159 & 9.26 & $0.165 \mathrm{U}$ & 0.245 & $0.165 \mathrm{U}$ & $0.165 \mathrm{U}$ \\
\hline Mean & & & & & & & & & 6.25 & $0.246 \mathrm{U}$ & 0.295 & 0.509 & $0.246 \mathrm{U}$ \\
\hline Stdev & & & & & & & & & 2.24 & -- & 0.105 & 0.245 & -- \\
\hline RSD & & & & & & & & & $36 \%$ & -- & $36 \%$ & $48 \%$ & -- \\
\hline $2941-178$ & SB & 1 & & $9 / 2 / 08$ & $9 / 18 / 08$ & 16 & 0.0 & 0.159 & 3.10 & $0.196 \mathrm{U}$ & $0.196 \mathrm{U}$ & 0.551 & $0.196 \mathrm{U}$ \\
\hline 2941-179 & SB & 1 & $\mathrm{x}$ & $9 / 2 / 08$ & $9 / 18 / 08$ & 16 & 0.0 & 0.159 & 2.97 & $0.196 \mathrm{U}$ & $0.196 \mathrm{U}$ & 0.415 & $0.196 \mathrm{U}$ \\
\hline 2941-186 & SB & 2 & & $9 / 18 / 08$ & $10 / 2 / 08$ & 14 & 1.5 & 0.159 & 7.83 & $0.225 \mathrm{U}$ & $0.225 \mathrm{U}$ & 0.871 & $0.225 \mathrm{U}$ \\
\hline $2941-187$ & SB & 2 & $\mathrm{x}$ & $9 / 18 / 08$ & $10 / 2 / 08$ & 14 & 1.5 & 0.159 & 7.39 & $0.225 \mathrm{U}$ & $0.225 \mathrm{U}$ & 0.609 & $0.225 \mathrm{U}$ \\
\hline 2941-195 & SB & 3 & & $10 / 2 / 08$ & $10 / 15 / 08$ & 13 & 1.5 & 0.159 & 8.60 & $0.242 \mathrm{U}$ & $0.242 \mathrm{U}$ & 0.854 & $0.242 \mathrm{U}$ \\
\hline $2941-205$ & SB & 4 & & $10 / 15 / 08$ & $10 / 30 / 08$ & 15 & 2.0 & 0.159 & 4.08 & $0.210 \mathrm{U}$ & $0.210 \mathrm{U}$ & $0.210 \mathrm{U}$ & $0.210 \mathrm{U}$ \\
\hline $2941-216$ & SB & 5 & & $10 / 30 / 08$ & $11 / 10 / 08$ & 11 & 14.0 & 0.159 & 8.99 & $0.286 \mathrm{U}$ & $0.286 \mathrm{U}$ & 0.495 & $0.286 \mathrm{U}$ \\
\hline $2941-218$ & SB & 6 & & $11 / 10 / 08$ & $11 / 25 / 08$ & 12 & 3.0 & 0.159 & 5.17 & $0.262 \mathrm{U}$ & $0.262 \mathrm{U}$ & $0.262 \mathrm{U}$ & $0.262 \mathrm{U}$ \\
\hline $2941-219$ & SB & 7 & & $11 / 25 / 08$ & $12 / 11 / 08$ & 16 & 2.0 & 0.159 & 4.91 & $0.196 \mathrm{U}$ & 0.332 & 0.344 & $0.196 \mathrm{U}$ \\
\hline $2941-245$ & SB & 8 & & $2 / 25 / 09$ & $3 / 12 / 09$ & 15 & 4.5 & 0.159 & 6.01 & $0.210 \mathrm{U}$ & 0.546 & 0.495 & $0.210 \mathrm{U}$ \\
\hline $2941-252$ & SB & 9 & & $3 / 12 / 09$ & $3 / 29 / 09$ & 17 & 5.0 & 0.159 & 3.42 & $0.185 \mathrm{U}$ & 0.264 & $0.185 \mathrm{U}$ & $0.185 \mathrm{U}$ \\
\hline $2941-260$ & SB & 10 & & $3 / 29 / 09$ & $4 / 13 / 09$ & 15 & 5.0 & 0.159 & 6.04 & $0.210 \mathrm{U}$ & $0.210 \mathrm{U}$ & 0.372 & $0.210 \mathrm{U}$ \\
\hline $2941-268$ & SB & 11 & & 4/13/09 & $4 / 28 / 09$ & 15 & 0.5 & 0.159 & 3.89 & $0.210 \mathrm{U}$ & $0.210 \mathrm{U}$ & 0.431 & $0.210 \mathrm{U}$ \\
\hline $2941-278$ & SB & 12 & & $4 / 28 / 09$ & $5 / 11 / 09$ & 13 & 2.0 & 0.159 & 4.95 & $0.242 \mathrm{U}$ & $0.242 \mathrm{U}$ & 0.460 & $0.242 \mathrm{U}$ \\
\hline $2941-281$ & SB & 13 & & $5 / 11 / 09$ & $5 / 27 / 09$ & 16 & 5.5 & 0.159 & 4.95 & $0.196 \mathrm{U}$ & $0.196 \mathrm{U}$ & 0.773 & $0.196 \mathrm{U}$ \\
\hline $2941-286$ & SB & 14 & & $5 / 27 / 09$ & $6 / 8 / 09$ & 12 & 0.0 & 0.159 & 5.97 & $0.262 \mathrm{U}$ & $0.262 \mathrm{U}$ & $0.262 \mathrm{U}$ & $0.262 \mathrm{U}$ \\
\hline $2941-303$ & SB & 15 & & 8/3/09 & $8 / 18 / 09$ & 15 & 1.8 & 0.159 & 7.00 & $0.210 \mathrm{U}$ & $0.210 \mathrm{U}$ & $0.210 \mathrm{U}$ & $0.210 \mathrm{U}$ \\
\hline $2941-313$ & SB & 16 & & $8 / 15 / 09$ & $8 / 29 / 09$ & 11 & 0.0 & 0.159 & 9.63 & $0.286 \mathrm{U}$ & $0.286 \mathrm{U}$ & $0.286 \mathrm{U}$ & $0.286 \mathrm{U}$ \\
\hline $2941-320$ & SB & 17 & & 8/29/09 & $9 / 11 / 09$ & 13 & 1.3 & 0.159 & 8.31 & $0.242 \mathrm{U}$ & $0.242 \mathrm{U}$ & $0.242 \mathrm{U}$ & $0.242 \mathrm{U}$ \\
\hline $2941-329$ & SB & 18 & & $9 / 11 / 09$ & $9 / 25 / 09$ & 14 & 1.0 & 0.159 & 8.66 & $0.225 \mathrm{U}$ & $0.225 \mathrm{U}$ & $0.225 \mathrm{U}$ & $0.225 \mathrm{U}$ \\
\hline $2941-336$ & SB & 19 & & $9 / 25 / 09$ & $10 / 13 / 09$ & 18 & 1.9 & 0.159 & 6.13 & $0.175 \mathrm{U}$ & $0.175 \mathrm{U}$ & $0.175 \mathrm{U}$ & $0.175 \mathrm{U}$ \\
\hline Mean & & & & & & & & & 5.53 & $0.221 \mathrm{U}$ & 0.260 & 0.468 & $0.221 \mathrm{U}$ \\
\hline Stdev & & & & & & & & & 2.02 & -- & 0.090 & 0.207 & -- \\
\hline RSD & & & & & & & & & $37 \%$ & -- & $35 \%$ & $44 \%$ & -- \\
\hline $2941-174$ & TCB & 1 & & $8 / 29 / 08$ & $9 / 12 / 08$ & 14 & 0.0 & 0.159 & 13.6 & $0.225 \mathrm{U}$ & $0.225 \mathrm{U}$ & 0.638 & $0.225 \mathrm{U}$ \\
\hline 2941-181 & TCB & 2 & & $9 / 12 / 08$ & $9 / 24 / 08$ & 12 & 1.5 & 0.159 & 28.7 & $0.262 \mathrm{U}$ & 0.631 & 1.04 & $0.262 \mathrm{U}$ \\
\hline $2941-188$ & TCB & 3 & & $9 / 24 / 08$ & $10 / 15 / 08$ & 21 & 6.0 & 0.159 & 38.8 & $0.150 \mathrm{U}$ & $0.150 \mathrm{U}$ & 1.88 & $0.150 \mathrm{U}$ \\
\hline $2941-203$ & TCB & 4 & & $10 / 15 / 08$ & $10 / 30 / 08$ & 15 & 2.0 & 0.159 & 27.5 & 0.401 & 0.844 & 1.18 & $0.210 \mathrm{U}$ \\
\hline $2941-212$ & TCB & 5 & & $10 / 30 / 08$ & $11 / 12 / 08$ & 13 & 20.0 & 0.159 & 171 & 0.562 & 1.19 & 37.2 & 1.64 \\
\hline $2941-229$ & TCB & 7 & & $11 / 12 / 08$ & $11 / 24 / 08$ & 17 & 1.5 & 0.159 & 25.0 & 0.323 & 0.610 & 8.10 & $0.185 \mathrm{U}$ \\
\hline $2941-240$ & TCB & 8 & & $11 / 24 / 08$ & $12 / 11 / 08$ & 15 & 5.5 & 0.159 & 10.1 & $0.210 \mathrm{U}$ & 2.34 & 2.65 & $0.210 \mathrm{U}$ \\
\hline $2941-245 b$ & TCB & 9 & & $2 / 25 / 09$ & $3 / 12 / 09$ & 13 & 8.0 & 0.159 & 21.8 & $0.242 \mathrm{U}$ & 0.507 & 1.80 & $0.242 \mathrm{U}$ \\
\hline $2941-247$ & TCB & 9 & $\mathrm{x}$ & 2/25/09 & $3 / 12 / 09$ & 13 & 10.0 & 0.159 & 17.2 & $0.242 \mathrm{U}$ & 0.505 & 1.63 & $0.242 \mathrm{U}$ \\
\hline $2941-256$ & TCB & 10 & & $3 / 12 / 09$ & $3 / 25 / 09$ & 14 & 6.5 & 0.159 & 9.09 & $0.225 \mathrm{U}$ & 0.513 & 0.932 & $0.225 \mathrm{U}$ \\
\hline $2941-267$ & TCB & 11 & & $4 / 8 / 09$ & $4 / 22 / 09$ & 14 & 5.0 & 0.159 & 46.8 & $0.225 \mathrm{U}$ & 0.588 & 2.17 & 0.321 \\
\hline $2941-274$ & TCB & 12 & & 4/22/09 & 5/7/09 & 15 & 3.0 & 0.159 & 7.14 & $0.210 \mathrm{U}$ & $0.210 \mathrm{U}$ & 0.573 & $0.210 \mathrm{U}$ \\
\hline $2941-282$ & TCB & 13 & & $5 / 7 / 09$ & $5 / 21 / 09$ & 14 & 10.0 & 0.159 & 20.4 & $0.225 \mathrm{U}$ & 0.573 & 2.27 & $0.225 \mathrm{U}$ \\
\hline $2941-288$ & TCB & 14 & & $5 / 21 / 09$ & $6 / 4 / 09$ & 14 & 0.0 & 0.159 & 26.6 & $0.225 \mathrm{U}$ & 0.487 & 1.29 & 0.261 \\
\hline $2941-301$ & TCB & 15 & & 7/30/09 & $8 / 12 / 09$ & 13 & 1.5 & 0.159 & 13.0 & $0.242 \mathrm{U}$ & 0.291 & 0.901 & $0.242 \mathrm{U}$ \\
\hline $2941-309$ & TCB & 16 & & 8/12/09 & $8 / 27 / 09$ & 15 & 1.0 & 0.159 & 15.4 & $0.210 \mathrm{U}$ & 0.275 & 0.671 & $0.210 \mathrm{U}$ \\
\hline $2941-316$ & TCB & 17 & & 8/27/09 & $9 / 8 / 09$ & 12 & 9.5 & 0.159 & 22.5 & $0.262 \mathrm{U}$ & $0.262 \mathrm{U}$ & 1.52 & $0.262 \mathrm{U}$ \\
\hline $2941-326$ & TCB & 18 & & $9 / 8 / 09$ & $9 / 24 / 09$ & 16 & 1.0 & 0.159 & 25.9 & $0.196 \mathrm{U}$ & $0.196 \mathrm{U}$ & 2.18 & $0.196 \mathrm{U}$ \\
\hline $2941-333$ & TCB & 19 & & $9 / 24 / 09$ & $10 / 7 / 09$ & 13 & 1.8 & 0.159 & 26.5 & $0.242 \mathrm{U}$ & 0.896 & 1.66 & $0.242 \mathrm{U}$ \\
\hline Mean & & & & & & & & & 29.8 & 0.257 & 0.594 & 3.70 & 0.303 \\
\hline
\end{tabular}


Field Sample Results - PBDEs

Org. Funnel

Sample Station Event Field Date Date Days Vol. Surface

ID ID No. Dup Deployed Recovered Deployed (L) Area $\left(\mathrm{m}^{2}\right)$

Sum

BDEs BDE-17 $\quad$ BDE-28 $\quad$ BDE-47 $\quad$ BDE-66

\begin{tabular}{|c|c|c|c|c|c|c|c|c|c|c|c|c|c|}
\hline & & & & & & & & Unit & & $\mathrm{ng} / \mathrm{m}^{2} /$ day & $\mathrm{ng} / \mathrm{m}^{2} /$ day & $\mathrm{ng} / \mathrm{m}^{2} /$ day & $\mathrm{ng} / \mathrm{m}^{2} /$ day \\
\hline Stdev & & & & & & & & & 35.5 & 0.0902 & 0.503 & 8.28 & 0.326 \\
\hline RSD & & & & & & & & & $119 \%$ & $35 \%$ & $85 \%$ & $224 \%$ & $107 \%$ \\
\hline $2941-172$ & WP & 1 & & $8 / 28 / 08$ & $9 / 12 / 08$ & 15 & 0.0 & 0.159 & 5.26 & $0.210 \mathrm{U}$ & 0.440 & 0.963 & $0.210 \mathrm{U}$ \\
\hline 2941-183 & WP & 2 & & 9/12/08 & $9 / 25 / 08$ & 13 & 2.0 & 0.159 & 7.47 & $0.242 \mathrm{U}$ & $0.242 \mathrm{U}$ & 0.782 & $0.242 \mathrm{U}$ \\
\hline 2941-190 & WP & 3 & & $9 / 25 / 08$ & $10 / 14 / 08$ & 19 & 5.0 & 0.159 & 3.68 & $0.165 \mathrm{U}$ & 0.238 & 0.718 & $0.165 \mathrm{U}$ \\
\hline 2941-201 & WP & 4 & & $10 / 14 / 08$ & 10/29/08 & 15 & 1.5 & 0.159 & 5.77 & $0.210 \mathrm{U}$ & $0.210 \mathrm{U}$ & 0.468 & $0.210 \mathrm{U}$ \\
\hline 2941-200 & WP & 5 & & $10 / 29 / 08$ & $11 / 13 / 08$ & 15 & 18.0 & 0.159 & 9.14 & $0.210 \mathrm{U}$ & $0.210 \mathrm{U}$ & 1.11 & $0.210 \mathrm{U}$ \\
\hline $2941-225$ & WP & 6 & & $11 / 13 / 08$ & $11 / 25 / 08$ & 12 & 1.0 & 0.159 & 4.25 & $0.262 \mathrm{U}$ & $0.262 \mathrm{U}$ & 0.494 & $0.262 \mathrm{U}$ \\
\hline $2941-230$ & WP & 7 & & $11 / 25 / 08$ & $12 / 11 / 08$ & 16 & 1.5 & 0.159 & 4.93 & $0.196 \mathrm{U}$ & 0.687 & 0.563 & $0.196 \mathrm{U}$ \\
\hline $2941-244$ & WP & 8 & & 2/26/09 & $3 / 11 / 09$ & 13 & 4.5 & 0.159 & 7.78 & 0.747 & 1.49 & 1.01 & $0.242 \mathrm{U}$ \\
\hline $2941-246$ & WP & 9 & & $3 / 11 / 09$ & $3 / 25 / 09$ & 14 & 6.0 & 0.159 & 5.61 & $0.225 \mathrm{U}$ & 0.340 & 0.679 & $0.225 \mathrm{U}$ \\
\hline $2941-258$ & WP & 10 & & $3 / 25 / 09$ & $4 / 8 / 09$ & 14 & 6.5 & 0.159 & 10.6 & $0.225 \mathrm{U}$ & 0.341 & 1.10 & $0.225 \mathrm{U}$ \\
\hline $2941-264$ & WP & 11 & & $4 / 8 / 09$ & $4 / 23 / 09$ & 15 & 4.0 & 0.159 & 10.5 & $0.210 \mathrm{U}$ & $0.210 \mathrm{U}$ & 2.09 & $0.210 \mathrm{U}$ \\
\hline $2941-272$ & WP & 12 & & 4/23/09 & $5 / 6 / 09$ & 13 & 2.0 & 0.159 & 5.24 & $0.242 \mathrm{U}$ & $0.242 \mathrm{U}$ & 0.757 & $0.242 \mathrm{U}$ \\
\hline $2941-284$ & WP & 13 & & $5 / 6 / 09$ & $5 / 21 / 09$ & 15 & 11.0 & 0.159 & 5.69 & $0.210 \mathrm{U}$ & $0.210 \mathrm{U}$ & 0.815 & $0.210 \mathrm{U}$ \\
\hline 2941-289 & WP & 14 & & $5 / 21 / 09$ & $6 / 3 / 09$ & 13 & 2.0 & 0.159 & 12.4 & $0.242 \mathrm{U}$ & $0.242 \mathrm{U}$ & 1.78 & 0.258 \\
\hline 2941-302 & WP & 15 & & 7/29/09 & $8 / 12 / 09$ & 14 & 1.5 & 0.159 & 11.1 & $0.225 \mathrm{U}$ & $0.225 \mathrm{U}$ & 0.594 & $0.225 \mathrm{U}$ \\
\hline 2941-308 & WP & 16 & & 8/12/09 & $8 / 26 / 09$ & 14 & 1.5 & 0.159 & 9.34 & $0.225 \mathrm{U}$ & $0.225 \mathrm{U}$ & 0.643 & $0.225 \mathrm{U}$ \\
\hline $2941-315$ & WP & 17 & & $8 / 26 / 09$ & $9 / 9 / 09$ & 14 & 4.5 & 0.159 & 12.9 & $0.225 \mathrm{U}$ & $0.225 \mathrm{U}$ & 0.706 & $0.225 \mathrm{U}$ \\
\hline $2941-327$ & WP & 18 & & 9/9/09 & $9 / 24 / 09$ & 15 & 2.0 & 0.159 & 8.62 & $0.210 \mathrm{U}$ & 0.283 & $0.210 \mathrm{U}$ & $0.210 \mathrm{U}$ \\
\hline $2941-332$ & WP & 19 & & $9 / 24 / 09$ & $10 / 7 / 09$ & 13 & 3.8 & 0.159 & 14.6 & $0.242 \mathrm{U}$ & $0.242 \mathrm{U}$ & 0.878 & $0.242 \mathrm{U}$ \\
\hline Mean & & & & & & & & & 8.15 & $0.248 \mathrm{U}$ & 0.345 & 0.861 & $0.223 \mathrm{U}$ \\
\hline Stdev & & & & & & & & & 3.21 & -- & 0.301 & 0.442 & -- \\
\hline RSD & & & & & & & & & $39 \%$ & -- & $87 \%$ & $51 \%$ & -- \\
\hline $2941-293$ & $\mathrm{TM}$ & 14 & & $5 / 20 / 2009$ & $6 / 4 / 2009$ & 15 & & 0.159 & 4.19 & $0.210 \mathrm{U}$ & $0.210 \mathrm{U}$ & 0.351 & $0.210 \mathrm{U}$ \\
\hline 2941-304 & $\mathrm{TM}$ & 15 & & $7 / 30 / 2009$ & $8 / 12 / 2009$ & 13 & & 0.159 & 21.9 & $0.242 \mathrm{U}$ & $0.242 \mathrm{U}$ & 0.461 & $0.242 \mathrm{U}$ \\
\hline $2941-312$ & $\mathrm{TM}$ & 16 & & $8 / 12 / 2009$ & $8 / 27 / 2009$ & 15 & & 0.159 & 10.2 & $0.210 \mathrm{U}$ & $0.210 \mathrm{U}$ & 0.597 & $0.210 \mathrm{U}$ \\
\hline $2941-318$ & $\mathrm{TM}$ & 17 & & $8 / 27 / 2009$ & 9/8/2009 & 12 & & 0.159 & 15.0 & $0.262 \mathrm{U}$ & $0.262 \mathrm{U}$ & $0.262 \mathrm{U}$ & $0.262 \mathrm{U}$ \\
\hline $2941-325$ & $\mathrm{TM}$ & 18 & & 9/8/2009 & $9 / 24 / 2009$ & 16 & & 0.159 & 13.7 & $0.196 \mathrm{U}$ & $0.196 \mathrm{U}$ & $0.196 \mathrm{U}$ & $0.196 \mathrm{U}$ \\
\hline $2941-333$ & $\mathrm{TM}$ & 19 & & $9 / 24 / 2009$ & $10 / 7 / 2009$ & 13 & & 0.159 & 15.6 & $0.242 \mathrm{U}$ & 0.317 & 0.547 & $0.242 \mathrm{U}$ \\
\hline Mean & & & & & & & & & 13.4 & $0.227 \mathrm{U}$ & $0.239 \mathrm{U}$ & 0.402 & $0.227 \mathrm{U}$ \\
\hline Stdev & & & & & & & & & 5.91 & -- & -- & 0.159 & -- \\
\hline RSD & & & & & & & & & $44 \%$ & -- & -- & $40 \%$ & -- \\
\hline \multicolumn{14}{|c|}{ FIELD DUPLICATES } \\
\hline $2941-210$ & $\mathrm{HC}$ & 7 & & $11 / 20 / 08$ & $12 / 11 / 08$ & 21 & 4 & 0.159 & & $0.150 \mathrm{U}$ & 0.297 & 0.551 & $0.150 \mathrm{U}$ \\
\hline 2941-234 & $\mathrm{HC}$ & 7 & $\mathrm{x}$ & $11 / 20 / 08$ & $12 / 11 / 08$ & 21 & 4 & 0.159 & & 0.522 & 0.929 & 0.471 & $0.150 \mathrm{U}$ \\
\hline RPD & & & & & & & & & & -- & $103 \%$ & $16 \%$ & -- \\
\hline $2941-265$ & NR & 11 & $\mathrm{x}$ & $4 / 8 / 09$ & $4 / 22 / 09$ & 14 & 4 & 0.159 & & $0.225 \mathrm{U}$ & $0.225 \mathrm{U}$ & 0.461 & $0.225 \mathrm{U}$ \\
\hline $2941-266$ & NR & 11 & & 4/8/09 & $4 / 22 / 09$ & 14 & 4 & 0.159 & & $0.225 \mathrm{U}$ & $0.225 \mathrm{U}$ & 0.674 & $0.225 \mathrm{U}$ \\
\hline RPD & & & & & & & & & & -- & -- & $37 \%$ & -- \\
\hline 2941-193 & $\mathrm{PO}$ & 3 & & $10 / 6 / 08$ & $10 / 16 / 08$ & 10 & 1.5 & 0.159 & & $0.314 \mathrm{U}$ & $0.314 \mathrm{U}$ & $0.314 \mathrm{U}$ & $0.314 \mathrm{U}$ \\
\hline 2941-199 & PO & 3 & $\mathrm{x}$ & $10 / 6 / 08$ & $10 / 16 / 08$ & 10 & 1.5 & 0.159 & & $0.314 \mathrm{U}$ & $0.314 \mathrm{U}$ & 0.649 & $0.314 \mathrm{U}$ \\
\hline RPD & & & & & & & & & & -- & -- & -- & -- \\
\hline 2941-206 & $\mathrm{PO}$ & 4 & & $10 / 16 / 08$ & $10 / 29 / 08$ & 13 & 1 & 0.159 & & $0.242 \mathrm{U}$ & $0.242 \mathrm{U}$ & 0.413 & $0.242 \mathrm{U}$ \\
\hline 2941-207 & PO & 4 & $\mathrm{x}$ & $10 / 16 / 08$ & $10 / 29 / 08$ & 13 & 1 & 0.159 & & $0.242 \mathrm{U}$ & $0.242 \mathrm{U}$ & $0.242 \mathrm{U}$ & $0.242 \mathrm{U}$ \\
\hline RPD & & & & & & & & & & -- & -- & -- & -- \\
\hline 2941-178 & SB & 1 & & $9 / 2 / 08$ & $9 / 18 / 08$ & 16 & $<20 \mathrm{~mL}$ & 0.159 & & $0.196 \mathrm{U}$ & $0.196 \mathrm{U}$ & 0.551 & $0.196 \mathrm{U}$ \\
\hline 2941-179 & SB & 1 & $\mathrm{x}$ & $9 / 2 / 08$ & $9 / 18 / 08$ & 16 & $<20 \mathrm{~mL}$ & 0.159 & & $0.196 \mathrm{U}$ & $0.196 \mathrm{U}$ & 0.415 & $0.196 \mathrm{U}$ \\
\hline RPD & & & & & & & & & & -- & -- & $28 \%$ & -- \\
\hline 2941-186 & SB & 2 & & $9 / 18 / 08$ & $10 / 2 / 08$ & 14 & 1.5 & 0.159 & & $0.225 \mathrm{U}$ & $0.225 \mathrm{U}$ & 0.871 & $0.225 \mathrm{U}$ \\
\hline 2941-187 & SB & 2 & $\mathrm{x}$ & 9/18/08 & $10 / 2 / 08$ & 14 & 1.5 & 0.159 & & $0.225 \mathrm{U}$ & $0.225 \mathrm{U}$ & 0.609 & $0.225 \mathrm{U}$ \\
\hline RPD & & & & & & & & & & -- & -- & $35 \%$ & -- \\
\hline $2941-245 b$ & TCB & 9 & & 2/25/09 & $3 / 12 / 09$ & 13 & 8 & 0.159 & & $0.242 \mathrm{U}$ & 0.507 & 1.80 & $0.242 \mathrm{U}$ \\
\hline $2941-247$ & TCB & 9 & $\mathrm{x}$ & 2/25/09 & $3 / 12 / 09$ & 13 & 8 & 0.159 & & $0.242 \mathrm{U}$ & 0.505 & 1.63 & $0.242 \mathrm{U}$ \\
\hline RPD & & & & & & & & & & -- & $0 \%$ & $10 \%$ & -- \\
\hline
\end{tabular}

U Not detected at or below DL shown

RPD Relative Percent Difference 
Field Sample Results - PBDEs

Sample Station Event Field Date Date Days $\begin{array}{lll}\text { Org. } & \text { Fonnel } \\ \text { Sol. } & \text { Surface }\end{array}$

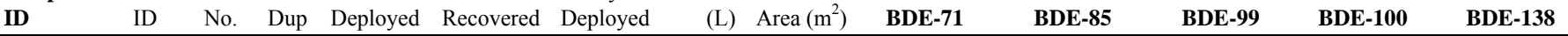

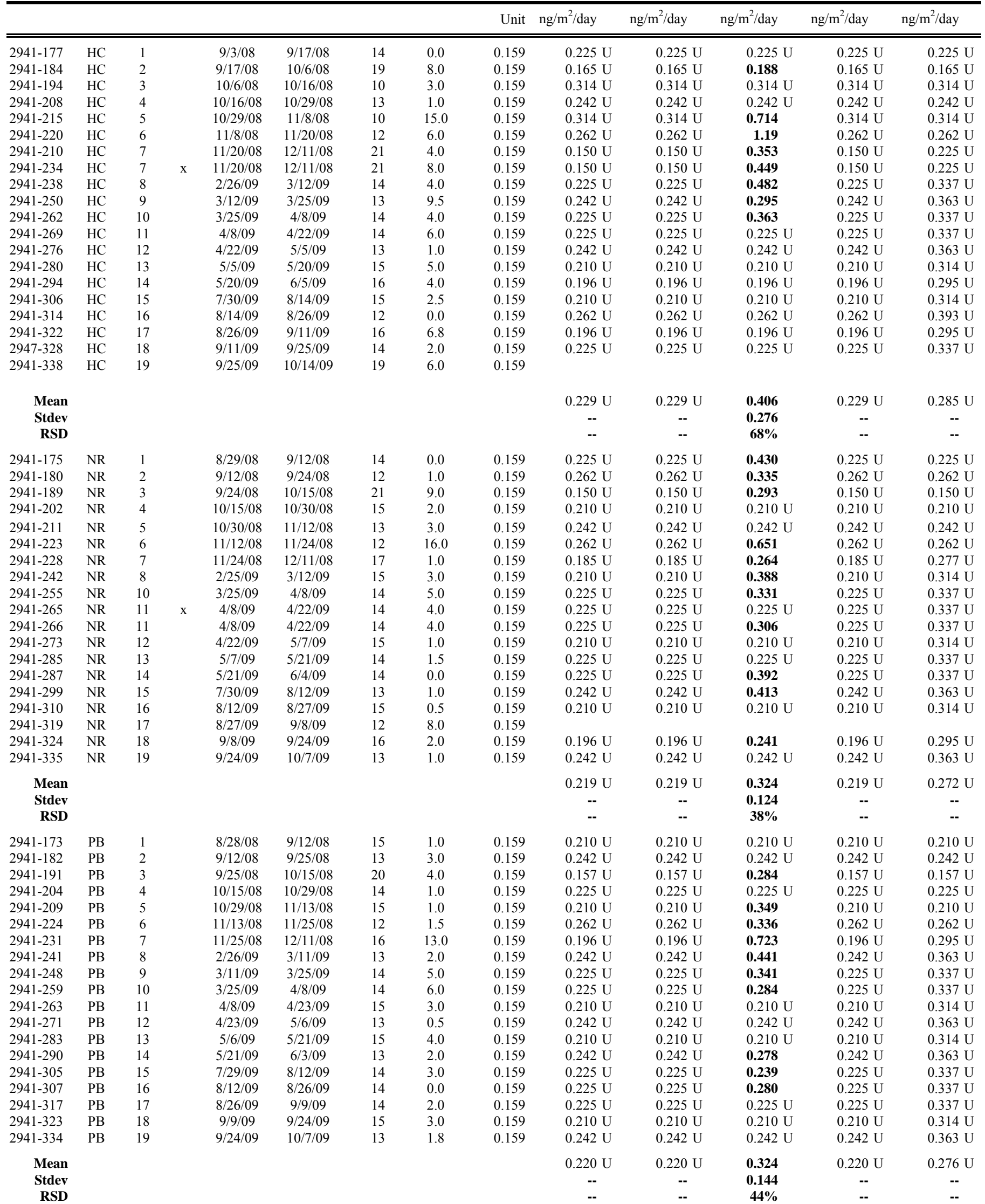


Field Sample Results - PBDEs

Sample Station Event Field Date Date Days $\begin{array}{lll}\text { Org. } & \text { Fonnel } \\ \text { Sol. } & \text { Surface }\end{array}$

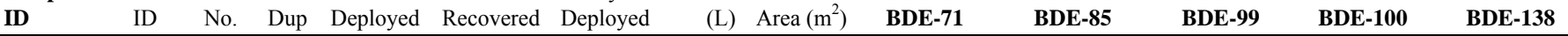

\begin{tabular}{|c|c|c|c|c|c|c|c|c|c|c|c|c|c|}
\hline & & & & & & & & Unit & $\mathrm{ng} / \mathrm{m}^{2} /$ day & $\mathrm{ng} / \mathrm{m}^{2} /$ day & $\mathrm{ng} / \mathrm{m}^{2} / \mathrm{day}$ & $\mathrm{ng} / \mathrm{m}^{2} /$ day & $\mathrm{ng} / \mathrm{m}^{2} /$ day \\
\hline 2941-185 & PO & 2 & & 9/17/08 & $10 / 6 / 08$ & 19 & 6.0 & 0.159 & $0.165 \mathrm{U}$ & $0.165 \mathrm{U}$ & 0.332 & $0.165 \mathrm{U}$ & $0.165 \mathrm{U}$ \\
\hline 2941-193 & PO & 3 & & $10 / 6 / 08$ & $10 / 16 / 08$ & 10 & 1.5 & 0.159 & $0.314 \mathrm{U}$ & $0.314 \mathrm{U}$ & 0.380 & $0.314 \mathrm{U}$ & $0.314 \mathrm{U}$ \\
\hline 2941-206 & PO & 4 & & $10 / 16 / 08$ & $10 / 29 / 08$ & 13 & 1.0 & 0.159 & $0.242 \mathrm{U}$ & $0.242 \mathrm{U}$ & $0.242 \mathrm{U}$ & $0.242 \mathrm{U}$ & $0.242 \mathrm{U}$ \\
\hline 2941-207 & PO & 4 & $\mathrm{x}$ & $10 / 16 / 08$ & $10 / 29 / 08$ & 13 & 1.0 & 0.159 & $0.242 \mathrm{U}$ & $0.242 \mathrm{U}$ & 0.332 & $0.242 \mathrm{U}$ & $0.242 \mathrm{U}$ \\
\hline $2941-213$ & PO & 5 & & $10 / 29 / 08$ & $11 / 7 / 08$ & 9 & 6.0 & 0.159 & $0.349 \mathrm{U}$ & $0.349 \mathrm{U}$ & 0.493 & $0.349 \mathrm{U}$ & $0.349 \mathrm{U}$ \\
\hline $2941-251$ & PO & 9 & & 3/12/09 & 3/25/09 & 13 & 8.0 & 0.159 & $0.242 \mathrm{U}$ & $0.242 \mathrm{U}$ & 0.448 & $0.242 \mathrm{U}$ & $0.363 \mathrm{U}$ \\
\hline 2941-261 & $\mathrm{PO}$ & 10 & & $3 / 25 / 09$ & $4 / 8 / 09$ & 14 & 6.0 & 0.159 & $0.225 \mathrm{U}$ & $0.225 \mathrm{U}$ & 0.588 & $0.225 \mathrm{U}$ & $0.337 \mathrm{U}$ \\
\hline $2941-270$ & PO & 11 & & 4/8/09 & 4/22/09 & 14 & 5.0 & 0.159 & $0.225 \mathrm{U}$ & $0.225 \mathrm{U}$ & 0.272 & $0.225 \mathrm{U}$ & $0.337 \mathrm{U}$ \\
\hline $2941-277$ & PO & 12 & & 4/22/09 & $5 / 5 / 09$ & 13 & 2.0 & 0.159 & $0.242 \mathrm{U}$ & $0.242 \mathrm{U}$ & 0.696 & $0.242 \mathrm{U}$ & $0.363 \mathrm{U}$ \\
\hline $2941-279$ & PO & 13 & & $5 / 5 / 09$ & $5 / 20 / 09$ & 15 & 11.0 & 0.159 & $0.210 \mathrm{U}$ & $0.210 \mathrm{U}$ & $0.210 \mathrm{U}$ & $0.210 \mathrm{U}$ & $0.314 \mathrm{U}$ \\
\hline 2941-292 & PO & 14 & & $5 / 20 / 09$ & $6 / 5 / 09$ & 16 & 4.0 & 0.159 & $0.196 \mathrm{U}$ & $0.196 \mathrm{U}$ & 0.224 & $0.196 \mathrm{U}$ & $0.295 \mathrm{U}$ \\
\hline 2941-300 & $\mathrm{PO}$ & 15 & & 7/30/09 & 8/14/09 & 15 & 2.0 & 0.159 & $0.210 \mathrm{U}$ & $0.210 \mathrm{U}$ & 0.266 & $0.210 \mathrm{U}$ & $0.314 \mathrm{U}$ \\
\hline Mean & & & & & & & & & $0.246 \mathrm{U}$ & $0.246 \mathrm{U}$ & 0.395 & $0.246 \mathrm{U}$ & $0.287 \mathrm{U}$ \\
\hline Stdev & & & & & & & & & -- & -- & 0.150 & -- & -- \\
\hline RSD & & & & & & & & & -- & -- & $38 \%$ & -- & -- \\
\hline
\end{tabular}

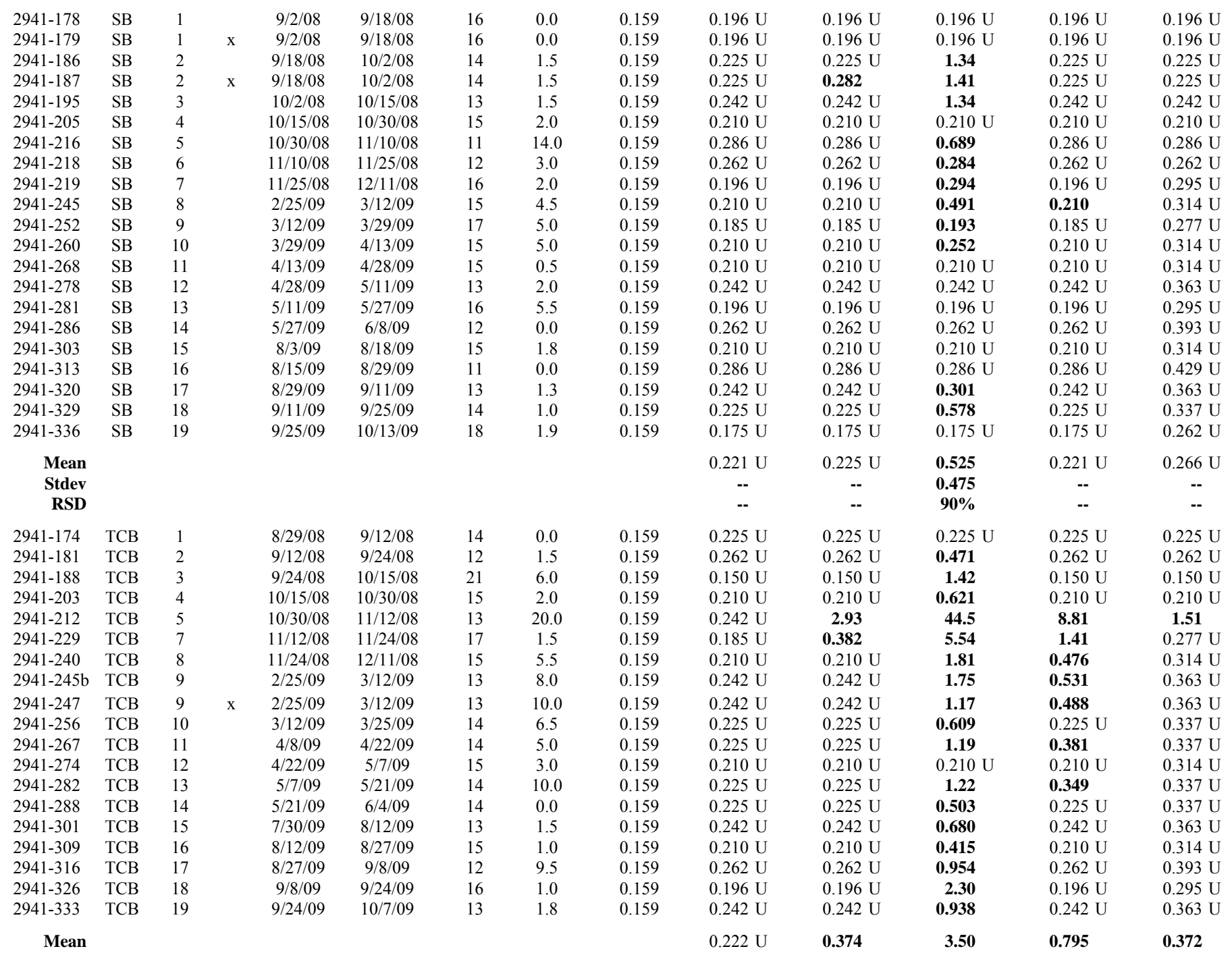


Field Sample Results - PBDEs

Org. Funnel

Sample Station Event Field Date Date Days Vol. Surface

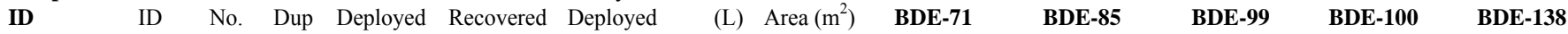

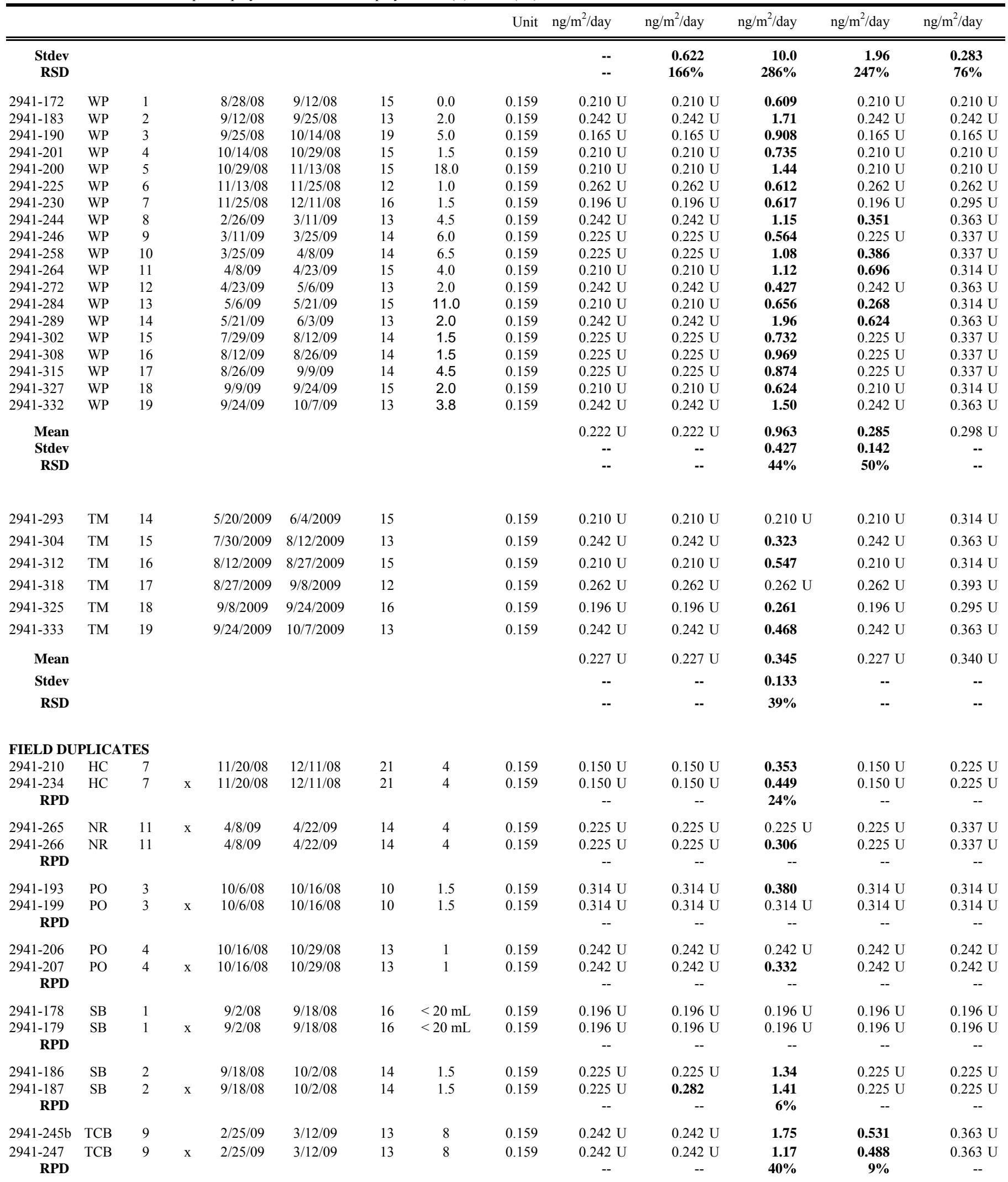

U Not detected at or below DL shown

RPD Relative Percent Difference 
Field Sample Results - PBDEs

Sample Station Event Field Date Date Days $\begin{array}{lll}\text { Org. } & \text { Funnel } \\ \text { Vol. } & \text { Surface }\end{array}$

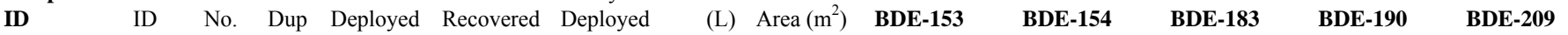

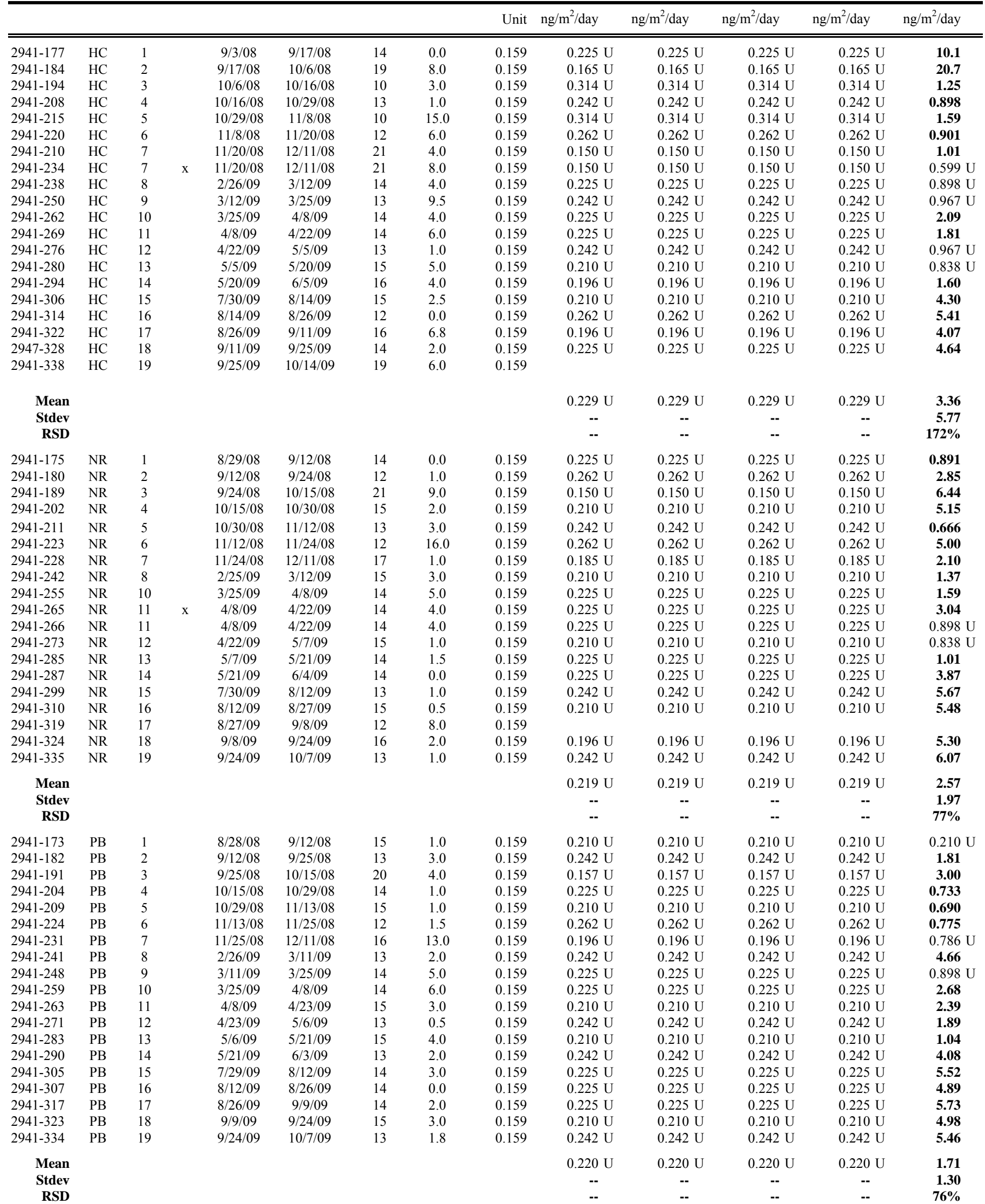


Field Sample Results - PBDEs

Sample Station Event Field Date Date Days $\begin{array}{lll}\text { Org. } & \text { Funnel } \\ \text { Vol. } & \text { Surface }\end{array}$

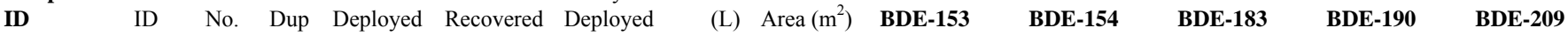

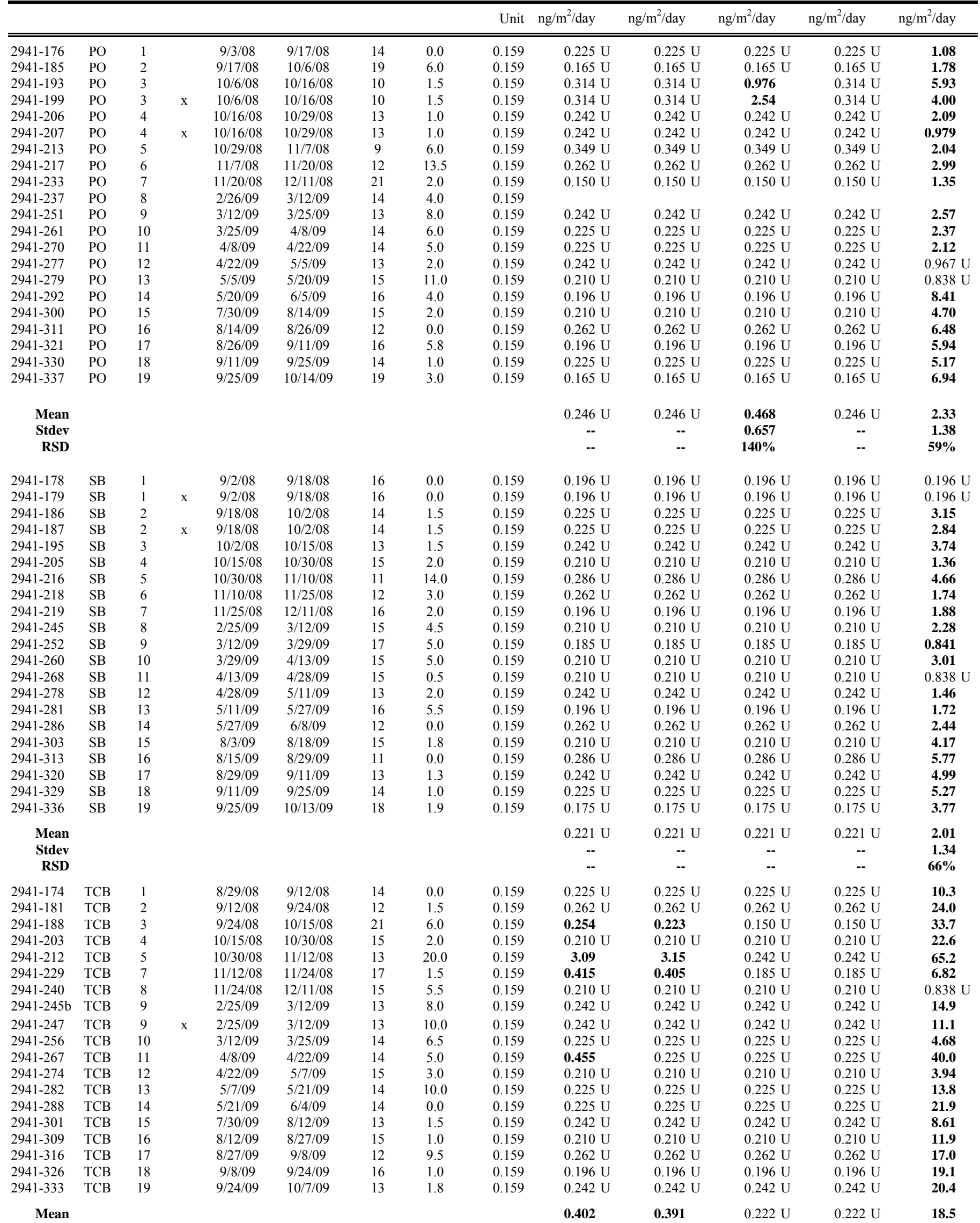


Field Sample Results - PBDEs

Sample Station Event Field Date Date Days $\begin{array}{lll}\text { Org. } & \text { Fol. } & \text { Surface }\end{array}$

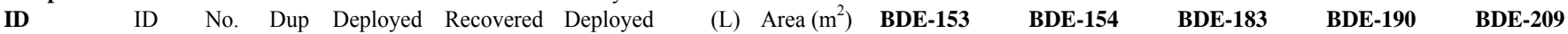

Unit $\mathrm{ng} / \mathrm{m}^{2} / \mathrm{day} \quad \mathrm{ng} / \mathrm{m}^{2} / \mathrm{day} \quad \mathrm{ng} / \mathrm{m}^{2} / \mathrm{day} \quad \mathrm{ng} / \mathrm{m}^{2} / \mathrm{day} \quad \mathrm{ng} / \mathrm{m}^{2} / \mathrm{day}$

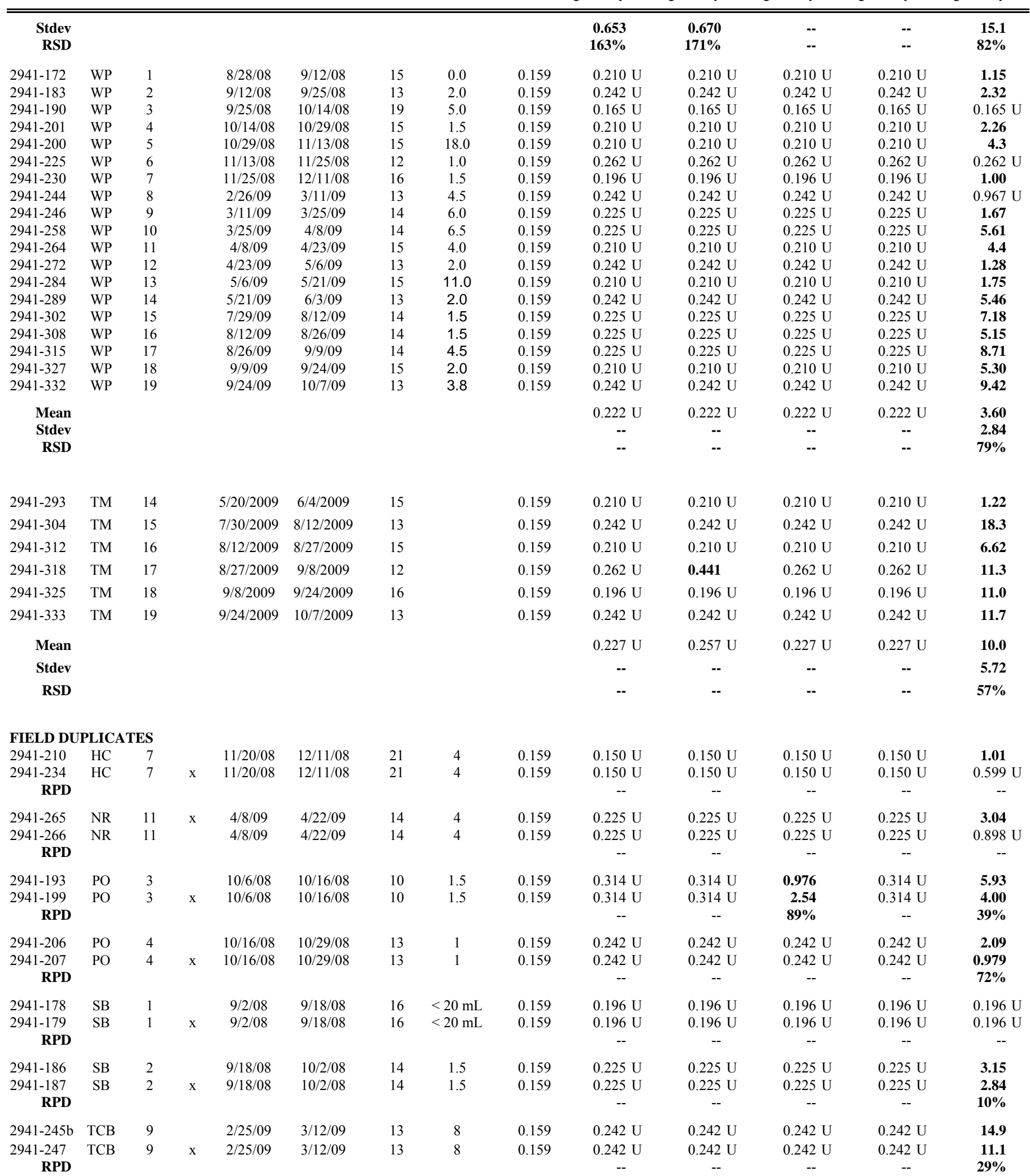

U Not detected at or below DL shown

RPD Relative Percent Difference 
Field Sample Results - PBDEs

\begin{tabular}{|c|c|c|c|c|c|c|c|c|c|c|c|}
\hline $\begin{array}{l}\text { Sample } \\
\text { ID }\end{array}$ & $\begin{array}{c}\text { Station } \\
\text { ID }\end{array}$ & $\begin{array}{c}\text { Event } \\
\text { No. }\end{array}$ & $\begin{array}{c}\text { Field } \\
\text { Dup }\end{array}$ & $\begin{array}{c}\text { Date } \\
\text { Deployed }\end{array}$ & $\begin{array}{c}\text { Date } \\
\text { Recovered }\end{array}$ & $\begin{array}{c}\text { Days } \\
\text { Deployed }\end{array}$ & $\begin{array}{r}\text { Org. } \\
\text { Vol. } \\
\text { (L) }\end{array}$ & $\begin{array}{r}\text { Funnel } \\
\text { Surface } \\
\text { Area }\left(\mathrm{m}^{2}\right)\end{array}$ & HBB & $\begin{array}{r}\text { PCB } \\
103\end{array}$ & $\begin{array}{r}\text { PCB } \\
198\end{array}$ \\
\hline & & & & & & & & Unit & Percent & Percent & Percent \\
\hline $2941-177$ & $\mathrm{HC}$ & 1 & & $9 / 3 / 08$ & $9 / 17 / 08$ & 14 & 0.0 & 0.159 & $113 \%$ & $88 \%$ & $97 \%$ \\
\hline 2941-184 & $\mathrm{HC}$ & 2 & & $9 / 17 / 08$ & $10 / 6 / 08$ & 19 & 8.0 & 0.159 & $137 \%$ & $82 \%$ & $83 \%$ \\
\hline 2941-194 & $\mathrm{HC}$ & 3 & & $10 / 6 / 08$ & $10 / 16 / 08$ & 10 & 3.0 & 0.159 & $172 \%$ & $91 \%$ & $96 \%$ \\
\hline $2941-208$ & $\mathrm{HC}$ & 4 & & $10 / 16 / 08$ & $10 / 29 / 08$ & 13 & 1.0 & 0.159 & $101 \%$ & $88 \%$ & $97 \%$ \\
\hline $2941-215$ & $\mathrm{HC}$ & 5 & & $10 / 29 / 08$ & $11 / 8 / 08$ & 10 & 15.0 & 0.159 & $92 \%$ & $91 \%$ & $96 \%$ \\
\hline $2941-220$ & $\mathrm{HC}$ & 6 & & $11 / 8 / 08$ & $11 / 20 / 08$ & 12 & 6.0 & 0.159 & $143 \%$ & $82 \%$ & $94 \%$ \\
\hline $2941-210$ & $\mathrm{HC}$ & 7 & & $11 / 20 / 08$ & $12 / 11 / 08$ & 21 & 4.0 & 0.159 & $105 \%$ & $93 \%$ & $93 \%$ \\
\hline $2941-234$ & $\mathrm{HC}$ & 7 & $\mathrm{x}$ & $11 / 20 / 08$ & $12 / 11 / 08$ & 21 & 8.0 & 0.159 & $100 \%$ & $96 \%$ & $94 \%$ \\
\hline $2941-238$ & $\mathrm{HC}$ & 8 & & $2 / 26 / 09$ & $3 / 12 / 09$ & 14 & 4.0 & 0.159 & $179 \%$ & $96 \%$ & $95 \%$ \\
\hline $2941-250$ & $\mathrm{HC}$ & 9 & & $3 / 12 / 09$ & $3 / 25 / 09$ & 13 & 9.5 & 0.159 & $148 \%$ & $85 \%$ & $93 \%$ \\
\hline $2941-262$ & $\mathrm{HC}$ & 10 & & $3 / 25 / 09$ & $4 / 8 / 09$ & 14 & 4.0 & 0.159 & $104 \%$ & $91 \%$ & $94 \%$ \\
\hline $2941-269$ & $\mathrm{HC}$ & 11 & & $4 / 8 / 09$ & $4 / 22 / 09$ & 14 & 6.0 & 0.159 & $99 \%$ & $91 \%$ & $96 \%$ \\
\hline $2941-276$ & $\mathrm{HC}$ & 12 & & $4 / 22 / 09$ & $5 / 5 / 09$ & 13 & 1.0 & 0.159 & $130 \%$ & $92 \%$ & $97 \%$ \\
\hline $2941-280$ & $\mathrm{HC}$ & 13 & & $5 / 5 / 09$ & $5 / 20 / 09$ & 15 & 5.0 & 0.159 & $84 \%$ & $91 \%$ & $113 \%$ \\
\hline 2941-294 & $\mathrm{HC}$ & 14 & & $5 / 20 / 09$ & $6 / 5 / 09$ & 16 & 4.0 & 0.159 & $89 \%$ & $93 \%$ & $112 \%$ \\
\hline $2941-306$ & $\mathrm{HC}$ & 15 & & $7 / 30 / 09$ & $8 / 14 / 09$ & 15 & 2.5 & 0.159 & $135 \%$ & $76 \%$ & $110 \%$ \\
\hline $2941-314$ & $\mathrm{HC}$ & 16 & & $8 / 14 / 09$ & $8 / 26 / 09$ & 12 & 0.0 & 0.159 & $117 \%$ & $74 \%$ & $111 \%$ \\
\hline $2941-322$ & $\mathrm{HC}$ & 17 & & $8 / 26 / 09$ & $9 / 11 / 09$ & 16 & 6.8 & 0.159 & $110 \%$ & $78 \%$ & $112 \%$ \\
\hline $2947-328$ & $\mathrm{HC}$ & 18 & & $9 / 11 / 09$ & $9 / 25 / 09$ & 14 & 2.0 & 0.159 & $120 \%$ & $77 \%$ & $109 \%$ \\
\hline $2941-338$ & $\mathrm{HC}$ & 19 & & $9 / 25 / 09$ & $10 / 14 / 09$ & 19 & 60 & 0159 & & & \\
\hline
\end{tabular}

\begin{tabular}{|c|c|c|c|c|c|c|c|c|c|c|c|}
\hline $\begin{array}{r}\text { Mean } \\
\text { Stdev } \\
\text { RSD }\end{array}$ & & & & & & & & & & & \\
\hline $2941-175$ & NR & 1 & & $8 / 29 / 08$ & $9 / 12 / 08$ & 14 & 0.0 & 0.159 & $104 \%$ & $90 \%$ & $102 \%$ \\
\hline $2941-180$ & NR & 2 & & $9 / 12 / 08$ & $9 / 24 / 08$ & 12 & 1.0 & 0.159 & $109 \%$ & $87 \%$ & $95 \%$ \\
\hline 2941-189 & NR & 3 & & $9 / 24 / 08$ & $10 / 15 / 08$ & 21 & 9.0 & 0.159 & $175 \%$ & $93 \%$ & $100 \%$ \\
\hline 2941-202 & NR & 4 & & $10 / 15 / 08$ & $10 / 30 / 08$ & 15 & 2.0 & 0.159 & $181 \%$ & $94 \%$ & $100 \%$ \\
\hline $2941-211$ & NR & 5 & & $10 / 30 / 08$ & $11 / 12 / 08$ & 13 & 3.0 & 0.159 & $120 \%$ & $88 \%$ & $96^{\circ}$ \\
\hline $2941-223$ & NR & 6 & & $11 / 12 / 08$ & $11 / 24 / 08$ & 12 & 16.0 & 0.159 & $107 \%$ & $93 \%$ & 97 \\
\hline $2941-228$ & NR & 7 & & $11 / 24 / 08$ & $12 / 11 / 08$ & 17 & 1.0 & 0.159 & $125 \%$ & $89 \%$ & $94^{\circ}$ \\
\hline $2941-242$ & NR & 8 & & $2 / 25 / 09$ & $3 / 12 / 09$ & 15 & 3.0 & 0.159 & $114 \%$ & $90 \%$ & 92 \\
\hline $2941-255$ & NR & 10 & & $3 / 25 / 09$ & 4/8/09 & 14 & 5.0 & 0.159 & $123 \%$ & $89 \%$ & 94 \\
\hline $2941-265$ & NR & 11 & $\mathrm{x}$ & 4/8/09 & $4 / 22 / 09$ & 14 & 4.0 & 0.159 & $103 \%$ & $97 \%$ & 99 \\
\hline $2941-266$ & NR & 11 & & $4 / 8 / 09$ & $4 / 22 / 09$ & 14 & 4.0 & 0.159 & $97 \%$ & $98 \%$ & $97^{\circ}$ \\
\hline $2941-273$ & NR & 12 & & $4 / 22 / 09$ & $5 / 7 / 09$ & 15 & 1.0 & 0.159 & $138 \%$ & $85 \%$ & $97^{\circ}$ \\
\hline $2941-285$ & NR & 13 & & $5 / 7 / 09$ & $5 / 21 / 09$ & 14 & 1.5 & 0.159 & $118 \%$ & $87 \%$ & $112^{\circ}$ \\
\hline $2941-287$ & NR & 14 & & $5 / 21 / 09$ & $6 / 4 / 09$ & 14 & 0.0 & 0.159 & $97 \%$ & $92 \%$ & $111^{\circ}$ \\
\hline 2941-299 & NR & 15 & & $7 / 30 / 09$ & $8 / 12 / 09$ & 13 & 1.0 & 0.159 & $125 \%$ & $73 \%$ & $112 \%$ \\
\hline $2941-310$ & NR & 16 & & $8 / 12 / 09$ & $8 / 27 / 09$ & 15 & 0.5 & 0.159 & $135 \%$ & $79 \%$ & $105^{\circ}$ \\
\hline 2941-319 & NR & 17 & & $8 / 27 / 09$ & $9 / 8 / 09$ & 12 & 8.0 & 0.159 & & & \\
\hline $2941-324$ & NR & 18 & & 9/8/09 & $9 / 24 / 09$ & 16 & 2.0 & 0.159 & $104 \%$ & $79 \%$ & $110^{\circ}$ \\
\hline $2941-335$ & NR & 19 & & $9 / 24 / 09$ & $10 / 7 / 09$ & 13 & 1.0 & 0.159 & $104 \%$ & $71 \%$ & 94 \\
\hline \multicolumn{12}{|l|}{$\begin{array}{r}\text { Mean } \\
\text { Stdev } \\
\text { RSD }\end{array}$} \\
\hline $2941-173$ & PB & 1 & & $8 / 28 / 08$ & $9 / 12 / 08$ & 15 & 1.0 & 0.159 & $99 \%$ & $79 \%$ & $98 \%$ \\
\hline $2941-182$ & PB & 2 & & $9 / 12 / 08$ & $9 / 25 / 08$ & 13 & 3.0 & 0.159 & $132 \%$ & $93 \%$ & $100 \%$ \\
\hline 2941-191 & PB & 3 & & $9 / 25 / 08$ & $10 / 15 / 08$ & 20 & 4.0 & 0.159 & $132 \%$ & $92 \%$ & $99^{\circ}$ \\
\hline 2941-204 & PB & 4 & & $10 / 15 / 08$ & $10 / 29 / 08$ & 14 & 1.0 & 0.159 & $205 \%$ & $84 \%$ & $99^{\circ}$ \\
\hline 2941-209 & PB & 5 & & $10 / 29 / 08$ & $11 / 13 / 08$ & 15 & 1.0 & 0.159 & $116 \%$ & $89 \%$ & $96^{\circ}$ \\
\hline $2941-224$ & PB & 6 & & $11 / 13 / 08$ & $11 / 25 / 08$ & 12 & 1.5 & 0.159 & $137 \%$ & $89 \%$ & $96^{\circ}$ \\
\hline $2941-231$ & PB & 7 & & $11 / 25 / 08$ & $12 / 11 / 08$ & 16 & 13.0 & 0.159 & $85 \%$ & $94 \%$ & $94 \%$ \\
\hline $2941-241$ & PB & 8 & & $2 / 26 / 09$ & $3 / 11 / 09$ & 13 & 2.0 & 0.159 & $99 \%$ & $90 \%$ & $92^{\circ}$ \\
\hline $2941-248$ & PB & 9 & & $3 / 11 / 09$ & $3 / 25 / 09$ & 14 & 5.0 & 0.159 & $137 \%$ & $87 \%$ & $90^{\circ}$ \\
\hline $2941-259$ & PB & 10 & & $3 / 25 / 09$ & 4/8/09 & 14 & 6.0 & 0.159 & $168 \%$ & $85 \%$ & 94 \\
\hline $2941-263$ & PB & 11 & & 4/8/09 & $4 / 23 / 09$ & 15 & 3.0 & 0.159 & $92 \%$ & $99 \%$ & $98^{\circ}$ \\
\hline $2941-271$ & PB & 12 & & $4 / 23 / 09$ & $5 / 6 / 09$ & 13 & 0.5 & 0.159 & $100 \%$ & $87 \%$ & $92 \%$ \\
\hline $2941-283$ & PB & 13 & & $5 / 6 / 09$ & $5 / 21 / 09$ & 15 & 4.0 & 0.159 & $104 \%$ & $84 \%$ & $112^{\circ}$ \\
\hline $2941-290$ & PB & 14 & & $5 / 21 / 09$ & 6/3/09 & 13 & 2.0 & 0.159 & $109 \%$ & $90 \%$ & $111^{\circ}$ \\
\hline $2941-305$ & $\mathrm{~PB}$ & 15 & & $7 / 29 / 09$ & $8 / 12 / 09$ & 14 & 3.0 & 0.159 & $102 \%$ & $73 \%$ & $110 \%$ \\
\hline 2941-307 & PB & 16 & & $8 / 12 / 09$ & $8 / 26 / 09$ & 14 & 0.0 & 0.159 & $201 \%$ & $77 \%$ & $109^{\circ}$ \\
\hline $2941-317$ & PB & 17 & & $8 / 26 / 09$ & 9/9/09 & 14 & 2.0 & 0.159 & $106 \%$ & $79 \%$ & $114^{\circ}$ \\
\hline $2941-323$ & PB & 18 & & 9/9/09 & $9 / 24 / 09$ & 15 & 3.0 & 0.159 & $110 \%$ & $81 \%$ & $110 \%$ \\
\hline $2941-334$ & PB & 19 & & $9 / 24 / 09$ & $10 / 7 / 09$ & 13 & 1.8 & 0.159 & $74 \%$ & $69 \%$ & $95^{\circ}$ \\
\hline
\end{tabular}


Field Sample Results - PBDEs

\begin{tabular}{|c|c|c|c|c|c|c|c|c|c|c|c|}
\hline $\begin{array}{l}\text { Sample } \\
\text { ID }\end{array}$ & $\begin{array}{c}\text { Station } \\
\text { ID }\end{array}$ & $\begin{array}{c}\text { Event } \\
\text { No. }\end{array}$ & $\begin{array}{c}\text { Field } \\
\text { Dup }\end{array}$ & $\begin{array}{c}\text { Date } \\
\text { Deployed }\end{array}$ & $\begin{array}{c}\text { Date } \\
\text { Recovered }\end{array}$ & $\begin{array}{c}\text { Days } \\
\text { Deployed }\end{array}$ & $\begin{array}{r}\text { Org. } \\
\text { Vol. } \\
\text { (L) }\end{array}$ & $\begin{array}{r}\text { Funnel } \\
\text { Surface } \\
\text { Area }\left(\mathrm{m}^{2}\right)\end{array}$ & HBB & $\begin{array}{r}\text { PCB } \\
103\end{array}$ & $\begin{array}{r}\text { PCB } \\
198\end{array}$ \\
\hline & & & & & & & & Unit & Percent & Percent & Percent \\
\hline 2941-176 & PO & 1 & & $9 / 3 / 08$ & $9 / 17 / 08$ & 14 & 0.0 & 0.159 & $113 \%$ & $89 \%$ & $96 \%$ \\
\hline $2941-185$ & $\mathrm{PO}$ & 2 & & $9 / 17 / 08$ & $10 / 6 / 08$ & 19 & 6.0 & 0.159 & $129 \%$ & $91 \%$ & $99 \%$ \\
\hline 2941-193 & $\mathrm{PO}$ & 3 & & $10 / 6 / 08$ & $10 / 16 / 08$ & 10 & 1.5 & 0.159 & $145 \%$ & $90 \%$ & $100 \%$ \\
\hline 2941-199 & $\mathrm{PO}$ & 3 & $\mathrm{x}$ & $10 / 6 / 08$ & $10 / 16 / 08$ & 10 & 1.5 & 0.159 & $144 \%$ & $89 \%$ & $99 \%$ \\
\hline 2941-206 & PO & 4 & & $10 / 16 / 08$ & $10 / 29 / 08$ & 13 & 1.0 & 0.159 & $159 \%$ & $90 \%$ & $100 \%$ \\
\hline $2941-207$ & $\mathrm{PO}$ & 4 & $\mathrm{x}$ & $10 / 16 / 08$ & $10 / 29 / 08$ & 13 & 1.0 & 0.159 & $99 \%$ & $86 \%$ & $96 \%$ \\
\hline $2941-213$ & PO & 5 & & $10 / 29 / 08$ & $11 / 7 / 08$ & 9 & 6.0 & 0.159 & $108 \%$ & $86 \%$ & $96 \%$ \\
\hline $2941-217$ & $\mathrm{PO}$ & 6 & & $11 / 7 / 08$ & $11 / 20 / 08$ & 12 & 13.5 & 0.159 & $125 \%$ & $90 \%$ & $95 \%$ \\
\hline $2941-233$ & $\mathrm{PO}$ & 7 & & $11 / 20 / 08$ & $12 / 11 / 08$ & 21 & 2.0 & 0.159 & $102 \%$ & $92 \%$ & $92 \%$ \\
\hline $2941-237$ & $\mathrm{PO}$ & 8 & & $2 / 26 / 09$ & $3 / 12 / 09$ & 14 & 4.0 & 0.159 & & & \\
\hline $2941-251$ & $\mathrm{PO}$ & 9 & & $3 / 12 / 09$ & $3 / 25 / 09$ & 13 & 8.0 & 0.159 & $162 \%$ & $87 \%$ & $95 \%$ \\
\hline $2941-261$ & $\mathrm{PO}$ & 10 & & $3 / 25 / 09$ & $4 / 8 / 09$ & 14 & 6.0 & 0.159 & $90 \%$ & $86 \%$ & $93 \%$ \\
\hline $2941-270$ & $\mathrm{PO}$ & 11 & & $4 / 8 / 09$ & $4 / 22 / 09$ & 14 & 5.0 & 0.159 & $97 \%$ & $91 \%$ & $95 \%$ \\
\hline $2941-277$ & $\mathrm{PO}$ & 12 & & $4 / 22 / 09$ & $5 / 5 / 09$ & 13 & 2.0 & 0.159 & $142 \%$ & $81 \%$ & $97 \%$ \\
\hline $2941-279$ & $\mathrm{PO}$ & 13 & & $5 / 5 / 09$ & $5 / 20 / 09$ & 15 & 11.0 & 0.159 & $132 \%$ & $87 \%$ & $113 \%$ \\
\hline $2941-292$ & $\mathrm{PO}$ & 14 & & $5 / 20 / 09$ & $6 / 5 / 09$ & 16 & 4.0 & 0.159 & $111 \%$ & $86 \%$ & $114 \%$ \\
\hline $2941-300$ & $\mathrm{PO}$ & 15 & & 7/30/09 & $8 / 14 / 09$ & 15 & 2.0 & 0.159 & $125 \%$ & $68 \%$ & $110 \%$ \\
\hline $2941-311$ & $\mathrm{PO}$ & 16 & & $8 / 14 / 09$ & $8 / 26 / 09$ & 12 & 0.0 & 0.159 & $124 \%$ & $77 \%$ & $109 \%$ \\
\hline $2941-321$ & $\mathrm{PO}$ & 17 & & $8 / 26 / 09$ & $9 / 11 / 09$ & 16 & 5.8 & 0.159 & $100 \%$ & $80 \%$ & $113 \%$ \\
\hline $2941-330$ & $\mathrm{PO}$ & 18 & & $9 / 11 / 09$ & $9 / 25 / 09$ & 14 & 1.0 & 0.159 & $116 \%$ & $79 \%$ & $109 \%$ \\
\hline $2941-337$ & $\mathrm{PO}$ & 19 & & $9 / 25 / 09$ & $10 / 14 / 09$ & 19 & 3.0 & 0.159 & $112 \%$ & $71 \%$ & $94 \%$ \\
\hline
\end{tabular}

\footnotetext{
Mean

Stdev

RSD
}

\begin{tabular}{|c|c|c|c|c|c|c|c|c|c|c|c|}
\hline 2941-178 & SB & 1 & & $9 / 2 / 08$ & $9 / 18 / 08$ & 16 & 0.0 & 0.159 & $97 \%$ & $83 \%$ & $95 \%$ \\
\hline 2941-179 & SB & 1 & $\mathrm{x}$ & $9 / 2 / 08$ & 9/18/08 & 16 & 0.0 & 0.159 & $121 \%$ & $84 \%$ & $98 \%$ \\
\hline $2941-186$ & SB & 2 & & $9 / 18 / 08$ & $10 / 2 / 08$ & 14 & 1.5 & 0.159 & $135 \%$ & $91 \%$ & $99 \%$ \\
\hline $2941-187$ & SB & 2 & $\mathrm{x}$ & $9 / 18 / 08$ & $10 / 2 / 08$ & 14 & 1.5 & 0.159 & $110 \%$ & $91 \%$ & $96 \%$ \\
\hline 2941-195 & SB & 3 & & $10 / 2 / 08$ & $10 / 15 / 08$ & 13 & 1.5 & 0.159 & $174 \%$ & $88 \%$ & $99 \%$ \\
\hline $2941-205$ & SB & 4 & & $10 / 15 / 08$ & $10 / 30 / 08$ & 15 & 2.0 & 0.159 & $201 \%$ & $88 \%$ & $99 \%$ \\
\hline $2941-216$ & SB & 5 & & $10 / 30 / 08$ & $11 / 10 / 08$ & 11 & 14.0 & 0.159 & $114 \%$ & $90 \%$ & $95 \%$ \\
\hline $2941-218$ & SB & 6 & & $11 / 10 / 08$ & $11 / 25 / 08$ & 12 & 3.0 & 0.159 & $113 \%$ & $88 \%$ & $96 \%$ \\
\hline $2941-219$ & SB & 7 & & $11 / 25 / 08$ & $12 / 11 / 08$ & 16 & 2.0 & 0.159 & $109 \%$ & $92 \%$ & $94 \%$ \\
\hline $2941-245$ & SB & 8 & & $2 / 25 / 09$ & $3 / 12 / 09$ & 15 & 4.5 & 0.159 & $111 \%$ & $91 \%$ & $92 \%$ \\
\hline $2941-252$ & SB & 9 & & $3 / 12 / 09$ & $3 / 29 / 09$ & 17 & 5.0 & 0.159 & $152 \%$ & $86 \%$ & $91 \%$ \\
\hline $2941-260$ & SB & 10 & & $3 / 29 / 09$ & 4/13/09 & 15 & 5.0 & 0.159 & $119 \%$ & $86 \%$ & $93 \%$ \\
\hline $2941-268$ & SB & 11 & & 4/13/09 & $4 / 28 / 09$ & 15 & 0.5 & 0.159 & $122 \%$ & $83 \%$ & $89 \%$ \\
\hline $2941-278$ & SB & 12 & & 4/28/09 & $5 / 11 / 09$ & 13 & 2.0 & 0.159 & $115 \%$ & $86 \%$ & $95 \%$ \\
\hline $2941-281$ & SB & 13 & & $5 / 11 / 09$ & $5 / 27 / 09$ & 16 & 5.5 & 0.159 & $84 \%$ & $86 \%$ & $111 \%$ \\
\hline $2941-286$ & SB & 14 & & $5 / 27 / 09$ & $6 / 8 / 09$ & 12 & 0.0 & 0.159 & $101 \%$ & $91 \%$ & $111 \%$ \\
\hline 2941-303 & SB & 15 & & $8 / 3 / 09$ & $8 / 18 / 09$ & 15 & 1.8 & 0.159 & $152 \%$ & $72 \%$ & $112 \%$ \\
\hline $2941-313$ & SB & 16 & & $8 / 15 / 09$ & $8 / 29 / 09$ & 11 & 0.0 & 0.159 & $100 \%$ & $73 \%$ & $110 \%$ \\
\hline $2941-320$ & SB & 17 & & $8 / 29 / 09$ & $9 / 11 / 09$ & 13 & 1.3 & 0.159 & $108 \%$ & $79 \%$ & $114 \%$ \\
\hline $2941-329$ & SB & 18 & & $9 / 11 / 09$ & $9 / 25 / 09$ & 14 & 1.0 & 0.159 & $116 \%$ & $75 \%$ & $110 \%$ \\
\hline $2941-336$ & SB & 19 & & $9 / 25 / 09$ & $10 / 13 / 09$ & 18 & 1.9 & 0.159 & $114 \%$ & $68 \%$ & $95 \%$ \\
\hline \multicolumn{12}{|l|}{$\begin{array}{r}\text { Mean } \\
\text { Stdev } \\
\text { RSD }\end{array}$} \\
\hline $2941-174$ & TCB & 1 & & $8 / 29 / 08$ & $9 / 12 / 08$ & 14 & 0.0 & 0.159 & $114 \%$ & $96 \%$ & $99 \%$ \\
\hline $2941-181$ & TCB & 2 & & $9 / 12 / 08$ & $9 / 24 / 08$ & 12 & 1.5 & 0.159 & $129 \%$ & $94 \%$ & $99 \%$ \\
\hline $2941-188$ & TCB & 3 & & $9 / 24 / 08$ & $10 / 15 / 08$ & 21 & 6.0 & 0.159 & $100 \%$ & $105 \%$ & $98 \%$ \\
\hline $2941-203$ & TCB & 4 & & $10 / 15 / 08$ & $10 / 30 / 08$ & 15 & 2.0 & 0.159 & $107 \%$ & $99 \%$ & $98 \%$ \\
\hline $2941-212$ & TCB & 5 & & $10 / 30 / 08$ & $11 / 12 / 08$ & 13 & 20.0 & 0.159 & $86 \%$ & $102 \%$ & $96 \%$ \\
\hline $2941-229$ & TCB & 7 & & $11 / 12 / 08$ & $11 / 24 / 08$ & 17 & 1.5 & 0.159 & $105 \%$ & $94 \%$ & $95 \%$ \\
\hline $2941-240$ & TCB & 8 & & $11 / 24 / 08$ & $12 / 11 / 08$ & 15 & 5.5 & 0.159 & $83 \%$ & $100 \%$ & $97 \%$ \\
\hline $2941-245 b$ & TCB & 9 & & $2 / 25 / 09$ & $3 / 12 / 09$ & 13 & 8.0 & 0.159 & $120 \%$ & $92 \%$ & $95 \%$ \\
\hline $2941-247$ & TCB & 9 & $\mathrm{x}$ & $2 / 25 / 09$ & $3 / 12 / 09$ & 13 & 10.0 & 0.159 & $112 \%$ & $92 \%$ & $94 \%$ \\
\hline $2941-256$ & TCB & 10 & & $3 / 12 / 09$ & $3 / 25 / 09$ & 14 & 6.5 & 0.159 & $153 \%$ & $91 \%$ & $94 \%$ \\
\hline $2941-267$ & TCB & 11 & & $4 / 8 / 09$ & $4 / 22 / 09$ & 14 & 5.0 & 0.159 & $74 \%$ & $103 \%$ & $98 \%$ \\
\hline $2941-274$ & TCB & 12 & & $4 / 22 / 09$ & $5 / 7 / 09$ & 15 & 3.0 & 0.159 & $121 \%$ & $81 \%$ & $84 \%$ \\
\hline $2941-282$ & TCB & 13 & & $5 / 7 / 09$ & $5 / 21 / 09$ & 14 & 10.0 & 0.159 & $105 \%$ & $95 \%$ & $111 \%$ \\
\hline $2941-288$ & TCB & 14 & & $5 / 21 / 09$ & $6 / 4 / 09$ & 14 & 0.0 & 0.159 & $193 \%$ & $93 \%$ & $118 \%$ \\
\hline 2941-301 & TCB & 15 & & 7/30/09 & $8 / 12 / 09$ & 13 & 1.5 & 0.159 & $110 \%$ & $76 \%$ & $112 \%$ \\
\hline 2941-309 & TCB & 16 & & $8 / 12 / 09$ & $8 / 27 / 09$ & 15 & 1.0 & 0.159 & $123 \%$ & $78 \%$ & $111 \%$ \\
\hline $2941-316$ & TCB & 17 & & $8 / 27 / 09$ & 9/8/09 & 12 & 9.5 & 0.159 & $100 \%$ & $85 \%$ & $113 \%$ \\
\hline $2941-326$ & TCB & 18 & & $9 / 8 / 09$ & $9 / 24 / 09$ & 16 & 1.0 & 0.159 & $76 \%$ & $83 \%$ & $111 \%$ \\
\hline $2941-333$ & TCB & 19 & & $9 / 24 / 09$ & 10/7/09 & 13 & 1.8 & 0.159 & $99 \%$ & $74 \%$ & $96 \%$ \\
\hline
\end{tabular}

Mean 
Field Sample Results - PBDEs

\begin{tabular}{|c|c|c|c|c|c|c|c|c|c|c|c|}
\hline $\begin{array}{l}\text { Sample } \\
\text { ID }\end{array}$ & $\begin{array}{c}\text { Station } \\
\text { ID }\end{array}$ & $\begin{array}{c}\text { Event } \\
\text { No. }\end{array}$ & $\begin{array}{l}\text { Field } \\
\text { Dup }\end{array}$ & $\begin{array}{c}\text { Date } \\
\text { Deployed }\end{array}$ & $\begin{array}{c}\text { Date } \\
\text { Recovered }\end{array}$ & $\begin{array}{c}\text { Days } \\
\text { Deployed }\end{array}$ & $\begin{array}{l}\text { Org. } \\
\text { Vol. } \\
\text { (L) }\end{array}$ & $\begin{array}{r}\text { Funnel } \\
\text { Surface } \\
\text { Area }\left(\mathrm{m}^{2}\right)\end{array}$ & HBB & $\begin{array}{r}\text { PCB } \\
103\end{array}$ & $\begin{array}{r}\text { PCB } \\
198\end{array}$ \\
\hline & & & & & & & & Unit & Percent & Percent & Percent \\
\hline \multicolumn{12}{|l|}{$\begin{array}{c}\text { Stdev } \\
\text { RSD }\end{array}$} \\
\hline $2941-172$ & WP & 1 & & $8 / 28 / 08$ & $9 / 12 / 08$ & 15 & 0.0 & 0.159 & $103 \%$ & $88 \%$ & $103 \%$ \\
\hline $2941-183$ & WP & 2 & & $9 / 12 / 08$ & $9 / 25 / 08$ & 13 & 2.0 & 0.159 & $114 \%$ & $92 \%$ & $97 \%$ \\
\hline $2941-190$ & WP & 3 & & $9 / 25 / 08$ & $10 / 14 / 08$ & 19 & 5.0 & 0.159 & $116 \%$ & $93 \%$ & $92 \%$ \\
\hline $2941-201$ & WP & 4 & & $10 / 14 / 08$ & $10 / 29 / 08$ & 15 & 1.5 & 0.159 & $138 \%$ & $89 \%$ & $98 \%$ \\
\hline $2941-200$ & WP & 5 & & $10 / 29 / 08$ & $11 / 13 / 08$ & 15 & 18.0 & 0.159 & $130 \%$ & $96 \%$ & $99 \%$ \\
\hline $2941-225$ & WP & 6 & & $11 / 13 / 08$ & $11 / 25 / 08$ & 12 & 1.0 & 0.159 & $190 \%$ & $88 \%$ & $98 \%$ \\
\hline $2941-230$ & WP & 7 & & $11 / 25 / 08$ & $12 / 11 / 08$ & 16 & 1.5 & 0.159 & $103 \%$ & $98 \%$ & $94 \%$ \\
\hline $2941-244$ & WP & 8 & & $2 / 26 / 09$ & $3 / 11 / 09$ & 13 & 4.5 & 0.159 & $103 \%$ & $93 \%$ & $94 \%$ \\
\hline $2941-246$ & WP & 9 & & $3 / 11 / 09$ & $3 / 25 / 09$ & 14 & 6.0 & 0.159 & $125 \%$ & $86 \%$ & $92 \%$ \\
\hline $2941-258$ & WP & 10 & & $3 / 25 / 09$ & $4 / 8 / 09$ & 14 & 6.5 & 0.159 & $118 \%$ & $85 \%$ & $93 \%$ \\
\hline $2941-264$ & WP & 11 & & 4/8/09 & $4 / 23 / 09$ & 15 & 4.0 & 0.159 & $24 \%$ & $100 \%$ & $96 \%$ \\
\hline $2941-272$ & WP & 12 & & $4 / 23 / 09$ & $5 / 6 / 09$ & 13 & 2.0 & 0.159 & $118 \%$ & $90 \%$ & $94 \%$ \\
\hline $2941-284$ & WP & 13 & & $5 / 6 / 09$ & $5 / 21 / 09$ & 15 & 11.0 & 0.159 & $116 \%$ & $84 \%$ & $111 \%$ \\
\hline $2941-289$ & WP & 14 & & $5 / 21 / 09$ & $6 / 3 / 09$ & 13 & 2.0 & 0.159 & $121 \%$ & $89 \%$ & $111 \%$ \\
\hline 2941-302 & WP & 15 & & 7/29/09 & $8 / 12 / 09$ & 14 & 1.5 & 0.159 & $115 \%$ & $72 \%$ & $111 \%$ \\
\hline $2941-308$ & WP & 16 & & $8 / 12 / 09$ & $8 / 26 / 09$ & 14 & 1.5 & 0.159 & $45 \%$ & $89 \%$ & $117 \%$ \\
\hline $2941-315$ & WP & 17 & & $8 / 26 / 09$ & 9/9/09 & 14 & 4.5 & 0.159 & $100 \%$ & $80 \%$ & $111 \%$ \\
\hline $2941-327$ & WP & 18 & & 9/9/09 & $9 / 24 / 09$ & 15 & 2.0 & 0.159 & $102 \%$ & $73 \%$ & $110 \%$ \\
\hline $2941-332$ & WP & 19 & & $9 / 24 / 09$ & $10 / 7 / 09$ & 13 & 3.8 & 0.159 & $108 \%$ & $69 \%$ & $94 \%$ \\
\hline
\end{tabular}

Mean

Stdev

RSD

\begin{tabular}{|c|c|c|c|c|c|c|c|c|c|c|c|}
\hline $2941-293$ & $\mathrm{TM}$ & 14 & & $5 / 20 / 2009$ & $6 / 4 / 2009$ & 15 & & 0.159 & $102 \%$ & $88 \%$ & $112 \%$ \\
\hline 2941-304 & $\mathrm{TM}$ & 15 & & $7 / 30 / 2009$ & $8 / 12 / 2009$ & 13 & & 0.159 & $111 \%$ & $71 \%$ & $111 \%$ \\
\hline $2941-312$ & $\mathrm{TM}$ & 16 & & $8 / 12 / 2009$ & $8 / 27 / 2009$ & 15 & & 0.159 & $140 \%$ & $71 \%$ & $111 \%$ \\
\hline $2941-318$ & $\mathrm{TM}$ & 17 & & $8 / 27 / 2009$ & 9/8/2009 & 12 & & 0.159 & $101 \%$ & $79 \%$ & $114 \%$ \\
\hline $2941-325$ & $\mathrm{TM}$ & 18 & & 9/8/2009 & $9 / 24 / 2009$ & 16 & & 0.159 & $104 \%$ & $80 \%$ & $111 \%$ \\
\hline $2941-333$ & $\mathrm{TM}$ & 19 & & $9 / 24 / 2009$ & $10 / 7 / 2009$ & 13 & & 0.159 & $99 \%$ & $71 \%$ & $95 \%$ \\
\hline $\begin{array}{c}\text { Mean } \\
\text { Stdev } \\
\text { RSD }\end{array}$ & & & & & & & & & & & \\
\hline \multicolumn{12}{|c|}{ FIELD DUPLICATES } \\
\hline $2941-210$ & $\mathrm{HC}$ & 7 & & $11 / 20 / 08$ & $12 / 11 / 08$ & 21 & 4 & 0.159 & $105 \%$ & $93 \%$ & $93 \%$ \\
\hline $\begin{array}{r}2941-234 \\
\text { RPD }\end{array}$ & $\mathrm{HC}$ & 7 & $\mathrm{x}$ & $11 / 20 / 08$ & $12 / 11 / 08$ & 21 & 4 & 0.159 & $100 \%$ & $96 \%$ & $94 \%$ \\
\hline $\begin{array}{r}2941-265 \\
2941-266 \\
\text { RPD }\end{array}$ & $\begin{array}{l}\text { NR } \\
\text { NR }\end{array}$ & $\begin{array}{l}11 \\
11\end{array}$ & $\mathrm{x}$ & $\begin{array}{l}4 / 8 / 09 \\
4 / 8 / 09\end{array}$ & $\begin{array}{l}4 / 22 / 09 \\
4 / 22 / 09\end{array}$ & $\begin{array}{l}14 \\
14\end{array}$ & $\begin{array}{l}4 \\
4\end{array}$ & $\begin{array}{l}0.159 \\
0.159\end{array}$ & $\begin{array}{r}103 \% \\
97 \%\end{array}$ & $\begin{array}{l}97 \% \\
98 \%\end{array}$ & $\begin{array}{l}99 \% \\
97 \%\end{array}$ \\
\hline $\begin{array}{r}2941-193 \\
2941-199 \\
\text { RPD }\end{array}$ & $\begin{array}{l}\text { PO } \\
\text { PO }\end{array}$ & $\begin{array}{l}3 \\
3\end{array}$ & $\mathrm{x}$ & $\begin{array}{l}10 / 6 / 08 \\
10 / 6 / 08\end{array}$ & $\begin{array}{l}10 / 16 / 08 \\
10 / 16 / 08\end{array}$ & $\begin{array}{l}10 \\
10\end{array}$ & $\begin{array}{l}1.5 \\
1.5\end{array}$ & $\begin{array}{l}0.159 \\
0.159\end{array}$ & $\begin{array}{l}145 \% \\
144 \%\end{array}$ & $\begin{array}{l}90 \% \\
89 \%\end{array}$ & $\begin{array}{r}100 \% \\
99 \%\end{array}$ \\
\hline $\begin{array}{r}2941-206 \\
2941-207 \\
\text { RPD }\end{array}$ & $\begin{array}{l}\text { PO } \\
\text { PO }\end{array}$ & $\begin{array}{l}4 \\
4\end{array}$ & $\mathrm{x}$ & $\begin{array}{l}10 / 16 / 08 \\
10 / 16 / 08\end{array}$ & $\begin{array}{l}10 / 29 / 08 \\
10 / 29 / 08\end{array}$ & $\begin{array}{l}13 \\
13\end{array}$ & $\begin{array}{l}1 \\
1\end{array}$ & $\begin{array}{l}0.159 \\
0.159\end{array}$ & $\begin{array}{r}159 \% \\
99 \%\end{array}$ & $\begin{array}{l}90 \% \\
86 \%\end{array}$ & $\begin{array}{r}100 \% \\
96 \%\end{array}$ \\
\hline $\begin{array}{r}2941-178 \\
2941-179 \\
\text { RPD }\end{array}$ & $\begin{array}{l}\text { SB } \\
\text { SB }\end{array}$ & $\begin{array}{l}1 \\
1\end{array}$ & $\mathrm{x}$ & $\begin{array}{l}9 / 2 / 08 \\
9 / 2 / 08\end{array}$ & $\begin{array}{l}9 / 18 / 08 \\
9 / 18 / 08\end{array}$ & $\begin{array}{l}16 \\
16\end{array}$ & $\begin{array}{l}<20 \mathrm{~mL} \\
<20 \mathrm{~mL}\end{array}$ & $\begin{array}{l}0.159 \\
0.159\end{array}$ & $\begin{array}{r}97 \% \\
121 \%\end{array}$ & $\begin{array}{l}83 \% \\
84 \%\end{array}$ & $\begin{array}{l}95 \% \\
98 \%\end{array}$ \\
\hline $\begin{array}{r}2941-186 \\
2941-187 \\
\text { RPD }\end{array}$ & $\begin{array}{l}\text { SB } \\
\text { SB }\end{array}$ & $\begin{array}{l}2 \\
2\end{array}$ & $\mathrm{x}$ & $\begin{array}{l}9 / 18 / 08 \\
9 / 18 / 08\end{array}$ & $\begin{array}{l}10 / 2 / 08 \\
10 / 2 / 08\end{array}$ & $\begin{array}{l}14 \\
14\end{array}$ & $\begin{array}{l}1.5 \\
1.5\end{array}$ & $\begin{array}{l}0.159 \\
0.159\end{array}$ & $\begin{array}{l}135 \% \\
110 \%\end{array}$ & $\begin{array}{l}91 \% \\
91 \%\end{array}$ & $\begin{array}{l}99 \% \\
96 \%\end{array}$ \\
\hline $2941-245 b$ & TCB & 9 & & $2 / 25 / 09$ & $3 / 12 / 09$ & 13 & 8 & 0.159 & $120 \%$ & $92 \%$ & $95 \%$ \\
\hline $2941-247$ & TCB & 9 & $\mathrm{x}$ & 2/25/09 & $3 / 12 / 09$ & 13 & 8 & 0.159 & $112 \%$ & $92 \%$ & $94 \%$ \\
\hline
\end{tabular}

RPD

U Not detected at or below DL shown

RPD Relative Percent Difference 
Quality Control Results - PBDEs

\begin{tabular}{|c|c|c|c|c|c|c|c|c|c|c|c|c|}
\hline $\begin{array}{c}\text { Extraction } \\
\text { Date }\end{array}$ & Sample ID & $\begin{array}{c}\text { Analytical } \\
\text { Batch ID }\end{array}$ & $\begin{array}{r}\text { BDE- } \\
17\end{array}$ & $\begin{array}{r}\text { BDE- } \\
28\end{array}$ & $\begin{array}{r}\text { BDE- } \\
47\end{array}$ & $\begin{array}{r}\text { BDE- } \\
66\end{array}$ & $\begin{array}{r}\text { BDE- } \\
71\end{array}$ & $\begin{array}{r}\text { BDE- } \\
85\end{array}$ & $\begin{array}{r}\text { BDE- } \\
99\end{array}$ & $\begin{array}{r}\text { BDE- } \\
100\end{array}$ & $\begin{array}{r}\text { BDE- } \\
138\end{array}$ & $\begin{array}{r}\text { BDE- } \\
153\end{array}$ \\
\hline \multicolumn{3}{|c|}{ Reporting Limit } & $0.5 \mathrm{ng} / \mathrm{L}$ & $0.5 \mathrm{ng} / \mathrm{L}$ & $0.5 \mathrm{ng} / \mathrm{L}$ & $0.5 \mathrm{ng} / \mathrm{L}$ & $0.5 \mathrm{ng} / \mathrm{L}$ & $0.5 \mathrm{ng} / \mathrm{L}$ & $0.5 \mathrm{ng} / \mathrm{L}$ & $0.5 \mathrm{ng} / \mathrm{L}$ & $0.5 \mathrm{ng} / \mathrm{L}$ & $0.5 \mathrm{ng} / \mathrm{L}$ \\
\hline \multicolumn{13}{|c|}{ Procedural Blanks (ng/L) } \\
\hline $1 / 26 / 2009$ & WA BLK0126 & 29411 & $0.500 \mathrm{U}$ & $0.500 \mathrm{U}$ & $0.500 \mathrm{U}$ & $0.500 \mathrm{U}$ & $0.500 \mathrm{U}$ & $0.500 \mathrm{U}$ & $0.500 \mathrm{U}$ & $0.500 \mathrm{U}$ & $0.500 \mathrm{U}$ & $0.500 \mathrm{U}$ \\
\hline $2 / 4 / 2009$ & WA_BLK0204 & 29411 & $0.500 \mathrm{U}$ & $0.500 \mathrm{U}$ & $0.500 \mathrm{U}$ & $0.500 \mathrm{U}$ & $0.500 \mathrm{U}$ & $0.500 \mathrm{U}$ & $0.500 \mathrm{U}$ & $0.500 \mathrm{U}$ & $0.500 \mathrm{U}$ & $0.500 \mathrm{U}$ \\
\hline $2 / 9 / 2009$ & WA_BLK0209 & 29411 & $0.500 \mathrm{U}$ & $0.500 \mathrm{U}$ & $0.500 \mathrm{U}$ & $0.500 \mathrm{U}$ & $0.500 \mathrm{U}$ & $0.500 \mathrm{U}$ & $0.500 \mathrm{U}$ & $0.500 \mathrm{U}$ & $0.500 \mathrm{U}$ & $0.500 \mathrm{U}$ \\
\hline $2 / 12 / 2009$ & WA_BLK0212 & 29411 & $0.500 \mathrm{U}$ & $0.500 \mathrm{U}$ & $0.500 \mathrm{U}$ & $0.500 \mathrm{U}$ & $0.500 \mathrm{U}$ & $0.500 \mathrm{U}$ & $0.500 \mathrm{U}$ & $0.500 \mathrm{U}$ & $0.500 \mathrm{U}$ & $0.500 \mathrm{U}$ \\
\hline $2 / 19 / 2009$ & WA_BLK0219 & 29412 & $0.500 \mathrm{U}$ & $0.500 \mathrm{U}$ & $0.500 \mathrm{U}$ & $0.500 \mathrm{U}$ & $0.500 \mathrm{U}$ & $0.500 \mathrm{U}$ & $0.500 \mathrm{U}$ & $0.500 \mathrm{U}$ & $0.500 \mathrm{U}$ & $0.500 \mathrm{U}$ \\
\hline $5 / 16 / 2009$ & WA BLK0516 & 29413 & $0.500 \mathrm{U}$ & $0.500 \mathrm{U}$ & $0.500 \mathrm{U}$ & $0.500 \mathrm{U}$ & $0.500 \mathrm{U}$ & $0.500 \mathrm{U}$ & $0.500 \mathrm{U}$ & $0.500 \mathrm{U}$ & $0.750 \mathrm{U}$ & $0.500 \mathrm{U}$ \\
\hline $5 / 23 / 2009$ & WA_BLK0523 & 29413 & $0.500 \mathrm{U}$ & $0.500 \mathrm{U}$ & $0.500 \mathrm{U}$ & $0.500 \mathrm{U}$ & $0.500 \mathrm{U}$ & $0.500 \mathrm{U}$ & $0.500 \mathrm{U}$ & $0.500 \mathrm{U}$ & $0.750 \mathrm{U}$ & $0.500 \mathrm{U}$ \\
\hline $5 / 31 / 2009$ & WA_BLK0531 & 29414 & $0.500 \mathrm{U}$ & $0.500 \mathrm{U}$ & $0.500 \mathrm{U}$ & $0.500 \mathrm{U}$ & $0.500 \mathrm{U}$ & $0.500 \mathrm{U}$ & $0.500 \mathrm{U}$ & $0.500 \mathrm{U}$ & $0.750 \mathrm{U}$ & $0.500 \mathrm{U}$ \\
\hline $6 / 3 / 2009$ & WA_BLK0603 & 29414 & $0.500 \mathrm{U}$ & $0.500 \mathrm{U}$ & $0.500 \mathrm{U}$ & $0.500 \mathrm{U}$ & $0.500 \mathrm{U}$ & $0.500 \mathrm{U}$ & $0.500 \mathrm{U}$ & $0.500 \mathrm{U}$ & $0.750 \mathrm{U}$ & $0.500 \mathrm{U}$ \\
\hline $6 / 26 / 2009$ & WA_BLK0626 & 29415 & $0.500 \mathrm{U}$ & $0.500 \mathrm{U}$ & $0.500 \mathrm{U}$ & $0.500 \mathrm{U}$ & $0.500 \mathrm{U}$ & $0.500 \mathrm{U}$ & $0.500 \mathrm{U}$ & $0.500 \mathrm{U}$ & $0.750 \mathrm{U}$ & $0.500 \mathrm{U}$ \\
\hline $7 / 3 / 2009$ & WA_BLK0703 & 29415 & $0.500 \mathrm{U}$ & $0.500 \mathrm{U}$ & $0.500 \mathrm{U}$ & $0.500 \mathrm{U}$ & $0.500 \mathrm{U}$ & $0.500 \mathrm{U}$ & $0.500 \mathrm{U}$ & $0.500 \mathrm{U}$ & $0.750 \mathrm{U}$ & $0.500 \mathrm{U}$ \\
\hline $9 / 16 / 2009$ & WA_BLK0916 & BDE_120709 & $0.500 \mathrm{U}$ & $0.500 \mathrm{U}$ & $0.500 \mathrm{U}$ & $0.500 \mathrm{U}$ & $0.500 \mathrm{U}$ & $0.500 \mathrm{U}$ & $0.500 \mathrm{U}$ & $0.500 \mathrm{U}$ & $0.750 \mathrm{U}$ & $0.500 \mathrm{U}$ \\
\hline $9 / 22 / 2009$ & WA_BLK0922 & BDE_120709 & $0.500 \mathrm{U}$ & $0.500 \mathrm{U}$ & $0.500 \mathrm{U}$ & $0.500 \mathrm{U}$ & $0.500 \mathrm{U}$ & $0.500 \mathrm{U}$ & 0.975 & $0.500 \mathrm{U}$ & $0.750 \mathrm{U}$ & $0.500 \mathrm{U}$ \\
\hline $10 / 12 / 2009$ & WA_BLK1012 & BDE_120709 & $0.500 \mathrm{U}$ & $0.500 \mathrm{U}$ & $0.500 \mathrm{U}$ & $0.500 \mathrm{U}$ & $0.500 \mathrm{U}$ & $0.500 \mathrm{U}$ & $0.500 \mathrm{U}$ & $0.500 \mathrm{U}$ & $0.750 \mathrm{U}$ & $0.500 \mathrm{U}$ \\
\hline 10/27/2009 & WA_BLK1027 & BDE_121109 & $0.500 \mathrm{U}$ & $0.500 \mathrm{U}$ & $0.500 \mathrm{U}$ & $0.500 \mathrm{U}$ & $0.500 \mathrm{U}$ & $0.500 \mathrm{U}$ & $0.500 \mathrm{U}$ & $0.500 \mathrm{U}$ & $0.750 \mathrm{U}$ & $0.500 \mathrm{U}$ \\
\hline $11 / 3 / 2009$ & WA_BLK1103 & BDE_121109 & $0.500 \mathrm{U}$ & $0.500 \mathrm{U}$ & $0.500 \mathrm{U}$ & $0.500 \mathrm{U}$ & $0.500 \mathrm{U}$ & $0.500 \mathrm{U}$ & $0.500 \mathrm{U}$ & $0.500 \mathrm{U}$ & $0.750 \mathrm{U}$ & $0.500 \mathrm{U}$ \\
\hline
\end{tabular}

SRM Results (ng/g)

\begin{tabular}{|c|c|c|c|c|c|c|c|c|c|c|c|c|}
\hline $1 / 26 / 2009$ & WA_UD0126 & 29411 & $9.43 \mathrm{U}$ & 59.2 & 68.2 & $9.43 \mathrm{U}$ & $9.43 \mathrm{U}$ & $9.43 \mathrm{U}$ & $9.43 \mathrm{U}$ & $9.43 \mathrm{U}$ & $9.43 \mathrm{U}$ & $9.43 \mathrm{U}$ \\
\hline $2 / 4 / 2009$ & WA_UD0204 & 29411 & $9.38 \mathrm{U}$ & 82.2 & 99.6 & $9.38 \mathrm{U}$ & $9.38 \mathrm{U}$ & $9.40 \mathrm{U}$ & $9.38 \mathrm{U}$ & $9.38 \mathrm{U}$ & $9.38 \mathrm{U}$ & $9.38 \mathrm{U}$ \\
\hline 2/9/2009 & WA_UD0209 & 29411 & $9.19 \mathrm{U}$ & 65.0 & 69.4 & $9.19 \mathrm{U}$ & $9.19 \mathrm{U}$ & $9.19 \mathrm{U}$ & $9.19 \mathrm{U}$ & $9.19 \mathrm{U}$ & $9.19 \mathrm{U}$ & $9.19 \mathrm{U}$ \\
\hline $2 / 12 / 2009$ & WA_UD0212 & 29412 & $8.55 \mathrm{U}$ & 76.7 & 88.5 & $8.55 \mathrm{U}$ & $8.55 \mathrm{U}$ & $8.55 \mathrm{U}$ & $8.55 \mathrm{U}$ & $8.55 \mathrm{U}$ & $8.55 \mathrm{U}$ & $8.55 \mathrm{U}$ \\
\hline $2 / 19 / 2009$ & WA_UD0219 & 29412 & $8.46 \mathrm{U}$ & 63.4 & 71.8 & $8.46 \mathrm{U}$ & $8.46 \mathrm{U}$ & $8.46 \mathrm{U}$ & $8.46 \mathrm{U}$ & $8.46 \mathrm{U}$ & $8.46 \mathrm{U}$ & $8.46 \mathrm{U}$ \\
\hline $4 / 8 / 2009$ & WA_UD0408 & 29413 & $9.21 \mathrm{U}$ & 65.4 & 88.0 & 30.8 & $9.21 \mathrm{U}$ & $9.21 \mathrm{U}$ & $9.21 \mathrm{U}$ & $9.21 \mathrm{U}$ & $13.8 \mathrm{U}$ & $9.21 \mathrm{U}$ \\
\hline $4 / 15 / 2009$ & WA_UD0415 & 29413 & $9.04 \mathrm{U}$ & 69.1 & 79.9 & 19.4 & $9.04 \mathrm{U}$ & $9.04 \mathrm{U}$ & $9.04 \mathrm{U}$ & $9.04 \mathrm{U}$ & $13.6 \mathrm{U}$ & $9.04 \mathrm{U}$ \\
\hline $4 / 15 / 2009$ & WA_UD0415b & 29413 & $9.63 \mathrm{U}$ & 67.0 & 99.6 & 14.8 & $9.63 \mathrm{U}$ & $9.63 \mathrm{U}$ & $9.63 \mathrm{U}$ & $9.63 \mathrm{U}$ & $14.5 \mathrm{U}$ & $9.63 \mathrm{U}$ \\
\hline $5 / 16 / 2009$ & WA_UD0516 & 29413 & $9.04 \mathrm{U}$ & 82.9 & 98.2 & $9.04 \mathrm{U}$ & $9.04 \mathrm{U}$ & 10.2 & $9.04 \mathrm{U}$ & $9.04 \mathrm{U}$ & $13.6 \mathrm{U}$ & $9.04 \mathrm{U}$ \\
\hline $5 / 23 / 2009$ & WA_UD0523 & 29413 & $8.98 \mathrm{U}$ & 72.4 & 98.2 & $8.98 \mathrm{U}$ & $8.98 \mathrm{U}$ & $8.98 \mathrm{U}$ & $8.98 \mathrm{U}$ & $8.98 \mathrm{U}$ & $13.5 \mathrm{U}$ & $8.98 \mathrm{U}$ \\
\hline $5 / 31 / 2009$ & WA_UD0531 & 29414 & $8.90 \mathrm{U}$ & 71.8 & 88.8 & $8.90 \mathrm{U}$ & $8.90 \mathrm{U}$ & $8.90 \mathrm{U}$ & $8.90 \mathrm{U}$ & $8.90 \mathrm{U}$ & $13.3 \mathrm{U}$ & $8.90 \mathrm{U}$ \\
\hline $6 / 3 / 2009$ & WA_UD0603 & 29414 & $9.12 \mathrm{U}$ & 89.3 & 110 & $9.12 \mathrm{U}$ & $9.12 \mathrm{U}$ & 11.3 & $9.12 \mathrm{U}$ & $9.12 \mathrm{U}$ & $13.7 \mathrm{U}$ & $9.12 \mathrm{U}$ \\
\hline $6 / 26 / 2009$ & WA_UD0626 & 29415 & $9.63 \mathrm{U}$ & 80.8 & 108 & 36.4 & $9.63 \mathrm{U}$ & $9.63 \mathrm{U}$ & $9.63 \mathrm{U}$ & $9.63 \mathrm{U}$ & $14.5 \mathrm{U}$ & $9.63 \mathrm{U}$ \\
\hline $7 / 3 / 2009$ & WA_UD0703 & 29415 & $9.71 \mathrm{U}$ & 76.7 & 85.2 & 9.71 & $9.71 \mathrm{U}$ & $9.71 \mathrm{U}$ & $9.71 \mathrm{U}$ & $9.71 \mathrm{U}$ & $14.6 \mathrm{U}$ & $9.71 \mathrm{U}$ \\
\hline $9 / 16 / 2009$ & WA_UD0916 & BDE_120709 & $9.77 \mathrm{U}$ & 75.7 & 98.5 & 20.3 & $9.77 \mathrm{U}$ & $9.77 \mathrm{U}$ & 12.8 & $9.77 \mathrm{U}$ & $14.6 \mathrm{U}$ & $9.77 \mathrm{U}$ \\
\hline $9 / 22 / 2009$ & WA_UD0922 & BDE_120709 & $9.54 \mathrm{U}$ & 45.9 & 64.1 & 12.9 & $9.54 \mathrm{U}$ & $9.54 \mathrm{U}$ & $9.54 \mathrm{U}$ & $9.54 \mathrm{U}$ & $14.3 \mathrm{U}$ & $9.54 \mathrm{U}$ \\
\hline $10 / 12 / 2009$ & WA_UD1012 & BDE_120709 & $9.45 \mathrm{U}$ & 77.9 & 98.0 & 20.1 & $9.45 \mathrm{U}$ & $9.45 \mathrm{U}$ & $9.45 \mathrm{U}$ & $9.45 \mathrm{U}$ & $14.2 \mathrm{U}$ & $9.45 \mathrm{U}$ \\
\hline $10 / 27 / 2009$ & WA_UD1027 & BDE_121109 & $9.67 \mathrm{U}$ & 76.0 & 101 & 31.3 & $9.67 \mathrm{U}$ & $9.67 \mathrm{U}$ & $9.67 \mathrm{U}$ & $9.67 \mathrm{U}$ & $14.5 \mathrm{U}$ & $9.67 \mathrm{U}$ \\
\hline \multirow[t]{4}{*}{$11 / 3 / 2009$} & WA_UD1103 & BDE_121109 & $9.23 \mathrm{U}$ & 87.2 & 108 & 29.7 & $9.23 \mathrm{U}$ & $9.23 \mathrm{U}$ & $9.23 \mathrm{U}$ & $9.23 \mathrm{U}$ & $13.8 \mathrm{U}$ & $9.23 \mathrm{U}$ \\
\hline & MEAN & & $9.26 \mathrm{U}$ & 72.9 & 90.7 & 16.1 & $9.26 \mathrm{U}$ & 9.44 & $9.42 \mathrm{U}$ & $9.26 \mathrm{U}$ & $12.7 \mathrm{U}$ & $9.26 \mathrm{U}$ \\
\hline & STDEV & & -- & 10.45 & 14.2 & 9.41 & -- & 0.629 & -- & -- & -- & -- \\
\hline & RSD & & -- & $14 \%$ & $16 \%$ & $58 \%$ & -- & $7 \%$ & -- & -- & -- & -- \\
\hline \multicolumn{13}{|c|}{ Field GFF+SPE Blank (QC) (ng/filter) } \\
\hline $4 / 8 / 2009$ & WA232 & 29413 & $0.500 \mathrm{U}$ & 1.46 & 3.44 & $0.500 \mathrm{U}$ & $0.500 \mathrm{U}$ & $0.500 \mathrm{U}$ & 2.63 & 0.814 & $0.750 \mathrm{U}$ & $0.500 \mathrm{U}$ \\
\hline $4 / 15 / 2009$ & WA235 & 29413 & $0.500 \mathrm{U}$ & 1.09 & 3.45 & $0.500 \mathrm{U}$ & $0.500 \mathrm{U}$ & $0.500 \mathrm{U}$ & 2.37 & 0.671 & $0.750 \mathrm{U}$ & $0.500 \mathrm{U}$ \\
\hline $4 / 15 / 2009$ & WA239 & 29413 & $0.500 \mathrm{U}$ & $0.500 \mathrm{U}$ & $0.500 \mathrm{U}$ & $0.500 \mathrm{U}$ & $0.500 \mathrm{U}$ & $0.500 \mathrm{U}$ & $0.500 \mathrm{U}$ & $0.500 \mathrm{U}$ & $0.750 \mathrm{U}$ & $0.500 \mathrm{U}$ \\
\hline $6 / 3 / 2009$ & WA295 & 29414 & $0.500 \mathrm{U}$ & $0.500 \mathrm{U}$ & 0.737 & $0.500 \mathrm{U}$ & $0.500 \mathrm{U}$ & $0.500 \mathrm{U}$ & $0.500 \mathrm{U}$ & $0.500 \mathrm{U}$ & $0.750 \mathrm{U}$ & $0.500 \mathrm{U}$ \\
\hline $6 / 3 / 2009$ & WA296 & 29414 & $0.500 \mathrm{U}$ & $0.500 \mathrm{U}$ & $0.500 \mathrm{U}$ & $0.500 \mathrm{U}$ & $0.500 \mathrm{U}$ & $0.500 \mathrm{U}$ & 0.616 & $0.500 \mathrm{U}$ & $0.750 \mathrm{U}$ & $0.500 \mathrm{U}$ \\
\hline $5 / 31 / 2009$ & WA297 & 29414 & $0.500 \mathrm{U}$ & $0.500 \mathrm{U}$ & $0.500 \mathrm{U}$ & $0.500 \mathrm{U}$ & $0.500 \mathrm{U}$ & $0.500 \mathrm{U}$ & $0.500 \mathrm{U}$ & $0.500 \mathrm{U}$ & $0.750 \mathrm{U}$ & $0.500 \mathrm{U}$ \\
\hline \multirow[t]{2}{*}{$5 / 31 / 2009$} & WA298 & 29414 & $0.500 \mathrm{U}$ & 0.585 & $0.500 \mathrm{U}$ & $0.500 \mathrm{U}$ & $0.500 \mathrm{U}$ & $0.500 \mathrm{U}$ & $0.500 \mathrm{U}$ & $0.500 \mathrm{U}$ & $0.750 \mathrm{U}$ & $0.500 \mathrm{U}$ \\
\hline & MEAN & & $0.500 \mathrm{U}$ & 0.734 & 1.37 & $0.500 \mathrm{U}$ & $0.500 \mathrm{U}$ & $0.500 \mathrm{U}$ & 1.09 & 0.569 & $0.750 \mathrm{U}$ & $0.500 \mathrm{U}$ \\
\hline \multicolumn{13}{|c|}{ Field Efficiency Test Using Rain Water (ng/filter) } \\
\hline \multirow[t]{3}{*}{$4 / 15 / 2009$} & WA253 & 29413 & 8.42 & 7.17 & 8.76 & 5.14 & 5.85 & 5.80 & 8.02 & 5.97 & 8.27 & 5.59 \\
\hline & Spike Amount & & 12.5 & 12.5 & 12.5 & 12.5 & 12.5 & 12.5 & 12.5 & 12.5 & 18.8 & 12.5 \\
\hline & Recovery & & $67 \%$ & $57 \%$ & $70 \%$ & $41 \%$ & $47 \%$ & $46 \%$ & $64 \%$ & $48 \%$ & $44 \%$ & $45 \%$ \\
\hline
\end{tabular}


Quality Control Results - PBDE

\begin{tabular}{|c|c|c|c|c|c|c|c|c|c|}
\hline $\begin{array}{c}\text { Extraction } \\
\text { Date }\end{array}$ & Sample ID & $\begin{array}{c}\text { Analytical } \\
\text { Batch ID }\end{array}$ & $\begin{array}{r}\text { BDE- } \\
154\end{array}$ & BDE-183 & $\begin{array}{r}\text { BDE- } \\
190\end{array}$ & $\begin{array}{r}\text { BDE- } \\
209\end{array}$ & $\begin{array}{r}\text { HBB } \\
\text { Recovery }\end{array}$ & $\begin{array}{l}\text { PCB } 103 \\
\text { Recovery }\end{array}$ & $\begin{array}{r}\text { PCB } 198 \\
\text { Recovery }\end{array}$ \\
\hline \multicolumn{3}{|c|}{ Reporting Limit } & $0.5 \mathrm{ng} / \mathrm{L}$ & $0.5 \mathrm{ng} / \mathrm{L}$ & $0.5 \mathrm{ng} / \mathrm{L}$ & $2 \mathrm{ng} / \mathrm{L}$ & & & \\
\hline \multicolumn{10}{|c|}{ Procedural Blanks (ng/L) } \\
\hline $1 / 26 / 2009$ & WA_BLK0126 & 29411 & $0.500 \mathrm{U}$ & $0.500 \mathrm{U}$ & $0.500 \mathrm{U}$ & $0.500 \mathrm{U}$ & $116 \%$ & $89 \%$ & $97 \%$ \\
\hline $2 / 4 / 2009$ & WA_BLK0204 & 29411 & $0.500 \mathrm{U}$ & $0.500 \mathrm{U}$ & $0.500 \mathrm{U}$ & 6.56 & $150 \%$ & $92 \%$ & $97 \%$ \\
\hline $2 / 9 / 2009$ & WA_BLK0209 & 29411 & $0.500 \mathrm{U}$ & $0.500 \mathrm{U}$ & $0.500 \mathrm{U}$ & $0.500 \mathrm{U}$ & $145 \%$ & $89 \%$ & $98 \%$ \\
\hline $2 / 12 / 2009$ & WA_BLK0212 & 29411 & $0.500 \mathrm{U}$ & $0.500 \mathrm{U}$ & $0.500 \mathrm{U}$ & $0.500 \mathrm{U}$ & $170 \%$ & $93 \%$ & $98 \%$ \\
\hline $2 / 19 / 2009$ & WA_BLK0219 & 29412 & $0.500 \mathrm{U}$ & $0.500 \mathrm{U}$ & $0.500 \mathrm{U}$ & $0.500 \mathrm{U}$ & $152 \%$ & $85 \%$ & $97 \%$ \\
\hline $5 / 16 / 2009$ & WA_BLK0516 & 29413 & $0.500 \mathrm{U}$ & $0.500 \mathrm{U}$ & $0.500 \mathrm{U}$ & $2.00 \mathrm{U}$ & $141 \%$ & $90 \%$ & $98 \%$ \\
\hline $5 / 23 / 2009$ & WA_BLK0523 & 29413 & $0.500 \mathrm{U}$ & $0.500 \mathrm{U}$ & $0.500 \mathrm{U}$ & $2.00 \mathrm{U}$ & $234 \%$ & $88 \%$ & $100 \%$ \\
\hline $5 / 31 / 2009$ & WA_BLK0531 & 29414 & $0.500 \mathrm{U}$ & $0.500 \mathrm{U}$ & $0.500 \mathrm{U}$ & $2.00 \mathrm{U}$ & $83 \%$ & $96 \%$ & $97 \%$ \\
\hline $6 / 3 / 2009$ & WA_BLK0603 & 29414 & $0.500 \mathrm{U}$ & $0.500 \mathrm{U}$ & $0.500 \mathrm{U}$ & $2.00 \mathrm{U}$ & $99 \%$ & $88 \%$ & $91 \%$ \\
\hline $6 / 26 / 2009$ & WA_BLK0626 & 29415 & $0.500 \mathrm{U}$ & $0.500 \mathrm{U}$ & $0.500 \mathrm{U}$ & $2.00 \mathrm{U}$ & $110 \%$ & $87 \%$ & $113 \%$ \\
\hline $7 / 3 / 2009$ & WA_BLK0703 & 29415 & $0.500 \mathrm{U}$ & $0.500 \mathrm{U}$ & $0.500 \mathrm{U}$ & $2.00 \mathrm{U}$ & $96 \%$ & $84 \%$ & $112 \%$ \\
\hline $9 / 16 / 2009$ & WA_BLK0916 & BDE_120709 & $0.500 \mathrm{U}$ & $0.500 \mathrm{U}$ & $0.500 \mathrm{U}$ & $2.00 \mathrm{U}$ & $118 \%$ & $76 \%$ & $111 \%$ \\
\hline $9 / 22 / 2009$ & WA_BLK0922 & BDE_120709 & $0.500 \mathrm{U}$ & $0.500 \mathrm{U}$ & $0.500 \mathrm{U}$ & $2.00 \mathrm{U}$ & $147 \%$ & $71 \%$ & $110 \%$ \\
\hline $10 / 12 / 2009$ & WA_BLK1012 & BDE_120709 & $0.500 \mathrm{U}$ & $0.500 \mathrm{U}$ & $0.500 \mathrm{U}$ & $2.00 \mathrm{U}$ & $105 \%$ & $78 \%$ & $114 \%$ \\
\hline 10/27/2009 & WA_BLK1027 & BDE_121109 & $0.500 \mathrm{U}$ & $0.500 \mathrm{U}$ & $0.500 \mathrm{U}$ & $2.00 \mathrm{U}$ & $112 \%$ & $76 \%$ & $110 \%$ \\
\hline $11 / 3 / 2009$ & WA_BLK1103 & BDE_121109 & $0.500 \mathrm{U}$ & $0.500 \mathrm{U}$ & $0.500 \mathrm{U}$ & $2.00 \mathrm{U}$ & $112 \%$ & $65 \%$ & $95 \%$ \\
\hline \multicolumn{10}{|c|}{$\underline{\text { SRM Results (ng/g) }}$} \\
\hline $1 / 26 / 2009$ & WA_UD0126 & 29411 & 19.3 & $9.43 \mathrm{U}$ & $9.43 \mathrm{U}$ & 127 & $126 \%$ & $101 \%$ & $101 \%$ \\
\hline 2/4/2009 & WA_UD0204 & 29411 & 23.9 & $9.38 \mathrm{U}$ & $9.38 \mathrm{U}$ & NA & $124 \%$ & $108 \%$ & $107 \%$ \\
\hline 2/9/2009 & WA_UD0209 & 29411 & 20.0 & $9.19 \mathrm{U}$ & $9.19 \mathrm{U}$ & 109 & $141 \%$ & $113 \%$ & $103 \%$ \\
\hline $2 / 12 / 2009$ & WA_UD0212 & 29412 & 24.4 & $8.55 \mathrm{U}$ & 11.3 & NA U & $112 \%$ & $106 \%$ & $101 \%$ \\
\hline $2 / 19 / 2009$ & WA_UD0219 & 29412 & 16.9 & $8.46 \mathrm{U}$ & $8.46 \mathrm{U}$ & NA U & $135 \%$ & $107 \%$ & $101 \%$ \\
\hline 4/8/2009 & WA_UD0408 & 29413 & 18.6 & $9.21 \mathrm{U}$ & $9.21 \mathrm{U}$ & 127 & $112 \%$ & $107 \%$ & $103 \%$ \\
\hline $4 / 15 / 2009$ & WA_UD0415 & 29413 & 22.4 & $9.04 \mathrm{U}$ & $9.04 \mathrm{U}$ & 116 & $134 \%$ & $106 \%$ & $100 \%$ \\
\hline $4 / 15 / 2009$ & WA_UD0415b & 29413 & 24.6 & $9.63 \mathrm{U}$ & $9.63 \mathrm{U}$ & 127 & $152 \%$ & $104 \%$ & $101 \%$ \\
\hline $5 / 16 / 2009$ & WA_UD0516 & 29413 & 30.2 & $9.04 \mathrm{U}$ & $9.04 \mathrm{U}$ & 192 & $113 \%$ & $106 \%$ & $105 \%$ \\
\hline $5 / 23 / 2009$ & WA_UD0523 & 29413 & 22.0 & $8.98 \mathrm{U}$ & $8.98 \mathrm{U}$ & 176 & $123 \%$ & $106 \%$ & $102 \%$ \\
\hline $5 / 31 / 2009$ & WA_UD0531 & 29414 & 26.2 & $8.90 \mathrm{U}$ & $8.90 \mathrm{U}$ & 191 & $95 \%$ & $98 \%$ & $97 \%$ \\
\hline $6 / 3 / 2009$ & WA_UD0603 & 29414 & 28.7 & $9.12 \mathrm{U}$ & $9.12 \mathrm{U}$ & 176 & $95 \%$ & $104 \%$ & $102 \%$ \\
\hline $6 / 26 / 2009$ & WA_UD0626 & 29415 & 20.5 & $9.63 \mathrm{U}$ & $9.63 \mathrm{U}$ & 165 & $132 \%$ & $98 \%$ & $118 \%$ \\
\hline $7 / 3 / 2009$ & WA_UD0703 & 29415 & 22.6 & $9.71 \mathrm{U}$ & $9.71 \mathrm{U}$ & 188 & $99 \%$ & $97 \%$ & $113 \%$ \\
\hline $9 / 16 / 2009$ & WA_UD0916 & BDE_120709 & 19.2 & $9.77 \mathrm{U}$ & $9.77 \mathrm{U}$ & 274 & $115 \%$ & $84 \%$ & $110 \%$ \\
\hline $9 / 22 / 2009$ & WA_UD0922 & BDE_120709 & $9.54 \mathrm{U}$ & $9.54 \mathrm{U}$ & $9.54 \mathrm{U}$ & 225 & $108 \%$ & $88 \%$ & $109 \%$ \\
\hline $10 / 12 / 2009$ & WA_UD1012 & BDE_120709 & 16.7 & $9.45 \mathrm{U}$ & $9.45 \mathrm{U}$ & 267 & $104 \%$ & $88 \%$ & $114 \%$ \\
\hline 10/27/2009 & WA_UD1027 & BDE_121109 & 16.3 & $9.67 \mathrm{U}$ & $9.67 \mathrm{U}$ & 267 & $172 \%$ & $85 \%$ & $112 \%$ \\
\hline $11 / 3 / 2009$ & WA_UD1103 & BDE_121109 & 17.8 & $9.23 \mathrm{U}$ & $9.23 \mathrm{U}$ & 281.6 & $93 \%$ & $79 \%$ & $98 \%$ \\
\hline & MEAN & & 21.0 & $9.26 \mathrm{U}$ & 9.41 & 188 & & & \\
\hline & STDEV & & 4.83 & -- & 0.571 & 59.7 & & & \\
\hline & RSD & & $23 \%$ & -- & $6 \%$ & $32 \%$ & & & \\
\hline \multicolumn{10}{|c|}{ Field GFF+SPE Blank (QC) (ng/filte) } \\
\hline $4 / 8 / 2009$ & WA232 & 29413 & $0.500 \mathrm{U}$ & $0.500 \mathrm{U}$ & $0.500 \mathrm{U}$ & $2.00 \mathrm{U}$ & $115 \%$ & $96 \%$ & $95 \%$ \\
\hline $4 / 15 / 2009$ & WA235 & 29413 & $0.500 \mathrm{U}$ & $0.500 \mathrm{U}$ & $0.500 \mathrm{U}$ & $2.00 \mathrm{U}$ & $123 \%$ & $88 \%$ & $93 \%$ \\
\hline $4 / 15 / 2009$ & WA239 & 29413 & $0.500 \mathrm{U}$ & $0.500 \mathrm{U}$ & $0.500 \mathrm{U}$ & $2.00 \mathrm{U}$ & $213 \%$ & $92 \%$ & $95 \%$ \\
\hline $6 / 3 / 2009$ & WA295 & 29414 & $0.500 \mathrm{U}$ & $0.500 \mathrm{U}$ & $0.500 \mathrm{U}$ & $2.00 \mathrm{U}$ & $94 \%$ & $83 \%$ & $94 \%$ \\
\hline $6 / 3 / 2009$ & WA296 & 29414 & $0.500 \mathrm{U}$ & $0.500 \mathrm{U}$ & $0.500 \mathrm{U}$ & $2.00 \mathrm{U}$ & $121 \%$ & $86 \%$ & $99 \%$ \\
\hline $5 / 31 / 2009$ & WA297 & 29414 & $0.500 \mathrm{U}$ & $0.500 \mathrm{U}$ & $0.500 \mathrm{U}$ & $2.00 \mathrm{U}$ & $115 \%$ & $84 \%$ & $99 \%$ \\
\hline \multirow[t]{2}{*}{$5 / 31 / 2009$} & WA298 & 29414 & $0.500 \mathrm{U}$ & $0.500 \mathrm{U}$ & $0.500 \mathrm{U}$ & $2.00 \mathrm{U}$ & $101 \%$ & $77 \%$ & $90 \%$ \\
\hline & MEAN & & $0.500 \mathrm{U}$ & $0.500 \mathrm{U}$ & $0.500 \mathrm{U}$ & $2.00 \mathrm{U}$ & & & \\
\hline \multicolumn{10}{|c|}{ Field Efficiency Test Using Rain Wa1 } \\
\hline \multirow[t]{3}{*}{$4 / 15 / 2009$} & WA253 & 29413 & 5.67 & 8.80 & 6.18 & 16.2 & $85 \%$ & $93 \%$ & $95 \%$ \\
\hline & Spike Amount & & 12.5 & 12.5 & 12.5 & 50.0 & & & \\
\hline & Recovery & & $45 \%$ & $70 \%$ & $49 \%$ & $32 \%$ & & & \\
\hline
\end{tabular}




\begin{tabular}{|c|c|c|c|c|c|c|c|c|c|c|c|c|c|c|c|c|c|c|c|}
\hline $\begin{array}{l}\text { Analytical } \\
\text { Batch ID } \\
\end{array}$ & Sample ID & Description & BDE-17 & BDE-28 & BDE-47 & BDE-66 & BDE-71 & BDE-85 & BDE-99 & $\begin{array}{r}\text { BDE- } \\
100 \\
\end{array}$ & $\begin{array}{r}\text { BDE- } \\
138 \\
\end{array}$ & $\begin{array}{r}\text { BDE- } \\
153 \\
\end{array}$ & $\begin{array}{r}\text { BDE- } \\
154 \\
\end{array}$ & $\begin{array}{r}\text { BDE- } \\
183 \\
\end{array}$ & $\begin{array}{r}\text { BDE- } \\
190 \\
\end{array}$ & $\begin{array}{r}\text { BDE- } \\
209 \\
\end{array}$ & HBB & $\begin{array}{r}\text { PCB } \\
103 \\
\end{array}$ & PCB 198 \\
\hline 29411 & 1348 & LCS & $117^{\circ}$ & $111 \%$ & $115 \%$ & 107 & 115 & 103 & 103 & ne & $93^{\circ}$ & $96 \%$ & 10 & $\%$ & $89 \%$ & $75 \%$ & $104 \%$ & $104 \%$ & $100 \%$ \\
\hline 29411 & $1348 \mathrm{c}$ CCV0 & ICV & $117 \%$ & $111 \%$ & $113 \%$ & $107 \%$ & $114 \%$ & $103 \%$ & 10 & $107 \%$ & $95 \%$ & $96 \%$ & $100 \%$ & $112 \%$ & $96 \%$ & $89 \%$ & $103 \%$ & $107 \%$ & $101 \%$ \\
\hline 29411 & $1348 \mathrm{C} \mathrm{CCV}$ & $\mathrm{CCV}$ & $115 \%$ & $110 \%$ & $111 \%$ & $107 \%$ & $112 \%$ & $103 \%$ & $100 \%$ & $107 \%$ & $94 \%$ & $96 \%$ & $100 \%$ & $107 \%$ & $79 \%$ & $93 \%$ & $103 \%$ & $103 \%$ & $99 \%$ \\
\hline 29411 & $1348 \mathrm{C} \mathrm{CCV}$ & $\mathrm{CCV}$ & $116 \%$ & $110 \%$ & $112 \%$ & $106 \%$ & $113 \%$ & $101 \%$ & $100 \%$ & $106 \%$ & $94 \%$ & $94 \%$ & $99 \%$ & $112 \%$ & $101 \%$ & $84 \%$ & $103 \%$ & $105 \%$ & $100 \%$ \\
\hline 29411 & $1348 \mathrm{C} \mathrm{CCV}$ & $\mathrm{CCV}$ & $115 \%$ & $109 \%$ & $111 \%$ & $106 \%$ & $112 \%$ & $101 \%$ & $101 \%$ & $107 \%$ & $93 \%$ & $93 \%$ & $99 \%$ & $113 \%$ & $102 \%$ & $74 \%$ & $105 \%$ & $104 \%$ & $100 \%$ \\
\hline 29412 & $1348 \mathrm{C} 12.5 \mathrm{ng} / \mathrm{ml}$ & LCS & $119 \%$ & $112 \%$ & $111 \%$ & $107 \%$ & $114 \%$ & $102 \%$ & $102 \%$ & $108 \%$ & $94 \%$ & $96 \%$ & $102 \%$ & $113 \%$ & $97 \%$ & $79 \%$ & $98 \%$ & $106 \%$ & $104^{\circ}$ \\
\hline 29412 & $1348 \mathrm{C} \mathrm{CCV}$ & $\mathrm{CCV}$ & $114 \%$ & $108 \%$ & $107 \%$ & $105 \%$ & $110 \%$ & $101 \%$ & $97 \%$ & $105 \%$ & $95 \%$ & $95 \%$ & $99 \%$ & $113 \%$ & $95 \%$ & $103 \%$ & $102 \%$ & $104 \%$ & $103 \%$ \\
\hline 29412 & $1348 \mathrm{C} \mathrm{CCV}$ & $\mathrm{CCV}$ & $112 \%$ & $106 \%$ & $106 \%$ & $102 \%$ & $110 \%$ & $102 \%$ & $98 \%$ & $105 \%$ & $95 \%$ & $95 \%$ & $99 \%$ & $113 \%$ & $95 \%$ & $104 \%$ & $105 \%$ & $102 \%$ & $99^{\circ}$ \\
\hline 29413 & $1348 \mathrm{C} 12.5 \mathrm{ng} / \mathrm{ml}$ & LCS & $114 \%$ & $104 \%$ & $104 \%$ & $99 \%$ & $109 \%$ & $98 \%$ & $95 \%$ & $112 \%$ & $93 \%$ & $95 \%$ & $100 \%$ & $109 \%$ & $85 \%$ & $98 \%$ & $101 \%$ & $105 \%$ & $100 \%$ \\
\hline 29413 & $1348 \mathrm{C} \mathrm{CCV}$ & $\mathrm{CCV}$ & $114 \%$ & $106 \%$ & $103 \%$ & $101 \%$ & $108 \%$ & $99 \%$ & $95 \%$ & $107 \%$ & $94 \%$ & $93 \%$ & $97 \%$ & $113 \%$ & $108 \%$ & $116 \%$ & $105 \%$ & $105 \%$ & $103 \%$ \\
\hline 29413 & $1348 \mathrm{C} \mathrm{CCV}$ & $\mathrm{CCV}$ & $115 \%$ & $107 \%$ & $105 \%$ & $103 \%$ & $110 \%$ & $99 \%$ & $95 \%$ & $108 \%$ & $94 \%$ & $93 \%$ & $98 \%$ & $114 \%$ & $107 \%$ & $91 \%$ & $106 \%$ & $104 \%$ & $102 \%$ \\
\hline 29413 & $1348 \mathrm{C} \mathrm{CCV}$ & $\mathrm{CCV}$ & $117 \%$ & $110 \%$ & $107 \%$ & $104 \%$ & $112 \%$ & $101 \%$ & $99 \%$ & $106 \%$ & $95 \%$ & $95 \%$ & $100 \%$ & $116 \%$ & $109 \%$ & $83 \%$ & $103 \%$ & $105 \%$ & $101 \%$ \\
\hline 29413 & $1348 \mathrm{C} \mathrm{CCV}$ & $\mathrm{CCV}$ & $114 \%$ & $106 \%$ & $106 \%$ & $105 \%$ & $110 \%$ & $105 \%$ & $100 \%$ & $107 \%$ & $103 \%$ & $103 \%$ & $105 \%$ & $126 \%$ & $121 \%$ & $86 \%$ & $105 \%$ & $101 \%$ & $100 \%$ \\
\hline
\end{tabular}


Appendix C:
Metals Data 
Field Sample Results - Metals

\begin{tabular}{|c|c|c|c|c|c|c|c|c|c|c|c|c|}
\hline Sample ID & $\begin{array}{c}\text { Station } \\
\text { ID }\end{array}$ & $\begin{array}{c}\text { Event } \\
\text { No. }\end{array}$ & $\begin{array}{r}\text { Rain } \\
\text { Collected }\end{array}$ & $\begin{array}{r}\text { Sample } \\
\text { Vol. }\end{array}$ & $\begin{array}{r}\text { Funnel } \\
\text { Surface Area }\end{array}$ & $\mathrm{Cr}^{1}$ & $\mathrm{Ni}$ & $\mathrm{Cu}$ & Zn & As & Cd & $\mathbf{P b}$ \\
\hline & & & $\mathrm{mL}$ & $\mathrm{L}$ & $\mathrm{m}^{2}$ & $\begin{array}{r}\mu \mathrm{g} / \mathrm{L} \\
0.0507 \\
0.161\end{array}$ & $\begin{array}{r}\mu \mathrm{g} / \mathrm{L} \\
0.0107 \\
0.0340\end{array}$ & $\begin{array}{r}\mu \mathrm{g} / \mathrm{L} \\
0.00532 \\
0.0169\end{array}$ & $\begin{array}{r}\mu \mathrm{g} / \mathrm{L} \\
0.0135 \\
0.0429\end{array}$ & $\begin{array}{r}\mu \mathrm{g} / \mathrm{L} \\
0.0071 \\
0.0226\end{array}$ & $\begin{array}{r}\mu \mathrm{g} / \mathrm{L} \\
0.0033 \\
0.0105\end{array}$ & $\begin{array}{r}\mu \mathrm{g} / \mathrm{L} \\
0.00219 \\
0.00696\end{array}$ \\
\hline $2941-1$ & EB & & & & 0.01720 & $0.0507 \mathrm{U}$ & 0.152 & $0.00532 \mathrm{U}$ & $0.0135 \mathrm{U}$ & 0.00963 & $0.00330 \mathrm{U}$ & $0.00219 \mathrm{U}$ \\
\hline $2941-6$ & EB & & & & 0.01720 & 0.113 & 0.314 & 0.0307 & 0.290 & $0.00710 \mathrm{U}$ & $0.00330 \mathrm{U}$ & 0.00372 \\
\hline 2941-101 & EB & & & & 0.01039 & $0.0507 \mathrm{U}$ & $0.0107 \mathrm{U}$ & $0.00532 \mathrm{U}$ & $0.0135 \mathrm{U}$ & $0.00710 \mathrm{U}$ & $0.00330 \mathrm{U}$ & $0.00219 \mathrm{U}$ \\
\hline 2941-107 & EB & & & & 0.01039 & 0.123 & 0.0313 & $0.00532 \mathrm{U}$ & 0.623 & $0.00710 \mathrm{U}$ & $0.00330 \mathrm{U}$ & $0.00219 \mathrm{U}$ \\
\hline Average & & & & & & 0.0592 & 0.124 & 0.00767 & 0.228 & 0.00773 & $0.0033 \mathrm{U}$ & 0.00257 \\
\hline Stdev & & & & & & 0.0684 & 0.143 & 0.0153 & 0.297 & 0.00126 & & 0.00076 \\
\hline Rinse Water Co & ontributi & ion ( $\mu \mathrm{g})$ & & & & 0.00355 & 0.00746 & 0.00046 & 0.0137 & 0.00046 & 0.00020 & 0.00015 \\
\hline 2941-10 & $\mathrm{HC}$ & 1 & 0.2 & 0.062 & 0.01720 & 0.357 & 0.550 & 1.61 & 29.7 & 0.0714 & 0.0167 & 0.183 \\
\hline $2941-20$ & $\mathrm{HC}$ & 2 & 860.2 & 0.922 & 0.01720 & 0.204 & 0.241 & 0.503 & 4.87 & 0.0608 & 0.0267 & 0.102 \\
\hline $2941-34$ & $\mathrm{HC}$ & 3 & 350 & 0.412 & 0.01720 & 0.204 & 0.114 & 0.248 & 1.85 & 0.0686 & 0.0120 & 0.153 \\
\hline $2941-42$ & $\mathrm{HC}$ & 4 & 67.9 & 0.130 & 0.01720 & 0.302 & 0.345 & 1.86 & 5.26 & 0.0767 & 0.0295 & 0.311 \\
\hline 2941-71 & $\mathrm{HC}$ & 6 & 446.9 & 0.509 & 0.01039 & $0.0507 \mathrm{U}$ & 0.134 & 0.0939 & 0.518 & 0.0266 & 0.00535 & 0.0309 \\
\hline $2941-72$ & $\mathrm{HC}$ & 6 & 483.9 & 0.546 & 0.01039 & $0.0507 \mathrm{U}$ & 0.0664 & 0.132 & 3.48 & 0.0333 & 0.00660 & 0.0343 \\
\hline $2941-81$ & $\mathrm{HC}$ & 7 & 272.1 & 0.334 & 0.01039 & 0.0694 & 0.290 & 0.285 & 4.36 & 0.0716 & 0.0156 & 0.110 \\
\hline $2941-80$ & $\mathrm{HC}$ & 7 & 257.7 & 0.320 & 0.01039 & 0.0688 & 0.165 & 0.290 & 1.72 & 0.0726 & 0.0142 & 0.0845 \\
\hline 2941-104 & $\mathrm{HC}$ & 8 & 363.7 & 0.426 & 0.01039 & 0.0886 & 0.111 & 0.159 & 2.75 & 0.0304 & 0.00585 & 0.0629 \\
\hline 2941-113 & $\mathrm{HC}$ & 9 & 666.2 & 0.728 & 0.01039 & 0.217 & 0.120 & 0.211 & 2.67 & 0.0577 & 0.00744 & 0.111 \\
\hline $2941-124$ & $\mathrm{HC}$ & 10 & 240.1 & 0.302 & 0.01039 & 0.209 & 0.902 & 0.382 & 3.79 & 0.0489 & 0.00577 & 0.158 \\
\hline 2941-151 & $\mathrm{HC}$ & 11 & 467.3 & 0.529 & 0.01039 & 0.160 & 0.0883 & 0.190 & 4.47 & 0.0525 & 0.00544 & 0.0850 \\
\hline $2941-159$ & $\mathrm{HC}$ & 12 & 713.1 & 0.775 & 0.01039 & 0.133 & 0.124 & 0.249 & 1.73 & 0.0538 & 0.00468 & 0.145 \\
\hline 2941-161 & $\mathrm{HC}$ & 13 & 630.2 & 0.692 & 0.01039 & $0.0507 \mathrm{U}$ & 0.102 & 0.143 & 1.02 & 0.0294 & 0.00628 & 0.114 \\
\hline $2941-373$ & $\mathrm{HC}$ & 14 & 0.00 & 0.070 & 0.01039 & 0.300 & 0.491 & 1.09 & 6.68 & 0.0759 & 0.0355 & 0.817 \\
\hline 2941-381 & $\mathrm{HC}$ & 15 & 239.5 & 0.302 & 0.01720 & 0.126 & 0.243 & 0.472 & 4.41 & 0.0680 & 0.00500 & 0.117 \\
\hline $2941-390$ & $\mathrm{HC}$ & 16 & 11.4 & 0.073 & 0.01720 & 0.445 & 1.32 & 4.07 & 3.77 & 0.0780 & 0.00800 & 0.356 \\
\hline $2941-387$ & $\mathrm{HC}$ & 17 & 749.2 & 0.811 & 0.01720 & 0.00905 & 0.113 & 0.287 & 1.09 & 0.0316 & 0.00352 & 0.131 \\
\hline 2941-399 & $\mathrm{HC}$ & 18 & 176.5 & 0.239 & 0.01720 & 0.218 & 0.624 & 0.535 & 2.07 & 0.0744 & 0.00533 & 0.334 \\
\hline $2941-403$ & $\mathrm{HC}$ & 19 & 606.8 & 0.669 & 0.01720 & 0.0108 & 0.137 & 0.414 & 1.83 & 0.0693 & 0.00493 & 0.198 \\
\hline Average & & & & & & 0.164 & 0.314 & 0.661 & 4.40 & 0.0576 & 0.0112 & 0.182 \\
\hline Stdev & & & & & & 0.121 & 0.324 & 0.936 & 6.17 & 0.0182 & 0.00927 & 0.175 \\
\hline Median & & & & & & 0.147 & 0.151 & 0.288 & 3.11 & 0.0644 & 0.00644 & 0.124 \\
\hline 25th & & & & & & 0.0643 & 0.114 & 0.206 & 1.80 & 0.0450 & 0.00534 & 0.0974 \\
\hline 75th & & & & & & 0.217 & 0.381 & 0.511 & 4.43 & 0.0718 & 0.0146 & 0.187 \\
\hline RSD & & & & & & $74 \%$ & $103 \%$ & $142 \%$ & $140 \%$ & $32 \%$ & $83 \%$ & $96 \%$ \\
\hline $2941-5$ & NR & 1 & 0.00 & 0.070 & 0.01720 & 0.950 & 3.01 & 1.92 & 10.1 & 0.167 & 0.0145 & 0.619 \\
\hline $2941-23$ & NR & 2 & 131.5 & 0.194 & 0.01720 & 0.598 & 0.671 & 2.06 & 11.2 & 0.256 & 0.0218 & 0.784 \\
\hline $2941-29$ & NR & 3 & 1002.5 & 1.005 & 0.01720 & 0.182 & 0.348 & 0.775 & 8.18 & 0.128 & 0.0161 & 0.411 \\
\hline $2941-35$ & NR & 4 & 237.2 & 0.299 & 0.01720 & 0.301 & 0.388 & 1.17 & 42.4 & 0.174 & 0.0223 & 0.880 \\
\hline $2941-77$ & NR & 6 & 208.1 & 0.270 & 0.01039 & 0.0889 & 0.0652 & 0.291 & 2.53 & 0.0539 & $0.00330 \mathrm{U}$ & 0.135 \\
\hline 2941-85 & NR & 7 & 52.0 & 0.114 & 0.006360 & 0.227 & 0.327 & 1.89 & 6.14 & 0.0831 & 0.0114 & 0.0626 \\
\hline 2941-103 & NR & 8 & 351.1 & 0.413 & 0.01039 & 0.104 & 0.177 & 0.385 & 2.85 & 0.0706 & 0.00464 & 0.180 \\
\hline 2941-112 & NR & 9 & 785.2 & 0.847 & 0.01039 & 0.135 & 0.0922 & 0.318 & 2.08 & 0.0649 & 0.00573 & 0.321 \\
\hline 2941-116 & NR & 10 & 380.7 & 0.443 & 0.01039 & 0.157 & 0.139 & 0.458 & 2.09 & 0.0434 & 0.00627 & 0.253 \\
\hline 2941-129 & NR & 11 & 397.9 & 0.460 & 0.01039 & 0.0958 & 0.0719 & 0.300 & 1.53 & 0.107 & 0.00720 & 0.208 \\
\hline $2941-128$ & NR & 11 & 467.2 & 0.529 & 0.01039 & 0.269 & 0.213 & 0.930 & 5.22 & 0.163 & 0.0145 & 0.453 \\
\hline 2941-155 AVG & NR & 12 & 970.2 & 1.032 & 0.01039 & 0.301 & 0.519 & 0.521 & 3.44 & 0.118 & 0.0140 & 0.236 \\
\hline $2941-153$ re & NR & 12 & 948.8 & 1.011 & 0.01039 & 0.259 & 0.556 & 0.403 & 2.41 & 0.0794 & 0.0133 & 0.274 \\
\hline $2941-165$ & NR & 13 & 373.8 & 0.436 & 0.01039 & 0.209 & 0.782 & 0.407 & 2.32 & 0.0581 & 0.00930 & 0.328 \\
\hline $2941-371$ & NR & 14 & 0.00 & 0.062 & 0.01039 & 0.696 & 0.888 & 3.47 & 13.6 & 0.246 & 0.0317 & 1.43 \\
\hline $2941-372$ & NR & 15 & 401.6 & 0.404 & 0.01720 & 0.502 & 0.592 & 1.60 & 6.16 & 0.185 & 0.0113 & 0.387 \\
\hline $2941-400$ & NR & 16 & 103.1 & 0.165 & 0.01720 & 0.419 & 1.34 & 1.73 & 7.43 & 0.244 & 0.0200 & 0.519 \\
\hline 2941-398 & NR & 17 & 943.2 & 1.005 & 0.01720 & 0.055 & 0.107 & 0.502 & 2.47 & 0.0616 & 0.00779 & 0.222 \\
\hline 2941-392 & NR & 18 & 144.4 & 0.206 & 0.01720 & 0.267 & 0.489 & 2.18 & 11.7 & 0.159 & 0.0420 & 1.53 \\
\hline $2941-424$ & NR & 19 & 87.8 & 0.150 & 0.01720 & 0.520 & 0.570 & 5.05 & 13.3 & 0.379 & 0.0447 & 0.796 \\
\hline Average & & & & & & 0.317 & 0.567 & 1.32 & 7.86 & 0.142 & 0.0161 & 0.501 \\
\hline Stdev & & & & & & 0.233 & 0.659 & 1.23 & 9.09 & 0.0876 & 0.0116 & 0.405 \\
\hline Median & & & & & & 0.263 & 0.438 & 0.852 & 5.68 & 0.123 & 0.0137 & 0.357 \\
\hline 25th & & & & & & 0.151 & 0.167 & 0.406 & 2.46 & 0.0691 & 0.00764 & 0.233 \\
\hline 75th & & & & & & 0.440 & 0.612 & 1.90 & 10.4 & 0.177 & 0.0204 & 0.660 \\
\hline RSD & & & & & & $74 \%$ & $116 \%$ & $94 \%$ & $116 \%$ & $62 \%$ & $72 \%$ & $81 \%$ \\
\hline $2941-3$ & PB & 1 & 101.1 & 0.242 & 0.01720 & 1.72 & 1.28 & 1.33 & 7.40 & 0.190 & 0.00628 & 0.167 \\
\hline 2941-19 & PB & 2 & 304 & 0.366 & 0.01720 & 0.340 & 0.701 & 1.26 & 17.4 & 0.112 & 0.0123 & 0.292 \\
\hline 2941-30 & PB & 3 & 388.8 & 0.451 & 0.01720 & 0.321 & 0.417 & 1.05 & 36.1 & 0.100 & 0.0213 & 0.331 \\
\hline $2941-36$ & PB & 4 & 122.7 & 0.185 & 0.01720 & 0.225 & 0.258 & 0.699 & 4.30 & 0.125 & 0.0152 & 0.328 \\
\hline $2941-76$ & PB & 6 & 74.6 & 0.137 & 0.010387 & 0.135 & 0.210 & 0.707 & 2.12 & 0.0662 & 0.0139 & 0.109 \\
\hline $2941-84$ & PB & 7 & 250.5 & 0.313 & 0.00636 & 0.0992 & 0.128 & 0.23 & 3.25 & 0.0668 & 0.00594 & 0.039 \\
\hline 2941-88 & PB & 8 & 124.4 & 0.186 & 0.01039 & 0.315 & 1.80 & 1.05 & 5.13 & 0.0949 & 0.0272 & 0.153 \\
\hline 2941-108 & PB & 9 & 308.7 & 0.371 & 0.01039 & 0.205 & 0.373 & 0.52 & 3.40 & 0.113 & 0.0140 & 0.183 \\
\hline
\end{tabular}


Field Sample Results - Metals

\begin{tabular}{|c|c|c|c|c|c|c|c|c|c|c|c|c|}
\hline Sample ID & $\begin{array}{l}\text { Station } \\
\text { ID }\end{array}$ & $\begin{array}{c}\text { Event } \\
\text { No. }\end{array}$ & $\begin{array}{r}\text { Rain } \\
\text { Collected }\end{array}$ & $\begin{array}{c}\text { Sample } \\
\text { Vol. }\end{array}$ & $\begin{array}{r}\text { Funnel } \\
\text { Surface Area }\end{array}$ & $\mathrm{Cr}^{1}$ & $\mathrm{Ni}$ & $\mathrm{Cu}$ & Zn & As & Cd & $\mathbf{P b}$ \\
\hline & & & $\mathrm{mL}$ & $\mathrm{L}$ & $\mathrm{m}^{2}$ & $\begin{array}{r}\mu \mathrm{g} / \mathrm{L} \\
0.0507 \\
0.161\end{array}$ & $\begin{array}{r}\mu \mathrm{g} / \mathrm{L} \\
0.0107 \\
0.0340\end{array}$ & $\begin{array}{r}\mu \mathrm{g} / \mathrm{L} \\
0.00532 \\
0.0169\end{array}$ & $\begin{array}{r}\mu \mathrm{g} / \mathrm{L} \\
0.0135 \\
0.0429\end{array}$ & $\begin{array}{r}\mu \mathrm{g} / \mathrm{L} \\
0.0071 \\
0.0226\end{array}$ & $\begin{array}{r}\mu \mathrm{g} / \mathrm{L} \\
0.0033 \\
0.0105\end{array}$ & $\begin{array}{r}\mu \mathrm{g} / \mathrm{L} \\
0.00219 \\
0.00696\end{array}$ \\
\hline $2941-125$ & PB & 11 & 260.8 & 0.323 & 0.01039 & 0.324 & 1.06 & 0.833 & 8.30 & 0.111 & 0.0621 & 0.443 \\
\hline $2941-156$ & PB & 12 & 164.1 & 0.226 & 0.01039 & 0.596 & 1.76 & 0.812 & 4.14 & 0.131 & 0.0217 & 0.487 \\
\hline $2941-164$ & PB & 13 & 608.9 & 0.671 & 0.01039 & 0.126 & 0.126 & 0.196 & 0.949 & 0.0434 & 0.00722 & 0.171 \\
\hline $2941-169$ & PB & 14 & 27.87 & 0.090 & 0.01039 & 0.916 & 1.20 & 17.7 & 116 & 0.161 & 0.639 & 0.749 \\
\hline $2941-379$ & PB & 15 & 290.9 & 0.353 & 0.01720 & 0.325 & 0.57 & 0.925 & 7.03 & 0.119 & 0.0120 & 0.408 \\
\hline $2941-404$ & PB & 16 & 3.2 & 0.065 & 0.01720 & 0.877 & 1.30 & 1.24 & 6.16 & 0.131 & 0.0200 & 0.531 \\
\hline $2941-385$ & PB & 17 & 149.8 & 0.212 & 0.01720 & 0.454 & 1.06 & 1.82 & 5.00 & 0.166 & 0.0182 & 0.587 \\
\hline 2941-396 & PB & 18 & 263.6 & 0.326 & 0.01720 & 0.306 & 0.578 & 0.915 & 3.14 & 0.0896 & 0.0130 & 0.319 \\
\hline $2941-421$ & PB & 19 & 145.1 & 0.207 & 0.01720 & 0.180 & 0.383 & 0.764 & 3.18 & 0.105 & 0.0116 & 0.442 \\
\hline Average & & & & & & 0.439 & 0.777 & 1.89 & 13.7 & 0.113 & 0.054 & 0.337 \\
\hline Stdev & & & & & & 0.407 & 0.551 & 4.10 & 27.7 & 0.0372 & 0.151 & 0.190 \\
\hline Median & & & & & & 0.321 & 0.578 & 0.915 & 5.00 & 0.112 & 0.0140 & 0.328 \\
\hline 25th & & & & & & 0.205 & 0.373 & 0.707 & 3.25 & 0.0949 & 0.0120 & 0.171 \\
\hline 75th & & & & & & 0.454 & 1.20 & 1.24 & 7.40 & 0.131 & 0.0213 & 0.443 \\
\hline RSD & & & & & & $93 \%$ & $71 \%$ & $217 \%$ & $202 \%$ & $33 \%$ & $279 \%$ & $56 \%$ \\
\hline $2941-9$ & PO & 1 & 0.00 & 0.059 & 0.01720 & 0.668 & 1.76 & 1.83 & 4.16 & 0.228 & 0.0106 & 0.442 \\
\hline 2941-24 AVG & PO & 2 & 658.6 & 0.721 & 0.01720 & 0.215 & 0.709 & 1.13 & 2.31 & 0.146 & 0.0108 & 0.203 \\
\hline $2941-33$ & PO & 3 & 170.9 & 0.233 & 0.01720 & 0.136 & 0.340 & 0.935 & 1.73 & 0.106 & 0.0123 & 0.199 \\
\hline $2941-32$ & PO & 3 & 151.5 & 0.214 & 0.01720 & 0.323 & 0.942 & 0.670 & 2.35 & 0.113 & 0.0126 & 0.331 \\
\hline 2941-39 & PO & 4 & 64.6 & 0.127 & 0.01720 & 0.387 & 0.570 & 0.737 & 2.39 & 0.116 & 0.00747 & 0.238 \\
\hline $2941-41$ & PO & 4 & 49.7 & 0.112 & 0.01720 & 0.314 & 0.243 & 1.11 & 3.45 & 0.184 & 0.0116 & 0.333 \\
\hline $2941-73$ & PO & 6 & 313.2 & 0.365 & 0.01039 & 0.0712 & 0.272 & 0.247 & 0.939 & 0.0569 & 0.00510 & 0.0526 \\
\hline $2941-82$ & PO & 7 & 129.6 & 0.192 & 0.01039 & 0.0887 & 0.197 & 0.411 & 1.32 & 0.109 & 0.00963 & 0.0835 \\
\hline $2941-106$ & PO & 8 & 270.4 & 0.332 & 0.01039 & 0.279 & 0.854 & 0.399 & 7.74 & 0.0667 & 0.00398 & 0.158 \\
\hline $2941-114$ & $\mathrm{PO}$ & 9 & 505.8 & 0.568 & 0.01039 & 0.174 & 0.125 & 0.381 & 3.01 & 0.0962 & 0.00887 & 0.151 \\
\hline 2941-118 & PO & 10 & 400.2 & 0.462 & 0.01039 & 0.141 & 0.120 & 0.521 & 1.86 & 0.0699 & 0.00703 & 0.141 \\
\hline $2941-152$ & PO & 11 & 335.3 & 0.397 & 0.01039 & 0.192 & 0.206 & 0.417 & 1.84 & 0.0568 & 0.00964 & 0.154 \\
\hline $2941-158$ & PO & 12 & 752.8 & 0.815 & 0.01039 & 0.171 & 0.475 & 0.421 & 1.55 & 0.0821 & 0.00481 & 0.176 \\
\hline $2941-163$ & PO & 13 & 586.3 & 0.648 & 0.01039 & 0.114 & 0.260 & 0.261 & 1.33 & 0.0473 & 0.00487 & 0.154 \\
\hline $2941-376$ & PO & 14 & 0.00 & 0.070 & 0.01039 & 0.660 & 0.515 & 1.38 & 4.49 & 0.0849 & 0.0104 & 1.03 \\
\hline $2941-380$ & PO & 15 & 212.5 & 0.275 & 0.01720 & 0.319 & 2.10 & 1.32 & 9.58 & 0.181 & 0.0198 & 0.302 \\
\hline $2941-394$ & PO & 16 & 0.0 & 0.066 & 0.01720 & 0.357 & 1.73 & 2.64 & 8.40 & 0.246 & 0.0154 & 0.570 \\
\hline $2941-401$ & PO & 17 & 571.1 & 0.633 & 0.01720 & 0.0468 & 0.227 & 0.672 & 2.65 & 0.0907 & 0.0116 & 0.181 \\
\hline $2941-405$ & PO & 18 & 122.0 & 0.184 & 0.01720 & 0.193 & 0.494 & 3.16 & 13.1 & 0.158 & 0.0458 & 0.317 \\
\hline $2941-422$ & PO & 19 & 349.8 & 0.412 & 0.01720 & 0.162 & 0.286 & 1.05 & 3.56 & 0.124 & 0.0100 & 0.405 \\
\hline Average & & & & & & 0.251 & 0.621 & 0.984 & 3.89 & 0.118 & 0.0116 & 0.281 \\
\hline Stdev & & & & & & 0.171 & 0.585 & 0.785 & 3.27 & 0.0565 & 0.00889 & 0.218 \\
\hline Median & & & & & & 0.193 & 0.408 & 0.705 & 2.52 & 0.108 & 0.0102 & 0.201 \\
\hline 25th & & & & & & 0.139 & 0.239 & 0.416 & 1.81 & 0.0790 & 0.00736 & 0.154 \\
\hline 75th & & & & & & 0.320 & 0.745 & 1.18 & 4.24 & 0.149 & 0.0118 & 0.332 \\
\hline RSD & & & & & & $68 \%$ & $94 \%$ & $80 \%$ & $84 \%$ & $48 \%$ & $77 \%$ & $78 \%$ \\
\hline $2941-7$ & SB & 1 & 4.3 & 0.066 & 0.01720 & 1.55 & 4.17 & 3.86 & 14.1 & 0.171 & 0.0229 & 0.642 \\
\hline $2941-8$ & SB & 1 & 3.7 & 0.066 & 0.01720 & 2.16 & 4.29 & 3.79 & 10.5 & 0.194 & 0.0214 & 0.744 \\
\hline $2941-25$ & SB & 2 & 139.7 & 0.202 & 0.01720 & 0.734 & 1.33 & 2.26 & 7.03 & 0.151 & 0.0235 & 0.585 \\
\hline $2941-26$ & SB & 2 & 143.3 & 0.205 & 0.01720 & 0.796 & 1.99 & 1.78 & 6.12 & 0.162 & 0.0212 & 0.573 \\
\hline 2941-31 AVG & SB & 3 & 119.8 & 0.182 & 0.01720 & 4.12 & 5.19 & 4.64 & 9.14 & 0.363 & 0.0327 & 1.25 \\
\hline 2941-50 Avg & SB & 5 & 999 & 1.002 & 0.01720 & 1.39 & 2.17 & 1.77 & 3.67 & 0.113 & 0.0120 & 0.421 \\
\hline 2941-74 AVG & SB & 6 & 306.9 & 0.379 & 0.01720 & 2.43 & 3.21 & 2.69 & 5.84 & 0.196 & 0.0215 & 0.950 \\
\hline $2941-79$ & SB & 7 & 160.9 & 0.223 & 0.01720 & 0.238 & 0.335 & 0.501 & 2.03 & 0.0713 & 0.00725 & 0.258 \\
\hline 2941-105 AVG & SB & 8 & 464.9 & 0.527 & 0.01720 & 0.868 & 1.25 & 1.02 & 18.6 & 0.0956 & 0.00978 & 0.348 \\
\hline $2941-115$ & SB & 9 & 609.6 & 0.672 & 0.01720 & 1.25 & 1.81 & 2.10 & 8.02 & 0.152 & 0.0191 & 0.654 \\
\hline 2941-119 & SB & 10 & 362.8 & 0.425 & 0.01720 & 0.266 & 0.371 & 0.714 & 3.14 & 0.0816 & 0.00664 & 0.355 \\
\hline $2941-130$ & SB & 11 & 88.1 & 0.150 & 0.01720 & 0.626 & 0.997 & 1.76 & 8.18 & 0.170 & 0.0248 & 0.725 \\
\hline $2941-160$ & $\mathrm{SB}$ & 12 & 221.7 & 0.284 & 0.01720 & 4.71 & 7.00 & 5.71 & 10.5 & 0.391 & 0.0388 & 1.51 \\
\hline $2941-162$ & SB & 13 & 723.7 & 0.786 & 0.01720 & 0.305 & 0.547 & 0.638 & 1.79 & 0.0612 & 0.0110 & 0.242 \\
\hline $2941-374$ & $\mathrm{SB}$ & 14 & 0.00 & 0.073 & 0.01720 & 0.745 & 1.19 & 4.03 & 28.3 & 0.184 & 0.0534 & 0.892 \\
\hline $2941-370$ & SB & 15 & 149.4 & 0.211 & 0.01720 & 0.639 & 3.25 & 1.03 & 11.3 & 0.146 & 0.0153 & 0.174 \\
\hline $2941-409$ & SB & 16 & 0.0 & 0.072 & 0.01720 & 1.21 & 1.91 & 2.41 & 9.03 & 0.113 & 0.0174 & 0.680 \\
\hline $2941-397$ & SB & 17 & 133.0 & 0.195 & 0.01720 & 1.32 & 1.97 & 2.00 & 5.27 & 0.158 & 0.0156 & 0.660 \\
\hline $2941-406$ & SB & 18 & 94.4 & 0.156 & 0.01720 & 0.324 & 0.561 & 1.10 & 3.84 & 0.0790 & 0.0100 & 0.420 \\
\hline $2941-420$ & SB & 19 & 107.4 & 0.169 & 0.01720 & 9.86 & 12.8 & 10.9 & 21.0 & 0.647 & 0.0659 & 2.564 \\
\hline Average & & & & & & 1.78 & 2.82 & 2.73 & 9.37 & 0.185 & 0.0225 & 0.732 \\
\hline Stdev & & & & & & 2.25 & 2.94 & 2.39 & 6.77 & 0.138 & 0.0152 & 0.544 \\
\hline Median & & & & & & 1.04 & 1.94 & 2.05 & 8.10 & 0.155 & 0.0202 & 0.648 \\
\hline 25th & & & & & & 0.635 & 1.14 & 1.08 & 4.91 & 0.109 & 0.0117 & 0.404 \\
\hline 75th & & & & & & 1.71 & 3.48 & 3.80 & 10.7 & 0.187 & 0.0238 & 0.781 \\
\hline RSD & & & & & & $127 \%$ & $104 \%$ & $87 \%$ & $72 \%$ & $75 \%$ & $68 \%$ & $74 \%$ \\
\hline
\end{tabular}


Field Sample Results - Metals

\begin{tabular}{|c|c|c|c|c|c|c|c|c|c|c|c|c|}
\hline Sample ID & $\begin{array}{l}\text { Station } \\
\text { ID }\end{array}$ & $\begin{array}{c}\text { Event } \\
\text { No. }\end{array}$ & $\begin{array}{r}\text { Rain } \\
\text { Collected }\end{array}$ & $\begin{array}{c}\text { Sample } \\
\text { Vol. }\end{array}$ & $\begin{array}{r}\text { Funnel } \\
\text { Surface Area }\end{array}$ & $\mathrm{Cr}^{1}$ & $\mathrm{Ni}$ & $\mathrm{Cu}$ & Zn & As & Cd & Pb \\
\hline & & & $\mathrm{mL}$ & $\mathrm{L}$ & $\mathrm{m}^{2}$ & $\begin{array}{r}\mu \mathrm{g} / \mathrm{L} \\
0.0507 \\
0.161\end{array}$ & $\begin{array}{r}\mu \mathrm{g} / \mathrm{L} \\
0.0107 \\
0.0340\end{array}$ & $\begin{array}{r}\mu \mathrm{g} / \mathrm{L} \\
0.00532 \\
0.0169\end{array}$ & $\begin{array}{r}\mu \mathrm{g} / \mathrm{L} \\
0.0135 \\
0.0429\end{array}$ & $\begin{array}{r}\mu \mathrm{g} / \mathrm{L} \\
0.0071 \\
0.0226\end{array}$ & $\begin{array}{r}\mu \mathrm{g} / \mathrm{L} \\
0.0033 \\
0.0105\end{array}$ & $\begin{array}{r}\mu \mathrm{g} / \mathrm{L} \\
0.00219 \\
0.00696\end{array}$ \\
\hline 2941-4 AVG & $\mathrm{TCB}$ & 1 & 0.00 & 0.139 & 0.01720 & 4.24 & 5.20 & 20.0 & 104 & 1.52 & 0.105 & 12.2 \\
\hline $2941-22$ & TCB & 2 & 127.5 & 0.190 & 0.01720 & 3.55 & 4.12 & 24.5 & 86.4 & 1.57 & 0.115 & 9.82 \\
\hline 2941-27 AVG & TCB & 3 & 597.7 & 0.660 & 0.01720 & 1.09 & 1.70 & 10.0 & 28.0 & 0.351 & 0.0610 & 3.13 \\
\hline 2941-37 AVG & TCB & 4 & 300.1 & 0.362 & 0.01720 & 1.44 & 2.35 & 14.0 & 38.1 & 0.394 & 0.0551 & 4.32 \\
\hline $2941-75$ & TCB & 6 & 154 & 0.216 & 0.01039 & 0.617 & 1.04 & 4.44 & 21.2 & 0.188 & 0.0250 & 2.87 \\
\hline $2941-86$ & TCB & 7 & 59.8 & 0.122 & 0.006360 & 0.913 & 1.57 & 5.69 & 23.2 & 0.218 & 0.0223 & 1.60 \\
\hline 2941-89 & TCB & 8 & 355.9 & 0.418 & 0.01039 & 0.374 & 0.602 & 1.97 & 11.8 & 0.136 & 0.0154 & 1.75 \\
\hline $2941-90$ & TCB & 8 & 325 & 0.387 & 0.01039 & 0.303 & 0.533 & 2.04 & 11.0 & 0.149 & 0.0111 & 1.21 \\
\hline 2941-111 & TCB & 9 & 799.7 & 0.862 & 0.01039 & 0.379 & 0.353 & 1.82 & 8.14 & 0.0799 & 0.0153 & 1.12 \\
\hline 2941-109 & TCB & 9 & 719.8 & 0.782 & 0.01039 & 0.443 & 0.471 & 2.06 & 8.68 & 0.117 & 0.0188 & 1.81 \\
\hline $2941-123$ & TCB & 10 & 435.5 & 0.498 & 0.01039 & 0.430 & 0.468 & 2.40 & 14.6 & 0.116 & 0.0149 & 1.02 \\
\hline 2941-127 AVG & TCB & 11 & 477.9 & 0.540 & 0.01039 & 0.369 & 0.475 & 3.26 & 13.7 & 0.142 & 0.0219 & 1.69 \\
\hline $2941-157$ & TCB & 12 & 845.7 & 0.908 & 0.01039 & 0.422 & 0.441 & 2.18 & 8.28 & 0.155 & 0.0138 & 1.45 \\
\hline 2941-167 AVG & TCB & 13 & 318.7 & 0.381 & 0.01039 & 0.574 & 0.75 & 3.27 & 10.6 & 0.137 & 0.0177 & 2.02 \\
\hline $2941-375$ & TCB & 14 & 0.00 & 0.058 & 0.01039 & 0.809 & 2.43 & 10.7 & 65.4 & 0.365 & 0.107 & 6.99 \\
\hline $2941-383$ & TCB & 15 & 186.6 & 0.249 & 0.01720 & 0.925 & 2.49 & 8.84 & 29.9 & 0.283 & 0.0392 & 4.69 \\
\hline $2941-407$ & TCB & 16 & 31.6 & 0.094 & 0.01720 & 2.35 & 2.54 & 33.1 & 67.2 & 1.07 & 0.124 & 11.3 \\
\hline $2941-395$ & TCB & 17 & 904.2 & 0.966 & 0.01720 & 0.230 & 0.397 & 5.35 & 14.1 & 0.175 & 0.0456 & 3.20 \\
\hline $2941-386$ & TCB & 18 & 104.9 & 0.167 & 0.01720 & 1.57 & 2.04 & 34.5 & 78.6 & 0.448 & 0.177 & 38.8 \\
\hline $2941-425$ & TCB & 19 & 192.7 & 0.255 & 0.01720 & 1.80 & 2.98 & 23.0 & 60.2 & 0.567 & 0.156 & 35.8 \\
\hline Average & & & & & & 1.14 & 1.65 & 10.7 & 35.1 & 0.409 & 0.0580 & 7.34 \\
\hline Stdev & & & & & & 1.10 & 1.37 & 10.7 & 30.3 & 0.451 & 0.0528 & 10.8 \\
\hline Median & & & & & & 0.713 & 1.31 & 5.52 & 22.2 & 0.203 & 0.0321 & 3.00 \\
\hline 25th & & & & & & 0.411 & 0.474 & 2.35 & 11.6 & 0.140 & 0.0171 & 1.67 \\
\hline 75th & & & & & & 1.48 & 2.44 & 15.5 & 61.5 & 0.407 & 0.105 & 7.69 \\
\hline RSD & & & & & & $97 \%$ & $83 \%$ & $100 \%$ & $86 \%$ & $110 \%$ & $91 \%$ & $147 \%$ \\
\hline $2941-377$ & $\mathrm{TM}$ & 14 & 0.00 & 0.057 & 0.01039 & 0.362 & 0.730 & 6.64 & 19.1 & 0.172 & 0.0770 & 0.654 \\
\hline $2941-382$ & $\mathrm{TM}$ & 15 & 169.70 & 0.232 & 0.01720 & 0.299 & 1.25 & 2.92 & 12.5 & 0.235 & 0.0175 & 0.913 \\
\hline $2941-408$ & $\mathrm{TM}$ & 16 & 26.00 & 0.088 & 0.01720 & 1.45 & 1.15 & 6.22 & 19.5 & 0.31 & 0.0309 & 2.32 \\
\hline $2941-393$ & TM & 17 & 798.20 & 0.860 & 0.01720 & 0.0315 & 0.253 & 1.31 & 3.25 & 0.08 & 0.006044 & 0.609 \\
\hline 2941-389 & TM & 18 & 93.90 & 0.156 & 0.01720 & 0.394 & 1.11 & 3.82 & 14.2 & 0.274 & 0.023 & 2.20 \\
\hline $2941-402$ & TM & 19 & 92.60 & 0.155 & 0.01720 & 0.423 & 1.21 & 4.97 & 19.8 & 0.366 & 0.04124 & 2.84 \\
\hline Average & & & & & & 0.493 & 0.950 & 4.313 & 14.721 & 0.239 & 0.033 & 1.589 \\
\hline Stdev & & & & & & 0.489 & 0.389 & 2.036 & 6.389 & 0.101 & 0.025 & 0.976 \\
\hline Median & & & & & & 0.378 & 1.130 & 4.394 & 16.670 & 0.254 & 0.027 & 1.554 \\
\hline 25th & & & & & & 0.315 & 0.824 & 3.143 & 12.938 & 0.187 & 0.019 & 0.719 \\
\hline 75th & & & & & & 0.42 & 1.20 & 5.91 & 19.39 & 0.30 & 0.04 & 2.29 \\
\hline RSD & & & & & & $99 \%$ & $41 \%$ & $47 \%$ & $43 \%$ & $42 \%$ & $76 \%$ & $61 \%$ \\
\hline $2941-2$ & WP & 1 & 0.00 & 0.138 & 0.01720 & 0.532 & 1.76 & 1.12 & 10.4 & 0.0800 & 0.0124 & 0.324 \\
\hline $2941-21$ & WP & 2 & 259.5 & 0.322 & 0.01720 & 0.311 & 0.851 & 1.43 & 4.78 & 0.155 & 0.0168 & 0.357 \\
\hline $2941-28$ & WP & 3 & 558.8 & 0.621 & 0.01720 & 0.290 & 0.605 & 1.80 & 7.59 & 0.0734 & 0.0150 & 0.439 \\
\hline $2941-38$ & WP & 4 & 136.7 & 0.199 & 0.01720 & 0.264 & 0.522 & 1.26 & 20.5 & 0.142 & 0.0164 & 0.445 \\
\hline $2941-78$ & WP & 6 & 78.2 & 0.140 & 0.01039 & 0.189 & 0.477 & 0.859 & 3.53 & 0.115 & 0.0129 & 0.269 \\
\hline $2941-83$ & WP & 7 & 91.0 & 0.153 & 0.006360 & 0.166 & 0.307 & 0.505 & 4.30 & 0.127 & 0.0102 & 0.101 \\
\hline $2941-87$ & WP & 8 & 295.3 & 0.357 & 0.01039 & 0.246 & 0.438 & 0.743 & 3.27 & 0.0677 & 0.0101 & 0.218 \\
\hline $2941-110$ & WP & 9 & 506.8 & 0.569 & 0.01039 & 0.296 & 0.232 & 0.700 & 3.61 & 0.110 & 0.00993 & 0.240 \\
\hline $2941-117$ & WP & 10 & 404.8 & 0.467 & 0.01039 & 0.205 & 0.254 & 0.624 & 2.80 & 0.0681 & 0.00857 & 0.206 \\
\hline $2941-126$ & WP & 11 & 258.8 & 0.321 & 0.01039 & 0.158 & 0.218 & 0.589 & 2.83 & 0.0799 & 0.00846 & 0.278 \\
\hline 2941-154 re & WP & 12 & 734.8 & 0.797 & 0.01039 & 0.131 & 0.123 & 0.499 & 1.98 & 0.0572 & 0.00429 & 0.229 \\
\hline $2941-166$ & WP & 13 & 535.9 & 0.598 & 0.01039 & 0.161 & 0.187 & 0.424 & 1.63 & 0.0355 & 0.00761 & 0.180 \\
\hline $2941-170$ re & WP & 14 & 0.00 & 0.059 & 0.01039 & 1.239 & 1.43 & 2.21 & 15.9 & 0.120 & 0.0376 & 2.18 \\
\hline $2941-378$ & WP & 15 & 150.5 & 0.213 & 0.01720 & 0.364 & 0.555 & 0.692 & 5.79 & 0.0914 & 0.00884 & 0.320 \\
\hline $2941-384$ & WP & 16 & 146.8 & 0.209 & 0.01720 & 0.353 & 1.927 & 1.081 & 5.27 & 0.0920 & 0.00666 & 0.423 \\
\hline $2941-388$ & WP & 17 & 505.1 & 0.567 & 0.01720 & 0.128 & 0.664 & 0.928 & 5.17 & 0.0701 & 0.00755 & 0.346 \\
\hline 2941-391 & WP & 18 & 194.3 & 0.256 & 0.01720 & 0.264 & 1.524 & 1.045 & 5.37 & 0.0814 & 0.00909 & 0.466 \\
\hline $2941-423$ & WP & 19 & 394.4 & 0.411 & 0.01720 & 0.226 & 0.613 & 0.926 & 4.89 & 0.124 & 0.0106 & 0.416 \\
\hline Average & & & & & & 0.307 & 0.704 & 0.968 & 6.092 & 0.094 & 0.012 & 0.413 \\
\hline Stdev & & & & & & 0.253 & 0.566 & 0.470 & 4.927 & 0.032 & 0.007 & 0.453 \\
\hline Median & & & & & & 0.255 & 0.538 & 0.892 & 4.832 & 0.086 & 0.010 & 0.322 \\
\hline 25th & & & & & & 0.172 & 0.267 & 0.641 & 3.334 & 0.071 & 0.008 & 0.231 \\
\hline 75th & & & & & & 0.31 & 0.80 & 1.11 & 5.68 & 0.12 & 0.01 & 0.42 \\
\hline RSD & & & & & & $83 \%$ & $80 \%$ & $49 \%$ & $81 \%$ & $34 \%$ & $61 \%$ & $110 \%$ \\
\hline
\end{tabular}


Field Sample Results - Metals

$\begin{array}{cccrrr} & \text { Station } & \text { Event } & \text { Rain } & \text { Sample } & \text { Funnel } \\ \text { Sample ID } & \text { ID } & \text { No. } & \text { Collected } & \text { Vol. } & \text { Surface Area }\end{array}$

$\mathrm{Ni}$

Cu

Zn

As

Cd

$\mathbf{P b}$

$\mathrm{mL} \quad \mathrm{L} \quad \mathrm{m}^{2} \mu \mathrm{g} / \mathrm{m}^{2} /$ day $\quad \mu \mathrm{g} / \mathrm{m}^{2} /$ day $\quad \mu \mathrm{g} / \mathrm{m}^{2} /$ day $\quad \mu \mathrm{g} / \mathrm{m}^{2} /$ day $\quad \mu \mathrm{g} / \mathrm{m}^{2} /$ day $\quad \mu \mathrm{g} / \mathrm{m}^{2} /$ day $\quad \mu \mathrm{g} / \mathrm{m}^{2} /$ day

\begin{tabular}{|c|c|c|c|c|c|c|c|c|c|c|c|c|}
\hline 2941-1 & EB & & & & 0.01720 & & & & & & & \\
\hline $2941-6$ & EB & & & & 0.01720 & & & & & & & \\
\hline 2941-101 & EB & & & & 0.01039 & & & & & & & \\
\hline 2941-107 & EB & & & & 0.01039 & & & & & & & \\
\hline \multicolumn{13}{|l|}{ Average } \\
\hline \multicolumn{13}{|l|}{ Stdev } \\
\hline \multicolumn{13}{|c|}{ Rinse Water Contribution ( $\mu \mathrm{g})$} \\
\hline 2941-10 & $\mathrm{HC}$ & 1 & 0.2 & 0.062 & 0.01720 & 0.0776 & 0.111 & 0.414 & 7.61 & 0.0165 & 0.00348 & 0.0467 \\
\hline 2941-20 & $\mathrm{HC}$ & 2 & 860.2 & 0.922 & 0.01720 & 0.564 & 0.658 & 1.42 & 13.7 & 0.170 & 0.0747 & 0.286 \\
\hline 2941-34 & $\mathrm{HC}$ & 3 & 350 & 0.412 & 0.01720 & 0.467 & 0.230 & 0.591 & 4.35 & 0.162 & 0.0277 & 0.366 \\
\hline 2941-42 & $\mathrm{HC}$ & 4 & 67.9 & 0.130 & 0.01720 & 0.160 & 0.167 & 1.08 & 2.99 & 0.0425 & 0.0162 & 0.180 \\
\hline 2941-71 & $\mathrm{HC}$ & 6 & 446.9 & 0.509 & 0.01039 & 0.179 & 0.488 & 0.380 & 2.00 & 0.105 & 0.0202 & 0.125 \\
\hline 2941-72 & $\mathrm{HC}$ & 6 & 483.9 & 0.546 & 0.01039 & 0.194 & 0.231 & 0.575 & 15.1 & 0.142 & 0.0273 & 0.149 \\
\hline 2941-81 & $\mathrm{HC}$ & 7 & 272.1 & 0.334 & 0.01039 & 0.0900 & 0.411 & 0.434 & 6.61 & 0.107 & 0.0230 & 0.168 \\
\hline 2941-80 & $\mathrm{HC}$ & 7 & 257.7 & 0.320 & 0.01039 & 0.0846 & 0.207 & 0.423 & 2.46 & 0.104 & 0.0199 & 0.123 \\
\hline 2941-104 & $\mathrm{HC}$ & 8 & 363.7 & 0.426 & 0.01039 & 0.235 & 0.274 & 0.463 & 7.95 & 0.0858 & 0.0157 & 0.183 \\
\hline 2941-113 & $\mathrm{HC}$ & 9 & 666.2 & 0.728 & 0.01039 & 1.14 & 0.592 & 1.13 & 14.3 & 0.308 & 0.0387 & 0.599 \\
\hline 2941-124 & $\mathrm{HC}$ & 10 & 240.1 & 0.302 & 0.01039 & 0.409 & 1.82 & 0.789 & 7.78 & 0.0983 & 0.0106 & 0.326 \\
\hline 2941-151 & $\mathrm{HC}$ & 11 & 467.3 & 0.529 & 0.01039 & 0.558 & 0.270 & 0.690 & 16.2 & 0.188 & 0.0184 & 0.308 \\
\hline $2941-159$ & $\mathrm{HC}$ & 12 & 713.1 & 0.775 & 0.01039 & 0.737 & 0.657 & 1.43 & 9.80 & 0.305 & 0.0254 & 0.829 \\
\hline 2941-161 & $\mathrm{HC}$ & 13 & 630.2 & 0.692 & 0.01039 & 0.202 & 0.407 & 0.633 & 4.45 & 0.127 & 0.0266 & 0.507 \\
\hline $2941-373$ & $\mathrm{HC}$ & 14 & 0.00 & 0.070 & 0.01039 & 0.105 & 0.161 & 0.454 & 2.72 & 0.0291 & 0.0137 & 0.342 \\
\hline $2941-381$ & $\mathrm{HC}$ & 15 & 239.5 & 0.302 & 0.01720 & 0.133 & 0.255 & 0.551 & 5.11 & 0.0778 & 0.0051 & 0.136 \\
\hline 2941-390 & $\mathrm{HC}$ & 16 & 11.4 & 0.073 & 0.01720 & 0.141 & 0.434 & 1.443 & 1.27 & 0.0255 & 0.0019 & 0.126 \\
\hline $2941-387$ & $\mathrm{HC}$ & 17 & 749.2 & 0.811 & 0.01720 & 0.014 & 0.306 & 0.843 & 3.16 & 0.0914 & 0.0096 & 0.386 \\
\hline 2941-399 & $\mathrm{HC}$ & 18 & 176.5 & 0.239 & 0.01720 & 0.201 & 0.587 & 0.528 & 1.99 & 0.0718 & 0.0045 & 0.330 \\
\hline $2941-403$ & $\mathrm{HC}$ & 19 & 606.8 & 0.669 & 0.01720 & 0.011 & 0.257 & 0.845 & 3.69 & 0.1403 & 0.0095 & 0.404 \\
\hline Average & & & & & & 0.285 & 0.426 & 0.756 & 6.66 & 0.120 & 0.0196 & 0.296 \\
\hline Stdev & & & & & & 0.284 & 0.370 & 0.359 & 4.79 & 0.0796 & 0.0162 & 0.190 \\
\hline Median & & & & & & 0.186 & 0.290 & 0.612 & 4.78 & 0.105 & 0.0173 & 0.297 \\
\hline 25th & & & & & & 0.101 & 0.231 & 0.460 & 2.93 & 0.0763 & 0.0096 & 0.146 \\
\hline 75th & & & & & & 0.424 & 0.513 & 0.904 & 8.42 & 0.147 & 0.0257 & 0.371 \\
\hline RSD & & & & & & $100 \%$ & $87 \%$ & $48 \%$ & $72 \%$ & $66 \%$ & $83 \%$ & $64 \%$ \\
\hline $2941-5$ & NR & 1 & 0.00 & 0.070 & 0.01720 & 0.259 & 0.838 & 0.551 & 2.86 & 0.0464 & 0.00337 & 0.178 \\
\hline 2941-23 & NR & 2 & 131.5 & 0.194 & 0.01720 & 0.544 & 0.593 & 1.93 & 10.4 & 0.238 & 0.0195 & 0.734 \\
\hline 2941-29 & NR & 3 & 1002.5 & 1.005 & 0.01720 & 0.495 & 0.947 & 2.15 & 22.7 & 0.355 & 0.0442 & 1.14 \\
\hline 2941-35 & NR & 4 & 237.2 & 0.299 & 0.01720 & 0.335 & 0.421 & 1.35 & 49.1 & 0.200 & 0.0251 & 1.02 \\
\hline 2941-77 & NR & 6 & 208.1 & 0.270 & 0.01039 & 0.164 & 0.081 & 0.627 & 5.38 & 0.113 & 0.00556 & 0.292 \\
\hline 2941-85 & NR & 7 & 52.0 & 0.114 & 0.006360 & 0.206 & 0.276 & 1.99 & 6.34 & 0.0833 & 0.0101 & 0.0646 \\
\hline 2941-103 & NR & 8 & 351.1 & 0.413 & 0.01039 & 0.252 & 0.421 & 1.02 & 7.48 & 0.184 & 0.0110 & 0.475 \\
\hline 2941-112 & NR & 9 & 785.2 & 0.847 & 0.01039 & 0.823 & 0.523 & 1.99 & 13.0 & 0.403 & 0.0345 & 2.01 \\
\hline $2941-116$ & NR & 10 & 380.7 & 0.443 & 0.01039 & 0.452 & 0.371 & 1.39 & 6.28 & 0.129 & 0.0177 & 0.770 \\
\hline $2941-129$ & NR & 11 & 397.9 & 0.460 & 0.01039 & 0.279 & 0.176 & 0.945 & 4.74 & 0.335 & 0.0214 & 0.656 \\
\hline $2941-128$ & NR & 11 & 467.2 & 0.529 & 0.01039 & 0.955 & 0.724 & 3.38 & 18.9 & 0.589 & 0.0512 & 1.65 \\
\hline 2941-155 AVG & NR & 12 & 970.2 & 1.032 & 0.01039 & 1.97 & 3.39 & 3.45 & 22.7 & 0.781 & 0.0916 & 1.56 \\
\hline 2941-153 re & NR & 12 & 948.8 & 1.011 & 0.01039 & 1.65 & 3.56 & 2.61 & 15.6 & 0.512 & 0.0850 & 1.77 \\
\hline $2941-165$ & NR & 13 & 373.8 & 0.436 & 0.01039 & 0.602 & 2.29 & 1.22 & 6.85 & 0.171 & 0.0265 & 0.981 \\
\hline 2941-371 & NR & 14 & 0.00 & 0.062 & 0.01039 & 0.270 & 0.324 & 1.47 & 5.64 & 0.101 & 0.0120 & 0.604 \\
\hline $2941-372$ & NR & 15 & 401.6 & 0.404 & 0.01720 & 0.890 & 1.036 & 2.89 & 11.1 & 0.332 & 0.0194 & 0.698 \\
\hline $2941-400$ & NR & 16 & 103.1 & 0.165 & 0.01720 & 0.254 & 0.826 & 1.11 & 4.70 & 0.154 & 0.0120 & 0.332 \\
\hline 2941-398 & NR & 17 & 943.2 & 1.005 & 0.01720 & 0.251 & 0.485 & 2.44 & 12.0 & 0.298 & 0.0370 & 1.080 \\
\hline 2941-392 & NR & 18 & 144.4 & 0.206 & 0.01720 & 0.187 & 0.340 & 1.63 & 8.72 & 0.118 & 0.0308 & 1.148 \\
\hline $2941-424$ & NR & 19 & 87.8 & 0.150 & 0.01720 & 0.332 & 0.348 & 3.38 & 8.87 & 0.252 & 0.0291 & 0.533 \\
\hline Average & & & & & & 0.559 & 0.899 & 1.88 & 12.2 & 0.270 & 0.0294 & 0.885 \\
\hline Stdev & & & & & & 0.492 & 1.00 & 0.909 & 10.5 & 0.188 & 0.0238 & 0.544 \\
\hline Median & & & & & & 0.334 & 0.504 & 1.78 & 8.79 & 0.219 & 0.0233 & 0.752 \\
\hline 25th & & & & & & 0.254 & 0.346 & 1.19 & 6.12 & 0.126 & 0.0120 & 0.518 \\
\hline 75th & & & & & & 0.657 & 0.865 & 2.48 & 13.6 & 0.340 & 0.0351 & 1.14 \\
\hline RSD & & & & & & $\mathbf{8 8} \%$ & $111 \%$ & $48 \%$ & $86 \%$ & $70 \%$ & $81 \%$ & $61 \%$ \\
\hline 2941-3 & PB & 1 & 101.1 & 0.242 & 0.01720 & 1.60 & 1.17 & 1.25 & 6.90 & 0.176 & 0.00512 & 0.156 \\
\hline 2941-19 & PB & 2 & 304 & 0.366 & 0.01720 & 0.540 & 1.11 & 2.06 & 28.4 & 0.181 & 0.0193 & 0.477 \\
\hline 2941-30 & PB & 3 & 388.8 & 0.451 & 0.01720 & 0.410 & 0.525 & 1.38 & 47.2 & 0.129 & 0.0273 & 0.433 \\
\hline 2941-36 & PB & 4 & 122.7 & 0.185 & 0.01720 & 0.158 & 0.167 & 0.534 & 3.24 & 0.0937 & 0.0108 & 0.251 \\
\hline 2941-76 & PB & 6 & 74.6 & 0.137 & 0.010387 & 0.120 & 0.170 & 0.771 & 2.21 & 0.0688 & 0.0136 & 0.118 \\
\hline 2941-84 & PB & 7 & 250.5 & 0.313 & 0.00636 & 0.270 & 0.318 & 0.701 & 9.83 & 0.200 & 0.0163 & 0.117 \\
\hline 2941-88 & PB & 8 & 124.4 & 0.186 & 0.01039 & 0.408 & 2.43 & 1.44 & 6.99 & 0.128 & 0.0361 & 0.210 \\
\hline $2941-108$ & PB & 9 & 308.7 & 0.371 & 0.01039 & 0.497 & 0.900 & 1.33 & 8.57 & 0.284 & 0.0344 & 0.464 \\
\hline
\end{tabular}


Field Sample Results - Metals

$\begin{array}{cccrrr} & \text { Station } & \text { Event } & \text { Rain } & \text { Sample } & \text { Funnel } \\ \text { Sample ID } & \text { ID } & \text { No. } & \text { Collected } & \text { Vol. } & \text { Surface Area }\end{array}$ Cr $\mathrm{Ni}$ Cu Zn As Cd $\mathbf{P b}$

$\mathrm{mL} \quad \mathrm{L} \quad \mathrm{m}^{2} \mu \mathrm{g} / \mathrm{m}^{2} /$ day $\quad \mu \mathrm{g} / \mathrm{m}^{2} /$ day $\quad \mu \mathrm{g} / \mathrm{m}^{2} /$ day $\quad \mu \mathrm{g} / \mathrm{m}^{2} /$ day $\quad \mu \mathrm{g} / \mathrm{m}^{2} /$ day $\quad \mu \mathrm{g} / \mathrm{m}^{2} / \mathrm{day} \quad \mu \mathrm{g} / \mathrm{m}^{2} /$ day

\begin{tabular}{|c|c|c|c|c|c|c|c|c|c|c|c|c|}
\hline $2941-125$ & PB & 11 & 260.8 & 0.323 & 0.01039 & 0.649 & 2.15 & 1.72 & 17.1 & 0.227 & 0.127 & 0.916 \\
\hline $2941-156$ & PB & 12 & 164.1 & 0.226 & 0.01039 & 0.971 & 2.89 & 1.36 & 6.82 & 0.217 & 0.0349 & 0.814 \\
\hline $2941-164$ & PB & 13 & 608.9 & 0.671 & 0.01039 & 0.522 & 0.495 & 0.841 & 4.00 & 0.184 & 0.0298 & 0.734 \\
\hline 2941-169 & PB & 14 & 27.87 & 0.090 & 0.01039 & 0.583 & 0.745 & 11.8 & 77.4 & 0.104 & 0.424 & 0.497 \\
\hline $2941-379$ & PB & 15 & 290.9 & 0.353 & 0.01720 & 0.461 & 0.804 & 1.35 & 10.2 & 0.172 & 0.0168 & 0.597 \\
\hline $2941-404$ & PB & 16 & 3.2 & 0.065 & 0.01720 & 0.223 & 0.320 & 0.334 & 1.61 & 0.0335 & 0.00459 & 0.143 \\
\hline $2941-385$ & PB & 17 & 149.8 & 0.212 & 0.01720 & 0.384 & 0.902 & 1.60 & 4.34 & 0.144 & 0.0151 & 0.516 \\
\hline $2941-396$ & PB & 18 & 263.6 & 0.326 & 0.01720 & 0.372 & 0.701 & 1.15 & 3.91 & 0.111 & 0.0156 & 0.402 \\
\hline $2941-421$ & PB & 19 & 145.1 & 0.207 & 0.01720 & 0.151 & 0.321 & 0.706 & 2.89 & 0.0955 & 0.00988 & 0.409 \\
\hline Average & & & & & & 0.490 & 0.95 & 1.78 & 14.2 & 0.150 & 0.0495 & 0.427 \\
\hline Stdev & & & & & & 0.356 & 0.807 & 2.62 & 20.0 & 0.0637 & 0.100 & 0.244 \\
\hline Median & & & & & & 0.410 & 0.745 & 1.33 & 6.90 & 0.144 & 0.0168 & 0.433 \\
\hline 25th & & & & & & 0.270 & 0.321 & 0.771 & 3.91 & 0.104 & 0.0136 & 0.210 \\
\hline 75th & & & & & & 0.540 & 1.11 & 1.44 & 10.2 & 0.184 & 0.0344 & 0.516 \\
\hline RSD & & & & & & $73 \%$ & $85 \%$ & $147 \%$ & $140 \%$ & $43 \%$ & $203 \%$ & $57 \%$ \\
\hline $2941-9$ & PO & 1 & 0.00 & 0.059 & 0.01720 & 0.148 & 0.396 & 0.443 & 0.953 & 0.0535 & 0.00175 & 0.107 \\
\hline 2941-24 AVG & $\mathrm{PO}$ & 2 & 658.6 & 0.721 & 0.01720 & 0.464 & 1.54 & 2.49 & 5.05 & 0.321 & 0.0233 & 0.446 \\
\hline $2941-33$ & $\mathrm{PO}$ & 3 & 170.9 & 0.233 & 0.01720 & 0.163 & 0.417 & 1.26 & 2.27 & 0.141 & 0.0156 & 0.269 \\
\hline $2941-32$ & $\mathrm{PO}$ & 3 & 151.5 & 0.214 & 0.01720 & 0.381 & 1.13 & 0.829 & 2.84 & 0.138 & 0.0145 & 0.410 \\
\hline 2941-39 & PO & 4 & 64.6 & 0.127 & 0.01720 & 0.203 & 0.289 & 0.415 & 1.29 & 0.0635 & 0.00334 & 0.134 \\
\hline $2941-41$ & $\mathrm{PO}$ & 4 & 49.7 & 0.112 & 0.01720 & 0.141 & 0.088 & 0.551 & 1.66 & 0.0898 & 0.00490 & 0.166 \\
\hline $2941-73$ & $\mathrm{PO}$ & 6 & 313.2 & 0.365 & 0.01039 & 0.166 & 0.681 & 0.665 & 2.44 & 0.151 & 0.0123 & 0.141 \\
\hline $2941-82$ & $\mathrm{PO}$ & 7 & 129.6 & 0.192 & 0.01039 & 0.0616 & 0.138 & 0.359 & 1.10 & 0.0939 & 0.00755 & 0.0726 \\
\hline $2941-106$ & PO & 8 & 270.4 & 0.332 & 0.01039 & 0.613 & 1.90 & 0.909 & 17.6 & 0.149 & 0.00774 & 0.360 \\
\hline $2941-114$ & PO & 9 & 505.8 & 0.568 & 0.01039 & 0.706 & 0.470 & 1.60 & 12.5 & 0.401 & 0.0358 & 0.634 \\
\hline 2941-118 & $\mathrm{PO}$ & 10 & 400.2 & 0.462 & 0.01039 & 0.423 & 0.329 & 1.65 & 5.83 & 0.219 & 0.0210 & 0.447 \\
\hline $2941-152$ & PO & 11 & 335.3 & 0.397 & 0.01039 & 0.500 & 0.513 & 1.14 & 4.92 & 0.152 & 0.0250 & 0.418 \\
\hline $2941-158$ & PO & 12 & 752.8 & 0.815 & 0.01039 & 1.01 & 2.81 & 2.54 & 9.23 & 0.492 & 0.0275 & 1.06 \\
\hline $2941-163$ & $\mathrm{PO}$ & 13 & 586.3 & 0.648 & 0.01039 & 0.451 & 1.03 & 1.08 & 5.44 & 0.194 & 0.0190 & 0.638 \\
\hline $2941-376$ & $\mathrm{PO}$ & 14 & 0.00 & 0.070 & 0.01039 & 0.256 & 0.171 & 0.577 & 1.80 & 0.0329 & 0.00319 & 0.431 \\
\hline $2941-380$ & $\mathrm{PO}$ & 15 & 212.5 & 0.275 & 0.01720 & 0.325 & 2.20 & 1.40 & 10.1 & 0.191 & 0.0203 & 0.321 \\
\hline $2941-394$ & PO & 16 & 0.0 & 0.066 & 0.01720 & 0.0977 & 0.519 & 0.846 & 2.64 & 0.0770 & 0.00398 & 0.183 \\
\hline $2941-401$ & $\mathrm{PO}$ & 17 & 571.1 & 0.633 & 0.01720 & 0.0946 & 0.494 & 1.54 & 6.05 & 0.207 & 0.0260 & 0.415 \\
\hline $2941-405$ & $\mathrm{PO}$ & 18 & 122.0 & 0.184 & 0.01720 & 0.133 & 0.346 & 2.41 & 9.95 & 0.118 & 0.0342 & 0.242 \\
\hline $2941-422$ & PO & 19 & 349.8 & 0.412 & 0.01720 & 0.193 & 0.337 & 1.32 & 4.44 & 0.155 & 0.0120 & 0.509 \\
\hline Average & & & & & & 0.326 & 0.790 & 1.20 & 5.41 & 0.172 & 0.0160 & 0.370 \\
\hline Stdev & & & & & & 0.245 & 0.757 & 0.682 & 4.44 & 0.116 & 0.0105 & 0.262 \\
\hline Median & & & & & & 0.230 & 0.482 & 1.11 & 4.68 & 0.150 & 0.0150 & 0.385 \\
\hline 25th & & & & & & 0.146 & 0.335 & 0.643 & 2.15 & 0.0929 & 0.00689 & 0.178 \\
\hline 75th & & & & & & 0.454 & 1.06 & 1.56 & 6.84 & 0.197 & 0.0237 & 0.446 \\
\hline RSD & & & & & & $75 \%$ & $96 \%$ & $57 \%$ & $82 \%$ & $67 \%$ & $66 \%$ & $71 \%$ \\
\hline $2941-7$ & SB & 1 & 4.3 & 0.066 & 0.01720 & 0.361 & 0.976 & 0.927 & 3.34 & 0.0396 & 0.00480 & 0.154 \\
\hline $2941-8$ & $\mathrm{SB}$ & 1 & 3.7 & 0.066 & 0.01720 & 0.504 & 0.997 & 0.902 & 2.44 & 0.0446 & 0.00438 & 0.177 \\
\hline $2941-25$ & SB & 2 & 139.7 & 0.202 & 0.01720 & 0.600 & 1.09 & 1.89 & 5.83 & 0.124 & 0.0188 & 0.489 \\
\hline $2941-26$ & SB & 2 & 143.3 & 0.205 & 0.01720 & 0.664 & 1.67 & 1.52 & 5.16 & 0.136 & 0.0172 & 0.488 \\
\hline 2941-31 AVG & SB & 3 & 119.8 & 0.182 & 0.01720 & 3.34 & 4.19 & 3.77 & 7.37 & 0.293 & 0.0257 & 1.01 \\
\hline 2941-50 Avg & SB & 5 & 999 & 1.002 & 0.01720 & 10.1 & 15.7 & 12.9 & 26.6 & 0.820 & 0.0860 & 3.07 \\
\hline 2941-74 AVG & $\mathrm{SB}$ & 6 & 306.9 & 0.379 & 0.01720 & 3.55 & 4.68 & 3.94 & 8.53 & 0.286 & 0.0309 & 1.39 \\
\hline $2941-79$ & $\mathrm{SB}$ & 7 & 160.9 & 0.223 & 0.01720 & 0.180 & 0.244 & 0.404 & 1.59 & 0.0561 & 0.00515 & 0.209 \\
\hline 2941-105 AVG & SB & 8 & 464.9 & 0.527 & 0.01720 & 1.76 & 2.52 & 2.09 & 38.0 & 0.193 & 0.0192 & 0.711 \\
\hline $2941-115$ & SB & 9 & 609.6 & 0.672 & 0.01720 & 2.85 & 4.13 & 4.83 & 18.4 & 0.347 & 0.0432 & 1.50 \\
\hline 2941-119 & SB & 10 & 362.8 & 0.425 & 0.01720 & 0.425 & 0.582 & 1.17 & 5.12 & 0.133 & 0.0102 & 0.584 \\
\hline $2941-130$ & SB & 11 & 88.1 & 0.150 & 0.01720 & 0.350 & 0.551 & 1.02 & 4.70 & 0.0969 & 0.0136 & 0.421 \\
\hline $2941-160$ & $\mathrm{SB}$ & 12 & 221.7 & 0.284 & 0.01720 & 5.96 & 8.85 & 7.25 & 13.2 & 0.494 & 0.0484 & 1.91 \\
\hline $2941-162$ & SB & 13 & 723.7 & 0.786 & 0.01720 & 0.858 & 1.54 & 1.82 & 5.07 & 0.173 & 0.0305 & 0.691 \\
\hline $2941-374$ & SB & 14 & 0.00 & 0.073 & 0.01720 & 0.246 & 0.385 & 1.42 & 9.94 & 0.0627 & 0.0179 & 0.314 \\
\hline $2941-370$ & SB & 15 & 149.4 & 0.211 & 0.01720 & 0.509 & 2.63 & 0.845 & 9.22 & 0.118 & 0.0118 & 0.142 \\
\hline $2941-409$ & SB & 16 & 0.0 & 0.072 & 0.01720 & 0.443 & 0.685 & 0.916 & 3.36 & 0.0406 & 0.00557 & 0.258 \\
\hline $2941-397$ & $\mathrm{SB}$ & 17 & 133.0 & 0.195 & 0.01720 & 1.14 & 1.69 & 1.75 & 4.53 & 0.1360 & 0.0127 & 0.575 \\
\hline $2941-406$ & SB & 18 & 94.4 & 0.156 & 0.01720 & 0.196 & 0.333 & 0.713 & 2.44 & 0.0494 & 0.00570 & 0.272 \\
\hline $2941-420$ & SB & 19 & 107.4 & 0.169 & 0.01720 & 5.38 & 6.98 & 5.94 & 11.4 & 0.352 & 0.0354 & 1.40 \\
\hline Average & & & & & & 1.97 & 3.02 & 2.80 & 9.31 & 0.200 & 0.0224 & 0.789 \\
\hline Stdev & & & & & & 2.59 & 3.80 & 3.04 & 9.06 & 0.193 & 0.0198 & 0.742 \\
\hline Median & & & & & & 0.632 & 1.60 & 1.63 & 5.50 & 0.134 & 0.0176 & 0.532 \\
\hline 25th & & & & & & 0.409 & 0.660 & 0.925 & 4.24 & 0.0611 & 0.00905 & 0.268 \\
\hline 75th & & & & & & 2.98 & 4.15 & 3.81 & 10.3 & 0.288 & 0.0306 & 1.11 \\
\hline RSD & & & & & & $132 \%$ & $126 \%$ & $108 \%$ & $97 \%$ & $96 \%$ & $89 \%$ & $94 \%$ \\
\hline
\end{tabular}


Field Sample Results - Metals

$\begin{array}{cccrrr} & \text { Station } & \text { Event } & \text { Rain } & \text { Sample } & \text { Funnel } \\ \text { Sample ID } & \text { ID } & \text { No. } & \text { Collected } & \text { Vol. } & \text { Surface Area }\end{array}$ $\mathrm{Cr}$ $\mathrm{Ni}$ Cu Zn Cd Pb

$\mathrm{mL} \quad \mathrm{L} \quad \mathrm{m}^{2} \mu \mathrm{g} / \mathrm{m}^{2} /$ day $\quad \mu \mathrm{g} / \mathrm{m}^{2} /$ day $\quad \mu \mathrm{g} / \mathrm{m}^{2} /$ day $\quad \mu \mathrm{g} / \mathrm{m}^{2} /$ day $\quad \mu \mathrm{g} / \mathrm{m}^{2} /$ day $\quad \mu \mathrm{g} / \mathrm{m}^{2} / \mathrm{day} \quad \mu \mathrm{g} / \mathrm{m}^{2} /$ day

\begin{tabular}{|c|c|c|c|c|c|c|c|c|c|c|c|c|}
\hline 2941-4 AVG & TCB & 1 & 0.00 & 0.139 & 0.01720 & 2.43 & 2.97 & 11.5 & 59.9 & 0.876 & 0.0597 & 7.05 \\
\hline $2941-22$ & TCB & 2 & 127.5 & 0.190 & 0.01720 & 3.24 & 3.74 & 22.5 & 79.2 & 1.44 & 0.105 & 9.01 \\
\hline 2941-27 AVG & TCB & 3 & 597.7 & 0.660 & 0.01720 & 1.98 & 3.09 & 18.3 & 51.1 & 0.640 & 0.111 & 5.72 \\
\hline 2941-37 AVG & TCB & 4 & 300.1 & 0.362 & 0.01720 & 2.01 & 3.27 & 19.7 & 53.4 & 0.550 & 0.0765 & 6.07 \\
\hline $2941-75$ & TCB & 6 & 154 & 0.216 & 0.01039 & 1.04 & 1.75 & 7.69 & 36.7 & 0.323 & 0.0418 & 4.98 \\
\hline $2941-86$ & TCB & 7 & 59.8 & 0.122 & 0.006360 & 0.996 & 1.70 & 6.41 & 26.0 & 0.241 & 0.0233 & 1.80 \\
\hline $2941-89$ & TCB & 8 & 355.9 & 0.418 & 0.01039 & 0.980 & 1.57 & 5.27 & 31.6 & 0.362 & 0.0401 & 4.68 \\
\hline $2941-90$ & TCB & 8 & 325 & 0.387 & 0.01039 & 0.730 & 1.27 & 5.06 & 27.2 & 0.368 & 0.0264 & 2.99 \\
\hline $2941-111$ & TCB & 9 & 799.7 & 0.862 & 0.01039 & 2.39 & 2.19 & 11.6 & 51.9 & 0.506 & 0.0959 & 7.11 \\
\hline 2941-109 & TCB & 9 & 719.8 & 0.782 & 0.01039 & 2.54 & 2.67 & 11.9 & 50.1 & 0.676 & 0.108 & 10.5 \\
\hline $2941-123$ & TCB & 10 & 435.5 & 0.498 & 0.01039 & 1.45 & 1.55 & 8.21 & 49.7 & 0.393 & 0.0496 & 3.49 \\
\hline 2941-127 AVG & TCB & 11 & 477.9 & 0.540 & 0.01039 & 1.35 & 1.71 & 12.1 & 50.8 & 0.523 & 0.0801 & 6.29 \\
\hline $2941-157$ & TCB & 12 & 845.7 & 0.908 & 0.01039 & 2.44 & 2.52 & 12.7 & 48.2 & 0.898 & 0.0791 & 8.47 \\
\hline 2941-167 AVG & TCB & 13 & 318.7 & 0.381 & 0.01039 & 1.48 & 1.92 & 8.56 & 27.7 & 0.354 & 0.0450 & 5.28 \\
\hline $2941-375$ & TCB & 14 & 0.00 & 0.058 & 0.01039 & 0.298 & 0.915 & 4.26 & 25.9 & 0.142 & 0.0411 & 2.78 \\
\hline $2941-383$ & TCB & 15 & 186.6 & 0.249 & 0.01720 & 1.01 & 2.73 & 9.83 & 33.2 & 0.312 & 0.0426 & 5.21 \\
\hline $2941-407$ & TCB & 16 & 31.6 & 0.094 & 0.01720 & 0.839 & 0.894 & 12.0 & 24.3 & 0.388 & 0.0443 & 4.08 \\
\hline $2941-395$ & TCB & 17 & 904.2 & 0.966 & 0.01720 & 1.06 & 1.82 & 25.1 & 66.0 & 0.819 & 0.2124 & 15.0 \\
\hline $2941-386$ & TCB & 18 & 104.9 & 0.167 & 0.01720 & 0.941 & 1.21 & 20.9 & 47.6 & 0.270 & 0.1065 & 23.5 \\
\hline $2941-425$ & TCB & 19 & 192.7 & 0.255 & 0.01720 & 2.03 & 3.36 & 26.2 & 68.5 & 0.643 & 0.1764 & 40.8 \\
\hline Average & & & & & & 1.56 & 2.14 & 13.0 & 45.4 & 0.536 & 0.0782 & 8.74 \\
\hline Stdev & & & & & & 0.772 & 0.850 & 6.78 & 15.9 & 0.302 & 0.0492 & 9.00 \\
\hline Median & & & & & & 1.40 & 1.87 & 11.8 & 48.9 & 0.450 & 0.0681 & 5.89 \\
\hline 25th & & & & & & 0.992 & 1.56 & 8.08 & 30.6 & 0.346 & 0.0424 & 4.53 \\
\hline 75th & & & & & & 2.12 & 2.79 & 18.6 & 52.2 & 0.652 & 0.105 & 8.60 \\
\hline RSD & & & & & & $49 \%$ & $40 \%$ & $52 \%$ & $35 \%$ & $56 \%$ & $63 \%$ & $103 \%$ \\
\hline $2941-377$ & $\mathrm{TM}$ & 14 & 0.00 & 0.057 & 0.01039 & 0.109 & 0.219 & 2.42 & 6.89 & 0.0597 & 0.0268 & 0.238 \\
\hline $2941-382$ & $\mathrm{TM}$ & 15 & 169.70 & 0.232 & 0.01720 & 0.294 & 1.26 & 3.02 & 12.9 & 0.241 & 0.0173 & 0.945 \\
\hline $2941-408$ & $\mathrm{TM}$ & 16 & 26.00 & 0.088 & 0.01720 & 0.480 & 0.365 & 2.12 & 6.59 & 0.102 & 0.0098 & 0.791 \\
\hline $2941-393$ & $\mathrm{TM}$ & 17 & 798.20 & 0.860 & 0.01720 & 0.114 & 1.016 & 5.44 & 13.5 & 0.338 & 0.0242 & 2.54 \\
\hline $2941-389$ & TM & 18 & 93.90 & 0.156 & 0.01720 & 0.210 & 0.599 & 2.16 & 8.00 & 0.154 & 0.0121 & 1.24 \\
\hline $2941-402$ & $\mathrm{TM}$ & 19 & 92.60 & 0.155 & 0.01720 & 0.276 & 0.802 & 3.43 & 13.6 & 0.251 & 0.0276 & 1.96 \\
\hline Average & & & & & & 0.247 & 0.710 & 3.101 & 10.239 & 0.191 & 0.020 & 1.286 \\
\hline Stdev & & & & & & 0.138 & 0.395 & 1.258 & 3.410 & 0.104 & 0.008 & 0.835 \\
\hline Median & & & & & & 0.243 & 0.701 & 2.722 & 10.452 & 0.197 & 0.021 & 1.094 \\
\hline 25th & & & & & & 0.138 & 0.423 & 2.225 & 7.172 & 0.115 & 0.013 & 0.830 \\
\hline 75th & & & & & & 0.29 & 0.96 & 3.33 & 13.32 & 0.25 & 0.03 & 1.78 \\
\hline RSD & & & & & & $56 \%$ & $56 \%$ & $41 \%$ & $33 \%$ & $55 \%$ & $39 \%$ & $65 \%$ \\
\hline $2941-2$ & WP & 1 & 0.00 & 0.138 & 0.01720 & 0.271 & 0.910 & 0.598 & 5.52 & 0.0410 & 0.00589 & 0.173 \\
\hline $2941-21$ & WP & 2 & 259.5 & 0.322 & 0.01720 & 0.432 & 1.19 & 2.05 & 6.80 & 0.221 & 0.0232 & 0.513 \\
\hline $2941-28$ & WP & 3 & 558.8 & 0.621 & 0.01720 & 0.540 & 1.13 & 3.41 & 14.4 & 0.138 & 0.0278 & 0.833 \\
\hline $2941-38$ & WP & 4 & 136.7 & 0.199 & 0.01720 & 0.189 & 0.373 & 0.965 & 15.7 & 0.107 & 0.0118 & 0.342 \\
\hline $2941-78$ & WP & 6 & 78.2 & 0.140 & 0.01039 & 0.184 & 0.477 & 0.962 & 3.86 & 0.125 & 0.0129 & 0.301 \\
\hline $2941-83$ & WP & 7 & 91.0 & 0.153 & 0.006360 & 0.215 & 0.388 & 0.754 & 6.32 & 0.187 & 0.0134 & 0.150 \\
\hline $2941-87$ & WP & 8 & 295.3 & 0.357 & 0.01039 & 0.625 & 1.10 & 1.96 & 8.55 & 0.176 & 0.0253 & 0.576 \\
\hline $2941-110$ & WP & 9 & 506.8 & 0.569 & 0.01039 & 1.13 & 0.857 & 2.73 & 14.0 & 0.427 & 0.0375 & 0.937 \\
\hline $2941-117$ & WP & 10 & 404.8 & 0.467 & 0.01039 & 0.632 & 0.762 & 2.00 & 8.88 & 0.215 & 0.0261 & 0.661 \\
\hline $2941-126$ & WP & 11 & 258.8 & 0.321 & 0.01039 & 0.302 & 0.401 & 1.21 & 5.74 & 0.161 & 0.0161 & 0.571 \\
\hline 2941-154 re & WP & 12 & 734.8 & 0.797 & 0.01039 & 0.744 & 0.668 & 2.94 & 11.6 & 0.334 & 0.0239 & 1.35 \\
\hline $2941-166$ & WP & 13 & 535.9 & 0.598 & 0.01039 & 0.593 & 0.669 & 1.62 & 6.17 & 0.133 & 0.0279 & 0.691 \\
\hline 2941-170 re & WP & 14 & 0.00 & 0.059 & 0.01039 & 0.512 & 0.566 & 0.955 & 6.82 & 0.0488 & 0.0149 & 0.948 \\
\hline $2941-378$ & WP & 15 & 150.5 & 0.213 & 0.01720 & 0.307 & 0.459 & 0.609 & 5.05 & 0.0788 & 0.00698 & 0.282 \\
\hline $2941-384$ & WP & 16 & 146.8 & 0.209 & 0.01720 & 0.291 & 1.64 & 0.935 & 4.52 & 0.0778 & 0.00495 & 0.366 \\
\hline $2941-388$ & WP & 17 & 505.1 & 0.567 & 0.01720 & 0.286 & 1.53 & 2.18 & 12.1 & 0.163 & 0.0170 & 0.814 \\
\hline $2941-391$ & WP & 18 & 194.3 & 0.256 & 0.01720 & 0.248 & 1.49 & 1.04 & 5.28 & 0.0790 & 0.00826 & 0.462 \\
\hline $2941-423$ & WP & 19 & 394.4 & 0.411 & 0.01720 & 0.400 & 1.09 & 1.70 & 8.93 & 0.225 & 0.0185 & 0.765 \\
\hline Average & & & & & & 0.439 & 0.872 & 1.590 & 8.351 & 0.163 & 0.018 & 0.596 \\
\hline Stdev & & & & & & 0.244 & 0.413 & 0.842 & 3.695 & 0.099 & 0.009 & 0.312 \\
\hline Median & & & & & & 0.353 & 0.809 & 1.416 & 6.813 & 0.150 & 0.017 & 0.573 \\
\hline 25th & & & & & & 0.275 & 0.499 & 0.957 & 5.575 & 0.086 & 0.012 & 0.348 \\
\hline 75th & & & & & & 0.58 & 1.12 & 2.04 & 10.92 & 0.21 & 0.02 & 0.80 \\
\hline RSD & & & & & & $56 \%$ & $47 \%$ & $53 \%$ & $44 \%$ & $60 \%$ & $50 \%$ & $52 \%$ \\
\hline
\end{tabular}


Quality Control Results - Trace Elements (Units: $\mu \mathrm{g} / \mathrm{L}$ )

\begin{tabular}{|c|c|c|c|c|c|c|c|c|c|}
\hline \multicolumn{10}{|c|}{ Analytical Batch } \\
\hline & Method Detection Limit & 0.311 & 0.0507 & 0.0107 & 0.00532 & 0.0135 & 0.0071 & 0.0033 & 0.00219 \\
\hline & Reporting Limit & 0.989 & 0.161 & 0.0340 & 0.0169 & 0.0429 & 0.0226 & 0.0105 & 0.00696 \\
\hline \multicolumn{10}{|c|}{ Method Blanks (ug/L) } \\
\hline $102808-6100$ & TRM Blank R1 & $\mathrm{NA}$ & 0.170 & $0.0107 \mathrm{U}$ & $0.00532 \mathrm{U}$ & $0.0135 \mathrm{U}$ & $0.0071 \mathrm{U}$ & $0.0033 \mathrm{U}$ & $0.00219 \mathrm{U}$ \\
\hline $102808-6100$ & TRM Blank R2 & NA & $0.161 \mathrm{U}$ & $0.0107 \mathrm{U}$ & $0.00532 \mathrm{U}$ & 0.0480 & $0.0071 \mathrm{U}$ & $0.0033 \mathrm{U}$ & $0.00219 \mathrm{U}$ \\
\hline $121708-6100$ & TRM Blank R1 & NA & 0.273 & $0.0107 \mathrm{U}$ & $0.00532 \mathrm{U}$ & $0.0135 \mathrm{U}$ & $0.0071 \mathrm{U}$ & $0.0033 \mathrm{U}$ & $0.00219 \mathrm{U}$ \\
\hline $121708-6100$ & TRM Blank R2 & NA & 0.298 & $0.0107 \mathrm{U}$ & $0.00532 \mathrm{U}$ & $0.0135 \mathrm{U}$ & $0.0071 \mathrm{U}$ & $0.0033 \mathrm{U}$ & $0.00219 \mathrm{U}$ \\
\hline 040109-6100 & TRM Blank R1 & $0.311 \mathrm{U}$ & 0.166 & $0.0107 \mathrm{U}$ & $0.00532 \mathrm{U}$ & 0.0269 & $0.0071 \mathrm{U}$ & $0.0033 \mathrm{U}$ & $0.00219 \mathrm{U}$ \\
\hline 041509-6100 & TRM Blank R1 & $0.311 \mathrm{U}$ & $0.161 \mathrm{U}$ & $0.0107 \mathrm{U}$ & $0.00532 \mathrm{U}$ & 0.0158 & $0.0071 \mathrm{U}$ & $0.0033 \mathrm{U}$ & $0.00219 \mathrm{U}$ \\
\hline 043009-6100 & TRM Blank & $0.311 \mathrm{U}$ & 0.205 & $0.0107 \mathrm{U}$ & $0.00532 \mathrm{U}$ & 0.0302 & $0.0071 \mathrm{U}$ & $0.0033 \mathrm{U}$ & $0.00219 \mathrm{U}$ \\
\hline 051409-6100 & TRM Blank & $0.311 \mathrm{U}$ & 0.175 & $0.0107 \mathrm{U}$ & $0.00532 \mathrm{U}$ & $0.0135 \mathrm{U}$ & $0.0071 \mathrm{U}$ & $0.0033 \mathrm{U}$ & $0.00327 \mathrm{U}$ \\
\hline 060809-6100 & TRM Blank R1 & $0.311 \mathrm{U}$ & 0.319 & $0.0107 \mathrm{U}$ & $0.00532 \mathrm{U}$ & 0.0205 & $0.0071 \mathrm{U}$ & $0.0033 \mathrm{U}$ & $0.00219 \mathrm{U}$ \\
\hline 060809-6100 & TRM Blank R2 & $0.311 \mathrm{U}$ & 0.304 & $0.0107 \mathrm{U}$ & $0.00532 \mathrm{U}$ & 0.0283 & $0.0071 \mathrm{U}$ & $0.0033 \mathrm{U}$ & $0.00219 \mathrm{U}$ \\
\hline $100609-6100$ & TRM Blank R1 & & 0.187 & $0.0107 \mathrm{U}$ & 0.0151 & 0.193 & $0.0071 \mathrm{U}$ & $0.0033 \mathrm{U}$ & $0.00219 \mathrm{U}$ \\
\hline $100609-6100$ & TRM Blank R2 & & $0.161 \mathrm{U}$ & $0.0107 \mathrm{U}$ & 0.00956 & 0.145 & $0.0071 \mathrm{U}$ & $0.0033 \mathrm{U}$ & $0.00219 \mathrm{U}$ \\
\hline $112309-6100$ & TRM Blank & & 0.310 & $0.0107 \mathrm{U}$ & $0.00532 \mathrm{U}$ & 0.0252 & $0.0071 \mathrm{U}$ & $0.0033 \mathrm{U}$ & $0.00219 \mathrm{U}$ \\
\hline \multirow[t]{2}{*}{$113009-6100$} & TRM Blank & & 0.344 & $0.0107 \mathrm{U}$ & 0.00668 & $0.0135 \mathrm{U}$ & $0.0071 \mathrm{U}$ & $0.0033 \mathrm{U}$ & $0.00219 \mathrm{U}$ \\
\hline & Average Method Blank & $0.311 U$ & 0.231 & 0.0107 & 0.00642 & 0.0429 & 0.0071 & 0.0033 & 0.00227 \\
\hline \multicolumn{10}{|c|}{ Instrument Check Sample Results } \\
\hline & Cert/Ref value & 52.0 & 38.6 & 27.4 & 85.2 & 53.2 & 26.67 & 22.79 & 27.89 \\
\hline $102808-6100$ & TRM 1640 R1 10x & NA & $\mathbf{9 9 \%}$ & $100 \%$ & $101 \%$ & $99 \%$ & $93 \%$ & $98 \%$ & $99 \%$ \\
\hline $102808-6100$ & TRM 1640 R2 10x & NA & $103 \%$ & $101 \%$ & $102 \%$ & $101 \%$ & $96 \%$ & $97 \%$ & $100 \%$ \\
\hline $121708-6100$ & TRM 1640 R1 10x & NA & $103 \%$ & $101 \%$ & $102 \%$ & $103 \%$ & $100 \%$ & $100 \%$ & $102 \%$ \\
\hline $121708-6100$ & TRM 1640 R2 10x & $\mathrm{NA}$ & $102 \%$ & $99 \%$ & $102 \%$ & $102 \%$ & $98 \%$ & $100 \%$ & $101 \%$ \\
\hline 040109-6100 & TRM 1640 R1 10x & $103 \%$ & $104 \%$ & $105 \%$ & $106 \%$ & $108 \%$ & $103 \%$ & $105 \%$ & $105 \%$ \\
\hline 041509-6100 & TRM 1640 R1 10x & $103 \%$ & $106 \%$ & $104 \%$ & $107 \%$ & $108 \%$ & $101 \%$ & $104 \%$ & $106 \%$ \\
\hline 043009-6100 & TRM 1640 10x & $108 \%$ & $109 \%$ & $104 \%$ & $107 \%$ & $108 \%$ & $105 \%$ & $106 \%$ & $109 \%$ \\
\hline 051409-6100 & TRM 1640 10x & $102 \%$ & $106 \%$ & $102 \%$ & $102 \%$ & $103 \%$ & $100 \%$ & $99 \%$ & $101 \%$ \\
\hline 060809-6100 & TRM 1640 10x R1 & $97 \%$ & $108 \%$ & $\mathbf{9 8 \%}$ & $101 \%$ & $104 \%$ & $98 \%$ & $98 \%$ & $103 \%$ \\
\hline 060809-6100 & TRM 1640 10x R2 & $93 \%$ & $97 \%$ & $92 \%$ & $95 \%$ & $97 \%$ & $91 \%$ & $96 \%$ & $100 \%$ \\
\hline $100609-6100$ & TRM 1640 R1 & & $100 \%$ & $97 \%$ & $100 \%$ & $104 \%$ & $98 \%$ & $100 \%$ & $101 \%$ \\
\hline $100609-6100$ & TRM 1640 R2 & & $100 \%$ & $99 \%$ & $100 \%$ & $109 \%$ & $98 \%$ & $99 \%$ & $101 \%$ \\
\hline $112309-6100$ & TRM 1640 & & $100 \%$ & $99 \%$ & $102 \%$ & $101 \%$ & $96 \%$ & $97 \%$ & $101 \%$ \\
\hline $113009-6100$ & TRM 1640 & & $109 \%$ & $101 \%$ & $106 \%$ & $105 \%$ & $99 \%$ & $103 \%$ & $103 \%$ \\
\hline \multicolumn{2}{|c|}{ Average Instrument Check Sample Result } & $101 \%$ & $103 \%$ & $100 \%$ & $102 \%$ & $104 \%$ & $98 \%$ & $100 \%$ & $102 \%$ \\
\hline
\end{tabular}

SRM Results for Urban Dust SRM $1648(\mu \mathrm{g} / \mathrm{g})$. Data are from a leach digestion.

\begin{tabular}{|c|c|c|c|c|c|c|c|c|c|}
\hline $102808-6100$ & TRM 1648 R1 10x & NA & 52.8 & 46.5 & 455 & 3634 & 101 & 57.6 & 5705 \\
\hline $102808-6100$ & TRM 1648 R2 10x & NA & 52.7 & 53.2 & 465 & 3659 & 104 & 57.1 & 5639 \\
\hline $121708-6100$ & TRM 1648 R1 10x & NA & 60.4 & 52.0 & 474 & 3996 & 106 & 61.2 & 6075 \\
\hline $121708-6100$ & TRM 1648 R2 5x & NA & 54.6 & 47.6 & 461 & 3673 & 102 & 58.5 & 5814 \\
\hline 040109-6100 & TRM 1648 R1 5x & 10310 & 62.5 & 54.3 & 496 & 3939 & 111 & 60.6 & 5554 \\
\hline 041509-6100 & TRM 1648 R1 5x & 11070 & 62.1 & 53.4 & 497 & 4068 & 114 & 61.4 & 5856 \\
\hline 043009-6100 & TRM 1648 R1 5x & 10080 & 63.5 & 52.7 & 483 & 3873 & 112 & 59.9 & 5849 \\
\hline 051409-6100 & TRM 1648 R1 5x & 10100 & 65.1 & 51.6 & 476 & 3895 & 106 & 59.8 & 5549 \\
\hline 060809-6100 & TRM 1648 R1 5x & 10030 & 59.1 & 47.5 & 447 & 3667 & 101 & 58.8 & 5776 \\
\hline $100609-6100$ & TRM 1648 R1 5x & & 64.1 & 53.8 & 477 & 3955 & 109 & 61.1 & 6038 \\
\hline $100609-6100$ & TRM 1648 R2 & & 61.0 & 52.8 & 475 & 3876 & 107 & 61.1 & 5989 \\
\hline $112309-6101$ & TRM 1648 & & 64.9 & 53.0 & 469 & 3786 & 104 & 60.1 & 6007 \\
\hline \multirow[t]{2}{*}{$113009-6100$} & TRM $16485 x$ & & 65.0 & 53.7 & 483 & 3929 & 109 & 61.7 & 6350 \\
\hline & Cert/Ref value & 34200 & 403 & 82 & 609 & 4760 & 115 & 75 & 6550 \\
\hline $102808-6100$ & $\% \operatorname{Rec}$ & NA & $13 \%$ & $57 \%$ & $75 \%$ & $76 \%$ & $88 \%$ & $77 \%$ & $87 \%$ \\
\hline $102808-6100$ & $\%$ Rec & NA & $13 \%$ & $65 \%$ & $76 \%$ & $77 \%$ & $91 \%$ & $76 \%$ & $86 \%$ \\
\hline $121708-6100$ & $\%$ Rec & NA & $15 \%$ & $63 \%$ & $78 \%$ & $84 \%$ & $92 \%$ & $82 \%$ & $93 \%$ \\
\hline $121708-6100$ & $\% \operatorname{Rec}$ & NA & $14 \%$ & $58 \%$ & $76 \%$ & $77 \%$ & $89 \%$ & $78 \%$ & $89 \%$ \\
\hline 040109-6100 & \% Rec & $30 \%$ & $16 \%$ & $66 \%$ & $81 \%$ & $83 \%$ & $97 \%$ & $81 \%$ & $85 \%$ \\
\hline 041509-6100 & $\%$ Rec & $32 \%$ & $15 \%$ & $65 \%$ & $82 \%$ & $85 \%$ & $99 \%$ & $82 \%$ & $89 \%$ \\
\hline 043009-6100 & \% Rec & $29 \%$ & $16 \%$ & $64 \%$ & $79 \%$ & $81 \%$ & $97 \%$ & $80 \%$ & $89 \%$ \\
\hline 051409-6100 & $\%$ Rec & $30 \%$ & $16 \%$ & $63 \%$ & $78 \%$ & $82 \%$ & $92 \%$ & $80 \%$ & $85 \%$ \\
\hline 060809-6100 & $\% \operatorname{Rec}$ & $29 \%$ & $15 \%$ & $58 \%$ & $73 \%$ & $77 \%$ & $\mathbf{8 8} \%$ & $78 \%$ & $88 \%$ \\
\hline $100609-6100$ & \% Rec & & $16 \%$ & $66 \%$ & $78 \%$ & $83 \%$ & $95 \%$ & $81 \%$ & $92 \%$ \\
\hline $100609-6100$ & $\%$ Rec & & $15 \%$ & $64 \%$ & $78 \%$ & $81 \%$ & $93 \%$ & $81 \%$ & $91 \%$ \\
\hline $112309-6100$ & \% Rec & & $16 \%$ & $65 \%$ & $77 \%$ & $80 \%$ & $90 \%$ & $80 \%$ & $92 \%$ \\
\hline $113009-6100$ & \% Rec & & $16 \%$ & $66 \%$ & $79 \%$ & $83 \%$ & $94 \%$ & $82 \%$ & $97 \%$ \\
\hline Average & & $30 \%$ & $15 \%$ & $63 \%$ & $78 \%$ & $81 \%$ & $93 \%$ & $80 \%$ & $89 \%$ \\
\hline Stdev & & $1 \%$ & $1 \%$ & $3 \%$ & $2 \%$ & $3 \%$ & $4 \%$ & $2 \%$ & $3 \%$ \\
\hline
\end{tabular}


Quality Control Results - Trace Elements (Units: $\mu \mathrm{g} / \mathrm{L}$ )

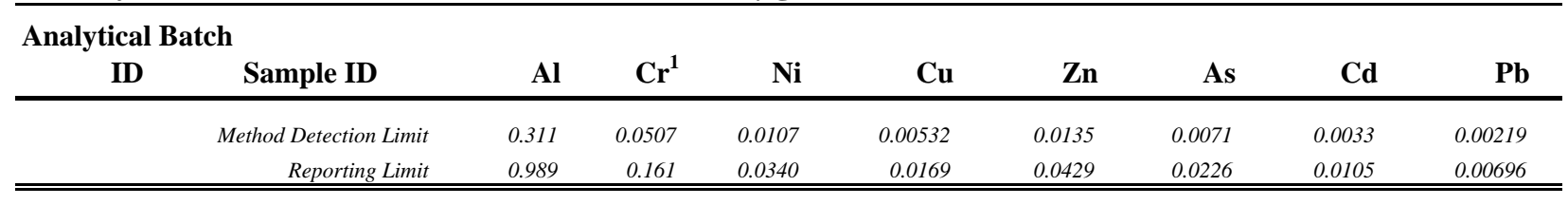

Blank Spike (LCS) Percent Recovery

$\begin{array}{ll}102808-6100 & \text { TRM LCS R1 } \\ 102808-6100 & \text { TRM LCS R2 } \\ 121708-6100 & \text { TRM LCS R1 } \\ 121708-6100 & \text { TRM LCS R2 } \\ 040109-6100 & \text { TRM LCS R1 } \\ 041509-6100 & \text { TRM LCS R1 } \\ 043009-6100 & \text { TRM LCS } \\ 051409-6100 & \text { TRM LCS } \\ 060809-6100 & \text { TRM LCS R1 } \\ 060809-6100 & \text { TRM LCS R2 } \\ 100609-6100 & \text { TRM LCS R1 } \\ 100609-6100 & \text { TRM LCS R2 } \\ 112309-6101 & \text { TRM LCS R1 } \\ 113009-6100 & \text { TRM LCS R1 }\end{array}$

\begin{tabular}{|c|c|c|c|c|c|c|c|}
\hline NA & $97 \%$ & $101 \%$ & $103 \%$ & $99 \%$ & $100 \%$ & $101 \%$ & $101 \%$ \\
\hline NA & $101 \%$ & $102 \%$ & $102 \%$ & $100 \%$ & $101 \%$ & $98 \%$ & $99 \%$ \\
\hline NA & $100 \%$ & $97 \%$ & $100 \%$ & $101 \%$ & $100 \%$ & $100 \%$ & $100 \%$ \\
\hline NA & $97 \%$ & $97 \%$ & $98 \%$ & $98 \%$ & $97 \%$ & $98 \%$ & 98\% \\
\hline $102 \%$ & $101 \%$ & $99 \%$ & $101 \%$ & $100 \%$ & $101 \%$ & $99 \%$ & $100 \%$ \\
\hline $101 \%$ & $101 \%$ & $100 \%$ & $104 \%$ & $103 \%$ & $102 \%$ & $103 \%$ & $102 \%$ \\
\hline $106 \%$ & $101 \%$ & $101 \%$ & $102 \%$ & $100 \%$ & $102 \%$ & $101 \%$ & $101 \%$ \\
\hline $112 \%$ & $117 \%$ & $99 \%$ & $101 \%$ & $105 \%$ & $99 \%$ & $98 \%$ & $98 \%$ \\
\hline $96 \%$ & $94 \%$ & $93 \%$ & $97 \%$ & $93 \%$ & $93 \%$ & $94 \%$ & $97 \%$ \\
\hline \multirow[t]{5}{*}{$96 \%$} & $91 \%$ & $94 \%$ & $97 \%$ & $96 \%$ & $96 \%$ & $100 \%$ & $102 \%$ \\
\hline & $106 \%$ & $104 \%$ & $106 \%$ & $110 \%$ & $101 \%$ & $103 \%$ & $102 \%$ \\
\hline & $98 \%$ & $103 \%$ & $100 \%$ & $90 \%$ & $101 \%$ & $98 \%$ & $100 \%$ \\
\hline & $102 \%$ & $97 \%$ & $100 \%$ & $96 \%$ & $98 \%$ & $97 \%$ & $99 \%$ \\
\hline & $103 \%$ & $99 \%$ & $101 \%$ & $102 \%$ & $102 \%$ & $99 \%$ & $104 \%$ \\
\hline $102 \%$ & $101 \%$ & $99 \%$ & $101 \%$ & $99 \%$ & $100 \%$ & $99 \%$ & $100 \%$ \\
\hline
\end{tabular}

\section{Matrix Spike Percent Recovery}

\begin{tabular}{|c|c|c|c|c|c|c|c|c|c|}
\hline $102808-6100$ & 2941-20 MS1 & NA & $99 \%$ & $100 \%$ & $101 \%$ & $98 \%$ & $98 \%$ & $97 \%$ & $98 \%$ \\
\hline $102808-6100$ & 2941-29 MS1 & NA & $98 \%$ & $98 \%$ & $99 \%$ & $100 \%$ & $96 \%$ & $96 \%$ & $97 \%$ \\
\hline $121708-6100$ & 2941-46 MS1 & NA & $99 \%$ & $98 \%$ & $99 \%$ & $99 \%$ & $98 \%$ & $98 \%$ & $100 \%$ \\
\hline $121708-6100$ & 2941-71 MS1 & NA & $98 \%$ & $98 \%$ & $99 \%$ & $99 \%$ & $96 \%$ & $97 \%$ & $99 \%$ \\
\hline 040109-6100 & 2941-109 MS1 & $98 \%$ & $101 \%$ & $100 \%$ & $102 \%$ & $105 \%$ & $101 \%$ & $98 \%$ & $99 \%$ \\
\hline $041509-6100$ & 2941-117 MS1 & $100 \%$ & $103 \%$ & $101 \%$ & $103 \%$ & $103 \%$ & $104 \%$ & $99 \%$ & $101 \%$ \\
\hline 043009-6100 & 2941-128 MS1 & $97 \%$ & $101 \%$ & $100 \%$ & $101 \%$ & $103 \%$ & $102 \%$ & $99 \%$ & $102 \%$ \\
\hline $051409-6100$ & 2941-153 MS1 & $87 \%$ & $100 \%$ & $101 \%$ & $101 \%$ & $108 \%$ & $100 \%$ & $100 \%$ & $99 \%$ \\
\hline 060809-6100 & 2941-161 MS1 & $110 \%$ & $97 \%$ & $93 \%$ & $97 \%$ & $94 \%$ & $94 \%$ & $95 \%$ & $97 \%$ \\
\hline 060809-6100 & 2941-161 MS2 & $95 \%$ & $92 \%$ & $93 \%$ & $94 \%$ & $92 \%$ & $94 \%$ & $95 \%$ & $96 \%$ \\
\hline $100609-6100$ & 2941-380 MS1 & & $100 \%$ & $94 \%$ & $100 \%$ & $103 \%$ & $98 \%$ & $98 \%$ & $101 \%$ \\
\hline $100609-6100$ & 2941-380 MS2 & & $98 \%$ & $97 \%$ & $99 \%$ & $98 \%$ & $99 \%$ & $97 \%$ & $99 \%$ \\
\hline $100609-6101$ & 2941-388 MS1 & & $102 \%$ & $101 \%$ & $99 \%$ & $105 \%$ & $100 \%$ & $100 \%$ & $102 \%$ \\
\hline $100609-6102$ & 2941-388 MS2 & & $100 \%$ & $100 \%$ & $102 \%$ & $102 \%$ & $103 \%$ & $98 \%$ & $100 \%$ \\
\hline $112309-6101$ & 2941-403 MS1 & & $97 \%$ & $97 \%$ & $99 \%$ & $99 \%$ & $95 \%$ & $96 \%$ & $101 \%$ \\
\hline $112309-6101$ & 2941-403 MS2 & & $95 \%$ & $95 \%$ & $97 \%$ & $95 \%$ & $95 \%$ & $94 \%$ & $96 \%$ \\
\hline $113009-6100$ & 2941-370 MS1 & & $107 \%$ & $103 \%$ & $106 \%$ & $94 \%$ & $102 \%$ & $103 \%$ & $108 \%$ \\
\hline
\end{tabular}

\section{Laboratory Replicate Results}

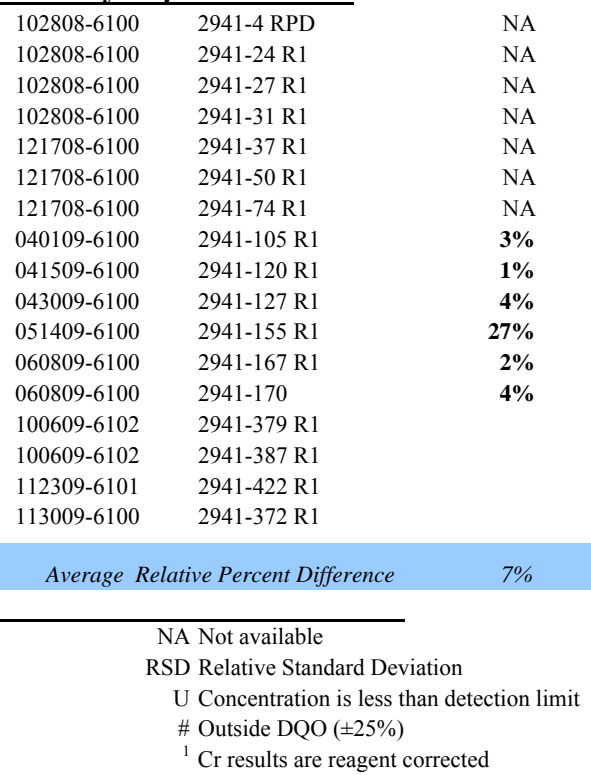




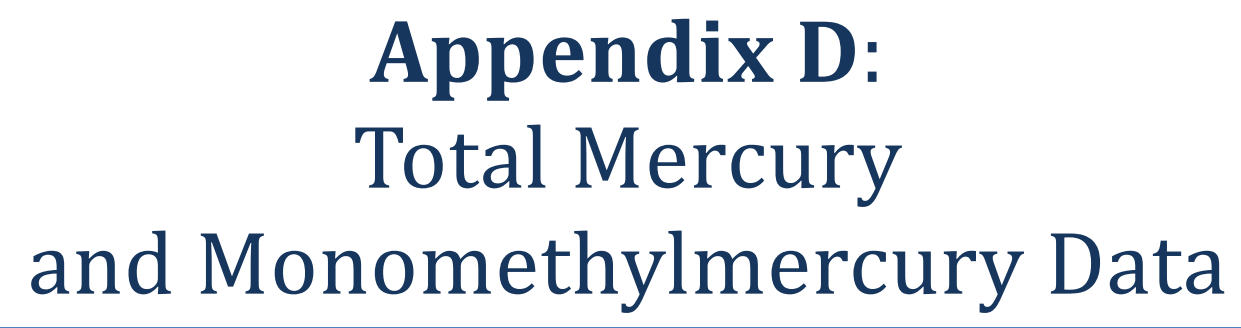


Field Sample Results - Total Mercury, Monomethylmercury

\begin{tabular}{|c|c|c|c|c|c|c|c|c|c|}
\hline Sample ID & $\begin{array}{l}\text { Station } \\
\text { ID }\end{array}$ & $\begin{array}{l}\text { Event } \\
\text { No. }\end{array}$ & $\begin{array}{c}\text { Days } \\
\text { Deployed }\end{array}$ & $\begin{array}{c}\text { Rain } \\
\text { Collected }\end{array}$ & $\begin{array}{c}\text { Sample } \\
\text { Vol. }\end{array}$ & $\begin{array}{c}\text { Funnel } \\
\text { Surface } \\
\text { Area }\end{array}$ & THg & MMHg & \% MMHg \\
\hline & Meth & $\begin{array}{r}\text { od Detec } \\
\text { Repor }\end{array}$ & $\begin{array}{r}\text { Unit } \\
\text { etion Limit } \\
\text { rting Limit }\end{array}$ & $\mathrm{mL}$ & $\mathrm{L}$ & $\mathrm{m}^{2}$ & $\begin{array}{r}\mathrm{ng} / \mathrm{L} \\
0.100 \\
0.318\end{array}$ & $\begin{array}{r}\mathrm{ng} / \mathrm{L} \\
0.010 \\
0.032\end{array}$ & \\
\hline $\begin{array}{l}2941-1 \\
2941-95 \\
2941-101 \\
2941-107 \\
\text { Average } \\
\text { Stdev } \\
\text { Rinse Water }\end{array}$ & $\begin{array}{l}\text { EB } \\
\text { EB } \\
\text { EB } \\
\text { EB }\end{array}$ & bution & $\begin{array}{c}14 \\
14 \\
14 \\
0\end{array}$ & & & $\begin{array}{l}0.0172 \\
0.0104 \\
0.0104 \\
0.0104\end{array}$ & $\begin{array}{r}0.193 \\
0.214 \\
0.233 \\
0.144 \\
\mathbf{0 . 1 9 6} \\
\mathbf{0 . 0 3 8 2} \\
\mathbf{0 . 0 1 1 8}\end{array}$ & $\begin{array}{c}0.0100 \mathrm{U} \\
0.0166 \\
0.0100 \mathrm{U} \\
0.0100 \mathrm{U} \\
\mathbf{0 . 0 1 6 6} \\
\mathbf{0 . 0 0 3 3 1} \\
\mathbf{0 . 0 0 1 0 0}\end{array}$ & \\
\hline 2941-10 & $\mathrm{HC}$ & 1 & 14 & 0.200 & 0.0622 & 0.0172 & 2.32 & & \\
\hline $2941-16$ & $\mathrm{HC}$ & 1 & 14 & 0.0 & 0.0605 & 0.0172 & & 0.750 & $32 \%$ \\
\hline 2941-13 & $\mathrm{HC}$ & 2 & 19 & 861.9 & 0.924 & 0.0172 & 2.55 & 0.0200 & $0.79 \%$ \\
\hline $2941-20$ & $\mathrm{HC}$ & 2 & 19 & 860.2 & 0.922 & 0.0172 & 7.38 & & \\
\hline 2941-34 & $\mathrm{HC}$ & 3 & 10 & 350.0 & 0.412 & 0.0172 & 4.38 & & \\
\hline $2941-54$ & $\mathrm{HC}$ & 3 & 10 & 350.8 & 0.413 & 0.0172 & 8.50 & 0.0565 & $0.66 \%$ \\
\hline $2941-42$ & $\mathrm{HC}$ & 4 & 13 & 67.9 & 0.130 & 0.0172 & 2.25 & & \\
\hline $2941-57$ & $\mathrm{HC}$ & 4 & 13 & 65.1 & 0.127 & 0.0172 & 3.81 & 0.235 & $6.2 \%$ \\
\hline $2941-63$ & $\mathrm{HC}$ & 6 & 12 & 461.9 & 0.525 & 0.0104 & 2.51 & 0.218 & $8.7 \%$ \\
\hline $2941-64$ & $\mathrm{HC}$ & 6 & 12 & 453.2 & 0.515 & 0.0104 & 2.93 & 0.293 & $10 \%$ \\
\hline $2941-71$ & $\mathrm{HC}$ & 6 & 12 & 446.9 & 0.509 & 0.0104 & 2.19 & & \\
\hline $2941-72$ & $\mathrm{HC}$ & 6 & 12 & 483.9 & 0.546 & 0.0104 & 2.17 & & \\
\hline $2941-80$ & $\mathrm{HC}$ & 7 & 21 & 257.7 & 0.320 & 0.0104 & 1.16 & & \\
\hline 2941-81 & $\mathrm{HC}$ & 7 & 21 & 272.1 & 0.334 & 0.0104 & 2.29 & & \\
\hline $2941-70$ & $\mathrm{HC}$ & 7 & 21 & 258.1 & 0.321 & 0.0104 & 3.12 & 0.144 & $4.6 \%$ \\
\hline 2941-94 & $\mathrm{HC}$ & 8 & 14 & 361.7 & 0.424 & 0.0104 & 4.81 & 0.0641 & $1.3 \%$ \\
\hline 2941-104 & $\mathrm{HC}$ & 8 & 14 & 363.7 & 0.426 & 0.0104 & 5.83 & & \\
\hline 2941-98 & $\mathrm{HC}$ & 9 & 13 & 691.1 & 0.757 & 0.0104 & 2.19 & 0.104 & $4.7 \%$ \\
\hline $2941-113$ & $\mathrm{HC}$ & 9 & 13 & 666.2 & 0.728 & 0.0104 & 2.01 & & \\
\hline $2941-124$ & $\mathrm{HC}$ & 10 & 14 & 240.1 & 0.302 & 0.0104 & 1.51 & & \\
\hline 2941-132 & $\mathrm{HC}$ & 10 & 14 & 240.7 & 0.303 & 0.0104 & 1.87 & 0.151 & $8.1 \%$ \\
\hline $2941-140$ & $\mathrm{HC}$ & 11 & 14 & 445.7 & 0.510 & 0.0104 & 1.83 & 0.0628 & $3.4 \%$ \\
\hline $2941-151$ & $\mathrm{HC}$ & 11 & 14 & 467.3 & 0.529 & 0.0104 & 1.51 & & \\
\hline 2941-145 & $\mathrm{HC}$ & 12 & 13 & 702.6 & 0.770 & 0.0104 & 3.23 & 0.174 & $5.4 \%$ \\
\hline 2941-159 & $\mathrm{HC}$ & 12 & 13 & 713.1 & 0.775 & 0.0104 & 7.93 & & \\
\hline $2941-147$ & $\mathrm{HC}$ & 13 & 15 & 620.0 & 0.685 & 0.0104 & 3.59 & 0.0346 & $1.0 \%$ \\
\hline 2941-161 & $\mathrm{HC}$ & 13 & 15 & 630.2 & 0.692 & 0.0104 & 2.33 & & \\
\hline $2941-354$ & $\mathrm{HC}$ & 14 & 16 & 0.0 & 0.068 & 0.0104 & & 0.0950 & $3.3 \%$ \\
\hline $2941-373$ & $\mathrm{HC}$ & 14 & 16 & 0.0 & 0.0697 & 0.0104 & 2.84 & & \\
\hline $2941-355$ & $\mathrm{HC}$ & 15 & 15 & 230.0 & 0.293 & 0.0172 & & 0.0217 & $0.45 \%$ \\
\hline $2941-381$ & $\mathrm{HC}$ & 15 & 15 & 239.5 & 0.302 & 0.0172 & 4.83 & & \\
\hline $2941-390$ & $\mathrm{HC}$ & 16 & 12 & 11.4 & 0.0734 & 0.0172 & 6.93 & & \\
\hline $2941-412$ & $\mathrm{HC}$ & 16 & 12 & 0.3 & 0.0623 & 0.0172 & & 0.0502 & $0.7 \%$ \\
\hline $2941-367$ & $\mathrm{HC}$ & 17 & 16 & 736.3 & 0.802 & 0.0172 & & 0.0716 & $1.1 \%$ \\
\hline $2941-387$ & $\mathrm{HC}$ & 17 & 16 & 749.2 & 0.811 & 0.0172 & 6.76 & & \\
\hline 2941-399 & $\mathrm{HC}$ & 18 & 14 & 176.5 & 0.239 & 0.0172 & 7.35 & & \\
\hline $2947-414$ & $\mathrm{HC}$ & 18 & 14 & 161.7 & 0.226 & 0.0172 & & 0.862 & $12 \%$ \\
\hline $2941-403$ & $\mathrm{HC}$ & 19 & 19 & 606.8 & 0.669 & 0.0172 & 4.59 & & \\
\hline $2941-418$ & $\mathrm{HC}$ & 19 & 19 & 582.2 & 0.643 & 0.0172 & & 0.0832 & $2.2 \%$ \\
\hline Average & & & & & & & 3.73 & 0.184 & \\
\hline Stdev & & & & & & & 2.13 & 0.233 & \\
\hline $2941-5$ & NR & 1 & 14 & 0.0 & 0.0695 & 0.0172 & 9.64 & & \\
\hline $2941-23$ & NR & 2 & 12 & 131.5 & 0.194 & 0.0172 & 12.8 & & \\
\hline $2941-29$ & NR & 3 & 21 & 1002.5 & 1.00 & 0.0172 & 5.35 & & \\
\hline $2941-35$ & NR & 4 & 15 & 237.2 & 0.299 & 0.0172 & 2.64 & & \\
\hline $2941-77$ & NR & 6 & 12 & 208.1 & 0.270 & 0.0104 & 2.34 & & \\
\hline $2941-85$ & NR & 7 & 17 & 52.0 & 0.114 & 0.0064 & 2.04 & & \\
\hline 2941-103 & NR & 8 & 15 & 351.1 & 0.413 & 0.0104 & 5.30 & & \\
\hline $2941-112$ & NR & 9 & 13 & 785.2 & 0.847 & 0.0104 & 1.83 & & \\
\hline $2941-116$ & NR & 10 & 14 & 380.7 & 0.443 & 0.0104 & 1.71 & & \\
\hline 2941-121 & NR & 10 & 14 & 382.9 & 0.445 & 0.0104 & 2.33 & & \\
\hline 2941-135 & NR & 10 & 14 & 378.9 & 0.443 & 0.0104 & 1.84 & 0.127 & $6.9 \%$ \\
\hline $2941-128$ & NR & 11 & 14 & 467.2 & 0.529 & 0.0104 & 3.74 & & \\
\hline 2941-129 & NR & 11 & 14 & 397.9 & 0.460 & 0.0104 & 3.39 & & \\
\hline $2941-137$ & NR & 11 & 14 & 451.5 & 0.516 & 0.0104 & 3.39 & 0.134 & $4.0 \%$ \\
\hline $2941-143$ & NR & 12 & 15 & 937.9 & 1.00 & 0.0104 & 3.55 & 0.167 & $4.7 \%$ \\
\hline $2941-153$ & NR & 12 & 15 & 948.8 & 1.01 & 0.0104 & 3.32 & & \\
\hline
\end{tabular}


Field Sample Results - Total Mercury, Monomethylmercury

\begin{tabular}{|c|c|c|c|c|c|c|c|c|c|}
\hline Sample ID & $\begin{array}{l}\text { Station } \\
\text { ID }\end{array}$ & $\begin{array}{l}\text { Event } \\
\text { No. }\end{array}$ & $\begin{array}{c}\text { Days } \\
\text { Deployed }\end{array}$ & $\begin{array}{c}\text { Rain } \\
\text { Collected }\end{array}$ & $\begin{array}{c}\text { Sample } \\
\text { Vol. }\end{array}$ & $\begin{array}{c}\text { Funnel } \\
\text { Surface } \\
\text { Area }\end{array}$ & THg & MMHg & \% MMHg \\
\hline & Metho & $\begin{array}{l}\text { od Detec } \\
\text { Repo }\end{array}$ & $\begin{array}{r}\text { Unit } \\
\text { ection Limit } \\
\text { orting Limit }\end{array}$ & $\mathrm{mL}$ & $\mathrm{L}$ & $\mathrm{m}^{2}$ & $\begin{array}{r}\mathrm{ng} / \mathrm{L} \\
0.100 \\
0.318\end{array}$ & $\begin{array}{r}\mathrm{ng} / \mathrm{L} \\
0.010 \\
0.032\end{array}$ & \\
\hline $2941-155$ & NR & 12 & 15 & 970.2 & 1.03 & 0.0104 & 3.47 & & \\
\hline $2941-150$ & NR & 13 & 14 & 383.6 & 0.448 & 0.0104 & 5.10 & 0.159 & $3.1 \%$ \\
\hline $2941-165$ & NR & 13 & 14 & 373.8 & 0.436 & 0.0104 & 4.02 & & \\
\hline $2941-358$ & NR & 14 & 14 & 0.0 & 0.0609 & 0.0104 & & 0.211 & $2.7 \%$ \\
\hline $2941-371$ & NR & 14 & 14 & 0.0 & 0.0615 & 0.0104 & 7.74 & & \\
\hline $2941-353$ & NR & 15 & 13 & 325.7 & 0.398 & 0.0172 & & 0.0448 & $1.0 \%$ \\
\hline $2941-372$ & NR & 15 & 13 & 401.6 & 0.404 & 0.0172 & 4.60 & & \\
\hline $2941-366$ & NR & 16 & 15 & 69.9 & 0.133 & 0.0172 & & 1.18 & $13.2 \%$ \\
\hline 2941-400 & NR & 16 & 15 & 103.1 & 0.165 & 0.0172 & 8.93 & & \\
\hline $2941-363$ & NR & 17 & 12 & 906.5 & 0.973 & 0.0172 & & 0.212 & $4.5 \%$ \\
\hline 2941-398 & NR & 17 & 12 & 943.2 & 1.01 & 0.0172 & 4.74 & & \\
\hline $2941-365$ & NR & 18 & 16 & 137.6 & 0.201 & 0.0172 & & 0.236 & $3.5 \%$ \\
\hline 2941-392 & NR & 18 & 16 & 144.4 & 0.206 & 0.0172 & 6.70 & & \\
\hline $2941-419$ & NR & 19 & 13 & 80.0 & 0.143 & 0.0172 & & 0.536 & $8.2 \%$ \\
\hline $2941-424$ & NR & 19 & 13 & 87.8 & 0.150 & 0.0172 & 6.57 & & \\
\hline Average & & & & & & & 4.68 & 0.301 & \\
\hline Stdev & & & & & & & 2.77 & 0.335 & \\
\hline 2941-3 & PB & 1 & 15 & 101.1 & 0.242 & 0.0172 & 3.59 & & \\
\hline 2941-19 & PB & 2 & 13 & 304.0 & 0.366 & 0.0172 & 8.08 & & \\
\hline $2941-30$ & PB & 3 & 20 & 388.8 & 0.451 & 0.0172 & 4.25 & & \\
\hline 2941-36 & PB & 4 & 14 & 122.7 & 0.185 & 0.0172 & 2.24 & & \\
\hline $2941-76$ & PB & 6 & 12 & 74.6 & 0.137 & 0.0104 & 2.93 & & \\
\hline $2941-84$ & PB & 7 & 16 & 250.5 & 0.313 & 0.0064 & 1.16 & & \\
\hline $2941-88$ & PB & 8 & 13 & 124.4 & 0.186 & 0.0104 & 4.48 & & \\
\hline 2941-108 & $\mathrm{PB}$ & 9 & 14 & 308.7 & 0.371 & 0.0104 & 3.58 & & \\
\hline $2941-125$ & PB & 11 & 15 & 260.8 & 0.323 & 0.0104 & 4.27 & & \\
\hline $2941-156$ & PB & 12 & 13 & 164.1 & 0.226 & 0.0104 & 3.60 & & \\
\hline $2941-164$ & PB & 13 & 15 & 608.9 & 0.671 & 0.0104 & 2.36 & & \\
\hline 2941-169 & PB & 14 & 13 & 27.9 & 0.0899 & 0.0104 & 20.3 & & \\
\hline $2941-379$ & PB & 15 & 14 & 290.9 & 0.353 & 0.0172 & 4.80 & & \\
\hline $2941-404$ & $\mathrm{~PB}$ & 16 & 14 & 3.2 & 0.0652 & 0.0172 & 5.22 & & \\
\hline $2941-385$ & PB & 17 & 14 & 149.8 & 0.212 & 0.0172 & 16.50 & & \\
\hline $2941-396$ & PB & 18 & 15 & 263.6 & 0.326 & 0.0172 & 11.10 & & \\
\hline $2941-421$ & PB & 19 & 13 & 145.1 & 0.207 & 0.0172 & 3.80 & & \\
\hline Average & & & & & & & 6.01 & & \\
\hline Stdev & & & & & & & 5.23 & & \\
\hline $2941-9$ & $\mathrm{PO}$ & 1 & 14 & 0.0 & 0.0585 & 0.0172 & 6.60 & & \\
\hline $2941-15$ & $\mathrm{PO}$ & 1 & 14 & 0.0 & 0.0582 & 0.0172 & & 0.509 & $7.7 \%$ \\
\hline $2941-17$ & $\mathrm{PO}$ & 2 & 19 & 653.9 & 0.716 & 0.0172 & 5.08 & 0.0233 & $0.22 \%$ \\
\hline $2941-24$ & $\mathrm{PO}$ & 2 & 19 & 658.6 & 0.721 & 0.0172 & 10.4 & & \\
\hline $2941-32$ & $\mathrm{PO}$ & 3 & 10 & 151.5 & 0.214 & 0.0172 & 4.83 & & \\
\hline $2941-33$ & $\mathrm{PO}$ & 3 & 10 & 170.9 & 0.233 & 0.0172 & 4.82 & & \\
\hline $2941-51$ & $\mathrm{PO}$ & 3 & 10 & 166.9 & 0.228 & 0.0172 & 10.9 & 0.101 & $0.89 \%$ \\
\hline $2941-53$ & PO & 3 & 10 & 172.0 & 0.234 & 0.0172 & 11.3 & 0.0201 & $0.89 \%$ \\
\hline 2941-39 & $\mathrm{PO}$ & 4 & 13 & 64.6 & 0.127 & 0.0172 & 2.25 & & \\
\hline 2941-41 & PO & 4 & 13 & 49.7 & 0.112 & 0.0172 & 2.34 & & \\
\hline $2941-56$ & $\mathrm{PO}$ & 4 & 13 & 64.5 & 0.126 & 0.0172 & 2.76 & $0.0100 \mathrm{U}$ & $0.31 \%$ \\
\hline $2941-58$ & PO & 4 & 13 & 64.7 & 0.125 & 0.0172 & 3.25 & 0.0172 & $0.30 \%$ \\
\hline $2941-65$ & $\mathrm{PO}$ & 6 & 13 & 378.5 & 0.431 & 0.0104 & 5.71 & 0.0723 & $2.0 \%$ \\
\hline $2941-73$ & PO & 6 & 13 & 313.2 & 0.365 & 0.0104 & 3.61 & & \\
\hline $2941-69$ & $\mathrm{PO}$ & 7 & 21 & 144.5 & 0.207 & 0.0104 & 3.28 & 0.0885 & $3.4 \%$ \\
\hline $2941-82$ & PO & 7 & 21 & 129.6 & 0.192 & 0.0104 & 2.62 & & \\
\hline $2941-96$ & $\mathrm{PO}$ & 8 & 14 & 276.5 & 0.339 & 0.0104 & 4.93 & 0.0750 & $1.2 \%$ \\
\hline 2941-106 & $\mathrm{PO}$ & 8 & 14 & 270.4 & 0.332 & 0.0104 & 6.18 & & \\
\hline 2941-99 & $\mathrm{PO}$ & 9 & 13 & 544.0 & 0.609 & 0.0104 & 5.92 & 0.146 & $2.5 \%$ \\
\hline 2941-114 & $\mathrm{PO}$ & 9 & 13 & 505.8 & 0.568 & 0.0104 & 5.94 & & \\
\hline 2941-118 & PO & 10 & 14 & 400.2 & 0.462 & 0.0104 & 1.94 & & \\
\hline $2941-133$ & PO & 10 & 14 & 414.1 & 0.478 & 0.0104 & 2.16 & 0.263 & $8.7 \%$ \\
\hline 2941-141 & $\mathrm{PO}$ & 11 & 14 & 323.8 & 0.388 & 0.0104 & 3.02 & 0.0358 & $1.4 \%$ \\
\hline $2941-152$ & PO & 11 & 14 & 335.3 & 0.397 & 0.0104 & 2.53 & & \\
\hline $2941-146$ & $\mathrm{PO}$ & 12 & 13 & 730.4 & 0.797 & 0.0104 & 2.68 & 0.0637 & $2.4 \%$ \\
\hline $2941-158$ & $\mathrm{PO}$ & 12 & 13 & 752.8 & 0.815 & 0.0104 & 2.66 & & \\
\hline $2941-148$ & PO & 13 & 15 & 598.8 & 0.664 & 0.0104 & 3.36 & 0.0681 & $2.4 \%$ \\
\hline $2941-163$ & $\mathrm{PO}$ & 13 & 15 & 586.3 & 0.648 & 0.0104 & 2.82 & & \\
\hline
\end{tabular}


Field Sample Results - Total Mercury, Monomethylmercury

\begin{tabular}{|c|c|c|c|c|c|c|c|c|c|}
\hline Sample ID & $\begin{array}{l}\text { Station } \\
\text { ID }\end{array}$ & $\begin{array}{c}\text { Event } \\
\text { No. }\end{array}$ & $\begin{array}{c}\text { Days } \\
\text { Deployed }\end{array}$ & $\begin{array}{c}\text { Rain } \\
\text { Collected }\end{array}$ & $\begin{array}{c}\text { Sample } \\
\text { Vol. }\end{array}$ & $\begin{array}{c}\text { Funnel } \\
\text { Surface } \\
\text { Area }\end{array}$ & THg & MMHg & \% MMHg \\
\hline & Meth & $\begin{array}{r}\text { od Dete } \\
\text { Repo }\end{array}$ & $\begin{array}{r}\text { Unit } \\
\text { ction Limit } \\
\text { rting Limit }\end{array}$ & $\mathrm{mL}$ & $\mathrm{L}$ & $\mathrm{m}^{2}$ & $\begin{array}{r}\mathrm{ng} / \mathrm{L} \\
0.100 \\
0.318\end{array}$ & $\begin{array}{r}\mathrm{ng} / \mathrm{L} \\
0.010 \\
0.032\end{array}$ & \\
\hline $2941-352$ & $\mathrm{PO}$ & 14 & 16 & 0.0 & 0.069 & 0.0104 & & 0.0723 & $1.4 \%$ \\
\hline $2941-376$ & $\mathrm{PO}$ & 14 & 16 & 0.0 & 0.070 & 0.0104 & 5.24 & & \\
\hline $2941-357$ & PO & 15 & 15 & 208.5 & 0.272 & 0.0172 & & 0.0245 & $0.44 \%$ \\
\hline $2941-380$ & $\mathrm{PO}$ & 15 & 15 & 212.5 & 0.275 & 0.0172 & 5.59 & & \\
\hline $2941-364$ & $\mathrm{PO}$ & 16 & 12 & 3.2 & 0.0752 & 0.0172 & & 0.0362 & $0.69 \%$ \\
\hline $2941-394$ & $\mathrm{PO}$ & 16 & 12 & -5.6 & 0.0664 & 0.0172 & 5.27 & & \\
\hline $2941-362$ & $\mathrm{PO}$ & 17 & 16 & 577.9 & 0.643 & 0.0172 & & 0.0425 & $0.77 \%$ \\
\hline $2941-401$ & $\mathrm{PO}$ & 17 & 16 & 571.1 & 0.633 & 0.0172 & 5.54 & & \\
\hline $2941-405$ & PO & 18 & 14 & 122.0 & 0.184 & 0.0172 & 4.75 & & \\
\hline $2941-410$ & $\mathrm{PO}$ & 18 & 14 & 125.9 & 0.190 & 0.0172 & & 0.189 & $4.0 \%$ \\
\hline $2941-417$ & PO & 19 & 19 & 342.0 & 0.406 & 0.0172 & & 0.0571 & $1.3 \%$ \\
\hline $2941-422$ & $\mathrm{PO}$ & 19 & 19 & 349.8 & 0.412 & 0.0172 & 4.30 & & \\
\hline Average & & & & & & & 4.68 & 0.0958 & \\
\hline Stdev & & & & & & & 2.42 & 0.116 & \\
\hline 2941-7 & SB & 1 & 16 & 4.3 & 0.0663 & 0.0172 & 8.82 & & \\
\hline 2941-8 & SB & 1 & 16 & 3.7 & 0.0657 & 0.0172 & 10.9 & & \\
\hline 2941-11 & SB & 1 & 16 & 0.0 & 0.0596 & 0.0172 & & 1.40 & $16 \%$ \\
\hline 2941-12 & SB & 1 & 16 & 4.3 & 0.0663 & 0.0172 & & 1.35 & $12 \%$ \\
\hline 2941-14 & SB & 2 & 14 & 159.3 & 0.221 & 0.0172 & 19.8 & 0.555 & $2.8 \%$ \\
\hline $2941-18$ & SB & 2 & 14 & 143.9 & 0.206 & 0.0172 & 25.2 & 0.525 & $2.1 \%$ \\
\hline $2941-25$ & SB & 2 & 14 & 139.7 & 0.202 & 0.0172 & 17.9 & & \\
\hline $2941-26$ & SB & 2 & 14 & 143.3 & 0.205 & 0.0172 & 13.9 & & \\
\hline $2941-31$ & SB & 3 & 13 & 119.8 & 0.182 & 0.0172 & 7.75 & & \\
\hline $2941-52$ & SB & 3 & 13 & 121.8 & 0.184 & 0.0172 & 8.21 & 0.0819 & $1.0 \%$ \\
\hline $2941-55$ & SB & 4 & 15 & 148.5 & 0.210 & 0.0172 & 3.14 & 0.0329 & $1.0 \%$ \\
\hline $2941-50$ & SB & 5 & 8 & 999.0 & 1.00 & 0.0172 & 2.10 & & \\
\hline $2941-61$ & SB & 5 & 8 & 1007.0 & 1.01 & 0.0172 & 3.31 & 0.0148 & $0.45 \%$ \\
\hline $2941-66$ & SB & 6 & 15 & 319.8 & 0.372 & 0.0172 & 3.52 & 0.0874 & $2.5 \%$ \\
\hline $2941-74$ & SB & 6 & 15 & 306.9 & 0.379 & 0.0172 & 3.05 & & \\
\hline $2941-67$ & SB & 7 & 16 & 162.8 & 0.225 & 0.0172 & 2.21 & 0.115 & $5.2 \%$ \\
\hline $2941-79$ & SB & 7 & 16 & 160.9 & 0.223 & 0.0172 & 2.07 & & \\
\hline $2941-93$ & SB & 8 & 15 & 442.9 & 0.505 & 0.0172 & 1.98 & 0.0456 & $2.3 \%$ \\
\hline 2941-105 & SB & 8 & 15 & 464.9 & 0.527 & 0.0172 & 2.58 & & \\
\hline $2941-97$ & SB & 9 & 17 & 605.7 & 0.671 & 0.0172 & 4.14 & 0.217 & $5.2 \%$ \\
\hline $2941-115$ & SB & 9 & 17 & 609.6 & 0.672 & 0.0172 & 3.64 & & \\
\hline $2941-136$ & SB & 10 & 15 & 364.1 & 0.428 & 0.0172 & 3.45 & 0.224 & $6.5 \%$ \\
\hline 2941-119 & SB & 10 & 15 & 362.8 & 0.425 & 0.0172 & 4.89 & & \\
\hline $2941-130$ & SB & 11 & 15 & 88.1 & 0.150 & 0.0172 & 6.71 & & \\
\hline 2941-139 & SB & 11 & 15 & 89.6 & 0.152 & 0.0172 & 12.2 & 1.56 & $13 \%$ \\
\hline 2941-144 & SB & 12 & 13 & 214.2 & 0.277 & 0.0172 & 7.92 & 0.185 & $2.3 \%$ \\
\hline $2941-160$ & SB & 12 & 13 & 221.7 & 0.284 & 0.0172 & 2.95 & & \\
\hline $2941-350$ & SB & 13 & 16 & 714.3 & 0.781 & 0.0172 & 3.97 & 0.144 & $3.6 \%$ \\
\hline $2941-162$ & SB & 13 & 16 & 723.7 & 0.786 & 0.0172 & 4.09 & & \\
\hline $2941-351$ & SB & 14 & 12 & 0.0 & 0.0716 & 0.0172 & & 0.318 & $2.7 \%$ \\
\hline $2941-374$ & SB & 14 & 12 & 0.0 & 0.0729 & 0.0172 & 11.7 & & \\
\hline $2941-370$ & SB & 15 & 15 & 149.4 & 0.211 & 0.0172 & 2.12 & & \\
\hline $2941-359$ & SB & 16 & 11 & -2.6 & 0.0694 & 0.0172 & & 0.0671 & $1.0 \%$ \\
\hline 2941-409 & SB & 16 & 11 & 0.0 & 0.0720 & 0.0172 & 7.02 & & \\
\hline $2941-369$ & SB & 17 & 13 & 131.3 & 0.194 & 0.0172 & & 0.202 & $4.1 \%$ \\
\hline $2941-397$ & SB & 17 & 13 & 133.0 & 0.195 & 0.0172 & 4.96 & & \\
\hline $2941-406$ & $\mathrm{SB}$ & 18 & 14 & 94.4 & 0.156 & 0.0172 & 3.82 & & \\
\hline $2941-413$ & SB & 18 & 14 & 92.9 & 0.156 & 0.0172 & & 0.0472 & $1.2 \%$ \\
\hline $2941-415$ & SB & 19 & 18 & 106.5 & 0.169 & 0.0172 & & 0.436 & \\
\hline $2941-420$ & SB & 19 & 18 & 107.4 & 0.169 & 0.0172 & 6.96 & & $6.3 \%$ \\
\hline Average & & & & & & & 6.88 & 0.380 & \\
\hline Stdev & & & & & & & 5.62 & 0.482 & \\
\hline 2941-4 & TCB & 1 & 14 & 0.0 & 0.139 & 0.0172 & 13.9 & & \\
\hline $2941-22$ & TCB & 2 & 12 & 127.5 & 0.190 & 0.0172 & 20.9 & & \\
\hline $2941-27$ & TCB & 3 & 21 & 597.7 & 0.660 & 0.0172 & 11.5 & & \\
\hline $2941-37$ & TCB & 4 & 15 & 300.1 & 0.362 & 0.0172 & 8.86 & & \\
\hline $2941-75$ & TCB & 6 & 12 & 154.0 & 0.216 & 0.0104 & 4.83 & & \\
\hline $2941-86$ & $\mathrm{TCB}$ & 7 & 17 & 59.8 & 0.122 & 0.0064 & 3.78 & & \\
\hline 2941-91 & TCB & 8 & 15 & 352.4 & 0.414 & 0.0104 & 4.05 & 0.126 & $3.1 \%$ \\
\hline 2941-92 & TCB & 8 & 15 & 352.5 & 0.415 & 0.0104 & 5.54 & 0.264 & $4.8 \%$ \\
\hline
\end{tabular}


Field Sample Results - Total Mercury, Monomethylmercury

\begin{tabular}{|c|c|c|c|c|c|c|c|c|c|}
\hline Sample ID & $\begin{array}{l}\text { Station } \\
\text { ID }\end{array}$ & $\begin{array}{c}\text { Event } \\
\text { No. }\end{array}$ & $\begin{array}{c}\text { Days } \\
\text { Deployed }\end{array}$ & $\begin{array}{c}\text { Rain } \\
\text { Collected }\end{array}$ & $\begin{array}{c}\text { Sample } \\
\text { Vol. }\end{array}$ & $\begin{array}{c}\text { Funnel } \\
\text { Surface } \\
\text { Area }\end{array}$ & THg & MMHg & \% MMHg \\
\hline & Metho & $\begin{array}{l}\text { od Detec } \\
\text { Repor }\end{array}$ & $\begin{array}{r}\text { Unit } \\
\text { ction Limit } \\
\text { rting Limit }\end{array}$ & $\mathrm{mL}$ & $\mathrm{L}$ & $\mathrm{m}^{2}$ & $\begin{array}{r}\mathrm{ng} / \mathrm{L} \\
0.100 \\
0.318\end{array}$ & $\begin{array}{r}\mathrm{ng} / \mathrm{L} \\
0.010 \\
0.032\end{array}$ & \\
\hline $2941-89$ & TCB & 8 & 15 & 355.9 & 0.418 & 0.0104 & 5.29 & & \\
\hline $2941-90$ & TCB & 8 & 15 & 325.0 & 0.387 & 0.0104 & 5.17 & & \\
\hline $2941-100$ & TCB & 9 & 13 & 721.9 & 0.788 & 0.0104 & 3.80 & 0.0715 & $1.9 \%$ \\
\hline 2941-131 & TCB & 9 & 13 & 721.2 & 0.785 & 0.0104 & 4.06 & 0.213 & $5.3 \%$ \\
\hline 2941-109 & TCB & 9 & 13 & 719.8 & 0.782 & 0.0104 & 3.34 & & \\
\hline 2941-111 & TCB & 9 & 13 & 799.7 & 0.862 & 0.0104 & 3.02 & & \\
\hline $2941-123$ & TCB & 10 & 14 & 435.5 & 0.498 & 0.0104 & 2.95 & & \\
\hline 2941-134 & TCB & 10 & 14 & 430.7 & 0.495 & 0.0104 & 3.18 & 0.194 & $6.1 \%$ \\
\hline $2941-127$ & TCB & 11 & 14 & 477.9 & 0.540 & 0.0104 & 3.87 & & \\
\hline 2941-138 & TCB & 11 & 14 & 429.0 & 0.493 & 0.0104 & 4.03 & 0.0727 & $1.8 \%$ \\
\hline 2941-142 & $\mathrm{TCB}$ & 12 & 15 & 864.2 & 0.931 & 0.0104 & 4.41 & 0.0624 & $1.4 \%$ \\
\hline $2941-157$ & TCB & 12 & 15 & 845.7 & 0.908 & 0.0104 & 4.03 & & \\
\hline 2941-149 & TCB & 13 & 14 & 327.7 & 0.392 & 0.0104 & 9.61 & 0.0227 & $0.24 \%$ \\
\hline $2941-167$ & TCB & 13 & 14 & 318.7 & 0.381 & 0.0104 & 5.20 & & \\
\hline $2941-356$ & TCB & 14 & 14 & 0.0 & 0.057 & 0.0104 & & $0.0100 \mathrm{U}$ & $0.14 \%$ \\
\hline $2941-375$ & TCB & 14 & 14 & 0.0 & 0.058 & 0.0104 & 7.17 & & \\
\hline $2941-360$ & TCB & 15 & 13 & 205.2 & 0.268 & 0.0172 & & 0.0956 & $1.8 \%$ \\
\hline $2941-383$ & TCB & 15 & 13 & 186.6 & 0.249 & 0.0172 & 5.24 & & \\
\hline $2941-407$ & TCB & 16 & 15 & 31.6 & 0.094 & 0.0172 & 15.30 & & \\
\hline $2941-411$ & TCB & 16 & 15 & 51.4 & 0.115 & 0.0172 & & 0.116 & $0.76 \%$ \\
\hline 2941-361 & $\mathrm{TCB}$ & 17 & 12 & 971.9 & 1.04 & 0.0172 & & 0.0707 & $1.0 \%$ \\
\hline $2941-395$ & TCB & 17 & 12 & 904.2 & 0.966 & 0.0172 & 6.95 & & \\
\hline $2941-368$ & $\mathrm{TCB}$ & 18 & 16 & 117.6 & 0.181 & 0.0172 & & 0.0983 & $0.36 \%$ \\
\hline $2941-386$ & TCB & 18 & 16 & 104.9 & 0.167 & 0.0172 & 27.00 & & \\
\hline $2941-416$ & TCB & 19 & 13 & 224.5 & 0.288 & 0.0172 & & 0.397 & $2.4 \%$ \\
\hline $2941-425$ & TCB & 19 & 13 & 192.7 & 0.255 & 0.0172 & 16.60 & & \\
\hline Average & & & & & & & 7.63 & 0.130 & \\
\hline Stdev & & & & & & & 6.00 & 0.105 & \\
\hline $2941-377$ & TM & 14 & 15 & 0.0 & 0.0569 & 0.0104 & 7.21 & & \\
\hline $2941-382$ & TM & 15 & 13 & 169.7 & 0.232 & 0.0172 & 4.15 & & \\
\hline $2941-408$ & TM & 16 & 15 & 26.0 & 0.0880 & 0.0172 & 6.05 & & \\
\hline 2941-393 & TM & 17 & 12 & 798.2 & 0.860 & 0.0172 & 3.93 & & \\
\hline 2941-389 & TM & 18 & 16 & 93.9 & 0.156 & 0.0172 & 9.48 & & \\
\hline $2941-402$ & $\mathrm{TM}$ & 19 & 13 & 92.6 & 0.155 & 0.0172 & 5.65 & & \\
\hline Average & & & & & & & 6.08 & & \\
\hline Stdev & & & & & & & 2.07 & & \\
\hline $2941-2$ & WP & 1 & 15 & 0.0 & 0.138 & 0.0172 & 3.42 & & \\
\hline $2941-21$ & WP & 2 & 13 & 259.5 & 0.322 & 0.0172 & 12.3 & & \\
\hline $2941-28$ & WP & 3 & 19 & 558.8 & 0.621 & 0.0172 & 9.73 & & \\
\hline 2941-38 & WP & 4 & 15 & 136.7 & 0.199 & 0.0172 & 4.38 & & \\
\hline $2941-78$ & WP & 6 & 12 & 78.2 & 0.140 & 0.0104 & 3.30 & & \\
\hline $2941-83$ & WP & 7 & 16 & 91.0 & 0.153 & 0.0064 & 1.89 & & \\
\hline $2941-87$ & WP & 8 & 13 & 295.3 & 0.357 & 0.0104 & 6.20 & & \\
\hline $2941-110$ & WP & 9 & 14 & 506.8 & 0.569 & 0.0104 & 4.79 & & \\
\hline $2941-117$ & WP & 10 & 14 & 404.8 & 0.467 & 0.0104 & 3.25 & & \\
\hline $2941-126$ & WP & 11 & 15 & 258.8 & 0.321 & 0.0104 & 3.44 & & \\
\hline $2941-154$ & WP & 12 & 13 & 734.8 & 0.797 & 0.0104 & 4.24 & & \\
\hline $2941-166$ & WP & 13 & 15 & 535.9 & 0.598 & 0.0104 & 6.05 & & \\
\hline $2941-170$ & WP & 14 & 13 & 0.0 & 0.059 & 0.0104 & 11.3 & & \\
\hline $2941-378$ & WP & 15 & 14 & 150.5 & 0.213 & 0.0172 & 7.49 & & \\
\hline $2941-384$ & WP & 16 & 14 & 146.8 & 0.209 & 0.0172 & 5.58 & & \\
\hline $2941-388$ & WP & 17 & 14 & 505.1 & 0.567 & 0.0172 & 9.62 & & \\
\hline 2941-391 & WP & 18 & 15 & 194.3 & 0.256 & 0.0172 & 8.03 & & \\
\hline $2941-423$ & WP & 19 & 13 & 394.4 & 0.411 & 0.0172 & 5.26 & & \\
\hline Average & & & & & & & 6.12 & & \\
\hline Stdev & & & & & & & 3.00 & & \\
\hline
\end{tabular}




\begin{tabular}{|c|c|c|c|c|c|c|c|c|c|}
\hline \multirow[t]{2}{*}{ Sample ID } & $\begin{array}{l}\text { Station } \\
\text { ID }\end{array}$ & $\begin{array}{c}\text { Event } \\
\text { No. }\end{array}$ & $\begin{array}{c}\text { Days } \\
\text { Deployed }\end{array}$ & $\begin{array}{c}\text { Rain } \\
\text { Collected }\end{array}$ & $\begin{array}{c}\text { Sample } \\
\text { Vol. }\end{array}$ & $\begin{array}{c}\text { Funnel } \\
\text { Surface } \\
\text { Area }\end{array}$ & \multicolumn{2}{|r|}{ Avg THg } & RPD/RSD \\
\hline & Meth & $\begin{array}{r}\text { d Dete } \\
\text { Repo }\end{array}$ & $\begin{array}{l}\text { Unit } \\
\text { ction Limit } \\
\text { rting Limit }\end{array}$ & $\mathrm{mL}$ & $\mathrm{L}$ & $\mathrm{m}^{2}$ & $\mathrm{ng} / \mathrm{m}^{2} /$ day & $\mathrm{ng} / \mathrm{m}^{2} /$ day & $\%$ \\
\hline $\begin{array}{l}2941-1 \\
2941-95 \\
2941-101 \\
2941-107 \\
\text { Average } \\
\text { Stdev } \\
\text { Rinse Wate }\end{array}$ & $\begin{array}{c}\text { EB } \\
\text { EB } \\
\text { EB } \\
\text { EB } \\
\end{array}$ & bution & $\begin{array}{c}14 \\
14 \\
14 \\
0\end{array}$ & & & $\begin{array}{l}0.0172 \\
0.0104 \\
0.0104 \\
0.0104\end{array}$ & & & \\
\hline 2941-10 & $\mathrm{HC}$ & 1 & 14 & 0.200 & 0.0622 & 0.0172 & 0.550 & 0.550 & \\
\hline 2941-16 & $\mathrm{HC}$ & 1 & 14 & 0.0 & 0.0605 & 0.0172 & & & \\
\hline 2941-13 & $\mathrm{HC}$ & 2 & 19 & 861.9 & 0.924 & 0.0172 & 7.16 & 14.0 & $98 \%$ \\
\hline 2941-20 & $\mathrm{HC}$ & 2 & 19 & 860.2 & 0.922 & 0.0172 & 20.8 & & \\
\hline 2941-34 & $\mathrm{HC}$ & 3 & 10 & 350.0 & 0.412 & 0.0172 & 10.4 & 15.4 & $64 \%$ \\
\hline 2941-54 & $\mathrm{HC}$ & 3 & 10 & 350.8 & 0.413 & 0.0172 & 20.3 & & \\
\hline 2941-42 & $\mathrm{HC}$ & 4 & 13 & 67.9 & 0.130 & 0.0172 & 1.26 & 1.68 & $51 \%$ \\
\hline 2941-57 & $\mathrm{HC}$ & 4 & 13 & 65.1 & 0.127 & 0.0172 & 2.11 & & \\
\hline 2941-63 & $\mathrm{HC}$ & 6 & 12 & 461.9 & 0.525 & 0.0104 & 10.5 & 10.2 & $14 \%$ \\
\hline 2941-64 & $\mathrm{HC}$ & 6 & 12 & 453.2 & 0.515 & 0.0104 & 12.0 & & \\
\hline 2941-71 & $\mathrm{HC}$ & 6 & 12 & 446.9 & 0.509 & 0.0104 & 8.83 & & \\
\hline 2941-72 & $\mathrm{HC}$ & 6 & 12 & 483.9 & 0.546 & 0.0104 & 9.39 & & \\
\hline 2941-80 & $\mathrm{HC}$ & 7 & 21 & 257.7 & 0.320 & 0.0104 & 1.65 & 3.21 & $45 \%$ \\
\hline 2941-81 & $\mathrm{HC}$ & 7 & 21 & 272.1 & 0.334 & 0.0104 & 3.45 & & \\
\hline 2941-70 & $\mathrm{HC}$ & 7 & 21 & 258.1 & 0.321 & 0.0104 & 4.54 & & \\
\hline 2941-94 & $\mathrm{HC}$ & 8 & 14 & 361.7 & 0.424 & 0.0104 & 13.9 & 15.5 & $20 \%$ \\
\hline 2941-104 & $\mathrm{HC}$ & 8 & 14 & 363.7 & 0.426 & 0.0104 & 17.0 & & \\
\hline 2941-98 & $\mathrm{HC}$ & 9 & 13 & 691.1 & 0.757 & 0.0104 & 12.2 & 11.5 & $13 \%$ \\
\hline 2941-113 & $\mathrm{HC}$ & 9 & 13 & 666.2 & 0.728 & 0.0104 & 10.7 & & \\
\hline 2941-124 & $\mathrm{HC}$ & 10 & 14 & 240.1 & 0.302 & 0.0104 & 3.05 & 3.43 & $22 \%$ \\
\hline 2941-132 & $\mathrm{HC}$ & 10 & 14 & 240.7 & 0.303 & 0.0104 & 3.81 & & \\
\hline 2941-140 & $\mathrm{HC}$ & 11 & 14 & 445.7 & 0.510 & 0.0104 & 6.32 & 5.87 & $15 \%$ \\
\hline 2941-151 & $\mathrm{HC}$ & 11 & 14 & 467.3 & 0.529 & 0.0104 & 5.43 & & \\
\hline $2941-145$ & $\mathrm{HC}$ & 12 & 13 & 702.6 & 0.770 & 0.0104 & 18.3 & 31.9 & $85 \%$ \\
\hline 2941-159 & $\mathrm{HC}$ & 12 & 13 & 713.1 & 0.775 & 0.0104 & 45.4 & & \\
\hline $2941-147$ & $\mathrm{HC}$ & 13 & 15 & 620.0 & 0.685 & 0.0104 & 15.7 & 13.0 & $42 \%$ \\
\hline 2941-161 & $\mathrm{HC}$ & 13 & 15 & 630.2 & 0.692 & 0.0104 & 10.3 & & \\
\hline $2941-354$ & $\mathrm{HC}$ & 14 & 16 & 0.0 & 0.068 & 0.0104 & & 1.12 & \\
\hline $2941-373$ & $\mathrm{HC}$ & 14 & 16 & 0.0 & 0.0697 & 0.0104 & 1.12 & & \\
\hline $2941-355$ & $\mathrm{HC}$ & 15 & 15 & 230.0 & 0.293 & 0.0172 & & & \\
\hline 2941-381 & $\mathrm{HC}$ & 15 & 15 & 239.5 & 0.302 & 0.0172 & 5.61 & & \\
\hline $2941-390$ & $\mathrm{HC}$ & 16 & 12 & 11.4 & 0.0734 & 0.0172 & 2.41 & & \\
\hline $2941-412$ & $\mathrm{HC}$ & 16 & 12 & 0.3 & 0.0623 & 0.0172 & & & \\
\hline $2941-367$ & $\mathrm{HC}$ & 17 & 16 & 736.3 & 0.802 & 0.0172 & & & \\
\hline $2941-387$ & $\mathrm{HC}$ & 17 & 16 & 749.2 & 0.811 & 0.0172 & 19.9 & & \\
\hline 2941-399 & $\mathrm{HC}$ & 18 & 14 & 176.5 & 0.239 & 0.0172 & 7.23 & & \\
\hline $2947-414$ & $\mathrm{HC}$ & 18 & 14 & 161.7 & 0.226 & 0.0172 & & & \\
\hline 2941-403 & $\mathrm{HC}$ & 19 & 19 & 606.8 & 0.669 & 0.0172 & 9.36 & & \\
\hline $2941-418$ & $\mathrm{HC}$ & 19 & 19 & 582.2 & 0.643 & 0.0172 & & & \\
\hline Average & & & & & & & 10.0 & 9.78 & \\
\hline Stdev & & & & & & & 8.83 & 8.70 & \\
\hline $2941-5$ & NR & 1 & 14 & 0.0 & 0.0695 & 0.0172 & 2.73 & 2.73 & \\
\hline 2941-23 & NR & 2 & 12 & 131.5 & 0.194 & 0.0172 & 12.0 & 12.0 & \\
\hline 2941-29 & NR & 3 & 21 & 1002.5 & 1.00 & 0.0172 & 14.9 & 14.9 & \\
\hline 2941-35 & NR & 4 & 15 & 237.2 & 0.299 & 0.0172 & 3.01 & 3.01 & \\
\hline 2941-77 & NR & 6 & 12 & 208.1 & 0.270 & 0.0104 & 4.97 & 4.97 & \\
\hline 2941-85 & NR & 7 & 17 & 52.0 & 0.114 & 0.0064 & 2.04 & 2.04 & \\
\hline 2941-103 & NR & 8 & 15 & 351.1 & 0.413 & 0.0104 & 14.0 & 14.0 & \\
\hline 2941-112 & NR & 9 & 13 & 785.2 & 0.847 & 0.0104 & 11.4 & 11.4 & \\
\hline 2941-116 & NR & 10 & 14 & 380.7 & 0.443 & 0.0104 & 5.11 & 5.89 & $17 \%$ \\
\hline 2941-121 & NR & 10 & 14 & 382.9 & 0.445 & 0.0104 & 7.04 & & \\
\hline 2941-135 & NR & 10 & 14 & 378.9 & 0.443 & 0.0104 & 5.53 & & \\
\hline 2941-128 & NR & 11 & 14 & 467.2 & 0.529 & 0.0104 & 13.5 & 12.0 & $12 \%$ \\
\hline 2941-129 & NR & 11 & 14 & 397.9 & 0.460 & 0.0104 & 10.6 & & \\
\hline $2941-137$ & NR & 11 & 14 & 451.5 & 0.516 & 0.0104 & 11.9 & & \\
\hline $2941-143$ & NR & 12 & 15 & 937.9 & 1.00 & 0.0104 & 22.8 & 22.4 & $3.7 \%$ \\
\hline $2941-153$ & NR & 12 & 15 & 948.8 & 1.01 & 0.0104 & 21.5 & & \\
\hline
\end{tabular}




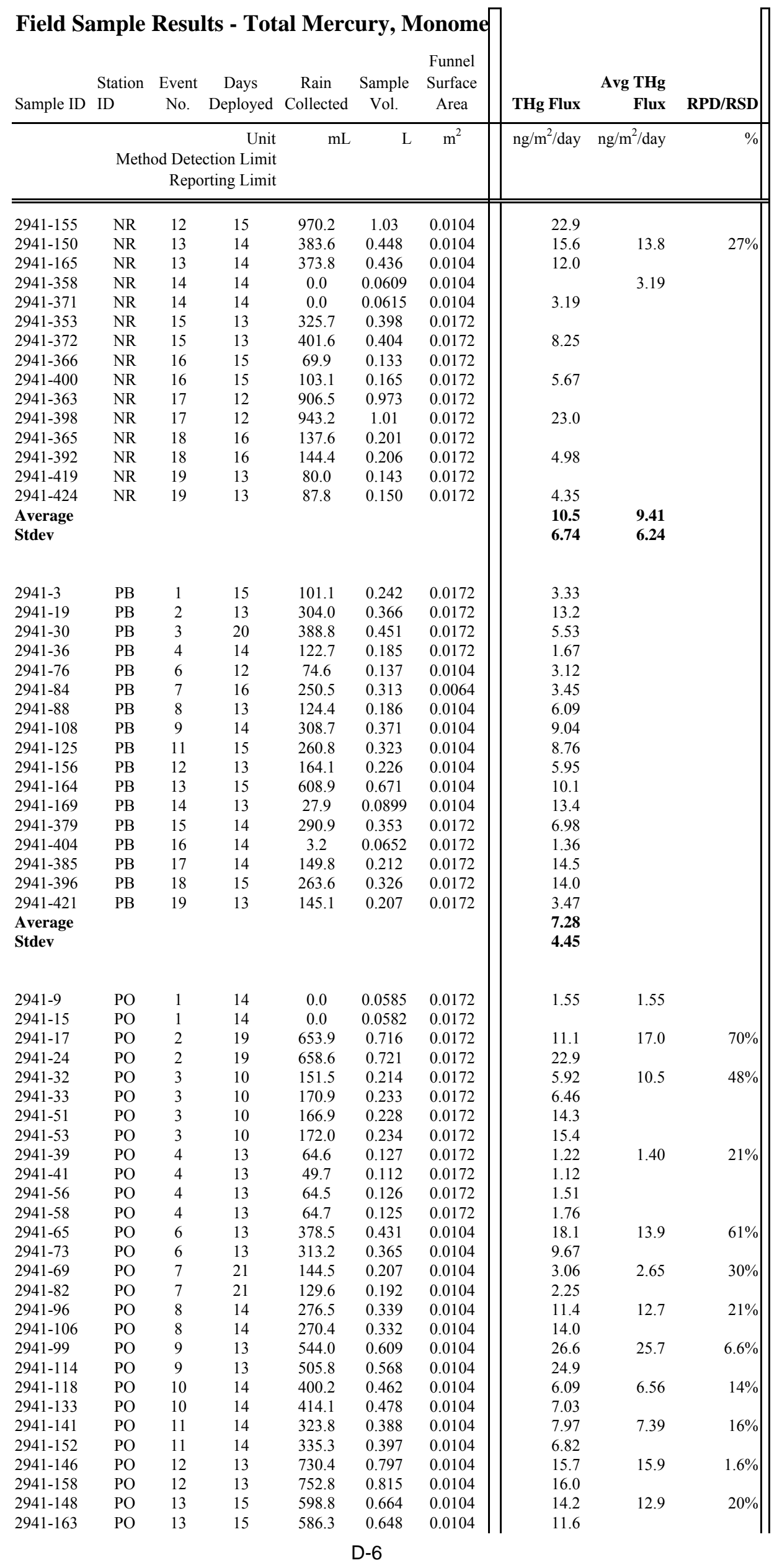




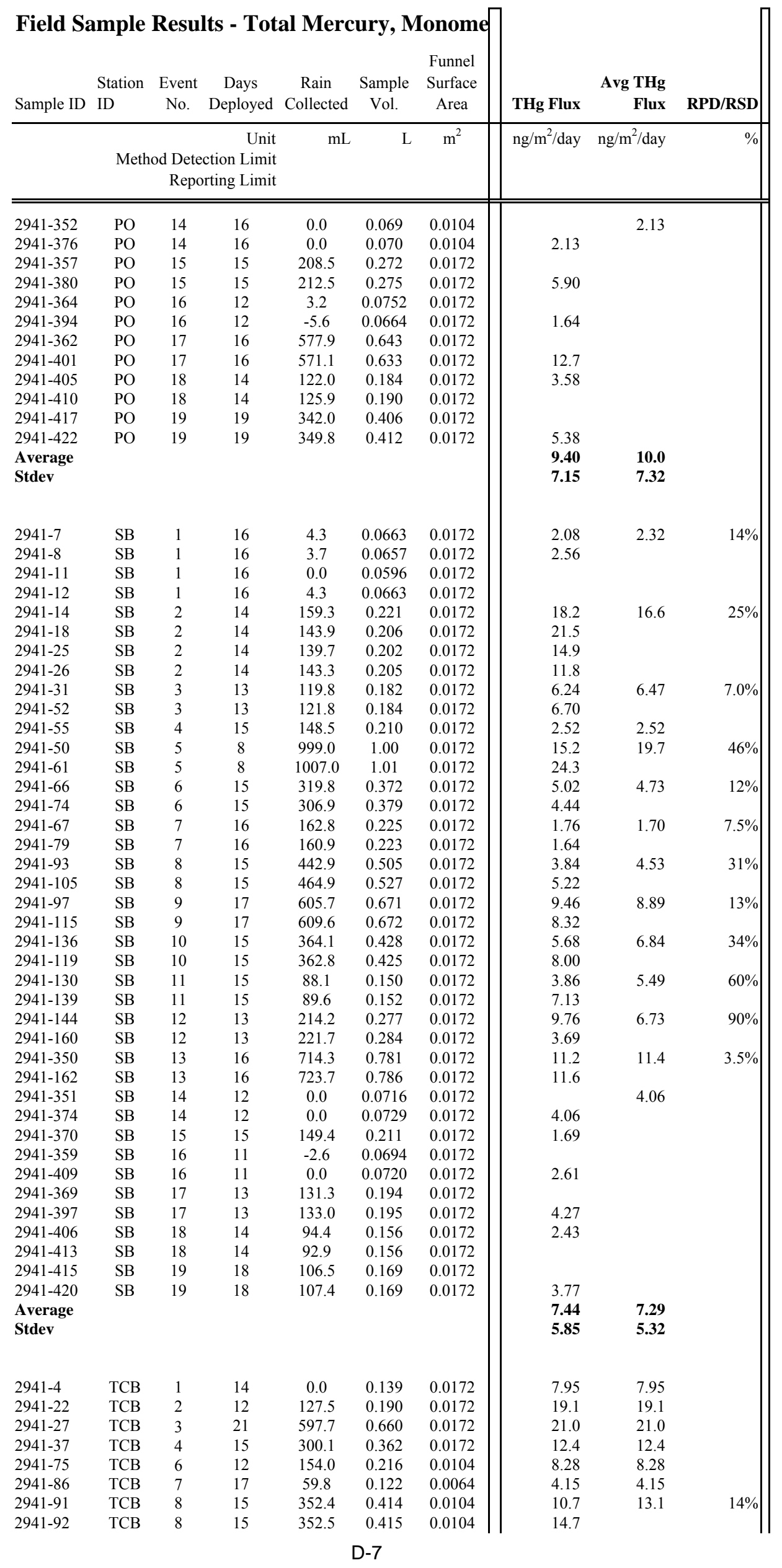




\begin{tabular}{|c|c|c|c|c|c|c|c|c|c|}
\hline \multirow[t]{2}{*}{ Sample ID } & $\begin{array}{l}\text { Station } \\
\text { ID }\end{array}$ & $\begin{array}{c}\text { Event } \\
\text { No. }\end{array}$ & $\begin{array}{c}\text { Days } \\
\text { Deployed }\end{array}$ & $\begin{array}{c}\text { Rain } \\
\text { Collected }\end{array}$ & $\begin{array}{c}\text { Sample } \\
\text { Vol. }\end{array}$ & $\begin{array}{c}\text { Funnel } \\
\text { Surface } \\
\text { Area }\end{array}$ & \multicolumn{3}{|c|}{ Avg THg } \\
\hline & Meth & $\begin{array}{r}\text { od Dete } \\
\text { Repo }\end{array}$ & $\begin{array}{r}\text { Unit } \\
\text { ection Limit } \\
\text { orting Limit }\end{array}$ & $\mathrm{mL}$ & $\mathrm{L}$ & $\mathrm{m}^{2}$ & $\mathrm{ng} / \mathrm{m}^{2} /$ day & $\mathrm{n}^{2} /$ day & $\%$ \\
\hline $2941-89$ & TCB & 8 & 15 & 355.9 & 0.418 & 0.0104 & 14.1 & & \\
\hline $2941-90$ & TCB & 8 & 15 & 325.0 & 0.387 & 0.0104 & 12.8 & & \\
\hline $2941-100$ & TCB & 9 & 13 & 721.9 & 0.788 & 0.0104 & 22.1 & 21.0 & $10 \%$ \\
\hline 2941-131 & TCB & 9 & 13 & 721.2 & 0.785 & 0.0104 & 23.5 & & \\
\hline 2941-109 & TCB & 9 & 13 & 719.8 & 0.782 & 0.0104 & 19.3 & & \\
\hline $2941-111$ & TCB & 9 & 13 & 799.7 & 0.862 & 0.0104 & 19.2 & & \\
\hline $2941-123$ & TCB & 10 & 14 & 435.5 & 0.498 & 0.0104 & 10.0 & 10.4 & $6.9 \%$ \\
\hline $2941-134$ & TCB & 10 & 14 & 430.7 & 0.495 & 0.0104 & 10.7 & & \\
\hline $2941-127$ & TCB & 11 & 14 & 477.9 & 0.540 & 0.0104 & 14.3 & 13.9 & $5.0 \%$ \\
\hline $2941-138$ & TCB & 11 & 14 & 429.0 & 0.493 & 0.0104 & 13.6 & & \\
\hline $2941-142$ & TCB & 12 & 15 & 864.2 & 0.931 & 0.0104 & 26.3 & 24.9 & $12 \%$ \\
\hline $2941-157$ & TCB & 12 & 15 & 845.7 & 0.908 & 0.0104 & 23.4 & & \\
\hline 2941-149 & TCB & 13 & 14 & 327.7 & 0.392 & 0.0104 & 25.8 & 19.7 & $62 \%$ \\
\hline $2941-167$ & TCB & 13 & 14 & 318.7 & 0.381 & 0.0104 & 13.5 & & \\
\hline $2941-356$ & TCB & 14 & 14 & 0.0 & 0.057 & 0.0104 & & 2.77 & \\
\hline $2941-375$ & TCB & 14 & 14 & 0.0 & 0.058 & 0.0104 & 2.77 & & \\
\hline $2941-360$ & TCB & 15 & 13 & 205.2 & 0.268 & 0.0172 & & & \\
\hline $2941-383$ & TCB & 15 & 13 & 186.6 & 0.249 & 0.0172 & 5.77 & & \\
\hline $2941-407$ & TCB & 16 & 15 & 31.6 & 0.094 & 0.0172 & 5.51 & & \\
\hline $2941-411$ & TCB & 16 & 15 & 51.4 & 0.115 & 0.0172 & & & \\
\hline $2941-361$ & TCB & 17 & 12 & 971.9 & 1.04 & 0.0172 & & & \\
\hline $2941-395$ & TCB & 17 & 12 & 904.2 & 0.966 & 0.0172 & 32.5 & & \\
\hline $2941-368$ & TCB & 18 & 16 & 117.6 & 0.181 & 0.0172 & & & \\
\hline $2941-386$ & TCB & 18 & 16 & 104.9 & 0.167 & 0.0172 & 16.3 & & \\
\hline $2941-416$ & TCB & 19 & 13 & 224.5 & 0.288 & 0.0172 & & & \\
\hline $2941-425$ & TCB & 19 & 13 & 192.7 & 0.255 & 0.0172 & 18.9 & & \\
\hline Average & & & & & & & 15.3 & 13.7 & \\
\hline Stdev & & & & & & & 7.36 & 6.97 & \\
\hline $2941-377$ & TM & 14 & 15 & 0.0 & 0.0569 & 0.0104 & 2.56 & & \\
\hline $2941-382$ & TM & 15 & 13 & 169.7 & 0.232 & 0.0172 & 4.25 & & \\
\hline $2941-408$ & $\mathrm{TM}$ & 16 & 15 & 26.0 & 0.0880 & 0.0172 & 2.02 & & \\
\hline $2941-393$ & TM & 17 & 12 & 798.2 & 0.860 & 0.0172 & 16.3 & & \\
\hline 2941-389 & TM & 18 & 16 & 93.9 & 0.156 & 0.0172 & 5.32 & & \\
\hline $2941-402$ & TM & 19 & 13 & 92.6 & 0.155 & 0.0172 & 3.85 & & \\
\hline Average & & & & & & & 5.72 & & \\
\hline Stdev & & & & & & & 5.33 & & \\
\hline $2941-2$ & WP & 1 & 15 & 0.0 & 0.138 & 0.0172 & 1.78 & & \\
\hline 2941-21 & WP & 2 & 13 & 259.5 & 0.322 & 0.0172 & 17.6 & & \\
\hline $2941-28$ & WP & 3 & 19 & 558.8 & 0.621 & 0.0172 & 18.4 & & \\
\hline $2941-38$ & WP & 4 & 15 & 136.7 & 0.199 & 0.0172 & 3.33 & & \\
\hline $2941-78$ & WP & 6 & 12 & 78.2 & 0.140 & 0.0104 & 3.62 & & \\
\hline $2941-83$ & WP & 7 & 16 & 91.0 & 0.153 & 0.0064 & 2.73 & & \\
\hline $2941-87$ & WP & 8 & 13 & 295.3 & 0.357 & 0.0104 & 16.3 & & \\
\hline $2941-110$ & WP & 9 & 14 & 506.8 & 0.569 & 0.0104 & 18.6 & & \\
\hline $2941-117$ & WP & 10 & 14 & 404.8 & 0.467 & 0.0104 & 10.4 & & \\
\hline $2941-126$ & WP & 11 & 15 & 258.8 & 0.321 & 0.0104 & 7.00 & & \\
\hline $2941-154$ & WP & 12 & 13 & 734.8 & 0.797 & 0.0104 & 24.9 & & \\
\hline $2941-166$ & WP & 13 & 15 & 535.9 & 0.598 & 0.0104 & 23.1 & & \\
\hline $2941-170$ & WP & 14 & 13 & 0.0 & 0.059 & 0.0104 & 4.81 & & \\
\hline $2941-378$ & WP & 15 & 14 & 150.5 & 0.213 & 0.0172 & 6.56 & & \\
\hline $2941-384$ & WP & 16 & 14 & 146.8 & 0.209 & 0.0172 & 4.79 & & \\
\hline $2941-388$ & WP & 17 & 14 & 505.1 & 0.567 & 0.0172 & 22.6 & & \\
\hline 2941-391 & WP & 18 & 15 & 194.3 & 0.256 & 0.0172 & 7.93 & & \\
\hline $2941-423$ & WP & 19 & 13 & 394.4 & 0.411 & 0.0172 & 9.63 & & \\
\hline Average & & & & & & & 11.3 & & \\
\hline Stdev & & & & & & & 7.86 & & \\
\hline
\end{tabular}


Field Sample Results - Total Mercury, Monome

\begin{tabular}{|c|c|c|c|c|c|c|c|c|c|}
\hline Sample ID & $\begin{array}{l}\text { Station } \\
\text { ID }\end{array}$ & $\begin{array}{c}\text { Event } \\
\text { No. }\end{array}$ & $\begin{array}{c}\text { Days } \\
\text { Deployed }\end{array}$ & $\begin{array}{c}\text { Rain } \\
\text { Collected }\end{array}$ & $\begin{array}{c}\text { Sample } \\
\text { Vol. }\end{array}$ & $\begin{array}{c}\text { Funnel } \\
\text { Surface } \\
\text { Area }\end{array}$ & $\begin{array}{r}\text { MMHg } \\
\text { Flux }\end{array}$ & $\begin{array}{r}\text { Avg } \\
\text { MMHg } \\
\text { Flux }\end{array}$ & RPD \\
\hline & Methe & $\begin{array}{l}\text { od Detec } \\
\text { Repor }\end{array}$ & $\begin{array}{r}\text { Unit } \\
\text { ction Limit } \\
\text { rting Limit }\end{array}$ & $\mathrm{mL}$ & $\mathrm{L}$ & $\mathrm{m}^{2}$ & $\mathrm{ng} / \mathrm{m}^{2} /$ day & $\mathrm{ng} / \mathrm{m}^{2} /$ day & $\overline{\%}$ \\
\hline $\begin{array}{l}2941-1 \\
2941-95 \\
2941-101 \\
2941-107 \\
\text { Average } \\
\text { Stdev } \\
\text { Rinse Wate }\end{array}$ & $\begin{array}{l}\text { EB } \\
\text { EB } \\
\text { EB } \\
\text { EB }\end{array}$ & ibution ( & $\begin{array}{c}14 \\
14 \\
14 \\
0\end{array}$ & & & $\begin{array}{l}0.0172 \\
0.0104 \\
0.0104 \\
0.0104\end{array}$ & & & \\
\hline 2941-10 & $\mathrm{HC}$ & 1 & 14 & 0.200 & 0.0622 & 0.0172 & & & \\
\hline 2941-16 & $\mathrm{HC}$ & 1 & 14 & 0.0 & 0.0605 & 0.0172 & 0.184 & & \\
\hline 2941-13 & $\mathrm{HC}$ & 2 & 19 & 861.9 & 0.924 & 0.0172 & 0.0535 & & \\
\hline 2941-20 & $\mathrm{HC}$ & 2 & 19 & 860.2 & 0.922 & 0.0172 & & & \\
\hline 2941-34 & $\mathrm{HC}$ & 3 & 10 & 350.0 & 0.412 & 0.0172 & & & \\
\hline 2941-54 & $\mathrm{HC}$ & 3 & 10 & 350.8 & 0.413 & 0.0172 & 0.130 & & \\
\hline 2941-42 & $\mathrm{HC}$ & 4 & 13 & 67.9 & 0.130 & 0.0172 & & & \\
\hline $2941-57$ & $\mathrm{HC}$ & 4 & 13 & 65.1 & 0.127 & 0.0172 & 0.129 & & \\
\hline 2941-63 & $\mathrm{HC}$ & 6 & 12 & 461.9 & 0.525 & 0.0104 & 0.910 & 1.06 & $28 \%$ \\
\hline 2941-64 & $\mathrm{HC}$ & 6 & 12 & 453.2 & 0.515 & 0.0104 & 1.20 & & \\
\hline 2941-71 & $\mathrm{HC}$ & 6 & 12 & 446.9 & 0.509 & 0.0104 & & & \\
\hline 2941-72 & $\mathrm{HC}$ & 6 & 12 & 483.9 & 0.546 & 0.0104 & & & \\
\hline 2941-80 & $\mathrm{HC}$ & 7 & 21 & 257.7 & 0.320 & 0.0104 & & & \\
\hline 2941-81 & $\mathrm{HC}$ & 7 & 21 & 272.1 & 0.334 & 0.0104 & & & \\
\hline 2941-70 & $\mathrm{HC}$ & 7 & 21 & 258.1 & 0.321 & 0.0104 & 0.208 & & \\
\hline 2941-94 & $\mathrm{HC}$ & 8 & 14 & 361.7 & 0.424 & 0.0104 & 0.180 & & \\
\hline 2941-104 & $\mathrm{HC}$ & 8 & 14 & 363.7 & 0.426 & 0.0104 & & & \\
\hline 2941-98 & $\mathrm{HC}$ & 9 & 13 & 691.1 & 0.757 & 0.0104 & 0.575 & & \\
\hline 2941-113 & $\mathrm{HC}$ & 9 & 13 & 666.2 & 0.728 & 0.0104 & & & \\
\hline 2941-124 & $\mathrm{HC}$ & 10 & 14 & 240.1 & 0.302 & 0.0104 & & & \\
\hline 2941-132 & $\mathrm{HC}$ & 10 & 14 & 240.7 & 0.303 & 0.0104 & 0.307 & & \\
\hline 2941-140 & $\mathrm{HC}$ & 11 & 14 & 445.7 & 0.510 & 0.0104 & 0.213 & & \\
\hline $2941-151$ & $\mathrm{HC}$ & 11 & 14 & 467.3 & 0.529 & 0.0104 & & & \\
\hline 2941-145 & $\mathrm{HC}$ & 12 & 13 & 702.6 & 0.770 & 0.0104 & 0.986 & & \\
\hline $2941-159$ & $\mathrm{HC}$ & 12 & 13 & 713.1 & 0.775 & 0.0104 & & & \\
\hline 2941-147 & $\mathrm{HC}$ & 13 & 15 & 620.0 & 0.685 & 0.0104 & 0.146 & & \\
\hline 2941-161 & $\mathrm{HC}$ & 13 & 15 & 630.2 & 0.692 & 0.0104 & & & \\
\hline 2941-354 & $\mathrm{HC}$ & 14 & 16 & 0.0 & 0.068 & 0.0104 & 0.0327 & & \\
\hline 2941-373 & $\mathrm{HC}$ & 14 & 16 & 0.0 & 0.0697 & 0.0104 & & & \\
\hline $2941-355$ & $\mathrm{HC}$ & 15 & 15 & 230.0 & 0.293 & 0.0172 & 0.0208 & & \\
\hline 2941-381 & $\mathrm{HC}$ & 15 & 15 & 239.5 & 0.302 & 0.0172 & & & \\
\hline 2941-390 & $\mathrm{HC}$ & 16 & 12 & 11.4 & 0.0734 & 0.0172 & & & \\
\hline $2941-412$ & $\mathrm{HC}$ & 16 & 12 & 0.3 & 0.0623 & 0.0172 & 0.0103 & & \\
\hline $2941-367$ & $\mathrm{HC}$ & 17 & 16 & 736.3 & 0.802 & 0.0172 & 0.205 & & \\
\hline $2941-387$ & $\mathrm{HC}$ & 17 & 16 & 749.2 & 0.811 & 0.0172 & & & \\
\hline 2941-399 & $\mathrm{HC}$ & 18 & 14 & 176.5 & 0.239 & 0.0172 & & & \\
\hline $2947-414$ & $\mathrm{HC}$ & 18 & 14 & 161.7 & 0.226 & 0.0172 & 0.803 & & \\
\hline $2941-403$ & $\mathrm{HC}$ & 19 & 19 & 606.8 & 0.669 & 0.0172 & & & \\
\hline $2941-418$ & $\mathrm{HC}$ & 19 & 19 & 582.2 & 0.643 & 0.0172 & 0.161 & & \\
\hline Average & & & & & & & 0.340 & & \\
\hline Stdev & & & & & & & 0.365 & & \\
\hline 2941-5 & NR & 1 & 14 & 0.0 & 0.0695 & 0.0172 & & & \\
\hline $2941-23$ & NR & 2 & 12 & 131.5 & 0.194 & 0.0172 & & & \\
\hline 2941-29 & NR & 3 & 21 & 1002.5 & 1.00 & 0.0172 & & & \\
\hline 2941-35 & NR & 4 & 15 & 237.2 & 0.299 & 0.0172 & & & \\
\hline 2941-77 & NR & 6 & 12 & 208.1 & 0.270 & 0.0104 & & & \\
\hline 2941-85 & NR & 7 & 17 & 52.0 & 0.114 & 0.0064 & & & \\
\hline $2941-103$ & NR & 8 & 15 & 351.1 & 0.413 & 0.0104 & & & \\
\hline $2941-112$ & NR & 9 & 13 & 785.2 & 0.847 & 0.0104 & & & \\
\hline $2941-116$ & NR & 10 & 14 & 380.7 & 0.443 & 0.0104 & & & \\
\hline 2941-121 & NR & 10 & 14 & 382.9 & 0.445 & 0.0104 & & & \\
\hline 2941-135 & NR & 10 & 14 & 378.9 & 0.443 & 0.0104 & 0.379 & & \\
\hline $2941-128$ & NR & 11 & 14 & 467.2 & 0.529 & 0.0104 & & & \\
\hline $2941-129$ & NR & 11 & 14 & 397.9 & 0.460 & 0.0104 & & & \\
\hline 2941-137 & NR & 11 & 14 & 451.5 & 0.516 & 0.0104 & 0.469 & & \\
\hline 2941-143 & NR & 12 & 15 & 937.9 & 1.00 & 0.0104 & 1.07 & & \\
\hline $2941-153$ & NR & 12 & 15 & 948.8 & 1.01 & 0.0104 & & & \\
\hline
\end{tabular}


Field Sample Results - Total Mercury, Monome

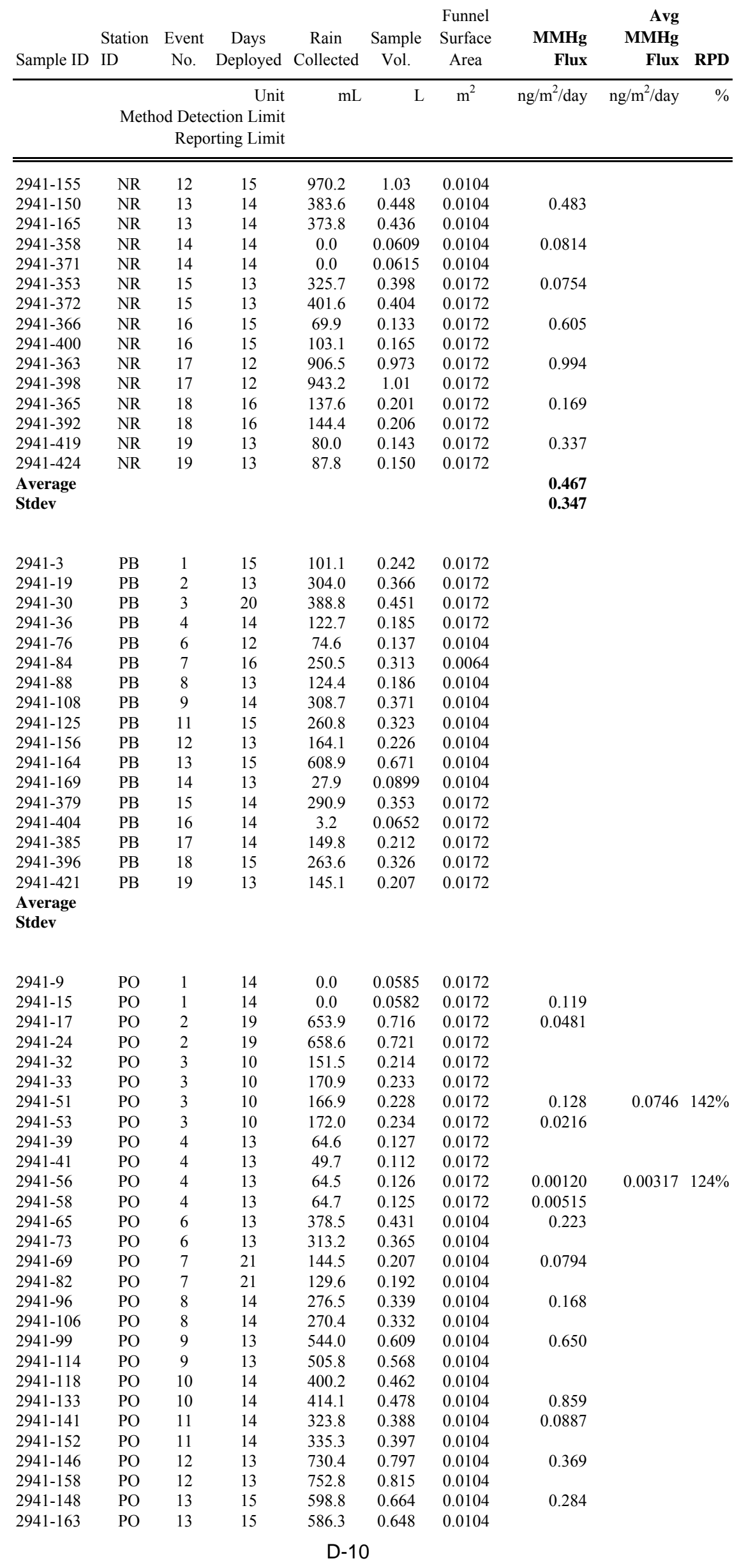


Field Sample Results - Total Mercury, Monome

\begin{tabular}{|c|c|c|c|c|c|c|c|c|c|}
\hline Sample ID & $\begin{array}{l}\text { Station } \\
\text { ID }\end{array}$ & $\begin{array}{c}\text { Event } \\
\text { No. }\end{array}$ & $\begin{array}{c}\text { Days } \\
\text { Deployed }\end{array}$ & $\begin{array}{c}\text { Rain } \\
\text { Collected }\end{array}$ & $\begin{array}{c}\text { Sample } \\
\text { Vol. }\end{array}$ & $\begin{array}{c}\text { Funnel } \\
\text { Surface } \\
\text { Area }\end{array}$ & $\begin{array}{r}\text { MMHg } \\
\text { Flux }\end{array}$ & $\begin{array}{r}\text { Avg } \\
\text { MMHg } \\
\text { Flux }\end{array}$ & RPD \\
\hline & Meth & $\begin{array}{l}\text { od Detec } \\
\text { Repo }\end{array}$ & $\begin{array}{r}\text { Unit } \\
\text { ction Limit } \\
\text { rting Limit }\end{array}$ & $\mathrm{mL}$ & $\mathrm{L}$ & $\mathrm{m}^{2}$ & $\mathrm{ng} / \mathrm{m}^{2} /$ day & $\mathrm{ng} / \mathrm{m}^{2} /$ day & $\overline{\%}$ \\
\hline $2941-352$ & $\mathrm{PO}$ & 14 & 16 & 0.0 & 0.069 & 0.0104 & 0.0240 & & \\
\hline $2941-376$ & PO & 14 & 16 & 0.0 & 0.070 & 0.0104 & & & \\
\hline $2941-357$ & $\mathrm{PO}$ & 15 & 15 & 208.5 & 0.272 & 0.0172 & 0.0219 & & \\
\hline $2941-380$ & $\mathrm{PO}$ & 15 & 15 & 212.5 & 0.275 & 0.0172 & & & \\
\hline $2941-364$ & PO & 16 & 12 & 3.2 & 0.0752 & 0.0172 & 0.00836 & & \\
\hline $2941-394$ & PO & 16 & 12 & -5.6 & 0.0664 & 0.0172 & & & \\
\hline $2941-362$ & PO & 17 & 16 & 577.9 & 0.643 & 0.0172 & 0.0956 & & \\
\hline $2941-401$ & $\mathrm{PO}$ & 17 & 16 & 571.1 & 0.633 & 0.0172 & & & \\
\hline 2941-405 & $\mathrm{PO}$ & 18 & 14 & 122.0 & 0.184 & 0.0172 & & & \\
\hline $2941-410$ & PO & 18 & 14 & 125.9 & 0.190 & 0.0172 & 0.145 & & \\
\hline $2941-417$ & $\mathrm{PO}$ & 19 & 19 & 342.0 & 0.406 & 0.0172 & 0.0678 & & \\
\hline $2941-422$ & PO & 19 & 19 & 349.8 & 0.412 & 0.0172 & & & \\
\hline Average & & & & & & & 0.170 & & \\
\hline Stdev & & & & & & & 0.225 & & \\
\hline $2941-7$ & SB & 1 & 16 & 4.3 & 0.0663 & 0.0172 & & & \\
\hline $2941-8$ & SB & 1 & 16 & 3.7 & 0.0657 & 0.0172 & & & \\
\hline $2941-11$ & SB & 1 & 16 & 0.0 & 0.0596 & 0.0172 & 0.299 & 0.310 & $7.5 \%$ \\
\hline 2941-12 & SB & 1 & 16 & 4.3 & 0.0663 & 0.0172 & 0.322 & & \\
\hline 2941-14 & SB & 2 & 14 & 159.3 & 0.221 & 0.0172 & 0.506 & 0.476 & $13 \%$ \\
\hline $2941-18$ & SB & 2 & 14 & 143.9 & 0.206 & 0.0172 & 0.445 & & \\
\hline $2941-25$ & SB & 2 & 14 & 139.7 & 0.202 & 0.0172 & & & \\
\hline $2941-26$ & SB & 2 & 14 & 143.3 & 0.205 & 0.0172 & & & \\
\hline 2941-31 & SB & 3 & 13 & 119.8 & 0.182 & 0.0172 & & & \\
\hline $2941-52$ & SB & 3 & 13 & 121.8 & 0.184 & 0.0172 & 0.0628 & & \\
\hline $2941-55$ & SB & 4 & 15 & 148.5 & 0.210 & 0.0172 & 0.0230 & & \\
\hline $2941-50$ & SB & 5 & 8 & 999.0 & 1.00 & 0.0172 & & & \\
\hline $2941-61$ & SB & 5 & 8 & 1007.0 & 1.01 & 0.0172 & 0.101 & & \\
\hline $2941-66$ & SB & 6 & 15 & 319.8 & 0.372 & 0.0172 & 0.122 & & \\
\hline $2941-74$ & SB & 6 & 15 & 306.9 & 0.379 & 0.0172 & & & \\
\hline $2941-67$ & SB & 7 & 16 & 162.8 & 0.225 & 0.0172 & 0.0908 & & \\
\hline $2941-79$ & SB & 7 & 16 & 160.9 & 0.223 & 0.0172 & & & \\
\hline $2941-93$ & SB & 8 & 15 & 442.9 & 0.505 & 0.0172 & 0.0853 & & \\
\hline 2941-105 & SB & 8 & 15 & 464.9 & 0.527 & 0.0172 & & & \\
\hline $2941-97$ & SB & 9 & 17 & 605.7 & 0.671 & 0.0172 & 0.494 & & \\
\hline $2941-115$ & SB & 9 & 17 & 609.6 & 0.672 & 0.0172 & & & \\
\hline $2941-136$ & SB & 10 & 15 & 364.1 & 0.428 & 0.0172 & 0.368 & & \\
\hline 2941-119 & SB & 10 & 15 & 362.8 & 0.425 & 0.0172 & & & \\
\hline 2941-130 & SB & 11 & 15 & 88.1 & 0.150 & 0.0172 & & & \\
\hline 2941-139 & SB & 11 & 15 & 89.6 & 0.152 & 0.0172 & 0.915 & & \\
\hline $2941-144$ & SB & 12 & 13 & 214.2 & 0.277 & 0.0172 & 0.225 & & \\
\hline $2941-160$ & SB & 12 & 13 & 221.7 & 0.284 & 0.0172 & & & \\
\hline $2941-350$ & SB & 13 & 16 & 714.3 & 0.781 & 0.0172 & 0.406 & & \\
\hline $2941-162$ & SB & 13 & 16 & 723.7 & 0.786 & 0.0172 & & & \\
\hline $2941-351$ & SB & 14 & 12 & 0.0 & 0.0716 & 0.0172 & 0.105 & & \\
\hline $2941-374$ & SB & 14 & 12 & 0.0 & 0.0729 & 0.0172 & & & \\
\hline $2941-370$ & SB & 15 & 15 & 149.4 & 0.211 & 0.0172 & & & \\
\hline $2941-359$ & SB & 16 & 11 & -2.6 & 0.0694 & 0.0172 & 0.0193 & & \\
\hline $2941-409$ & SB & 16 & 11 & 0.0 & 0.0720 & 0.0172 & & & \\
\hline $2941-369$ & SB & 17 & 13 & 131.3 & 0.194 & 0.0172 & 0.171 & & \\
\hline $2941-397$ & SB & 17 & 13 & 133.0 & 0.195 & 0.0172 & & & \\
\hline $2941-406$ & SB & 18 & 14 & 94.4 & 0.156 & 0.0172 & & & \\
\hline $2941-413$ & SB & 18 & 14 & 92.9 & 0.156 & 0.0172 & 0.0265 & & \\
\hline $2941-415$ & SB & 19 & 18 & 106.5 & 0.169 & 0.0172 & 0.235 & & \\
\hline $2941-420$ & SB & 19 & 18 & 107.4 & 0.169 & 0.0172 & & & \\
\hline Average & & & & & & & 0.251 & & \\
\hline Stdev & & & & & & & 0.225 & & \\
\hline $2941-4$ & $\mathrm{TCB}$ & 1 & 14 & 0.0 & 0.139 & 0.0172 & & & \\
\hline $2941-22$ & $\mathrm{TCB}$ & 2 & 12 & 127.5 & 0.190 & 0.0172 & & & \\
\hline $2941-27$ & $\mathrm{TCB}$ & 3 & 21 & 597.7 & 0.660 & 0.0172 & & & \\
\hline $2941-37$ & $\mathrm{TCB}$ & 4 & 15 & 300.1 & 0.362 & 0.0172 & & & \\
\hline $2941-75$ & $\mathrm{TCB}$ & 6 & 12 & 154.0 & 0.216 & 0.0104 & & & \\
\hline $2941-86$ & $\mathrm{TCB}$ & 7 & 17 & 59.8 & 0.122 & 0.0064 & & & \\
\hline 2941-91 & $\mathrm{TCB}$ & 8 & 15 & 352.4 & 0.414 & 0.0104 & 0.328 & 0.512 & $72 \%$ \\
\hline 2941-92 & $\mathrm{TCB}$ & 8 & 15 & 352.5 & 0.415 & 0.0104 & 0.697 & & \\
\hline
\end{tabular}


Field Sample Results - Total Mercury, Monome

\begin{tabular}{|c|c|c|c|c|c|c|c|c|c|}
\hline Sample ID & $\begin{array}{l}\text { Station } \\
\text { ID }\end{array}$ & $\begin{array}{c}\text { Event } \\
\text { No. }\end{array}$ & $\begin{array}{c}\text { Days } \\
\text { Deployed }\end{array}$ & $\begin{array}{c}\text { Rain } \\
\text { Collected }\end{array}$ & $\begin{array}{c}\text { Sample } \\
\text { Vol. }\end{array}$ & $\begin{array}{c}\text { Funnel } \\
\text { Surface } \\
\text { Area }\end{array}$ & $\begin{array}{r}\text { MMHg } \\
\text { Flux }\end{array}$ & $\begin{array}{r}\text { Avg } \\
\text { MMHg } \\
\text { Flux }\end{array}$ & RPD \\
\hline & Meth & $\begin{array}{r}\text { od Dete } \\
\text { Repo }\end{array}$ & $\begin{array}{r}\text { Unit } \\
\text { ection Limit } \\
\text { orting Limit }\end{array}$ & $\mathrm{mL}$ & $\mathrm{L}$ & $\mathrm{m}^{2}$ & $\mathrm{ng} / \mathrm{m}^{2} /$ day & $\mathrm{ng} / \mathrm{m}^{2} /$ day & $\%$ \\
\hline 2941-89 & TCB & 8 & 15 & 355.9 & 0.418 & 0.0104 & & & \\
\hline $2941-90$ & TCB & 8 & 15 & 325.0 & 0.387 & 0.0104 & & & \\
\hline 2941-100 & TCB & 9 & 13 & 721.9 & 0.788 & 0.0104 & 0.410 & 0.822 & $100 \%$ \\
\hline 2941-131 & TCB & 9 & 13 & 721.2 & 0.785 & 0.0104 & 1.23 & & \\
\hline 2941-109 & TCB & 9 & 13 & 719.8 & 0.782 & 0.0104 & & & \\
\hline 2941-111 & TCB & 9 & 13 & 799.7 & 0.862 & 0.0104 & & & \\
\hline $2941-123$ & TCB & 10 & 14 & 435.5 & 0.498 & 0.0104 & & & \\
\hline 2941-134 & TCB & 10 & 14 & 430.7 & 0.495 & 0.0104 & 0.653 & & \\
\hline $2941-127$ & TCB & 11 & 14 & 477.9 & 0.540 & 0.0104 & & & \\
\hline 2941-138 & TCB & 11 & 14 & 429.0 & 0.493 & 0.0104 & 0.240 & & \\
\hline 2941-142 & TCB & 12 & 15 & 864.2 & 0.931 & 0.0104 & 0.366 & & \\
\hline $2941-157$ & TCB & 12 & 15 & 845.7 & 0.908 & 0.0104 & & & \\
\hline 2941-149 & TCB & 13 & 14 & 327.7 & 0.392 & 0.0104 & 0.0545 & & \\
\hline 2941-167 & TCB & 13 & 14 & 318.7 & 0.381 & 0.0104 & & & \\
\hline $2941-356$ & TCB & 14 & 14 & 0.0 & 0.057 & 0.0104 & 0.00 & & \\
\hline $2941-375$ & TCB & 14 & 14 & 0.0 & 0.058 & 0.0104 & & & \\
\hline $2941-360$ & TCB & 15 & 13 & 205.2 & 0.268 & 0.0172 & 0.110 & & \\
\hline $2941-383$ & TCB & 15 & 13 & 186.6 & 0.249 & 0.0172 & & & \\
\hline $2941-407$ & TCB & 16 & 15 & 31.6 & 0.094 & 0.0172 & & & \\
\hline $2941-411$ & TCB & 16 & 15 & 51.4 & 0.115 & 0.0172 & 0.0476 & & \\
\hline 2941-361 & TCB & 17 & 12 & 971.9 & 1.04 & 0.0172 & 0.351 & & \\
\hline $2941-395$ & TCB & 17 & 12 & 904.2 & 0.966 & 0.0172 & & & \\
\hline $2941-368$ & TCB & 18 & 16 & 117.6 & 0.181 & 0.0172 & 0.0611 & & \\
\hline $2941-386$ & TCB & 18 & 16 & 104.9 & 0.167 & 0.0172 & & & \\
\hline $2941-416$ & TCB & 19 & 13 & 224.5 & 0.288 & 0.0172 & 0.506 & & \\
\hline $2941-425$ & TCB & 19 & 13 & 192.7 & 0.255 & 0.0172 & & & \\
\hline Average & & & & & & & 0.361 & & \\
\hline Stdev & & & & & & & 0.337 & & \\
\hline $2941-377$ & $\mathrm{TM}$ & 14 & 15 & 0.0 & 0.0569 & 0.0104 & & & \\
\hline 2941-382 & $\mathrm{TM}$ & 15 & 13 & 169.7 & 0.232 & 0.0172 & & & \\
\hline $2941-408$ & $\mathrm{TM}$ & 16 & 15 & 26.0 & 0.0880 & 0.0172 & & & \\
\hline 2941-393 & $\mathrm{TM}$ & 17 & 12 & 798.2 & 0.860 & 0.0172 & & & \\
\hline 2941-389 & $\mathrm{TM}$ & 18 & 16 & 93.9 & 0.156 & 0.0172 & & & \\
\hline 2941-402 & $\mathrm{TM}$ & 19 & 13 & 92.6 & 0.155 & 0.0172 & & & \\
\hline $\begin{array}{l}\text { Average } \\
\text { Stdev }\end{array}$ & & & & & & & & & \\
\hline $2941-2$ & WP & 1 & 15 & 0.0 & 0.138 & 0.0172 & & & \\
\hline 2941-21 & WP & 2 & 13 & 259.5 & 0.322 & 0.0172 & & & \\
\hline $2941-28$ & WP & 3 & 19 & 558.8 & 0.621 & 0.0172 & & & \\
\hline 2941-38 & WP & 4 & 15 & 136.7 & 0.199 & 0.0172 & & & \\
\hline 2941-78 & WP & 6 & 12 & 78.2 & 0.140 & 0.0104 & & & \\
\hline 2941-83 & WP & 7 & 16 & 91.0 & 0.153 & 0.0064 & & & \\
\hline 2941-87 & WP & 8 & 13 & 295.3 & 0.357 & 0.0104 & & & \\
\hline 2941-110 & WP & 9 & 14 & 506.8 & 0.569 & 0.0104 & & & \\
\hline 2941-117 & WP & 10 & 14 & 404.8 & 0.467 & 0.0104 & & & \\
\hline $2941-126$ & WP & 11 & 15 & 258.8 & 0.321 & 0.0104 & & & \\
\hline $2941-154$ & WP & 12 & 13 & 734.8 & 0.797 & 0.0104 & & & \\
\hline 2941-166 & WP & 13 & 15 & 535.9 & 0.598 & 0.0104 & & & \\
\hline $2941-170$ & WP & 14 & 13 & 0.0 & 0.059 & 0.0104 & & & \\
\hline $2941-378$ & WP & 15 & 14 & 150.5 & 0.213 & 0.0172 & & & \\
\hline $2941-384$ & WP & 16 & 14 & 146.8 & 0.209 & 0.0172 & & & \\
\hline 2941-388 & WP & 17 & 14 & 505.1 & 0.567 & 0.0172 & & & \\
\hline 2941-391 & WP & 18 & 15 & 194.3 & 0.256 & 0.0172 & & & \\
\hline $2941-423$ & WP & 19 & 13 & 394.4 & 0.411 & 0.0172 & & & \\
\hline
\end{tabular}


Quality Control Results - Total Mercury

\begin{tabular}{|c|c|c|}
\hline $\begin{array}{l}\text { Digestion } \\
\text { Batch ID }\end{array}$ & Sample ID & THg Flag \\
\hline & Method Detection Limit & 0.100 \\
\hline & Reporting Limit & 0.318 \\
\hline \multicolumn{3}{|c|}{ Method Blank Results (ng/L) } \\
\hline 082908 & Method Blank1 & $0.100 \mathrm{U}$ \\
\hline 082908 & Method Blank2 & $0.100 \mathrm{U}$ \\
\hline 082908 & Method Blank3 & $0.100 \mathrm{U}$ \\
\hline 110608 & Method Blank1 & $0.100 \mathrm{U}$ \\
\hline 110608 & Method Blank2 & $0.100 \mathrm{U}$ \\
\hline 110608 & Method Blank3 & $0.100 \mathrm{U}$ \\
\hline 110708 & Method Blank1 & $0.100 \mathrm{U}$ \\
\hline 110708 & Method Blank2 & $0.100 \mathrm{U}$ \\
\hline 110708 & Method Blank3 & $0.100 \mathrm{U}$ \\
\hline 121508 & Method Blank1 & $0.100 \mathrm{U}$ \\
\hline 121508 & Method Blank2 & 0.109 \\
\hline 121508 & Method Blank3 & $0.100 \mathrm{U}$ \\
\hline 121608 & Method Blank1 & $0.100 \mathrm{U}$ \\
\hline 121608 & Method Blank2 & 0.111 \\
\hline 121608 & Method Blank3 & $0.100 \mathrm{U}$ \\
\hline 010509 & Method Blank1 & $0.100 \mathrm{U}$ \\
\hline 010509 & Method Blank2 & $0.100 \mathrm{U}$ \\
\hline 010509 & Method Blank3 & $0.100 \mathrm{U}$ \\
\hline 032409 & Method Blank1 & $0.100 \mathrm{U}$ \\
\hline 032409 & Method Blank2 & $0.100 \mathrm{U}$ \\
\hline 032409 & Method Blank3 & $0.100 \mathrm{U}$ \\
\hline 040709 & Method Blank1 & $0.100 \mathrm{U}$ \\
\hline 040709 & Method Blank2 & $0.100 \mathrm{U}$ \\
\hline 040709 & Method Blank3 & $0.100 \mathrm{U}$ \\
\hline 041409 & Method Blank1 & $0.100 \mathrm{U}$ \\
\hline 041409 & Method Blank2 & $0.100 \mathrm{U}$ \\
\hline 041409 & Method Blank3 & $0.100 \mathrm{U}$ \\
\hline 042409 & Method Blank1 & $0.100 \mathrm{U}$ \\
\hline 042409 & Method Blank2 & $0.100 \mathrm{U}$ \\
\hline 042409 & Method Blank3 & $0.100 \mathrm{U}$ \\
\hline 042909 & Method Blank1 & $0.100 \mathrm{U}$ \\
\hline 042909 & Method Blank2 & $0.100 \mathrm{U}$ \\
\hline 042909 & Method Blank3 & $0.100 \mathrm{U}$ \\
\hline 051309 & Method Blank1 & $0.100 \mathrm{U}$ \\
\hline 051309 & Method Blank2 & $0.100 \mathrm{U}$ \\
\hline 051309 & Method Blank3 & $0.100 \mathrm{U}$ \\
\hline 060109 & Method Blank1 & $0.100 \mathrm{U}$ \\
\hline 060109 & Method Blank2 & $0.100 \mathrm{U}$ \\
\hline 060109 & Method Blank3 & $0.100 \mathrm{U}$ \\
\hline 062509 & Method Blank1 & $0.100 \mathrm{U}$ \\
\hline 062509 & Method Blank2 & $0.100 \mathrm{U}$ \\
\hline 062509 & Method Blank3 & $0.100 \mathrm{U}$ \\
\hline 90309 & Method Blank1 & $0.100 \mathrm{U}$ \\
\hline 90309 & Method Blank2 & $0.100 \mathrm{U}$ \\
\hline 90309 & Method Blank3 & $0.100 \mathrm{U}$ \\
\hline 101609 & Method Blank1 & $0.100 \mathrm{U}$ \\
\hline 101609 & Method Blank2 & $0.100 \mathrm{U}$ \\
\hline 101609 & Method Blank3 & $0.100 \mathrm{U}$ \\
\hline 102709 & Method Blank1 & $0.100 \mathrm{U}$ \\
\hline 102709 & Method Blank2 & $0.100 \mathrm{U}$ \\
\hline 102709 & Method Blank3 & $0.100 \mathrm{U}$ \\
\hline & Average Method Blank & 0.1004 \\
\hline
\end{tabular}


Quality Control Results - Total Mercury

\begin{tabular}{lrr}
\hline $\begin{array}{c}\text { Digestion } \\
\text { Batch ID }\end{array}$ & Sample ID & THg Flag \\
\hline & Method Detection Limit & 0.100 \\
& Reporting Limit & 0.318 \\
\hline \hline
\end{tabular}

\section{Blank Spike (OPR) Percent Recovery}

\begin{tabular}{|c|c|c|}
\hline 082908 & OPR 082908 run 1 & $102 \%$ \\
\hline 082908 & OPR 082908 run 2 & $102 \%$ \\
\hline 110608 & OPR 110608 run 1 & $100 \%$ \\
\hline 110608 & OPR 110608 run2 & $103 \%$ \\
\hline 110708 & OPR 110708 run 1 & $98 \%$ \\
\hline 110708 & OPR 110708 run2 & $99 \%$ \\
\hline 121508 & OPR 121508 run 1 & $101 \%$ \\
\hline 121508 & OPR 121508 run2 & $102 \%$ \\
\hline 121608 & OPR 121608 run 1 & $98 \%$ \\
\hline 121608 & OPR 121608 run2 & $99 \%$ \\
\hline 010509 & OPR 010509 run 1 & $100 \%$ \\
\hline 010509 & OPR 010509 run2 & $97 \%$ \\
\hline 032409 & OPR 032409 run 1 & $99 \%$ \\
\hline 032409 & OPR 032409 run2 & $99 \%$ \\
\hline 040709 & OPR 040709 run 1 & $103 \%$ \\
\hline 040709 & OPR 040709 run2 & $107 \%$ \\
\hline 041409 & OPR 041409 run 1 & $101 \%$ \\
\hline 041409 & OPR 041409 run2 & $109 \%$ \\
\hline 042409 & OPR 042409 run 1 & $99 \%$ \\
\hline 042409 & OPR 042409 run2 & $101 \%$ \\
\hline 042909 & OPR 042909 run 1 & $102 \%$ \\
\hline 042909 & OPR 042909 run2 & $109 \%$ \\
\hline 051309 & OPR 051309 run 1 & $95 \%$ \\
\hline 051309 & OPR 051309 run2 & $95 \%$ \\
\hline 060109 & OPR 060109 run1 & $100 \%$ \\
\hline 060109 & OPR 060109 run2 & $107 \%$ \\
\hline 062509 & OPR 062509 run 1 & $97 \%$ \\
\hline 062509 & OPR 062509 run2 & $105 \%$ \\
\hline 90309 & OPR 090209 run1 & $100 \%$ \\
\hline 90309 & OPR 090209 run2 & $104 \%$ \\
\hline 101609 & OPR 101509 run 1 & $105 \%$ \\
\hline 101609 & OPR 101509 run2 & $97 \%$ \\
\hline 102709 & OPR 102609run1 & $96 \%$ \\
\hline \multirow[t]{2}{*}{102709} & OPR 102609run2 & $100 \%$ \\
\hline & Average $O$ & $101 \%$ \\
\hline
\end{tabular}

\section{Standard Reference Material Percent Recovery}

NIST SRM1641d certified value

$1590000 \pm 18000$

082908

110608

110708

121508

121608

010509

032409

040709

041409
$1641 \mathrm{~d} 082908$

$1641 \mathrm{~d} 110608$

$1641 \mathrm{~d} 110708$

$1641 \mathrm{~d} 121508$

$1641 \mathrm{~d} 121608$

$1641 \mathrm{~d} 010509$

$1641 \mathrm{~d} 032409$

$1641 \mathrm{~d} 040709$

$1641 \mathrm{~d} 041409$ $\begin{array}{r}102 \% \\ 102 \% \\ 100 \% \\ 103 \% \\ 98 \% \\ 99 \% \\ 101 \% \\ 102 \% \\ 98 \% \\ 99 \% \\ 100 \% \\ 97 \% \\ 99 \% \\ 99 \% \\ 103 \% \\ 107 \% \\ 101 \% \\ 109 \% \\ 99 \% \\ 101 \% \\ \hline 102 \% \\ 109 \% \\ 95 \% \\ \hline 95 \% \\ \hline 100 \% \\ \hline 107 \% \\ \hline 107 \% \\ \hline 100 \% \\ \hline 104 \% \\ \hline 105 \% \\ \hline\end{array}$ 
Quality Control Results - Total Mercury

\begin{tabular}{|c|c|c|}
\hline \multirow[t]{2}{*}{$\begin{array}{l}\text { Digestion } \\
\text { Batch ID }\end{array}$} & Sample ID & THg Flag \\
\hline & $\begin{array}{r}\text { Method Detection Limit } \\
\text { Reporting Limit }\end{array}$ & $\begin{array}{l}0.100 \\
0.318\end{array}$ \\
\hline $\begin{array}{c}042409 \\
042909 \\
051309 \\
060109 \\
062509 \\
90309 \\
101609 \\
102709\end{array}$ & $\begin{array}{l}1641 \mathrm{~d} 042409 \\
1641 \mathrm{~d} 042909 \\
1641 \mathrm{~d} 051309 \\
1641 \mathrm{~d} 060109 \\
1641 \mathrm{~d} 062509 \\
1641 \mathrm{~d} 090209 \\
1641 \mathrm{~d} 101509 \\
1641 \mathrm{~d} 102609\end{array}$ & $\begin{array}{l}99 \% \\
97 \% \\
97 \% \\
98 \% \\
98 \% \\
97 \% \\
98 \% \\
96 \%\end{array}$ \\
\hline & Average SRM Percent Recovery & $97 \%$ \\
\hline \multicolumn{3}{|c|}{ Matrix Spike/Martrix Spike Duplicate Percent Recovery } \\
\hline $\begin{array}{l}110608 \\
110608\end{array}$ & $\begin{array}{ll}2941- & 19 \mathrm{MS} \\
2941- & 19 \mathrm{MSD}\end{array}$ & $\begin{array}{l}96 \% \\
97 \%\end{array}$ \\
\hline $\begin{array}{l}110608 \\
110608\end{array}$ & $\begin{array}{l}\text { 2941- } 24 \mathrm{MS} \\
\text { 2941- } 24 \mathrm{MSD}\end{array}$ & $\begin{array}{l}95 \% \\
95 \%\end{array}$ \\
\hline $\begin{array}{l}110708 \\
110708\end{array}$ & $\begin{array}{l}\text { 2941- } 28 \mathrm{MS} \\
\text { 2941- } 28 \mathrm{MSD}\end{array}$ & $\begin{array}{l}97 \% \\
98 \%\end{array}$ \\
\hline $\begin{array}{l}110708 \\
110708\end{array}$ & $\begin{array}{l}\text { 2941- } 29 \mathrm{MS} \\
\text { 2941- } 29 \mathrm{MSD}\end{array}$ & $\begin{array}{r}101 \% \\
96 \%\end{array}$ \\
\hline $\begin{array}{l}121608 \\
121608\end{array}$ & $\begin{array}{l}\text { 2941- } 43 \mathrm{MS} \\
\text { 2941- } 43 \mathrm{MSD}\end{array}$ & $\begin{array}{r}98 \% \\
102 \%\end{array}$ \\
\hline $\begin{array}{l}121608 \\
121608\end{array}$ & $\begin{array}{l}\text { 2941- } 48 \mathrm{MS} \\
2941-48 \mathrm{MSD}\end{array}$ & $\begin{array}{l}102 \% \\
100 \%\end{array}$ \\
\hline $\begin{array}{l}121508 \\
121508\end{array}$ & $\begin{array}{l}\text { 2941- } 59 \mathrm{MS} \\
\text { 2941- } 59 \mathrm{MSD}\end{array}$ & $\begin{array}{r}100 \% \\
97 \%\end{array}$ \\
\hline $\begin{array}{l}121508 \\
121508\end{array}$ & $\begin{array}{l}2941-62 \mathrm{MS} \\
2941-62 \mathrm{MSD}\end{array}$ & $\begin{array}{r}100 \% \\
99 \%\end{array}$ \\
\hline $\begin{array}{l}010509 \\
010509\end{array}$ & $\begin{array}{l}\text { 2941- } 71 \mathrm{MS} \\
\text { 2941- } 71 \mathrm{MSD}\end{array}$ & $\begin{array}{l}98 \% \\
94 \%\end{array}$ \\
\hline $\begin{array}{l}010509 \\
010509\end{array}$ & $\begin{array}{l}\text { 2941- } 81 \mathrm{MS} \\
\text { 2941- } 81 \mathrm{MSD}\end{array}$ & $\begin{array}{l}96 \% \\
95 \%\end{array}$ \\
\hline $\begin{array}{l}032509 \\
032509\end{array}$ & $\begin{array}{l}\text { 2941- } 91 \mathrm{MS} \\
\text { 2941- } 91 \mathrm{MSD}\end{array}$ & $\begin{array}{l}103 \% \\
101 \%\end{array}$ \\
\hline $\begin{array}{l}040809 \\
040809\end{array}$ & $\begin{array}{l}\text { 2941- } 97 \mathrm{MS} \\
\text { 2941- } 97 \mathrm{MSD}\end{array}$ & $\begin{array}{l}105 \% \\
105 \%\end{array}$ \\
\hline $\begin{array}{l}032509 \\
032509\end{array}$ & $\begin{array}{ll}2941- & 104 \mathrm{MS} \\
2941- & 104 \mathrm{MSD}\end{array}$ & $\begin{array}{l}102 \% \\
103 \%\end{array}$ \\
\hline $\begin{array}{l}041509 \\
041509\end{array}$ & $\begin{array}{l}2941-113 \mathrm{MS} \\
2941-113 \mathrm{MSD}\end{array}$ & $\begin{array}{l}104 \% \\
105 \%\end{array}$ \\
\hline $\begin{array}{l}042709 \\
042709\end{array}$ & $\begin{array}{l}2941-119 \mathrm{MS} \\
2941-119 \mathrm{MSD}\end{array}$ & $\begin{array}{l}105 \% \\
103 \%\end{array}$ \\
\hline $\begin{array}{l}043009 \\
043009\end{array}$ & $\begin{array}{l}\text { 2941- } 126 \mathrm{MS} \\
2941-126 \mathrm{MSD}\end{array}$ & $\begin{array}{l}105 \% \\
104 \%\end{array}$ \\
\hline $\begin{array}{l}043009 \\
043009\end{array}$ & $\begin{array}{l}2941-137 \mathrm{MS} \\
2941-137 \mathrm{MSD}\end{array}$ & $\begin{array}{l}103 \% \\
107 \%\end{array}$ \\
\hline $\begin{array}{l}051409 \\
051409\end{array}$ & $\begin{array}{l}\text { 2941- } 143 \mathrm{MS} \\
2941-143 \mathrm{MSD}\end{array}$ & $\begin{array}{l}106 \% \\
101 \%\end{array}$ \\
\hline 051409 & 2941- $154 \mathrm{MS}$ & $102 \%$ \\
\hline & $\mathrm{D}-15$ & \\
\hline
\end{tabular}


Quality Control Results - Total Mercury

\begin{tabular}{ccc}
\hline $\begin{array}{c}\text { Digestion } \\
\text { Batch ID }\end{array}$ & Sample ID & THg Flag \\
\hline & Method Detection Limit & 0.100 \\
& Reporting Limit & 0.318 \\
\hline \hline 051409 & $2941-154 \mathrm{MSD}$ & $102 \%$ \\
060109 & $2941-147 \mathrm{MS}$ & $103 \%$ \\
060109 & $2941-147 \mathrm{MSD}$ & $104 \%$ \\
060109 & $2941-162 \mathrm{MS}$ & $101 \%$ \\
060109 & $2941-162 \mathrm{MSD}$ & $104 \%$ \\
062509 & $2941-373 \mathrm{MS}$ & $95 \%$ \\
90309 & $2941-372 \mathrm{MS}$ & $105 \%$ \\
90309 & $2941-372 \mathrm{MSD}$ & $103 \%$ \\
90309 & $2941-379 \mathrm{MS}$ & $105 \%$ \\
90309 & $2941-379 \mathrm{MSD}$ & $106 \%$ \\
101609 & $2941-387 \mathrm{MS}$ & $95 \%$ \\
101609 & $2941-387 \mathrm{MSD}$ & $104 \%$ \\
101609 & $2941-398 \mathrm{MS}$ & $103 \%$ \\
102709 & $2941-398 \mathrm{MSD}$ & $97 \%$
\end{tabular}

\section{Replicate Analysis Relative Percent Difference}

110608
110708
121608
121608
121508
010509
032509
040809
041509
042709
043009
051409
060109
90309
101609
102709

110608

121608

121608

010509

32509

040809

042709

043009

90309

102709
2941- 20 RPD $4 \%$

2941- 27 RPD

2941- 40 RPD

2941 - 46 RPD

2941- 70 RPD

2941- 84 RPD

2941- 89 RPD

2941- 100 RPD

2941- 109 RPD

2941- 118 RPD

2941- 123 RPD

2941- 157 RPD

2941- 164 RPD

2941- 381 RPD

2941- 395 RPD

2941- 423 RPD
$4 \%$
$2 \%$
$14 \%$
$2 \%$
$10 \%$
$5 \%$
$1 \%$
$10 \%$
$4 \%$
$6 \%$
$16 \%$
$11 \%$
$11 \%$
$12 \%$
$1 \%$
$8 \%$

$7 \%$

NA Not available
\# Outside DQO $( \pm 25 \%)$ 
Quality Control Results - Methylmercury

\begin{tabular}{|c|c|c|}
\hline \multicolumn{3}{|l|}{ Digestion } \\
\hline \multirow[t]{2}{*}{ Batch ID } & Sample ID & MMHg Flag \\
\hline & $\begin{array}{r}\text { Method Detection Limit } \\
\text { Reporting Limit }\end{array}$ & $\begin{array}{ll}0.010 & n g / L \\
0.032 & n g / L\end{array}$ \\
\hline \multicolumn{3}{|c|}{ Method Blank Results (ng/L) } \\
\hline 102908 & BLANK 102908 r1 & 0.0128 \\
\hline 102908 & BLANK 102908 r2 & $0.0100 \mathrm{U}$ \\
\hline 102908 & BLANK 102908 r3 & 0.0131 \\
\hline 121509 & BLANK 121508 r1 & $0.0100 \mathrm{U}$ \\
\hline 121509 & BLANK 121508 r2 & $0.0100 \mathrm{U}$ \\
\hline 121509 & BLANK 121508 r3 & $0.0100 \mathrm{U}$ \\
\hline 010809 & BLANK 010809 r1 & $0.0100 \mathrm{U}$ \\
\hline 010809 & BLANK 010809 r2 & $0.0100 \mathrm{U}$ \\
\hline 010809 & BLANK 010809 r3 & $0.0100 \mathrm{U}$ \\
\hline 032409 & BLANK 032409 r1 & $0.0100 \mathrm{U}$ \\
\hline 032409 & BLANK 032409 r2 & $0.0100 \mathrm{U}$ \\
\hline 032409 & BLANK 032409 r3 & $0.0100 \mathrm{U}$ \\
\hline 040809 & BLANK 040809 r1 & $0.0100 \mathrm{U}$ \\
\hline 040809 & BLANK 040809 r2 & $0.0100 \mathrm{U}$ \\
\hline 040809 & BLANK 040809 r3 & $0.0100 \mathrm{U}$ \\
\hline 042309 & BLANK 042309 r1 & $0.0100 \mathrm{U}$ \\
\hline 042309 & BLANK 042309 r2 & $0.0100 \mathrm{U}$ \\
\hline 042309 & BLANK 042309 r3 & $0.0100 \mathrm{U}$ \\
\hline 051409 & BLANK 051409 r1 & 0.0187 \\
\hline 051409 & BLANK 051409 r2 & 0.0114 \\
\hline 051409 & BLANK 051409 r3 & 0.0259 \\
\hline 060109 & BLANK 060109 r1 & 0.0178 \\
\hline 060109 & BLANK 060109 r2 & 0.0115 \\
\hline 060109 & BLANK 060109 r3 & 0.0173 \\
\hline 062509 & BLANK 062509 r1 & $0.0100 \mathrm{U}$ \\
\hline 062509 & BLANK 062509 r2 & $0.0100 \mathrm{U}$ \\
\hline 062509 & BLANK 062509 r3 & 0.0294 \\
\hline 90309 & BLANK 090209 r1 & 0.0193 \\
\hline 90309 & BLANK 090210 r2 & 0.0189 \\
\hline 90309 & BLANK 090211 r3 & $0.0100 \mathrm{U}$ \\
\hline 91709 & BLANK 091609 r1 & $0.0100 \mathrm{U}$ \\
\hline 91709 & BLANK 091610 r2 & 0.0171 \\
\hline 91709 & BLANK 091611 r3 & 0.0267 \\
\hline 110309 & BLANK 110209 r1 & 0.0193 \\
\hline 110309 & BLANK 110210 r2 & 0.0252 \\
\hline 110309 & BLANK 110211 r3 & 0.0164 \\
\hline 113009 & BLANK 113009 r1 & 0.0153 \\
\hline 113009 & BLANK 113009 r2 & $0.0100 \mathrm{U}$ \\
\hline 113009 & BLANK 113009 r3 & 0.0210 \\
\hline & Average Method Blank Result & 0.0140 \\
\hline
\end{tabular}

\section{Blank Spike (OPR) Percent Recovery}

102908

102908

121509

121509

121509

010809

010809
OPR 102908

OPR 102908

OPR 121508

OPR 121508

OPR 121508

OPR 010809

OPR 010809

$$
\begin{aligned}
& 97 \% \\
& 97 \% \\
& 54 \% \# \\
& 34 \% \# \\
& 67 \% \\
& 95 \% \\
& 92 \%
\end{aligned}
$$


Quality Control Results - Methylmercury

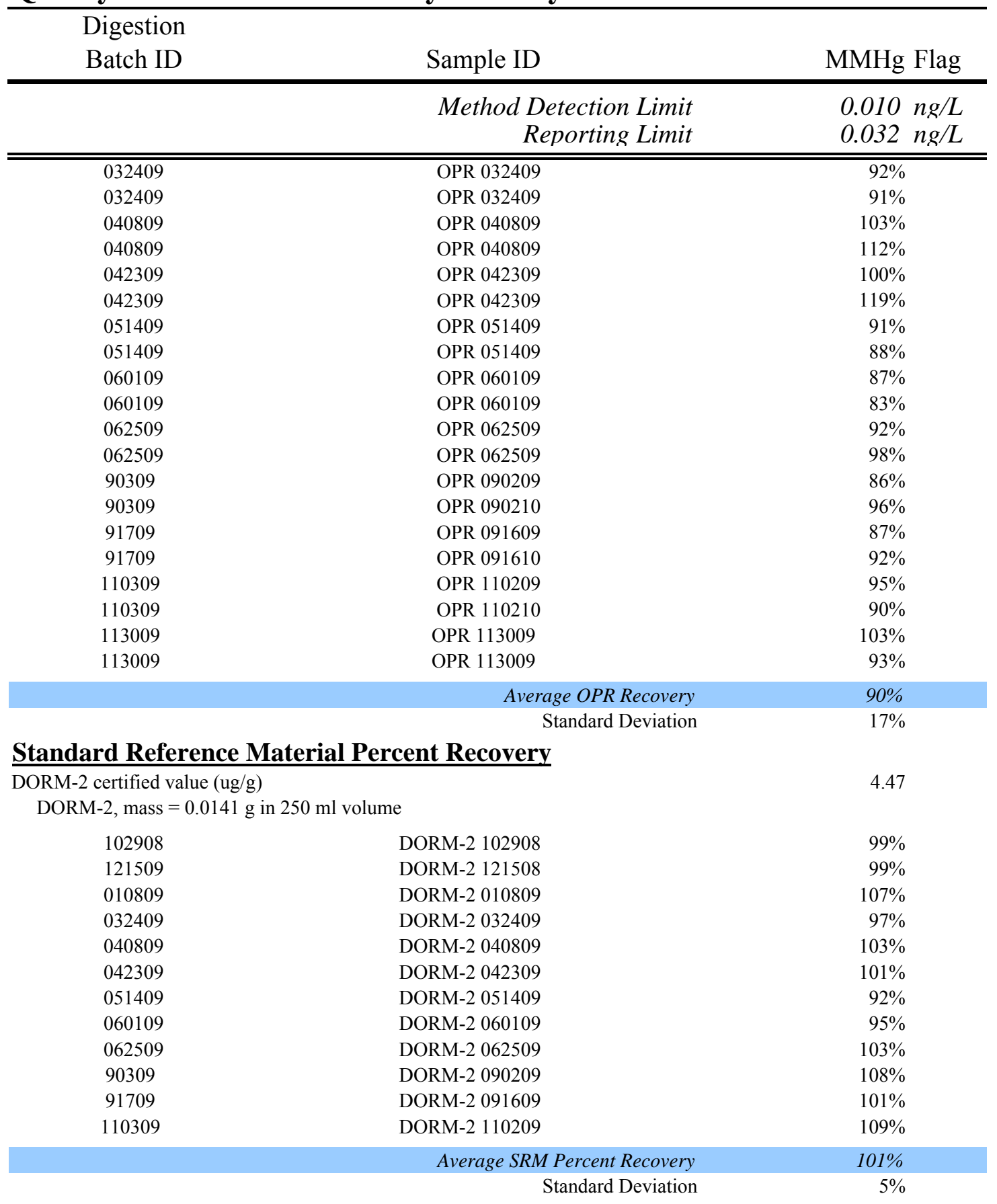

Matrix Spike/Martrix Spike Duplicate Percent Recovery

$$
\begin{aligned}
& 102908 \\
& 102908 \\
& 102908 \\
& 102908 \\
& 121509 \\
& 121509 \\
& 010809
\end{aligned}
$$

\author{
2941- 13 MS \\ 2941- 13 MSD \\ 2941- $53 \mathrm{MS}$ \\ 2941- 53 MSD \\ 2941- $59 \mathrm{MS}$ \\ 2941- 59 MSD \\ 2941- 59 MS-rerun
}
$94 \%$
$93 \%$
$89 \%$
$81 \%$
$74 \%$
$58 \%$ \#
$92 \%$ 
Quality Control Results - Methylmercury

\begin{tabular}{|c|c|c|}
\hline $\begin{array}{l}\text { Digestion } \\
\text { Batch ID }\end{array}$ & Sample ID & MMHg Flag \\
\hline & $\begin{array}{r}\text { Method Detection Limit } \\
\text { Reporting Limit }\end{array}$ & $\begin{array}{ll}0.010 & n g / L \\
0.032 & n g / L\end{array}$ \\
\hline 010809 & 2941- 59 MSD-rerun & $75 \%$ \\
\hline $\begin{array}{l}121509 \\
121509\end{array}$ & $\begin{array}{l}\text { 2941- } 62 \mathrm{MS} \\
2941-62 \mathrm{MSD}\end{array}$ & $\begin{array}{l}69 \% \\
90 \%\end{array}$ \\
\hline $\begin{array}{l}010809 \\
010809\end{array}$ & $\begin{array}{l}\text { 2941- } 62 \text { MS-rerun } \\
\text { 2941- } 62 \text { MSD-rerun }\end{array}$ & $\begin{array}{l}67 \% \\
75 \%\end{array}$ \\
\hline $\begin{array}{l}032409 \\
032409\end{array}$ & $\begin{array}{l}\text { 2941- } 92 \mathrm{MS} \\
\text { 2941- } 92 \mathrm{MSD}\end{array}$ & $\begin{array}{l}92 \% \\
93 \%\end{array}$ \\
\hline $\begin{array}{l}040809 \\
040809\end{array}$ & $\begin{array}{l}\text { 2941- } 97 \mathrm{MS} \\
\text { 2941- } 97 \mathrm{MSD}\end{array}$ & $\begin{array}{l}79 \% \\
80 \%\end{array}$ \\
\hline $\begin{array}{l}042309 \\
042309\end{array}$ & $\begin{array}{l}2941-134 \mathrm{MS} \\
2941-134 \mathrm{MSD}\end{array}$ & $\begin{array}{l}93 \% \\
22 \% \#\end{array}$ \\
\hline $\begin{array}{l}051409 \\
051409\end{array}$ & $\begin{array}{ll}2941- & 137 \mathrm{MS} \\
2941- & 137 \mathrm{MSD}\end{array}$ & $\begin{array}{l}84 \% \\
82 \%\end{array}$ \\
\hline $\begin{array}{l}060109 \\
060109\end{array}$ & $\begin{array}{l}2941-147 \mathrm{MS} \\
2941-147 \mathrm{MSD}\end{array}$ & $\begin{array}{l}95 \% \\
76 \%\end{array}$ \\
\hline $\begin{array}{l}90309 \\
90309\end{array}$ & $\begin{array}{l}2941-353 \mathrm{MS} \\
2941-353 \mathrm{MSD}\end{array}$ & $\begin{array}{l}89 \% \\
80 \%\end{array}$ \\
\hline $\begin{array}{l}91709 \\
91709\end{array}$ & $\begin{array}{l}2941-363 \mathrm{MS} \\
2941-363 \mathrm{MSD}\end{array}$ & $\begin{array}{l}74 \% \\
90 \%\end{array}$ \\
\hline $\begin{array}{l}110309 \\
110309\end{array}$ & $\begin{array}{l}2941-418 \mathrm{MS} \\
2941-418 \mathrm{MSD}\end{array}$ & $\begin{array}{r}100 \% \\
97 \%\end{array}$ \\
\hline & Average Matrix Spike Recovery & $82 \%$ \\
\hline
\end{tabular}

\section{$\underline{\text { Replicate Analysis Relative Percent Difference }}$}

$\begin{array}{lr}2941-60 \text { RPD } & 22 \% \\ 2941-70 \text { RPD } & 7 \% \\ 2941-93 \text { RPD } & 29 \% \\ 2941-100 \text { RPD } & 15 \% \\ 2941-135 \text { RPD } & 5 \% \\ 2941-142 \text { RPD } & 18 \% \\ 2941-149 \text { RPD } & 27 \% \\ 2941-360 \text { RPD } & 1 \% \\ 2941-361 \text { RPD } & 2 \% \\ 2941-417 \text { RPD } & 38 \%\end{array}$

\footnotetext{
NA Not available \# Outside DQO $( \pm 35 \%)$
} 


$$
\begin{gathered}
\text { Appendix E: } \\
\text { Task } 1 \text { - Literature Review } \\
\text { and Sampling Plan }
\end{gathered}
$$




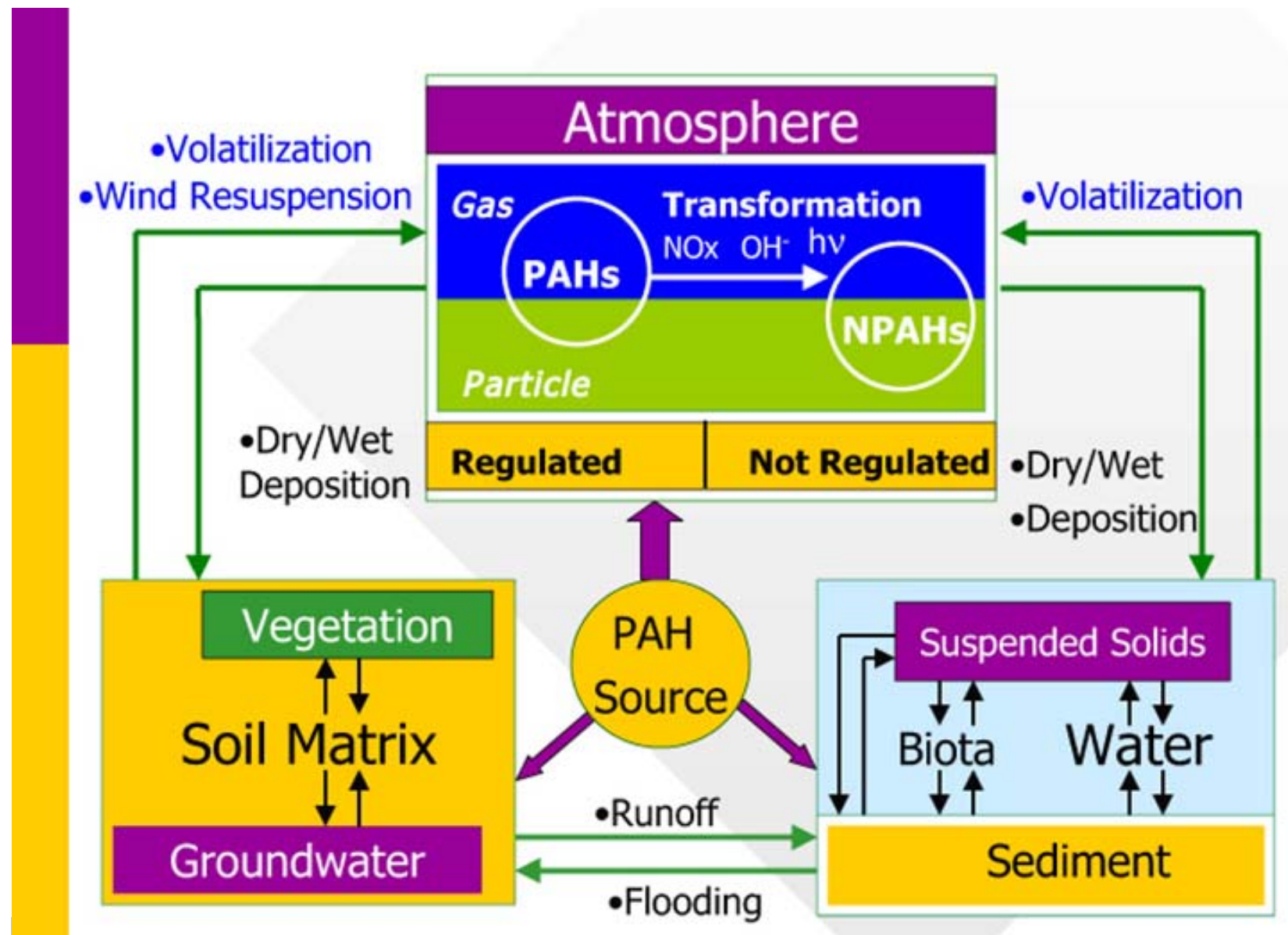

\section{Study of Atmospheric Deposition of Air Toxics to the Waters of Puget Sound RFQQ NO. 0828 AQP}

Task 1: Report of the Study of Atmospheric Deposition of Air Toxics to the Waters of Puget Sound

Submitted to

Department of Ecology,

State of Washington

August 21, 2008

Prepared by Battelle Pacific Northwest Division

Battelle

The Burbeas of Inowation 


\section{Table of Contents}

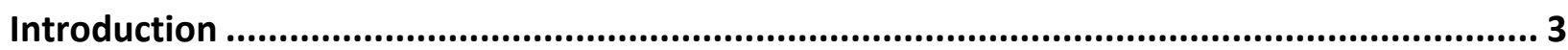

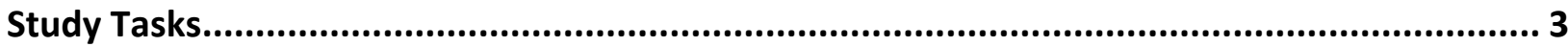

Literature Review .............................................................................................................. 4

Published Studies on the Atmospheric Deposition of Toxics in Puget Sound Region ............... 4

City of Tacoma Air Deposition Study .............................................................................. 6

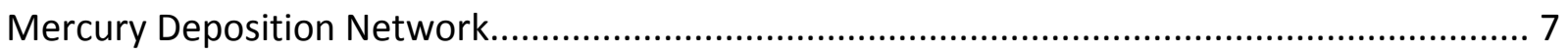

Selection of Air Toxics....................................................................................................... 7

Field Sampling Procedures and Analytical Chemistry Procedures ........................................ 8

Sampling Procedures for PAHs and PBDEs.................................................................... 8

PAHs, PBDEs, and Biomass Combustion Biomarker Analytical Procedures ............................ 9

Trace Element Sampling Procedures ......................................................................... 10

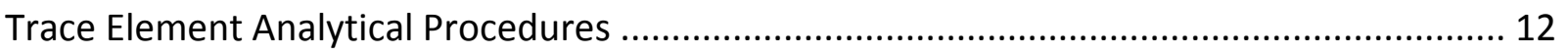

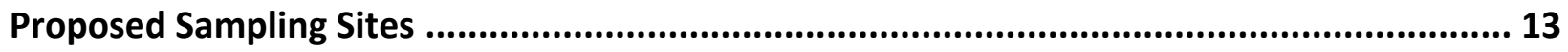

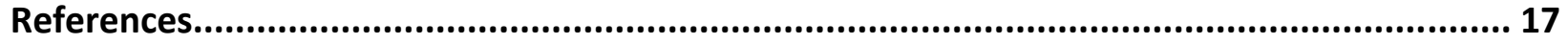

\section{List of Figures}

Figure 1. Atmospheric Deposition Sampler for the Collection of Organic Components................ 9

Figure 2. Flow diagram for collection and analysis of organic compounds. .............................. 11

Figure 3. Atmospheric deposition sampler for the collection of trace elements in rainfall and dry deposition.

Figure 4. Proposed locations of the seven Puget Sound atmospheric deposition sites. From north to south: 1-Padilla Bay, 2-Sequim Bay, 3-West Point, 4- Manchester, 5- Big Beef Creek on Hood Canal, 6- Tacoma, and 7- Nisqually River delta. (Base map reprinted from Collias et al 1974)

Figure 5. Average annual precipitation for Greater Puget Sound area. 16 


\section{Introduction}

Tons of toxic chemicals are emitted into the air from mobile, industrial and commercial sources in western Washington each day. Some of these toxic pollutants are deposited to the waters of Puget Sound. Over time these toxins accumulate in the water, sediments and biota of Puget Sound. The Control of Toxic Chemicals in Puget Sound report (Phase 1: Initial Estimate of Loadings http://www.ecy.wa.gov/programs/wq/pstoxics/index.html) suggested that run-off from land surfaces and deposition from air (directly to marine waters) are the two most important avenues of contaminate inputs to Puget Sound. In addition, the report found atmospheric deposition directly to Puget Sound to be an important source of toxic loadings for polycyclic aromatic hydrocarbons (PAHs) and polybrominated diphenyl ethers (PBDEs). Atmospheric loading of PAHs and PBDEs directly to the marine waters and tidelands was found to be greater than or comparable to the loading from surface runoff. Due to these findings and the associated large data uncertainties for these toxic chemicals, the report recommended collecting and analyzing atmospheric deposition samples to better understand their atmospheric deposition rates to the waters of Puget Sound.

This current report represents the first of three tasks designed to address the concerns about the introduction of toxics into Puget Sound from direct atmospheric deposition. The three tasks are briefly described below.

\section{Study Tasks}

The following three tasks are designed to answer the question "What is the loading of combustion products to waters of the Puget Sound?" and to provide preliminary source apportionment data that will support a comprehensive source control strategy for Puget Sound.

\section{Task 1. Literature Review, Sampling Site Selection, and Field and Analytic Methods}

Task 1 consists of a literature review, specifically targeting available regional data. The report will include the proposed sampling site locations, appropriate sampling equipment, analytical chemistry methods, and the selected chemicals of interest.

\section{Task 2. Field Measurements of Total Atmospheric Deposition}

Atmospheric deposition samples will be collected at a minimum of seven sites distributed along the shoreline of Puget Sound. In order to capture the dry season (May through October) and the wet season (November through April), sampling will begin in the Fall of 2008 and continue into the spring of 2009. Due to funding constraints, only one month of the dry season will be sampled. 
Task 3. Calculate the Average Annual Atmospheric Deposition; Compare Results to Sediment Accumulation Rates in Core Samples; and Source Apportion the PAHs Identified in the Atmospheric Deposition

The total atmospheric deposition to the entire surface of Puget Sound will be calculated for the toxics identified in Task 1 . The PAH sources will be apportioned using statistical methods and chemical markers. The results of this study will both estimate the relative contribution of PAHs by source type, such as motor vehicle or wood burning, and determine the percentage of PAHs in marine sediments that are derived from atmospheric deposition.

\section{Literature Review}

\section{Published Studies on the Atmospheric Deposition of Toxics in Puget Sound Region}

A review of the published literature on total deposition of air toxics to Puget Sound turned up only four published studies over the last 30 years. The deposition of metals was determined at Sequim and near the Pacific coast, at Quillayute, by Crecelius (1981) using both a bucket to collect total deposition and high volume filters to calculate deposition velocities. The dry deposition rates of PAHs were estimated by Prahl et al (1984) at Seattle, Sequim and Quillayute using high volume filters and deposition velocities taken from the literature. Crecelius (1991) estimated the atmospheric deposition of metals, PAHs, and PCBs on Commencement Bay using wet trays to collect total deposition and high volume filters for source apportionment (USEPA 1991). Recently, Tiffany (King County 2008) reported on total deposition sampling along the Duwamish waterway in south Seattle. All of these studies were able to measure the concentrations of either metals or PAHs in deposition samples or air filters. Some of these data were used to prioritize the chemicals of concern for toxic chemical loadings to Puget Sound (WDOE 2007).

\section{Polycyclic Aromatic Hydrocarbons (PAH's)}

Published atmospheric deposition rates are limited with only one study in Puget Sound for PAH and no regional information for PCB. The atmospheric deposition study in Commencement Bay (Crecelius, 1991) reported rates at the Riverside School (RS) site for LPAH and HPAH (Table 1).

\section{Polychlorinated Biphenyls (PCB's)}

There are no published studies for atmospheric deposition of PCBs in the Puget Sound region. Water bodies with reported rates include Chesapeake Bay, $5.2 \mu \mathrm{g} / \mathrm{m}^{2} / \mathrm{yr}$ (Leister and Baker 1994), Lake Superior $1.04 \mu \mathrm{g} / \mathrm{m}^{2} / \mathrm{yr}$ (Hoff et al. 1996), Lake Michigan $1.19 \mu \mathrm{g} / \mathrm{m}^{2} / \mathrm{yr}$ (Hoff et al. 1996), Galveston Bay $6.4 \mu \mathrm{g} / \mathrm{m}^{2} / \mathrm{yr}$ (Park et al. 2001), Corpus Christi Bay $4.9 \mu \mathrm{g} / \mathrm{m}^{2} / \mathrm{yr}$ (Park et 
al. 2002), Baltic Sea ranged 0.44 to $2.0 \mu \mathrm{g} / \mathrm{m}^{2} / \mathrm{yr}$ (Agrell et al. 2002), and the range estimated for the deep ocean 0.4 to $1.8 \mu \mathrm{g} / \mathrm{m}^{2} / \mathrm{yr}$ (Wania and Daly 2002).

Table 1. Atmospheric Deposition Rates for Polycyclic Aromatic Hydrocarbons at Riverside School (Crecelius, 1991)

\begin{tabular}{|c|c|c|}
\hline PAH Class & \multicolumn{2}{|c|}{ Mean Deposition Rate } \\
\hline \multicolumn{3}{|l|}{ LPAH } \\
\hline Naphthalene & 160 & $\mathrm{ng} / \mathrm{m}^{2} / \mathrm{yr}$ \\
\hline Acenaphthalene & 10 & $\mathrm{ng} / \mathrm{m}^{2} / \mathrm{yr}$ \\
\hline \multicolumn{3}{|l|}{ Acenaphthene } \\
\hline Fluorene & 7 & $\mathrm{ng} / \mathrm{m}^{2} / \mathrm{yr}$ \\
\hline phenanthrene & 260 & $\mathrm{ng} / \mathrm{m}^{2} / \mathrm{yr}$ \\
\hline anthracene & 9 & $\mathrm{ng} / \mathrm{m}^{2} / \mathrm{yr}$ \\
\hline \multicolumn{3}{|l|}{ HPAH } \\
\hline fluoranthene & 820 & $\mathrm{ng} / \mathrm{m}^{2} / \mathrm{yr}$ \\
\hline pyrene & 510 & $\mathrm{ng} / \mathrm{m}^{2} / \mathrm{yr}$ \\
\hline benzo[a] anthracene & 170 & $\mathrm{ng} / \mathrm{m}^{2} / \mathrm{yr}$ \\
\hline chrysene & 1100 & $\mathrm{ng} / \mathrm{m}^{2} / \mathrm{yr}$ \\
\hline Total benzofluoranthenes & 676 & $\mathrm{ng} / \mathrm{m}^{2} / \mathrm{yr}$ \\
\hline benzo [a] pyrene & 87 & $\mathrm{ng} / \mathrm{m}^{2} / \mathrm{yr}$ \\
\hline indeno $[1,2,3-c, d]$ pyrene & 83 & $\mathrm{ng} / \mathrm{m}^{2} / \mathrm{yr}$ \\
\hline dibenzo $[\mathrm{a}, \mathrm{h}]$ anthracene & 32 & $\mathrm{ng} / \mathrm{m}^{2} / \mathrm{yr}$ \\
\hline benzo[g,h,i] perylene & 110 & $\mathrm{ng} / \mathrm{m}^{2} / \mathrm{yr}$ \\
\hline
\end{tabular}

\section{Trace Elements}

Regional studies measured the deposition of $\mathrm{Cu}, \mathrm{Pb}, \mathrm{Zn}$, and other contaminants at several locations in Western Washington, including five sites around Commencement Bay in Tacoma, near Sequim Bay, and at Quillayute near the northwestern Washington coast (Crecelius 1981; Crecelius 1991a; Crecelius 1991b). The deposition rates for $\mathrm{Cu}, \mathrm{Pb}$, and $\mathrm{Zn}$ at the Riverside School in the Puyallup River valley site were $7.3,8.0$ and $13.1 \mathrm{mg} / \mathrm{m}^{2} / \mathrm{yr}$, respectively.

The data noted above were collected almost 20 years ago and are limited in scope. To get more recent information and expand the available information it is necessary to look at studies outside of the Puget Sound area. A summary of selected published information on the wet and dry deposition of trace elements is given in Tables 2 and 3, respectively. 
Table 2. Selected Studies of Atmospheric Wet Deposition of Trace Elements

\begin{tabular}{|l|cccccc|l|}
\hline \multirow{2}{*}{ Region } & \multicolumn{6}{|c|}{ Trace Element Wet Deposition Flux $\left(\mu \mathrm{g} / \mathrm{m}^{2} / \mathbf{y r}\right)$} & \\
& Cu & Cd & Pb & Zn & Cr & As & Reference \\
\hline Chesapeake Bay & 430 & 46 & 510 & 3000 & 140 & & Kim et al. (2000) \\
Delaware Bay & 490 & 36 & 390 & 1900 & 150 & & Kim et al. (2000) \\
San Fernando & & & & & & & \\
$\quad$ Valley, CA & 200 & - & 29 & 1500 & 18 & & Sabin et al (2005) \\
Lake Superior & 700 & 78 & 550 & & 78 & 78 & Sweet et al. (1998) \\
Lake Michigan & 570 & 72 & 640 & & 72 & 72 & Sweet et al. (1998) \\
Lake Erie & 850 & 94 & 1000 & & 63 & 94 & Sweet et al. (1998) \\
\hline
\end{tabular}

Table 3. Selected Studies of Atmospheric Dry Deposition of Trace Elements

\begin{tabular}{|c|c|c|c|c|c|c|c|}
\hline \multirow[b]{2}{*}{ Region } & \multicolumn{6}{|c|}{ Trace Element Dry Deposition Flux $\left(\mu \mathrm{g} / \mathrm{m}^{2} / \mathrm{yr}\right)$} & \multirow[b]{2}{*}{ Reference } \\
\hline & $\mathrm{Cu}$ & Cd & $\mathrm{Pb}$ & $\mathrm{Zn}$ & $\mathrm{Cr}$ & As & \\
\hline San Fernando & & & & & & & \\
\hline Valley, CA & 3,211 & - & 2,000 & 13,000 & 440 & & Sabin et al (2005) \\
\hline New Brunswick, & & & & & & & \\
\hline NJ & $3,650^{a}$ & $360^{\mathrm{a}}$ & $2,900^{\mathrm{a}}$ & $14,000^{\mathrm{a}}$ & $3,600^{a}$ & & Yi et al. (2006) \\
\hline Jersey City, NJ & $13,870^{a}$ & $720^{\mathrm{a}}$ & $18,000^{\mathrm{a}}$ & $50,000^{a}$ & $5,100^{a}$ & & Yi et al. (2006) \\
\hline Lake Superior & 2400 & 380 & 920 & & 130 & 91 & Sweet et al. (1998) \\
\hline Lake Michigan & 1300 & 380 & 950 & & 130 & 66 & Sweet et al. (1998) \\
\hline Lake Erie & 3,300 & 400 & 780 & & 1,000 & 88 & Sweet et al. (1998) \\
\hline
\end{tabular}

${ }^{\mathrm{a}}$ Estimated from figure

\section{City of Tacoma Air Deposition Study}

As part of a comprehensive effort to address contaminant concerns in the Thea Foss and Wheeler-Osgood Waterways originating from storm water run-off (see: http://www.cityoftacoma.org/Page.aspx?hid=6215), the city of Tacoma has conducted an atmospheric deposition study of selected compounds including phthalates, combustion PAH's and zinc. The program was initiated in May 2006 at four sampling locations in the Thea Foss Watershed, in Tacoma, Washington. Information on sampling through April 2007 is contained in Appendix D of the report (http://www.cityoftacoma.org/File.ashx?cid=6923). To illustrate some results, Benzyl phthalate, pyrene and zinc atmospheric deposition fluxes ranged from ND to $1.73 \mu \mathrm{g} / \mathrm{m}^{2} /$ day for benzyl phthalate, ND to $0.411 \mu \mathrm{g} / \mathrm{m}^{2} /$ day for pyrene, and ND to 261 $\mu \mathrm{g} / \mathrm{m}^{2} /$ day for zinc. The report indicates that the city of Tacoma plans to continue sampling and coordinate with King County on data analysis in 2007. 


\section{Mercury Deposition Network}

The total atmospheric deposition flux for $\mathrm{Hg}$ (wet and dry) is being determined at several sites around the U. S. as part of the Mercury Deposition Network (MDN), which is associated with the National Atmospheric Deposition Program (NADP). The MDN network maintains a wet deposition collector in Seattle, WA (site WA18 at NOAA). The wet deposition rates from 2002 through 2005 averaged $6.13 \pm 0.35 \mu \mathrm{g} / \mathrm{m}^{2} / \mathrm{yr}$ (NADP 2002-2005). In order to estimate a total flux for Puget Sound (wet + dry) an estimate of dry deposition flux is necessary.

\section{Selection of Air Toxics}

The selection of air toxics that will be quantified in total deposition samples was based on the WDOE (2007) report entitled "Control of Toxic Chemicals in Puget Sound, Phase 1: Initial Estimate of Loading." (http://www.ecy.wa.gov/programs/wq/pstoxics/index.html) This report used available data to calculate the toxic chemical loadings to the Puget Sound Basin, including atmospheric deposition. The major criteria that Battelle used for selection of toxics to monitor was whether atmospheric deposition was identified in the report as a potentially important source to Puget Sound or because there was a paucity of information making it difficult to assess atmospheric deposition. Not all toxics of concern could be sampled due to budget constraints. Toxics to be measured in this study include: 5 metals, carcinogenic PAHs, other high molecular weight PAHs, and total PBDEs. Below is a list of the toxics and the biomarkers that we propose for analysis as part of this study.

\section{Metals:}

Arsenic

Cadmium

Copper

Lead

Zinc

Total Mercury and Methyl Mercury (as a separate program funded by the U. S. Navy)

\section{Combustion PAHs:}

Phenanthrene

Anthracene

Fluoranthene

Pyrene

Benzo(a)anthracene

Chrysene

Benzo(a)pyrene

Benzo(e)pyrene (not on EPA list)

Benzo(g, h, i)perylene 
Benzo(k)fluoranthene

Dibenzo(a, h)anthracene

Indeno(1, 2, 3-c, d) pyrene

Additional PAH Markers:

Perylene (not on EPA list)

Retene (not on EPA list)

2, 6-Dimethylphenanthrene (not on EPA list)

2, 7-Dimethylphenanthrene (not on EPA list)

1, 7-Dimethylphenanthrene (not on EPA list)

\section{Biomass Combustion Biomarkers:}

Levoglucosan

Mannosan

Galactosan

Dehydroabietic acid

Methoxyphenols (lignin-derived acids)

\section{PBDEs:}

The dominant congeners present in the commercial products and the environment that will be quantified include; 28, 47, 66, 99, 100, 153, 154, 183, 209.

\section{Field Sampling Procedures and Analytical Chemistry Procedures}

Atmospheric deposition samples will be collected at seven sites distributed along the shoreline of Puget Sound. Sampling will begin in the fall of 2008 and continue into spring of 2009. A total of 12 samples from each site are anticipated, with sampling periods of about two weeks. This provides a total of about 84 plus 12 field duplicate samples. The sampling equipment is passive and does not require electrical power or frequent attention, therefore minimizing equipment and labor costs.

\section{Sampling Procedures for PAHs and PBDEs}

Atmospheric deposition samples for organic chemicals will be collected using a large stainless steel funnel (Figure 1) connected to a cartridge containing both a glass fiber filter and a pair of Empore ${ }^{\circledR}$ extraction disks, designed to preconcentrate various organic chemicals from the bulk deposition. The volume of rain water that is processed will be collected in a reservoir and recorded. The cartridge and tubing will be replaced every two weeks and the funnel will be cleaned with high purity water and a precleaned natural bristle brush. 


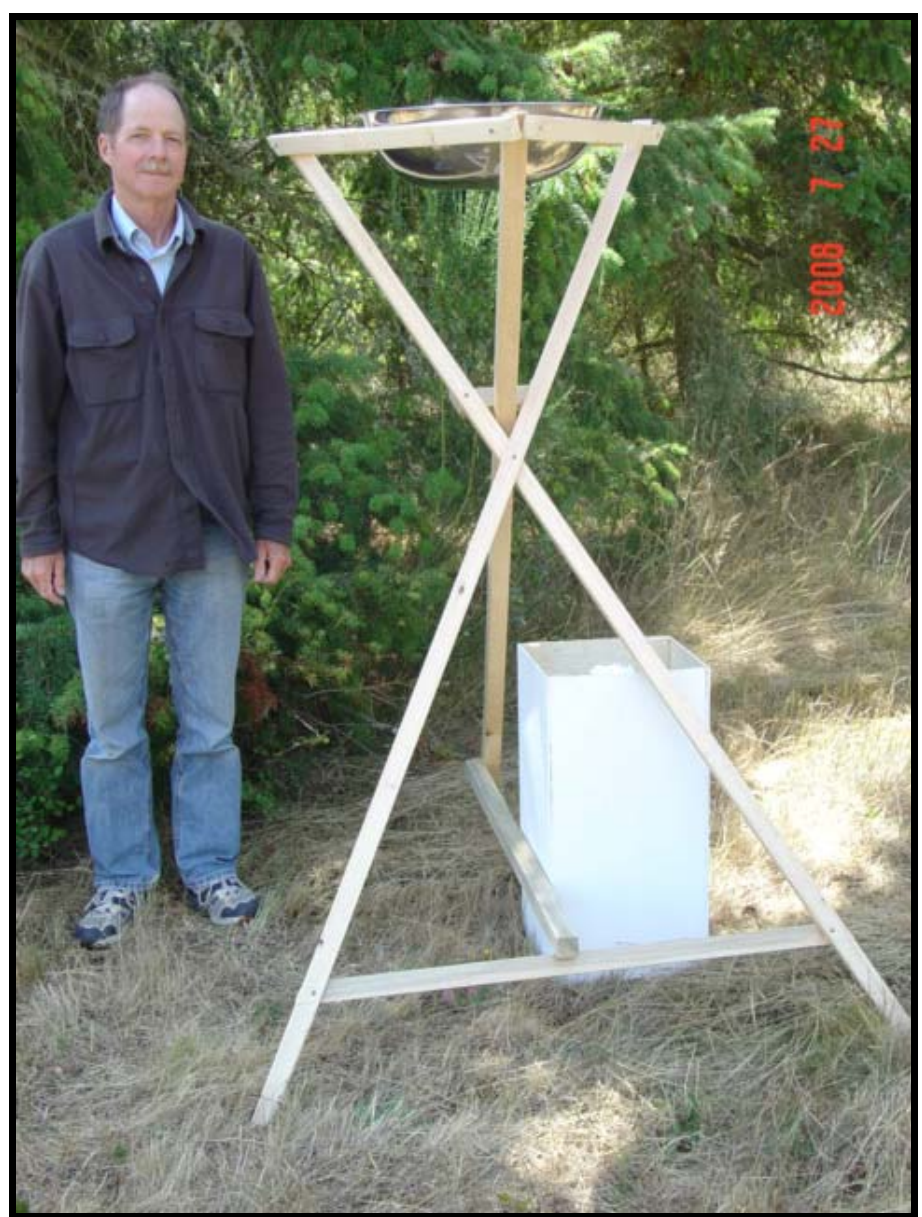

Figure 1. Atmospheric Deposition Sampler for the Collection of Organic Components.

\section{PAHs, PBDEs, and Biomass Combustion Biomarker Analytical Procedures}

Samples will be spiked with multiple perdeuterated surrogate standards or artificial internal standards according to established methods (Fraser and Lakshmanan 2000; Usenko et al., 2005; Kuo et al. 2008a). The solid phase extraction (SPE) disks and glass fiber filters (GFF) will be extracted by accelerated solvent extraction, using dichloromethane (DCM) and methanol (MeOH), according to Fine et al. (2004) and Kuo et al. (2008a) as shown in the flow diagram, Figure 2. The PAHs and biomass combustion biomarkers will then be quantified by Gas Chromatography-Mass Spectrometry on a Varian 4000 GC/MS-MS in a full scan (FS) or selective ion storage (SIS) mode (Kuo et al. 2008a; Kuo et al. 2008b).

The PBDEs will be quantified by gas chromatography - electron capture detection, similar to the EPA Method 8082 used for PCBs. Surrogate standards will be added to the SPE disks and GFF before extraction of the PAHs and PBDEs. A split of the extract will be quantified for nine congeners listed previously. 


\section{Trace Element Sampling Procedures}

Atmospheric deposition samples for trace element determinations will be collected using a "bulk deposition" sampler, following procedures similar to that described in Landing et al. (1998) and Guentzel et al. $(1998,2001)$. An example of the sampler to be used is given in Figure 3. The sampler consists of three components: an upward facing funnel, a Teflon ${ }^{\circledR}$ collar, and a Teflon $^{\circledR}$ sample bottle. The funnel will be made by cutting of the bottom half of a 1,2 or $4 \mathrm{~L}$ Nalgene ${ }^{\circledR}$ High Density Polyethylene or Polycarbonate bottle. A "crown of thorns" will be attached to the outside rim of the funnel to deter birds from sitting on the funnel rim. The crown of thorns consists of short lengths of Teflon ${ }^{\circledR}$ tubing held in place with cable ties. The Teflon collar mates the funnel to the Teflon sample bottle and is manufactured from a solid block of PTFE Teflon ${ }^{\circledR}$. Threads are cut into two sides of the Teflon block to allow the funnel and sample bottle to be secured into the Teflon ${ }^{\circledR}$ block. An air port is necessary on the side of the collar to allow air inside the sample bottle to escape as rainfall enters. The bulk deposition sampler is held in place with a stainless steel three finger clamp and attached to the framework that holds the deposition sampler for organic sampling. The clamp and rod will be covered with plastic to prevent potential contamination. A second sampler will be deployed for collection of mercury and methylmercury samples. For mercury samples a opaque Teflon ${ }^{\circledR}$ sample bottle will be used to prevent photodegradation of monomethyl mercury.

The components of the deposition sampler will be rigorously cleaned using a series of steps including laboratory detergent (Micro) and hot acid soaks, each for several days. Following each cleaning step, the components will be thoroughly rinsed with high purity water and finally dried on a class-100 clean-air bench. For transport into the field, the components will be doubly bagged in polyethylene bags and will be handled using gloved hands and the "clean hands - dirty hands" sampling approach.

Prior to deployment, each sampler will be pre-acidified with a small amount of $50 \% \mathrm{HNO}_{3}$ to prevent adsorption of trace elements in the rainfall from adhering onto the bottle walls. No $\mathrm{HNO}_{3}$ acid will be added to the mercury deposition samplers during the collection period as this might promote degradation of monomethyl mercury. 


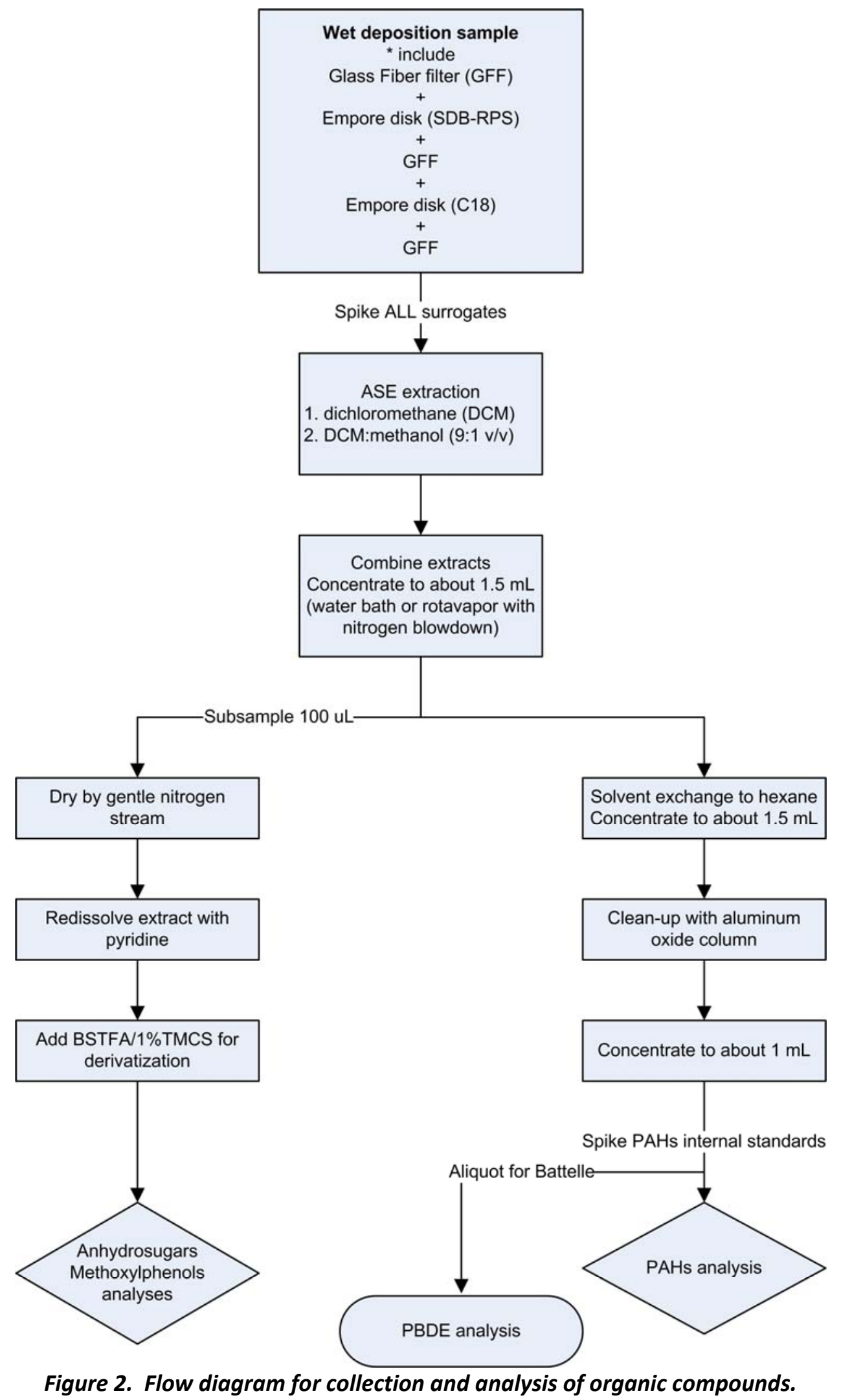

E-11 


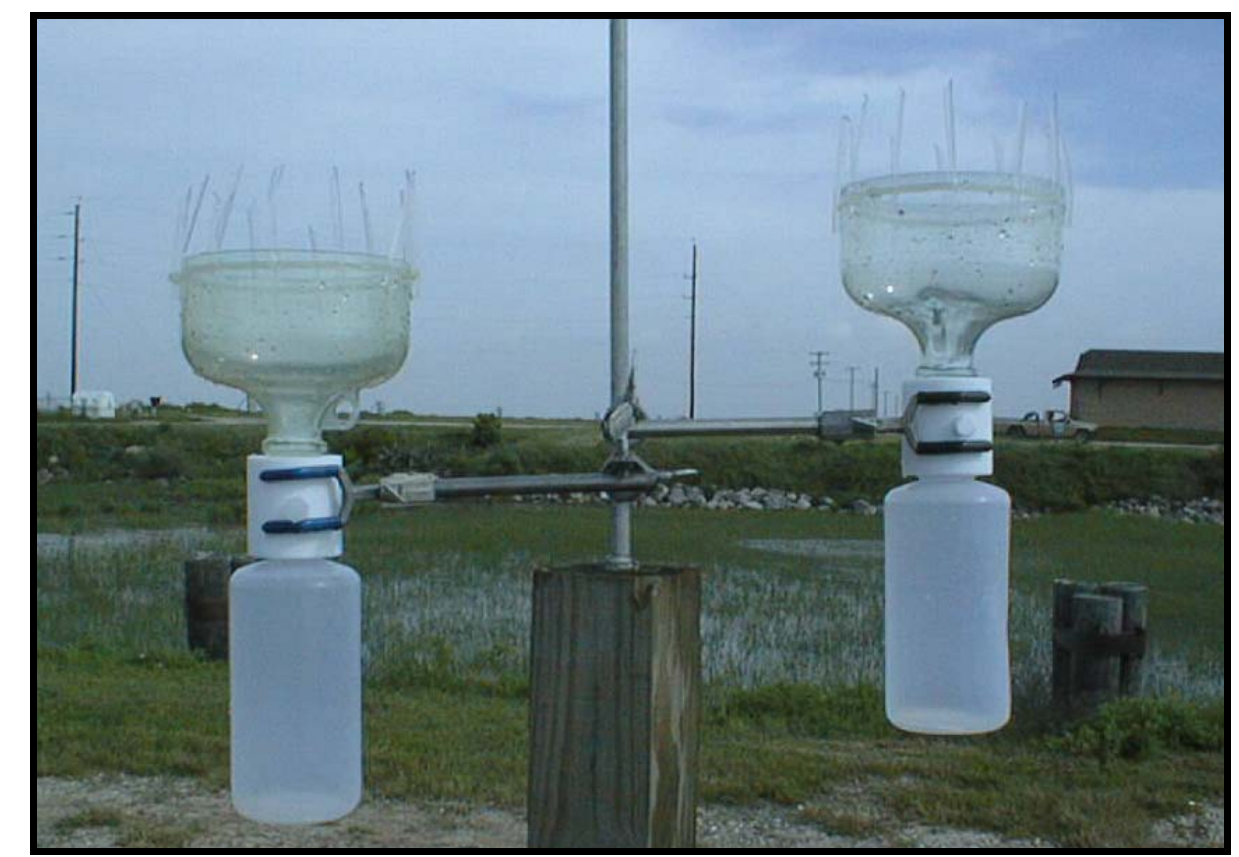

Figure 3. Atmospheric deposition sampler for the collection of trace elements in rainfall and dry deposition.

\section{Trace Element Analytical Procedures}

Trace element determinations, except mercury, will be conducted on digested samples using a Perkin-Elmer Model 6100 inductively coupled plasma mass spectrometer (ICPMS) following a modified version of U. S. EPA Method 1638. Mercury and monomethylmercury measurements will be conducted using modified versions of U. S. EPA methods 1631 e and 1630 , respectively (U. S. EPA, 1998, 2002 ). Prior to analysis, rainfall samples will be digested at elevated temperature using nitric acid or a mixed-acid digestion procedure. The exact acid or mixture concentration, digestion temperature and digestion time will be determined by conducting a series of digestion experiments using NIST standard reference material 1648 - Urban Dust added into pure water. The goal here is to use a method that effectively recovers $90 \%$ or greater of the elements of interest using the reference material as a simulated rainfall sample. Sample digestion will be conducted by placing an aliquot of the sample in a polypropylene vial, shown to be clean for trace elements, fitted with a snap cap (Capitol Vial) and placing the vial in a non-metallic heated block (ModBlock ${ }^{\circledR}$ ). Quality control samples including method blanks, matrix spikes, and duplicates will be processed with the field samples. 


\section{Proposed Sampling Sites}

We have proposed seven sites for the collection of total deposition. The sites are distributed around Puget Sound with the goal of representing different geographical regions, precipitation patterns, and air pollution sources.

\section{Padilla Bay, Northern Sound}

2. Sequim Bay, Straits of Juan de Fuca

3. West Point, Seattle, Central Sound Eastern Shoreline

4. Manchester Laboratory, Port Orchard, Central Sound Western Shoreline

5. Seabeck, Hood Canal

6. Tacoma, Central Sound Eastern Shoreline

7. Nisqually River Delta, South Sound

The locations of the sites are shown in Figure 4. The Padilla Bay site is located on the east side of the bay on property of the Padilla Bay National Estuarine Research Reserve. This site represents the northern Puget Sound that includes the San Juan Islands, southern Strait of Georgia, and Whidbey Island. Some of the sources of air emissions near this site include the farm lands of the Skagit Valley, several oil refineries, and the urban region of the city of Vancouver, British Columbia, Canada.

The Sequim Bay site is located at the entrance of the bay on the Battelle Marine Research Laboratory site. This site represents the Strait of Juan de Fuca and is in the dry shadow of the Olympic Mountains with the lowest rainfall of the sites.

The central region of Puget Sound has three sites extending from the shoreline of Seattle, westward to Hood Canal. The West Point site, at the northern margin of Elliott Bay, is located on the beach property of the METRO King County waste water treatment plant. West Point is located in the center of the main basin of the Sound and is influenced by ships, trains, as well as other urban air emissions.

In Kitsap County, the western boundary of the main basin, a sampler will be set up at the Manchester Laboratory site maintained by USEPA and the location of WDOE and NOAA labs. This site represents moderate density urban areas located in the central sound region and receives the second largest amount of total annual rainfall.

In the sub-basin of Hood Canal a site will be set up near the community of Seabeck, situated on a salt marsh managed by the University of Washington as part of the Big Beef Creek fisheries research station. This site represents air quality for Hood Canal and the western area of southern Puget Sound near rural forested land and receives the highest amount of rainfall relative to other Puget Sound stations. 


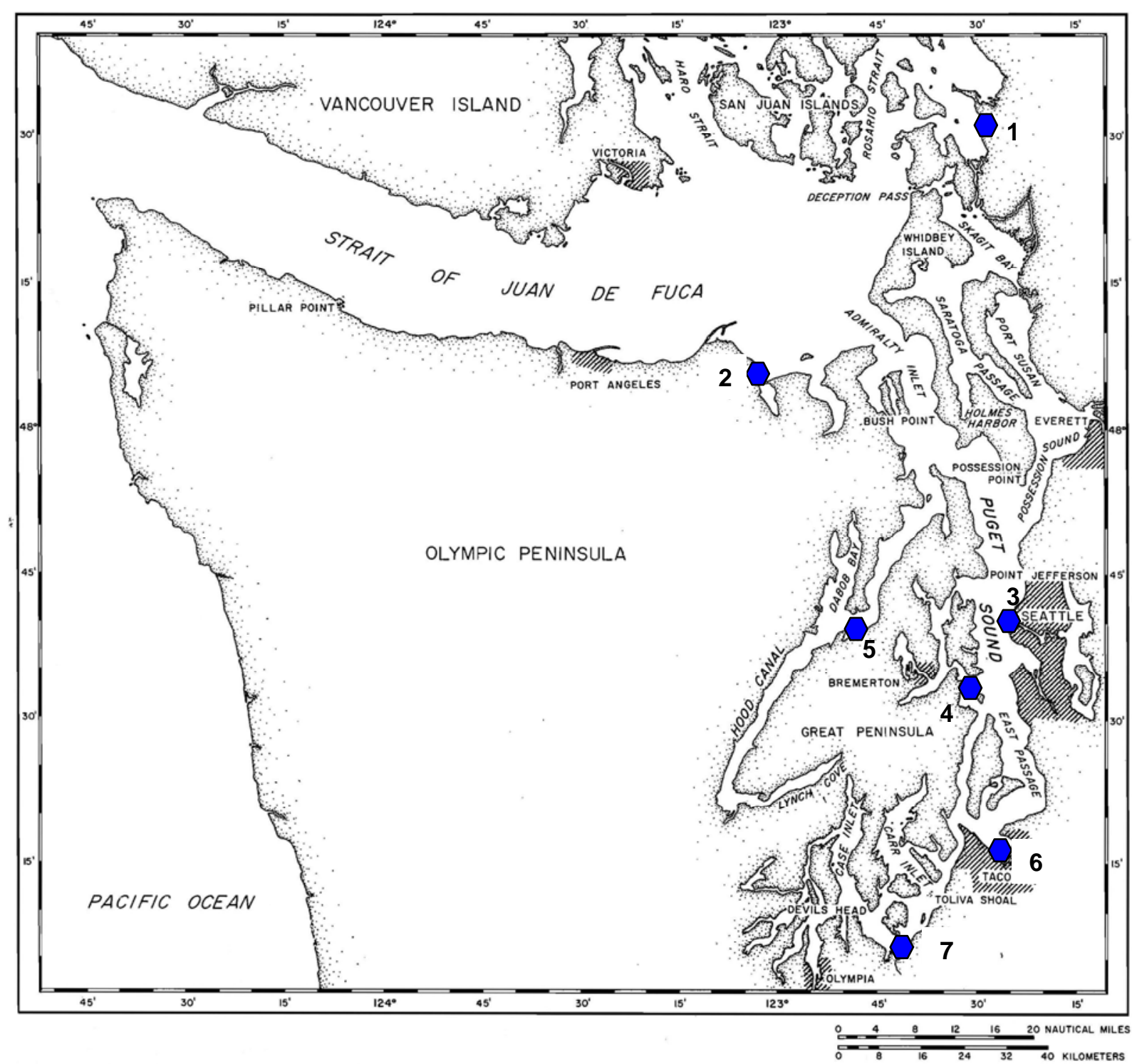

Figure 4. Proposed locations of the seven Puget Sound atmospheric deposition sites. From north to south: 1- Padilla Bay, 2- Sequim Bay, 3- West Point, 4- Manchester, 5- Big Beef Creek on Hood Canal, 6- Tacoma, and 7- Nisqually River delta. (Base map reprinted from Collias et al 1974)

The Tacoma site represents an urban/industrial area. It is located downtown on the Tacoma campus of the University of Washington near $21^{\text {st }}$ Street and Jefferson Ave., overlooking the industrial area of the Commencement Bay tide flats.

The site in southern Puget Sound is located at the edge of the Nisqually river delta, on the property of the Nisqually Reach Nature Center.

The annual rainfall in the Puget Sound Basin ranges from less than 20 inches at Sequim to over 60 inches at sites near Bremerton and Hood Canal. The annual precipitation for 18 locations 
over the last 13 years is shown in Figure 5 . The seven sites Battelle has selected include sites that cover most of the range of rainfall for the basin. 


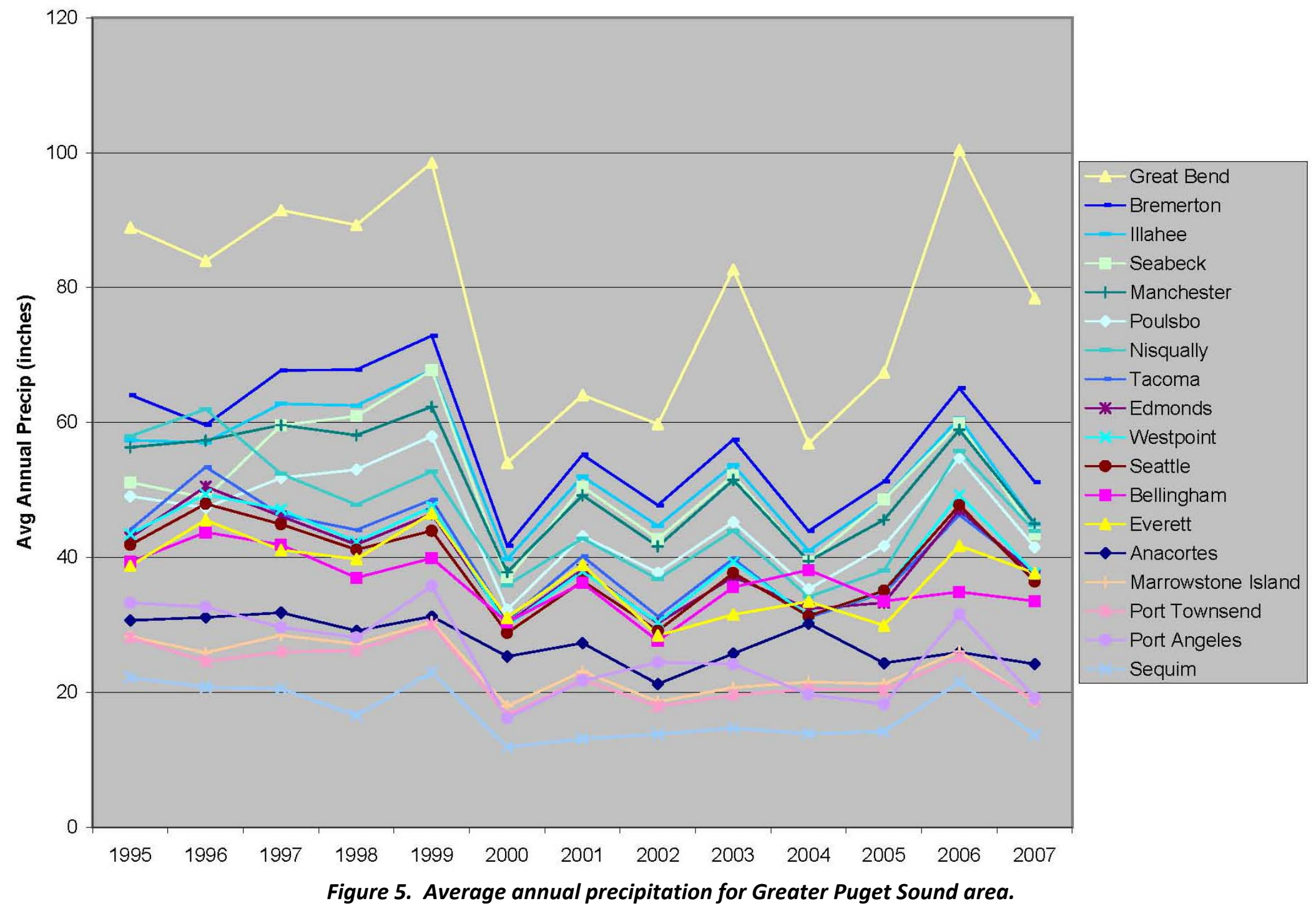




\section{References}

Agrell, C., P. Larsson, L. Okla and J. Agrell (2002). "PCB congeners in precipitation wash out ratios and depositional fluxes within the Baltic Sea region, Europe." Atmospheric Environment 36: 371-383.

Collias, E. E., N. McGary, and C.A. Barnes. 1974. Atlas of physical and chemical properties of Puget Sound and its approaches. University of Washington Press. Seattle.

Crecelius, E. A. 1981. Prediction of marine atmospheric deposition rates using total Be-7 deposition velocities. Atmospheric Environment, 15(4):579-82.

Crecelius, E. A. (1991a). Estimate of the Atmospheric Deposition of Contaminants on Commencement Bay. Washington, 84th Annual Meeting and Exhibition, Vancouver, British Columbia.

Crecelius, E. A. (1991b). Estimate of the atmospheric deposition of contaminants on Commencement Bay, Washington. Washington, D. C., USEPA.

Crecelius, E. A. (1991c). "Six-Month Aerosol and Deposition Study." Chapter 4. In Evaluation of the atmospheric deposition of toxic contaminants to Puget Sound. Prepared for U.S. EPA Region 10, Seattle, Washington. EPA 910/9-91-027.

Fine, P.M., B. Chakrabarti, M. Krudysz, J.J. Schauer and C. Sioutas (2004). Diurnal variations of individual organic compound constituents of ultrafine and accumulation mode particulate matter in the Los Angeles basin. Environmental Science \& Technology, 38(5): 1296-1304.

Fraser, M. P., and K. Lakshmanan. 2000. Using levoglucosan as a molecular marker for the long-range transport of biomass combustion aerosols. Environmental Science \& Technology, 34: 4560-4564.

Golomb, D., D. Ryan, N. Eby, J. Underhill and S. Zemba (1997). Atmospheric deposition of toxics onto Massachusetts Bay - I. Metals. Atmospheric Environment, 31(9): 1349-1359.

Graney, J. R., J. T. Dvonch and G. J. Keeler. 2004. Use of multi-element tracers to source apportion mercury in south Florida aerosols. Atmospheric Environment, 38: $1715-1726$. 
Guentzel, J. L., W. M. Landing, G. A. Gill and C. D. Pollman. 2001. Processes influencing rainfall deposition of mercury in Florida: The FAMS Project (1992-1996). Environmental Science and Technology, 35: 863-873.

Guentzel, J. L., W. M. Landing, G. A. Gill, and C. D. Pollman. 1998. Mercury and major ions in rainfall, throughfall and foliage from the Florida Everglades. The Science of the Total Environment, 213: 43-51.

Hart-Crowser, Inc. 2007. Phase 1: Initial estimate of toxic chemical loadings to Puget Sound. Prepared for Washington State DOE, US EPA, and Puget Sound Partnership, 07-10-079.

Hoff, R. M., M. J. Strachan, C. W. Sweet, C. H. Chan, M. Shackleton, T. F. Bidleman, K. A. Brice, D. A. Burniston, S. Cussion, D. F. Gatz, K. Harlin and W. H. Schroeder (1996). "Atmospheric deposition of toxic chemicals to the Greak Lakes: A review of data through 1994." Atmospheric Environment, 30(20): 3505-3527.

Hope, B. K. (2006). An assessment of anthropogenic source impacts on mercury cycling in the Willamette Basin, Oregon, USA. Science of The Total Environment 356(1-3): 165-191.

Injuk, J. and R. Van Grieken (1998). "Deposition of atmospheric trace elements into the North Sea: Coastal, ship, platform measurements and model predictions." Atmospheric Environment, 32(17): 3011-3025.

Kim, G., J. R. Scudlark, and T. M. Church (2000). Atmospheric Wet Deposition of trace elements to Chesapeake and Delaware Bays. Atmospheric Environment, 34: 3437-3444.

Kuo, L.-J., B. E. Herbert, and P. Louchouarn. 2008a. Can levoglucosan be used to characterize and quantify char/charcoal black carbon in environmental media. Organic Geochemistry. In Press.

Kuo, L.-J., P. Louchouarn, and B. E. Herbert. 2008b. Fate of CuO-derived lignin oxidation products during plant combustion: Application to the evaluation of charcoal inputs to soil organic. In Press.

Landing, W. M., J. L. Guentzel, J.J. Perry, jr., G. A. Gill, and C. D. Pollman. 1998. Methods for measuring mercury and other trace species in rainfall and aerosols in Florida. Atmospheric Environment, 32: 909-918.

Leister, D. L. and J. E. Baker (1994). Atmospheric deposition of organic contaminants to the Chesapeake Bay. Atmospheric Environment, 28(8): 1499-1520. 
Park, J. S., T. L. Wade and S. T. Sweet (2001). Atmospheric deposition of organochlorine contaminants to Galveston Bay, Texas. Atmospheric Environment, 35(19): 33153324.

Park, J. S., T. L. Wade and S. T. Sweet (2002). Atmospheric deposition of PAHs, PCBs, and organochlorine pesticides to Corpus Christi, Bay, Texas. Atmospheric Environment, 36(10): 1707-1720.

Prahl, F. G., E. Crecelius, and R. Carpenter (1984). Polycyclic Aromatic Hydrocarbons in Washington Coastal Sediments: An Evaluation of atmospheric and riverine routes of introduction. Environmental Science and Technology, 18:687-693.

Sabin, L. D., J. H. Lim, K. D. Stolzenbach, and K. C. Schiff (2005). Contribution of trace metals from atmospheric deposition to stormwater runoff in a small impervious urban catchment. Water Research, 39: 3929-3937.

Sweet, C., A. Weiss and S. J. Vermette (1998). Atmospheric Deposition of trace metals at three sites near the Great Lakes. Water, Air, and Soil Pollution, 103: 423-439.

U. S. Environmental Protection Agency (2002). Method 1631, Revision E: Mercury in water by oxidation, purge and trap, and cold vapor atomic fluorescence Spectrometry. EPA-821-R-02-019.

U. S. Environmental Protection Agency (1998). Method 1630 - Methyl mercury in water by distillation, aqueous ethylation, purge and trap, and cold vapor atomic fluorescence spectrometry. Office of Water, U.S. Environmental Protection Agency.

U. S. Environmental Protection Agency (1996). Method 1638 - Determination of trace elements in ambient waters by inductively coupled plasma - mass spectrometry. Office of Water, U.S. Environmental Protection Agency.

U. S. Environmental Protection Agency (1991). Evaluation of the atmospheric deposition of toxic contaminants to Puget Sound. EPA 910/9-91-027.

Wania, F. and G. L. Daly (2002). Estimating the contribution of degradation in air and deposition to the deep sea to the global loss of PCBs. Atmospheric Environment, 36: 5581-5593.

Yi, S.-M., L. A. Totten, S. Thota, S. Yan, J. H. Offenberg, S. J. Eisenreich, J. Graney, and T. M. Holsen (2006). Atmospheric dry deposition of trace elements measured around the urban and industrially impacted NY-NJ harbour. Atmospheric Environment, 40: 6626-6637. 


$$
\begin{gathered}
\text { Appendix F: } \\
\text { Task } 2 \text { - Toxics Air Deposition } \\
\text { Year } 1 \text { Data Report }
\end{gathered}
$$




\title{
Study of Atmospheric Deposition of Air Toxics to the Waters of Puget Sound: Year One Data Report
}

\author{
J. M. Brandenberger \\ G.A. Gill \\ E.A. Crecelius \\ Battelle Marine Sciences Laboratory \\ Sequim, Washington \\ P. Louchouarn \\ L-G Kuo \\ Texas A\&M University \\ Galveston, Texas
}

August 2009

Prepared for the

Department of Ecology,

State of Washington

Olympia, Washington 


\title{
DISCLAIMER
}

This report was prepared as an account of work sponsored by an agency of the United States Government. Neither the United States Government nor any agency thereof, nor Battelle Memorial Institute, nor any of their employees, makes any warranty, express or implied, or assumes any legal liability or responsibility for the accuracy, completeness, or usefulness of any information, apparatus, product, or process disclosed, or represents that its use would not infringe privately owned rights. Reference herein to any specific commercial product, process, or service by trade name, trademark, manufacturer, or otherwise does not necessarily constitute or imply its endorsement, recommendation, or favoring by the United States Government or any agency thereof, or Battelle Memorial Institute. The views and opinions of authors expressed herein do not necessarily state or reflect those of the United States Government or any agency thereof.

\author{
PACIFIC NORTHWEST NATIONAL LABORATORY \\ operated by \\ BATTELLE MEMORIAL INSTITUTE \\ for the \\ UNITED STATES DEPARTMENT OF ENERGY \\ under Contract DE-AC06-76RLO 1830 \\ Printed in the United States of America \\ Available to DOE and DOE contractors from the \\ Office of Scientific and Technical Information, \\ P.O. Box 62, Oak Ridge, TN 37831; \\ prices available from (615) 576-8401.
}

Available to the public from the National Technical Information Service,

U.S. Department of Commerce,

5285 Port Royal Rd., Springfield, VA 22161

This document was printed on recycled paper.

PNWD-4091 


\section{Table of Contents}

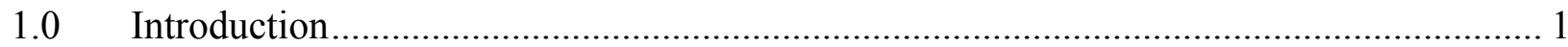

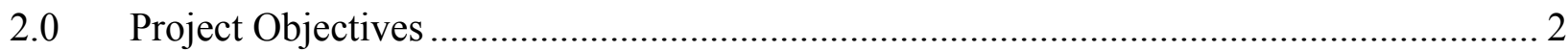

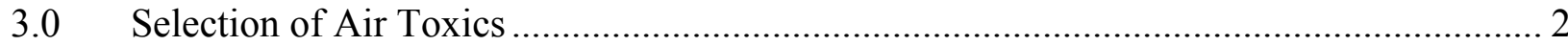

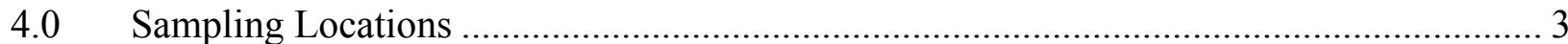

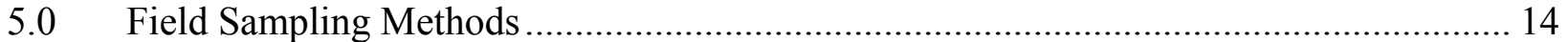

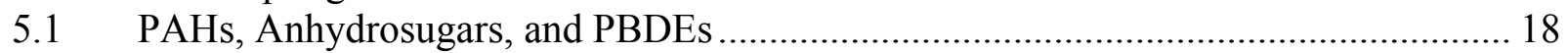

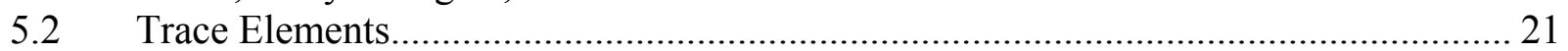

6.0 Analytical Methods and Quality Control........................................................................ 22

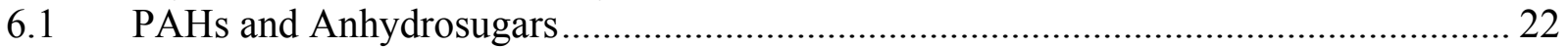

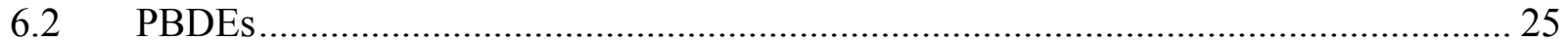

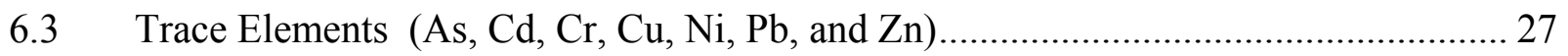

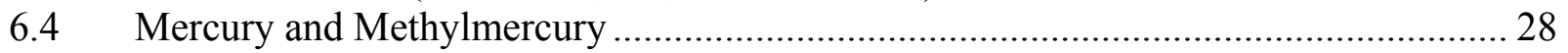

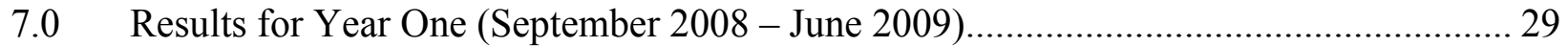

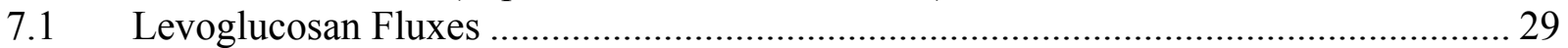

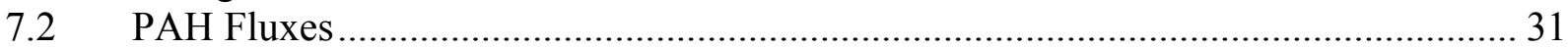

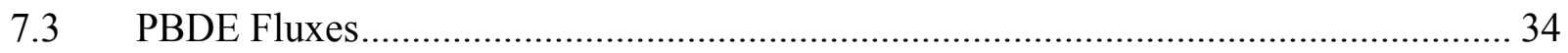

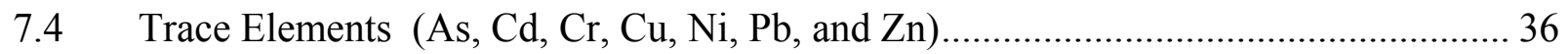

7.5 Mercury and Methylmercury ………………………......................................... 46

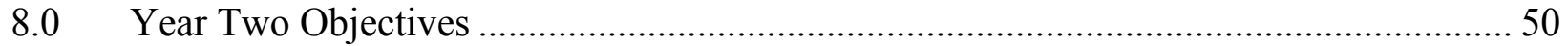

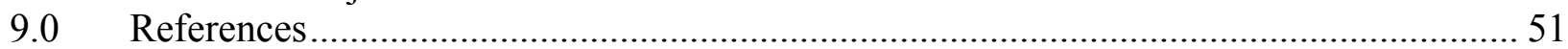

Appendix A PAH and Anhydrosugar Results

Appendix B PBDE Results

Appendix C Trace Elements Results

Appendix D Mercury and Monomethylmercury Results 


\section{Figures}

Figure 1. Seven core sites (red) and one additional site in Tacoma (yellow). Sampling sites are Padilla Bay (PB), Sequim Bay (SB), West Point (WP), Port Orchard (PO), Hood Canal (HC), Tacoma Commencement Bay (TCB), Nisqually River (NR), and Tyee Marina (TM) ....................................................... 4

Figure 2. Padilla Bay (PB) site in northern Puget Sound. .................................................... 6

Figure 3. Sequim Bay (SB) site on Sequim Bay on the Strait of Juan de Fuca.......................... 7

Figure 4. West Point (WP) site on the eastern shore of central Puget Sound............................ 9

Figure 5. Port Orchard (PO) site at Manchester Environmental Laboratories. .......................... 10

Figure 6. Hood Canal (HC) site with roaming duplicate station deployed during event 5.

Figure 7. Tacoma Commencement Bay (TCB) site marked in red on the map and pictured on the bottom left. The Tyee Marina (TM) site marked in yellow on the map and pictured on the bottom right. The Tyee Marina site was added in May 2009 to further understand the potential transport of toxics across Commencement Bay from the TCB site.

Figure 8. Nisqually River site located in south Puget Sound.

Figure 9. Average annual total precipitation (inches) for Puget Sound from 1995-2007 and during the 08/09 project sampling period (used June 4, 2008 through June 5, 2009 for full year record). Historical data provided by PRISM Climate Group, Oregon State University, http://www.prismclimate.org, created June 2008. The 08/09 sampling data was provided by the Community Collaborative Rain, Hail, and Snow Network (CoCoRaHS), National Oceanic and Atmospheric Administration, http://www.cocorahs.org, created June 2009.

Figure10. Bulk atmospheric deposition collector with stainless steel funnel in the center draining down into the wood box for organic parameters, clear Teflon ${ }^{\circledR} 1 \mathrm{~L}$ bottles for trace elements (left arm), and opaque Teflon ${ }^{\circledR} 1 \mathrm{~L}$ bottles for mercury speciation (right arm).

Figure11. Flow diagram for on-site, field extraction of bulk deposition and subsequent laboratory sample extractions for PAHs, anhydrosugars, and PBDEs.

Figure 12. Relationship between pyrogenic PAHs [fluoranthene, pyrene, benzo(a)anthracene, chrysene, benzo(b)fluoranthene, benzo(k)fluoranthene, benzo(a)pyrene, indeno(1,2,3-c,d)pyrene, dibenz(a,h)anthracene, benzo(g,h,i)perylene] and high molecular weight PAHs [benzo(b)fluoranthene, benzo(k)fluoranthene, benzo(a)pyrene, indeno(1,2,3-c,d)pyrene, dibenz(a,h)anthracene, benzo(g,h,i)perylene].

Figure 13. Levoglucosan fluxes from the seven sites for events 1 through 12 .

Figure 14. The levoglucosan/mannosan ratio discriminates sources of combustion. It indicates whether it is hardwood or softwood combustion. The relationship of the slope $(4 \pm 1)$ indicates softwood combustion is the main source of biomass combustion

Figure 15. Fluxes of HMW PAHs for the seven sites during events 1 through 12 .................. 32 
Figure 16. Fluxes of HMW PAHs for six sites (TCB removed) during events 1 through 12.32

Figure 17. The values of the phenanthrene/anthracene (Phen/Anth) and fluoranthene/pyrene (Fl/Py) ratios show a strong source input from pyrogenic PAHs.

Figure 18. The methylphenanthrene/phenanthrene (MP/P) and fluoranthene/fluoranthene+pyrene) ratios of the seven sites discriminated between combustion sources (pyrogenic) and oil sources (petrogenic). All sites indicated a mixed source of biomass and fossil fuel combustion.

Figure 19. The retene/(retene+chrysene) and 1,7-dimethylphenanthrene/(1,7+2,6 dimethylphenanthrene) ratios suggest the PM was derived from two main sources: a) softwood combustion and b) fossil fuel combustion.

Figure 20. The sum of PBDE fluxes for events 1 through 12 at all seven sites: Hood Canal (HC), Padilla Bay (PB), Sequim Bay (SB), West Point (WP), Nisqually River (NR), Port Orchard (PO), and Tacoma Commencement Bay (TCB). The error bars represent the variability of the field duplicates.

Figure 21. The distribution of PBDE fluxes (ng/ $\mathrm{m}^{2} /$ day) for each site over the twelve events sampled from September 2008 though June 2009. The lower box boundary represents the 25 th percentile, the solid line is the median, the upper box boundary is the 75th percentile, and the dashed blue line is the mean. Whiskers represent the 10th and 90th percentiles and the asterisk are potential outliers assuming no temporal trends are present. 36

Figure 22. Arsenic concentrations $(\mu \mathrm{g} / \mathrm{L})$ in bulk deposition samples from events 1 through 14 with error bars representing field duplicate measurements. 37

Figure 23. Cadmium concentrations $(\mu \mathrm{g} / \mathrm{L})$ in bulk deposition samples from events 1 through 14 with error bars representing field duplicate measurements.

Figure 24. Chromium concentrations $(\mu \mathrm{g} / \mathrm{L})$ in bulk deposition samples from events 1 through 14 with error bars representing field duplicate measurements. 38

Figure 25. Copper concentrations $(\mu \mathrm{g} / \mathrm{L})$ in bulk deposition samples from events 1 through 14 with error bars representing field duplicate measurements. 38

Figure 26. Nickel concentrations $(\mu \mathrm{g} / \mathrm{L})$ in bulk deposition samples from events 1 through 14 with error bars representing field duplicate measurements. 39

Figure 27. Lead concentrations $(\mu \mathrm{g} / \mathrm{L})$ in bulk deposition samples from events 1 through 14 with error bars representing field duplicate measurements. 39

Figure 28. Zinc concentrations $(\mu \mathrm{g} / \mathrm{L})$ in bulk deposition samples from events 1 through 14 with error bars representing field duplicate meaurements. 40

Figure 29. Bulk deposition fluxes $\left(\mu \mathrm{g} / \mathrm{m}^{2} / \mathrm{d}\right)$ for arsenic during events 1 through $14 \ldots \ldots \ldots \ldots \ldots . . . .43$

Figure 30. Bulk deposition fluxes $\left(\mu \mathrm{g} / \mathrm{m}^{2} / \mathrm{d}\right)$ for cadmium during events 1 through $14 \ldots \ldots \ldots \ldots . . .43$

Figure 31. Bulk deposition fluxes $\left(\mu \mathrm{g} / \mathrm{m}^{2} / \mathrm{d}\right)$ for chromium during events 1 through $14 \ldots \ldots \ldots \ldots . . .44$

Figure 32. Bulk deposition fluxes $\left(\mu \mathrm{g} / \mathrm{m}^{2} / \mathrm{d}\right)$ for copper during events 1 through $14 \ldots \ldots \ldots \ldots \ldots . . . . .44$

Figure 33. Bulk deposition fluxes $\left(\mu \mathrm{g} / \mathrm{m}^{2} / \mathrm{d}\right)$ for nickel during events 1 through $14 \ldots \ldots \ldots \ldots \ldots \ldots . . . . .45$

Figure 34. Bulk deposition fluxes $\left(\mu \mathrm{g} / \mathrm{m}^{2} / \mathrm{d}\right)$ for lead during events 1 through $14 \ldots \ldots \ldots \ldots \ldots \ldots . . . . .45$

Figure 35. Bulk deposition fluxes $\left(\mu \mathrm{g} / \mathrm{m}^{2} / \mathrm{d}\right)$ for zinc during events 1 through $14 \ldots \ldots \ldots \ldots \ldots \ldots \ldots . . . . . . . . .46$

Figure 36. Total mercury concentrations (ng/L) in bulk deposition samples for events 1 through 14 with error bars representing field duplicate measurements. 
Figure 37. Monomethylmercury concentrations (ng/L) in bulk deposition samples for events 1 through 14 with error bars representing field duplicate measurements.

Figure 38. Washout of atmospheric mercury for events 1 through 14 .................................... 48

Figure 39. Bulk atmospheric deposition fluxes $\left(\mathrm{ng} / \mathrm{m}^{2} / \mathrm{d}\right)$ for total mercury during sampling events 1 through 14 with error bars representing field duplicate measurements.

Figure 40. Bulk atmospheric deposition fluxes $\left(\mathrm{ng} / \mathrm{m}^{2} / \mathrm{d}\right)$ for monomethylmercury during sampling events 1 through 14 with error bars representing field duplicate measurements. 


\section{Tables}

Table 1. List of chemical constituents measured in bulk atmospheric deposition in Puget Sound.

Table 2. Atmospheric deposition station number, identification code, name, and coordinates.

Table 3. Sampling dates for each of the seven core sites with days deployed, rain collected at the site, regional precipitation guage data reported by the Community Collaborative Rain, Hail, and Snow Network (CoCoRaHS) and sampling events where a duplicate station was deployed at that site. The Tyee Marina was a new site added in May 2009 with only one sampling event.

Table 4. Summary of bulk atmospheric deposition concentrations and estimates of daily and annual trace element deposition fluxes for events 1 through 14.

Table 5. Summary of bulk atmospheric deposition concentrations and estimates of daily and annual total mercury and monomethylmercury deposition fluxes for events 1 through 14. 


\subsection{Introduction}

Urban centers are significant sources of combustion-derived particulate matter (PM), black carbon, and volatile organic carbon to the atmosphere. In Puget Sound, population growth trends in most of the coastal counties have been linear over the last 50 years. The growth of urban centers in coastal zones has been linked to environmental impacts that range from local health effects on human populations, to regional hydrologic cycling, or even global influences. Evidence is mounting that atmospheric emissions from combustion sources remain major contributors to air pollution of urban systems. Each day tons of toxic chemicals are emitted into the air from mobile, industrial, and commercial sources. The pathways for transporting these toxics to Puget Sound waters range from direct deposition on the water surface to deposition on the landscape and subsequent mobilization during runoff events. A complete understanding of the biogeochemical transport pathways of these deposited airborne toxics is required in order to best protect and restore the health of Puget Sound as deposited toxins may accumulate in the water, sediments, and/or biota. The first stage to understanding these pathways is to calculate an inventory of current toxic loadings into Puget Sound. The Washington Department of Ecology (WDOE) funded the production of the first two inventory reports. The Phase 1 Control of Toxic Chemicals in Puget Sound report suggested that run-off from land surfaces and deposition from air (directly to marine waters) are the two most important avenues of contamints to enter Puget Sound (Hart Crowser et al. 2007). The Phase 2 Control of Toxic Chemicals in Puget Sound Pollutant Loading Estimates for Surface Runoff and Roadways estimated toxic chemical loadings from roadways to further refine the surface runoff estimates with more recent land use data and alternate runoff coefficients (EnviroVision Corporation and Herrera Environmental Consultants, Inc. 2008).

These reports found atmospheric deposition directly to Puget Sound to be an important source of toxics loading for polycyclic aromatic hydrocarbons (PAHs), polybrominated diphenyl ethers (PBDEs), and select trace elements. Atmospheric loading of PAHs and PBDEs directly to the marine waters and tidelands was greater than or comparable to the loading from surface runoff. In particular, the transport and deposition of ultrafine PM and associated black carbon constituents (i.e. PAHs). Due to these findings and the associated large data uncertainties for these toxic chemicals, the report recommended collecting and analyzing atmospheric deposition samples to better understand the atmospheric deposition rates to the waters of Puget Sound. Understanding the temporal trends of combustion sources and subsequent deposition chemistry is thus vital to the purpose of developing effective environmental policies targeting Puget Sound restoration.

In response to this identified data gap, WDOE and the U. S. Navy collaborated to fund a two year study on atmospheric deposition fluxes for select metals, PAHs, PBDE, and biomarkers used to conduct source apportionment of the PAH deposition. This data report summarizes the year one sampling data collected from September-December 2008 and February-June 2009. This report includes a description of the seven core monitoring sites, an additional site added in the Tacoma region, collection and analytical methods for 
the project, a brief summary of the data available in year one, and a description of tasks planned for year two.

\subsection{Project Objectives}

The overarching question this project was designed to answer is, "What is the loading of combustion products to waters of the Puget Sound?" Addressing this question requires answering additional questions such as:

1. What are the toxics associated with combustion processes?

2. Does the average annual load of these toxics vary seasonally and /or spatially in Puget Sound?

3. Do certain types of combustion processes (i.e. wood burning stoves vs. gasoline combustion) contribute a larger relative proportion of the total load of atmospherically derived PAHs to the waters of Puget Sound?

With these objectives in mind, the following three project tasks were identified and the status of each is reported.

Task 1 - Summarize the current literature on atmospheric deposition in Puget Sound and relevant national studies, select a list of toxics and biomarkers required to meet the project objectives, select representative field locations in Puget Sound, define the field collection methodology, and define the analytical chemistry methods for all selected toxics. This task was completed in year one and was reported previously (Battelle 2008).

Task 2 - Conduct field measurements of bulk atmospheric deposition during the winter wet season and summer dry season. Due to contracting cycles, only the winter wet season was adequately characterized during year one. Therefore, the summer dry season deposition measurements will be collected during year two (July through September 2009).

Task 3 - Calculate the average seasonal and annual atmospheric deposition rates; compare results to sediment accumulation rates in core samples; and conduct source apportionment of the PAHs identified in the atmospheric deposition. This task was partially completed during year one and will be completed in year two.

\subsection{Selection of Air Toxics}

Recent data for atmospheric deposition of various toxics are extremely limited for many areas of Puget Sound. Therefore, a literature review was used to guide the selection of toxics to characterize atmospheric deposition (Battelle 2008). The list of chemical constituents selected was derived considering many factors including availability of regional data, chemical stability, and known regional and/or global atmospheric transport pathways. Emerging toxics not represented in regional studies (e.g. PBDE), national literature values, toxicity, and available budget were also considerations. Table 1 lists both the selected toxics and required biomarkers to support source apportionment of the PAH data. The creation of this list was largely supported by the estimated loads of these 
toxics to Puget Sound summarized in the two reports on Control of Toxic Chemicals in Puget Sound (Hart Crowser et al. 2007; EnviroVision Corporation and Herrera Environmental Consultants, Inc. 2008).

Highly specialized analytical chemistry techniques are required for many of the selected toxics and the biomarkes required for source apportionment. Therefore, a collaborative project was developed with the U.S. Navy to support the addition of total mercury (THg) and monomethylmercury (MMHg) determinations. In addition, the U. S. Navy recently confirmed the support of adding the National Oceanic and Atmospheric Administration (NOAA) Status and Trends program list of 18 polychlorinated biphenyl (PCBs) congeners to the list of toxics, see footnote in Table 1. The new atmospheric deposition fluxes for $\mathrm{Hg}$ and the first available Puget Sound wide PCB fluxes will be used to update the mass balances for $\mathrm{Hg}$ and PCBs calculated for Sinclair and Dyes Inlet (currently draft final report Brandenberger et al. to be finalized by September 2009).

Table 1. List of chemical constituents measured in bulk atmospheric deposition in Puget Sound ${ }^{1}$.

\begin{tabular}{|c|c|c|c|c|}
\hline $\begin{array}{l}\text { Trace } \\
\text { Elements }\end{array}$ & PBDE & Combustion PAHs & $\begin{array}{l}\text { Additional PAH } \\
\text { Markers (not on EPA } \\
\text { list) }\end{array}$ & $\begin{array}{l}\text { Biomass } \\
\text { Combustion } \\
\text { Markers } \\
\end{array}$ \\
\hline Arsenic & BDE-17 & Phenanthrene & Perylene & Levoglucosan \\
\hline Cadmium & BDE-28 & Anthracene & Retene & Mannosan \\
\hline Copper & BDE-47 & Fluoranthene & 2,6-dimethylphenanthrene & Galactosan \\
\hline Lead & BDE-66 & Pyrene & 2,7-dimethylphenanthrene & $\begin{array}{l}\text { Dehydroabietic } \\
\text { acid }\end{array}$ \\
\hline Zinc & BDE-71 & Benzo(a)anthracene & 1,7-dimethylphenanthrene & Methoxyphenols \\
\hline Mercury & BDE-85 & Chrysene & & \\
\hline Monomethyl & BDE-99 & Benzo(a)pyrene & & \\
\hline & BDE-100 & Benzo(e)pyrene & & \\
\hline & BDE-138 & Benzo(g,h,i)perylene & & \\
\hline & BDE-153 & Benzo(k)fluoranthene & & \\
\hline & BDE-154 & Dibenzo(a,h)anthracene & & \\
\hline & BDE-183 & Indeno(1,2,3-c,d)pyrene & & \\
\hline & BDE-190 & & & \\
\hline & BDE-209 & & & \\
\hline
\end{tabular}

${ }^{1}$ In year two the NOAA Status and trends $18 \mathrm{PCB}$ congeners will be added to the list including PCB8, PCB18, PCB28, PCB44, PCB52, PCB66, PCB101, PCB105, PCB118, PCB128, PCB138, PCB153, PCB170, PCB180, PCB187, PCB195, PCB206, and PCB209 (O'Connor 2002). Archived splits from year one will be analyzed for these PCBs.

\subsection{Sampling Locations}

Seven sampling locations were selected as core sites around Puget Sound that represent a range of geographic regions, precipitation patterns, potential air pollution sources, and deposition directly on the waters of Puget Sound (Figure 1 - Red markers). An eighth location was added on the shores of Commencement Bay (Tyee Marina [TM]; see Figure 1 - yellow marker), which is directly across the waters of Commencement Bay from the Tacoma Commencement Bay (TCB) core sampling site. The TM site was added to better 
understand the sphere of influence for the TCB site, which exhibited significantly different chemistry from all other stations. Table 2 lists the site numbers, identification codes, names, and coordinates.

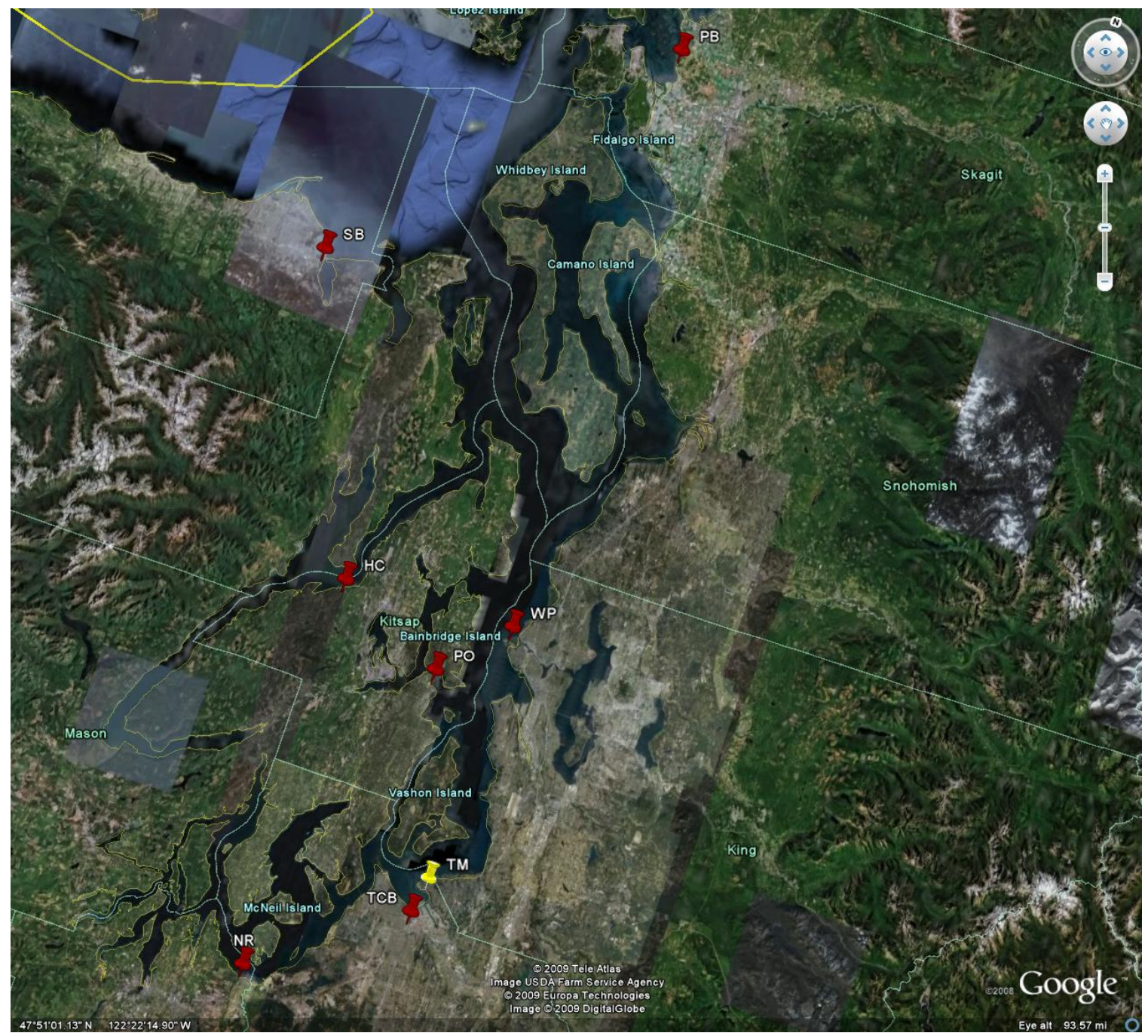

Figure 1. Seven core sites (red) and one additional site in Tacoma (yellow). Sampling sites are Padilla Bay (PB), Sequim Bay (SB), West Point (WP), Port Orchard (PO), Hood Canal (HC), Tacoma Commencement Bay (TCB), Nisqually River (NR), and Tyee Marina (TM). 
Table 2. Atmospheric deposition site number, identification code, name, and coordinates.

\begin{tabular}{|lllll|}
\hline $\begin{array}{l}\text { Site } \\
\text { Num. }\end{array}$ & $\begin{array}{l}\text { Site } \\
\text { ID }\end{array}$ & Name & $\begin{array}{l}\text { Coordinates } \\
\text { (degrees, minutes, seconds) }\end{array}$ \\
\hline \hline 1 & PB & Padilla Bay & $48^{\circ} 29^{\prime} 39.40^{\prime \prime} \mathrm{N}$ & $122^{\circ} 28^{\prime} 44.7^{\prime \prime} \mathrm{W}$ \\
2 & SB & Sequim Bay & $48^{\circ} 04^{\prime} 42.29^{\prime \prime} \mathrm{N}$ & $123^{\circ} 02^{\prime} 41.17^{\prime \prime} \mathrm{W}$ \\
3 & WP & West Point, Seattle & $47^{\circ} 39^{\prime} 50.34^{\prime \prime} \mathrm{N}$ & $122^{\circ} 25^{\prime} 34.20^{\prime \prime} \mathrm{W}$ \\
4 & PO & Port Orchard, Manchester & $47^{\circ} 34^{\prime} 26.03^{\prime \prime} \mathrm{N}$ & $122^{\circ} 33^{\prime} 04^{\prime \prime} 7^{\prime \prime} \mathrm{W}$ \\
5 & HC & Hood Canal, Seabeck & $47^{\circ} 39^{\prime} 07.13^{\prime \prime} \mathrm{N}$ & $122^{\circ} 46^{\prime} 51.16^{\prime \prime} \mathrm{W}$ \\
6 & TCB & Tacoma Commencement Bay & $47^{\circ} 14^{\prime} 45.59^{\prime \prime} \mathrm{N}$ & $122^{\circ} 26^{\prime} 13.95^{\prime \prime} \mathrm{W}$ \\
7 & NR & Nisqually River Delta & $47^{\circ} 06^{\prime} 02.39^{\prime \prime} \mathrm{N}$ & $122^{\circ} 43^{\prime} 37.16^{\prime \prime} \mathrm{W}$ \\
8 & TM & Tyee Marina & $47^{\circ} 17^{\prime} 51.52^{\prime \prime} \mathrm{N}$ & $122^{\circ} 25^{\prime} 27.70^{\prime \prime} \mathrm{W}$ \\
\hline
\end{tabular}

The Padilla Bay site is located on the Padilla Bay National Estuarine Research Reserve on the east side of the bay. This site is intended to represent northern Puget Sound, including the San Juan Islands, southern Strait of Georgia, and Whidbey Island (Figure 2). Some of the sources of air emissions near this site include the farm lands of the Skagit Valley, several oil refineries, and the urban region of the city of Vancouver, British Columbia, Canada. The average annual rainfall is $\sim 28$ inches/yr.

The Sequim Bay site is located at the Battelle Marine Sciences Laboratory (Figure 3). This site is intended to represent the Strait of Juan de Fuca and is in the rain shadow of the Olympic Mountains with the lowest rainfall of all sites averaging $~ 17$ inches/yr. Some of the sources of air emissions near this site include farm lands and wood burning stoves. The area is generally characterized as rural to low-density urban development. 

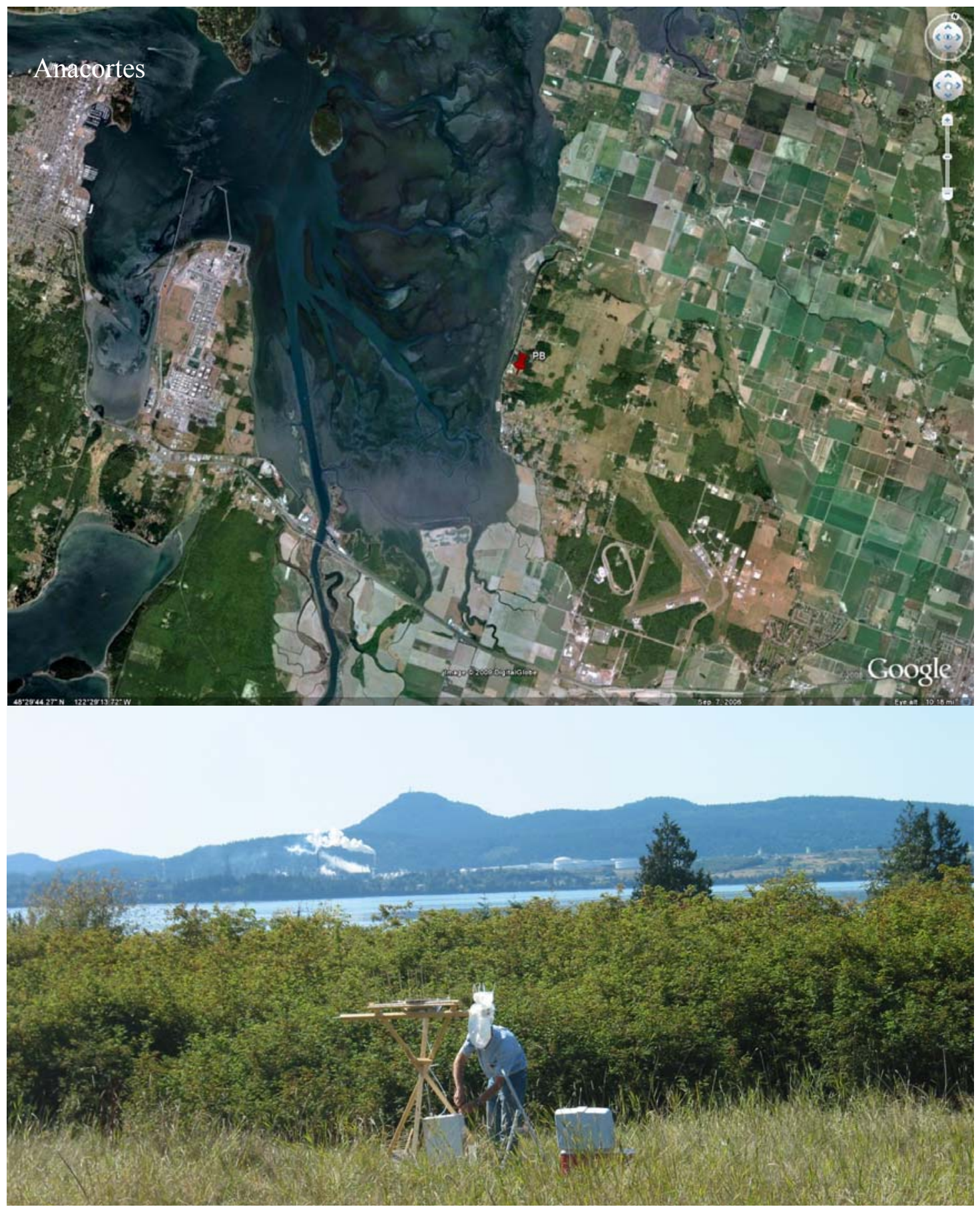

Figure 2. Padilla Bay (PB) site in northern Puget Sound. 


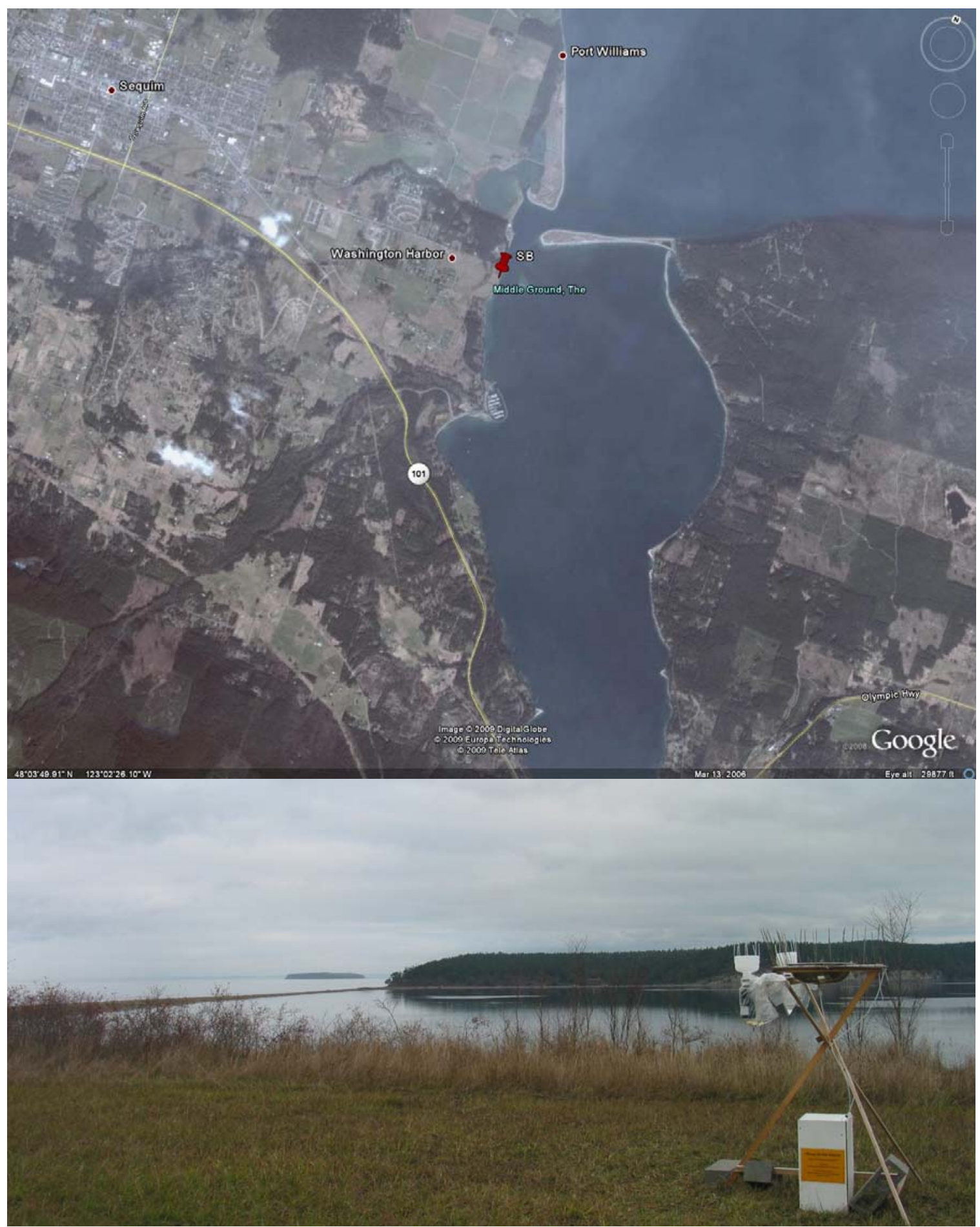

Figure 3. Sequim Bay (SB) site on Sequim Bay on the Strait of Juan de Fuca.

The central basin of Puget Sound has three sites extending from the shoreline of Seattle, westward to Hood Canal and south to Tacoma. On the northern margin of Elliot Bay, the West Point (WP) site is located on the beach property of the METRO King County waste water treatment plant (Figure 4). The wind patterns at the site are generally north/south providing primarily marine air masses over the site. Possible air emission sources 
influencing the West Point locations are ships, trains, and other urban air emissions. The surrounding city is characterized as high density urban development. The average annual rainfall is $\sim 40$ inches/yr.

On the western edge of the central Puget Sound basin, the Port Orchard (PO) site is located at the U.S. Environmental Protection Agency (EPA), WDOE, and NOAA Manchester Environmental Laboratories (Figure 5). The site potentially receives emissions from shipping, select industry, and low to moderate density urban development emissions from the surrounding cities and communities (Silverdale, Bremerton, and Bainbridge Island).

Further northwest, is the Hood Canal site located on a salt marsh at the University of Washington Big Beef Creek Fisheries Research Station near the community of Seabeck (Figure 6). This site was selected to represent air quality for Hood Canal and the western area of southern Puget Sound near rural forested lands. Both the Port Orchard and Hood Canal sites are in the Puget Sound convergence zone with an average annual precipitation of $\sim 60$ inches/yr.

At the southern end of the central basin, the Tacoma (TCB) site is located on the University of Washington, Tacoma campus near 21st Street and Jefferson Avenue (Figure 7). The site resides on the top of the West-Side Grocery Building and is surrounded by high density urban development and industrial activities within the Port of Tacoma on Commencement Bay tide flats. This is the most industrialized sampling location with a range of pulp and paper mills, metal refining, and other industrial activities that combust both wood and hydrocarbon fuels. The average annual rainfall is $\sim 41$ inches/yr. The deposition chemistry for TCB was significantly different from the other sites; therefore, an additional site was added in the Commencement Bay region. The site is located at the Tyee Marina (TM) off Marine Drive and directly across Commencement Bay from the TCB site. The TM site was only sampled during event 14 in May/June 2009 (see Table 2). The TM site was at sea level surrounded by the marina, a forested bluff, and the other industrial activities operating within Commencement Bay tide flats (Figure 7).

The sampling site in southern Puget Sound is located at the edge of the Nisqually river delta, on the property of the Nisqually Reach Nature Center (Figure 8). The site is surrounded by moderate density development and forested areas. The average annual rain fall is $\sim 46$ inches/year. 

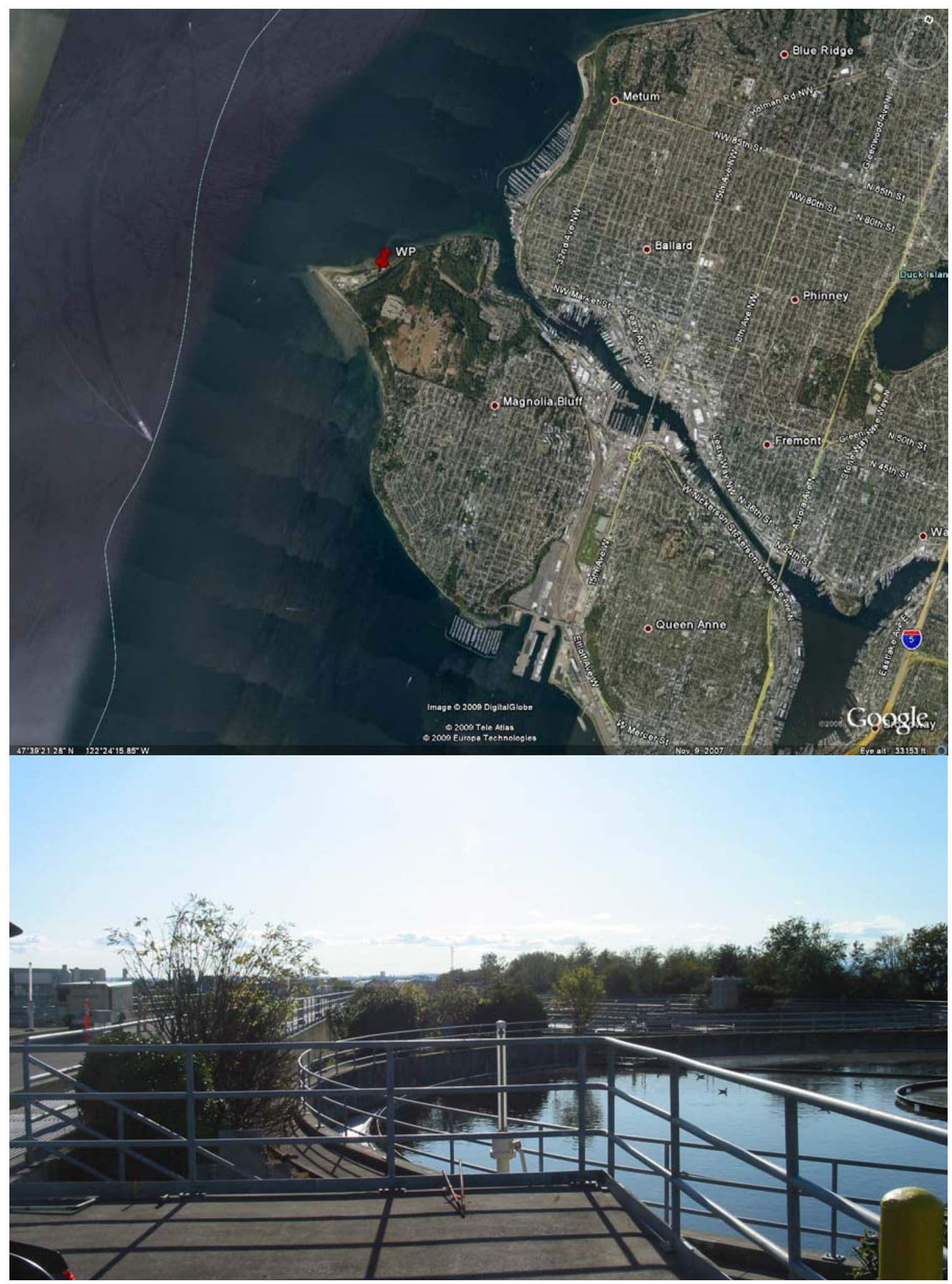

Figure 4. West Point (WP) site on the eastern shore of central Puget Sound. 

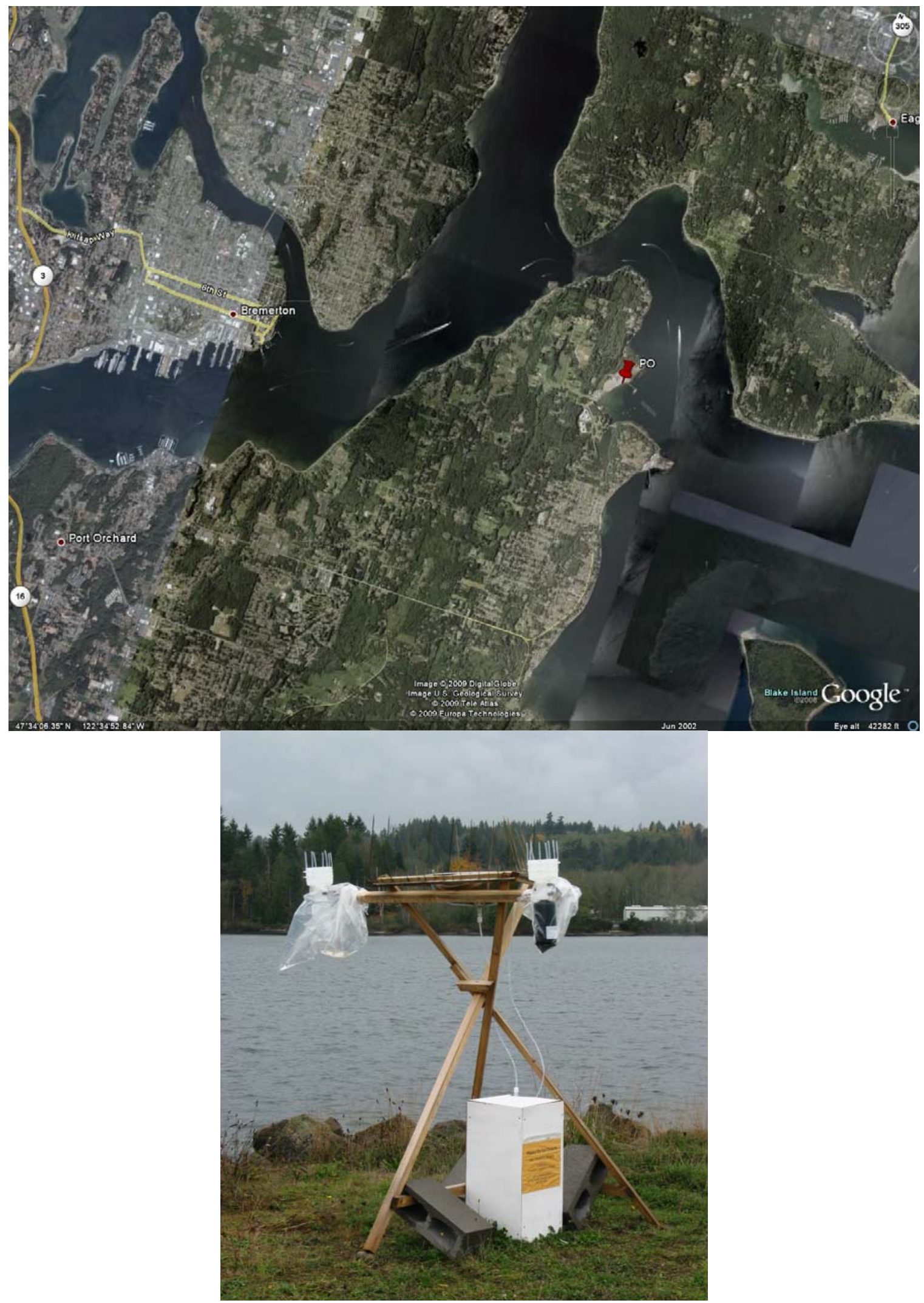

Figure 5. Port Orchard (PO) site at Manchester Environmental Laboratories. 


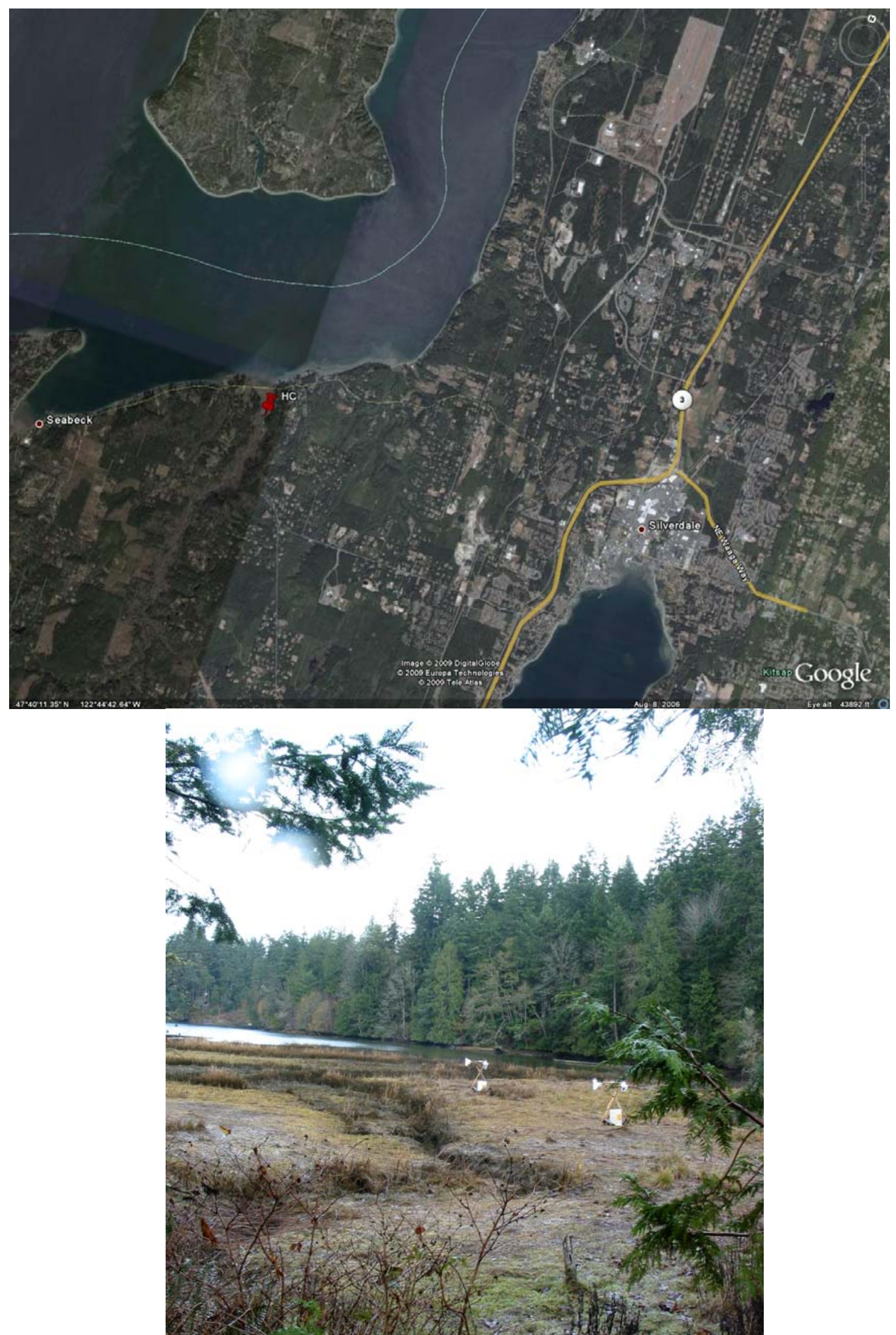

Figure 6. Hood Canal (HC) site with roaming duplicate station deployed during event 5. 


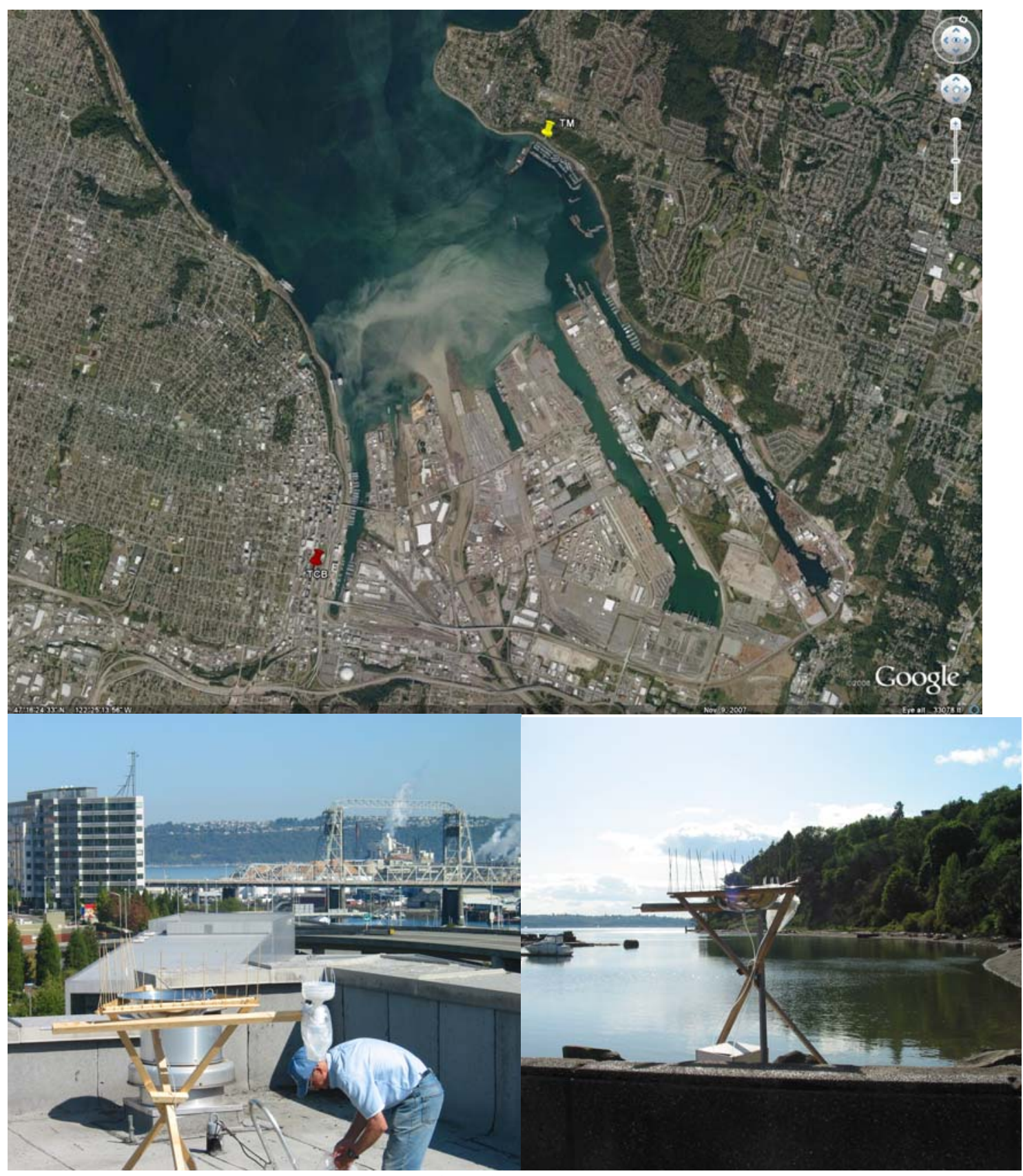

Figure 7. Tacoma Commencement Bay (TCB) site marked in red on the map and pictured on the bottom left. The Tyee Marina (TM) site marked in yellow on the map and pictured on the bottom right. The Tyee Marina site was added in May 2009 to further understand the potential transport of toxics across Commencement Bay from the TCB site. 

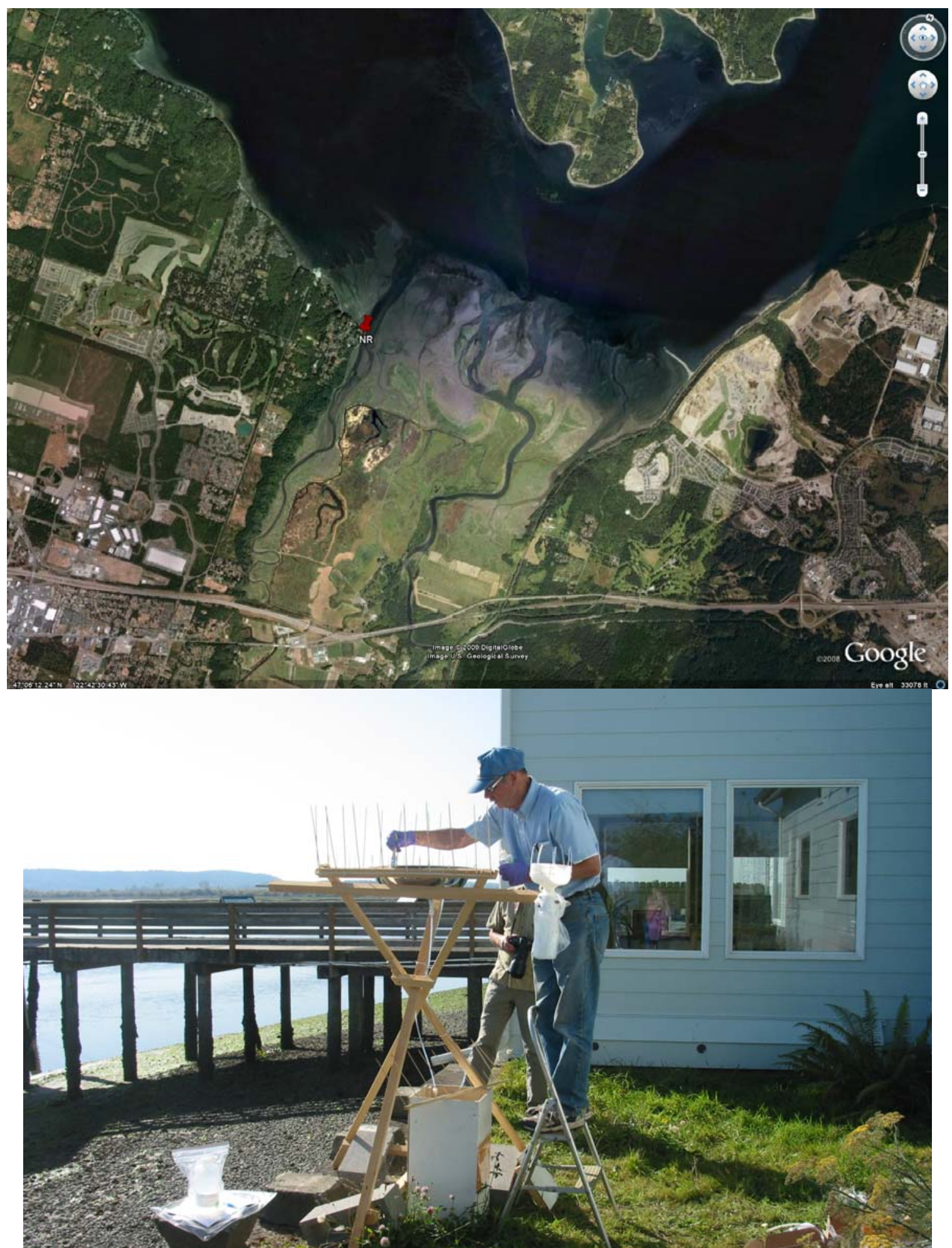

Figure 8. Nisqually River site located in south Puget Sound.

The average annual rainfall at the sampling locations in Puget Sound ranges from less than 20 inches in Sequim to over 60 inches near Port Orchard and Hood Canal stations. The average annual precipitation from 1995-2007 near each of the stations is shown in 
Figure 9. This illustrates the annual variability for each of the locations compared to the total precipitation during the year one sampling from September 2008 through June 2009. The total precipitation during this sampling period was generally representative of the average annual precipitation with a relative percent difference of $<10 \%$ for all stations except West Point, Port Orchard, and Hood Canal which were about 30\% below average annual rainfall amounts during the year one sampling.

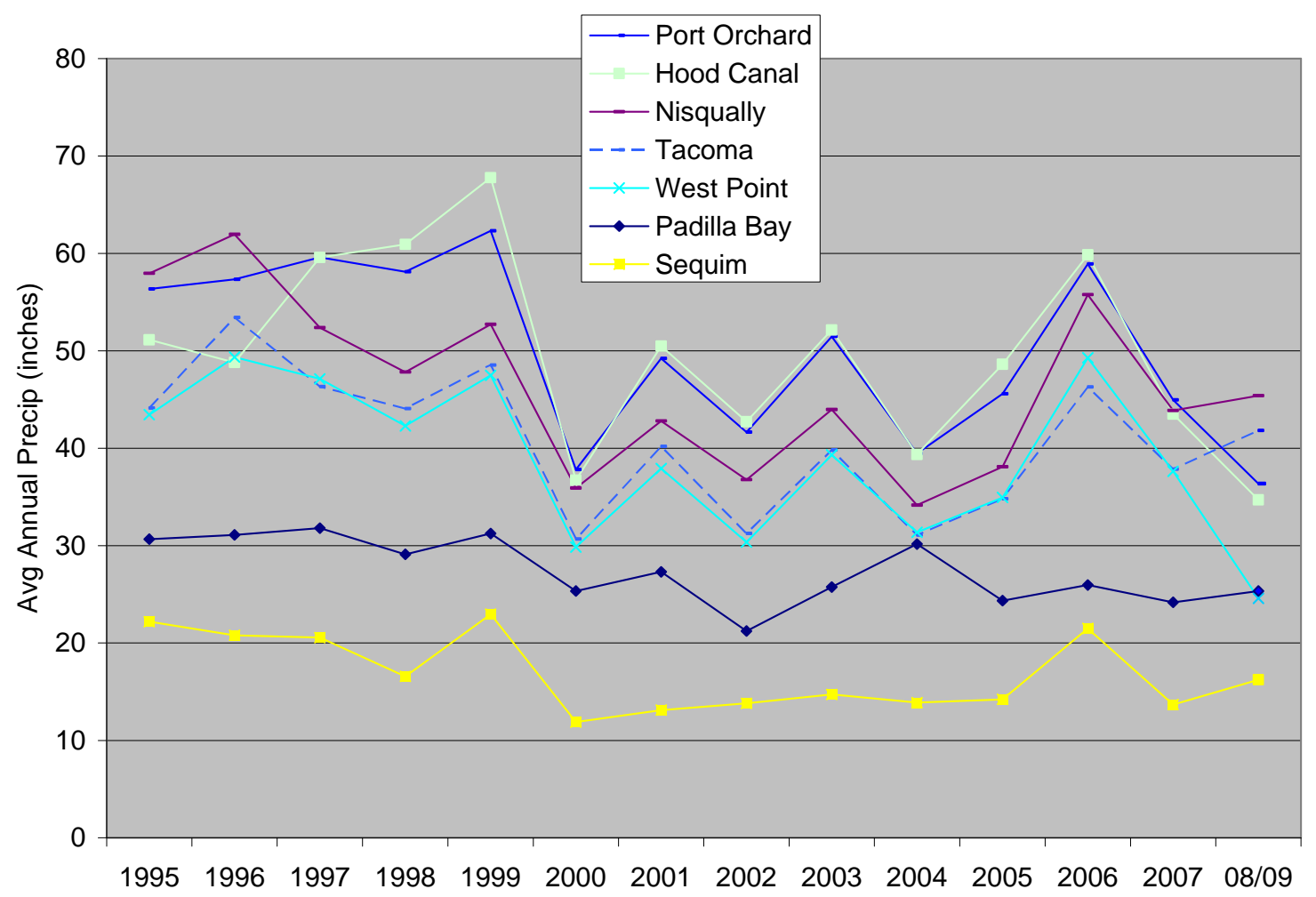

Figure 9. Average annual total precipitation (inches) for Puget Sound from 1995-2007 and during the 08/09 project sampling period (used June 4, 2008 through June 5, 2009 for full year record). Historical data provided by PRISM Climate Group, Oregon State University, http://www.prismclimate.org, created June 2008. The 08/09 sampling data was provided by the Community Collaborative Rain, Hail, and Snow Network (CoCoRaHS), National Oceanic and Atmospheric Administration, http://www.cocorahs.org, created June 2009.

\subsection{Field Sampling Methods}

Year 1 atmospheric deposition samples were collected from August 28, 2008 through June 5, 2009 at seven core sites, one roaming duplicate station, and one additional site added in May 2009. The duplicate was deployed for at least two events at the Sequim Bay, Port Orchard, Hood Canal, Tacoma Commencement Bay, and Nisqually River stations. Table 3 summarizes the sampling information for year one of this project.

The field equipment was designed to passively collect bulk atmospheric deposition without requiring electrical power or frequent attention. Deposition collectors were placed approximately 6 feet off the ground on a framework constructed from untreated wood in a tripod design. The framework held separate sample collection apparatus for 
organic and trace metal collections. The organics samples were collected in a $45 \mathrm{~cm}$ diameter stainless steel funnel. The trace metal samplers were mounted on two aluminum bars drilled into one side of the wooden tripod and held in place with stainless steel clamps (Figure 10). Multiple non-metallic funnel sizes were required for collection of trace metals that were varied depending upon the average rainfall at the site during the sampling period. The diameters of the funnels were 9.0, 11.5, or $14.8 \mathrm{~cm}$. See Appendix $\mathrm{C}$ and $\mathrm{D}$ for the surface area of the funnel used for each sample.

A chain of custody (COC) was filled out and held on file at the Marine Sciences Laboratory (MSL) for each event and field team. The COC contained, at a minimum, the site ID, unique sample ID for each container (i.e. capsule, metals, $\mathrm{MMHg}$, etc.), parameters requested, date of deployment and recovery, volume of rinse water for the metals, volume of water extracted by the capsule, field anomalies, or unusual weather conditions over the sampling period. The field work was divided into two teams: 1) King County Environmental Laboratory maintained PB, WP, TCB, and NR sites and 2) MSL maintained $\mathrm{PO}, \mathrm{SB}$, and $\mathrm{HC}$. Each laboratory maintains a quality assurance and quality control program (QA/QC) and the COCs were reviewed by the MSL QA/QC program. All QA/QC procedures, such as equipment blanks and field duplicates are discussed in Section 6.0.

Table 3. Sampling dates for each of the fourteen events sampled with days deployed, rain collected at the site, regional precipitation guage data reported by the Community Collaborative Rain, Hail, and Snow Network (CoCoRaHS) and sampling events where a duplicate station (DUP) was deployed at that site. The Tyee Marina was a new site added in May 2009 with only one sampling event.

\begin{tabular}{|c|c|c|c|c|c|c|c|}
\hline Site ID & $\begin{array}{l}\text { Event } \\
\text { No. } \\
\end{array}$ & $\begin{array}{l}\text { Deploy } \\
\text { Date }\end{array}$ & $\begin{array}{l}\text { Recover } \\
\text { Date }\end{array}$ & $\begin{array}{l}\text { Days } \\
\text { Sampled }\end{array}$ & $\begin{array}{l}\text { Rain } \\
\text { Collected } \\
\text { (inches) }\end{array}$ & $\begin{array}{l}\text { Precip. } \\
\text { Guage } \\
\text { (inches) }\end{array}$ & DUP \\
\hline PB & 1 & $8 / 28 / 08$ & $9 / 12 / 08$ & 15 & 0.23 & 0.13 & \\
\hline PB & 2 & $9 / 12 / 08$ & $9 / 25 / 08$ & 13 & 0.70 & 0.53 & \\
\hline PB & 3 & $9 / 25 / 08$ & $10 / 15 / 08$ & 20 & 0.89 & 0.73 & \\
\hline PB & 4 & $10 / 15 / 08$ & $10 / 29 / 08$ & 14 & 0.28 & 0.06 & \\
\hline PB & 5 & $10 / 29 / 08$ & $11 / 13 / 08$ & 15 & $3.88^{*}$ & 4.99 & \\
\hline PB & 6 & $11 / 13 / 08$ & $11 / 25 / 08$ & 12 & 0.28 & 0.39 & \\
\hline PB & 7 & $11 / 25 / 08$ & $12 / 11 / 08$ & 16 & 1.55 & 1.51 & \\
\hline PB & 8 & $2 / 26 / 09$ & $3 / 11 / 09$ & 13 & 0.47 & 1.26 & \\
\hline PB & 9 & $3 / 11 / 09$ & $3 / 25 / 09$ & 14 & 1.17 & 0.62 & \\
\hline PB & 10 & $3 / 25 / 09$ & $4 / 8 / 09$ & 14 & 1.49 & 1.85 & \\
\hline PB & 11 & $4 / 8 / 09$ & 4/23/09 & 15 & 0.99 & 1.16 & \\
\hline PB & 12 & $4 / 23 / 09$ & $5 / 6 / 09$ & 13 & 0.62 & 0.47 & \\
\hline PB & 13 & $5 / 6 / 09$ & $5 / 21 / 09$ & 15 & 2.31 & 2.24 & \\
\hline PB & 14 & $5 / 21 / 09$ & $6 / 3 / 09$ & 13 & 0.11 & 0.03 & \\
\hline SB & 1 & $9 / 2 / 08$ & $9 / 18 / 08$ & 16 & 0.01 & 0.00 & $X$ \\
\hline SB & 2 & $9 / 18 / 08$ & $10 / 2 / 08$ & 14 & 0.32 & 0.22 & $\mathrm{X}$ \\
\hline SB & 3 & $10 / 2 / 08$ & $10 / 15 / 08$ & 13 & 0.27 & 0.32 & \\
\hline SB & 4 & $10 / 15 / 08$ & $10 / 30 / 08$ & 15 & 0.35 & 0.29 & \\
\hline SB & 5 & $10 / 30 / 08$ & $11 / 7 / 08$ & 8 & 2.29 & 2.60 & \\
\hline SB & 6 & $11 / 10 / 08$ & $11 / 25 / 08$ & 15 & 0.70 & 1.06 & \\
\hline SB & 7 & $11 / 25 / 08$ & $12 / 11 / 08$ & 16 & 0.37 & 0.72 & \\
\hline
\end{tabular}


2008-09 Atmospheric Deposition Data Report

\begin{tabular}{|c|c|c|c|c|c|c|c|}
\hline Site ID & $\begin{array}{l}\text { Event } \\
\text { No. }\end{array}$ & $\begin{array}{l}\text { Deploy } \\
\text { Date } \\
\end{array}$ & $\begin{array}{l}\text { Recover } \\
\text { Date }\end{array}$ & $\begin{array}{l}\text { Days } \\
\text { Sampled }\end{array}$ & $\begin{array}{l}\text { Rain } \\
\text { Collected } \\
\text { (inches) }\end{array}$ & $\begin{array}{l}\text { Precip. } \\
\text { Guage } \\
\text { (inches) }\end{array}$ & DUP \\
\hline SB & 8 & $2 / 25 / 09$ & $3 / 12 / 09$ & 15 & 1.06 & 1.61 & \\
\hline SB & 9 & $3 / 12 / 09$ & $3 / 29 / 09$ & 17 & 1.40 & 1.28 & \\
\hline SB & 10 & $3 / 29 / 09$ & $4 / 13 / 09$ & 15 & 0.83 & 1.40 & \\
\hline SB & 11 & 4/13/09 & $4 / 28 / 09$ & 15 & 0.20 & 0.41 & \\
\hline SB & 12 & $4 / 28 / 09$ & $5 / 11 / 09$ & 13 & 0.51 & 0.69 & \\
\hline SB & 13 & $5 / 11 / 09$ & $5 / 27 / 09$ & 16 & 1.66 & 0.66 & \\
\hline SB & 14 & $5 / 27 / 09$ & $6 / 8 / 09$ & 12 & 0.00 & 0.00 & \\
\hline WP & 1 & $8 / 28 / 08$ & $9 / 12 / 08$ & 15 & 0.00 & 0.00 & \\
\hline WP & 2 & $9 / 12 / 08$ & $9 / 25 / 08$ & 13 & 0.59 & 0.62 & \\
\hline WP & 3 & $9 / 25 / 08$ & $10 / 14 / 08$ & 19 & 1.28 & 0.58 & \\
\hline WP & 4 & $10 / 14 / 08$ & $10 / 29 / 08$ & 15 & 0.31 & 0.65 & \\
\hline WP & 5 & $10 / 29 / 08$ & $11 / 13 / 08$ & 15 & $3.81 *$ & 4.16 & \\
\hline WP & 6 & $11 / 13 / 08$ & $11 / 25 / 08$ & 12 & 0.30 & 0.44 & \\
\hline WP & 7 & $11 / 25 / 08$ & $12 / 11 / 08$ & 16 & 0.56 & 1.06 & \\
\hline WP & 8 & $2 / 26 / 09$ & $3 / 11 / 09$ & 13 & 1.12 & 1.50 & \\
\hline WP & 9 & $3 / 11 / 09$ & $3 / 25 / 09$ & 14 & 1.92 & 1.60 & \\
\hline WP & 10 & $3 / 25 / 09$ & 4/8/09 & 14 & 1.53 & 1.80 & \\
\hline WP & 11 & 4/8/09 & $4 / 23 / 09$ & 15 & 0.98 & 1.00 & \\
\hline WP & 12 & $4 / 23 / 09$ & $5 / 6 / 09$ & 13 & 2.79 & 2.46 & \\
\hline WP & 13 & $5 / 6 / 09$ & $5 / 21 / 09$ & 15 & 2.03 & 2.78 & \\
\hline WP & 14 & $5 / 21 / 09$ & $6 / 3 / 09$ & 13 & 0.00 & 0.00 & \\
\hline $\mathrm{PO}$ & 1 & 9/3/08 & $9 / 17 / 08$ & 14 & 0.00 & 0.00 & \\
\hline PO & 2 & $9 / 17 / 08$ & $10 / 6 / 08$ & 19 & 1.51 & 1.66 & \\
\hline PO & 3 & $10 / 6 / 08$ & $10 / 16 / 08$ & 10 & 0.35 & 0.71 & $\mathrm{X}$ \\
\hline PO & 4 & $10 / 16 / 08$ & $10 / 29 / 08$ & 13 & 0.15 & 0.49 & $X$ \\
\hline PO & 5 & $10 / 29 / 08$ & $11 / 7 / 08$ & 9 & $3.87^{*}$ & 5.90 & \\
\hline PO & 6 & $11 / 7 / 08$ & $11 / 20 / 08$ & 13 & 1.19 & 4.65 & \\
\hline PO & 7 & $11 / 20 / 08$ & $12 / 11 / 08$ & 21 & 0.49 & 0.91 & \\
\hline PO & 8 & 2/26/09 & $3 / 12 / 09$ & 14 & 1.02 & 1.40 & \\
\hline PO & 9 & $3 / 12 / 09$ & $3 / 25 / 09$ & 13 & 1.92 & 2.07 & \\
\hline PO & 10 & $3 / 25 / 09$ & 4/8/09 & 14 & 1.52 & 1.88 & \\
\hline PO & 11 & 4/8/09 & $4 / 22 / 09$ & 14 & 1.27 & 1.58 & \\
\hline PO & 12 & $4 / 22 / 09$ & $5 / 5 / 09$ & 13 & 2.85 & 2.92 & \\
\hline PO & 13 & $5 / 5 / 09$ & $5 / 20 / 09$ & 15 & 2.22 & 5.24 & \\
\hline $\mathrm{PO}$ & 14 & $5 / 20 / 09$ & $6 / 5 / 09$ & 16 & 0.00 & 0.40 & \\
\hline $\mathrm{HC}$ & 1 & $9 / 3 / 08$ & $9 / 17 / 08$ & 14 & 0.00 & 0.00 & \\
\hline $\mathrm{HC}$ & 2 & $9 / 17 / 08$ & $10 / 6 / 08$ & 19 & 1.97 & 2.09 & \\
\hline $\mathrm{HC}$ & 3 & $10 / 6 / 08$ & $10 / 16 / 08$ & 10 & 0.80 & 0.85 & \\
\hline $\mathrm{HC}$ & 4 & $10 / 16 / 08$ & $10 / 29 / 08$ & 13 & 0.16 & 0.42 & \\
\hline $\mathrm{HC}$ & 5 & $10 / 29 / 08$ & $11 / 8 / 08$ & 10 & $3.87^{*}$ & 5.07 & $\mathrm{X}$ \\
\hline $\mathrm{HC}$ & 6 & $11 / 8 / 08$ & $11 / 20 / 08$ & 12 & 1.69 & 3.40 & $X$ \\
\hline $\mathrm{HC}$ & 7 & $11 / 20 / 08$ & $12 / 11 / 08$ & 21 & 0.98 & 1.09 & $\mathrm{X}$ \\
\hline $\mathrm{HC}$ & 8 & $2 / 26 / 09$ & $3 / 12 / 09$ & 14 & 1.38 & 1.63 & \\
\hline $\mathrm{HC}$ & 9 & $3 / 12 / 09$ & $3 / 25 / 09$ & 13 & 2.53 & 3.16 & \\
\hline
\end{tabular}


2008-09 Atmospheric Deposition Data Report

\begin{tabular}{|c|c|c|c|c|c|c|c|}
\hline Site ID & $\begin{array}{l}\text { Event } \\
\text { No. }\end{array}$ & $\begin{array}{l}\text { Deploy } \\
\text { Date }\end{array}$ & $\begin{array}{l}\text { Recover } \\
\text { Date }\end{array}$ & $\begin{array}{l}\text { Days } \\
\text { Sampled } \\
\end{array}$ & $\begin{array}{l}\text { Rain } \\
\text { Collected } \\
\text { (inches) }\end{array}$ & $\begin{array}{l}\text { Precip. } \\
\text { Guage } \\
\text { (inches) }\end{array}$ & DUP \\
\hline $\mathrm{HC}$ & 10 & $3 / 25 / 09$ & $4 / 8 / 09$ & 14 & 0.91 & 1.19 & \\
\hline $\mathrm{HC}$ & 11 & $4 / 8 / 09$ & $4 / 22 / 09$ & 14 & 1.77 & 2.11 & \\
\hline $\mathrm{HC}$ & 12 & $4 / 22 / 09$ & $5 / 5 / 09$ & 13 & 2.70 & 1.78 & \\
\hline $\mathrm{HC}$ & 13 & $5 / 5 / 09$ & $5 / 20 / 09$ & 15 & 2.39 & 4.29 & \\
\hline $\mathrm{HC}$ & 14 & $5 / 20 / 09$ & $6 / 5 / 09$ & 16 & 0.00 & 0.20 & \\
\hline TCB & 1 & $8 / 29 / 08$ & $9 / 12 / 08$ & 14 & 0.00 & 0.00 & \\
\hline TCB & 2 & $9 / 12 / 08$ & $9 / 24 / 08$ & 12 & 0.29 & 0.34 & \\
\hline $\mathrm{TCB}$ & 3 & $9 / 24 / 08$ & $10 / 15 / 08$ & 21 & 1.37 & 1.81 & \\
\hline TCB & 4 & $10 / 15 / 08$ & $10 / 30 / 08$ & 15 & 0.69 & 0.61 & \\
\hline TCB & 5 & $10 / 30 / 08$ & $11 / 12 / 08$ & 13 & $3.87^{*}$ & 7.81 & \\
\hline TCB & 6 & $11 / 12 / 08$ & $11 / 24 / 08$ & 12 & 0.58 & 2.07 & \\
\hline TCB & 7 & $11 / 24 / 08$ & $12 / 11 / 08$ & 17 & 0.37 & 0.05 & \\
\hline TCB & 8 & $2 / 25 / 09$ & $3 / 12 / 09$ & 15 & 1.35 & 2.19 & $\mathrm{X}$ \\
\hline TCB & 9 & $3 / 12 / 09$ & $3 / 25 / 09$ & 13 & 2.73 & 3.30 & $\mathrm{X}$ \\
\hline TCB & 10 & $3 / 25 / 09$ & $4 / 8 / 09$ & 14 & 1.65 & 1.71 & \\
\hline TCB & 11 & $4 / 8 / 09$ & $4 / 22 / 09$ & 14 & 1.81 & 1.79 & \\
\hline TCB & 12 & $4 / 22 / 09$ & $5 / 7 / 09$ & 15 & 3.21 & 3.71 & \\
\hline $\mathrm{TCB}$ & 13 & $5 / 7 / 09$ & $5 / 21 / 09$ & 14 & 1.21 & 2.63 & \\
\hline $\mathrm{TCB}$ & 14 & $5 / 21 / 09$ & $6 / 4 / 09$ & 14 & 0.00 & 0.00 & \\
\hline NR & 1 & $8 / 29 / 08$ & $9 / 12 / 08$ & 14 & 0.00 & 0.06 & \\
\hline NR & 2 & $9 / 12 / 08$ & $9 / 24 / 08$ & 12 & 0.30 & 0.15 & \\
\hline NR & 3 & $9 / 24 / 08$ & $10 / 15 / 08$ & 21 & 2.29 & 2.57 & \\
\hline NR & 4 & $10 / 15 / 08$ & $10 / 30 / 08$ & 15 & 0.54 & 0.51 & \\
\hline NR & 5 & $10 / 30 / 08$ & $11 / 12 / 08$ & 13 & $3.93 *$ & 9.50 & \\
\hline NR & 6 & $11 / 12 / 08$ & $11 / 24 / 08$ & 12 & 0.79 & 2.70 & \\
\hline NR & 7 & $11 / 24 / 08$ & $12 / 11 / 08$ & 17 & 0.32 & 0.02 & \\
\hline NR & 8 & $2 / 25 / 09$ & $3 / 12 / 09$ & 15 & 1.33 & 2.09 & \\
\hline NR & 9 & $3 / 12 / 09$ & $3 / 25 / 09$ & 13 & 2.98 & 3.21 & \\
\hline NR & 10 & $3 / 25 / 09$ & $4 / 8 / 09$ & 14 & 1.44 & 1.81 & $X$ \\
\hline NR & 11 & $4 / 8 / 09$ & 4/22/09 & 14 & 1.77 & 2.04 & $\mathrm{X}$ \\
\hline NR & 12 & $4 / 22 / 09$ & $5 / 7 / 09$ & 15 & 3.60 & 3.95 & $X$ \\
\hline NR & 13 & $5 / 7 / 09$ & $5 / 21 / 09$ & 14 & 1.42 & 1.45 & \\
\hline NR & 14 & $5 / 21 / 09$ & $6 / 4 / 09$ & 14 & 0.00 & 0.01 & \\
\hline $\mathrm{TM}$ & 1 & $5 / 20 / 09$ & $6 / 4 / 09$ & 15 & 0.00 & 0.00 & \\
\hline
\end{tabular}




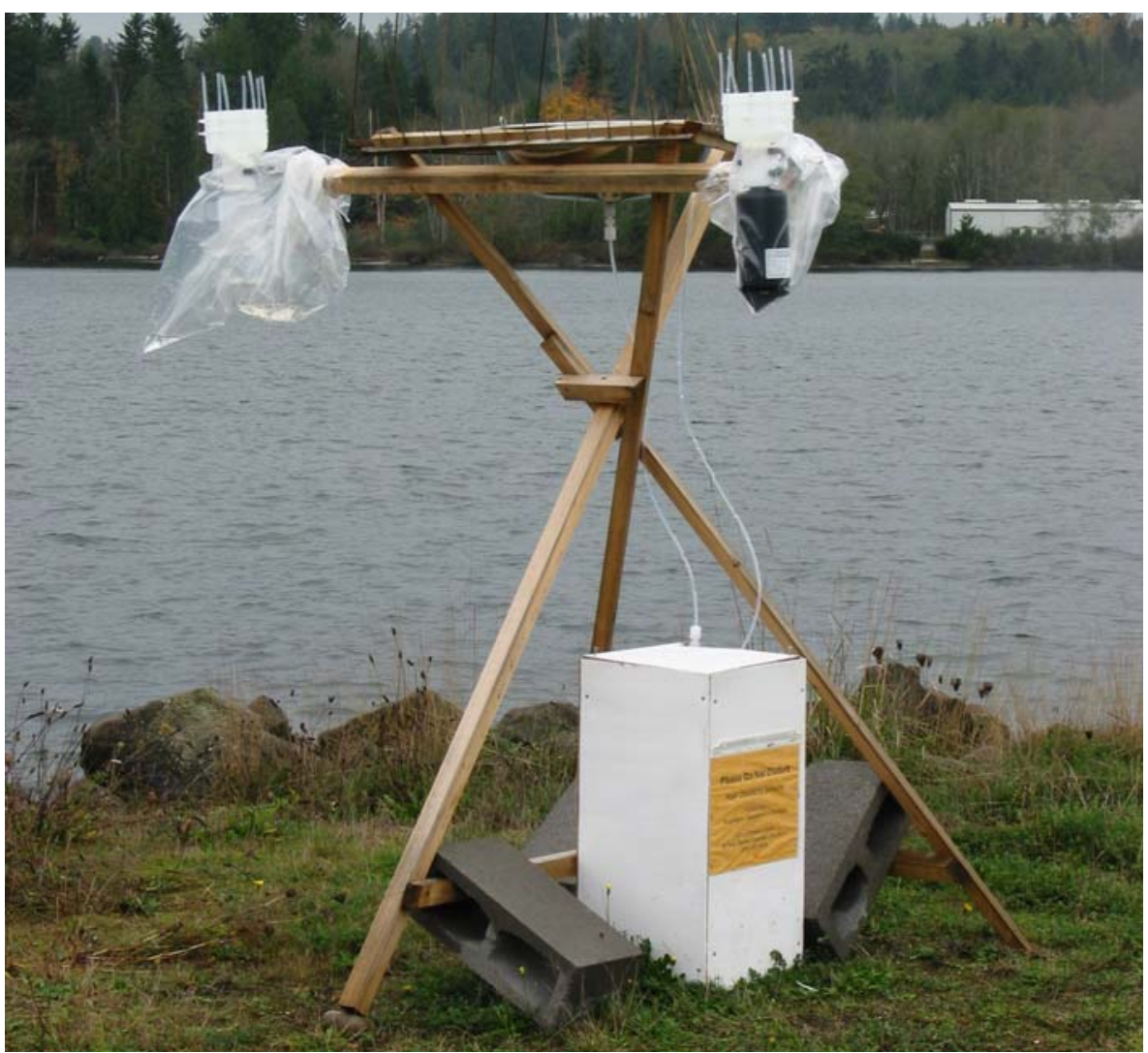

Figure 10. Bulk atmospheric deposition collector with stainless steel funnel in the center draining down into the wood box for organic parameters, clear Teflon ${ }^{\circledR} 1 \mathrm{~L}$ bottles for trace elements (left arm), and opaque Teflon ${ }^{\circledR} 1 \mathrm{~L}$ bottles for mercury speciation (right arm).

\subsection{PAHs, Anhydrosugars, and PBDEs}

Atmospheric deposition samples for PAHs, anhydrosugars, and PBDEs were collected using a stainless steel funnel with a diameter of $45 \mathrm{~cm}$ and surface area of $0.159 \mathrm{~m}^{2}$. Wet deposition and dry deposition (rinsed from the funnel by deionized water) gravity feeds down a length of Teflon ${ }^{\circledR}$ tubing into a Teflon ${ }^{\circledR}$ filter cartridge capsule housed inside a wooden box. The samples were shielded from light exposure to prevent photo-oxidation. The transfer tubing was equipped with a vent line made of Teflon $\AA$ and fitted with a Teflon ${ }^{\circledR}$ screen at the height of the funnel top (Figure 10). The deposition water was "extracted" onsite at a rate of $\sim 3 \mathrm{~mL}$ per minute through a series of three glass fiber filters (GFF) separating two different types of Empore ${ }^{\circledR}$ extraction disks with different sorbent materials. The first extraction was with an Empore ${ }^{\circledR}$ SDB-RPS disk which is a poly(styrenedivinylbenzene) copolymer that has been modified with sulfonic acid groups to make it hydrophilic. The second disk was the Empore ${ }^{\circledR} \mathrm{C} 18$, which has an octadecyl functional group bonded to a silica surface to provide non polar interaction sites. The extraction scheme is illustrated in Figure 11 along with the PAH, anhydrosugar, and PBDE flow diagram for the collection and sample extraction process. This sampling method was adapted from that used by the Chesapeake Bay program (Baker et al. 1992).

Large wooden "skewers" jutted up from the sampling frame to deter birds from landing on the sampling apparatus. One side of this "crown of thorns" was designed to be 
removed during sample recovery allowing access to the funnel for washing of dry deposition into the capsule prior to recovery. A natural hair paint brush pre-cleaned with methanol prior to each recovery was use to scrub particles from the inside of the funnel. The funnel surface was washed with deionized water (DI) using a pre-cleaned Teflon ${ }^{\circledR}$ squirt bottle and the brush. The outlet of the extraction capsule was fitted with another piece of Teflon ${ }^{\circledR}$ tubing that drained into a calibrated reservoir to provide a volume of water extracted. When recovering the capsule, the Teflon ${ }^{\circledR}$ tubing was used to create a closed system to prevent further extraction of air during transit back to the laboratory. A Teflon ${ }^{\circledR}$ plug was used to seal the vent tubing connector and the entire capsule was bagged and stored in a cooler at $4 \pm 2{ }^{\circ} \mathrm{C}$. Samples were transported to MSL where the capsules were opened, all GFF and extract disks were removed using stainless steel tweezers, and samples were stored in a pre-cleaned 2 oz. glass jar at $-80 \pm 1{ }^{\circ} \mathrm{C}$. Samples were shipped to Texas A\&M University for extraction of all organic compounds and the analysis of PAHs and biomarkers. 


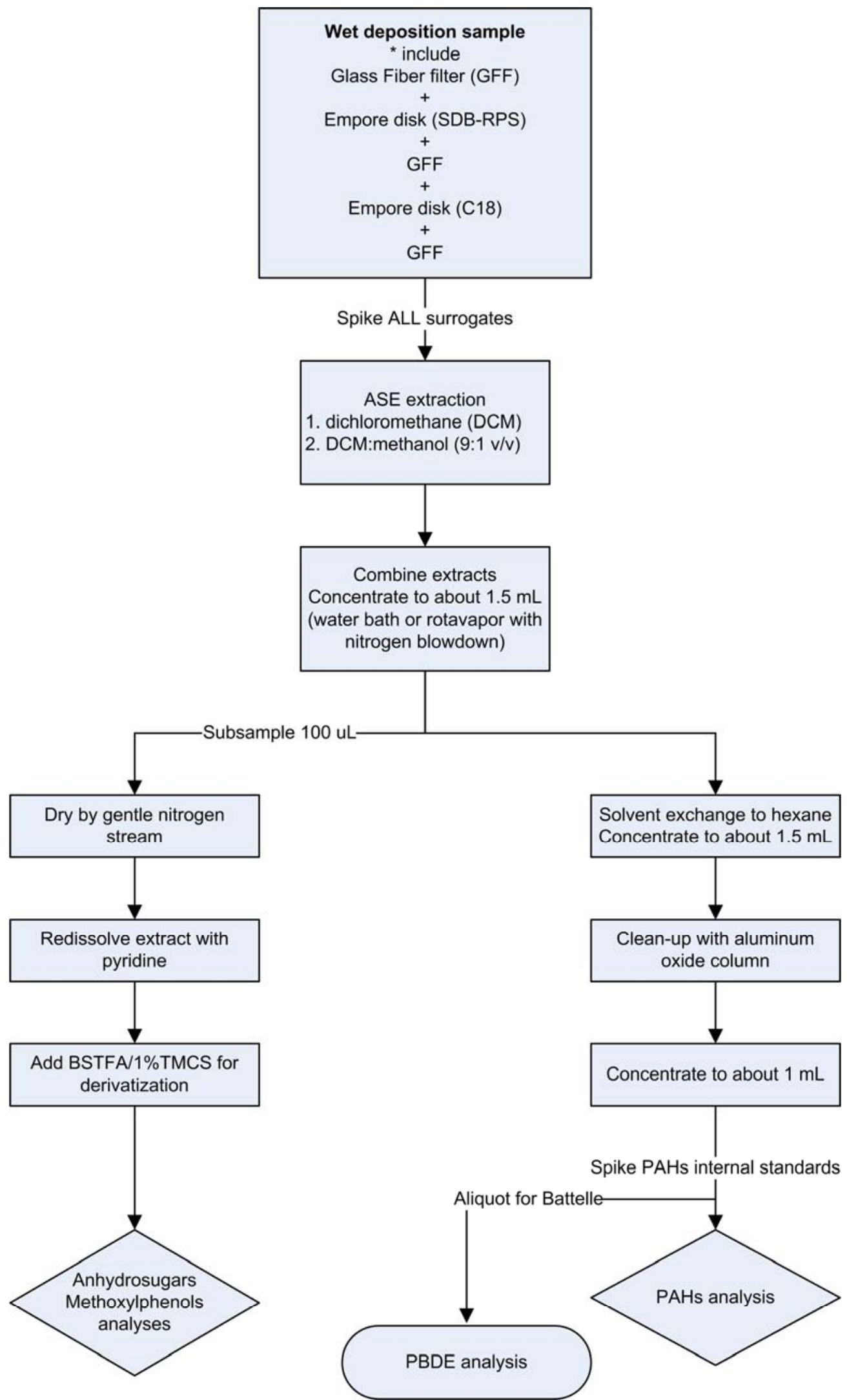

Figure 11. Flow diagram for on-site, field extraction of bulk deposition and subsequent laboratory sample extractions for PAHs, anhydrosugars, and PBDEs. 


\subsection{Trace Elements}

Atmospheric deposition samples for trace element measurements were collected using a "bulk deposition" sampler, following procedures similar to those described in Landing et al. (1998) and Guentzel et al. (1998, 2001). The sampler consists of three components: an upward facing funnel made of fluorocarbon high density polyethylene (F-HDPE), a Teflon ${ }^{\circledR}$ collar, and a $1 \mathrm{~L}$ Teflon ${ }^{\circledR}$ sample bottle. Opaque (black) Teflon ${ }^{\circledR}$ bottles were used for sample collections in which MMHg was to be determined to prevent photodegradation of $\mathrm{MMHg}$. Clear Teflon ${ }^{\circledR}$ bottles were used for all other total trace element collections. A "crown of thorns" made from Teflon ${ }^{\circledR}$ tubing was attached to the outside rim of the funnel to deter birds from sitting on the funnel rim. The Teflon ${ }^{\circledR}$ collar mates the funnel to the Teflon ${ }^{\circledR}$ sample bottle and was manufactured from a solid block of PTFE Teflon ${ }^{\circledR}$. Threads were cut into two sides of the Teflon ${ }^{\circledR}$ block to allow the funnel and sample bottle to be secured into the Teflon ${ }^{\circledR}$ block. An air port was necessary on the side of the collar to allow air inside the sample bottle to escape as rainfall enters. The bulk deposition sampler was held in place with a new stainless steel three finger clamp and attached to the wooden tripod. The clamp and bottle were covered with a plastic bag to prevent back splash contamination from the stainless steel clamps. The size of the funnel for all trace elements depended on the annual precipitation patterns at the specific site. Three sizes of funnels were deployed during year one. They were identified as $4 \mathrm{~L}, 2 \mathrm{~L}$, and $1 \mathrm{~L}$ funnels (noted on COC) with a surface area of $0.0172 \mathrm{~m}^{2}, 0.0104 \mathrm{~m}^{2}$, and $0.00636 \mathrm{~m}^{2}$, respectively. The surface areas of the funnel used for each sample were provided in the appendices.

All equipment (funnels, thorns, bottles, etc.) were rigorously cleaned with laboratory detergent (Micro) and soaked in nitric acid for at least three days. Teflon ${ }^{\circledR}$ equipment was soaked in hot concentrated nitric acid followed by a hydrochloric acid soak at $65^{\circ} \mathrm{C}$. Each cleaning step was followed by a thorough rinsing with 18 megaohm high purity DI water and dried in a class-100 clean-air bench. All equipment was double bagged in polyethylene bags and handled using gloved hands and the "clean hands - dirty hands" sampling approach detailed by the EPA 1600 series methods. The clear Teflon ${ }^{\circledR}$ bottles were used to collect samples for arsenic (As), cadmium (Cd), chromium (Cr), copper $(\mathrm{Cu})$, nickel $(\mathrm{Ni})$, lead $(\mathrm{Pb})$, zinc $(\mathrm{Zn})$, and $\mathrm{THg}$ analysis and were pre-acidified with 2 $\mathrm{mL}$ of $50 \%$ double distilled nitric acid $\left(\mathrm{HNO}_{3}\right)$ to prevent adsorption of trace elements onto the bottle walls. The opaque bottles were used for a duplicate of the THg and $\mathrm{MMHg}$ and were pre-acidified with $2 \mathrm{~mL}$ of $10 \%$ hydrochloric acid for preserving the $\mathrm{THg}$ and $\mathrm{MMHg}$ collections.

After approximately a two week integrated sampling period, the samplers were recovered using the EPA Method 1669 protocol for trace element sampling. Non-powder latex or nitrile gloves were used throughout the recovery process. The funnel surface was rinsed with DI water to remove any particles not washed into the funnel during the deployment. A calibrated $10 \mathrm{~mL}$ pipette was used to deliver each volume of DI water and the total rinse volume was recorded on the COC. The deployed 1L Teflon ${ }^{\circledR}$ bottle was unscrewed from the funnel and collar, re-capped, and stored double bagged in a cooler. The $\mathrm{pH}$ of 
each sample was checked and adjusted with additional acid (if necessary) to be $<2.0$ or approximately $0.2 \%$ nitric acid for the trace elements and $0.5 \%$ hydrochloric acid for the $\mathrm{THg}$ and $\mathrm{MMHg}$ samples. Anomolies, such as bird droppings in the funnel or missing equipment, were recorded on the COC.

\subsection{Analytical Methods and Quality Control}

The extraction and analyses for PAHs and biomarkers were conducted at Texas A\&M University, Galveston, TX and College Station, TX. This report and Appendix A summarize the data for events 1 through 12. The last two events (13 and 14) have been extracted and the data will be included in the final report. Splits of each extract were shipped to MSL for PBDE analyses. This report and Appendix B summarize the PBDE data for events 1 through 12 . Events 13 and 14 will be included in the final report. Finally, this report and Appendices C and D summarize the trace elements and mercury speciation, respectively, analyzed at MSL. All 14 events collected during year one are included in this report.

\subsection{PAHs and Anhydrosugars}

The GFF and extraction disks recovered from the field capsules were lyophilized prior to extraction. This process was conducted at both Texas A\&M and MSL, which is discussed in detail below. The dried samples were then spiked with multiple perdeuterated surrogate standards or artificial internal standards according to established methods (Fraser and Lakshmanan 2000; Usenko et al., 2005; Kuo et al. 2008). The samples were spiked with $d_{7}$-levoglucosan (NIST SRM 2267) for anhydrosugar analyses, five perdeuterated standards ( $d_{8}$-naphthalene, $d_{10}$-acenaphthene, $d_{10}$-phenanthrene, $d_{12}$ chrysene, and $d_{12}$-perylene) for the PAH analyses, and a mixture of chlorinated and brominated surrogates (PCB 103, PCB 198, Hexabromobiphenyl) for the PBDE analyses. The two solid phase extraction (SPE) disks and three GFF's in each sample were extracted via pressurized fluid extraction (PFE) with an accelerated solvent extractor (ASE) (Dionex ASE-200) at $10.3 \mathrm{MPa}$ and $100^{\circ} \mathrm{C}$. The samples were then extracted sequentially, first with dichloromethane (DCM) to extract hydrophobic constituents (PAHs and PBDE) and then using a more polar solvent mixture (DCM:MeOH: 9:1, v/v) to extract anhydrosugars (Figure 11).

The dichloromethane extracts (for PAH analyses) were reduced in volume to 1-2 $\mathrm{mL}$ and solvent exchanged to hexane using a water bath. The concentrated extracts were cleaned up by using aluminum oxide columns. The eluent was then concentrated to $1 \mathrm{~mL}$ and stored until gas chromatography mass spectrometry (GC/MS) analysis. Prior to injection, $50 \mu \mathrm{L}$ of a PAH internal standard solution $\left(d_{10}\right.$-Fluorene and $d_{12}$-Benzo(a)pyrene) was added to assess the analytical recoveries along with the extraction surrogates. The dichloromethane: methanol extracts (anhydrosugars) were evaporated to dryness using a LabConco $^{\mathrm{TM}}$ solvent concentrator. Samples were then redissolved in $500 \mu \mathrm{L}$ pyridine. An aliquot $(75 \mu \mathrm{L})$ was transferred to a glass vial and combined with $75 \mu \mathrm{L}$ of N,Obis(trimethylsilyl)trifluoroacetamide (BSTFA) containing 1\% trimethylchlorosilane (TMCS; Supelco, PA, USA). The sample was derivatized by heating at $75^{\circ} \mathrm{C}$ for $1 \mathrm{~h}$ in a heating block. After derivatization, $50 \mu \mathrm{L}$ of tri-isopropylbenzene (Aldrich, MO, USA) 
was added to serve as a GC-internal standard for calculation of $d_{7}$-levoglucosan recovery (Simpson et al. 2004).

The samples were analyzed using GC/MS with a Varian Ion Trap 3800/4000 system fitted with a fused silica column (VF 5MS, $30 \mathrm{~m}$ x $0.25 \mathrm{~mm}$ i.d.; Varian Inc.). Each sample was injected, under splitless mode, into a straight glass liner inserted into the GC injection port; helium was used as the carrier gas $(1.0 \mathrm{~mL} / \mathrm{min}$. $)$. The $\mathrm{GC}$ oven was programmed from $65^{\circ} \mathrm{C}\left(2 \mathrm{~min}\right.$. isothermal) to $300^{\circ} \mathrm{C}\left(5 \mathrm{~min}\right.$ isothermal) at $6^{\circ} \mathrm{C} / \mathrm{min}$ for anhydrosugar analysis, whereas for PAHs analysis, the $\mathrm{GC}$ oven was programmed from $60^{\circ} \mathrm{C}$ to $150^{\circ} \mathrm{C}$ at a temperature ramp rate $15^{\circ} \mathrm{C} / \mathrm{min}$, from $150^{\circ} \mathrm{C}$ to $220^{\circ} \mathrm{C}$ at $5^{\circ} \mathrm{C} / \mathrm{min}$, and from $220^{\circ} \mathrm{C}$ to $300^{\circ} \mathrm{C}\left(20 \mathrm{~min}\right.$ isothermal) at $10^{\circ} \mathrm{C} / \mathrm{min}$. The $\mathrm{GC}$ injector and $\mathrm{GC} / \mathrm{MS}$ interface were maintained at $280^{\circ} \mathrm{C}$ and $270^{\circ} \mathrm{C}$, respectively. The MS was operated in the electron ionization (EI, $70 \mathrm{eV}$ ) and full scan modes for anhydrosugar monitoring and selective ion storage mode for PAH monitoring. Data were acquired and processed with the Varian MS Workstation software (version 6.6). Compound identification was performed using GC retention times and by comparing mass spectra with those of commercially available standards. Quantification was performed using relative response factors obtained from the analysis of calibration solutions made with certified standards.

Initial tests demonstrated that the use of methanol reduces the recovery of the more hydrophobic hydrocarbons, such as PAHs, from Empore ${ }^{\mathrm{TM}}$ disks. Repeated extractions using two different ASE filling agents (diatomaceous earth and combusted sand) also showed lower recoveries of PAHs with combusted sand. We thus tested a sequential extraction procedure using diatomaceous earth to fill the extraction cells and in which we extracted first the hydrophobic hydrocarbons using only dichloromethane followed by a second extraction, using the dichloromethane:methanol mixture $(9: 1, \mathrm{v} / \mathrm{v})$, to extract the anhydrosugars (levoglucosan and its isomers). Recovery efficiency was tested in two ways. First, SPE disks were spiked with known amounts of levoglucosan as well as $d_{7^{-}}$ levoglucosan and extracted using the sequential extraction protocol mentioned above. Secondly, replicates of the NIST standard reference material (SRM) 1649 Organics in Urban Particulate Matter were extracted using the same sequential protocol. The first DCM extraction yielded undetectable levoglucosan levels, whereas levoglucosan recovery in the DCM:MeOH extract averaged $105 \pm 13 \%(n=3)$.

The average recoveries of the PAH surrogates were $45 \pm 9 \%, 57 \pm 10 \%, 74 \pm 8 \%, 73 \pm 8 \%$, and $80 \pm 9 \%$ for $d_{8}$-naphthalene, $d_{10}$-acenaphthene, $d_{10}$-phenanthrene, $d_{12}$-chrysene, and $d_{12}$-perylene, respectively. Analytical precision determined from repeat analyses of selected samples ( 1 or 2 for each GC/MS analysis series) ranged from 1.3 to $7.9 \%$. In addition, accuracy was assessed using the NIST SRM 1649 included in each extraction series $(n=12)$. All concentrations of individual PAHs were within $\pm 20 \%$ of the certificate value. One matrix blank of diatomaceous earth was also included in each extraction series and the signal was used to calculate the method detection limit (MDL), defined as three times the standard deviation of replicate procedural blanks $(n=9)$. The MDL, converted into units similar to those of bi-weekly fluxes, ranged $0.1-3.4 \mathrm{ng} / \mathrm{m}^{2} / \mathrm{d}$ with low molecular weight (LMW) PAHs showing the highest range $\left(0.8 \pm 1.0 \mathrm{ng} / \mathrm{m}^{2} / \mathrm{d}\right)$ and high molecular weight (HMW) PAHs showing the lowest range $\left(0.2 \pm 0.1 \mathrm{ng} / \mathrm{m}^{2} / \mathrm{d}\right)$. 
On average, the measured PAH fluxes were one to four orders of magnitude higher than the MDLs. Blank SPE samples were lyophilized, extracted, and analyzed with the samples. Except for a few cases (see discussion below), the SPE blanks yielded limited PAH levels (0.05-22 ng) with HMW PAHs being at or below the MDL.

The blank SPEs associated with four events (\#s 7-10) showed substantial contamination of LMW PAHs with values ranging 50-7500 ng. The source was traced back to the lypophilization unit at MSL, which was later discovered to have been used for sediments highly contaminated with volatile hydrocarbons. For events 1-6 and later 11-14, the samples were lyophilized at Texas A\&M. Only samples from events 7-10 were lyophilized at MSL. Upon discovery of the contamination, the lyophilization process was transferred back to Texas A\&M. Additional testes were performed on this unit to confirm there was no sample contamination. A complete lack of HMW contamination in events 710 and a strong correlation between HMW PAHs and the sum of pyrogenic PAHs in all non-contaminated series (events 1-6 and 11-12 for this report; Figure 12) provides a means to estimate the sum of pyrogenic PAHs in events 7-10 using the measured fluxes of HMW PAHs. However, for this report, only HMW PAHs are presented and discussed and all data corrections will be conducted prior to the final report and source apportionment analysis.

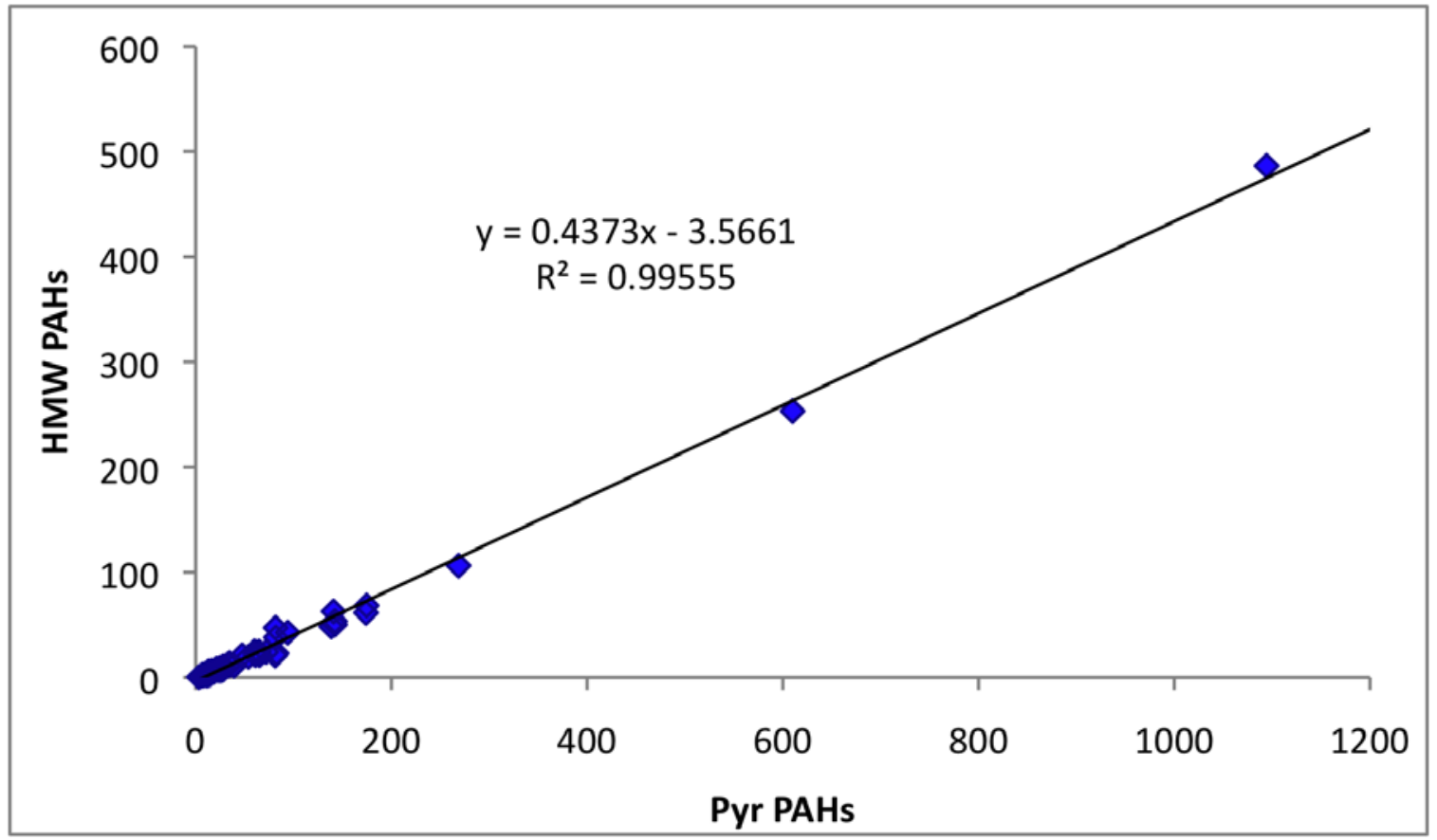

Figure 12. Relationship between pyrogenic PAHs [fluoranthene, pyrene, benzo(a)anthracene, chrysene, benzo(b)fluoranthene, benzo(k)fluoranthene, benzo(a)pyrene, indeno(1,2,3-c,d)pyrene,

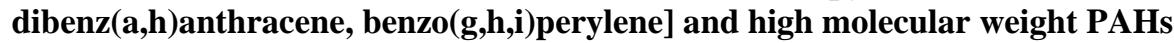
[benzo(b)fluoranthene, benzo(k)fluoranthene, benzo(a)pyrene, indeno(1,2,3-c,d)pyrene, $\operatorname{dibenz}(\mathbf{a}, \mathrm{h})$ anthracene, benzo(g,h,i)perylene].

Field duplicates had an average variability of $26 \%$ (range: $1-43 \%$ ) with highest values during periods of low PAH fluxes. The relatively low sample variability suggests that each sampling is indicative of flux conditions at the site during the sampling period. 
The average recovery of the $d_{7}$-levoglucosan surrogate was consistent throughout the entire study at $75 \pm 11 \%$. Replicate extractions of the SRM 1649 yielded an average levoglucosan concentration of $139.1 \pm 6.1 \mu \mathrm{g} / \mathrm{g}(\mathrm{n}=9)$. This value represents $\sim 85 \%$ of the previously reported levoglucosan concentration for this NIST SRM but shows a similar precision of 4-5\% (Kuo et al. 2008; Louchouarn et al. 2009). Further tests demonstrated that this $15 \%$ loss in recovery could be explained by a change in filling matrix used in the ASE cells. The diatomaceous earth sorbent used here may shield fine particles from the solvent generating lower levoglucosan yields than when combusted sand was used in prior studies (Kuo et al. 2008; Louchouarn et al. 2009). Since we sought to optimize the PAH extraction and demonstrated that the levoglucosan extraction was consistent (precision $<5 \%$ ) and quantitative (recovery of $\sim 100 \%$ in spiked SPE disks), we used diatomaceous earth as the filling matrix of choice in our extraction protocol.

Blank SPE samples were extracted and treated similarly as sample SPE. In all cases, levoglucosan was undetectable in the SPE blanks. The MDL of $20 \mathrm{ng}$, recently reported by Kuo et al. (2008), was converted to flux units using a surface area of $0.159 \mathrm{~m}^{2}$ and time of 14 days to yield $9.0 \mathrm{ng} / \mathrm{m}^{2} / \mathrm{d}$. This value was three orders of magnitude lower than the lowest levoglucosan flux measured in the present study $\left(11 \mu \mathrm{g} / \mathrm{m}^{2} / \mathrm{d}\right)$. Sample duplicates showed an average variability of 19\% (range: $6-30 \%$ ) with the highest values during periods of low levoglucosan fluxes. The relatively low sample variability suggests that each sampling is indicative of flux conditions at the site during the sampling period.

\subsection{PBDEs}

The samples for PBDE analyses were simultaneously extracted with the PAHs. A combination of chlorinated and brominated surrogates (PCB 103, PCB 198, Hexabromobiphenyl [HBB]) and internal standards were used to assess/correct the efficiencies for both the extraction and analysis methods. See Section 6.1 and Figure 11 for the extraction methodology. A split $(\sim 500 \mu 1)$ of the extract following aluminum oxide clean up was shipped to MSL for PBDE analyses. The aluminum oxide cleanup did not sufficiently remove interfering, co-extracted compounds and an additional sulfuric acid cleanup step (see review paper by Covaci et al. 2003) was conducted on the sample extracts split from Texas A\&M University. Equal amounts of the hexane sample extract and concentrated sulfuric acid were added to a screw cap GC vial, agitated for about 30 seconds, and then allowed to separate. The hexane sample extract was removed and placed into another GC autosampler vial for analysis. Prior to injection, $25 \mu \mathrm{L}$ of a PBDE internal standard solution containing octachlroronaphthalene (OCN) and tetrachlorometaxylene (TCMX) was added to assess analytical recoveries.

The PBDE analyses were performed using a GC-Electron Capture Detector (GC/ECD) with an Agilent $6890 \mathrm{GC}$, micro ECD system fitted with two fused silica columns (J+W DB-5HT and J+W DB17HT) for dual column confirmation. Each sample was injected, under splitless mode, into a straight glass liner inserted into the GC injection port; Helium was used as the carrier gas $(\sim 1.0 \mathrm{~mL} / \mathrm{min})$. The $\mathrm{GC}$ oven was programmed from $100^{\circ} \mathrm{C} \mathrm{(3} \mathrm{min} \mathrm{isothermal)} \mathrm{to} 300^{\circ} \mathrm{C}(30 \mathrm{~min}$ isothermal $)$ at $5^{\circ} \mathrm{C} / \mathrm{min}$. The $\mathrm{GC}$ injector was 
maintained at $290^{\circ} \mathrm{C}$ and the detectors at $310^{\circ} \mathrm{C}$. Compound identification was performed using GC retention times and compared to calibration standards. Quantification was performed using a linear or quadratic equations calculated from the analysis of calibration solutions made with certified standards. Dual column confirmation for each PBDE congener was conducted on all samples. If the concentrations from both columns were within $25 \%$, the value was accepted while outside this window the value was rejected and re-analyzed. In all cases, data were reported from column J+W DB5HT.

Three types of quality control samples were extracted and analyzed with the samples: 1) field duplicates and field blanks, 2) laboratory blanks and quality control samples, and 3) field extraction efficiency test samples. The PBDE fluxes $\left(\mathrm{ng} / \mathrm{m}^{2} /\right.$ day) with field duplicate fluxes, the quality control data reported in units of $\mathrm{ng} / \mathrm{L}$ or $\mathrm{ng} /$ filter, and the calibration confirmation samples as percent recovery are all reported in Appendix B.

Nine field duplicates were collected during the year one sampling. The average relative percent differences (RPD) between the field duplicate fluxes were $38 \%$ with a range of 0 $123 \%$ if all values were included. However, many duplicates with high RPDs were less than two times the reporting limit (RL). If these data are removed, the average and range become $21 \%$ and $0-40 \%$, respectively. Seven field blanks were also analyzed and consisted of capsules packed using the cleaning and transport protocol discussed above, taken to the field, returned to the lab and treated as samples taken through the storage and lyophilization process. The PBDEs were generally less than the RL; however, two blanks contained detectable BDE-28, -47, -99, and -100. The detected values resulted from contamination during lyophilization of events ( 7 thru 10) as discussed above. The data for these events are qualified in Appendix B. The magnitude of the bias was calculated using the three blanks prepared during these events identified as WA232, 235, and 239. The average concentration was used to calculate a bias rate using the average number of days the samples were deployed (14). This indicated the fluxes for these PBDEs may be biased high by the following amounts: BDE- $28=0.46, \mathrm{BDE}-47=1.1, \mathrm{BDE}-99=0.82$, and BDE-100 $=0.30 \mathrm{ng} / \mathrm{m}^{2} / \mathrm{d}$. Comparing the deposition fluxes from events potentially contaminated to others from the same site, yield similar fluxes and would suggest the data were not significantly impacted during the lypophilization contamination period. The corrective action of changing the lyophilization process to Texas A\&M University successfully removed any traces of contamination as noted in the other four field blanks.

The laboratory extraction and analysis quality control samples included a procedural blank and SRM 1649, as discussed above in Section 6.1.1. Nine procedural blanks were prepared with the samples and were all less than the RL, except one for BDE-209. Twelve replicates of the SRM 1649 were used as a reference, as it is not certified for PBDEs. The extraction of the urban dust consistently yielded detectable concentrations for BDE-28, $-47,-154$, and -209 with relative standard deviations (RSD) of $13-23 \%$.

The data are surrogate corrected with an average for HBB of $123 \pm 33 \%(n=132)$, PCB103 of $93 \pm 7 \%$, and PCB-198 of $97 \pm 4 \%$. The internal standard OCN had an average of $108 \pm 26 \%$. Analytical stability and accuracy determined from analyses of continuing 
calibration standards was $103 \%$ with a range for all PBDEs of $90-113 \%$. The RL was reported as the lowest calibration standard of $0.5 \mathrm{ng} / \mathrm{L}$ except BDE-209 was $2.0 \mathrm{ng} / \mathrm{L}$.

The final quality control check was a field extraction efficiency test where rain water was collected, passed through a GFF filter, spiked with a known mass of a PBDE mixture (12.5 ng), and poured into a field deployed collector. The spiked rain water was allowed to passively drip through the capsule simulating a field collection event. The results for the efficiency test averaged 52\% recovery and ranged from 32\% for BDE-209 to $70 \%$ for BDE-47 and BDE-183. All results are provided in Appendix B and indicate the collection equipment sufficiently captures the PBDEs from the rain water, but may underestimate the fluxes of BDE-209. Alternatively, the lower recoveries may result from a relatively low spiking level and additional tests are planned with a range of concentrations.

\subsection{Trace Elements (As, $\mathrm{Cd}, \mathrm{Cr}, \mathrm{Cu}, \mathrm{Ni}, \mathrm{Pb}$, and $\mathrm{Zn}$ )}

The water samples representing two week integrated bulk atmospheric deposition were analyzed for $\mathrm{As}, \mathrm{Cd}, \mathrm{Cr}, \mathrm{Cu}, \mathrm{Ni}, \mathrm{Pb}$, and $\mathrm{Zn}$. The samples were acid solubilized to destroy colloidal complexes following EPA Method 1640 Section 12.2.7 - Total Recoverable Analytes (TRM). The digested samples were analyzed on a Perkin Elmer 6100 inductively coupled plasma-mass spectrometer (ICP-MS) following a modification of EPA Method 1638 utilizing in-line addition of the internal standards indium and bismuth. The ICP-MS was run in peak hopping mode with a dwell time of $100 \mathrm{~ms}$ and integration time of $1000 \mathrm{~ms}$ with values reported as the average of three injections. Calibration was performed daily as a linear regression of a five point curve using certified standards and yielding a correlation coefficient of $r^{2}>0.9999$. All data are provided in Appendix C. Instrumental drift was $<7 \%$ for all analyses and the calibration was verified using the riverine SRM $1640(n=10)$ with average recoveries of $102 \pm 4 \%$. Low level verification samples were analyzed at 3-5 times the RL to ensure acceptable accuracy near the RL on a daily basis.

The SRM 1648 Trace Elements in Urban Particulate Matter was used to verify the digestion efficiency on a similar matrix. A solution was prepared containing $50 \mathrm{mg}$ of the SRM mixed with $200 \mathrm{~mL}$ of DI water, which was then acidified to $0.2 \%$ using double distilled nitric acid (similar to the samples). Nine replicates of SRM 1648 were leached and results are presented in Appendix C. Since the TRM digestion method is only a leach, the $\mathrm{Al}$ recoveries were $30 \pm 1 \%$. This was also true for $\mathrm{Cr}(15 \pm 1 \%)$. Both low recoveries resulted from the incomplete dissolution of the mineral phases present in the urban particulate matter. The SRM is certified based on a total dissolution and not directly comparable to the deposition samples. However, multiple replicates were used to ensure good precision throughout the year one sampling. The average and RSD for the other metals were Ni $62 \pm 4 \%$, Cu $78 \pm 3 \%, \mathrm{Zn} 80 \pm 3 \%$, As $93 \pm 4 \%, \mathrm{Cd} 79 \pm 2 \%$, and $\mathrm{Pb} 88 \pm 3 \%$. The leach method was selected to represent environmentally relevant conditions of release into natural waters. Additional laboratory quality control samples prepared with each analytical batch included method blanks, laboratory control samples/blank spikes, laboratory duplicates, a riverine water SRM, and matrix spikes. 
Ten method blanks were prepared and analyzed with the samples. The concentrations were less than the RL for all metals except $\mathrm{Cr}$, which averaged $(0.220 \pm 0.071 \mu \mathrm{g} / \mathrm{L})$ and was slightly higher than the RL $(0.152 \mu \mathrm{g} / \mathrm{L})$. The contribution of $\mathrm{Cr}$ resulted from the leaching of an interfering compound during the TRM processes and was therefore subtracted from the sample concentrations. Matrix spike recoveries were used to further assess potential interferences. Ten matrix spikes were analyzed with the samples averaging $99 \pm 3 \%$ for all elements. Blank spikes or laboratory control samples were also analyzed with average recoveries for all elements of $100 \pm 4 \%$. Analytical precision was determined using laboratory replicates $(n=13)$ with an average RPD of $3 \pm 4 \%$.

Field quality control samples included field duplicates $(n=10)$ and field equipment blanks $(\mathrm{n}=4)$. The average RPD for the field duplicate fluxes were $35 \%$ with a range from $0 \%$ to $153 \%$. The higher RPDs were generally associated with samples with visible differences between the two collection bottles, such as small insects. The equipment blank concentrations were generally less than the RL, except for Ni and $\mathrm{Zn}$. The detected equipment blanks were used to correct the data for contributions from the equipment or DI water used to rinse the funnel. All trace element deposition fluxes were corrected for the small DI rinse contributions.

\subsection{Mercury and Methylmercury}

The water samples representing two week integrated bulk atmospheric deposition were analyzed for $\mathrm{THg}$ and $\mathrm{MMHg}$ (at a subset of sites). The THg concentrations in solution were determined following EPA Method 1631, Revision E. The method is a cold vapor atomic fluorescence technique (CVAF), based upon the emission of $254 \mathrm{~nm}$ radiation by excited elemental mercury $\left(\mathrm{Hg}^{0}\right)$ atoms in an inert gas stream. Mercuric ions in the oxidized sample are reduced to elemental $\mathrm{Hg}^{0}$ with stannous chloride $\left(\mathrm{SnCl}_{2}\right)$ reductant and then purged onto gold-coated sand traps as a means of pre-concentration and interference removal. Mercury vapor is thermally desorbed to a second analytical gold trap, and from that into a gas phase fluorescence cell at room temperature. The fluorescence signal (peak area) is proportional to the quantity of mercury collected, which is quantified using a minimum of five certified standards.

The MMHg concentrations were determined using modifications of the Bloom (1989) method, which was submitted as a draft EPA Method 1630 (never promulgated). The method also uses CVAF detection, but first the sample was distilled into a clean water matrix. Then an ethylating agent was added to the distilled sample to form a volatile methyl-ethylmercury derivative, and then purged onto graphite carbon traps as a means of preconcentration and interference removal. The sample was then isothermally chromatographed, pyrolitically broken down to $\mathrm{Hg}^{0}$, and detected using CVAF. Both the $\mathrm{THg}$ and $\mathrm{MMHg}$ methods use a calibration factor for each standard, which was the peak units divided by the picograms of $\mathrm{Hg}$. The calibration curve was acceptable if the RSD for the calibration factor was $\leq 15 \%$. Laboratory quality control samples prepared with each analytical batch included method blanks, ongoing precision and recovery (OPR), laboratory duplicates, SRM, and matrix spikes. All data are provided in Appendix D. 
The five-point daily calibration curves for $\mathrm{THg}$ and $\mathrm{MMHg}$ yielded an average RSD of $3.9 \%(\mathrm{n}=14)$ and $5.8 \%(\mathrm{n}=9)$, respectively. Instrumental drift was $<8 \%$ for $\mathrm{THg}$ and $<15 \%$ for MMHg. Accuracy was independently verified using SRM $1641(n=14)$ for THg with average recoveries of $98 \pm 2 \%$ and SRM DORM-2 (Dogfish Muscle; $n=9$ ) for $\mathrm{MMHg} 100 \pm 5 \%$. Low level verification samples were also analyzed at 3-5 times the RL to ensure acceptable accuracy near the RL on a daily basis. The RL for $\mathrm{THg}$ was 0.318 $\mathrm{ng} / \mathrm{L}$ and $\mathrm{MMHg}$ was $0.032 \mathrm{ng} / \mathrm{L}$. Three method blanks were prepared and analyzed with each batch of samples. The THg $(n=42)$ and MMHg $(n=27)$ method blanks were all less than the RL. Matrix spike/matrix spike duplicate pairs were analyzed with each analytical batch and averaged $101 \pm 4 \%$ for THg $(n=43)$ and $80 \pm 16 \%$ for MMHg $(n=22)$. Two OPRs were analyzed with each analytical batch. The average recoveries were $101 \pm 4 \%$ for $\mathrm{THg}(\mathrm{n}=28)$ and $89 \pm 19 \%$ for $\mathrm{MMHg}(\mathrm{n}=19)$. Analytical precision was determined using laboratory replicates. The average RPD for $\mathrm{THg}$ was $7 \pm 5 \%(\mathrm{n}=13)$ and $\mathrm{MMHg}$ was $18 \pm 9 \%(n=7)$.

Field quality control samples included field duplicates and field equipment blanks. For many sites, THg was measured from both the black or opaque Teflon ${ }^{\circledR}$ and the clear Teflon ${ }^{\circledR}$ providing for 44 field replicate measurements. The average RPD or RSD was $29 \%$ with a range from $2 \%$ to $98 \%$. The higher relative errors were generally associated with sample concentrations near or below the RL or samples with visable differences such as insects. The MMHg samples were collected at a subset of sites and seven field duplicates were collected. The average RPD was $70 \%$ with a range from $8 \%$ to $142 \%$. Field duplicates with high RPDs were attributed to the presence of small winged insects or beetles. Four equipment blanks were collected during year one and concentrations were less than the RL. Traces of THg and MMHg were detected and subsequently subtracted from the calculated fluxes as discussed above.

\subsection{Results for Year One (September 2008 - June 2009)}

The fluxes for the organic compounds (anhydrosugars, PAHs, and PBDEs) and the trace elements were calculated for each sample. The organic compounds were quantified based on the mass of each compound extracted by the GFF and SPE disks. Therefore, only flux measurements are reported for each sample. The fluxes were calculated as the mass of each compound divided by the surface area of the stainless steel funnel $\left(0.159 \mathrm{~m}^{2}\right)$ and the number of days deployed. This provided mass fluxes in units of $\mathrm{ng}$ or $\mu \mathrm{g} / \mathrm{m}^{2} / \mathrm{d}$. For the trace elements, the mass of each element deposited during the deployment was determined from the sample solution (total volume $=$ volume of rainfall collected plus volume of DI rinse water). The solution concentration (ng or $\mu \mathrm{g} / \mathrm{L}$ ) was multiplied by the total volume, corrected for the mass of an element contributed by the DI rinse, divided by the surface area of the funnel, and then the number of days deployed. Additional information for the flux calculations is provided in the sections below. All data for these calculations are provided in the appendices for each of the toxics.

\subsection{Levoglucosan Fluxes}

Levoglucosan and its anhydrosugar isomers (mannosan and galactosan) were prevalent at all seven sampling locations. Levoglucosan is an unambiguous molecular biomarker for 
biomass combustion (Simoneit et al. 1999; Simoneit 2002; Kuo et al. 2008; Schmidl et al. 2008). Total levoglucosan fluxes, observed from early September-early November (Figure 13) showed a first marked peak in fluxes during event 2 in September (200-400 $\mu \mathrm{g} / \mathrm{m}^{2} / \mathrm{d}$ ). From early October to December levoglucosan fluxes remained relatively low ranging $10-270 \mu \mathrm{g} / \mathrm{m}^{2} / \mathrm{d}$. In the winter period, levoglucosan levels increased by an order of magnitude ranging $100-1750 \mu \mathrm{g} / \mathrm{m}^{2} / \mathrm{d}$ from late February to late April. This peak in late March-early April was then followed by decreasing fluxes back to ranges observed in early fall $\left(40-200 \mu \mathrm{g} / \mathrm{m}^{2} / \mathrm{d}\right)$. Detailed characterization of the yield of levoglucosan to one of its isomers (mannosan) in fuel source emissions can further discriminate between specific inputs of biomass combustion (i.e. softwood vs. hardwood, recent biomass vs. brown coal) in atmospheric PM (Fabbri et al. 2008; Schmidl et al. 2008; Caseiro et al. 2009; Fabbri et al. 2009). The positive relationship between levoglucosan and mannosan (Figure 14) confirms that both anhydrosugars are indeed derived from the same source. The slope of the relationship ( 4.0) further points to softwood as the primary source of biomass being combusted (Ward et al. 2006; Schmidl et al. 2008; Caseiro et al. 2009; Fabbri et al. 2009). However, this relationship is only valid for the late summer to early winter period (Aug.-Dec.) as mannosan and galactosan became undetectable in the winter to spring period (Feb.-May). This suggests a shift in combustion source (i.e. biomass $v s$. brown coals) and/or a change in combustion temperature conditions (Kuo et al. 2009 in preparation). The levoglucosan fluxes are also shown to be independent of precipitation patterns. The average total flux of the entire study area and sampling events was 300 $\mu \mathrm{g} / \mathrm{m}^{2} / \mathrm{d}$ (range: $11-1751 \mu \mathrm{g} / \mathrm{m}^{2} / \mathrm{d}$ ).

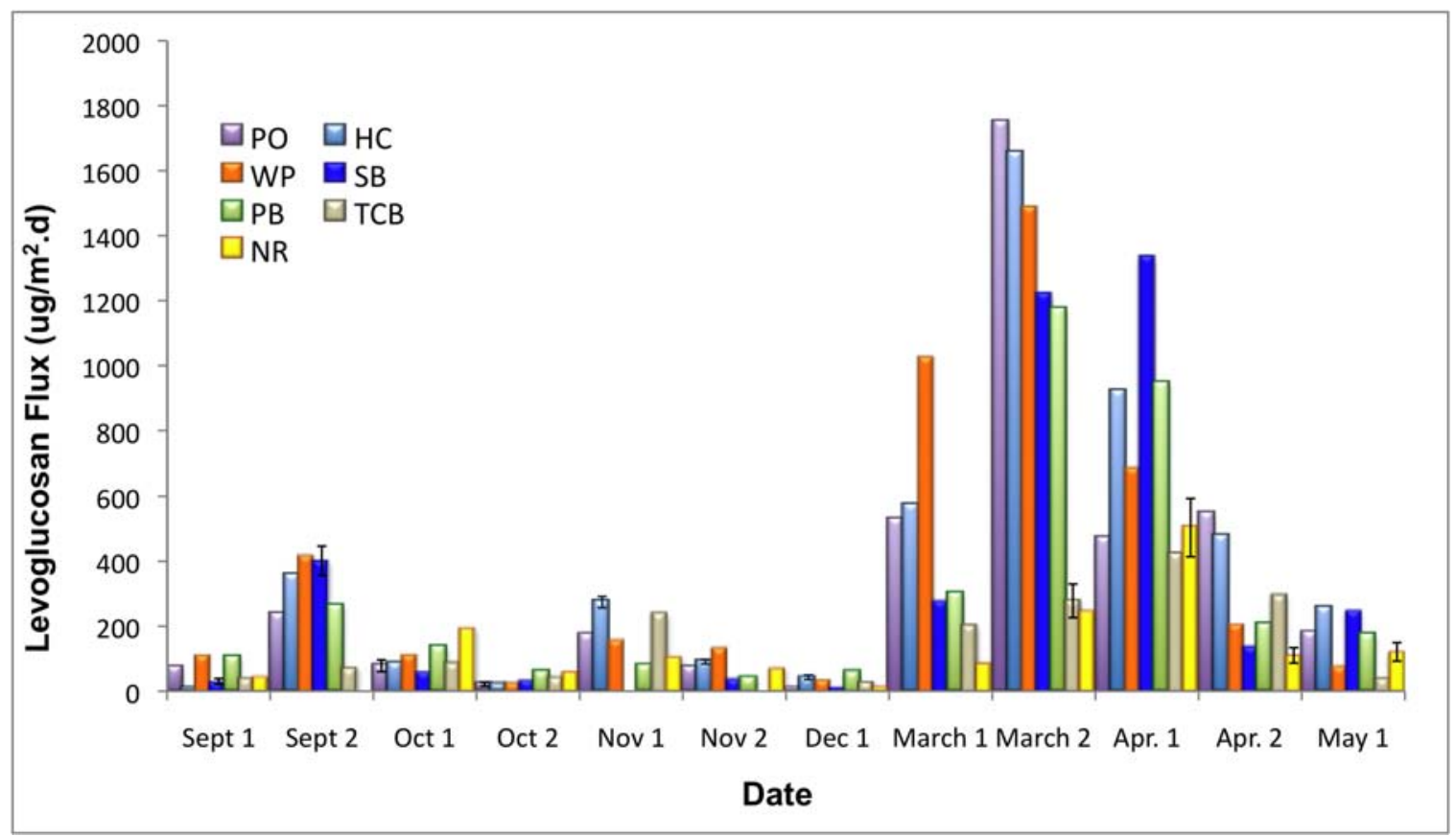

Figure 13. Levoglucosan fluxes from the seven sites for events 1 through 12. 


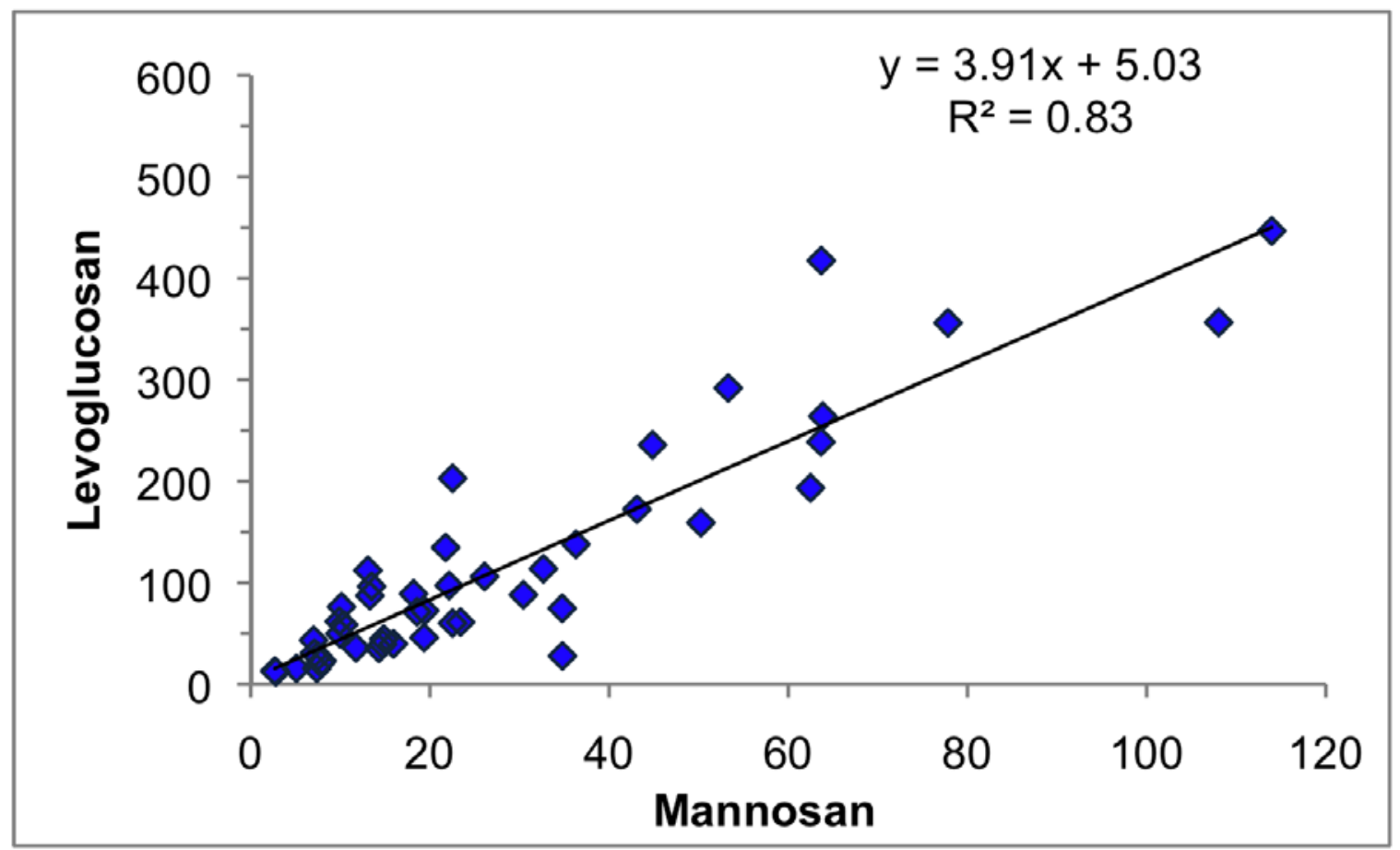

Figure 14. The levoglucosan/mannosan ratio discriminates sources of combustion. It indicates whether it is hardwood or softwood combustion. The relationship of the slope $(4 \pm 1)$ indicates softwood combustion is the main source of biomass combustion.

\subsection{PAH Fluxes}

High molecular weight PAHs contributed about half of the total proportion of pyrogenic PAHs (see Figure 12). In contrast to levoglucosan fluxes, there was no strong seasonality in flux variations but rather a site-specific influence. The Tacoma TCB site showed consistently higher fluxes relative to other stations and in some cases by as much as one order of magnitude (Figure 15). At this site, HMW PAH fluxes ranged 50-500 ng/ $\mathrm{m}^{2} / \mathrm{d}$ with the highest values during the Oct.-Apr. sampling periods $\left(100-500 \mathrm{ng} / \mathrm{m}^{2} / \mathrm{d}\right)$. The second highest fluxes were recorded at the other urban site (Seattle; WP) with levels ranging from 20 to $100 \mathrm{ng} / \mathrm{m}^{2} / \mathrm{d}$ (Figure 16). All other stations showed much lower fluxes throughout the entire sampling period, with ranges of $5-50 \mathrm{ng} / \mathrm{m}^{2} / \mathrm{d}$ (Figure 16).

Figures 17 and 18 show the relative distribution of specific PAHs, which help discriminate between input sources of these organic contaminants. Both figures demonstrate that the PAHs in all atmospheric particles are predominantly derived from combustion sources (pyrogenic) rather than oil sources (petrogenic). Additional diagnostic ratios can also be used to further characterize the sources of combustionderived atmospheric particulates. Figures 18 and 19 show that the source of pyr-PAHs was likely derived from a mixture of petroleum and biomass combustion sources. For example, the retene/(retene+chrysene), as well as 1,7-dimethylphenanthrene/(1,7+2,6 dimethylphenanthrene) ratios show the PM to be derived from two main sources: a) softwood combustion and b) fossil fuel combustion (Yunker et al. 2002; Yan et al. 2005). The two urban sites (TCB and WP) show strong inputs of fossil fuel combustion, whereas 
the other sites show a much more important input from biomass combustion, which appears to be softwood derived (confirming the anhydrosugar data).

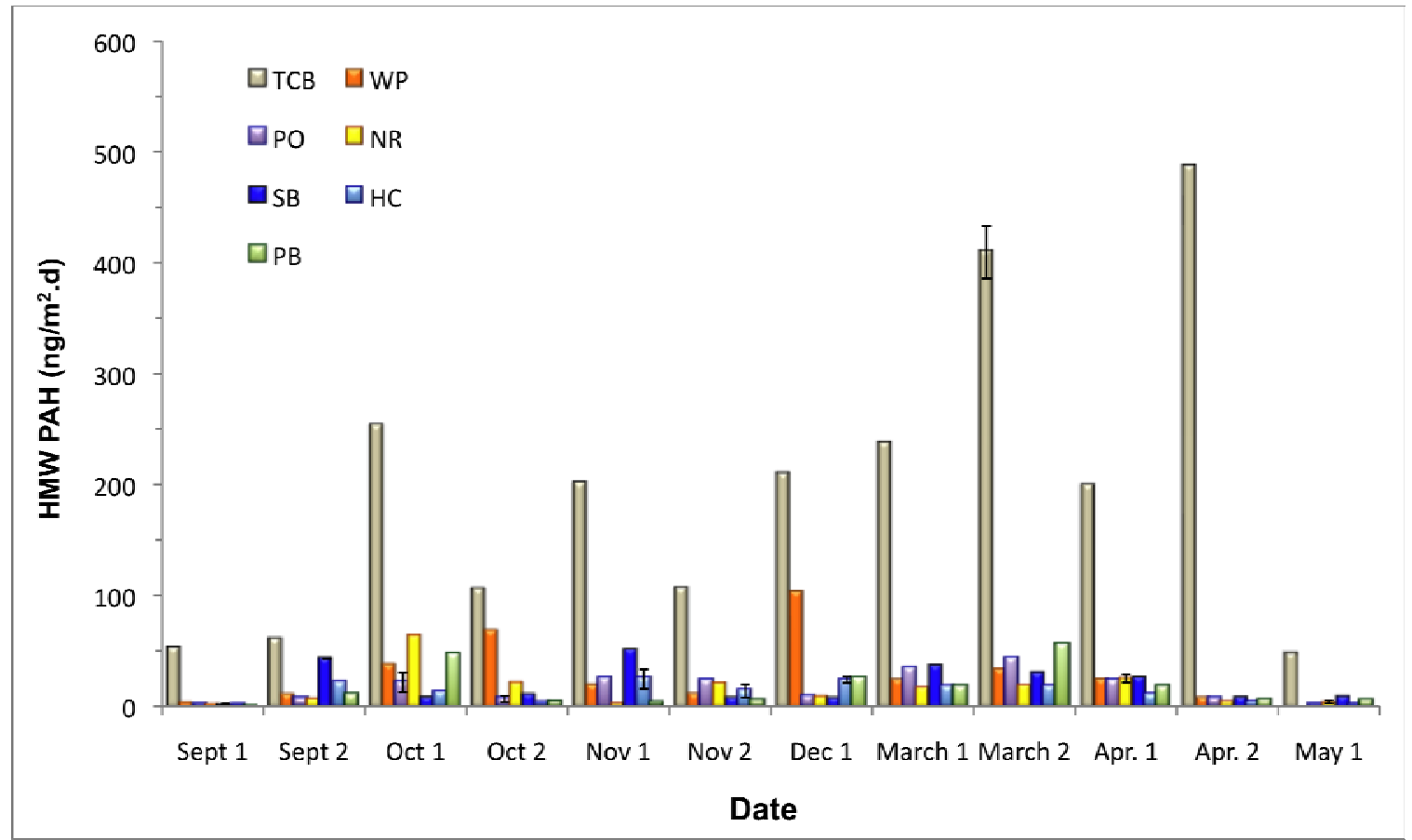

Figure 15. Fluxes of HMW PAHs for the seven sites during events 1 through 12.

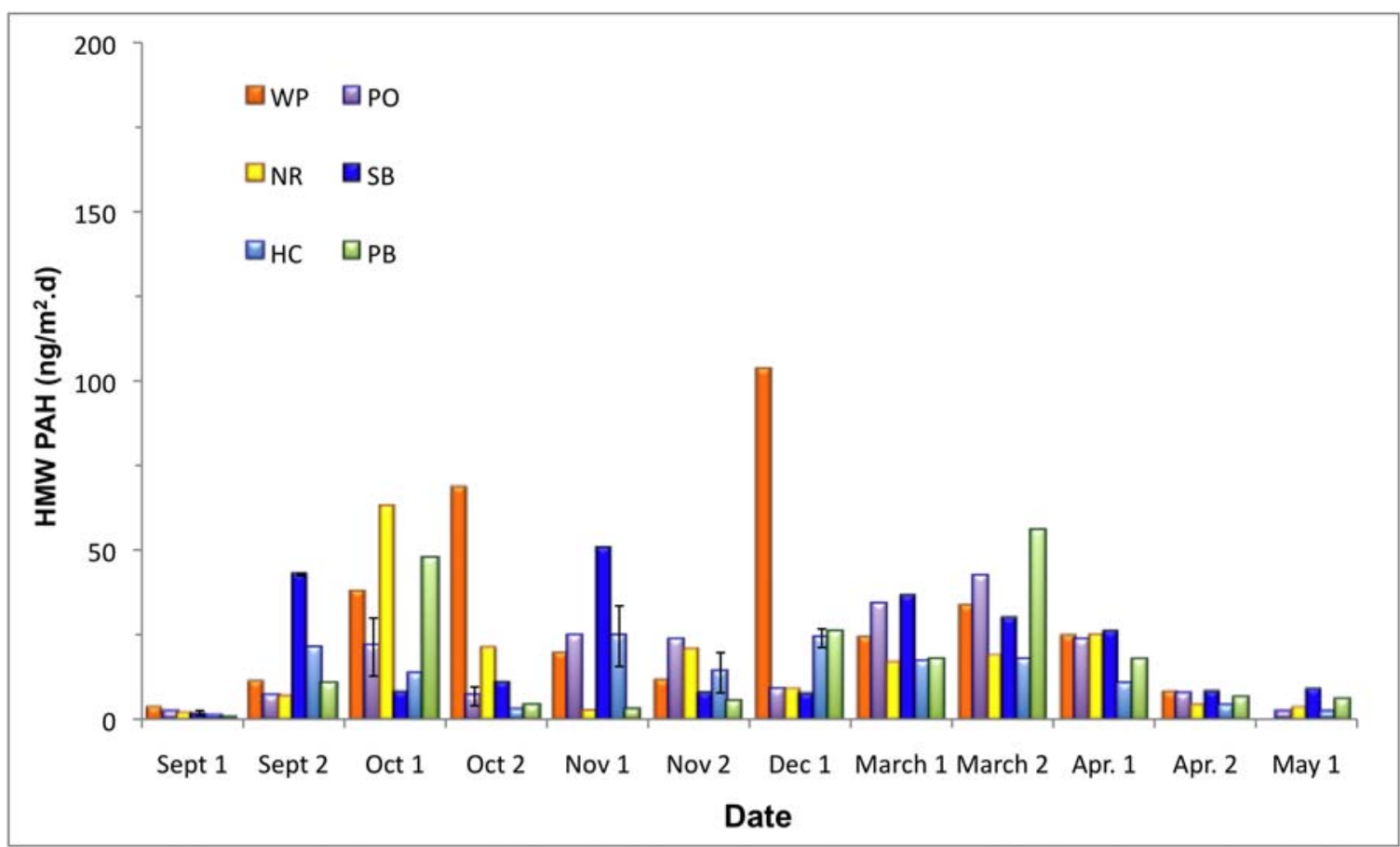

Figure 16. Fluxes of HMW PAHs for six sites (TCB removed) during events 1 through 12. 


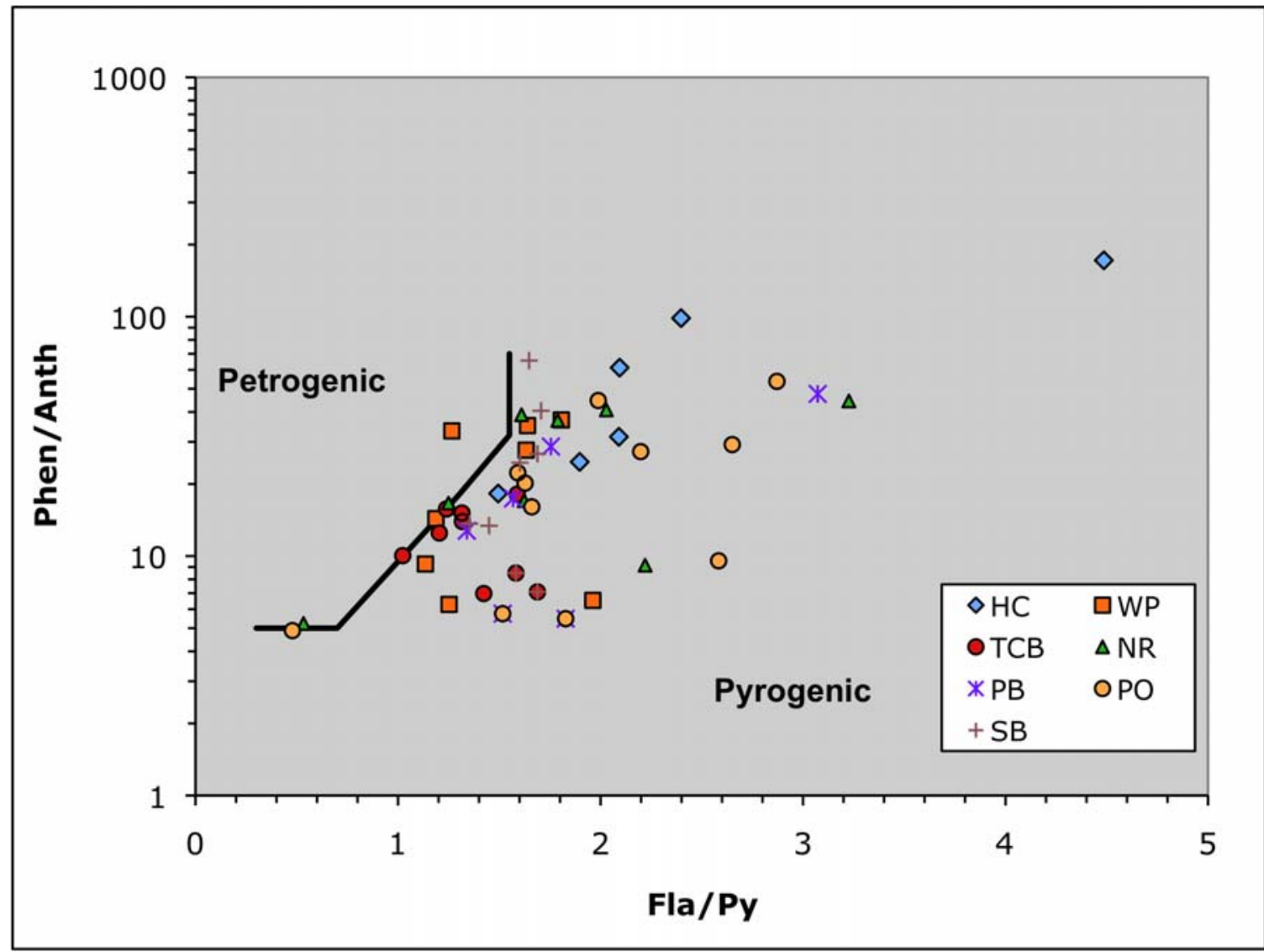

Figure 17. The values of the phenanthrene/anthracene (Phen/Anth) and fluoranthene/pyrene (F1/Py) ratios show a strong source input from pyrogenic PAHs.

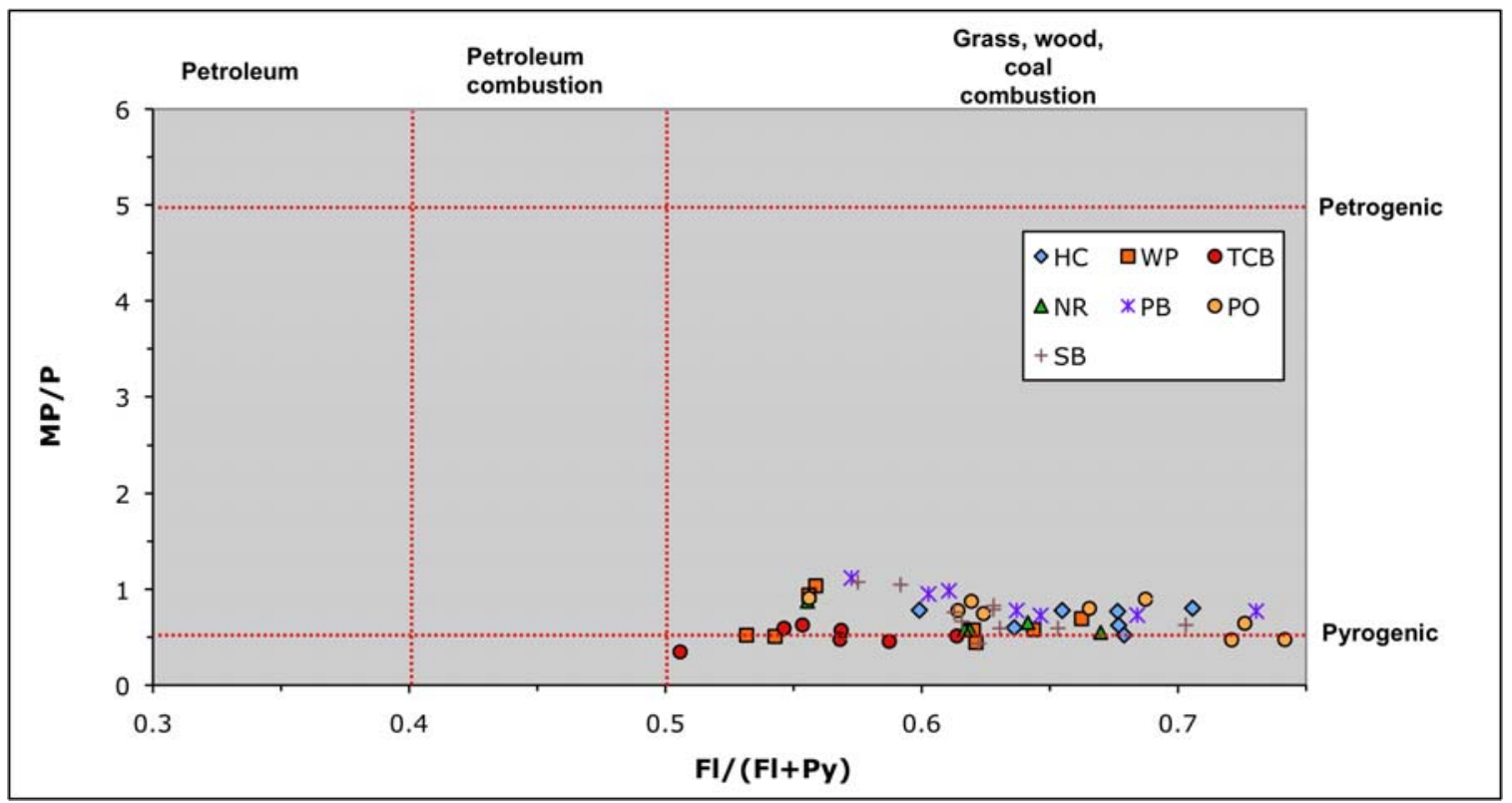

Figure 18. The methylphenanthrene/phenanthrene (MP/P) and fluoranthene/fluoranthene+pyrene) ratios of the seven sites discriminated between combustion sources (pyrogenic) and oil sources (petrogenic). All sites indicated a mixed source of biomass and fossil fuel combustion. 


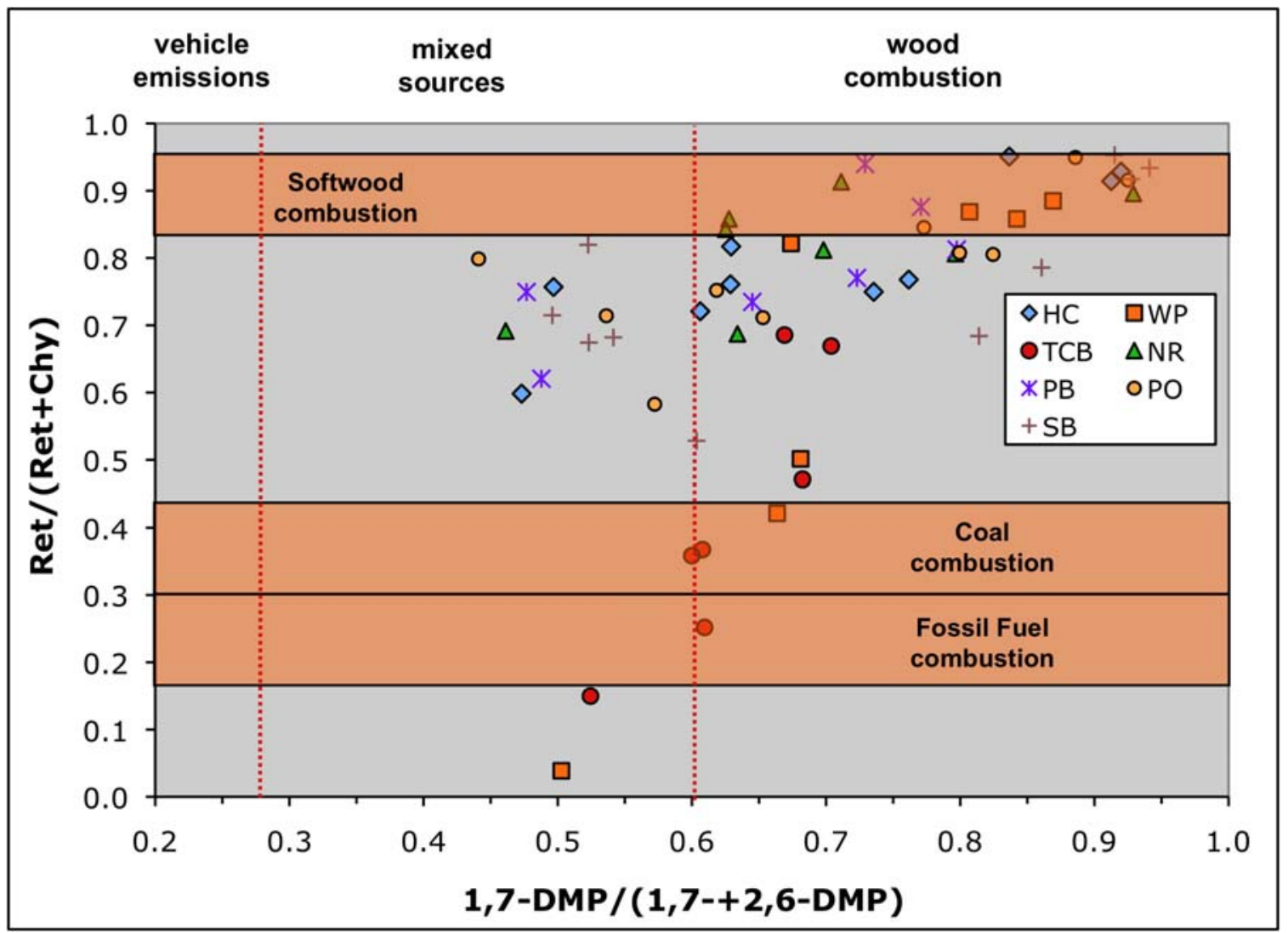

Figure 19. The retene/(retene+chrysene) and 1,7-dimethylphenanthrene/(1,7+2,6 dimethylphenanthrene) ratios suggest the PM was derived from two main sources: a) softwood combustion and b) fossil fuel combustion.

\subsection{PBDE Fluxes}

The sum of the 14 PBDE congeners (BDE 17, 28, 47, 66, 71, 85, 99, 100, 138, 153, 154, 183,190 , and 209) were graphed for events 1 through 12 (if available) at the seven sites (Figure 20). The error bars represent the range for the field duplicates. The fluxes for BDEs not detected were calculated based on the instrument MDL and collection information for that sample. The fluxes for the undetected BDEs ranged from 0.20-0.90 $\mathrm{ng} / \mathrm{m}^{2} / \mathrm{d}$ and were included in the sum. The BDEs 47, 99, and 209 were prevalent at all seven sites and comprised the largest portion of the sum of the PBDEs. The PBDE fluxes across all sites and events averaged $10.4 \mathrm{ng} / \mathrm{m}^{2} / \mathrm{d}$ (range: $3.04-171 \mathrm{ng} / \mathrm{m}^{2} / \mathrm{d}$ ). If the BDE congeners that were not detected are removed from the sum the average becomes 7.79 $\mathrm{ng} / \mathrm{m}^{2} / \mathrm{d}$ (range: $0.422-170 \mathrm{ng} / \mathrm{m}^{2} /$ day). This is considerably higher than the flux of 2 $\mathrm{ng} / \mathrm{m}^{2} / \mathrm{d}$ reported in the Phase 1 Toxics Loading Report (Hart Crowser, Inc. et al. 2007).

Similar to the PAHs, there was no strong seasonality in flux variations but rather a sitespecific influence. Spatially, the fluxes were similar with averages ranging from $\sim 5$ to 7 $\mathrm{ng} / \mathrm{m}^{2} / \mathrm{d}$ and RSDs of $29-78 \%$ (Figure 21 ). However the highest fluxes and seasonal variability were recorded at the Tacoma TCB site, which was almost an order of magnitude higher $\left(34.7 \mathrm{ng} / \mathrm{m}^{2} / \mathrm{d}\right.$ and range: $\left.7.14-171 \mathrm{ng} / \mathrm{m}^{2} / \mathrm{d}\right)$ and more variable (RSD $128 \%$ ). The influence of potential outliers will be investigated in the final report along with the potential for temporal trends. 


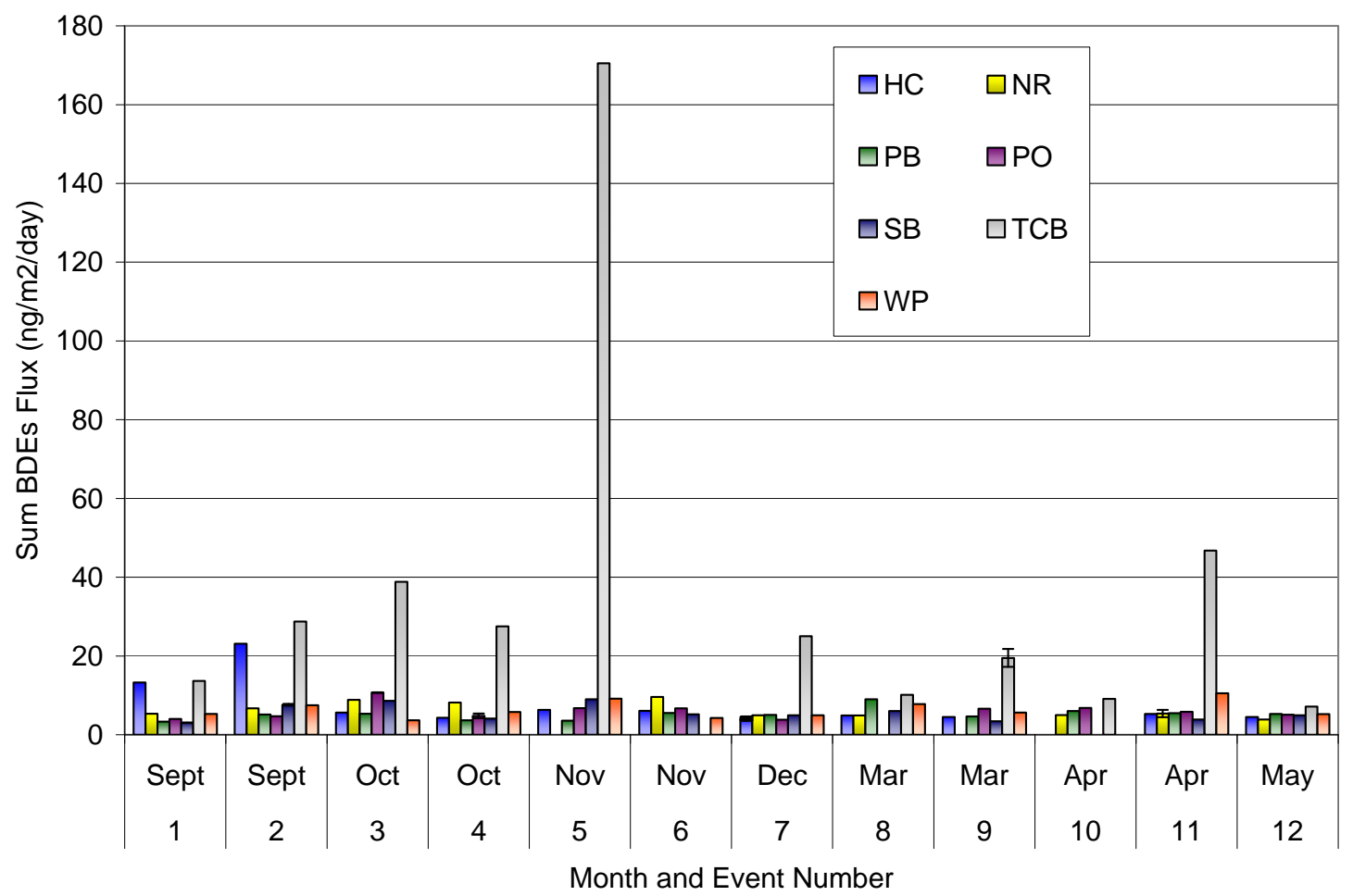

Figure 20. The sum of PBDE fluxes for events 1 through 12 at all seven sites: Hood Canal (HC), Padilla Bay (PB), Sequim Bay (SB), West Point (WP), Nisqually River (NR), Port Orchard (PO), and Tacoma Commencement Bay (TCB). The error bars represent the variability of the field duplicates. 


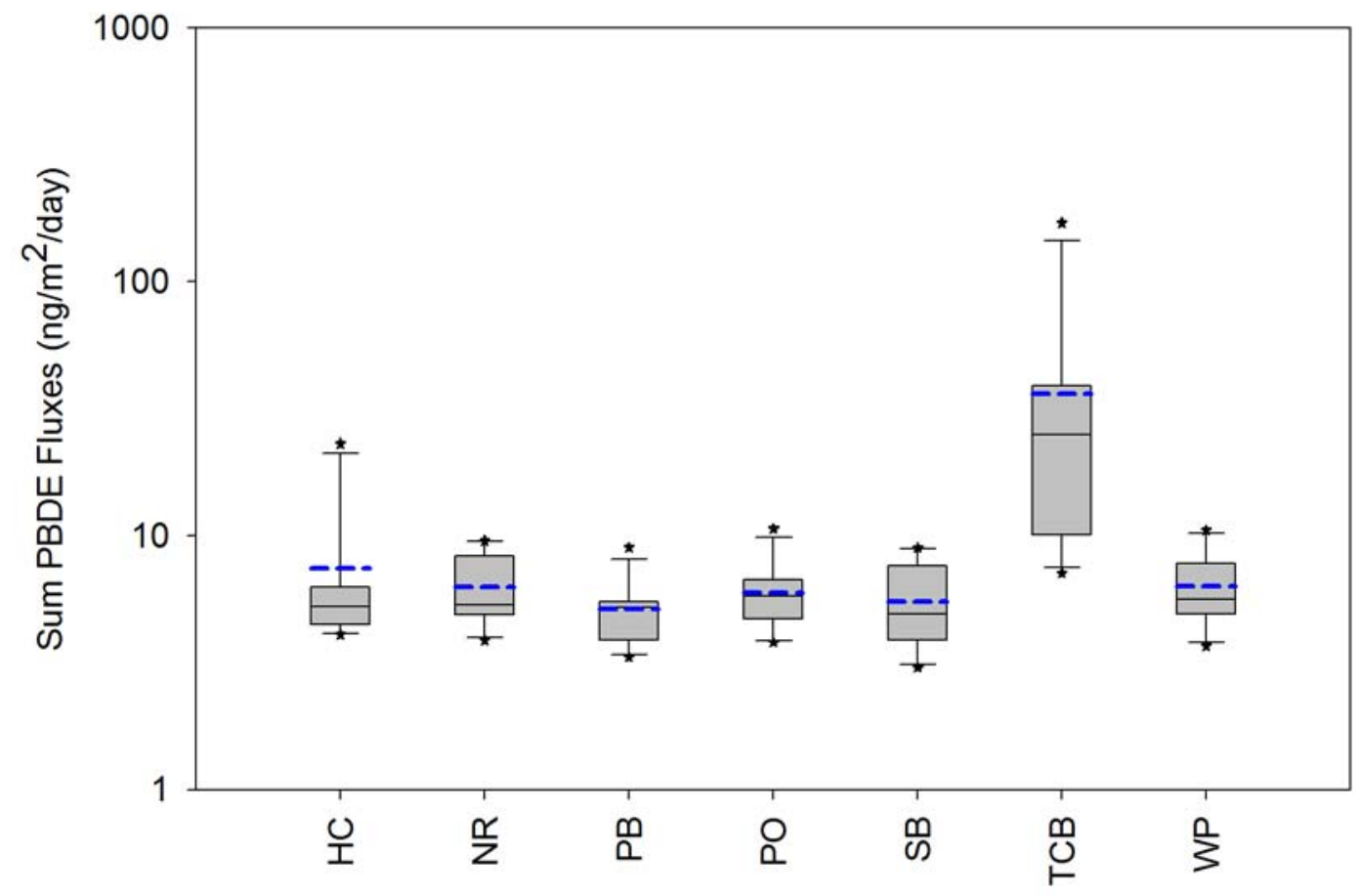

Figure 21. The distribution of PBDE fluxes (ng/ $\left.\mathrm{m}^{2} / \mathrm{day}\right)$ for each site over the twelve events sampled from September 2008 though June 2009. The lower box boundary represents the 25th percentile, the solid line is the median, the upper box boundary is the 75th percentile, and the dashed blue line is the mean. Whiskers represent the 10th and 90th percentiles and the asterisk are potential outliers assuming no temporal trends are present.

\subsection{Trace Elements (As, $\mathrm{Cd}, \mathrm{Cr}, \mathrm{Cu}, \mathrm{Ni}, \mathrm{Pb}$, and $\mathrm{Zn}$ )}

Figures 22 through 28 graph the concentrations of $\mathrm{As}, \mathrm{Cd}, \mathrm{Cr}, \mathrm{Cu}, \mathrm{Ni}, \mathrm{Pb}$, and $\mathrm{Zn}$, respectively, for events 1 - 14 for the clear Teflon ${ }^{\circledR}$ bulk deposition sampler. The concentration for the Tyee Marina (TM) event 14 was also provided for spatial comparison. The TM concentrations were lower than the TCB site by a factor of two or three for these elements except $\mathrm{Pb}$ (order of magnitude lower) and mercury (discussed below). A strong temporal variability in the concentrations was evident for most of the trace elements with generally lower concentrations correlated with significant precipitation during deployment. The concentrations between sites generally fall in the same range with the exception of a few outliers and the TCB site. The TCB site consistently has the highest concentrations of $\mathrm{As}, \mathrm{Cu}$, and $\mathrm{Pb}$. Higher concentrations were also recorded at SB and attributed to sand deposition from periodic high winds from the north hitting the nearby bluff. The concentrations at SB were periodically elevated in $\mathrm{Cr}$, $\mathrm{Ni}$, and $\mathrm{Zn}$ when visible sand grains were noted in the funnels. The station has been moved further back from the bluff to alleviate this issue. 


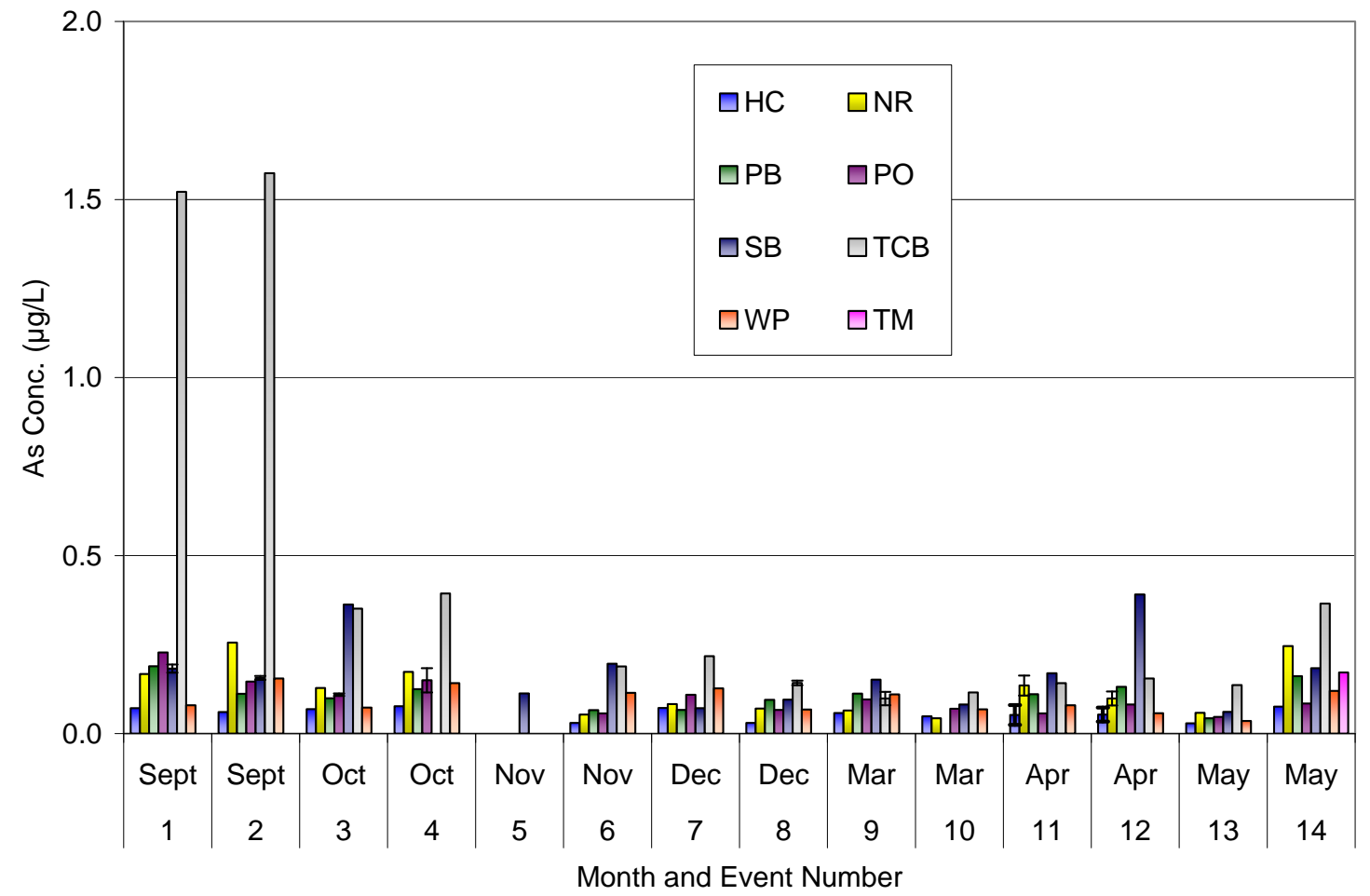

Figure 22. Arsenic concentrations $(\mu \mathrm{g} / \mathrm{L})$ in bulk deposition samples from events 1 through 14 with error bars representing field duplicate measurements.

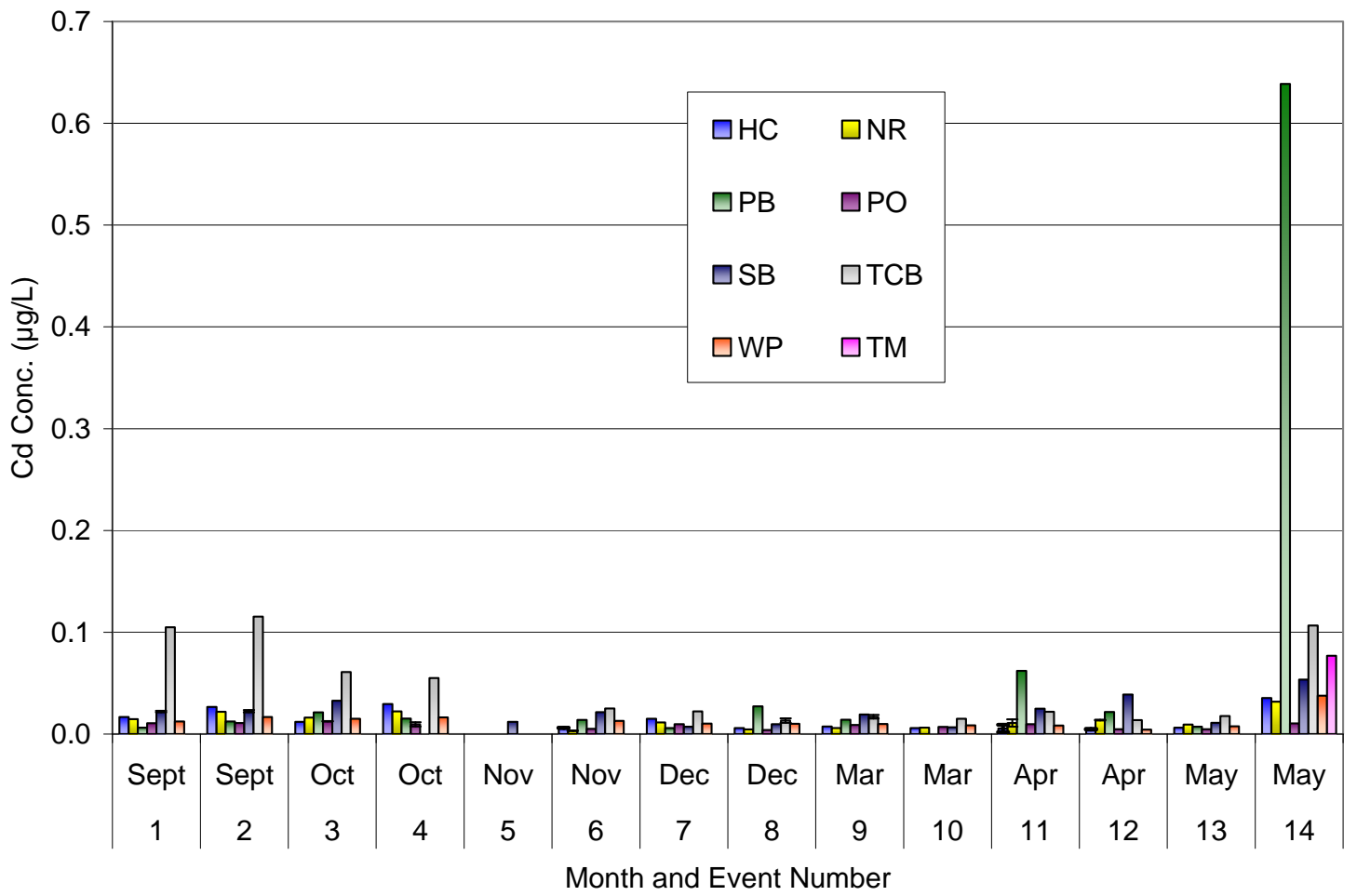

Figure 23. Cadmium concentrations $(\mu \mathrm{g} / \mathrm{L})$ in bulk deposition samples from events 1 through 14 with error bars representing field duplicate measurements. 


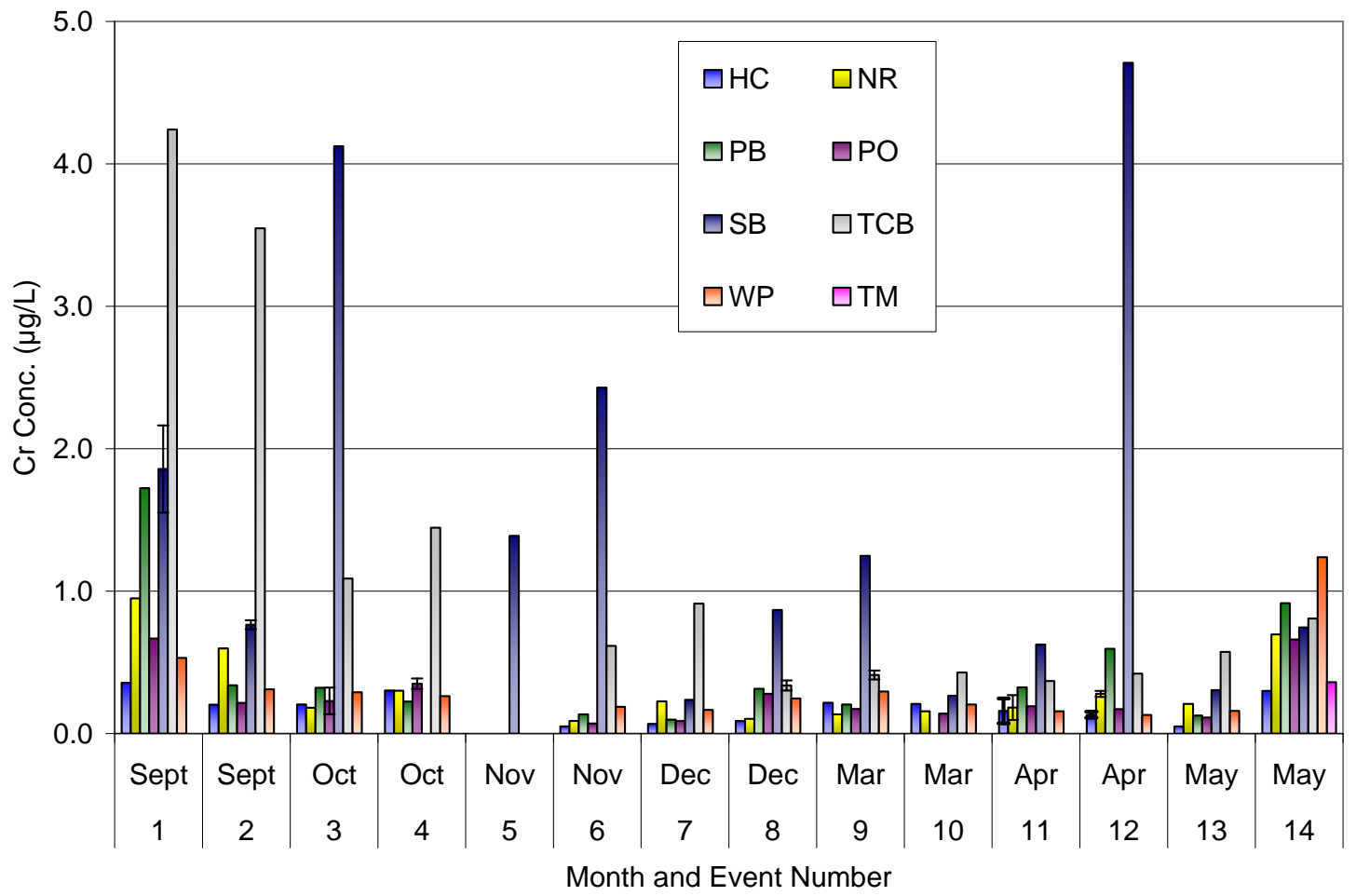

Figure 24. Chromium concentrations $(\mu \mathrm{g} / \mathrm{L})$ in bulk deposition samples from events 1 through 14 with error bars representing field duplicate measurements.

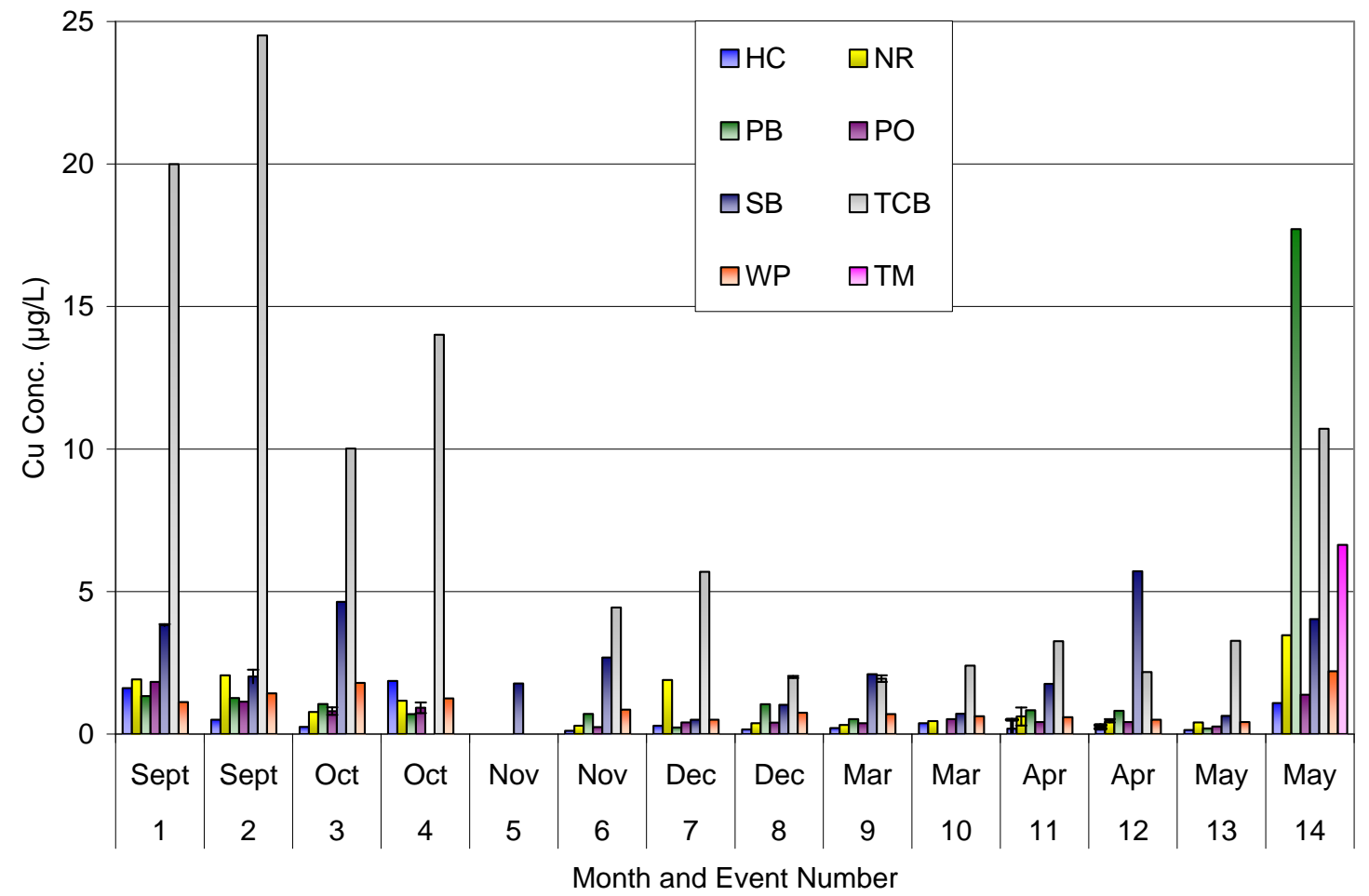

Figure 25. Copper concentrations ( $\mu \mathrm{g} / \mathrm{L}$ ) in bulk deposition samples from events 1 through 14 with error bars representing field duplicate measurements. 


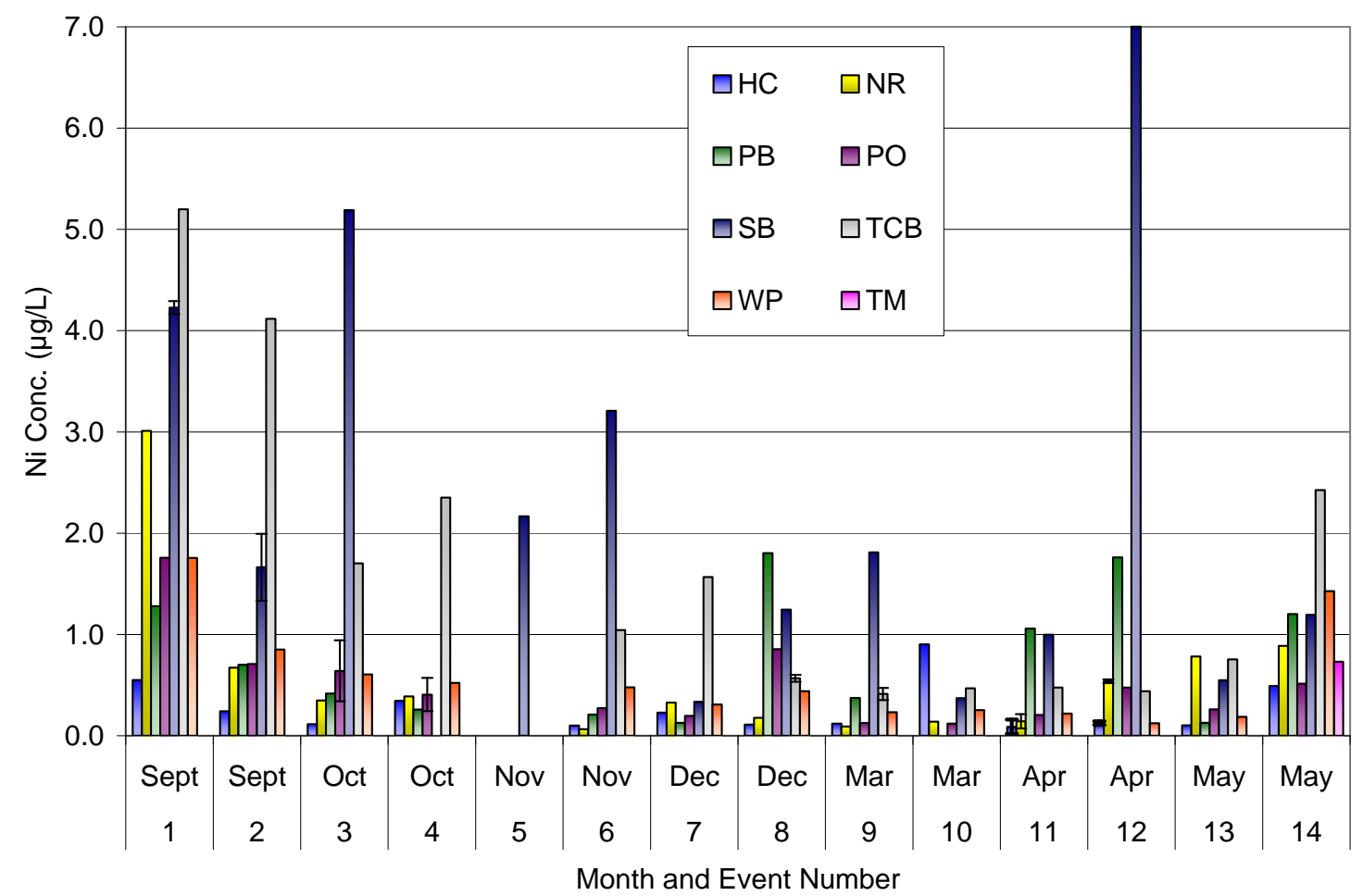

Figure 26. Nickel concentrations $(\mu \mathrm{g} / \mathrm{L})$ in bulk deposition samples from events 1 through 14 with error bars representing field duplicate measurements.

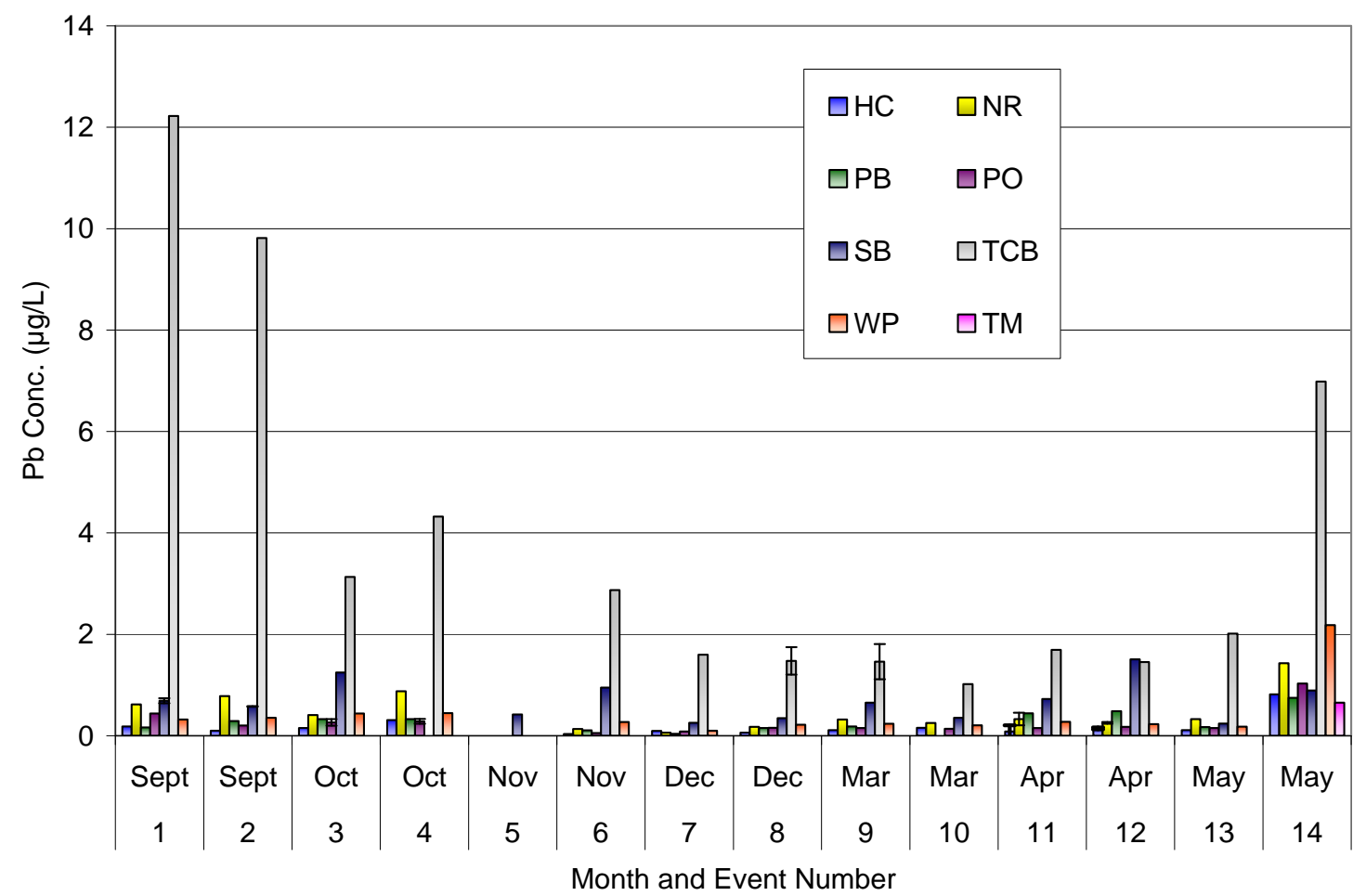

Figure 27. Lead concentrations $(\mu \mathrm{g} / \mathrm{L})$ in bulk deposition samples from events 1 through 14 with error bars representing field duplicate measurements. 


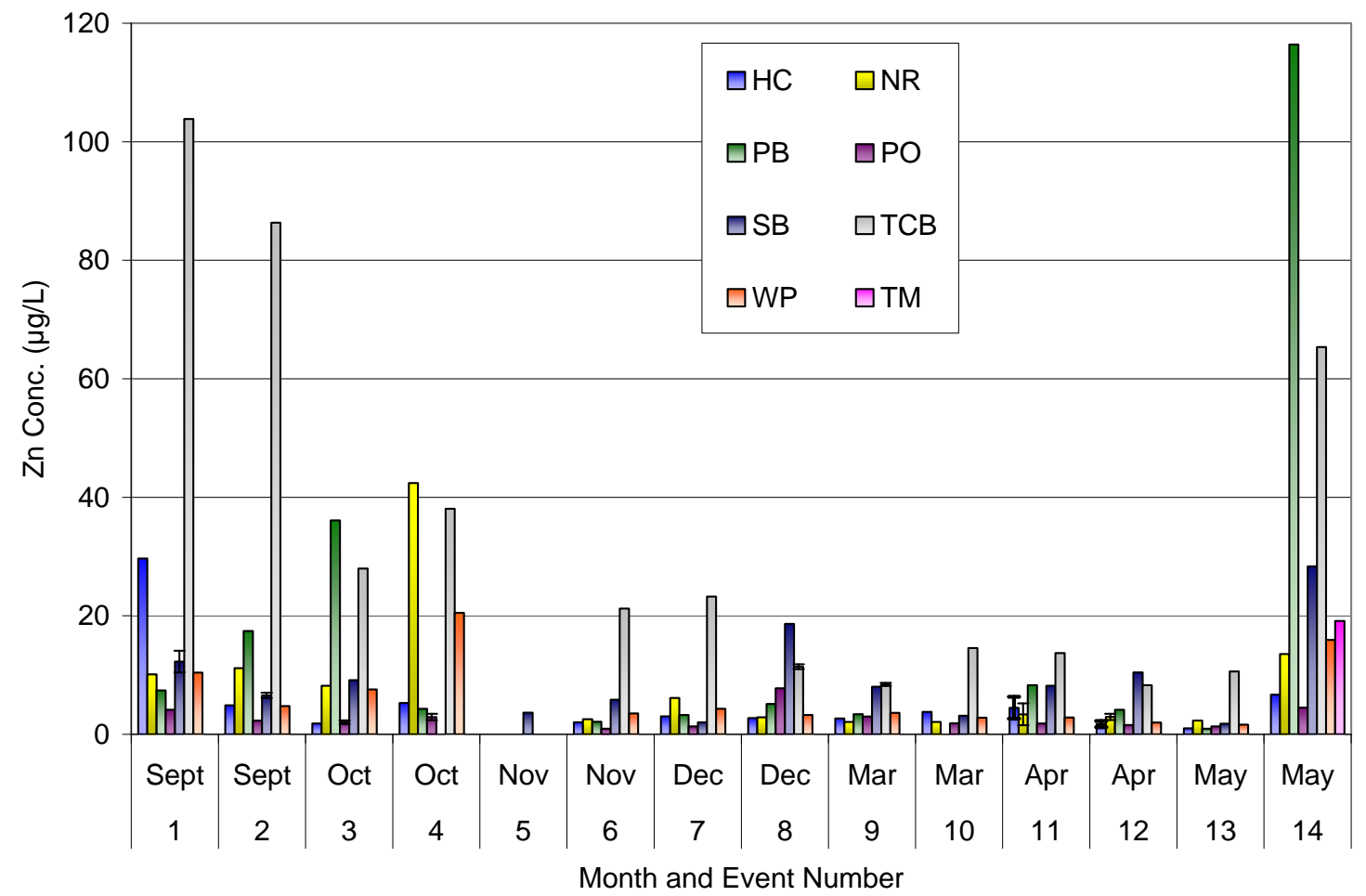

Figure 28. Zinc concentrations $(\mu \mathrm{g} / \mathrm{L})$ in bulk deposition samples from events 1 through 14 with error bars representing field duplicate meaurements.

The fluxes for each trace element were calculated based on the surface area of the funnel and the number of days deployed. The concentrations measured in the collectors are multiplied by the volume collected $(60 \mathrm{~mL}$ if no precipitation during the event) to determine the mass of each element deposited during the deployment. This mass was then corrected for the mass of each element contributed by the DI rinse water. Table 4 summarizes the mean, median, volume-weighted, daily, and annual fluxes for these elements. Volume-weighted concentrations provide a measure of the elemental concentration relative to the volume of sample collected. This sample weighting procedure gives less emphasis to small sample volumes which contribute little total mass input flux. Volume-weighted concentrations were determined using the following equation:

$$
\text { Volume - Weighted Concentration }(\text { ng or } \mu \mathrm{g} / \mathrm{L})=\frac{\sum\left[\text { Element }_{\mathrm{i}}(\text { Sample Volume })_{\mathrm{i}}\right.}{\sum(\text { Sample Volume })_{\mathrm{i}}}
$$

The mass of each element collected during the sampling event was divided by the surface area of the funnel and the days deployed to give units of $\mu \mathrm{g} / \mathrm{m}^{2} / \mathrm{d}$. All data for these calculations are provided in Appendix C. 
Table 4. Summary of bulk atmospheric deposition concentrations $(\mu \mathrm{g} / \mathrm{L})$ and estimates of daily $\left(\mu \mathrm{g} / \mathrm{m}^{2} / \mathrm{d}\right)$ and annual trace element deposition fluxes $\left(\mu \mathrm{g} / \mathrm{m}^{2} / \mathrm{yr}\right)$ for events 1 through 14 .

\begin{tabular}{|c|c|c|c|c|c|c|}
\hline \multirow[t]{2}{*}{ Site } & \multirow{2}{*}{$\begin{array}{c}\text { Number } \\
\text { of } \\
\text { Samples }\end{array}$} & \multicolumn{3}{|c|}{ Concentration $(\mu \mathrm{g} / \mathrm{L})$} & \multicolumn{2}{|c|}{ Average Flux } \\
\hline & & Mean & Median & $\begin{array}{l}\text { Volume- } \\
\text { Weighted }\end{array}$ & $\mu \mathrm{g} / \mathrm{m}^{2} / \mathrm{d}$ & $\mu \mathrm{g} / \mathrm{m}^{2} / \mathrm{yr}$ \\
\hline \multicolumn{7}{|c|}{ Arsenic } \\
\hline $\mathrm{HC}$ & 13 & 0.0560 & 0.0577 & 0.0514 & $0.13 \pm 0.086$ & $48 \pm 31$ \\
\hline $\mathrm{NR}$ & 13 & 0.121 & 0.0989 & 0.0945 & $0.28 \pm 0.21$ & $100 \pm 77$ \\
\hline PB & 12 & 0.109 & 0.111 & 0.0939 & $0.17 \pm 0.063$ & $61 \pm 23$ \\
\hline $\mathrm{PO}$ & 13 & 0.100 & 0.0849 & 0.0839 & $0.18 \pm 0.13$ & $66 \pm 48$ \\
\hline SB & 13 & 0.171 & 0.157 & 0.133 & $0.22 \pm 0.21$ & $80 \pm 77$ \\
\hline TCB & 13 & 0.415 & 0.188 & 0.260 & $0.55 \pm 0.33$ & $200 \pm 120$ \\
\hline TM & 1 & 0.172 & -- & -- & 0.060 & 22 \\
\hline WP & 13 & 0.0946 & 0.0800 & 0.0793 & $0.18 \pm 0.11$ & $65 \pm 39$ \\
\hline \multicolumn{7}{|c|}{ Cadmium } \\
\hline $\mathrm{HC}$ & 13 & 0.0136 & 0.0074 & 0.0109 & $0.024 \pm 0.016$ & $8.8 \pm 6.0$ \\
\hline NR & 13 & 0.0132 & 0.0114 & 0.0107 & $0.031 \pm 0.027$ & $11 \pm 9.9$ \\
\hline PB & 12 & 0.0705 & 0.0146 & 0.0244 & $0.065 \pm 0.12$ & $24 \pm 43$ \\
\hline $\mathrm{PO}$ & 13 & 0.00829 & 0.00953 & 0.00710 & $0.015 \pm 0.10$ & $5.4 \pm 3.8$ \\
\hline SB & 13 & 0.0216 & 0.0215 & 0.0150 & $0.025 \pm 0.21$ & $9.2 \pm 7.8$ \\
\hline TCB & 13 & 0.0453 & 0.0223 & 0.0323 & $0.066 \pm 0.030$ & $24 \pm 11$ \\
\hline TM & 1 & 0.0770 & -- & -- & 0.027 & 9.9 \\
\hline WP & 13 & 0.0131 & 0.0102 & 0.00979 & $0.021 \pm 0.0087$ & $7.5 \pm 3.2$ \\
\hline \multicolumn{7}{|c|}{ Chromium } \\
\hline $\mathrm{HC}$ & 13 & 0.180 & 0.204 & 0.160 & $0.35 \pm 0.30$ & $130 \pm 110$ \\
\hline NR & 13 & 0.316 & 0.209 & 0.182 & $0.62 \pm 0.54$ & $230 \pm 200$ \\
\hline PB & 12 & 0.444 & 0.318 & 0.311 & $0.56 \pm 0.40$ & $210 \pm 150$ \\
\hline $\mathrm{PO}$ & 13 & 0.258 & 0.192 & 0.166 & $0.38 \pm 0.26$ & $140 \pm 94$ \\
\hline SB & 13 & 1.51 & 0.868 & 1.29 & $2.1 \pm 2.8$ & $770 \pm 1000$ \\
\hline TCB & 13 & 1.18 & 0.617 & 0.781 & $1.7 \pm 0.82$ & $620 \pm 300$ \\
\hline TM & 1 & 0.362 & -- & -- & 0.109 & 40 \\
\hline WP & 13 & 0.322 & 0.246 & 0.217 & $0.49 \pm 0.27$ & $188 \pm 99$ \\
\hline \multicolumn{7}{|c|}{ Copper } \\
\hline $\mathrm{HC}$ & 13 & 0.542 & 0.249 & 0.297 & $0.45 \pm 0.42$ & $160 \pm 150$ \\
\hline NR & 13 & 1.09 & 0.615 & 0.623 & $1.7 \pm 0.89$ & $630 \pm 330$ \\
\hline PB & 12 & 2.20 & 0.823 & 0.869 & $2.1 \pm 3.1$ & $770 \pm 1100$ \\
\hline $\mathrm{PO}$ & 13 & 0.702 & 0.421 & 0.505 & $1.1 \pm 0.70$ & $400 \pm 260$ \\
\hline SB & 13 & 2.42 & 2.02 & 1.76 & $3.1 \pm 3.3$ & $1100 \pm 1200$ \\
\hline TCB & 13 & 8.03 & 4.44 & 2.98 & $11 \pm 5.5$ & $4000 \pm 2000$ \\
\hline TM & 1 & 6.64 & -- & -- & 2.4 & 910 \\
\hline WP & 13 & 0.981 & 0.743 & 0.837 & $1.7 \pm 0.90$ & $620 \pm 320$ \\
\hline \multicolumn{7}{|c|}{ Nickel } \\
\hline $\mathrm{HC}$ & 13 & 0.270 & 0.124 & 0.184 & $0.45 \pm 0.42$ & $160 \pm 150$ \\
\hline $\mathrm{NR}$ & 13 & 0.582 & 0.348 & 0.295 & $1.0 \pm 1.1$ & $360 \pm 410$ \\
\hline
\end{tabular}




\begin{tabular}{|c|c|c|c|c|c|c|}
\hline \multirow[t]{2}{*}{ Site } & \multirow{2}{*}{$\begin{array}{c}\text { Number } \\
\text { of } \\
\text { Samples }\end{array}$} & \multicolumn{3}{|c|}{ Concentration $(\mu \mathrm{g} / \mathrm{L})$} & \multicolumn{2}{|c|}{ Average Flux } \\
\hline & & Mean & Median & $\begin{array}{l}\text { Volume- } \\
\text { Weighted }\end{array}$ & $\mu \mathrm{g} / \mathrm{m}^{2} / \mathrm{d}$ & $\mu \mathrm{g} / \mathrm{m}^{2} / \mathrm{yr}$ \\
\hline PB & 12 & 0.776 & 0.559 & 0.584 & $1.1 \pm 0.92$ & $400 \pm 340$ \\
\hline $\mathrm{PO}$ & 13 & 0.503 & 0.407 & 0.379 & $0.79 \pm 0.77$ & $290 \pm 290$ \\
\hline SB & 13 & 2.31 & 1.66 & 1.89 & $3.2 \pm 4.2$ & $1200 \pm 1500$ \\
\hline TCB & 13 & 1.66 & 1.04 & 1.07 & $0.22 \pm 0.82$ & $800 \pm 300$ \\
\hline TM & 1 & 0.730 & -- & -- & 0.22 & 80 \\
\hline WP & 13 & 0.569 & 0.438 & 0.335 & $0.73 \pm 0.29$ & $270 \pm 110$ \\
\hline \multicolumn{7}{|c|}{ Lead } \\
\hline $\mathrm{HC}$ & 13 & 0.182 & 0.114 & 0.117 & $0.30 \pm 0.21$ & $110 \pm 76$ \\
\hline $\mathrm{NR}$ & 13 & 0.461 & 0.328 & 0.366 & $0.93 \pm 0.60$ & $340 \pm 220$ \\
\hline PB & 12 & 0.287 & 0.237 & 0.251 & $0.43 \pm 0.28$ & $160 \pm 100$ \\
\hline $\mathrm{PO}$ & 13 & 0.253 & 0.158 & 0.154 & $0.38 \pm 0.26$ & $140 \pm 95$ \\
\hline SB & 13 & 0.682 & 0.654 & 0.534 & $0.88 \pm 0.80$ & $320 \pm 300$ \\
\hline TCB & 13 & 3.85 & 2.02 & 2.44 & $5.8 \pm 2.4$ & $2100 \pm 890$ \\
\hline TM & 1 & 0.654 & -- & -- & 0.30 & 110 \\
\hline WP & 13 & 0.421 & 0.269 & 0.268 & $0.62 \pm 0.34$ & $230 \pm 130$ \\
\hline \multicolumn{7}{|c|}{ Zinc } \\
\hline $\mathrm{HC}$ & 13 & 5.37 & 3.04 & 2.95 & $7.9 \pm 4.9$ & $2900 \pm 1800$ \\
\hline NR & 13 & 8.44 & 3.37 & 7.06 & $13 \pm 12$ & $4800 \pm 4300$ \\
\hline PB & 12 & 17.4 & 4.72 & 10.9 & $18 \pm 22$ & $6700 \pm 8300$ \\
\hline $\mathrm{PO}$ & 13 & 2.73 & 2.04 & 2.25 & $5.0 \pm 4.8$ & $1800 \pm 1700$ \\
\hline SB & 13 & 9.08 & 8.02 & 6.38 & $10 \pm 10$ & $3800 \pm 3700$ \\
\hline TCB & 13 & 33.3 & 21.2 & 20.2 & $45 \pm 15$ & $16000 \pm 8800$ \\
\hline TM & 1 & 19.1 & -- & -- & 6.9 & 2500 \\
\hline WP & 13 & 6.40 & 3.61 & 4.13 & $8.8 \pm 3.9$ & $3200 \pm 1400$ \\
\hline
\end{tabular}

Figures 29 through 35 show the fluxes for each element from events 1 through 14 . The overall fluxes for As averaged $0.24 \mu \mathrm{g} / \mathrm{m}^{2} / \mathrm{d}$ (range: $0.017-1.4 \mu \mathrm{g} / \mathrm{m}^{2} / \mathrm{d}$ ) with two high events at TCB in September followed by a decrease during the winter wet months, an increase in April, and then back to values similar to September (except TCB). The Cd fluxes averaged $0.034 \mu \mathrm{g} / \mathrm{m}^{2} / \mathrm{d}$ (range: $0.0018-0.42 \mu \mathrm{g} / \mathrm{m}^{2} / \mathrm{d}$ ) with a similar pattern except the highest flux was measured in May at Padilla Bay. The Cr fluxes averaged 0.91 $\mu \mathrm{g} / \mathrm{m}^{2} / \mathrm{d}$ (range: $0.062-10 \mu \mathrm{g} / \mathrm{m}^{2} / \mathrm{d}$ ) with the highest fluxes measured at Sequim Bay and a pattern at TCB similar to As and Cd. The average $\mathrm{Cu}$ fluxes were $3.2 \mu \mathrm{g} / \mathrm{m}^{2} / \mathrm{d}$ (range: $0.36-22 \mu \mathrm{g} / \mathrm{m}^{2} / \mathrm{d}$ ) and were at least an order of magnitude higher at TCB. The Cu fluxes do not show strong temporal variability, but are significantly influenced by the sand deposition at SB. The Ni fluxes averaged $1.4 \mu \mathrm{g} / \mathrm{m}^{2} / \mathrm{d}$ (range: $0.081-16 \mu \mathrm{g} / \mathrm{m}^{2} / \mathrm{d}$ ) and showed little temporal variability except possibly at TCB. The highest fluxes were measured at $\mathrm{SB}$ due to the wind-blown sand. The average fluxes for $\mathrm{Pb}$ (1.3 range: $0.047-$ $9.0 \mu \mathrm{g} / \mathrm{m}^{2} / \mathrm{d}$ ) were completely driven by the TCB site, which was more than an order of magnitude higher. For $\mathrm{Zn}$, the fluxes are highly variable with an average of $16 \mu \mathrm{g} / \mathrm{m}^{2} / \mathrm{d}$ 
(range: $0.95-79 \mu \mathrm{g} / \mathrm{m}^{2} / \mathrm{d}$ ). The TCB site was generally the highest, but PB and NR were also elevated at times.

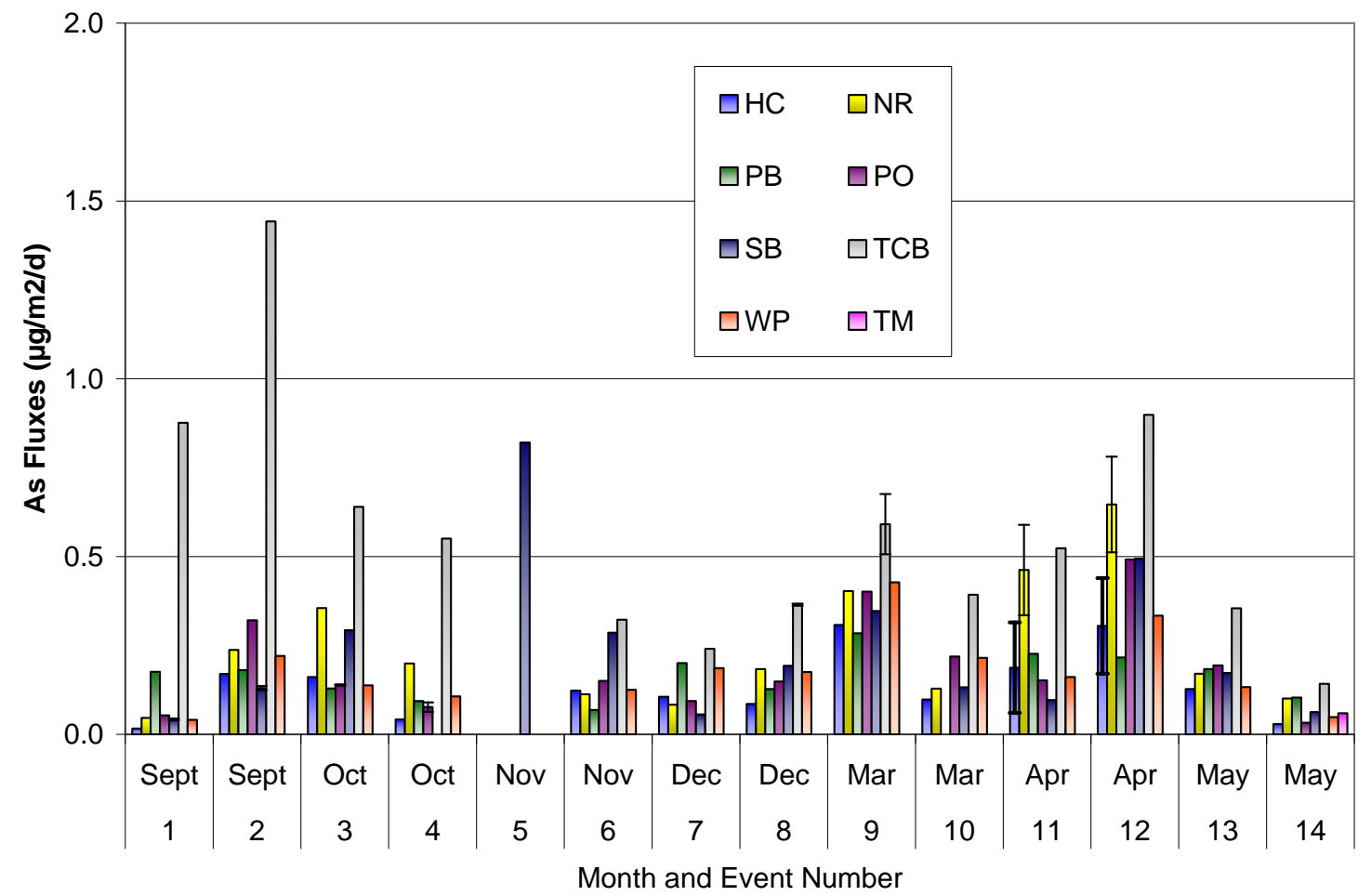

Figure 29. Bulk deposition fluxes $\left(\mu \mathrm{g} / \mathrm{m}^{2} / \mathrm{d}\right)$ for arsenic during events 1 through 14 .

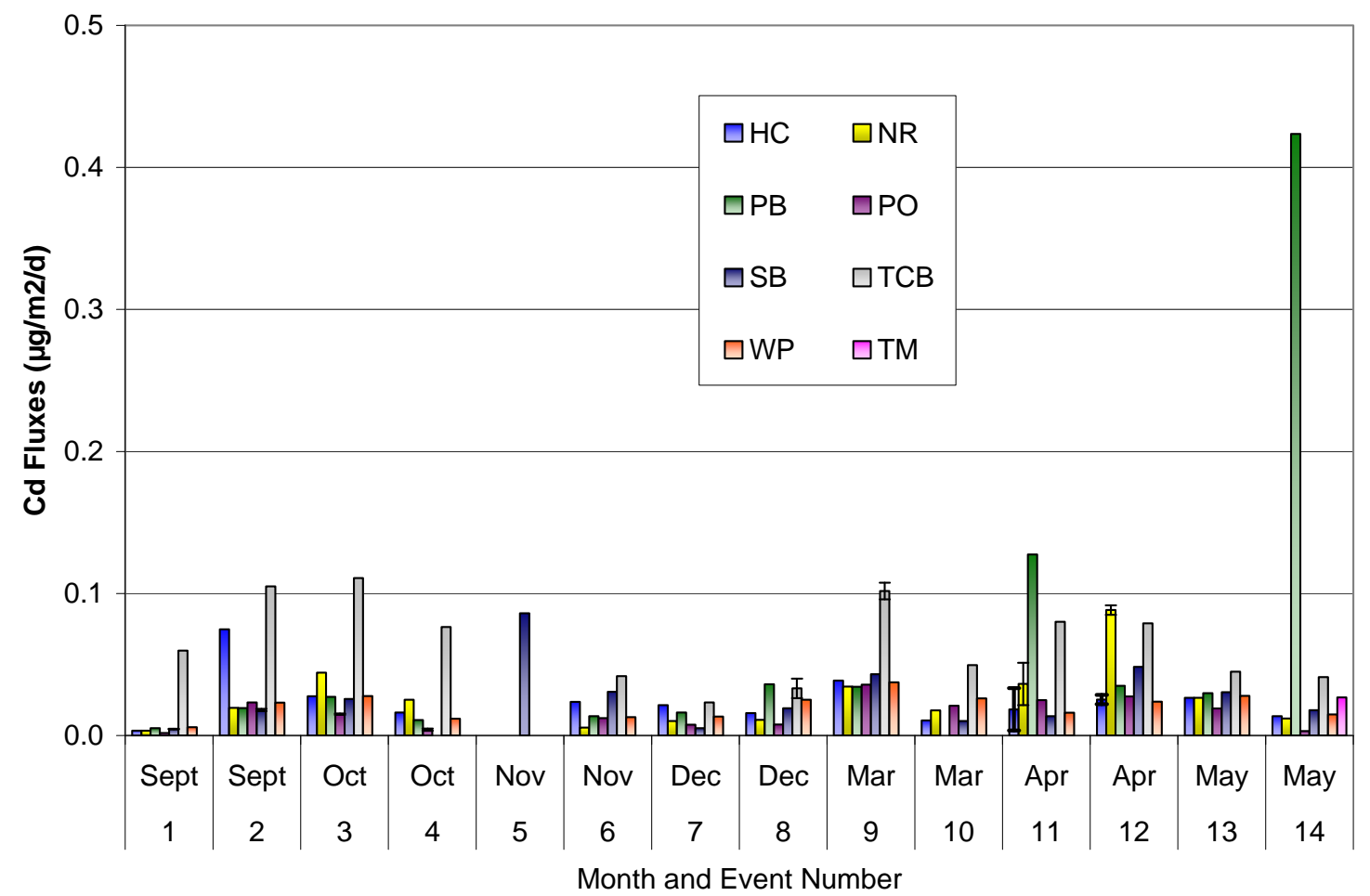

Figure 30. Bulk deposition fluxes $\left(\mu \mathrm{g} / \mathrm{m}^{2} / \mathrm{d}\right)$ for cadmium during events 1 through 14 . 


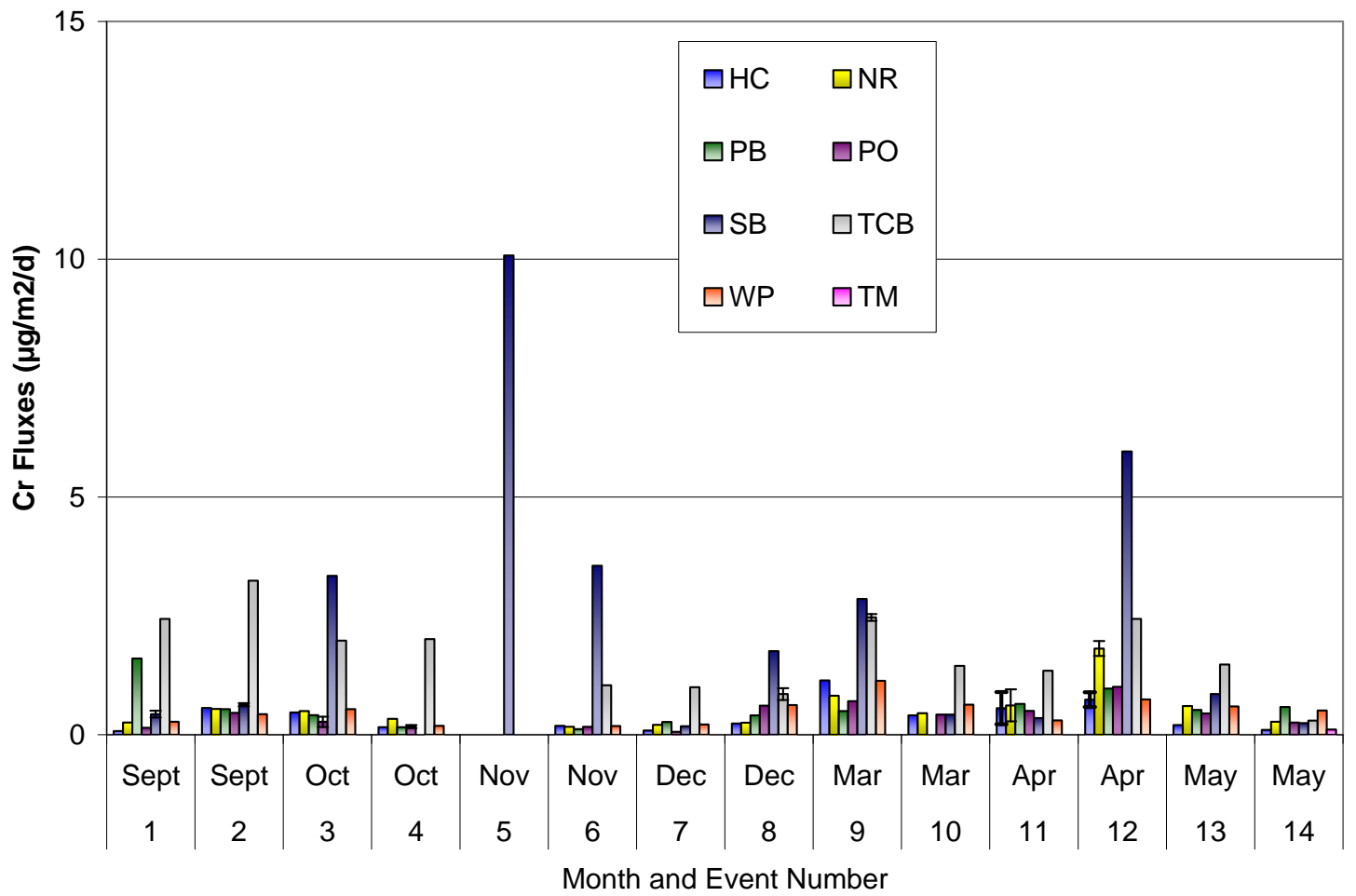

Figure 31. Bulk deposition fluxes $\left(\mu \mathrm{g} / \mathrm{m}^{2} / \mathrm{d}\right)$ for chromium during events 1 through 14 .

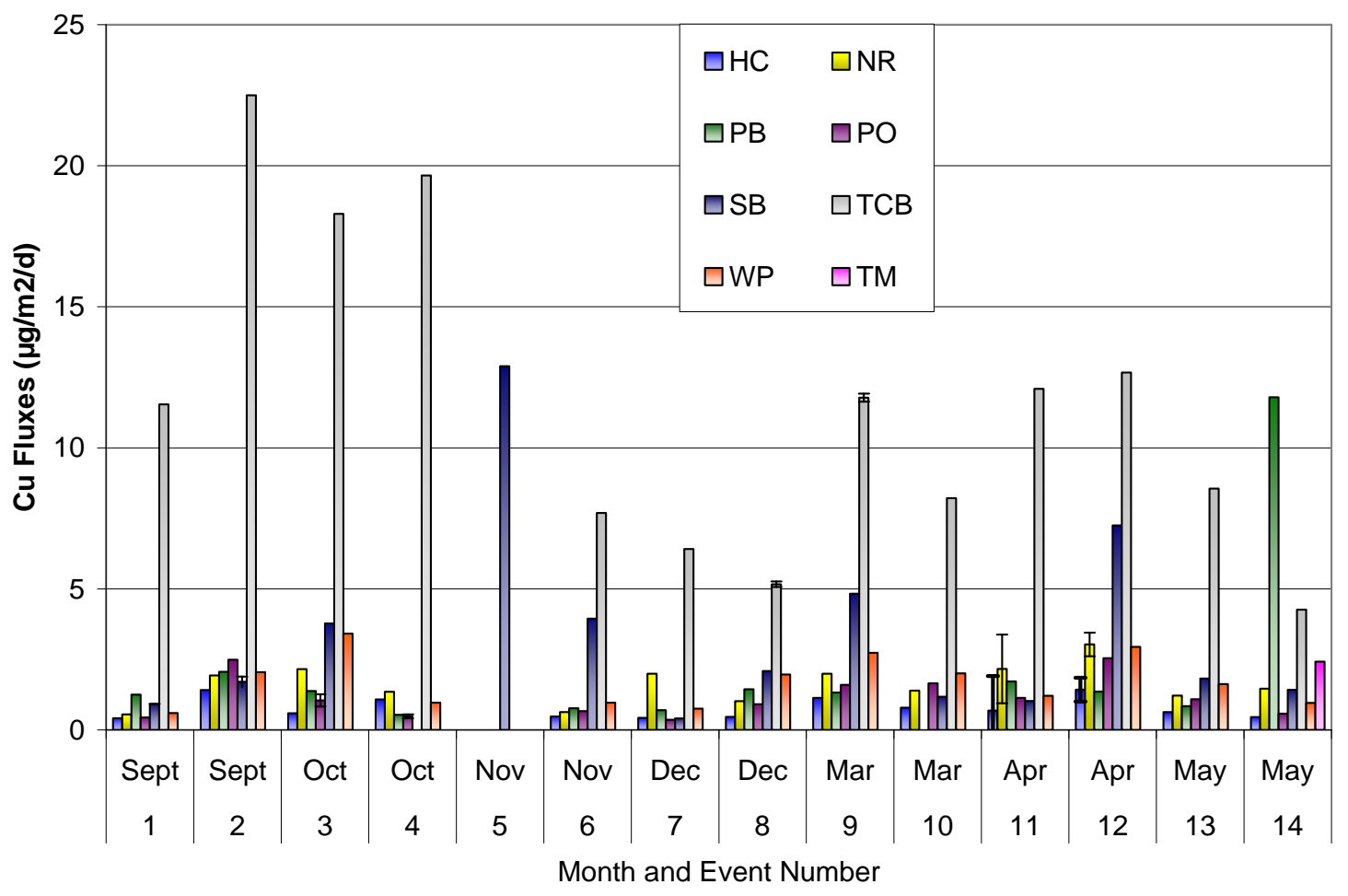

Figure 32. Bulk deposition fluxes ( $\left.\mu \mathrm{g} / \mathrm{m}^{2} / \mathrm{d}\right)$ for copper during events 1 through 14 . 


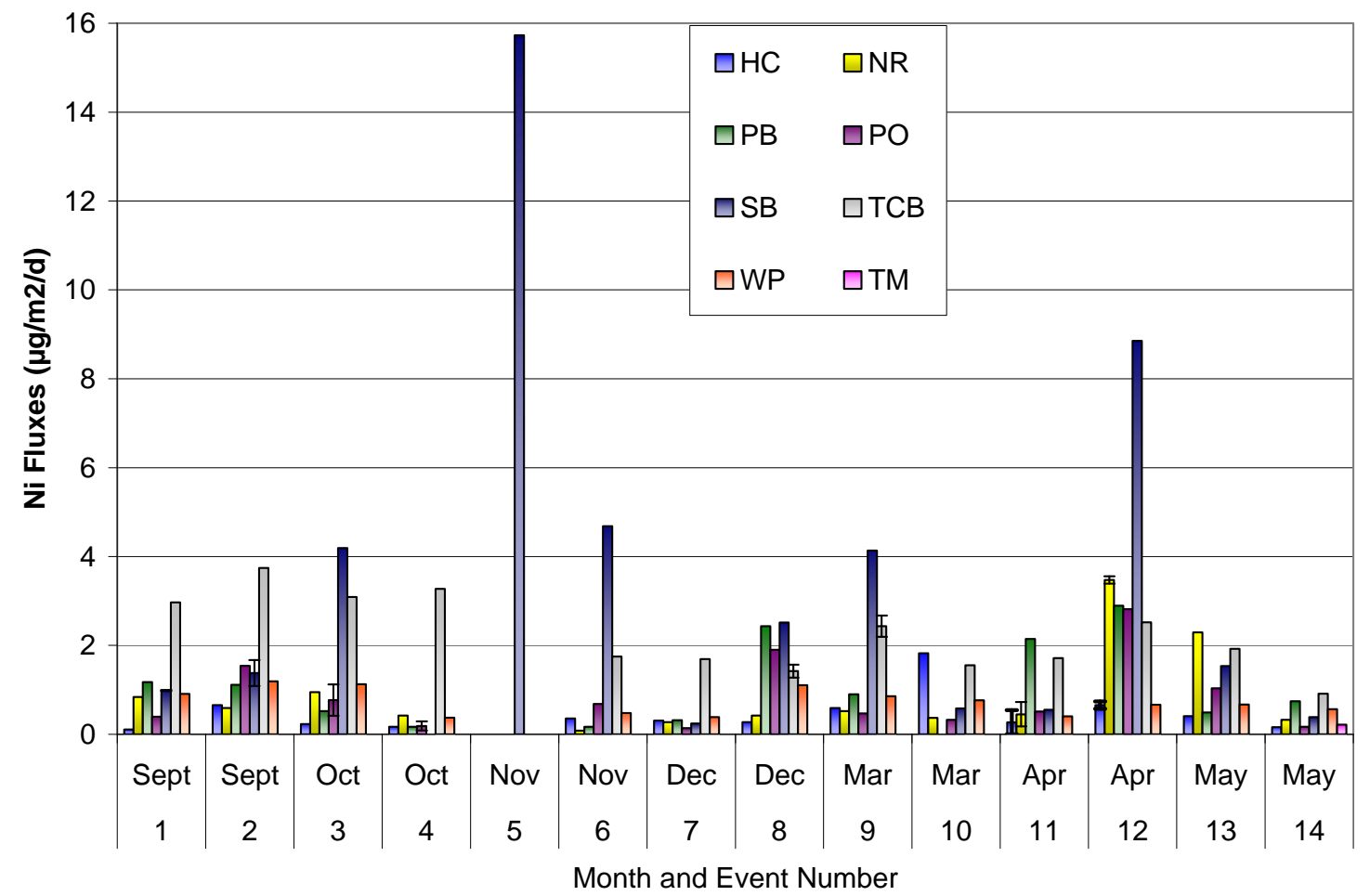

Figure 33. Bulk deposition fluxes $\left(\mu \mathrm{g} / \mathrm{m}^{2} / \mathrm{d}\right)$ for nickel during events 1 through 14 .

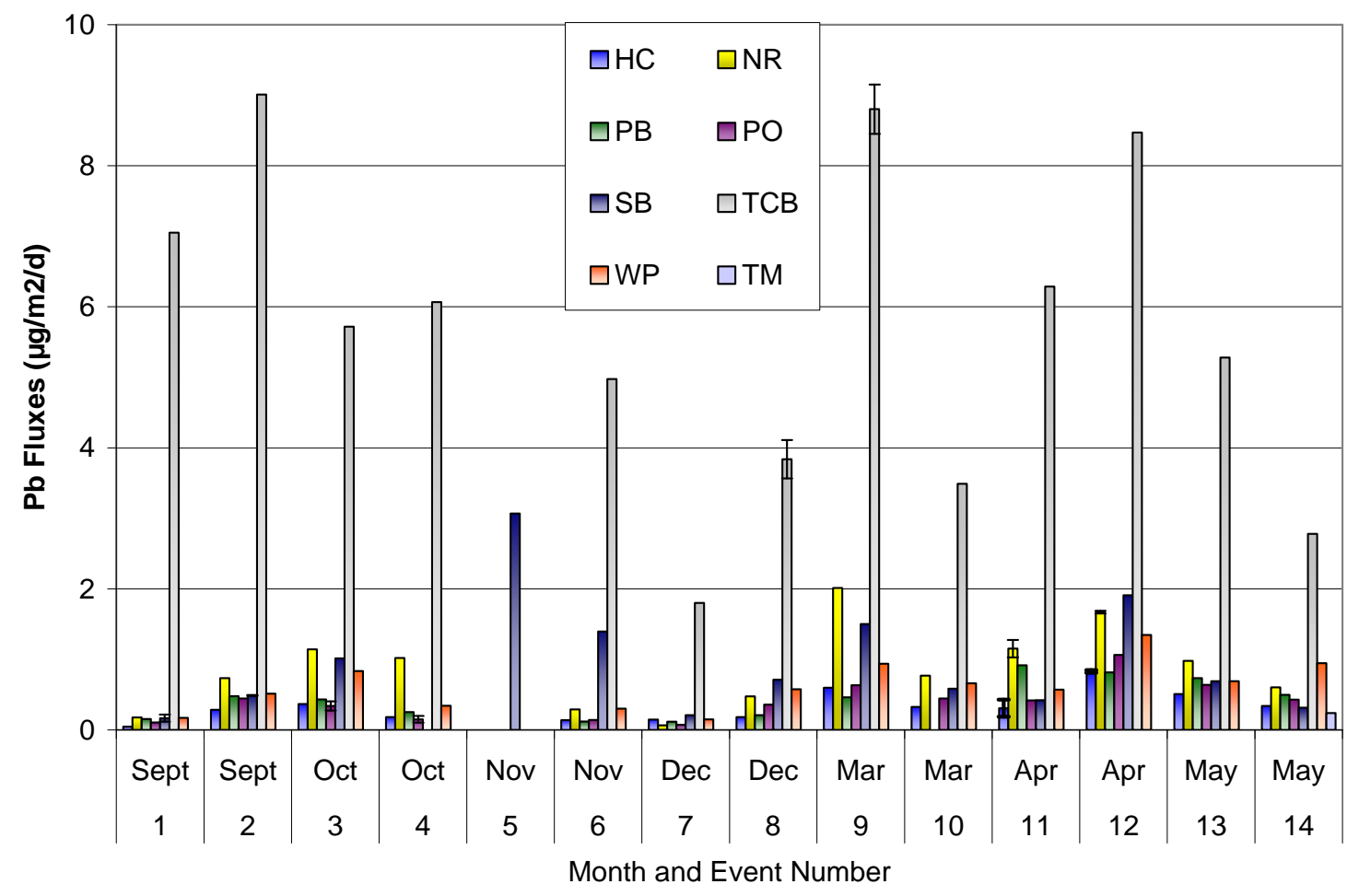

Figure 34. Bulk deposition fluxes $\left(\mu \mathrm{g} / \mathrm{m}^{2} / \mathrm{d}\right)$ for lead during events 1 through 14. 


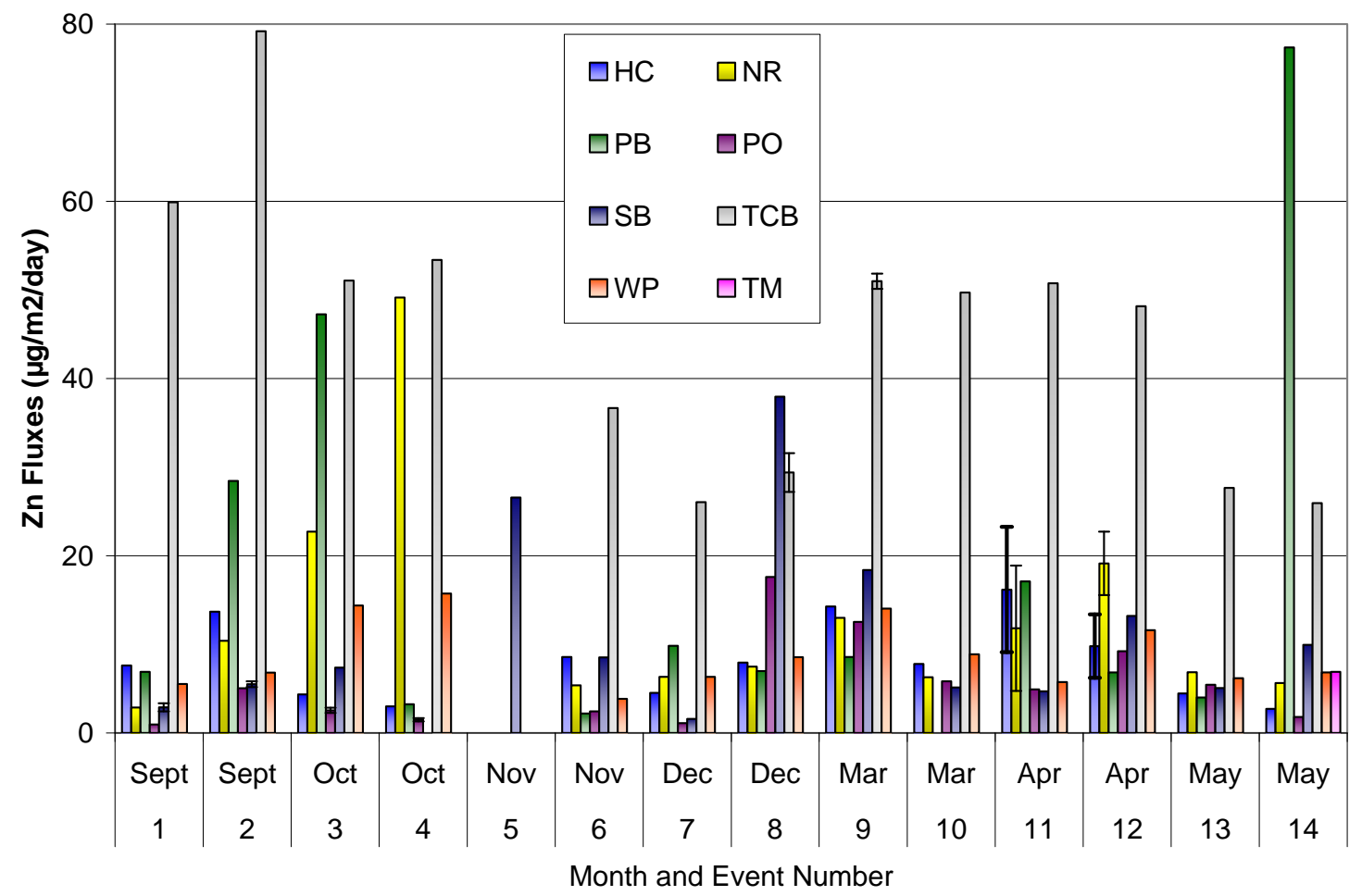

Figure 35. Bulk deposition fluxes $\left(\mu \mathrm{g} / \mathrm{m}^{2} / \mathrm{d}\right)$ for zinc during events 1 through 14 .

\subsection{Mercury and Methylmercury}

The concentrations of THg and $\mathrm{MMHg}$ for events 1 through 14 are graphed in Figures 36 and 37, respectively. The THg concentrations at the new TM site and the core TCB site were the same for event 14 (only event for TM). The distribution of the concentration data illustrates a temporal factor with a washout effect during wet winter months (Figure 38). Unlike other elements, the TCB site was not significantly higher than other sites. Monomethyl mercury was measured at a subset of the sites which included SB, PO, and HC plus periodic sampling at NR and TCB. Similar to the THg concentrations, the $\mathrm{MMHg}$ concentrations were higher during dryer sampling events. All data are available in Appendix D and Table 5 summarizes the mean, median, and volume-weight concentrations for $\mathrm{THg}$ and $\mathrm{MMHg}$. 


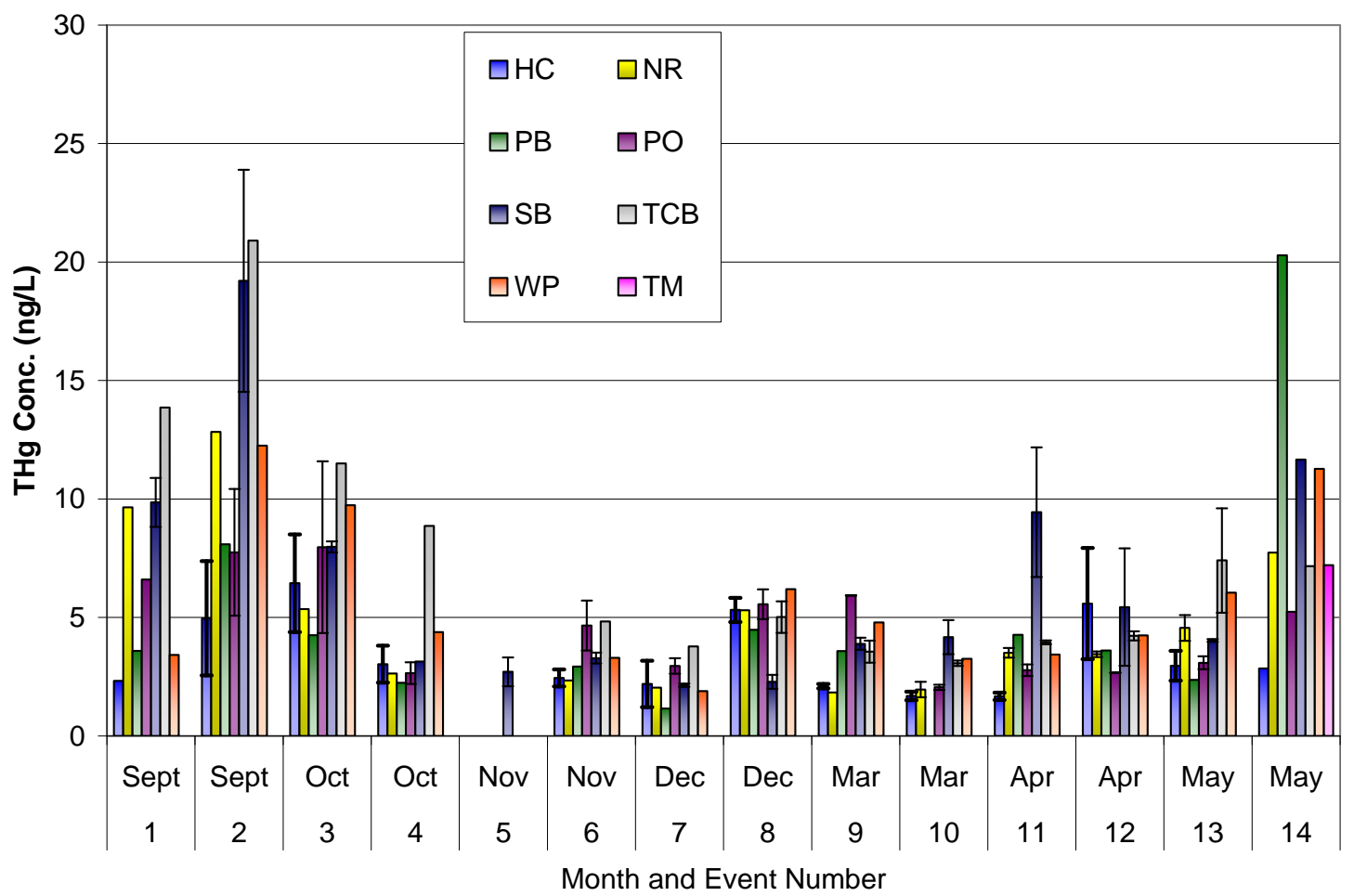

Figure 36. Total mercury concentrations (ng/L) in bulk deposition samples for events 1 through 14 with error bars representing field duplicate measurements.

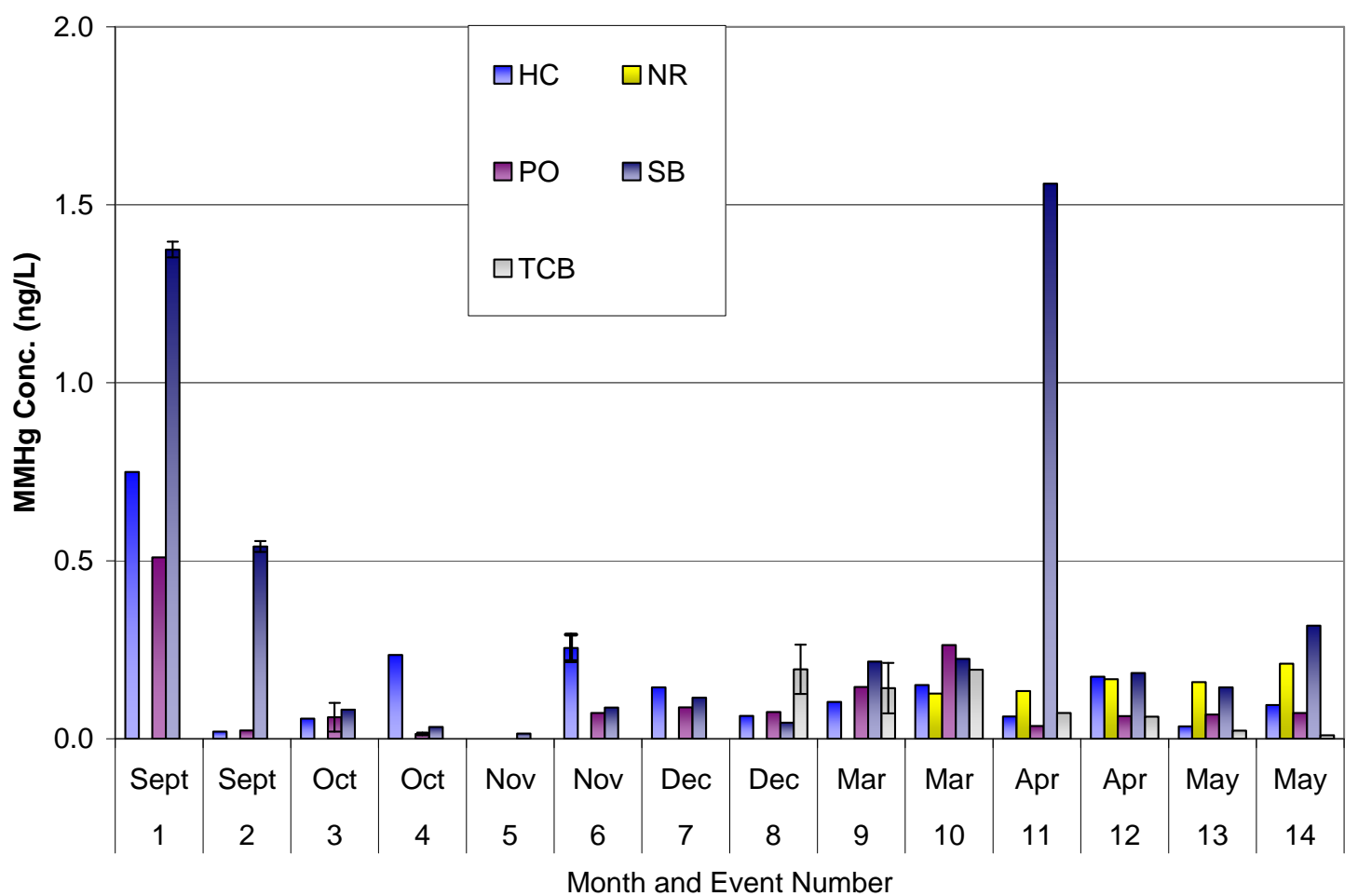

Figure 37. Monomethylmercury concentrations (ng/L) in bulk deposition samples for events 1 through 14 with error bars representing field duplicate measurements. 


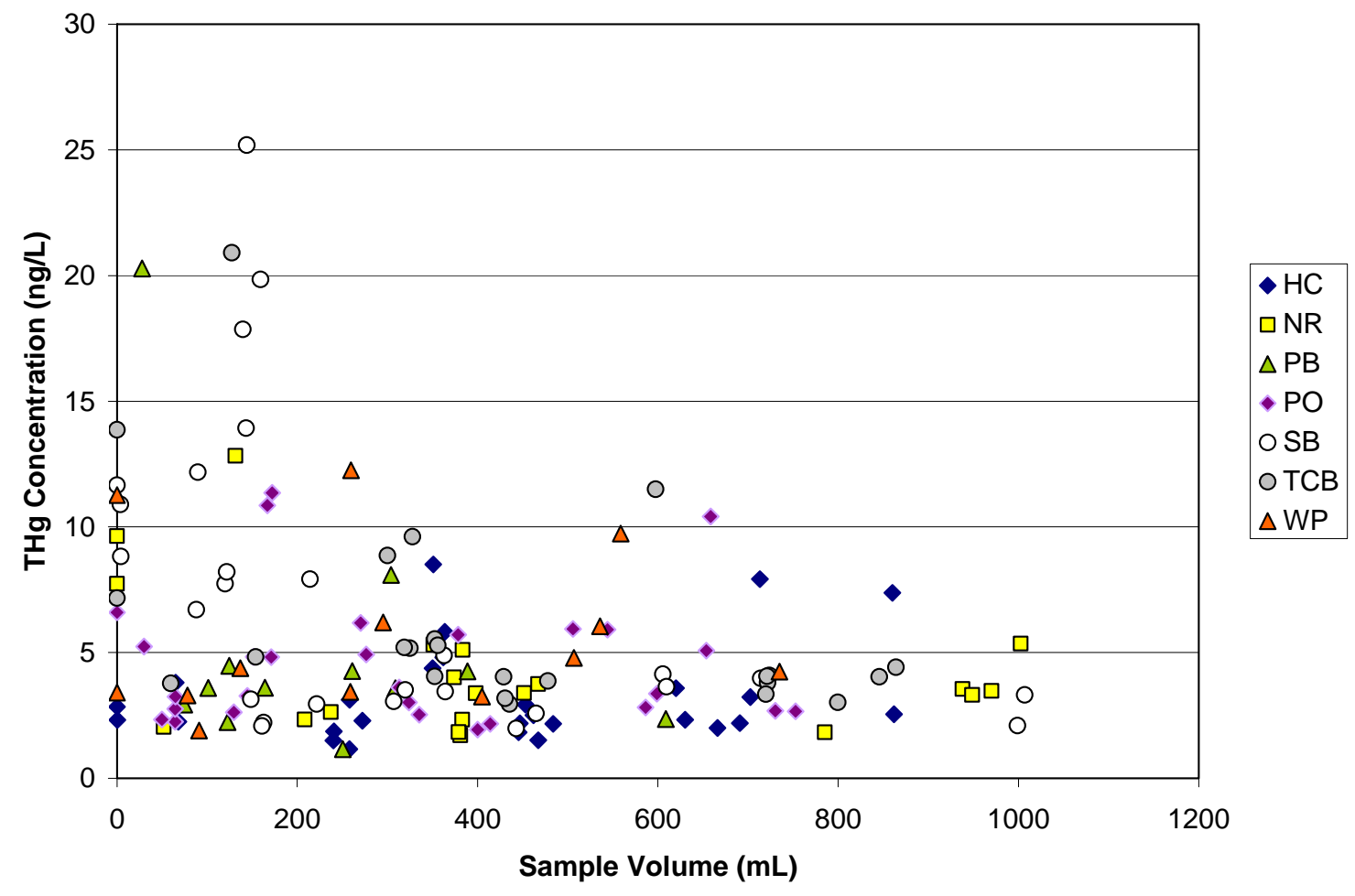

Figure 38. Washout of atmospheric mercury for events 1 through 14.

Table 5. Summary of bulk atmospheric deposition concentrations (ng/L) and estimates of daily (ng/m $\left.\mathrm{m}^{2} / \mathrm{d}\right)$ and annual total mercury and monomethylmercury deposition fluxes (ng/m $\left./ \mathrm{m}^{2} / \mathrm{yr}\right)$ for events 1 through 14.

\begin{tabular}{|c|c|c|c|c|c|c|}
\hline \multirow[t]{2}{*}{ Site } & \multirow{2}{*}{$\begin{array}{c}\text { Number } \\
\text { of } \\
\text { Samples }\end{array}$} & \multicolumn{3}{|c|}{ Concentration (ng/L) } & \multicolumn{2}{|c|}{ Average Flux } \\
\hline & & Mean & Median & $\begin{array}{l}\text { Volume- } \\
\text { Weighted }\end{array}$ & $\mathrm{ng} / \mathrm{m}^{2} / \mathrm{d}$ & $\mu \mathrm{g} / \mathrm{m}^{2} / \mathrm{yr}$ \\
\hline \multicolumn{7}{|c|}{$\mathrm{THg}$} \\
\hline $\mathrm{HC}$ & 27 & 3.30 & 2.51 & 3.56 & $9.8 \pm 8.7$ & $3.6 \pm 3.2$ \\
\hline NR & 20 & 4.28 & 3.43 & 3.59 & $9.4 \pm 6.2$ & $3.4 \pm 2.3$ \\
\hline PB & 12 & 5.07 & 3.60 & 3.88 & $7.0 \pm 3.9$ & $2.5 \pm 1.4$ \\
\hline $\mathrm{PO}$ & 28 & 4.61 & 3.48 & 4.55 & $10.0 \pm 7.3$ & $3.7 \pm 2.7$ \\
\hline SB & 28 & 7.22 & 4.11 & 4.70 & $7.3 \pm 5.3$ & $2.7 \pm 1.9$ \\
\hline TCB & 23 & 6.19 & 4.41 & 5.03 & $14 \pm 7.0$ & $5.0 \pm 2.5$ \\
\hline TM & 1 & 7.21 & -- & -- & 2.6 & 0.93 \\
\hline WP & 13 & 5.71 & 4.38 & 5.82 & $12 \pm 8.4$ & $4.3 \pm 3.1$ \\
\hline \multicolumn{7}{|c|}{$\mathrm{MMHg}$} \\
\hline $\mathrm{HC}$ & 14 & 0.172 & 0.124 & 0.0553 & $0.38 \pm 0.38$ & $0.14 \pm 0.14$ \\
\hline NR & 5 & 0.160 & 0.159 & 0.0369 & $0.50 \pm 0.36$ & $0.18 \pm 0.13$ \\
\hline $\mathrm{PO}$ & 15 & 0.104 & 0.0723 & 0.0432 & $0.20 \pm 0.25$ & $0.075 \pm 0.091$ \\
\hline SB & 16 & 0.428 & 0.201 & 0.0861 & $0.29 \pm 0.24$ & $0.10 \pm 0.086$ \\
\hline TCB & 9 & 0.115 & 0.0727 & 0.0534 & $0.44 \pm 0.38$ & $0.16 \pm 0.14$ \\
\hline
\end{tabular}


The fluxes were calculated based on the surface area of the funnel and the number of days deployed as discussed above for the other trace elements. All data for these calculations are provided in Appendix D. The flux data are graphed in Figures 39 and 40.

While the mechanism for the presence of MMHg in rainfall is not understood, numerous observations have been made which suggest that it is typically present at levels less than $1.5 \%$ of the total mercury in rainfall (Bloom and Watras, 1989; Ebinghaus et al., 1999; Mason et al., 1997; Mason et al. 2000; Lawson and Mason, 2001; Nguyen et al., 2005). Exceptions to this generalization on $\mathrm{MMHg}$ levels in rainfall include higher values reported for the Great Lakes area (up to 18\%) and in Sweden (3\%) (Hall et al., 2005; Munthe et al., 1995). The MMHg averaged 4\% and ranged from $0.1-32 \%$ of the $\mathrm{THg}$ concentrations in the bulk deposition samples. Several samples were removed due to bird droppings in the funnel causing significant increases in the $\mathrm{THg}$ and $\mathrm{MMHg}$ concentrations (see Appendix D). The higher $\mathrm{MMHg}$ ratios for select samples may also result from small insects trapped inside the collection bottle. The opening at the bottom of the Teflon ${ }^{\circledR}$ collar is $5 \mathrm{~mm}$ and allows small winged insects to enter the sample collection bottle.

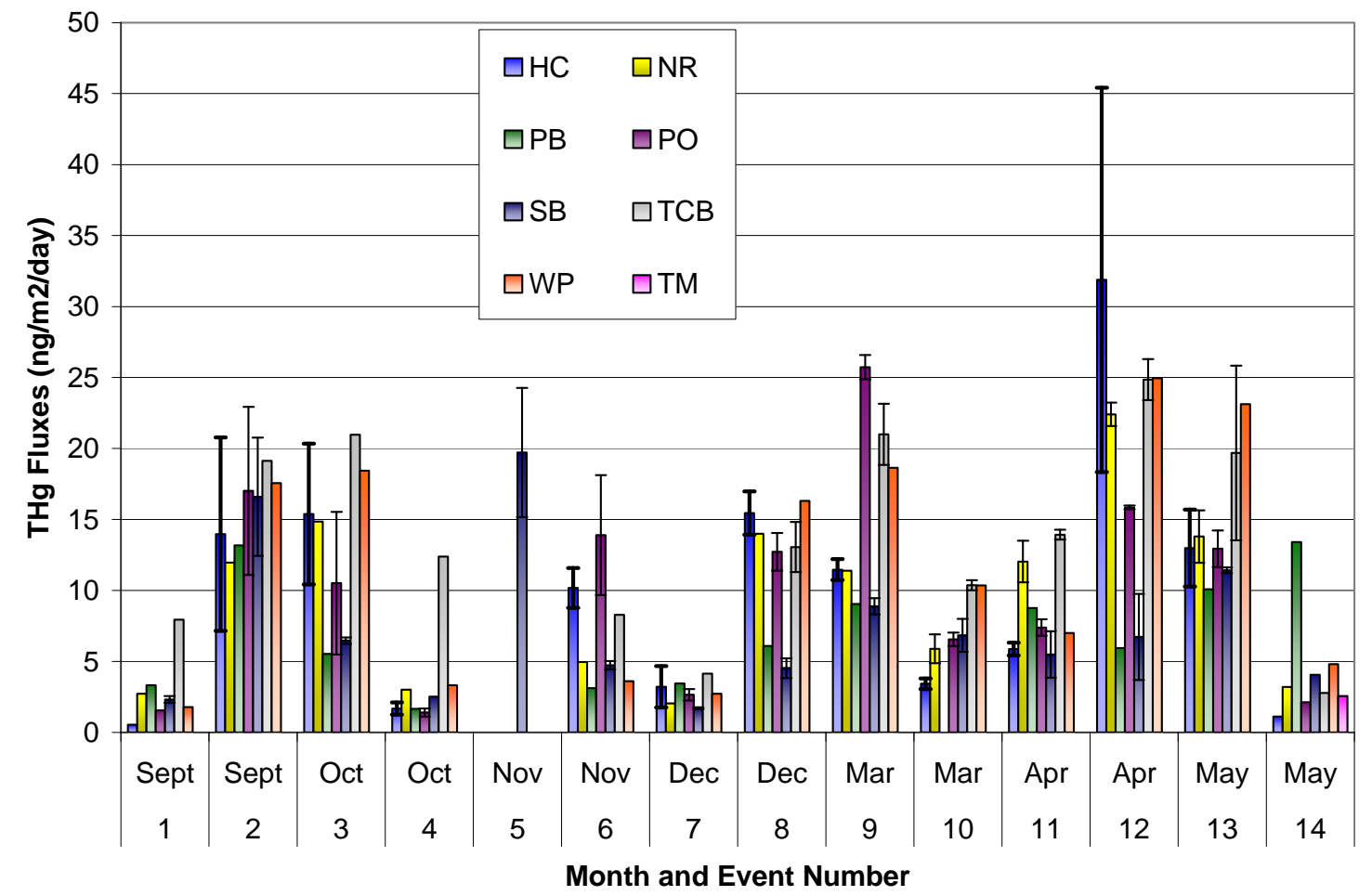

Figure 39. Bulk atmospheric deposition fluxes $\left(\mathrm{ng} / \mathrm{m}^{2} / \mathrm{d}\right)$ for total mercury during sampling events 1 through 14 with error bars representing field duplicate measurements. 


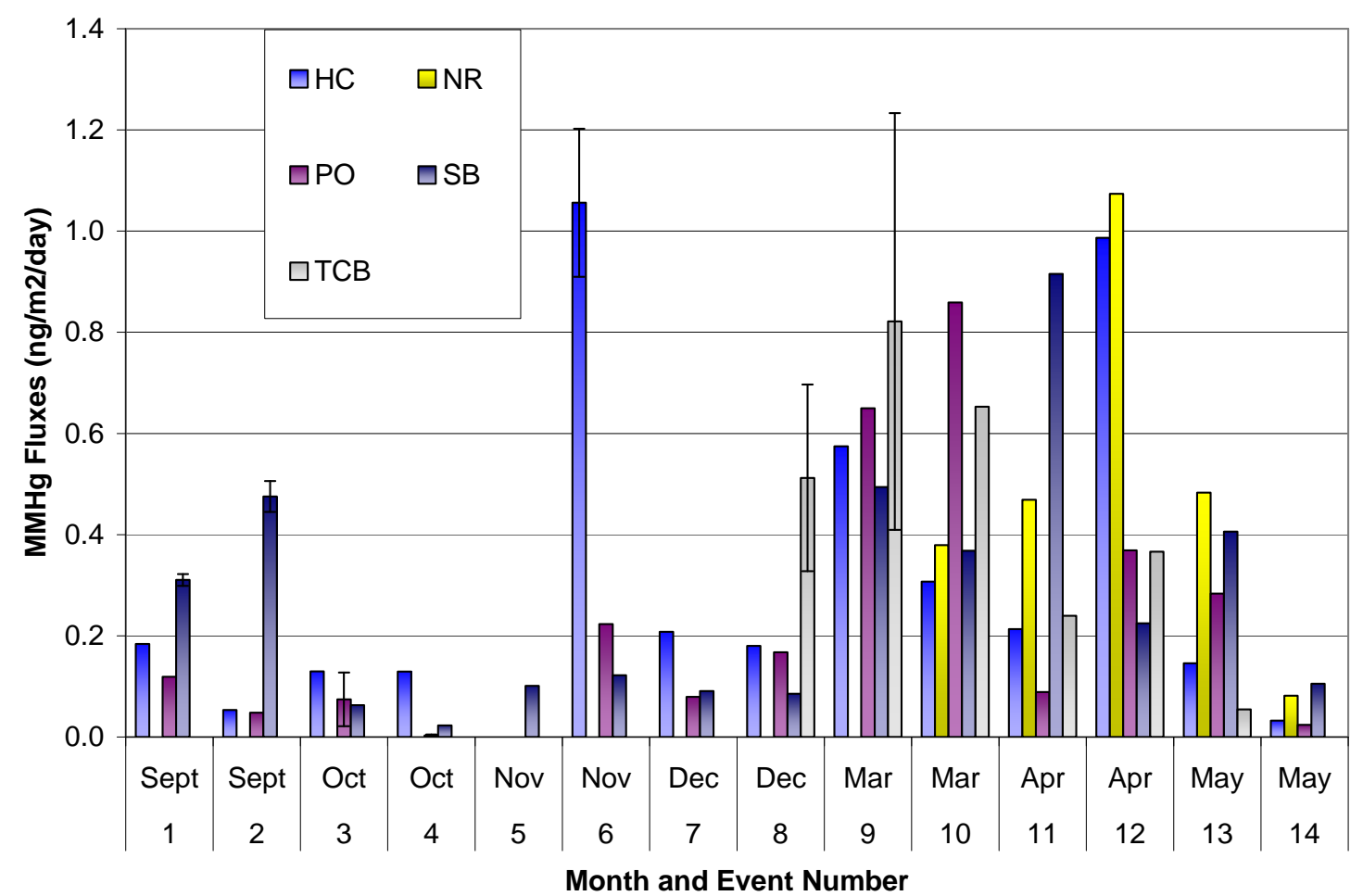

Figure 40. Bulk atmospheric deposition fluxes $\left(\mathrm{ng} / \mathrm{m}^{2} / \mathrm{d}\right)$ for monomethylmercury during sampling events 1 through 14 with error bars representing field duplicate measurements.

\subsection{Year Two Objectives}

The second year of this project will address two primary tasks required to complete the overall program objectives of determining the mass loading of toxics to the waters of Puget Sound. The first is to address critical data gaps and add additional dry season sampling not measured during the first year of this study. This will include four additional dry season events from the end of July through September. The sites will consist of the seven core locations and the additional Tacoma site (TM). The data from year one and two will then be compiled for statistical analysis to derive average annual mass loadings to Puget Sound from direct atmospheric deposition on the water surface. The statistical analysis will address potential outliers, temporal trends, spatial trends, the sphere of influence to use for the TCB station, and attempt to apportion the sources of PAHs using unique chemical fingerprinting and multivariate analysis. The mass loading from the atmosphere will be compared to the sediment burial rates that can be estimated from previously dated sediment cores for all parameters except PBDE (Brandenberger et al. 2008). The sources of PAHs will be apportioned using statistical methods and chemical markers. The results of this study will both estimate the relative contribution of PAHs by source type, such as motor vehicle or wood burning, and determine the percentage of PAHs in marine sediments that are derived from atmospheric deposition.

A suite of molecular markers (PAH and anhydrosugars) will be used to characterize the sources of combustion-derived materials as either from fossil fuel (PAH ratios) and/or biomass combustion (anhydrosugars). Even though PAHs are released from petrogenic 
(e.g. oil spill and oil seepage), biogenic (diagenetic processes), and pyrogenic sources [e.g. fossil fuels combustion and wildfire; (Wakeham et al. 1980; Yunker et al. 1996)], different sources of PAHs yield different molecular distribution patterns providing for a unique fingerprint.

The source and/or process responsible for PAH's found in atmospherically deposited particles can thus be identified through the use of appropriate PAH source diagnostic ratios. Moreover, because of the different emission factors of certain fuels, different combustion sources (e.g. oil, coal, and wood combustion) can also be distinguished (Bucheli et al. 2004; Yunker and Macdonald 2003; Yunker et al. 2002). Additional markers include compounds specific to biomass burning, such as levoglucosan, galactosan, and mannosan, and a resin-derived marker (dehydroabietic acid). These anhydrosugars are exclusive markers of cellulose and hemicellulose combustion (Kuo et al. 2008a; Simoneit 2002) and their presence in aerosols, soils, and sediments has been used to characterize the inputs of char particles derived from biomass burning (Fine et al. 2001; Fraser and Lakshmanan 2000; Kuo et al. 2008).

\subsection{References}

Baker, J.E., Dickhut, R.M., Cutter, G.A., Church, T.M., Ondov J.M. (1992). The Chesapeake Bay Atmospheric Deposition Study. CBADS Quality Assurance Plan.

Battelle (2008). Task 1: Report of the Study of Atmospheric Deposition of Air Toxics to the Waters of Puget Sound. For Washington Department of Ecology. pp. 60.

Bloom, N.S. (1989). Determination of Picogram Levels of Methylmercury by Aqueous Phase Ethylation, Followed by Cryogenic Gas Chromatography with Cold Vapor Atomic Fluorescence Detection. Can. J. Fish Aq. Sci. 7:1131.

Bloom, N. S. and C. J. Watras (1989). Observations of methylmercury in Precipitation, The Science of the Total Environment, 87/88: 199-207.

Brandenberger, J.M., E.A. Crecelius, and P. Louchouarn (2008). Historical inputs an natural recovery rates of heavy metals and organic biomarkers in Puget Sound during the $20^{\text {th }}$ Century. Environmental Science and Technology 42: 6786-6790.

Brandenberger, J.M. E.A. Crecelius, G.A. Gill, and R.K. Johnston. (2009- in final draft). Contaminant mass balance for Sinclair and Dyes Inlets, Puget Sound, Washington. Prepared for the Puget Sound Naval Shipyard and Intermediate Maintenance Facility Project ENVVEST.

Bucheli, T. D., Blum, F., Desaules, A., \& Gustafsson, Ö. (2004). Polycyclic aromatic hydrocarbons, black carbon, and molecular markers in soils of Switzerland. Chemosphere 56: 1061-1076.

Caseiro, A., Bauer, H., Schmidl, C., Pio, C.A. Puxbaum, H. (2009). Wood burning impact on PM10 in three Austrian regions. Atmospheric Environment 43: 21862195.

Covaci, A., Voorspoels, S., de Boer, J. 2003. Determination of brominated flame retardants, with emphasis on polybrominated diphenyl ethers (PBDEs) in 
environmental and human samples - a review. Environment International 29:735756.

Ebinghaus, R., S. G. Jennings, W. H. Schroeder, T. Berg, T. Donaghy, J. Guentzel, C. Kenny, H.H. Kock, K. Kvietkus, W. Landing, T. Muhleck, J. Munthe, E.M. Prestbo, D. Schneeberger, F. Slemr, J. Sommar, A. Urba, D. Wallschlager, and Z. Xiao (1999). International field intercomparison measurements of atmospheric mercury species at Mace Head, Ireland. Atmospheric Environment 33: 3063-3073.

EnviroVision Corporation; Herrera Environmental Consultants, Inc.; Washington Department of Ecology. (2008). Phase 2: Improved Estimates of Toxic Chemical Loadings to Puget Sound from Surface Runoff and Roadways. Ecology Publication Number 08-10-084. August 2008. Olympia, Washington http://www.ecy.wa.gov/biblio/0810084.html

Fabbri, D., Marynowski, L., Fabianska, M.J., Zaton, M. Simoneit, B.R.T. (2008). Levoglucosan and other cellulose markers in pyrolysates of Miocene lignites geochemical and environmental implications. Environmental Science and Technology 42: 2957-2963.

Fabbri, D., Torri, C., Simoneit, B.R.T., Leszek, M., Rushdi, A.I. Fabianska, M.J. (2009). Levoglucosan and other cellulose and lignin markers in emissions from burning of Miocene lignites. Atmospheric Environment 43: 2286-2295.

Fine, P.M., Cass, G.R., Simoneit, B.R. (2001). Chemical characterization of fine particle emissions from fireplace combustion of woods grown in the northeastern United States. Environmental Science and Technology 35: 2665-2675.

Fraser, M. P., and K. Lakshmanan. (2000). Using levoglucosan as a molecular marker for the long-range transport of biomass combustion aerosols. Environmental Science \& Technology 34: 4560-4564.

Guentzel, J. L., W. M. Landing, G. A. Gill and C. D. Pollman (2001). Processes influencing rainfall deposition of mercury in Florida: The FAMS Project (19921996). Environmental Science and Technology 35: 863-873.

Guentzel, J. L., W. M. Landing, G. A. Gill, and C. D. Pollman (1998). Mercury and major ions in rainfall, throughfall and foliage from the Florida Everglades. The Science of the Total Environment 213: 43-51.

Hall, B. D., H. Manolopoulos, J.P. Hurley, J.J. Schauer, V.L.St. Louis, D. Kenski, J. Graydon, C.L. Babiarz, L.B. Cleckner, and G.J. Keeler (2005). Methyl and total mercury in precipitation in the Great lakes region. Atmospheric Environment 39: 7557-7569.

Hart Crowser, Inc.; Washington Department of Ecology; U.S. Environmental Protection Agency; and Puget Sound Partnership (2007). Phase 1: Initial Estimate of Toxic Chemical Loadings to Puget Sound. Ecology Publication Number 07-10-079. October 2007. Olympia, Washington. http://www.ecy.wa.gov/programs/wq/pstoxics/index.html

Kuo, L.-J., Herbert, B.E. Louchouarn, P. (2008). Can levoglucosan be used to characterize and quantify char/charcoal black carbon in environmental media? Organic Geochemistry 39: 1466-1478.

Kuo, L-J., Herbert B.E., and Louchouarn P. (2009 - In preparation). Solvent extractable lignin-derived monomers in plant charcoals: tracers of biomass combustion inputs to soils, aquatic systems, and aerosols. Organic Geochemistry. 
Landers, D.H., S.L. Simonich, D.A. Jaffe, L.H. Geiser, D.H. Campbell, A.R. Schwindt, C.B. Schreck, M.L. Kent, W.D. Hafner, H.E. Taylor, K.J. Hageman, S. Usenko, L.K. Ackerman, J.E. Schrlau, N.L. Rose, T.F. Blett, and M.M. Erway (2008). The Fate, Transport, and Ecological Impacts of Airborne Contaminants in Western National Parks (USA). EPA/600/R-07/138. U.S. Environmental Protection Agency, Office of Research and Development, NHEERL, Western Ecology Division, Corvallis, Oregon.

Landing, W. M., J. L. Guentzel, J.J. Perry, jr., G. A. Gill, and C. D. Pollman (1998). Methods for measuring mercury and other trace species in rainfall and aerosols in Florida. Atmospheric Environment 32: 909-918.

Lawson, N. M. and R. P. Mason (2001). Concentration of Mercury, Methylmercury, Cadmium, Lead, Arsenic, and Selenium in the Rain and Stream Water of two Contrasting Watersheds in Western Maryland, Water Research 35: 4039-4052.

Louchouarn, P., Kuo, L.-J., Wade, T. L., Schantz, M. (2009). Determination of Levoglucosan and its Isomers in Size Fractions of Aerosol Standard Reference Materials. Atmospheric Environment. Submitted.

Mason, R. P., N. M. Lawson, and G. R. Sheu (2000). Annual and seasonal trends in mercury deposition in Maryland. Atmospheric Environment 34: 1691-1701.

Mason, R. P., N. M. Lawson, and K. A. Sullivan (1997). The concentration, speciation and sources of mercury in Chesapeake Bay Precipitation. Atmospheric Environment 31: 3541-3350.

Munthe, J.; Hultberg, H.; Lee, Y.-H.; Parkman, H.; Iverfeldt, Å., and Renberg, I. (1995). Trends of mercury and methyl-mercury in deposition, run-off water and sediments in relation to experimental manipulations and acidification. Water Air Soil Pollut. 85: 43-748

Nguyen, H. L., M. Leermakers, S. Kurunczi, L. Bozo, and W. Baeyens (2005). Mercury distribution and speciation in Lake Balaton, Hungary. Science of the Total Environment 340: 231-246.

O'Connor, T.P. (2002), National distribution of chemical concentrations in mussels and oysters in the USA. Marine Environmental Research 53: 117-143.

Schmidl, C., Marr, L.L., Caseiro, A., Kotianova, P., Berner, A., Bauer, H., Kasper-Giebl, A. Puxbaum, H. (2008). Chemical characterisation of fine particle emissions from wood stove combustion of common woods growing in mid-European Alpine regions. Atmospheric Environment 42: 126-141.

Simoneit, B.R.T. (2002). Biomass burning - a review of organic tracers for smoke from incomplete combustion. Applied Geochemistry 17: 129-162.

Simoneit, B.R.T., Schauer, J.J., Nolte, C.G., Oros, D.R., Elias, V.O., Fraser, M.P., Rogge, W.F. Cass, G.R. (1999). Levoglucosan, a tracer for cellulose in biomass burning and atmospheric particles. Atmospheric Environment 33: 173-182.

Simpson, C.D., Dills, R.L., Katz, B.S. Kalman, D.A. (2004). Determination of levoglucosan in atmospheric fine particulate matter. Journal of Air and Waste Management Association 54: 689-694.

Ward, T.J., Hamilton, R.F., Dixon, R.W., Paulsen, M. Simpson, C.D. (2006). Characterization and evaluation of smoke tracers in PM: Results from the 2003 Montana wildfire season. Atmospheric Environment 40: 7005-7017. 
Usenko, S., K.J. Hageman, D.W. Schmedding, G.R. Wilson, and S.L. Simonich (2005). Trace analysis of semivolatile organic compounds in large volume samples of snow, lake water, and groundwater. Environmental Science and Technology 39: 6006-6015.

Wakeham, S.G., C. Schaffner, and W. Giger (1980). Polycyclic aromatic hydrocarbons in recent lake sediments-I, Compounds having anthropogenic origins. Geochimica et Cosmochimica Acta 44: 403-413

Yan, B.Z., Abrajano, T.A., Bopp, R.F., Chaky, D.A., Benedict, L.A., Chillrud, S.N., (2005). Molecular tracers of saturated and polycyclic aromatic hydrocarbon inputs into Central Park Lake, New York City. Environmental Science \& Technology 39: 7012-7019.

Yunker, M.B., Snowdon, L.R., Macdonald, R.W., Smith, J.N., Fowler, M.G., Skibo, D.N., McLaughlin, F.A., Danyushevskaya, A.I., Petrova, V.I., Ivanov, G.I., 1996. Polycyclic aromatic hydrocarbon composition and potential sources for sediment samples from the Beaufort and Barents Seas. Environ. Sci. Technol. 30: 13101320.

Yunker, M.B., Macdonald, R.W., Vingarzan, R., Mitchell, R.H., Goyette, D., Sylvestre, S. (2002). PAHs in the Fraser River basin: a critical appraisal of PAH ratios as indicators of PAH source and composition. Organic Geochemistry 33: 489-515.

Yunker, M.B. and R.W. Macdonald (2003). Alkane and PAH depositional history, sources and fluxes in sediments from the Fraser River Basin and Strait of Georgia, Canada. Organic Geochemistry 34: 1429-1454. 